

\section{DISCLAIMER}

This report was prepared as an account of work sponsored by an agency of the United States Government. Neither the United States Government nor any agency Thereof, nor any of their employees, makes any warranty, express or implied, or assumes any legal liability or responsibility for the accuracy, completeness, or usefulness of any information, apparatus, product, or process disclosed, or represents that its use would not infringe privately owned rights. Reference herein to any specific commercial product, process, or service by trade name, trademark, manufacturer, or otherwise does not necessarily constitute or imply its endorsement, recommendation, or favoring by the United States Government or any agency thereof. The views and opinions of authors expressed herein do not necessarily state or reflect those of the United States Government or any agency thereof. 


\section{DISCLAIMER}

Portions of this document may be illegible in electronic image products. Images are produced from the best available original document. 


\section{DISTRIBUTION}

UC-79 Basic (186)

UC-79b (42)

ERDA-RL
A. G. Fremling
R. E. Constant

FFTF-P0 (2)

R. L. Ferguson

ERDA-HQ (2)

Director, RDD

HEDL (91)
E. R. Appleby (BNW) (2)
E. N. Heck
(2)
R. B. Baker (2)
T. Hikido
F. E. Bard (2)
R. J. Jackson (2)
R. E. Bardsley
G. A. Last (2)
R. A. Bennett
F. J. Leitz (2)
A. G. Blasewitz
H. D. Lenkersdorfer
C. L. Boyd
W. W. Little
H. L. Bunch
D. E. Mahagin
C. A. Burgess
D. A. Cantley
W. J. McShane
M. K. Millhollen
R. J. Cash
T. T. Claudson
L. D. Muhlestein
C. A. Munro
B. H. Noordhoff
C. M. Cox (2)
G. E. Culley
R. E. Dahl
A. W. DeMerschman
R. P. Omberg
D. G. Ott
M. B. Parker
R. R. Derusseau
D. S. Dutt (2)
W. E. Eterlein (2)
R. E. Peterson (2)
W. E. Roake (2)
W. F. Sheely
E. A. Evans (2)
F. R. Shober
T. W. Evans (2)
D. E. Simpson
A. Squire
G. L. Fox (2)
W. H. Sutherland
B. C. Gneiting (2)
J. E. Hanson (2)
A. E. Waltar
S. A. Weber
A. Harness
W. R. Wykoff (2)
B. R. Hayward 
HEDL-TME 75-12

UC-79b

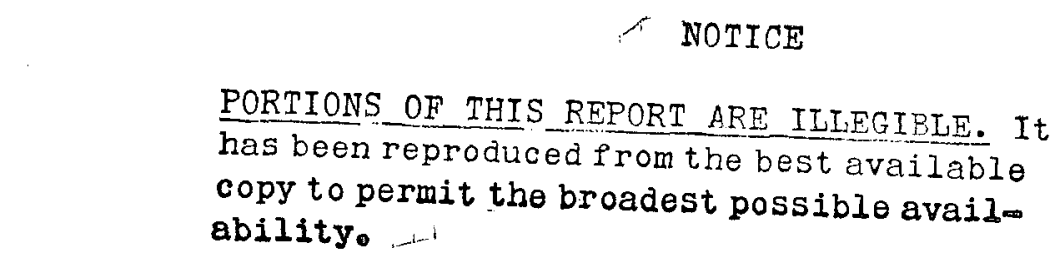

COMPILATION OF DATA

AND DESCRIPTIONS

FOR UNITED STATES AND FOREIGN

LIQUID METAL

FAST BREEDER REACTORS

E. R. Appleby

August, 1975

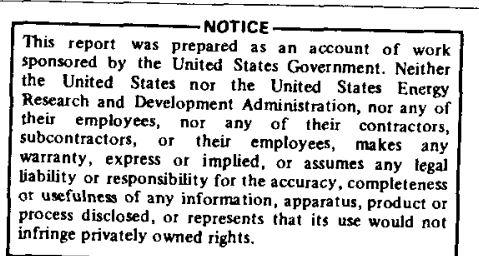

This report was prepared as an account of work the United States nor States Government. Neither Research and Development Administration, nor any of subcontractors, or their omploy ir contractors, process disclosed,

Hanford Engineering Development Laboratory

Operated by the

Westinghouse

Hanford Company for the United States

Energy Research and

Development Administration

Contract No.AT(45.1)2170
Westinghouse Electric

Corporation 


\title{
COMPILATION OF DATA AND DESCRIPTIONS \\ FOR UNITED STATES AND FOREIGN \\ LIQUID METAL FAST BREEDER REACTORS
}

\author{
E. R. Appleby
}

\begin{abstract}
This document is a compization of design and engineering information pertaining to liquid metal cooled fast breeder reactors which have operated, are operating, or are currently under construction, in the United States and abroad. All data has been taken from publicly available documents, journals, and books.
\end{abstract}




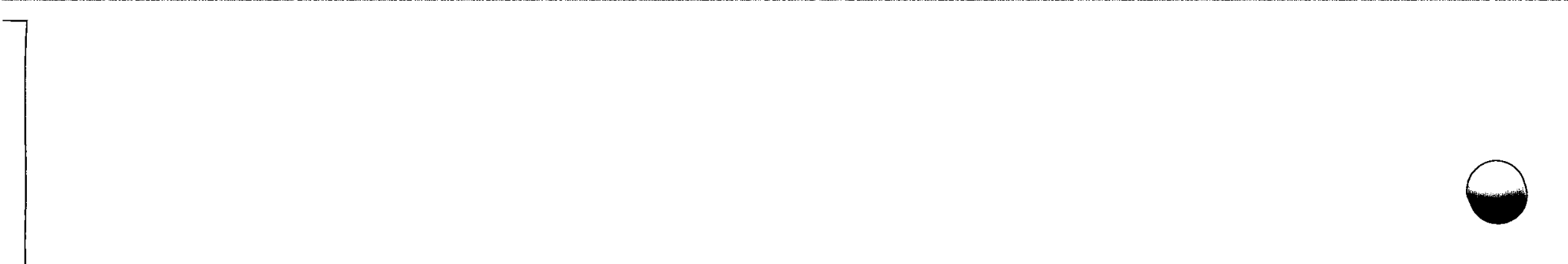

$\bullet$
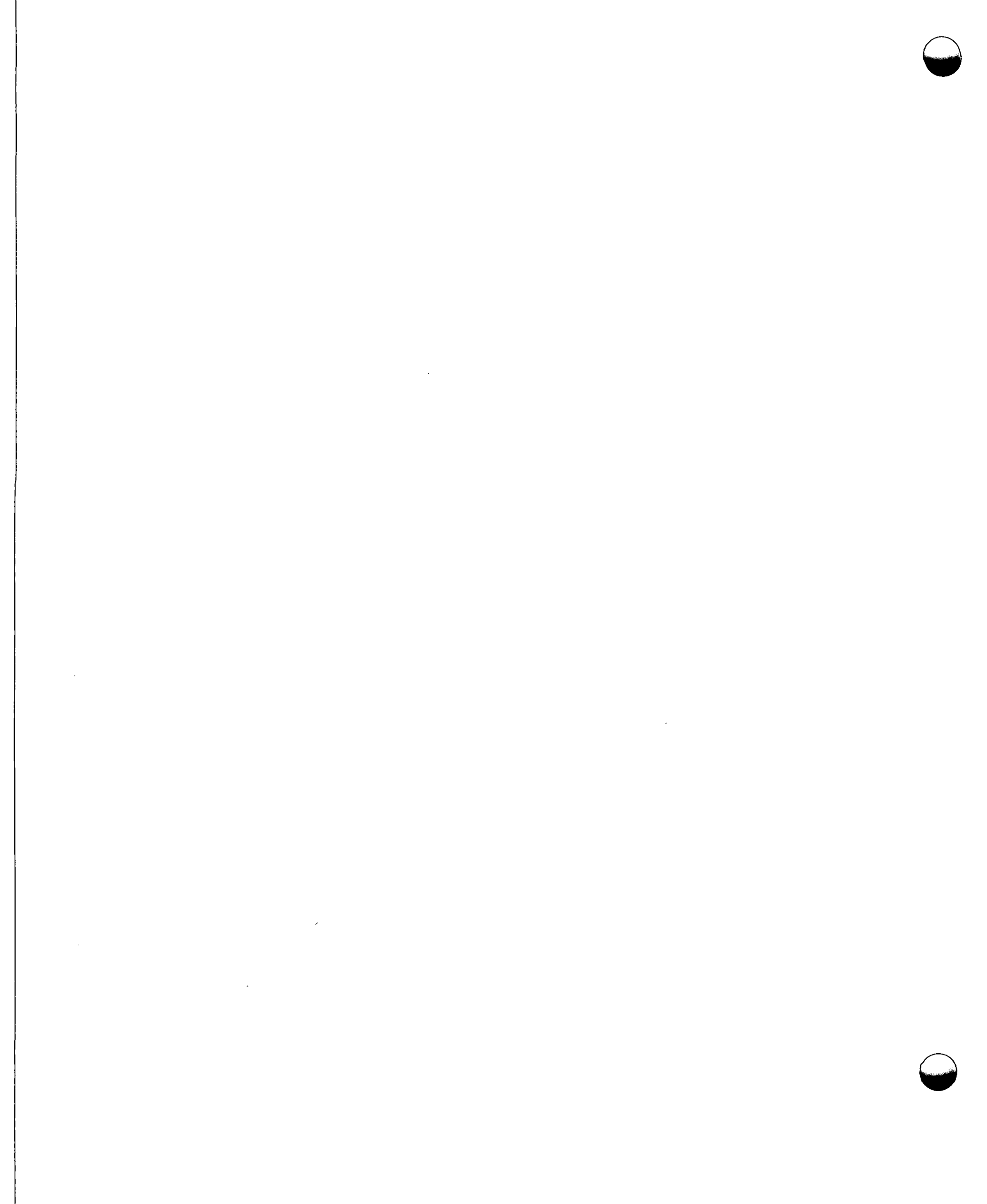

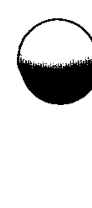

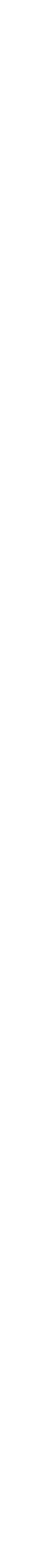




\section{CONTENTS}

REACTOR

CHAPTER

RAPSODIE

I

PHENIX

II

SUPER-PHENIX

I I I

BR-5/BR-10

IV

BOR-60

V

$\mathrm{BN}-350$

VI

$B N-600$

VI I

JoYO

VIII

MONJU

IX

KNK

$x$

SNR-300

$X I$

DOUNREAY

XI I

PFR

XI I I

FERMI

XIV

EBR-2

$X V$

FFTF

$X V I$

CLINCH RIVER

XVII 


\section{RAPSODIE}

LOCATION: Cadarache Nuclear Center Cadarache, France

OPERATION: 1967

Fortissimo 1970

Rapsodie has been in operation at the Cadarache Nuclear Center in France since January 1967. It is essentially a test bed for fast reactor fuels, and an installation for gaining operating experience for future fast reactor power stations. The 20 MWt reactor was designed and built and is operated by The Commissariat a' l'Energie Atomique. Operation has been satisfactory, with availability averaging about $84 \%$. Incidents which contributed to downtime consisted mainly of problems with the control rod mechanisms, the electricity and computer control systems, the argon circuit, and the fuel handling equipment. In 1970, a "Fortissimo" core was loaded, raising the power to 40 MWt. 
INDEX

$\underline{\text { Page }}$

REFERENCES

$\mathrm{I}-5$

REACTOR PARAMETERS

I-7

SECTIONS

A. CORE AND BLANKET (FORTISSIMO p. I.A-1) I.A-1

B. CORE SUPPORT AND VESSEL INTERNALS I.B-1

C. REACTOR VESSELS AND SHIELDING I.C-1

D. CONTROL ELEMENTS I.D-I

E. HEAT TRANSFER SYSTEMS (SODIUM SYSTEMS) I.E-1

F. SODIUM PURIFICATION AND INSTRUMENTATION I.F-1

G. COVER GAS AND AUXILIARY SYSTEMS I.G-1

H. TERMINAL HEAT EXCHANGER I.H-I

I. REACTOR INSTRUMENTATION AND CONTROL I.I-1

J. FUEL HANDLING I.J-1

K. CONTAINMENT I.K-T 


\section{REFERENCES}

1. Rapsodie

G. Vendryes

Energie Nucleaire 3(1): 25-46, 1961 (In French)

2. The Fast Reactor Rapsodie

C. Zaleski, G. Vendryes

CEA-N-2193, Volumes 1 and 2, 1962 (In French)

3. Rapsodie--A Vital Fast Reactor Project

R. Wustner

Nuclear Engineering 8: 316-321, Sept., 1963

4. Rapsodie

G. Vendryes, et al

Proc. Third International Conf., Peaceful Uses of Atomic Energy, Geneva 1964, Vol. 6, pp 13-22, United Nations, N.Y. 1965

5. Fast Reactor Technology Plant Design

J. G. Yevick, ed.

MIT Press. 1966

6. Plain Technical Problems Raised by the Construction and Testing of Rapsodie

A. Chapelot, et al

Fast Reactors, ANS National Topical Meeting, Apri1, 1967. ANS-101, pp 6.1-6.13

7. Intelligence Directed to the Fabrication of the First Rapsodie Core

S. Bataller, et al

Plutonium as a Power Reactor Fuel, Proc. Symposium, Brussels 1967, STI/PUB/153, pp 301-323

International Atomic Agency, 1967.

8. Sodium Purification in Rapsodie

B. Girard

CEA-R-3395, 1968 (In French)

9. Situation and rerspectives for Fast lleutron Reactors in France

G Vendryes, et al

Proc. 4th Internationa1 Conf., Peaceful Uses of Atomic Energy, Geneva, 1971, Vol. 5: 21-35

United Nations and Internationa? Atomic Energy Agency, 1972

10. Fabrication of the First Rapsodie Core, Part 2

Y. Masselot, et al

CEA-R-3501 (2) June, 1970 [Translation: BNWL-TR-95(2)]

11. Behavior of the Fuel Elements of Rapsodie during 1971 and 1972

J. L. Ratier, et al

Fuel and Fuel Elements for Fast Reactors, Vol. 1, p 101. Proc. Symposium, Brussels, July 1973

International Atomic Energy Agency, STI/PUB/346

12. Experience Gained from the Final Construction Phase and Approach to Power of Rapsodie G. Gajac, R. Reynes

Proc. International Conf. on Fast Reactors, Aix-en-Provence, France, 1967. pp Va-5 to Va-12, CEA, France, 1967

13 Upgrading a Fast Flux Test Reactor, Rapsodie-Fortissimo

J. M. Chaumont, et al

Conference on Fast Reactors, Palo Alto, Calif., March 1971

CONF-710315-19 
I. RAPSODIE

\section{REFERENCES-(Cont'd)}

14. The Fast Reactor Station Rapsodie

G. Vendryes

Bulletin d'Inform Sci. Tech. No. 95, July-Aug. 1965, pp 5-45

15. Reactors for Irradiation: Rapsodie

Bulletin d'Inform Sci. Tech. No. 153-154 (Nov.-Dec., 1970) pp 31-35

16. Reactimeter--Its Utilization

G. Chauvet, et al

Proc. International Conf. Safety of Fast Reactors, Aix-en-Provence, France, 1967, pp Va-6.1, Va-6.3, CEA, France, 1967

17. Equipment Adopted for the Control of Radioactive Effluents for Fast Reactor Stations Developed in France

$P$. Candes

Environmental Aspects of Nuclear Power Stations, Proc. Symposium, N.Y., Aug. 1970, pp 159-173, STI/PUB/261, IAEA, 1971 
Table - 1

GENERAL PARAMETERS

FORTISSIMO (Ref. 13)

\begin{tabular}{|c|c|c|}
\hline Type & Pot type & Pot type \\
\hline No. loops & 2 & 2 \\
\hline Coolant & Sodium & Sodium \\
\hline Core inlet temp $\left({ }^{\circ} \mathrm{C}\right)$ & 450 & 400 \\
\hline Core outlet temp $\left({ }^{\circ} \mathrm{C}\right)$ & 540 & 514 \\
\hline Flow direction & Upward & Upward \\
\hline Driver fuel & $\mathrm{UO}_{2}-\mathrm{PuO}_{2}$ & $\mathrm{UO}-\mathrm{PuO}_{2}$ \\
\hline Blanket fuel & $\mathrm{UO}_{2}$ depleted & $\mathrm{UO}_{2}$ \\
\hline Core diameter $(\mathrm{cm})$ & 38 & \\
\hline Core volume (liters) & 40 & $\approx 40$ \\
\hline No. enrichment zones in core & 3 & \\
\hline Output MWe/Mwt & $0 / 20$ & $0 / 40$ \\
\hline Neutron 1 ifetime & $8 \times 10^{-8} \mathrm{sec}$ & \\
\hline Delayed neutron fraction & 0.00520 & \\
\hline Max. can temp $\left({ }^{\circ} \mathrm{C}\right)$ & 625 & 650 \\
\hline Linear power, max. & $380 \mathrm{w} / \mathrm{cm}$ & $400 \mathrm{w} / \mathrm{cm}$ \\
\hline Neutron flux, total & $2 \times 10^{15} \mathrm{n} / \mathrm{cm}^{2} \mathrm{sec}$. & $3.2 \times 10^{15} \mathrm{n} / \mathrm{cm}^{2} \mathrm{sec}$. \\
\hline Doppler $(\Delta K / K) /{ }^{\circ} \mathrm{C}$ total & $10^{-8}$ & \\
\hline Power Density & $407 \mathrm{~kW} / \mathrm{l}$ & $>1 \mathrm{Mw} / \mathrm{e}$ \\
\hline No. Driver elements & 53 & 64 to 66 \\
\hline No. Radial blanket elements & 500 & Nickel reflector \\
\hline No. In-core control elements & 6 & 6 \\
\hline Goal burnup & $5 \%$ & $6.5 \%$ \\
\hline
\end{tabular}


I. RAPSODIE

Table 2

CORE AND BLANKET

\begin{tabular}{|c|c|c|c|c|}
\hline & Driver zone & Axial blanket & Radial blank & $\begin{array}{l}\text { FORTISSIMO } \\
\text { (Ref. 13) }\end{array}$ \\
\hline Fuel material & $\mathrm{UO}_{2}-\mathrm{PuO}_{2}$ & $\mathrm{UO}_{2}$ depleted & $\mathrm{UO}_{2}$ depleted & $\mathrm{UO}_{2}-\mathrm{PuO}_{2}$ \\
\hline Form & \multicolumn{4}{|c|}{ Sintered pellets } \\
\hline Composition & \multicolumn{3}{|c|}{$80 \% \mathrm{U}-20 \% \mathrm{Pu}$} & $30 \% \mathrm{PuO}_{2}$ \\
\hline Stoichiometry & \multicolumn{3}{|l|}{$2.00 \pm 0.05$} & $1.97-1.98$ \\
\hline $240 \mathrm{pu}_{\mathrm{u}}$ & \multicolumn{3}{|l|}{$10.2 \%$} & \\
\hline $235 \mathrm{U}$ inner zone & \multicolumn{3}{|l|}{$60 \%$} & $85 \%$ \\
\hline \multicolumn{5}{|l|}{ outer zone } \\
\hline Density & \multicolumn{3}{|l|}{$96 \%$ TD } & $92 \%$ TD $(84 \%$ smear \\
\hline Pellet $00(\mathrm{~mm})$ & \multicolumn{2}{|l|}{5.7} & 15.4 & 4.3 axial $14.5 \mathrm{~mm}$ \\
\hline Rod cladding & $316 \mathrm{SS}$ & $316 \mathrm{SS}$ & $316 \mathrm{SS}$ & SS \\
\hline $00(\mathrm{~mm})$ & \multicolumn{2}{|l|}{6.7} & & 5.1 \\
\hline Wall thickness (mm) & \multicolumn{2}{|l|}{0.45} & & 0.37 \\
\hline Fuel-clad gap (mm) & \multicolumn{2}{|l|}{0.23} & & $\frac{0.31}{0.13}$ \\
\hline Bond material & \multicolumn{3}{|l|}{ Hel i um } & \multirow[b]{2}{*}{$\begin{array}{l}320 \mathrm{~mm} \\
\text { axial }+60 \mathrm{~mm} \\
\text { axial }+106 \mathrm{~mm}\end{array}$} \\
\hline Column length (mm) & 340 & $200 \times 2$ & 1090 & \\
\hline $\begin{array}{c}\text { Gas plenum length } \\
(\mathrm{mm})\end{array}$ & \multicolumn{2}{|l|}{101} & 110 & Below fuel \\
\hline Pin length $(\mathrm{mm})$ & \multicolumn{3}{|l|}{485} & \multirow{4}{*}{$\begin{array}{l}\text { Top axial blanket } \\
\text { replaced by stain- } \\
\text { less steel rods; } \\
\text { radial blanket by } \\
\text { nickel reflectors. }\end{array}$} \\
\hline Vented/non-vented & \multicolumn{3}{|l|}{ No } & \\
\hline Assembly material & \multicolumn{3}{|l|}{ SS } & \\
\hline Shape & \multicolumn{3}{|l|}{ Hexagonal } & \\
\hline $\begin{array}{c}\text { Across-flats dia. } \\
(\mathrm{mm})\end{array}$ & \multicolumn{3}{|l|}{49.8} & \\
\hline $\begin{array}{c}\text { Wall thickness } \\
(\mathrm{mm})\end{array}$ & \multicolumn{2}{|l|}{1} & & \\
\hline $\begin{array}{c}\text { Overall length } \\
(\mathrm{mm})\end{array}$ & \multicolumn{2}{|l|}{1661.5} & & \\
\hline No. pins/assembly & 37 & $7 \times 2$ & 7 & 61 \\
\hline Pin spacing & \multicolumn{2}{|l|}{ Spiral fins } & Spiral wire & Spiral wire \\
\hline Pin pitch & \multicolumn{2}{|l|}{$P / D=1 / 12$} & & \\
\hline Assy. in core & \multicolumn{2}{|l|}{53 to 64} & $500+$ refiector & 64 to 66 \\
\hline Volume fraction $(\%)$ & & & & \\
\hline Fuel & 42.2 & 44.2 & 58.3 & \\
\hline Steel & 22.8 & 19.8 & 15.6 & \\
\hline Sodium & 33.5 & 35.4 & 25.4 & \\
\hline
\end{tabular}




\section{A. CORE AND BLANKET}

A mixed oxide fuel was chosen for the first Rapsodie core. Axial blanket sections of depleted $\mathrm{LO}_{2}$ occupied the top and bottom regions of the driver assembly, the 7-pin bundles being held by grid devices in the hexagonal can. The gas plenum was above the fissile core. A buffer pellet of $\mathrm{UO}_{2}$ was placed at each end of the fuel pellet stack, which was held by a spring in the plenum section. The stainles steel clad pin has integral spiral pins. Bonding was helium, and the pins were sealed. (Refs. 1, 10.)

Filters designed for installation in the foot of each subassembly were found to be inconvenient and were discarded (Ref. 6). Hold-down has been made more certain by a system of flexible blades in the assembly foot, which engage in the grid. (Ref. 9,) (Figs. I.A-1, I.A-2, I.A-3)

An assembly with the U-Mo-Pu tertiary alloy as fuel was also studied. Pin cladding consisted of an inner niobium cylinder joined to the fuel by a metallurgical bond, and an outer stainless steel cylinder. The thermal bond between the niobium and the stainless steel tubes was sodium. Spacing was by a spiral wire wrap.
Radial and reflector assemblies have the same hexagonal can dimension as the driver assemblies. Pin spacing for the radial assembly is by spiral wire wrap (wire dia. $0.0365 \mathrm{~cm}$ ). The gas plenum is $11 \mathrm{~cm}$. Pins are sealed. The Fortissimo version replaces all radial blanket assemblies with nickel reflector assemblies. (Fig. 1. A-5.)

\section{FORTISSIMO CORE}

A new core (Fortissimo) was loaded in 1970. The fuel section consists of 67 rods. The mixed oxide fuel is slightly substoichiometric, with a smear densitv of $84 \%$ TD. Fuel length is $320 \mathrm{~mm}$; gas plenums occupy $60 \mathrm{~mm}$ below and $106 \mathrm{~mm}$ above the fuel section. Pellet-clad gap is $0.13 \mathrm{~mm}$. The top axial blanket is replaced by stainless steel rods, and the radial blanket elements are replaced by nickel reflector elements. (Fig. I.A-6) (Ref. 13) 


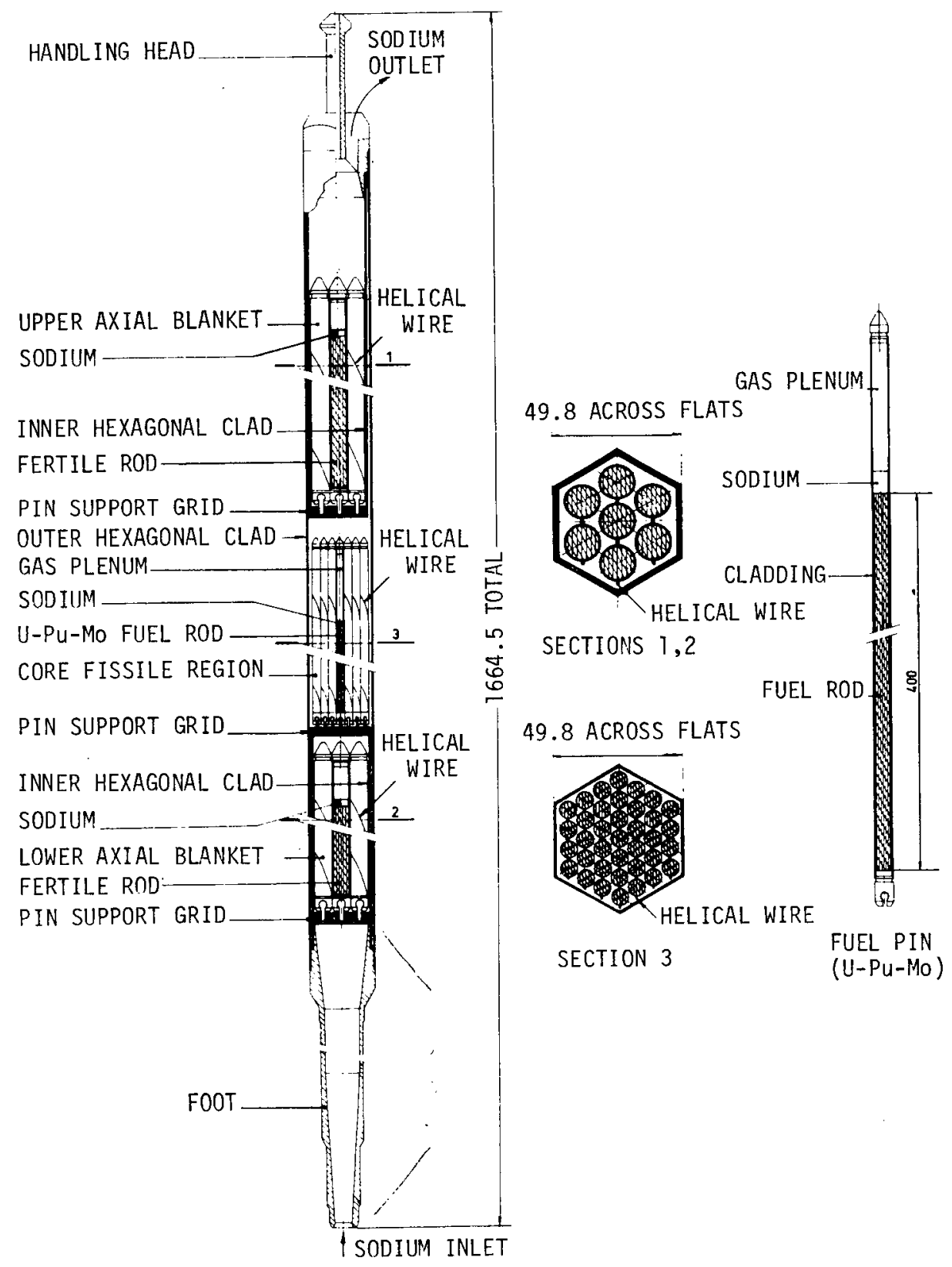

Figure I.A-1. Rapsodie Fuel Assembly (Ref. 7) 
RAPSODIE I.A.

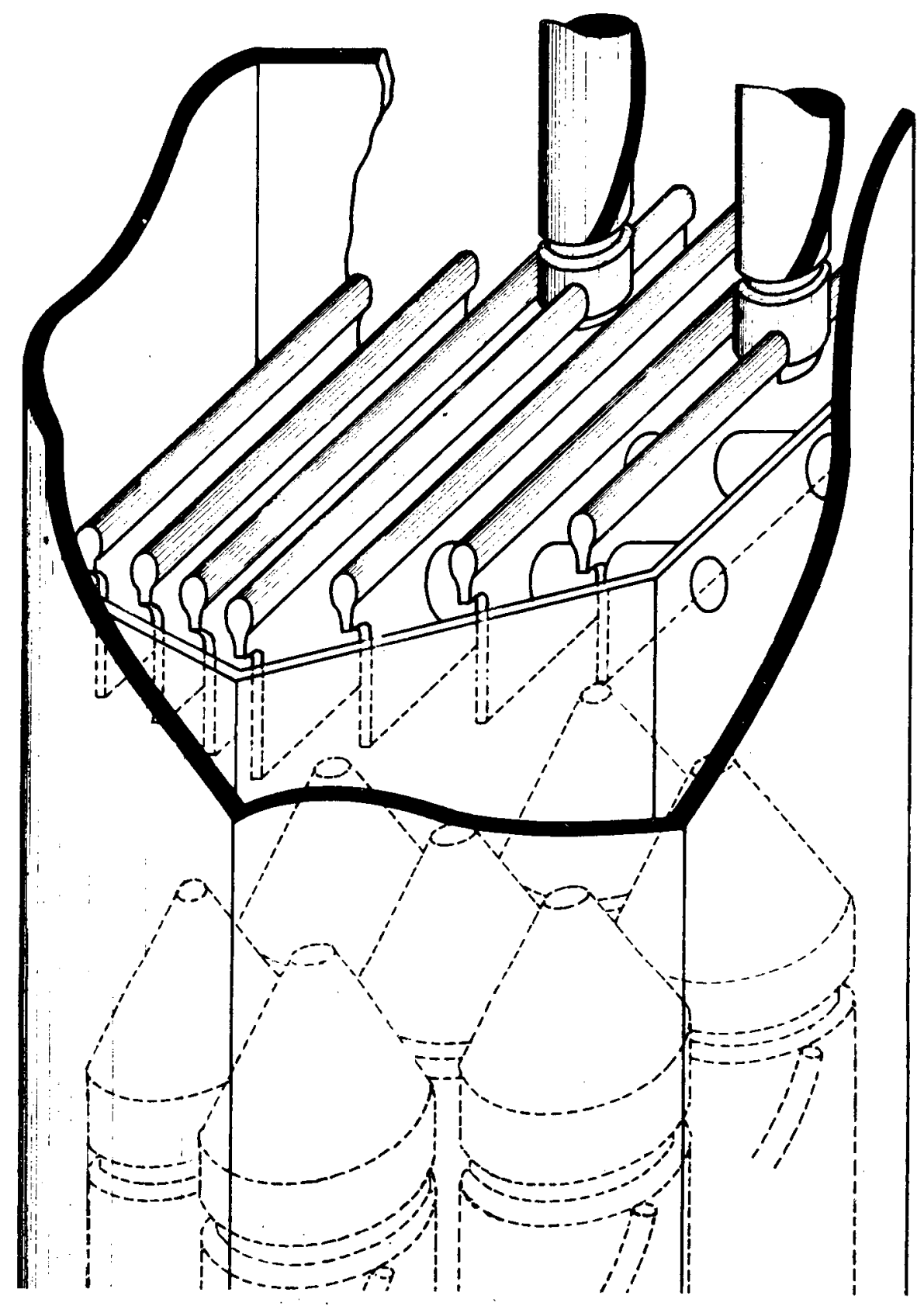

Figure I.A-2. Grid For Holding Pins (Ref. 2) 


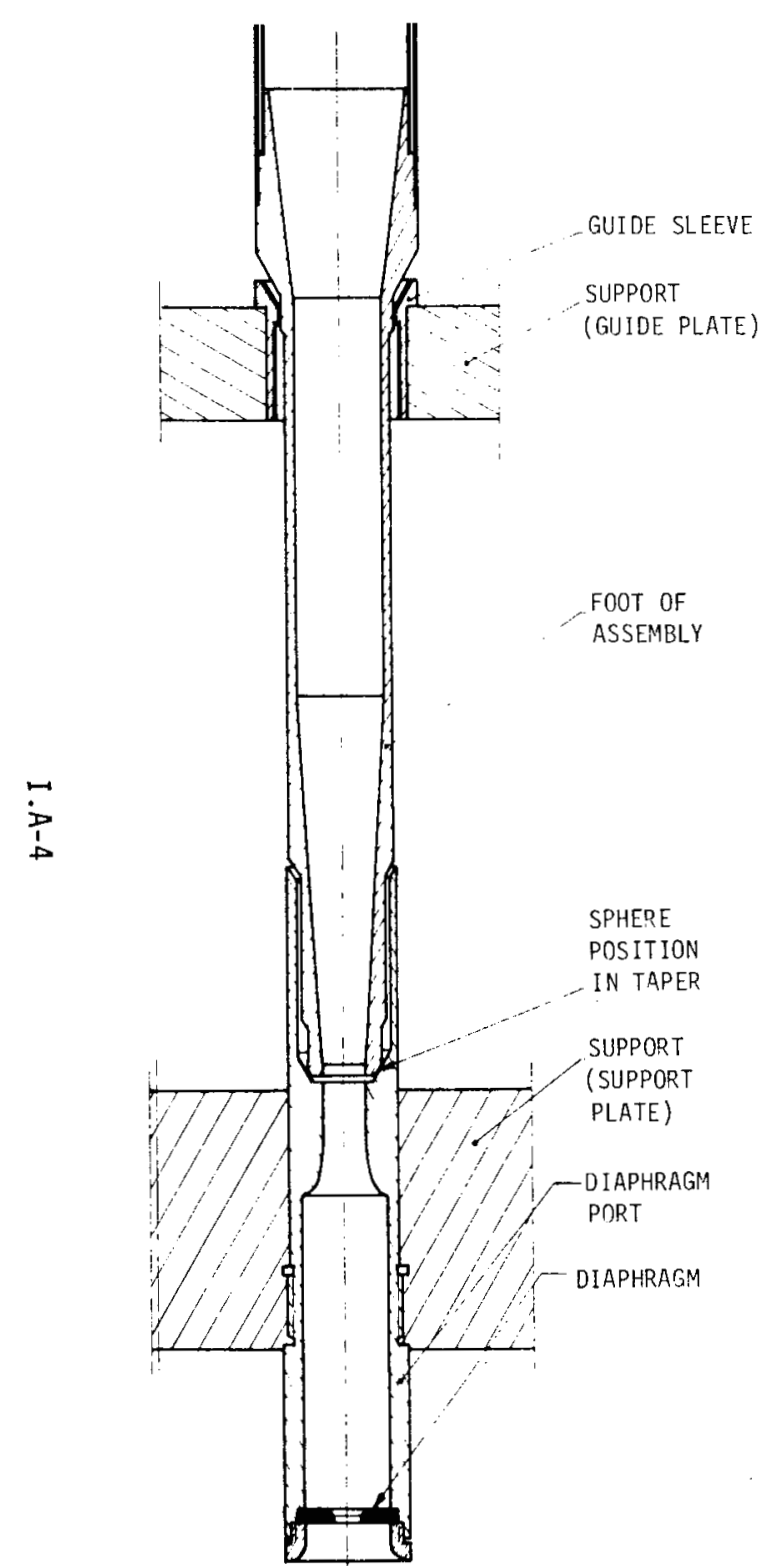

Figure I.A-3. Foot of Fuel Assembly (Ref. 2)

Figure 1.A-3. Foot of Fuel Assembly (Ref. 2)

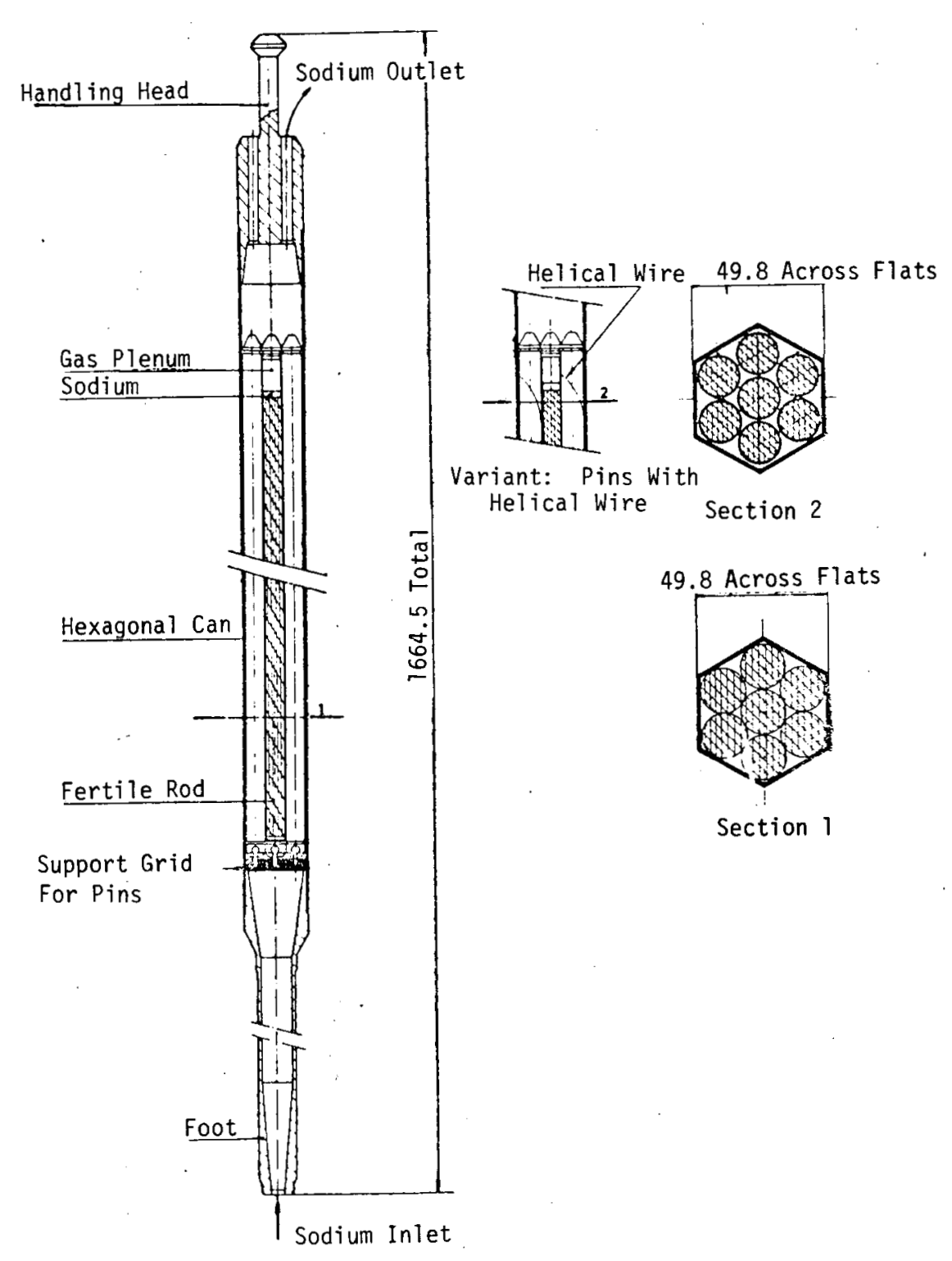

Figure I.A-4. Radial Blanket Assembly 


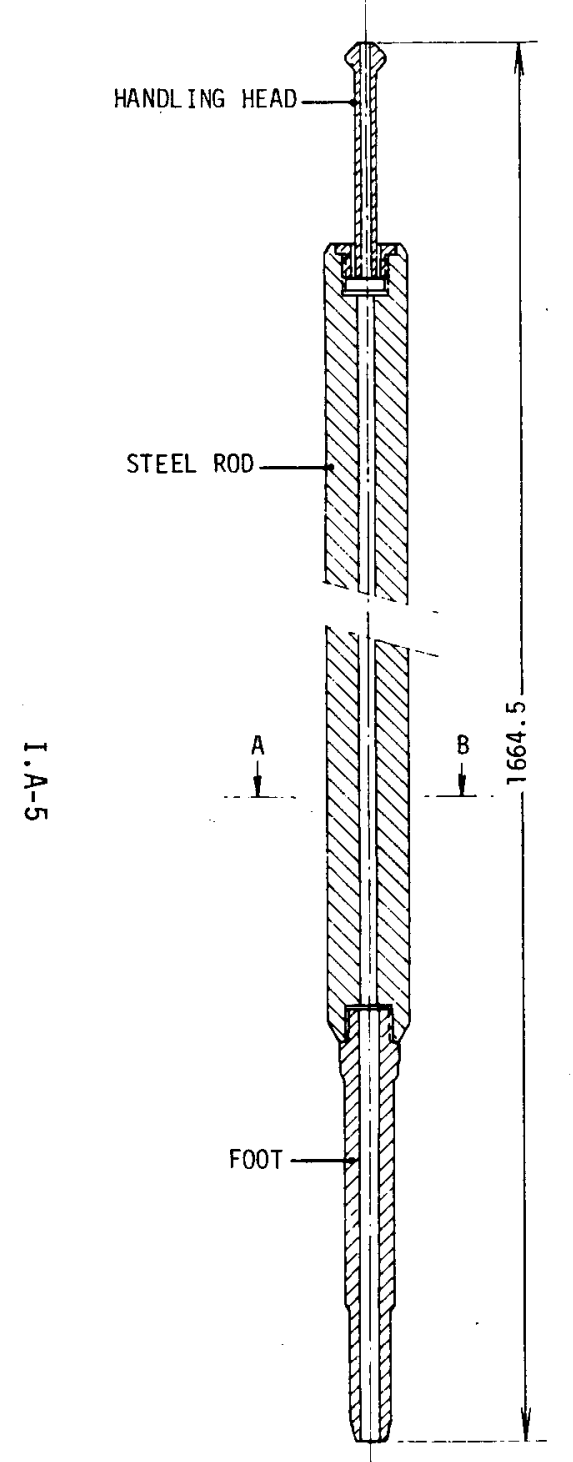

Figure I.A -5. Reflector Assembly (Ref. 2)

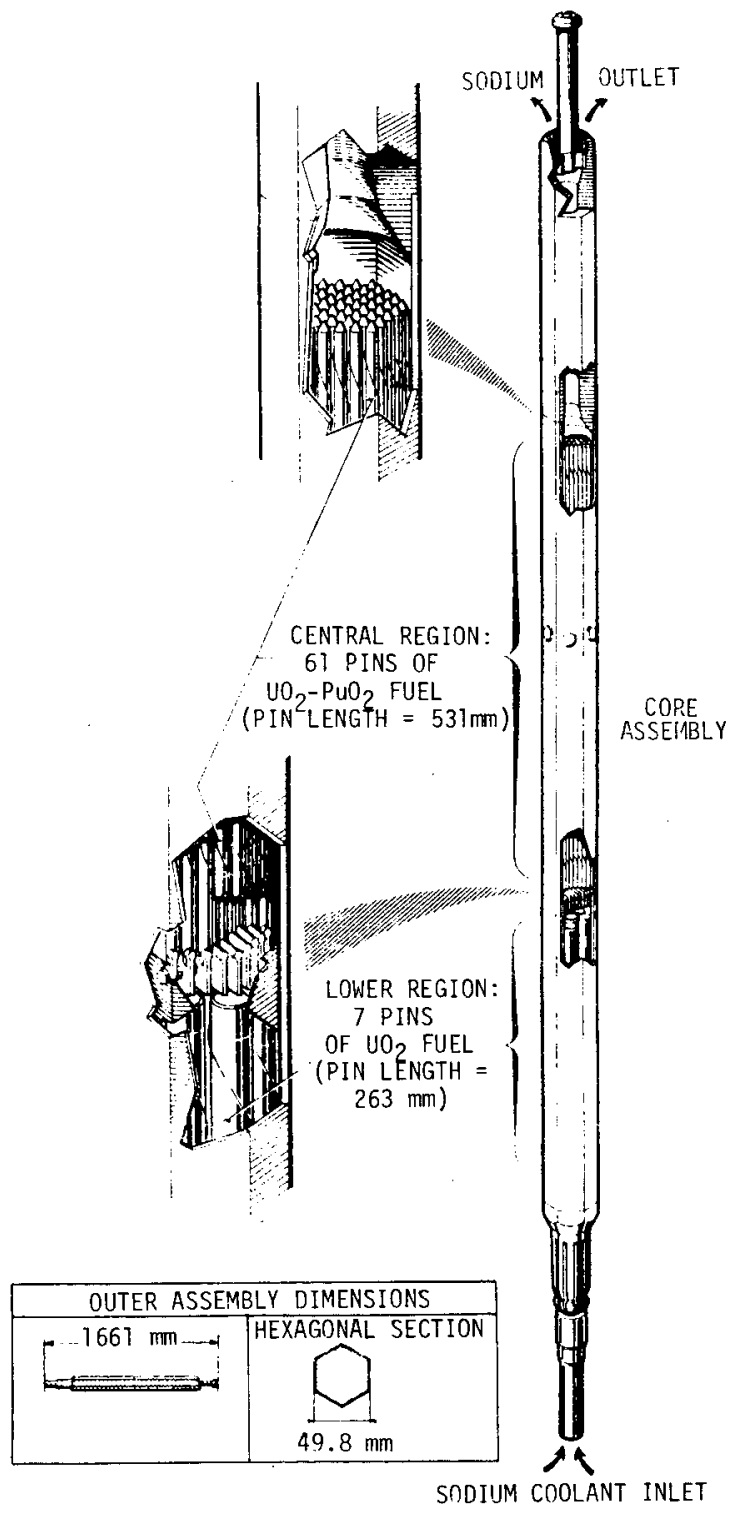

D
总
号
m
† 


\section{B. CORE SUPPORT AND VESSEL INTERNALS}

The core grid gives axial and radial positioning of fuel, fertile, and reflector assemblies and control rods; distributes the sodium flow; and controls the flow through different zones in the core. The grid assembly has been modified from the original design to allow for a greater number of assemblies to receive high-pressure sodium, providing for a possible increase in core diameter.

The grid assembly consists of two horizontal plates separated by $206 \mathrm{~mm}$. The top, or guide, plate is $35 \mathrm{~mm}$ thick, and has openings for passage of assemblies. The bottom, or support, plate is $90 \mathrm{~mm}$ thick, and rests on a support flange. The central parts of the two plates are connected by a hexagonal sleeve. The central area is the high-pressure zone. (Fig. I.B-1, I.B-2, I.B-3.)

The core-catcher assembly ("recuperator" in Fig. I.B-4) was omitted because of questions as to its usefulness and accessibility. The revised plenum arrangement is illustrated by Fig. I.B-5.

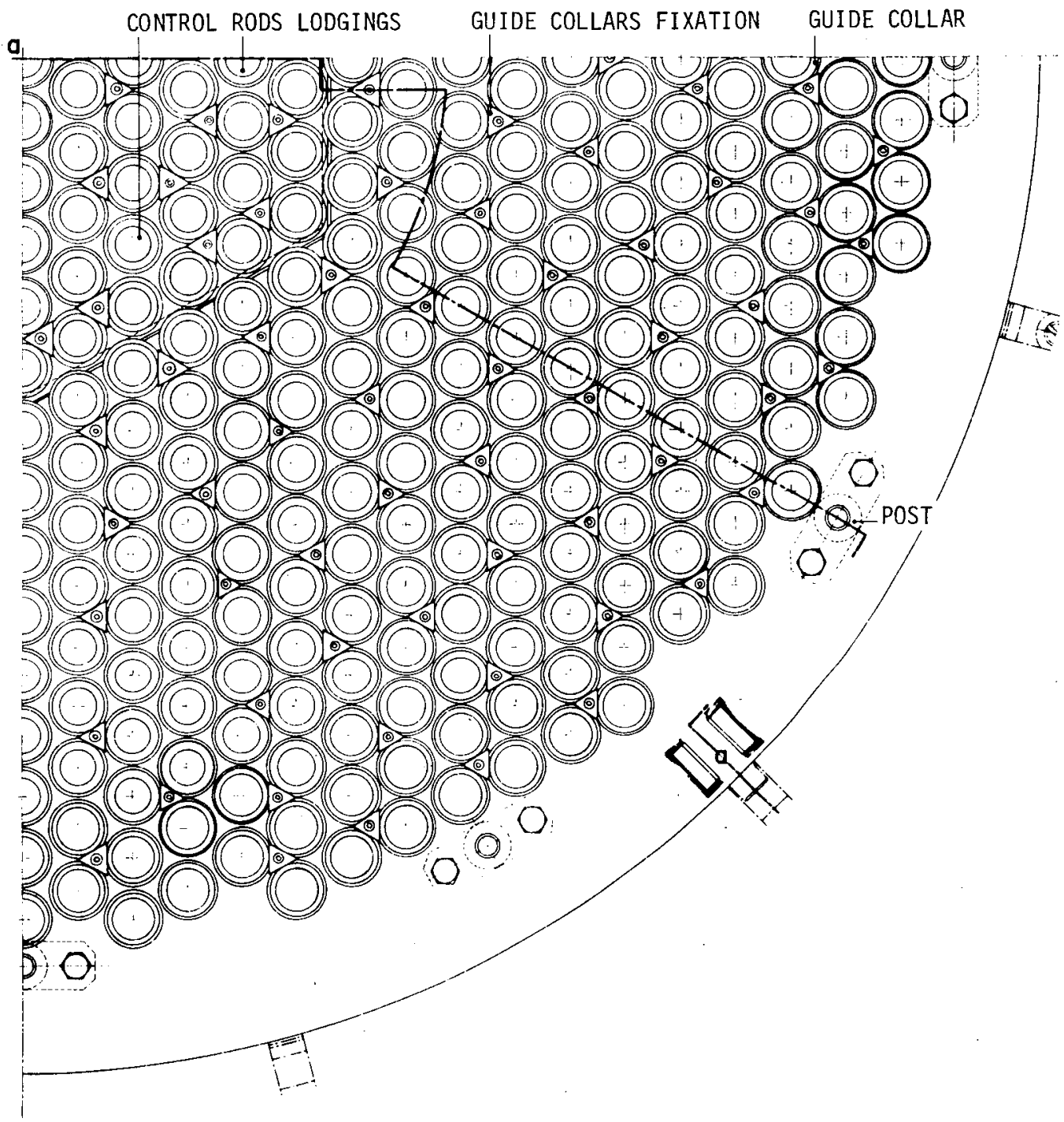

Figure I.B-T. Support Grid-Top View (Ref. 2) 


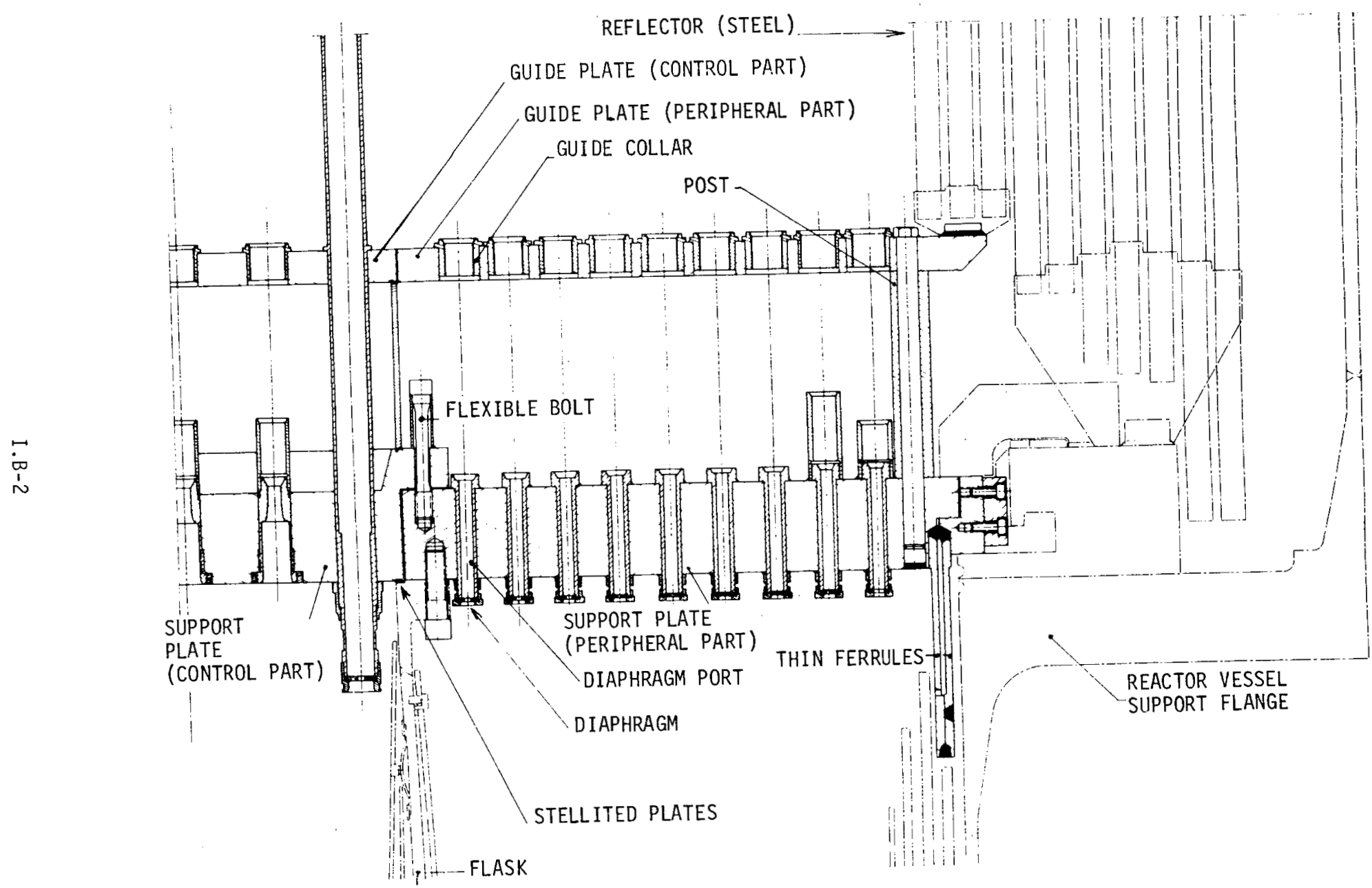

Figure I.B-2. Grid Plenum Cross-Section (Ref. 2) 
RAPSODIE I.B.

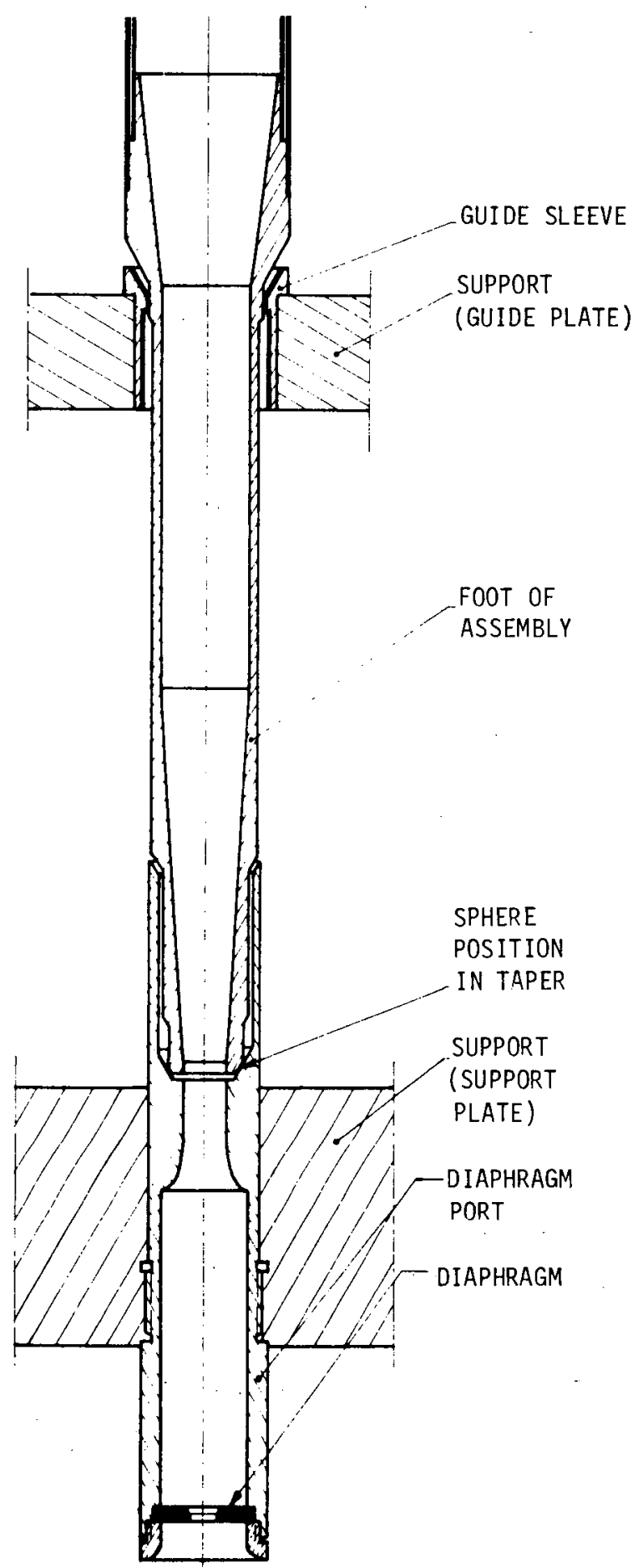

Figure I.B-3. Assembly Foot in Grid-plenum Device (Ref. 2)

I. B-3 


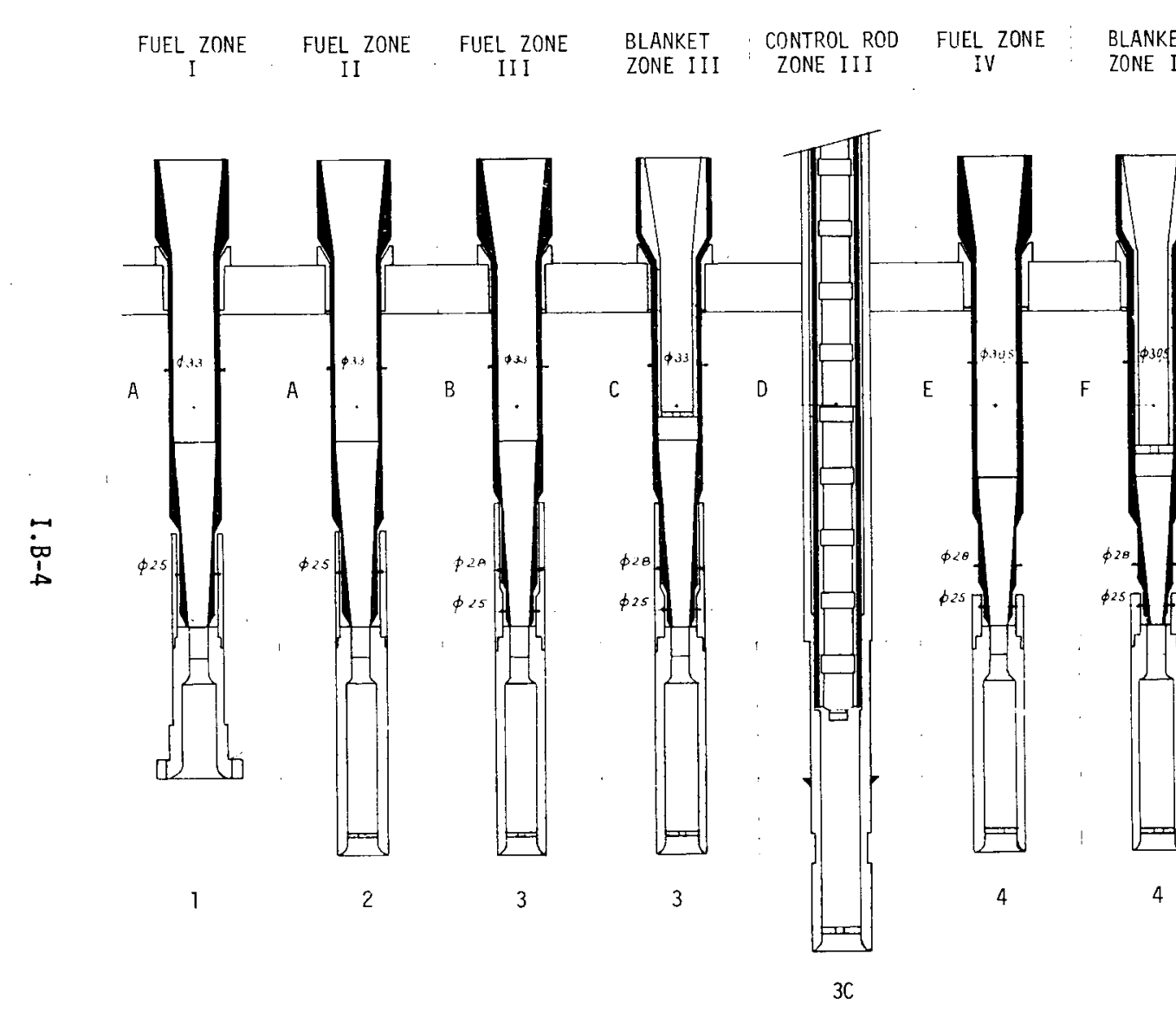

$\begin{array}{clll}\text { BLANKET ZONES STEEL } & \text { SPECIAL LODGING } & \text { STEEL FOR } & \vdots \\ \text { V, VI, VII } & \text { ZONE VII } & \text { IN ZONE VII } & \text { SPECIAL }\end{array}$ FOR FUEL LODGING ZONES I, II IN ZONE VII

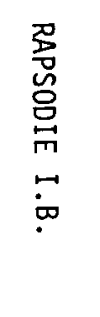

NOTE: THERE ARE 9 TYPES OF ASSEMBLY FEET (A THRU I) AND 8 TYPES OF LODGINGS IN THE SUPPORT PLATE $(1,2,3,3 \mathrm{C}, 4$ $6,7,7$ SPECIAL)

Figure I.B-4. Different Types of Lodgings in the Grid Support (Ref. 2) 


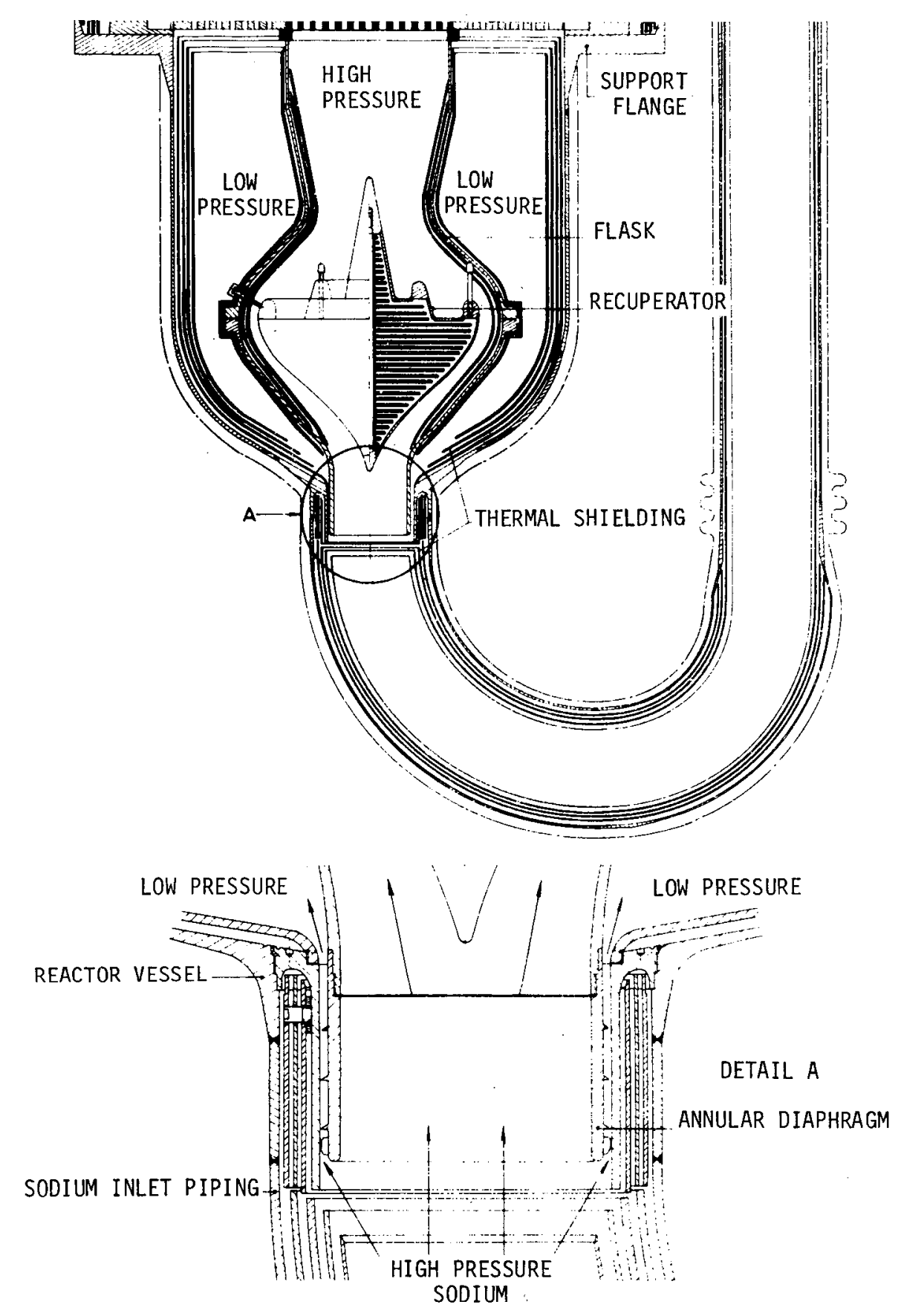

Figure I.B-5. Vessel With "Recuperator" and Annular Diaphragm (Ref. 2) 


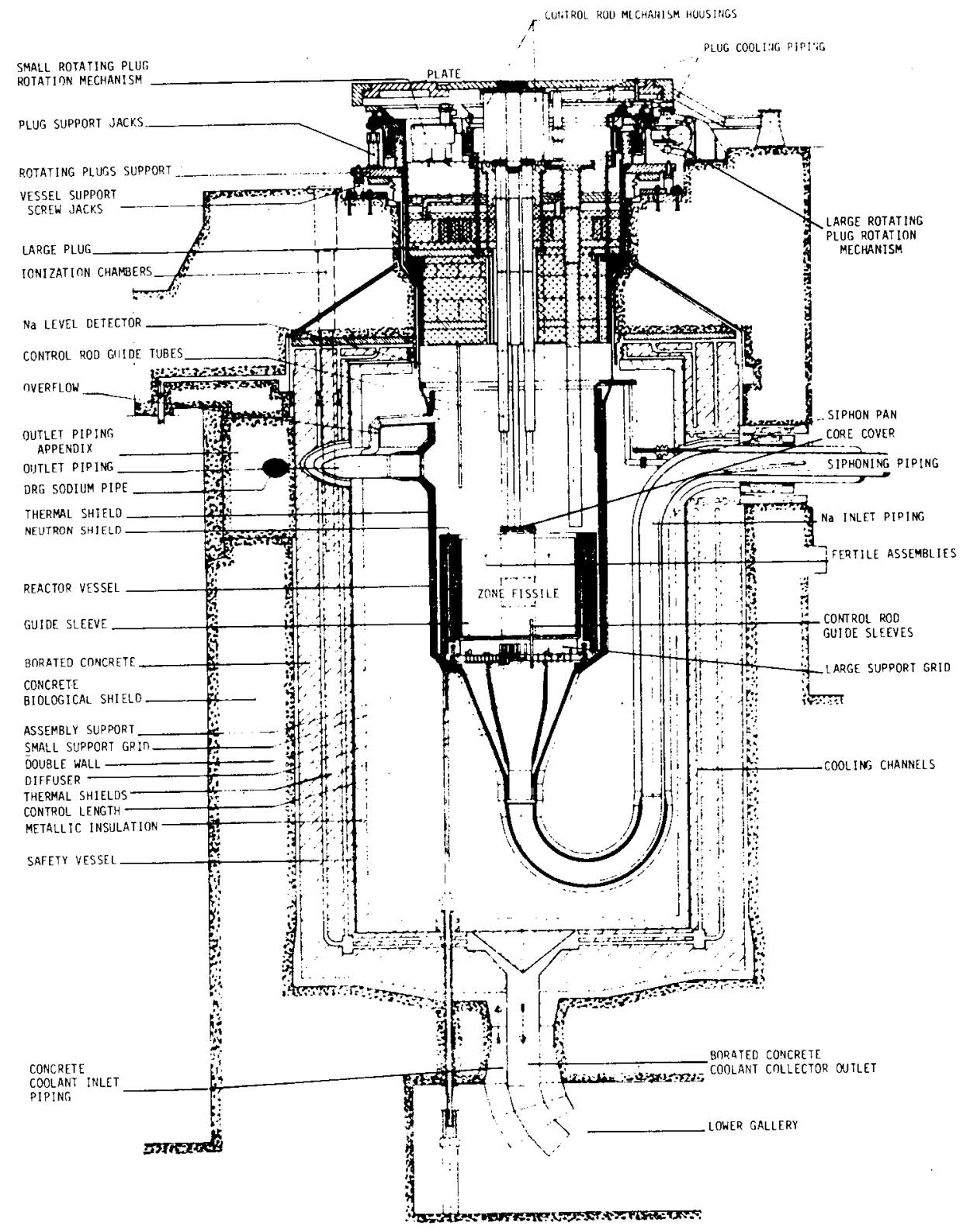

Figure I.B-6. Revised Vessel Arrangement with Diffuser (Ref. 5) 


\section{C. REACTOR VESSELS AND SHIELDING}

The reactor vessel is a clyindrical structure of 316 stainless steel, connected at the lower end to the inlet sodium pipe. The main sleeve has a wall thickness of $15 \mathrm{~mm}$, and receives the outlet piping. A double jacket surrounds the reactor vessel and sodium pipes, providing for circulation of a gas (nitrogen or argon), preheating, and evacuation of residual heat in case of cooling loop malfunction.

The fixed core cover is a steel plat located about $15 \mathrm{~mm}$ above the assembly heads; it reduces sodium flow at the assembly outlets. A large rotating plug is centered on the fixed plate by self-centering ball bearings. A handling channel and two experimental channels pass through it. The small rotating plug is off-set, and supported on the large rotating plug by self-centering ball-bearings. Rapsodie top seals are rotary seals containing a bismuth-tin alloy, fitted in series with a plastic seal. The reactor vessel and vessel covers are suspended at the upper part of a fixed concrete structure in the form of a circular cornice. (Fig. I.C-1, I.C-2, I. C-3 and I.C-4)
Originally, vessel support was designed to transmit the weight of the vessel and internals to five support posts through a support flange, while the fixed plug rested on five rings and supported the two rotating plugs. (Ref. 3, 4, 5.)

A containment tank, the safety vessel, is a mild steel cylindrical structure with a $15 \mathrm{~mm}$ thick wal (Fig. I.C-1 and I.C-2). Thermal insulation consisting of steel caissons filled with steel mesh or alumina elements occupies the space between the vessels. Gas at the interface is nitrogen. Around the safety vessel there is a $600 \mathrm{~mm}$ thick ring of borated graphite bricks and a $400 \mathrm{~mm}$ thick cellular concrete ring. The $70 \mathrm{~mm}$ space between the two rings is cooled by circulating gas. Ordinary and reinforced concrete form the outer shielding layers, with a sleeve of special concrete around the sodium outlet piping that penetrates through the structure. (Ref. 2.) 


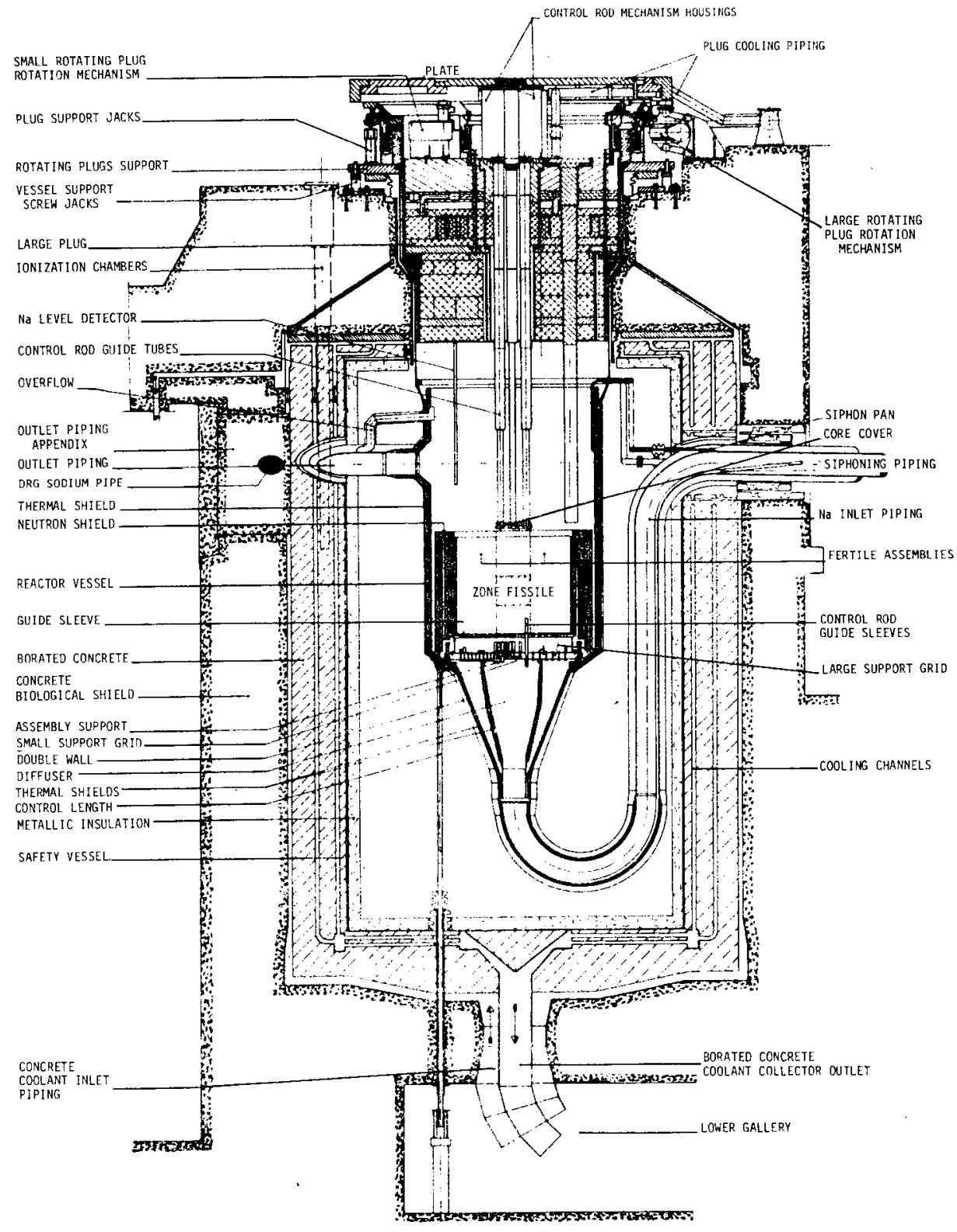

Figure I.C-1. Rapsodie, Vertical Section (Ref. 4)

1.C-2 


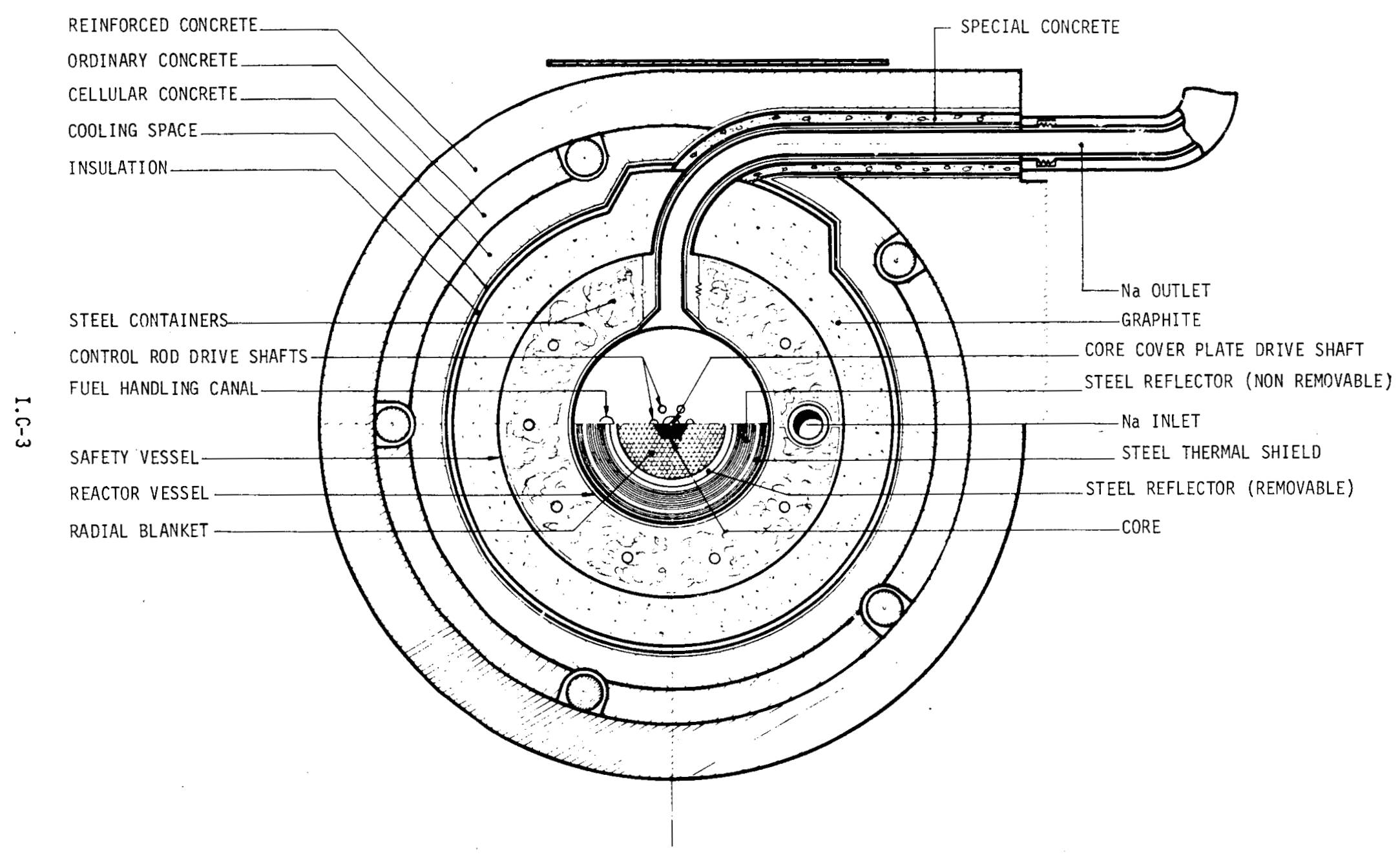

Figure I.C-2. Horizontal Cross-Section of Rapsodie Vessels and Shielding (Ref. 2) 


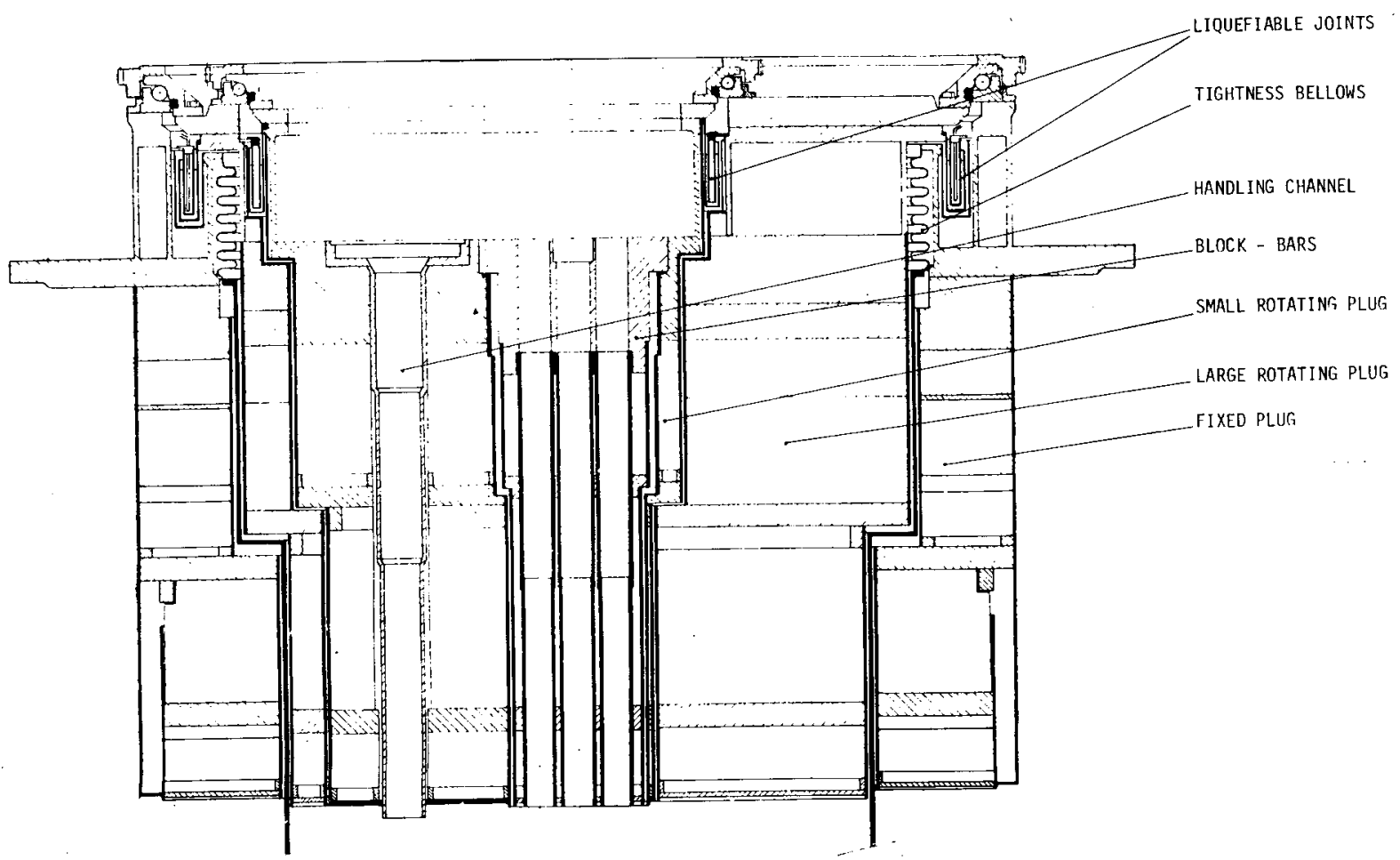

Figure I.C-3. Rotating Plug Structure (Ref. 2)

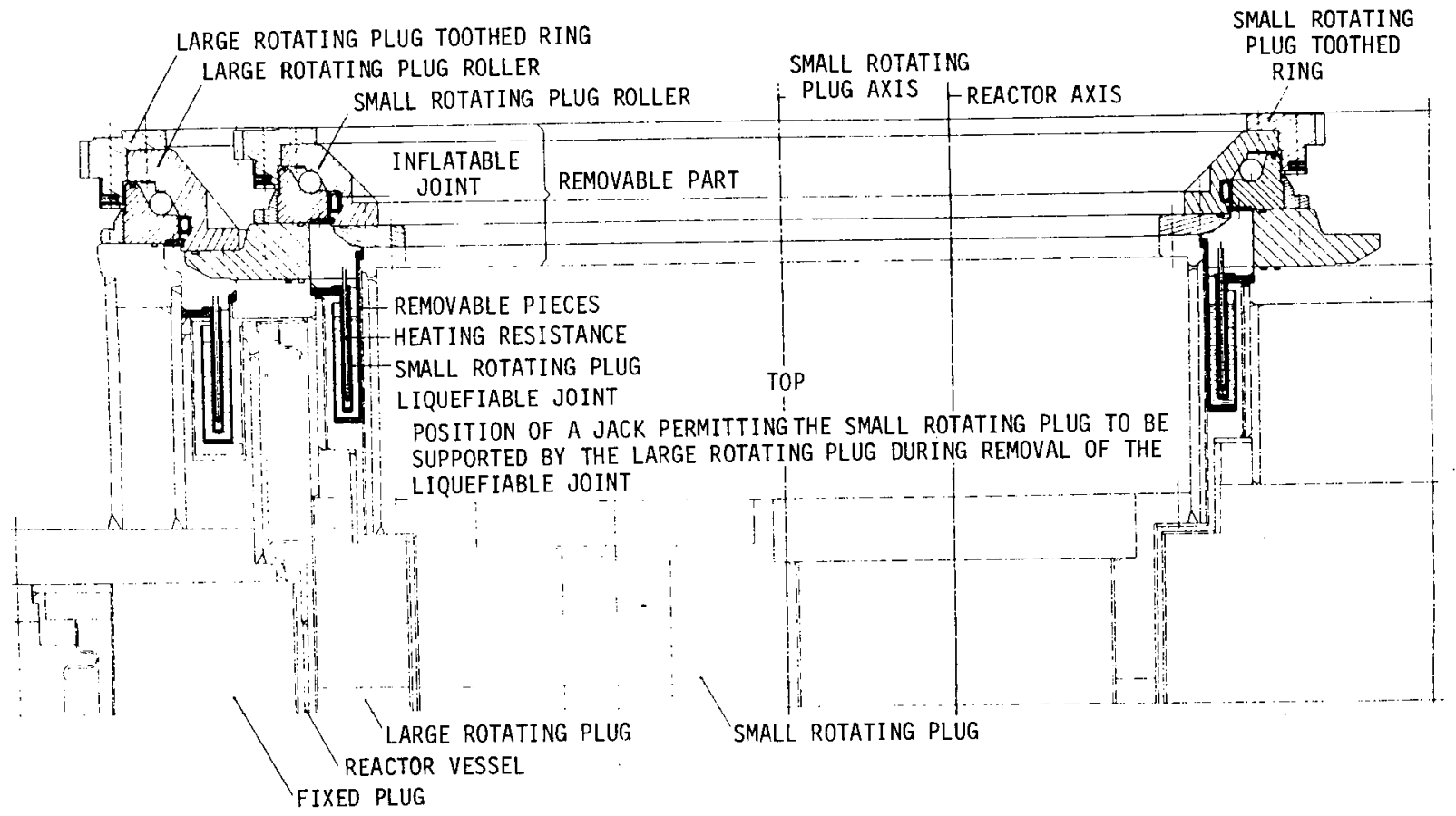

Figure I.C-4. Upper Part of Rotating Plugs and Freeze Seals (Ref. 2)

I. C-4 


\section{D. CONTROL ELEMENTS}

There are six control assemblies located in the periphery of the core. Each rod moves up and down in a hexagonal sleeve $49.8 \mathrm{~mm}$ across the flats. The rod consists of a cylindrical sleeve filled with boron carbide pellets and fitted with a gripping-head similar to that of the fuel element. The boron carbide pellet is $1.5-1.6$ in. dia. The rods are sealed and include a gas plenum for helium generated by neutron reactions with boron.

Drives are located in the upper part of the small plug and can be changed according to the desired funtion: handling, shim, oscillation. The rod moves a distance of $450 \mathrm{~mm}$ in the sleeve. (Fig. I.D-1, I.D-2.)
Vented assemblies are being tested in Fortissimo; both sintered and valved vents are being studied.

7-pin bundle

$\mathrm{B}_{4} \mathrm{C}$ pellets: $38 \mathrm{~mm}$ dia.

Column: $440 \mathrm{~mm}$

Pin 0D: 1.5 in.

Bottom tantalum pellet: $28 \mathrm{~mm}$ high

Hexagonal assembly, 7 rods

Max, specific power: $160 \mathrm{~W} / \mathrm{cm}^{3}$

Antireactivity, 1 rod $1700 \mathrm{pcm}$

$\mathrm{Na}$ coolant flow $500 \mathrm{~cm} / \mathrm{sec}: 410^{\circ} \mathrm{C}$ inlet

(Ref. 13.)

CONTROL ROD DATA

No. of rods

L of borated rods $(\mathrm{cm} / \mathrm{in}$.

Dia borated rod:

ID $(\mathrm{cm} /$ in.)

10 OD $(\mathrm{cm} / \mathrm{in}$.

$B_{10}(\mathrm{~kg} / 1 \mathrm{~b})$

$\mathrm{B}^{10}$, in boron $(\%)$

Total travel (cm/in.)

Velocity:

Raise, (cm/sec)/(in./min)

Lower, (cm/sec)/(in./min)

Scram
Regulating

control rod

2

$45 / 17.7$

$31.4 / 12.4$

$43.5 / 17.1$

$0.1 / 0.22$

18.8

$45 / 17.7$

$0.5 / 11.8$

$0.5 / 11.8$
Safety and

compensation

4

$45 / 17.7$

$31.4 / 12.4$

$43.5 / 17.1$

$1.0 / 2.2$

90

$45 / 17.7$

$36.0 / 850$

$360.0 / 8500$

$0.4 \mathrm{sec}$ for $90 \%$ of travel

(Refs. 2, 3.) 
RAPSODIE I.D.
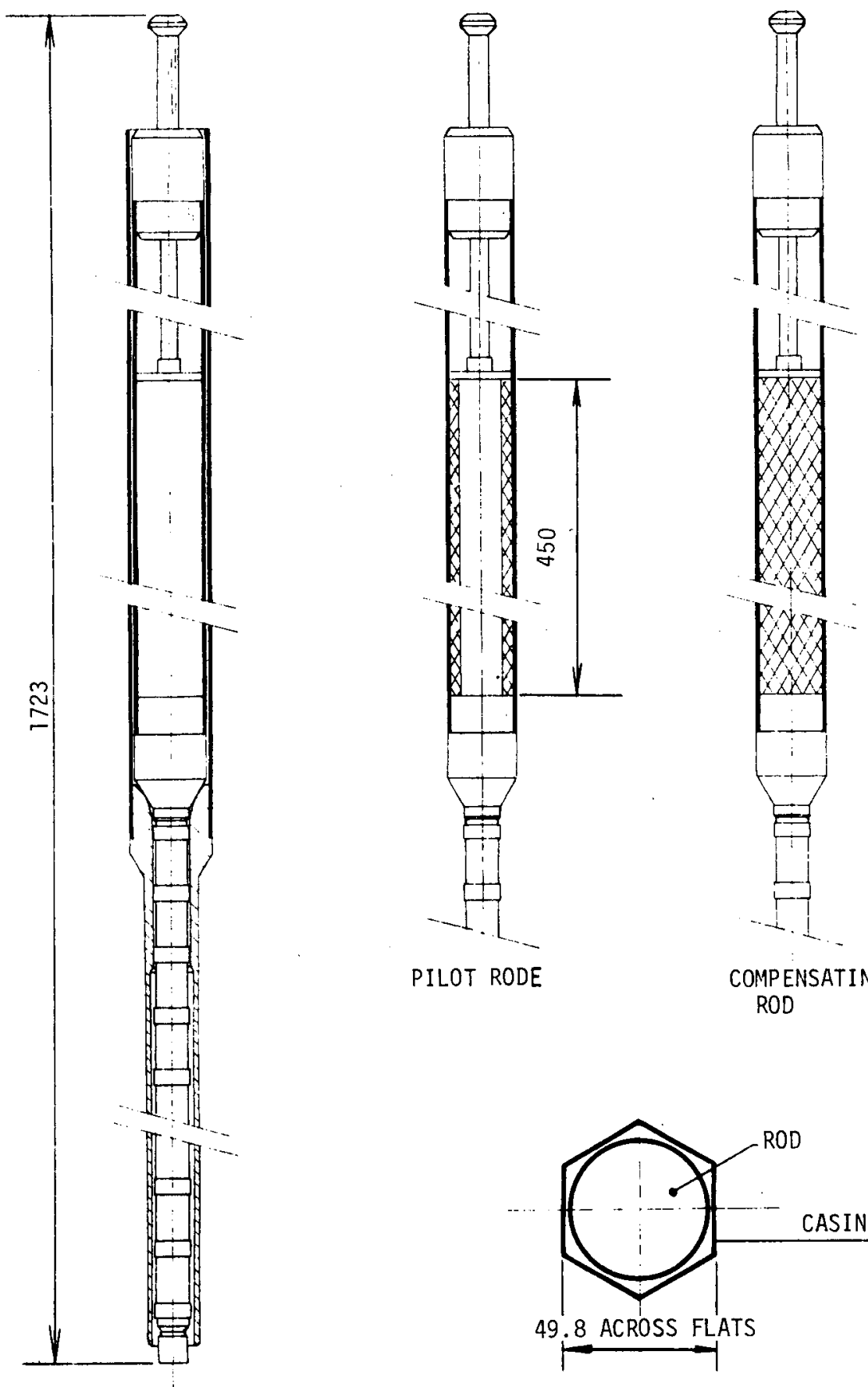

COMPENSATING

ROD

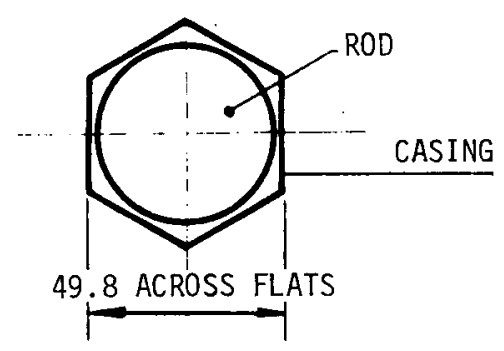

Figure I.D-1. Rapsodie Control Rod and Sheath (Ref. 2)

$$
\text { I.D-2 }
$$




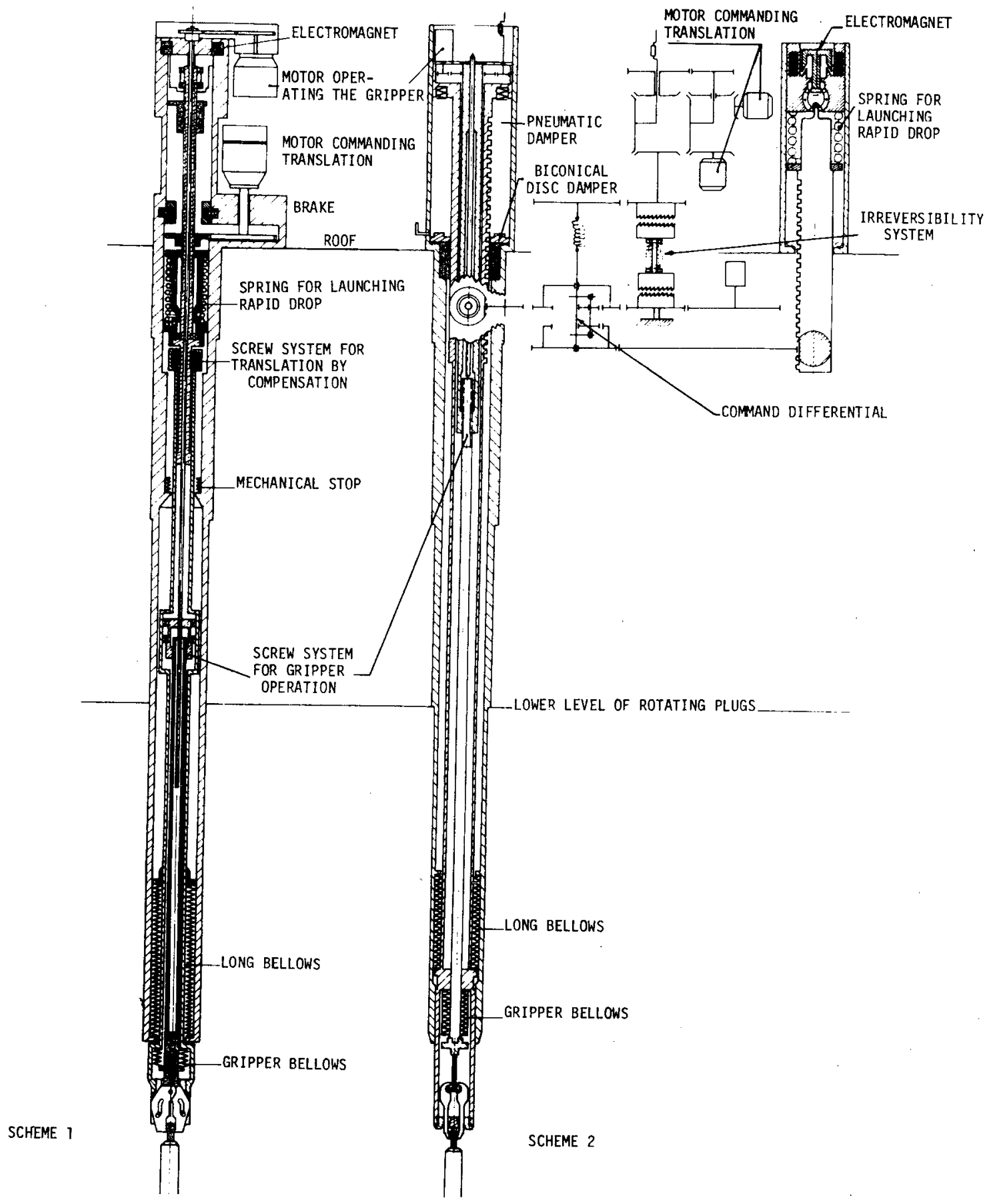

Figure I.D-2. Rapsodie Control Rod Mechanisms (Ref. 2) 


\section{E. HEAT TRANSFER SYSTEMS}

Heat transfer is by means of a two-10op system. The two primary loops have doublewall piping, and each is located in a separate chamber. Primary pipes are jacketed and heated. Sodium flows into the core through the inlet piping at the lower end of the reactor vessel, is distributed into highpressure and low-pressure zones in the plenum structure, flows upward through the core to the outlet piping. Flow is to the shell side of a vertical tube-and-shell heat exchanger. A vertical centrifugal pump moves the sodium from the intermediate heat exchanger back to the reactor.

\section{Parameters}

Piping, reactor $\rightarrow$ IHX $300 \mathrm{~mm}$ dia

Power/loop $10 \mathrm{MWt}$

Flow 496,000 1b/hr

Core inlet temperature $410-450^{\circ} \mathrm{C}$

Core outlet temperature $500-540^{\circ} \mathrm{C}$

Max velocity of sodium in core $6.4 \mathrm{ft} / \mathrm{sec}$

Pressure drop in reactor 49 psi

Pressure drop in loop 3.8 psi

Secondary coolant is sodium (NaK was called for originally). Loops are of single wall stainless steel piping. Flow is downward through the tubes of the intermediate heat exchanger and to the terminal sodium-air heat exchanger. It is pumped back to the intermediate heat exchanger. There is no shielding for the inactive sodium system. (Refs. 5, 8.)

The intermediate heat exchanger is a vertical tube-and shell unit with a floating lower tube sheet. It is installed in a vertical sleeve which maintains the sodium surface. Expansion bends in the upper parts of each tube compensate for differential expansion between tubes. The units are top-suspended. (Fig. I.E-1.)

\begin{tabular}{lcc}
\multicolumn{3}{c}{ Specifications } \\
Primary (she11) \\
side Secondary (tube) \\
Inlet Temp ( ${ }^{\circ}$ F) & 644 & 428 \\
Outlet Temp ( ${ }^{\circ} \mathrm{F}$ ) & 428 & 590 \\
Op. pressure (psig) & 2.9 & 24 \\
Flow (1b/hr) & $675 \times 10^{3}$ & $875 \times 10^{3}$ \\
She11 ID (in.) & 34.8 & \\
Shel1 wall (in.) & 0.63 & \\
No. tubes & & 888 \\
Tube 0D (in.) & & 0.551 \\
Tube wal1 (in.) & & 0.079 \\
Tube pitch (in.) & 0.78 \\
Effective tube sur- & & 904 \\
face (ft2) &
\end{tabular}

(Ref. 5, 8.)

The primary pump, located in the cold leg, is a vertical centrifugal unit with a free sodium level. Delivery is axial and aspiration is lateral. The outer cylinder is fixed, while the pump unit can be dismounted and includes a shield plug. The unit is top-suspended. (Fig. I.E-2.)

For Fortissimo, the impellers of the pumps were changed to increase output to $550 \mathrm{~m}^{3} / \mathrm{hr}$ per pump.

Secondary pumps are also vertical centrifugal units. (Ref. 5.)

An electromagnetic pump collects sodium at the outlet of the terminal heat exchanger and sends it to a cold trap in the secondary circuit purification line. Flow is $1000 \mathrm{~kg} /$ $\mathrm{hr}$. The rate is controlled by an electromagnetic flow-meter at the cold-trap outlet.

In the primary loop, an electromagentic pump withdraws sodium into the overflow reservoir and sends it back to the reactor through $33 / 42 \mathrm{~mm}$ dia. piping which feeds the purification line. (Fig. I.E-3.) (Ref. 8.) 
RAPSODIE I.E.

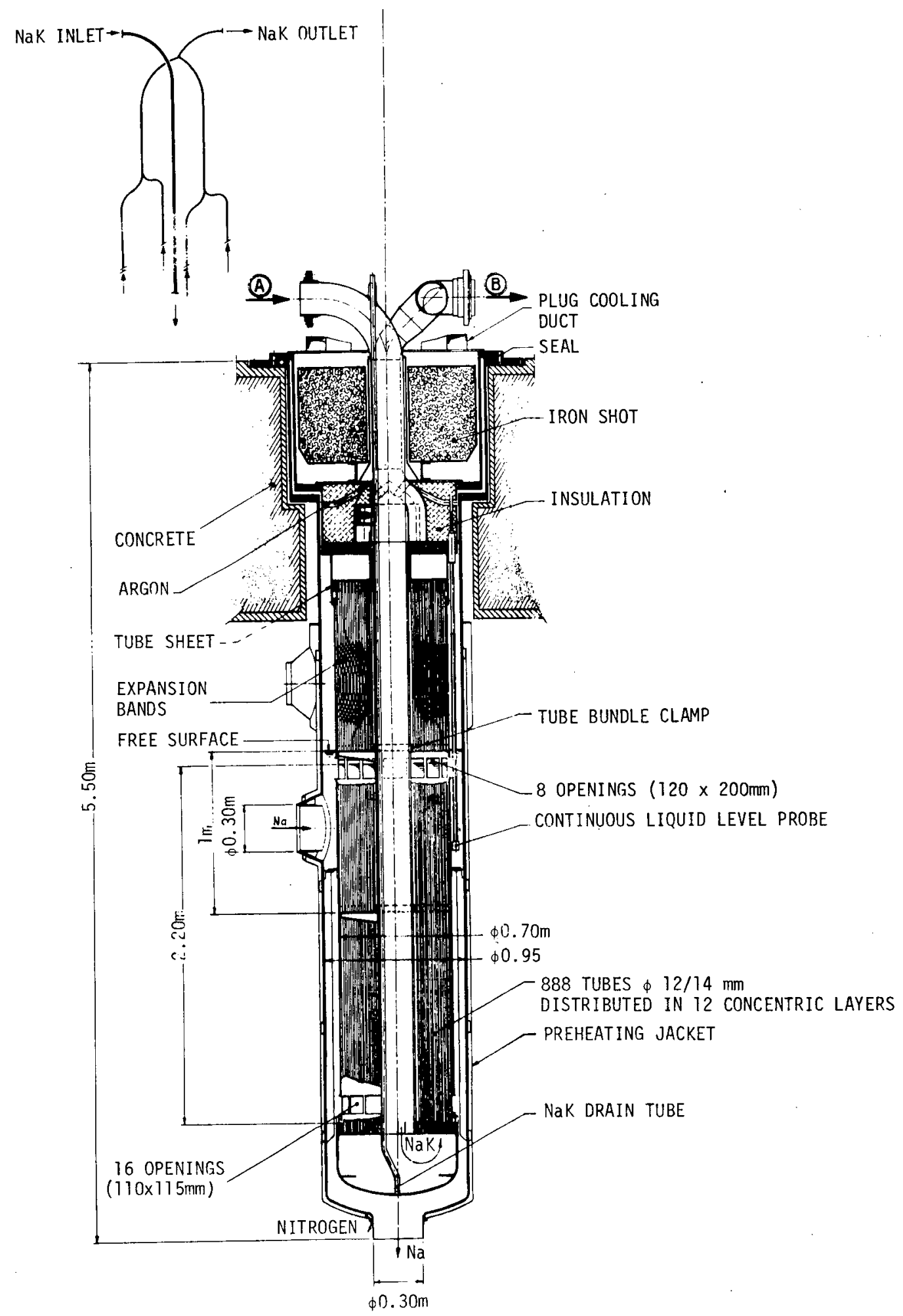

Figure I.E-1. Rapsodie Intermediate Heat Exchanger (Ref. 5)

I.E-2 


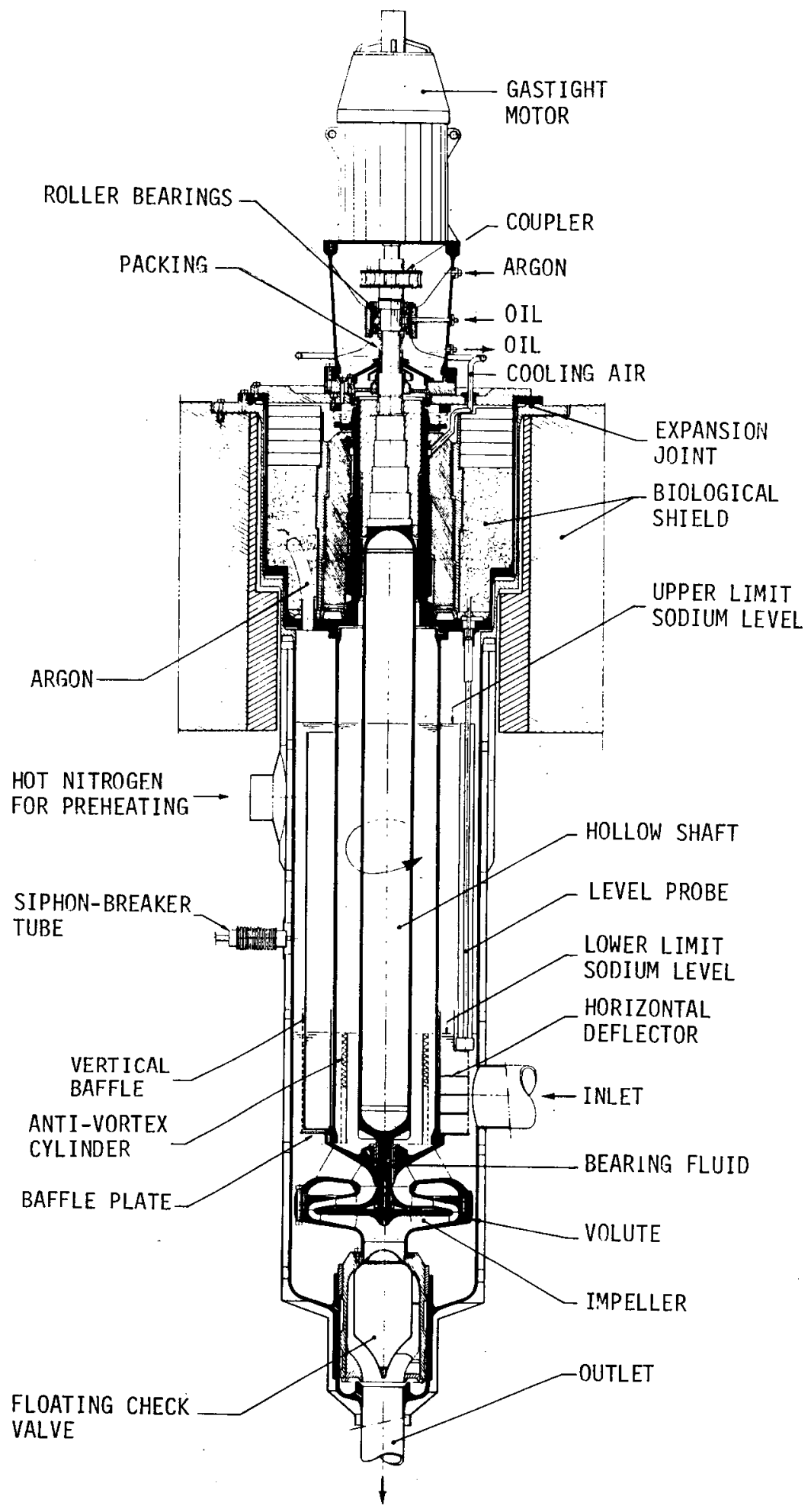

Figure I.E-2. Rapsodie Primary Pump (Ref. 5)

\section{E-3}


RAPSODIE I.E.

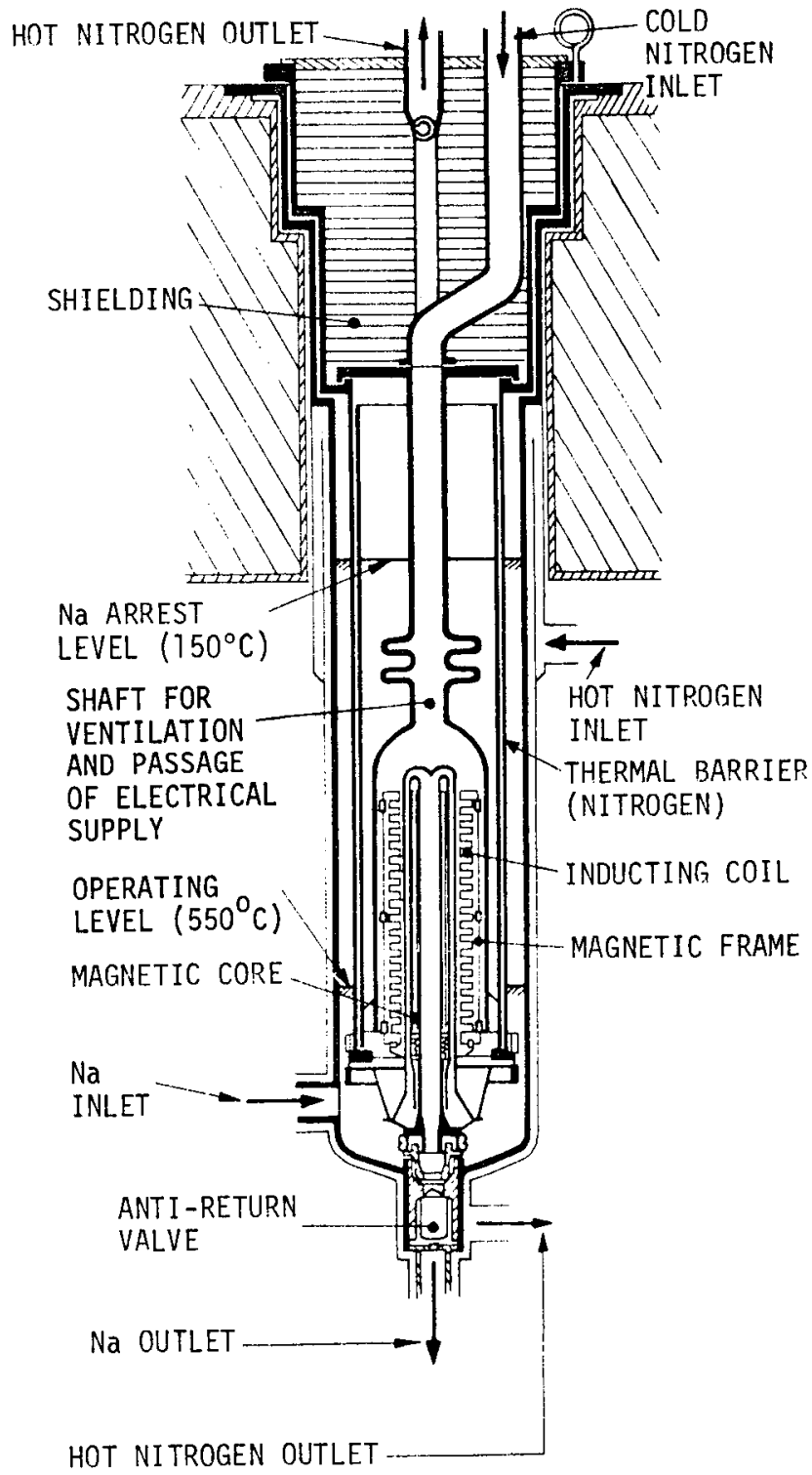

Figure I.E-3. Rapsodie Electromagnetic Pump (Ref. 1)

I. E-4 


\section{F. SODIUM PURIFICATION AND INSTRUMENTATION}

Each of the secondary loops has a purification circuit which includes an alternating current electromagnetic pump, a cold trap, a filter, and a plugging indicator. (Fig. I.F-1.) There is no safety vessel or radiation shielding. (Ref. 8.)

The secondary cold trap (Fig. I.F-2) is a cylindrical vessel, cooled externally with a flow of air and containing an exchangereconomizer coil and steel wool for trapping the oxides.

Na flow $(\mathrm{kg} / \mathrm{hr}) \quad 1000$

Exchanger operation: Na inlet temp $\left({ }^{\circ} \mathrm{C}\right) 550$ $\mathrm{Na}$ outlet temp $\left({ }^{\circ} \mathrm{C}\right) 160$

Purified $\mathrm{Na}$ inlet temp $\left({ }^{\circ} \mathrm{C}\right) 130$

Purified $\mathrm{Na}$ outlet temp $\left({ }^{\circ} \mathrm{C}\right) 520$

Trap operation: inlet temp $\left({ }^{\circ} \mathrm{C}\right) 160$

Air flow $(\mathrm{kg} / \mathrm{hr}) \quad 4050$ out let temp $\left({ }^{\circ} \mathrm{C}\right) 130$

\section{(Ref. 8.)}

The plugging indicator (Fig I.F-3) consists of a finned tube cooled externally by a flow of air and enclosing the return pipe. Sodium cooled in the annular space passes through six orifices of the plugging indicator and leaves by a tube interior to that of the cooler. The four-meter length of the two concentric tubes constitutes an economizer.

Flow $(\mathrm{kg} / \mathrm{hr}) 200$

Economizer inlet temp $\left({ }^{\circ} \mathrm{C}\right) 540$

Economizer outlet temp $\left({ }^{\circ} \mathrm{C}\right) 512$

Plugging indicator inlet temp $\left({ }^{\circ} \mathrm{C}\right) 188$

Plugging indicator outlet temp $\left({ }^{\circ} \mathrm{C}\right) 160$

Cold point, temp minimum $\left({ }^{\circ} \mathrm{C}\right) 110$

Air flow $(\mathrm{kg} / \mathrm{hr}) 200$

Al1 equipment of the primary purification circuit is in shielded cells (Fig. I.F-6). The circuit consists of an exchanger-economizer, a plugging indicator, the Rhometer circuit, and cold-traps. The exchangereconomizer is a bundle of 19 tubes welded to two tube plates. The body of the exchanger is a hairpin-shaped pipe. The plugging indicator and filter are identical to those of the secondary circuit. The Rhometer circuit consists of an exchanger-economizer as a bundle of seven tubes welded to two tube plates, and a finned tube cooler. Sodium circulates inside this piping. The annular space formed by a cladding is supplied with a flow of nitrogen. There is a buffer reservoir with sodium. All valves in the system are of the single-bellows type, enclosed in a steel box with outer insulation and heating. (Ref. 6, 8.)

The primary cold trap (Fig. I.F-7.) differs from the secondary cold trap by the provision of biological shielding and direct cooling of the interior by means of a coil for nitrogen circulation. There is no economizer. Equipment for the primary purification line is contained in a metallic shield located in another cell.

Flow-meters are of the electromagnetic type. A double safety containment is provided. The flow in each primary loop is iegulated by a flow-meter; others are provided for different pipe-lines of the installation.

Temperatures are measured by chromelalumel thermocouples clad in stainless steel, lodged in gloved fingers in pipes or equipment (Ref. 2.)

Level indicators are of two types. Continuous probes (Fig. I.F-8.) monitor the level between two defined points. They consist of three vertical stainless steel tubes connected at the lower part, in a box within which there is a resistance compensator for temperature effect. The box is located at the end of a support tube welded to the upper part of the vessel to be monitored. The box is supplied by direct current.

The discontinuous probe (Fig. I.F-9) consists of a stainless steel tube located vertically in the reservoir to be monitored. It is closed at the bottom. An insulated stainless steel wire passes into the interior and is welded to the base of the tube. It is fed by alternating current between the reservoir mass and the copper wire by means of an adjustable resistance. For the two primary loops, there are about sixty of these probes, varying in length from 0.5 to 3 meters. (Ref. 2.) 
RAPSODIE I.F.

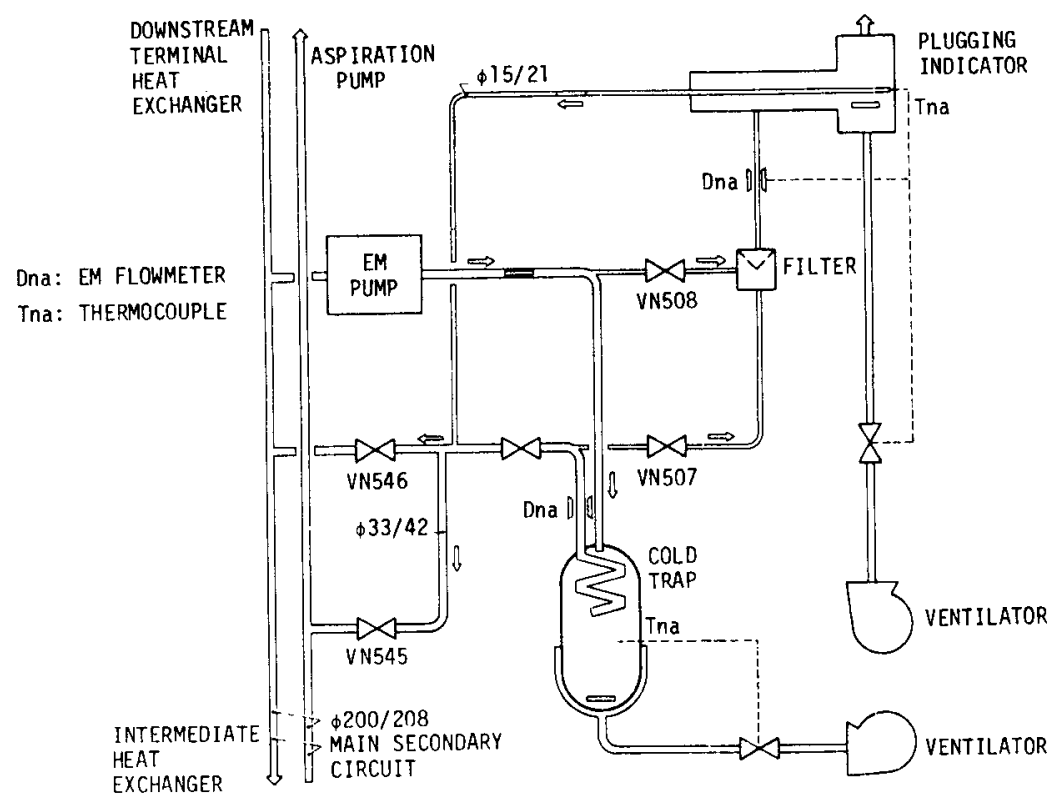

Figure I.F-1. Rapsodie Secondary Purification Circuit (Ref. 8)

I. F-2 
RAPSODIE I.F.

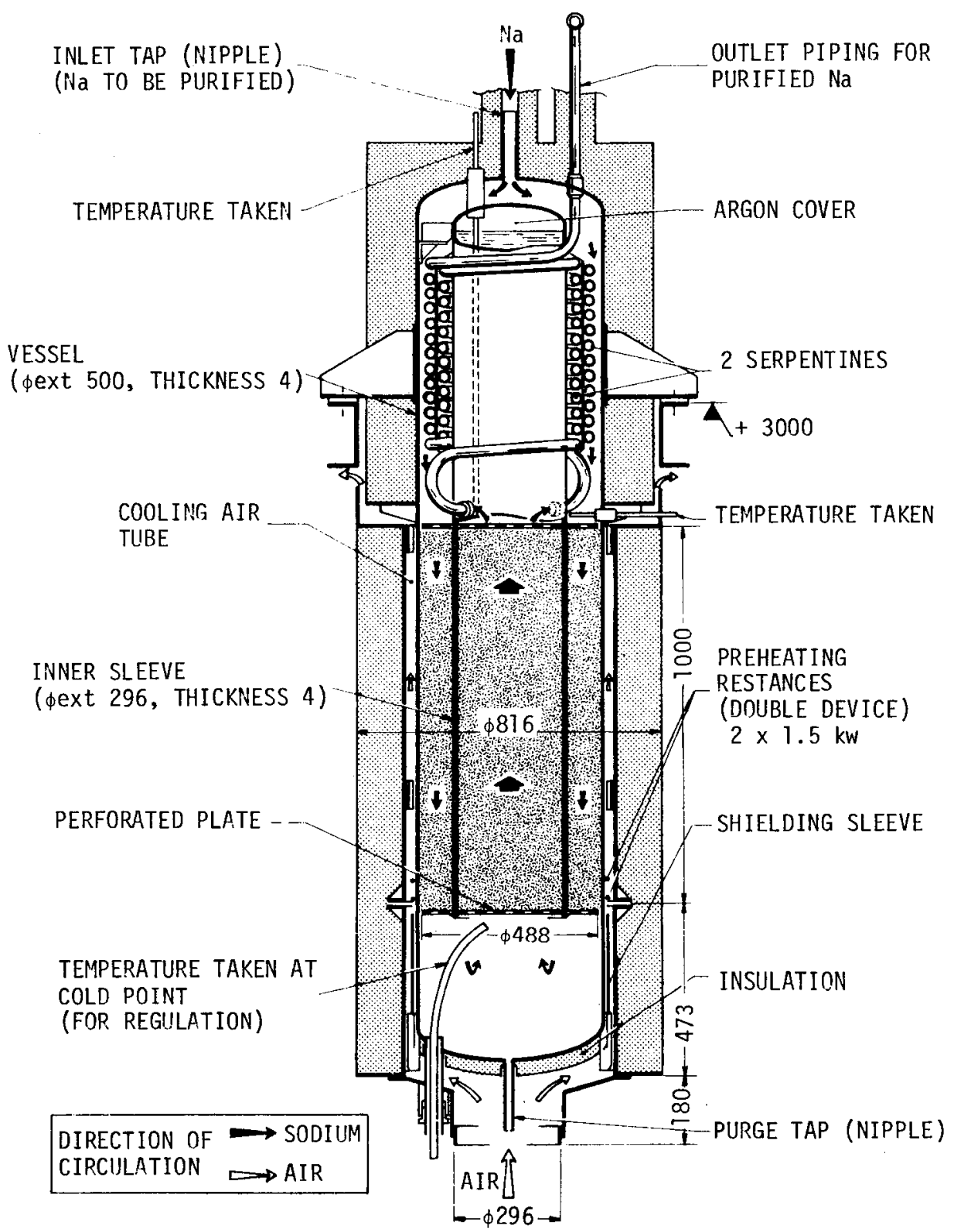

Figure I.F-2. Rapsodie Secondary Cold Trap (Ref. 8)

I. F-3 


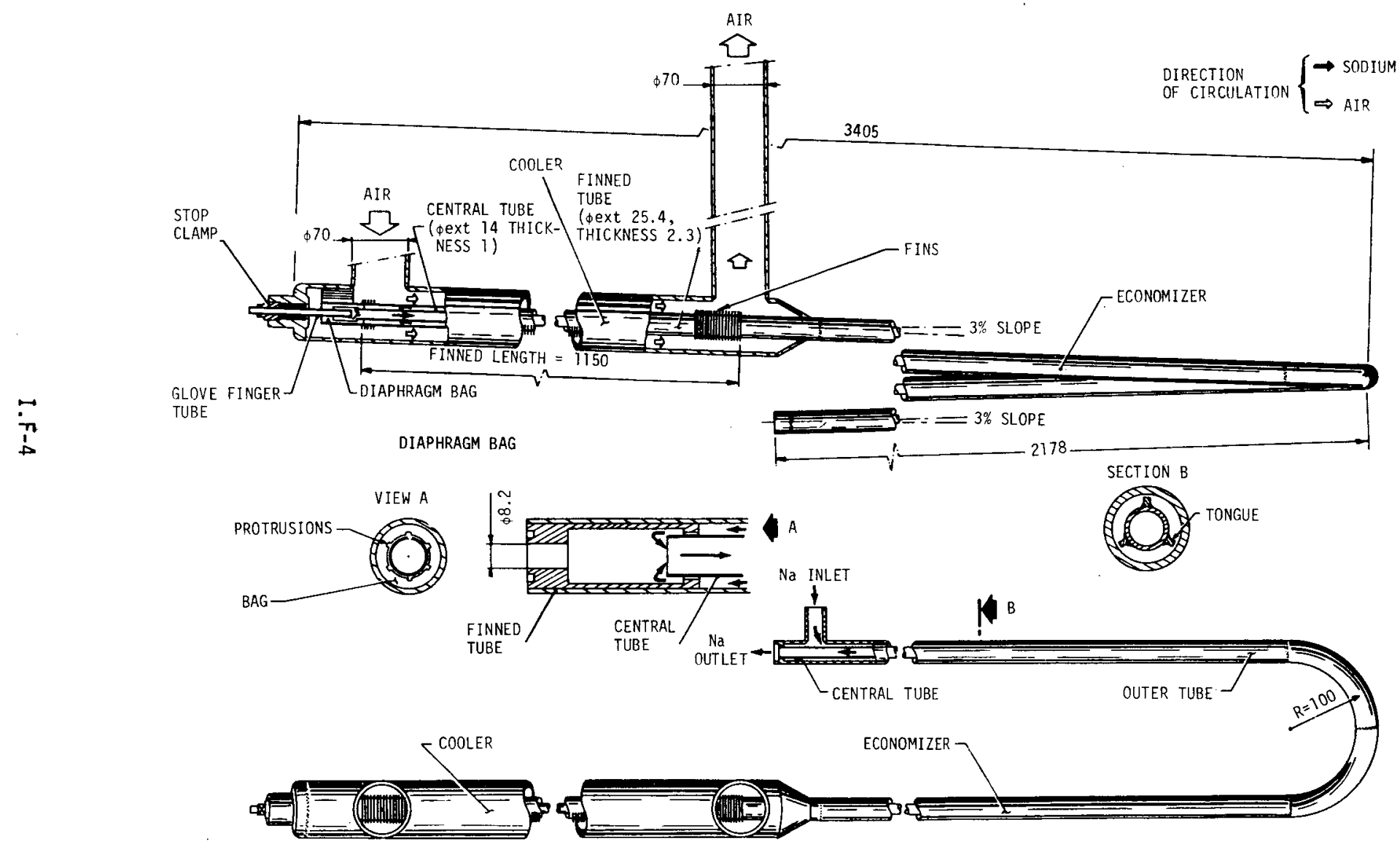

Figure I.F-3. Rapsodie Plugging Indicator (Ref. 8) 


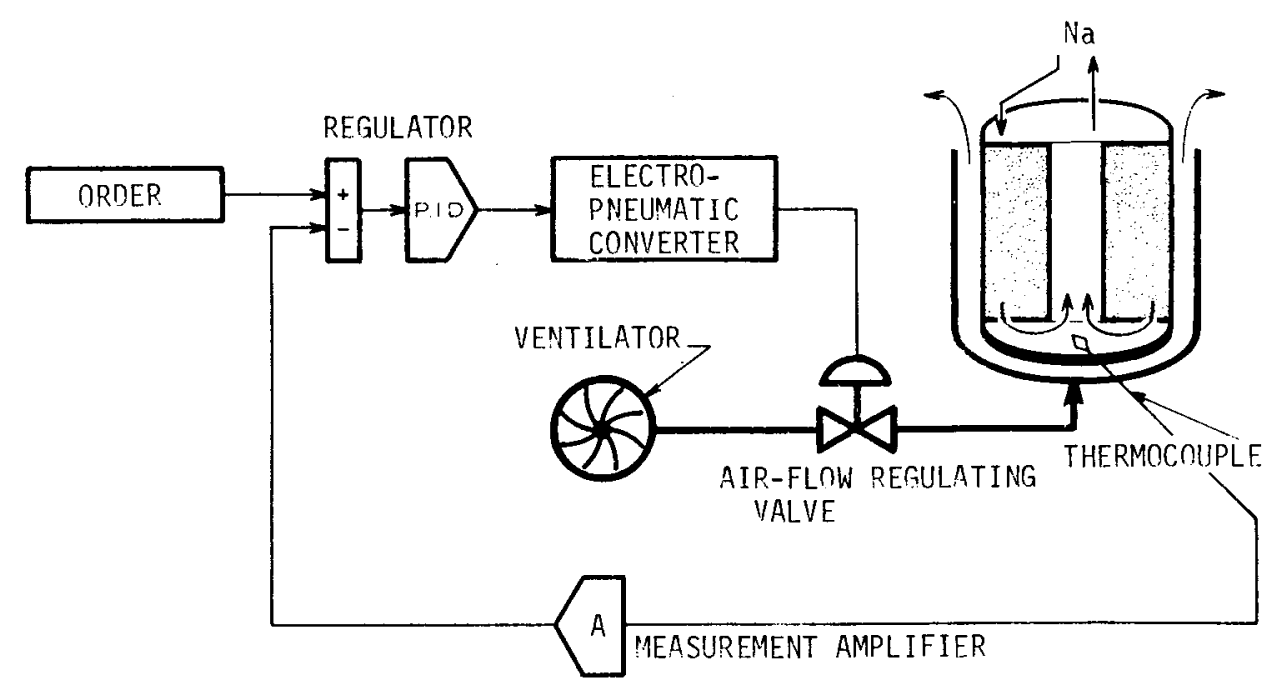

Figure I.F-4. Rapsodie Cold Trap Regulation (Ref. 8)

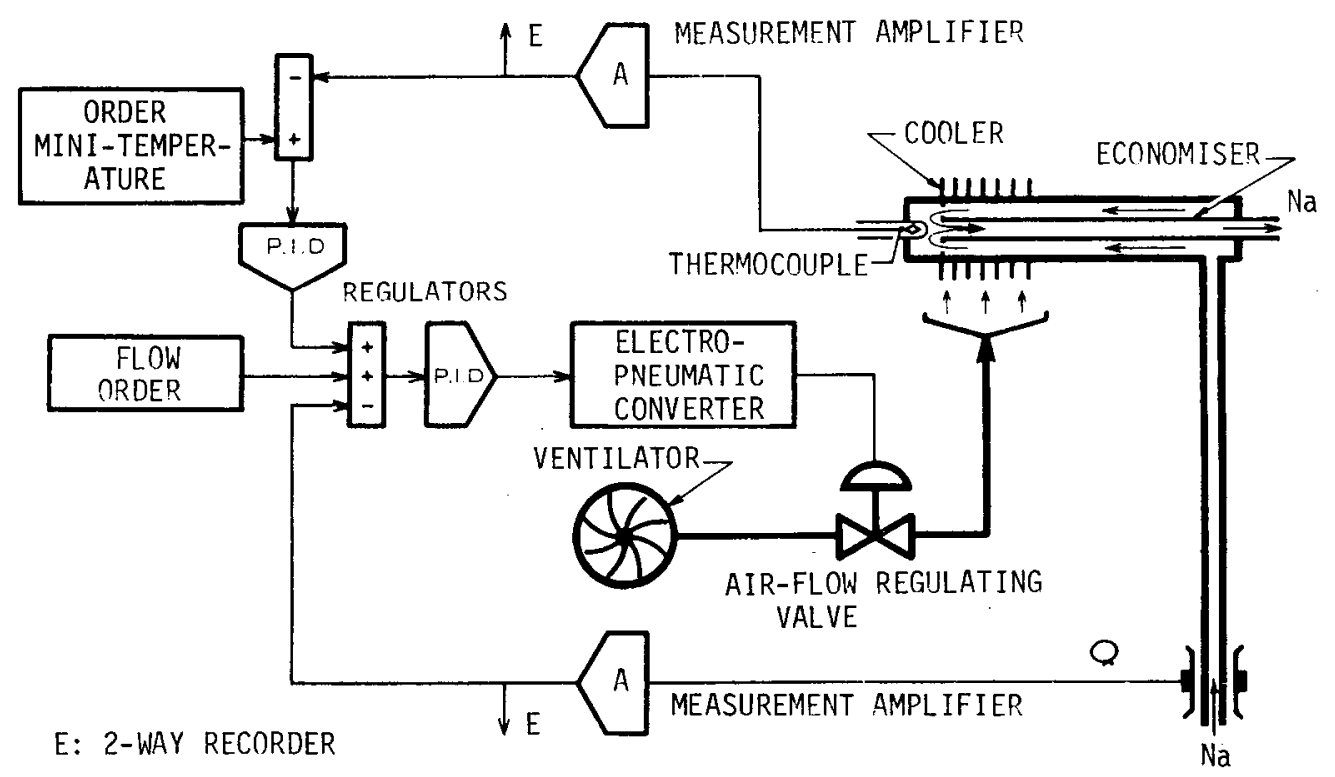

Figure 1.F-5. Rapsodie Plugging Meter Regulation (Ref. 8) 


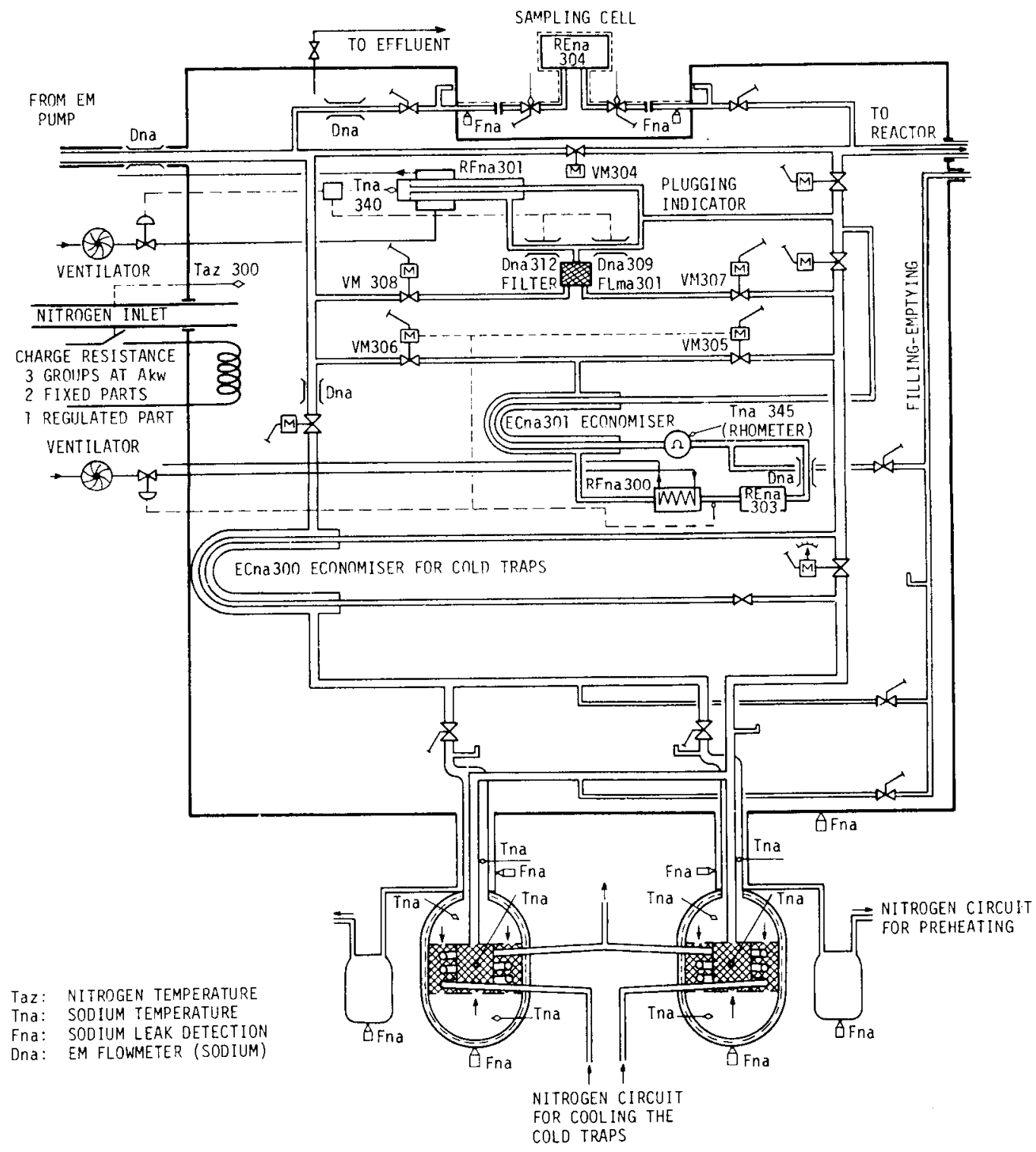

Figure I.F-6. Rapsodie Primary Purification Loop and Chamber (Ref. 8) 


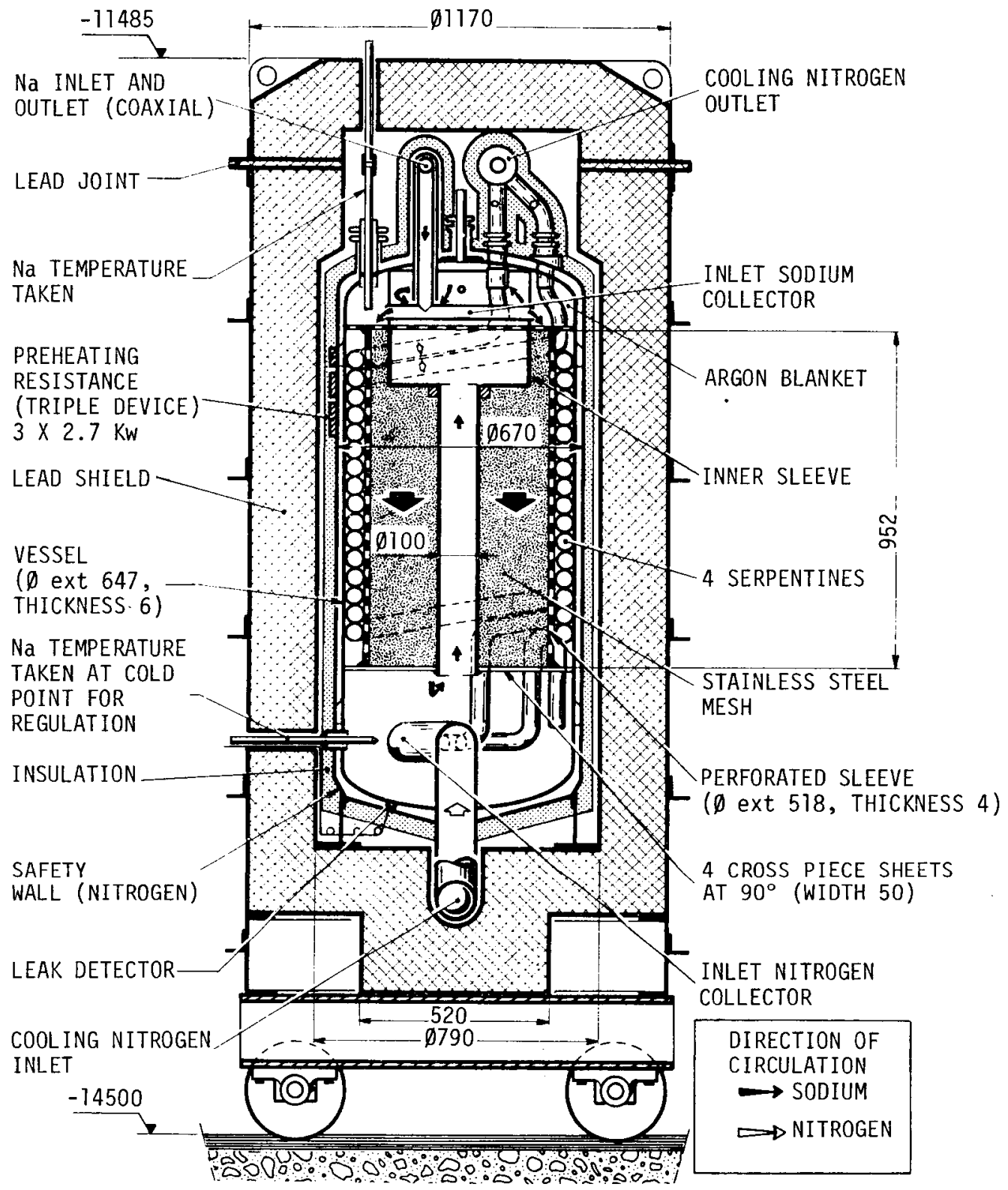

Figure I.F-7. Rapsodie Primary Cold Trap (Ref. 8) 
RAPSODIE I.F.

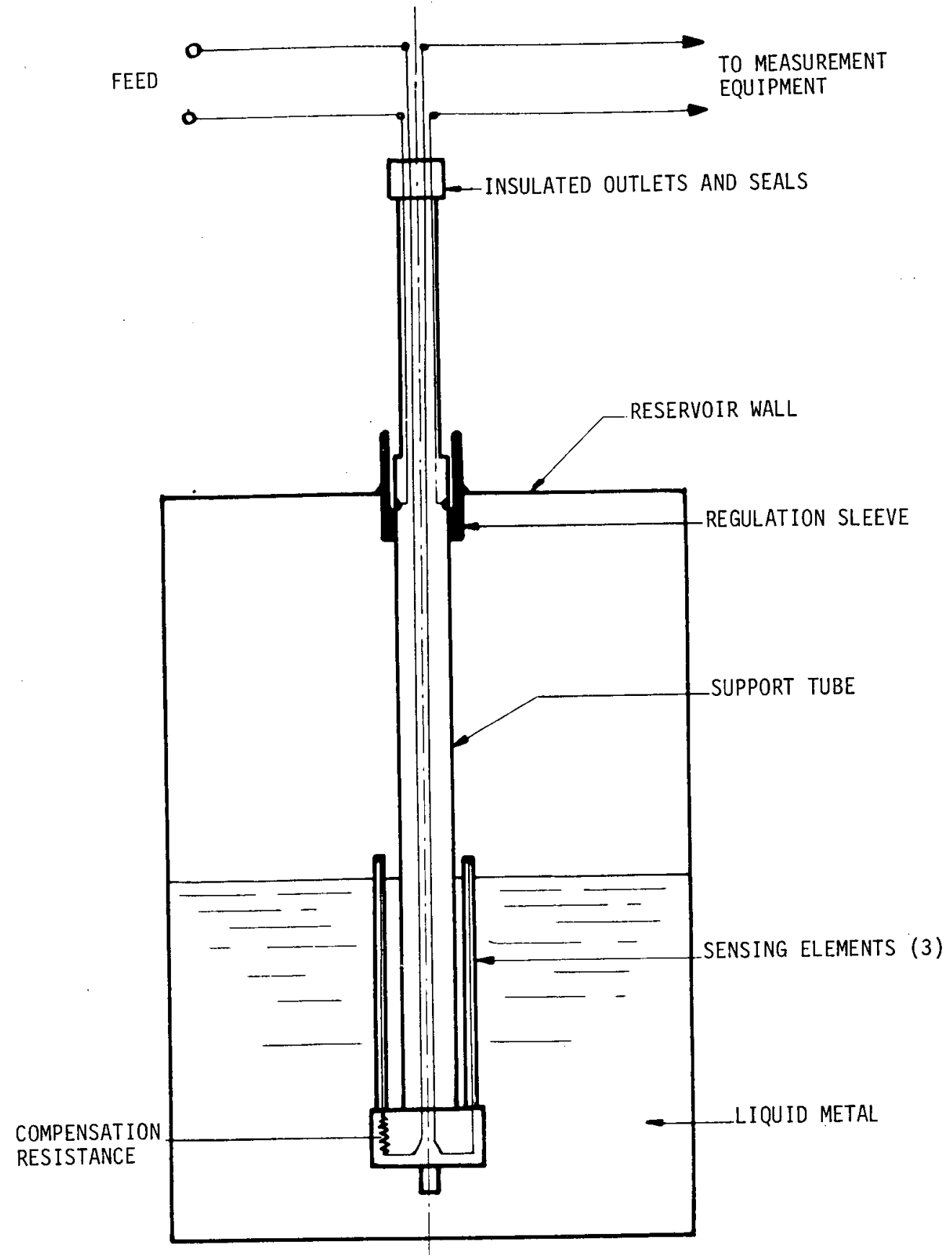

Figure I.F-8. Rapsodie Continuous Sodium Level Probe (Ref. 2)

$$
\text { I. F-8 }
$$




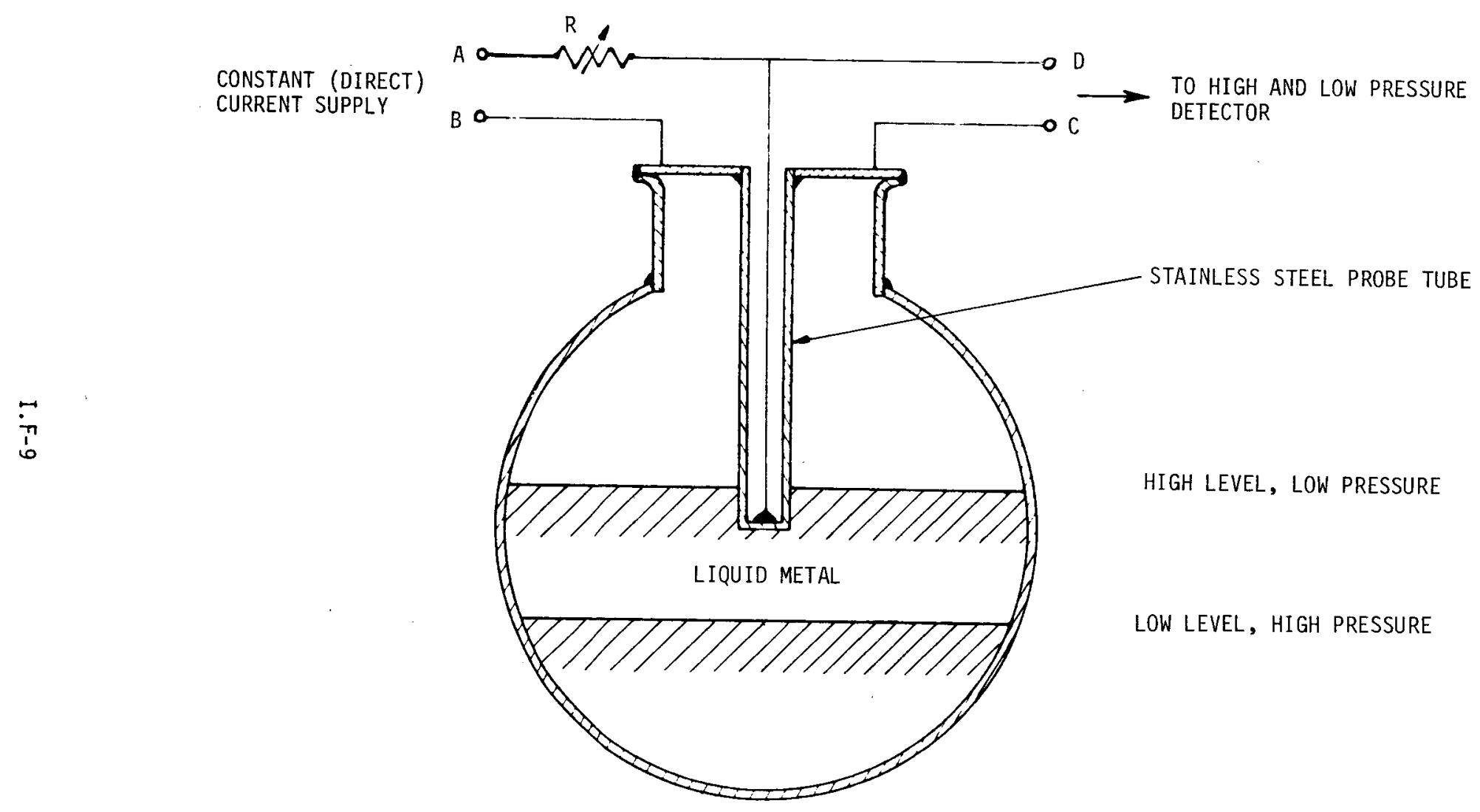

Figure I.F-9. Rapsodie Intermittent Level Indicator (Ref. 2) 
I. G. COVER GAS AND AUXILIARY SYSTEMS

Cover gas is argon. It is distributed to the vessel heat exchangers, pumps, and all equipment having a free sodium level, from a storage reservoir where the gas is held at a pressure of about $5 \mathrm{~kg} / \mathrm{cm}^{2}$. Contact manometers regulate the pressure. Argon from the reservoir is dried and purified in sodium. (Fig. I.G-1.)

Large-diameter hydraulic valves are included in the system to avoid over-pressure in the argon blanket. (Ref. 2,6.)

A sodium vapor trap (Fig. I.G-2) prevents vapor from being transmitted to the cold argon piping, where it could condense and cause blockages.
To avoid thermal stresses in the metal of the core plugs and vessels, a system is provided to evacuate about $100 \mathrm{kw}$ of heat to two cooling beds. The first is located at the first $300 \mathrm{~mm}$ of the graphite, and the second above the mild steel plate. About $90 \%$ of the heat is dropped in the first boron carbide layer. Air in open circuit provides the cooling.

The reactor vessel is preheated before sodium loading by means of circulating hot nitrogen in the gap provided by the double jacket surrounding the vessel. Nitrogen flow is $7000 \mathrm{~m} / \mathrm{hr}$ at $250^{\circ} \mathrm{C}$. (Ref. 2.) 


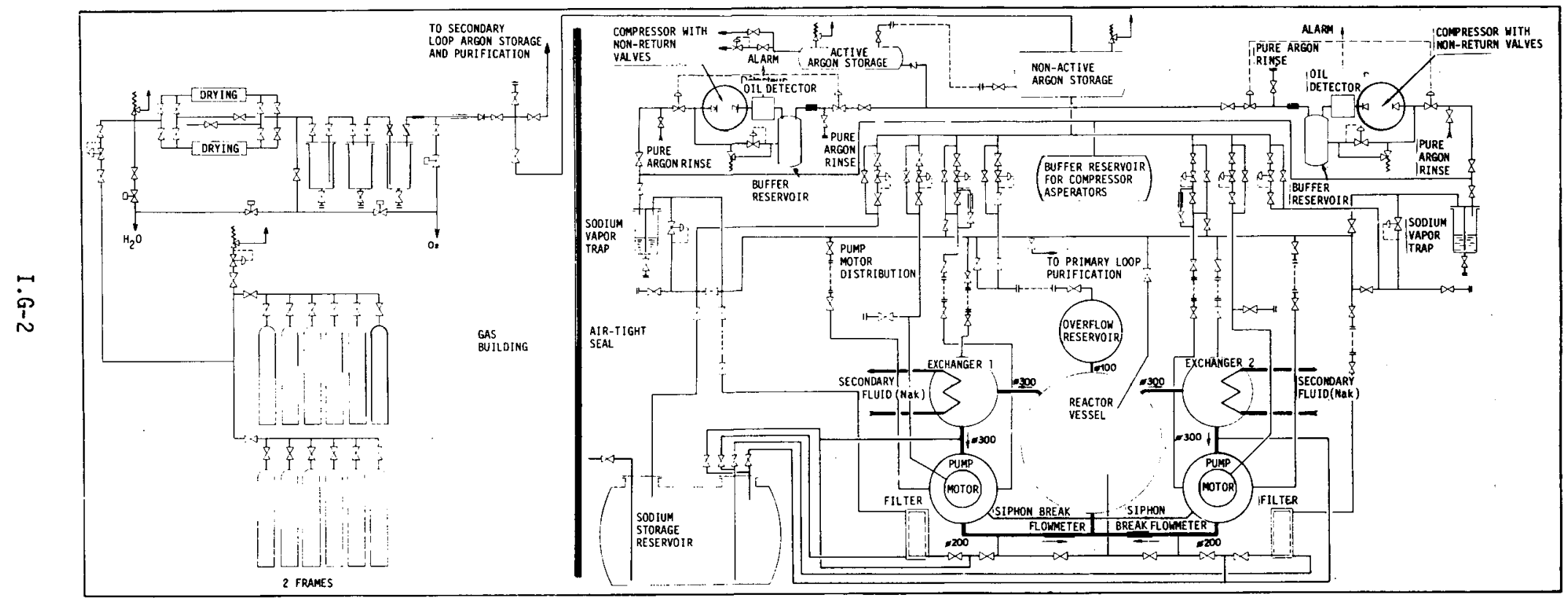

Figure I.G-1. Rapsodie Primary Sodium and Argon Loops (Ref. 2) 


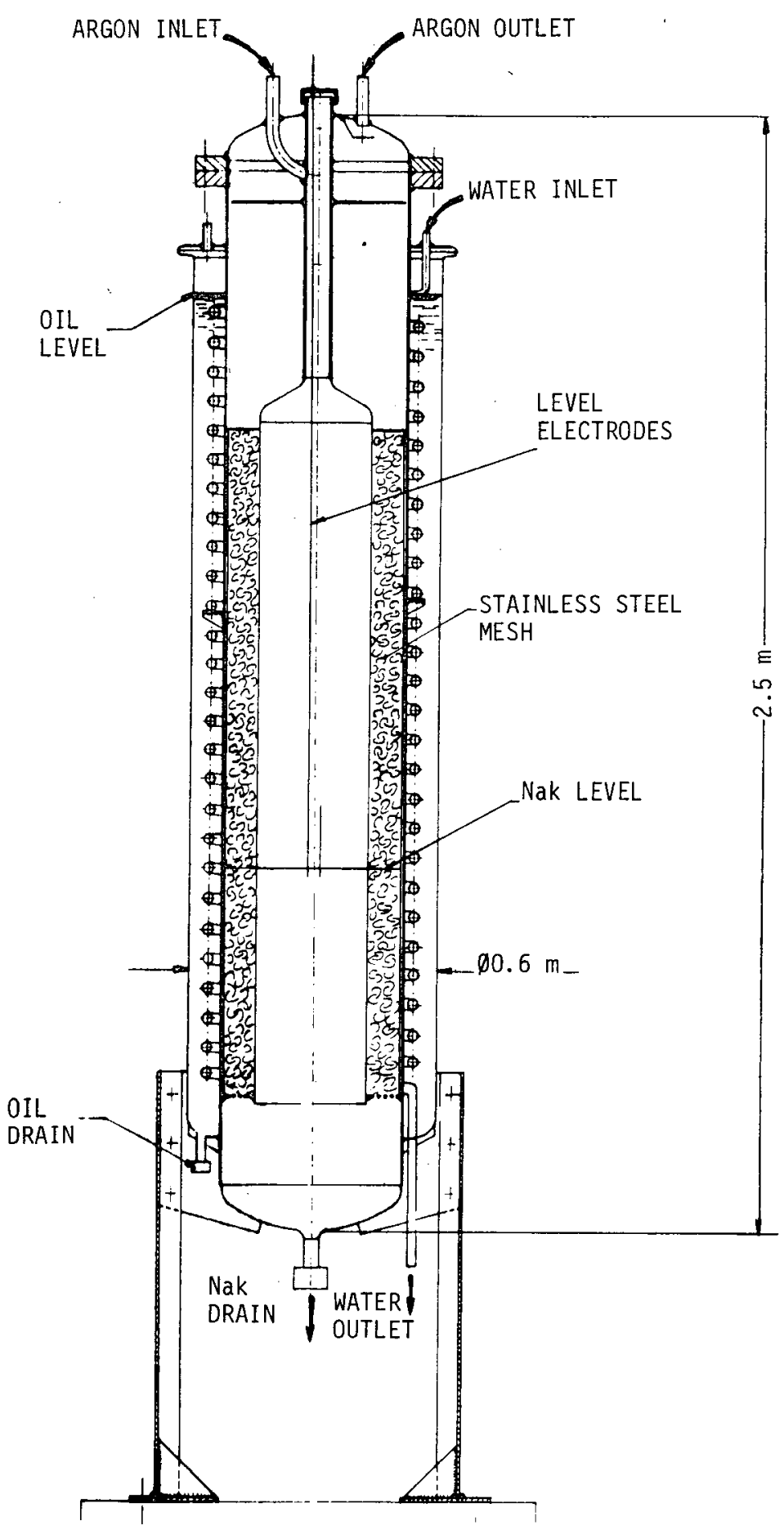

Figure I.G-2. Rapsodie Sodium Vapor Trap (Ref. 2) 


\section{H. TERMINAL IIEAT EXCHANGER}

There is no power take-off for Rapsodie. Heat is evacuated by means of the Terminal Heat Exchanger--a tube bundle containing the Na to be cooled--which is located in a flue cooled by forced air ciculation.
Tube bundle: 262 tubes in parallel, attached to inlet collector and outlet collector. Arrangment is in a grouping of 786 tubes in staggered array. Tubes are finned.

Ventilator: Standard high-yield type.

Terminal HX parameters (sodium-to-air):

$\mathrm{Na}$ inlet temp $\left({ }^{\circ} \mathrm{C}\right) 310$

Na outlet temp $\left({ }^{\circ} \mathrm{C}\right) 220$

Air inlet temp $\left({ }^{\circ} \mathrm{C}\right) 30$

Air outlet temp $\left({ }^{\circ} \mathrm{C}\right) 185$

Tube dia (mm) 21 ID, 2400

No. tubes 262

Heat exchange area $\left(\mathrm{m}^{2}\right) 115$

(Refs. 2, 8.) 
I. I . REACTOR INSTRUMENTATION AND CONTROL

Information from various measurement channels is collected in a single control building. A complete information system with centralization and data recording allows much of the system to be automated. Indicators and controls at the console are reduced to essentials and grouped in displays arranged in logical order. One operator can control the reactor. There are two read-out instruments for each measurement channel. A special incident channel gives information on power surges to about $140 \mathrm{MW}$.

of the twelve control channels, three are for startup (fission chamber monitors), three are for power rise, five for linear power (two control and three safety), one for the incident channel.

Three fission chamber monitors and eight compensated ionization chambers are located in the graphite shield.

In the Rapsodie reactor, an instrument called the reactimeter is used to monitor startup and approach to power. It consists of a power measurement channel, a calibrated circuit, and an electronic divider. Reactivity is measured continuously and instantaneously. Response time is 0.1 second. (Ref. 16.) 
I. J. FUEL HANDLING

Rapsodie refueling is accomplished by means of two rotating plugs; the smaller plug is off-set, and has a handling channel vertically through it. This channel can be aligned with any assembly by rotating the plugs. Originally, a single fuel handling machine was used, but early in the program, this machine was replaced by a system of two lighter machines. Assemblies removed from the core are not stored in the reactor vessel, but transferred by primary cask car to an examination cell. A secondary cask car moves the assembly out of the reactor building into a decay pool area. New fuel is stored in a shielded area, canned, and brought to the reactor by reversing the above procedure. (Ref. 14.) 


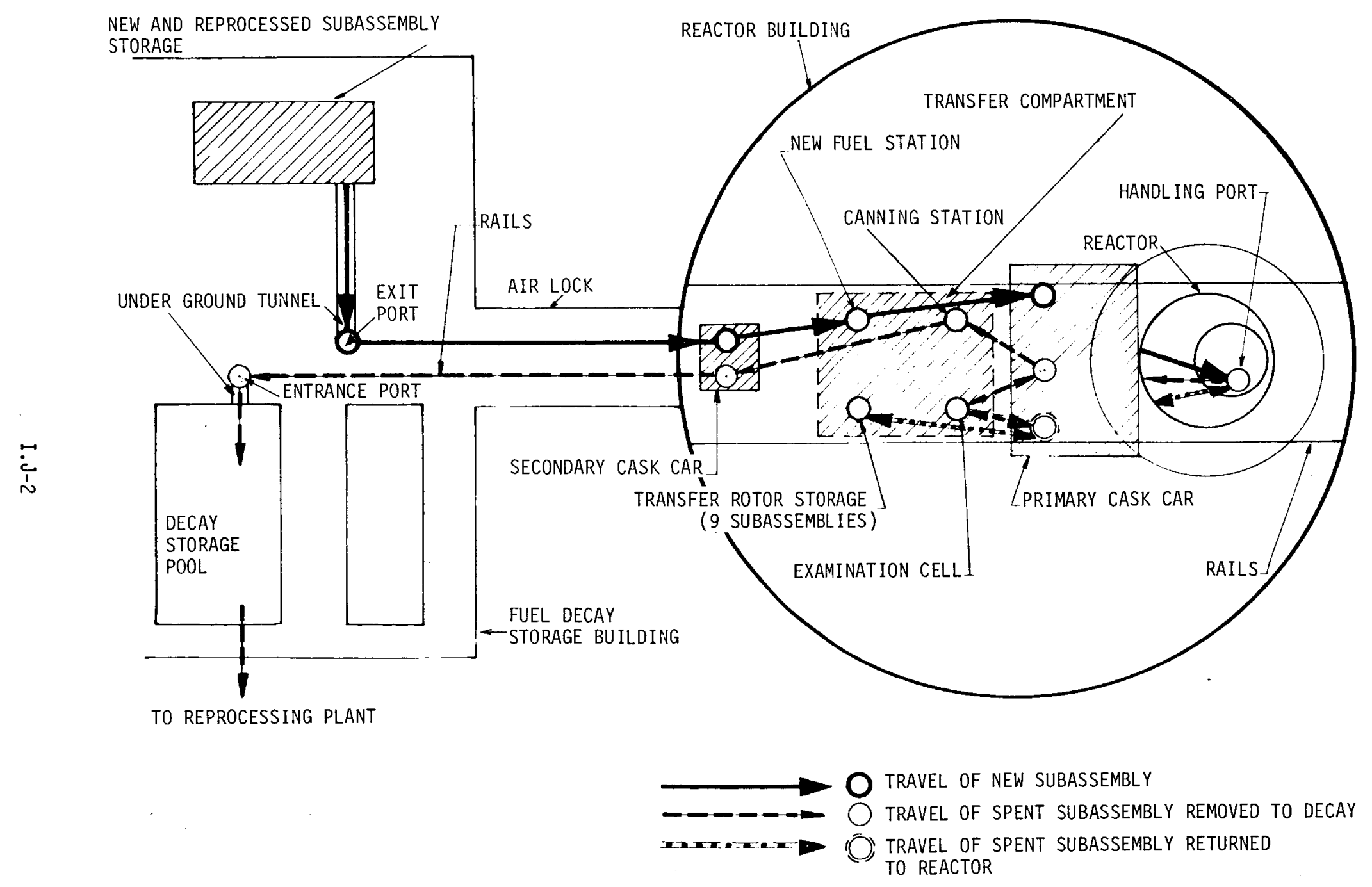

Figure I.J-1. Rapsodie Circulation of Assemblies (Ref. 5) 


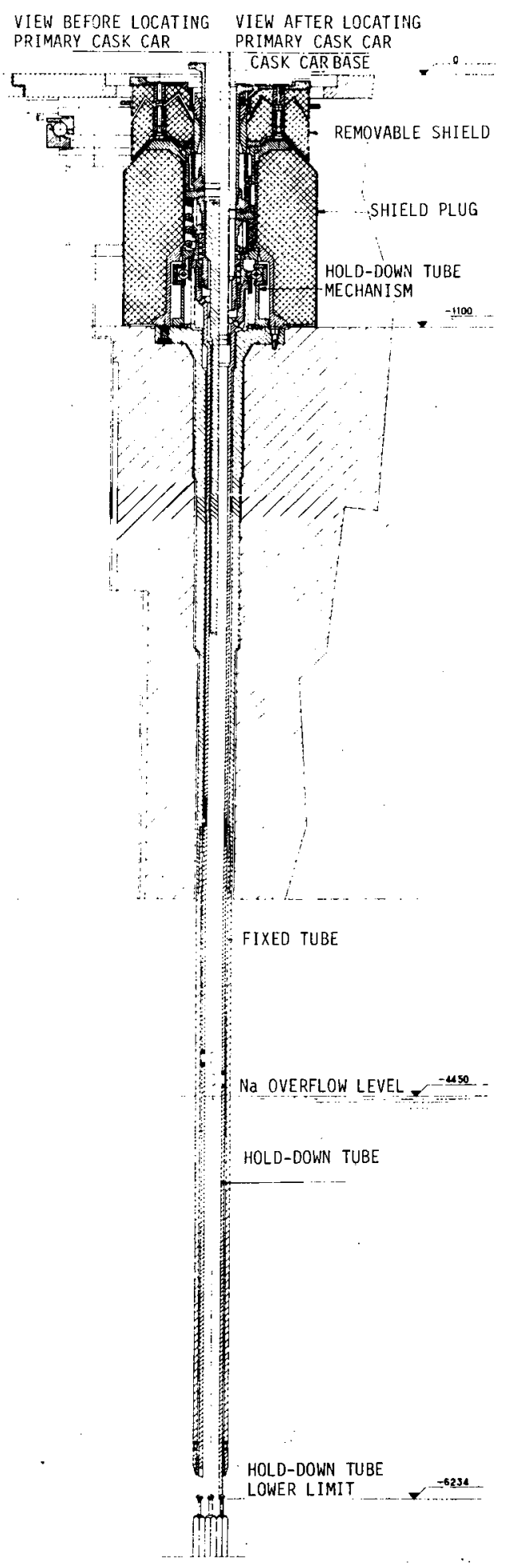

Figure I.J-2. Rapsodie Fuel Handling Channel (Ref. 5)

\section{I.J-3}




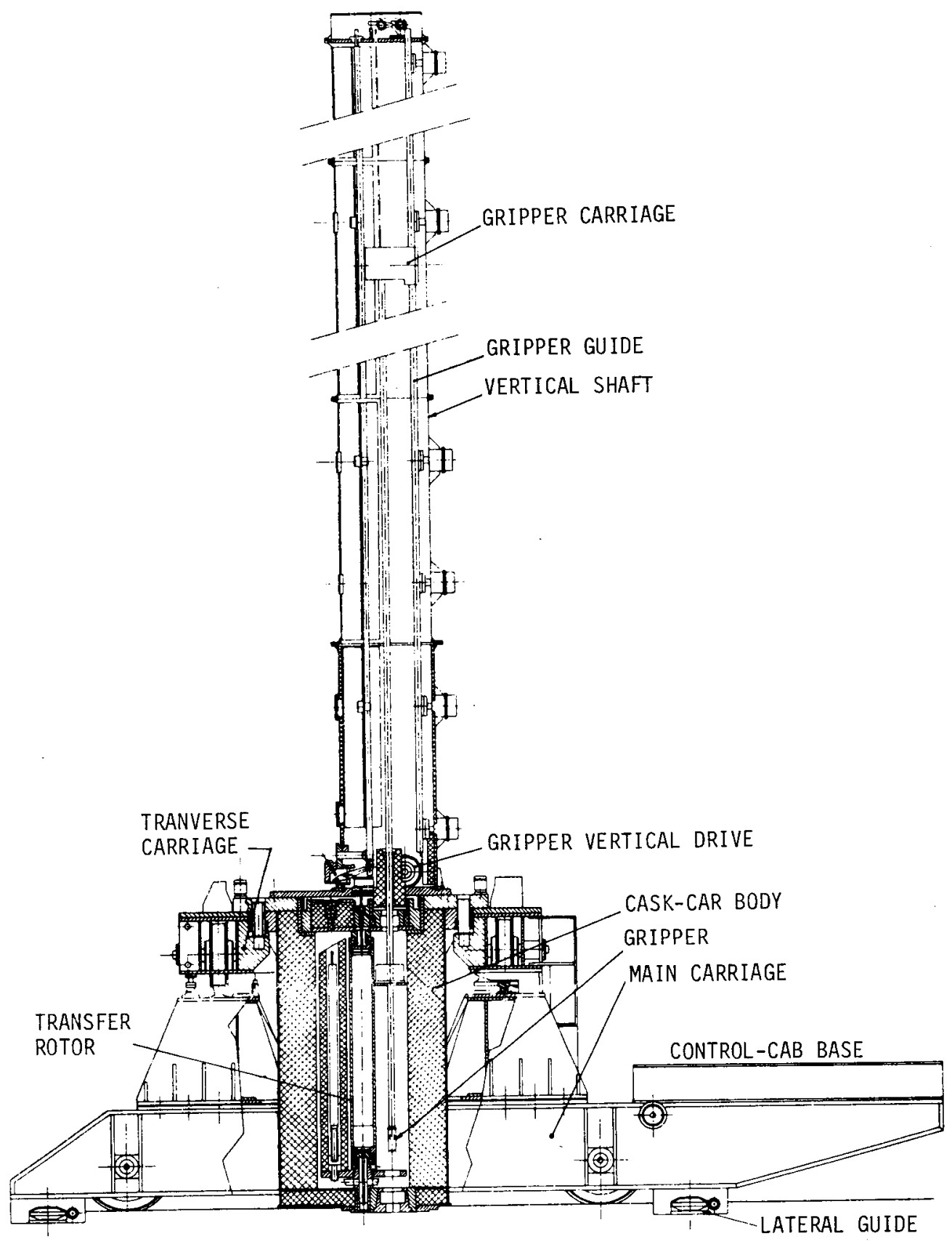

Figure I.J-3. Rapsodie Primary Cask Car (Ref. 2) 


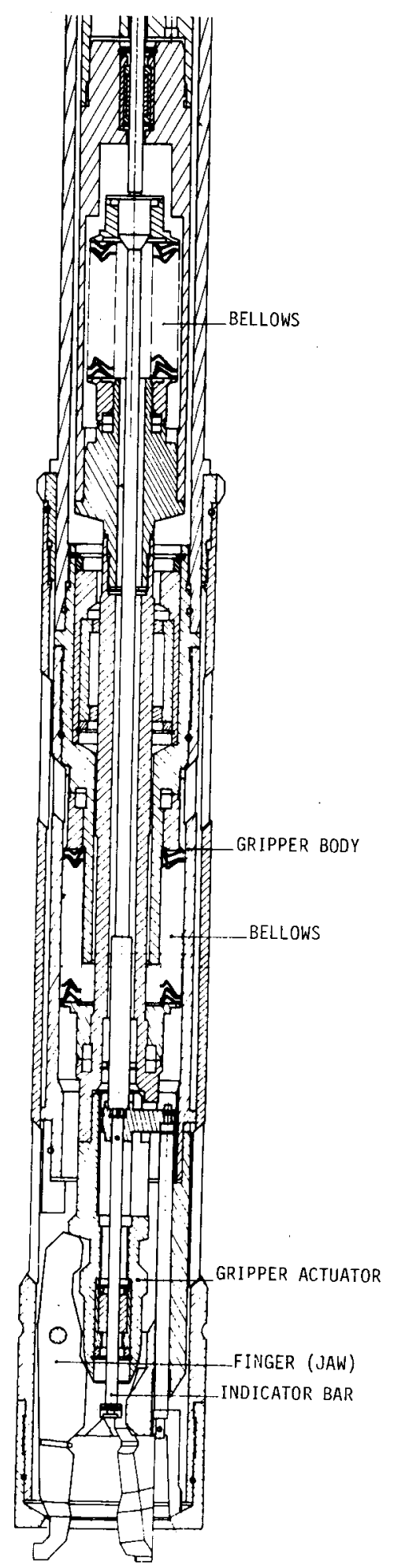

Figure I.J-4. Rapsodie Primary Cask Car Gripper (Ref. 2)

$$
\text { I.J-5 }
$$


RAPSODIE I.J.

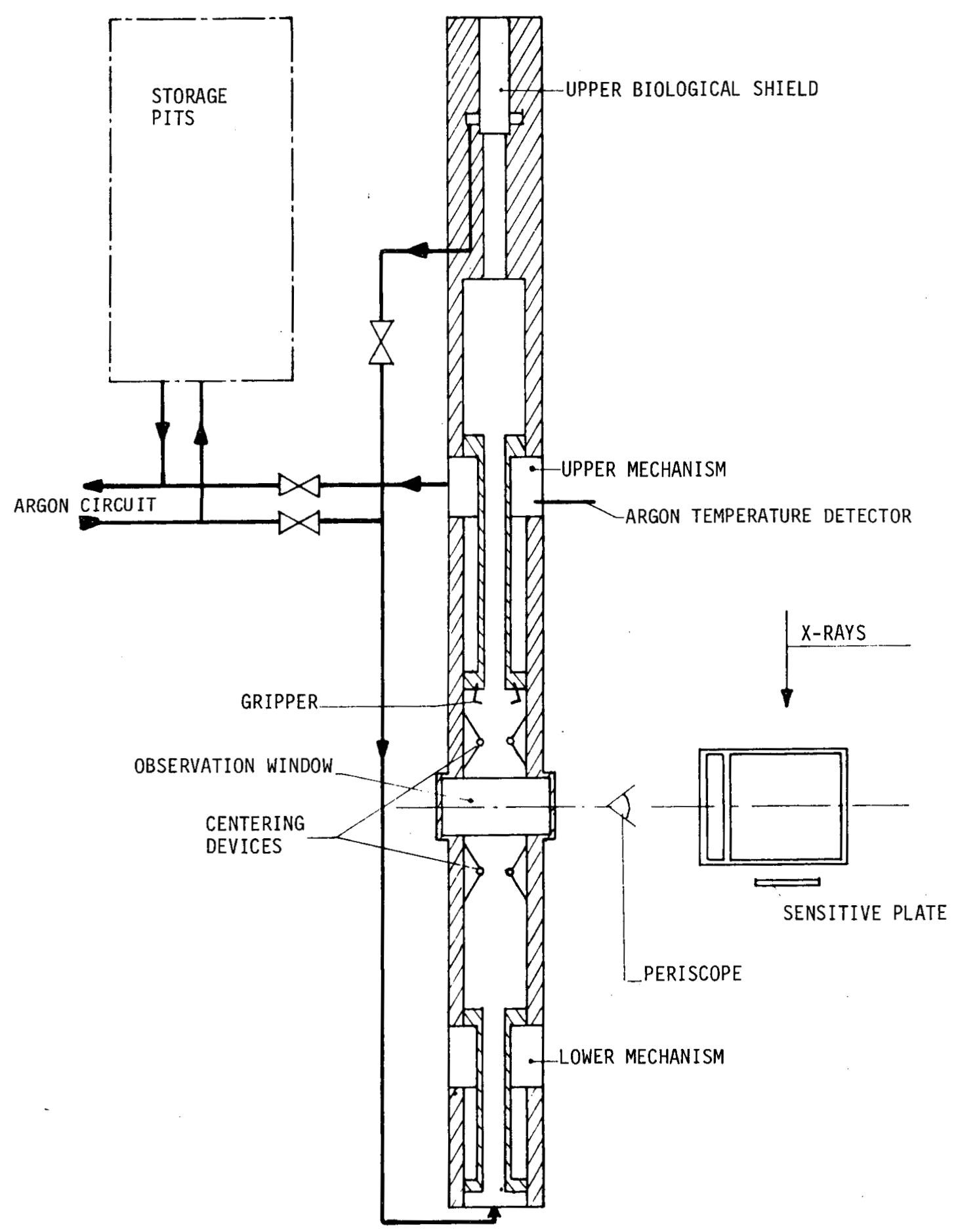

Figure I.J-5. Rapsodie Examination Cell (Ref. 2)

I.ง-6 


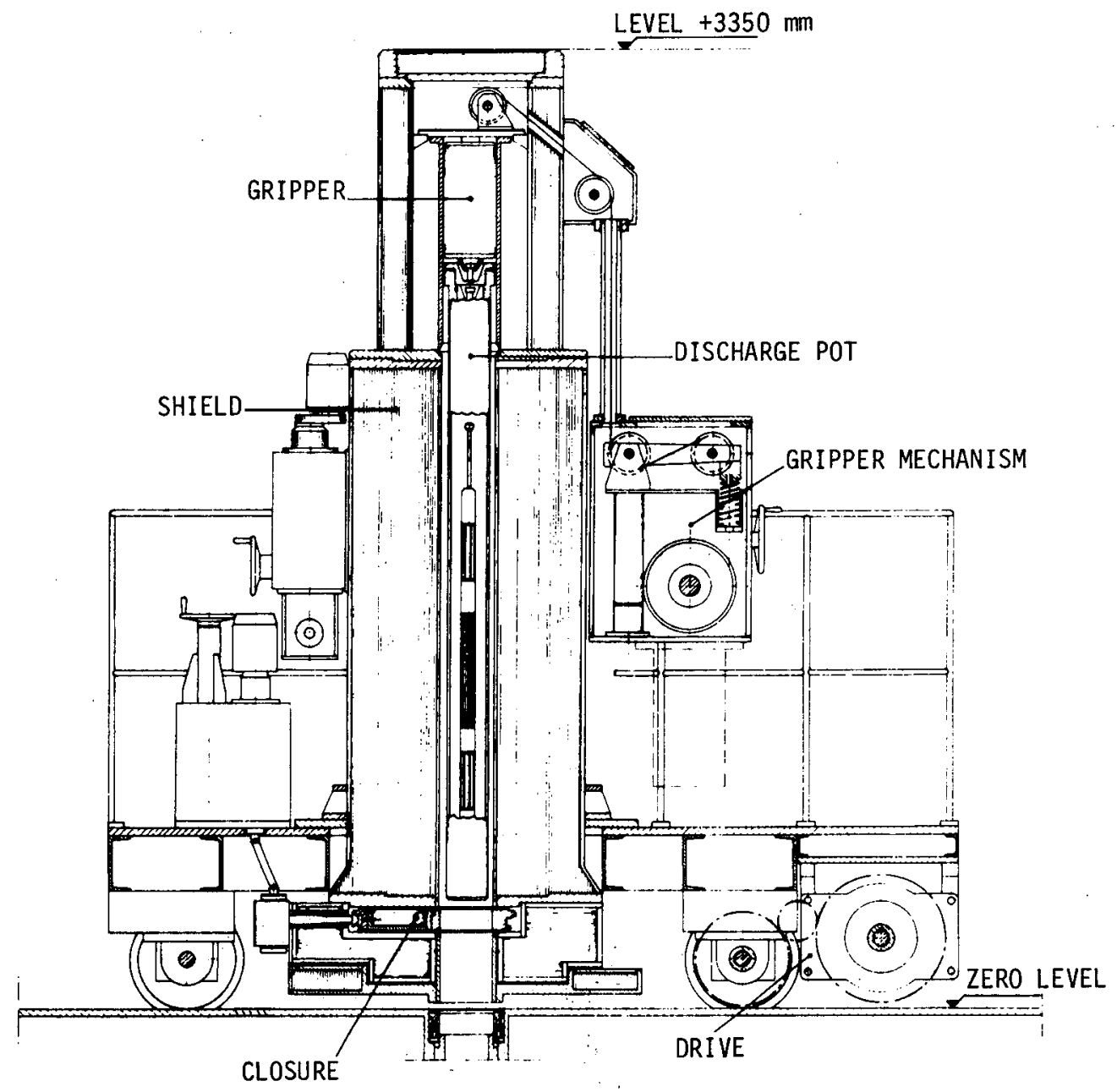

Figure I.J-6. Rapsodie Secondary Cask Car (Ref. 2) 


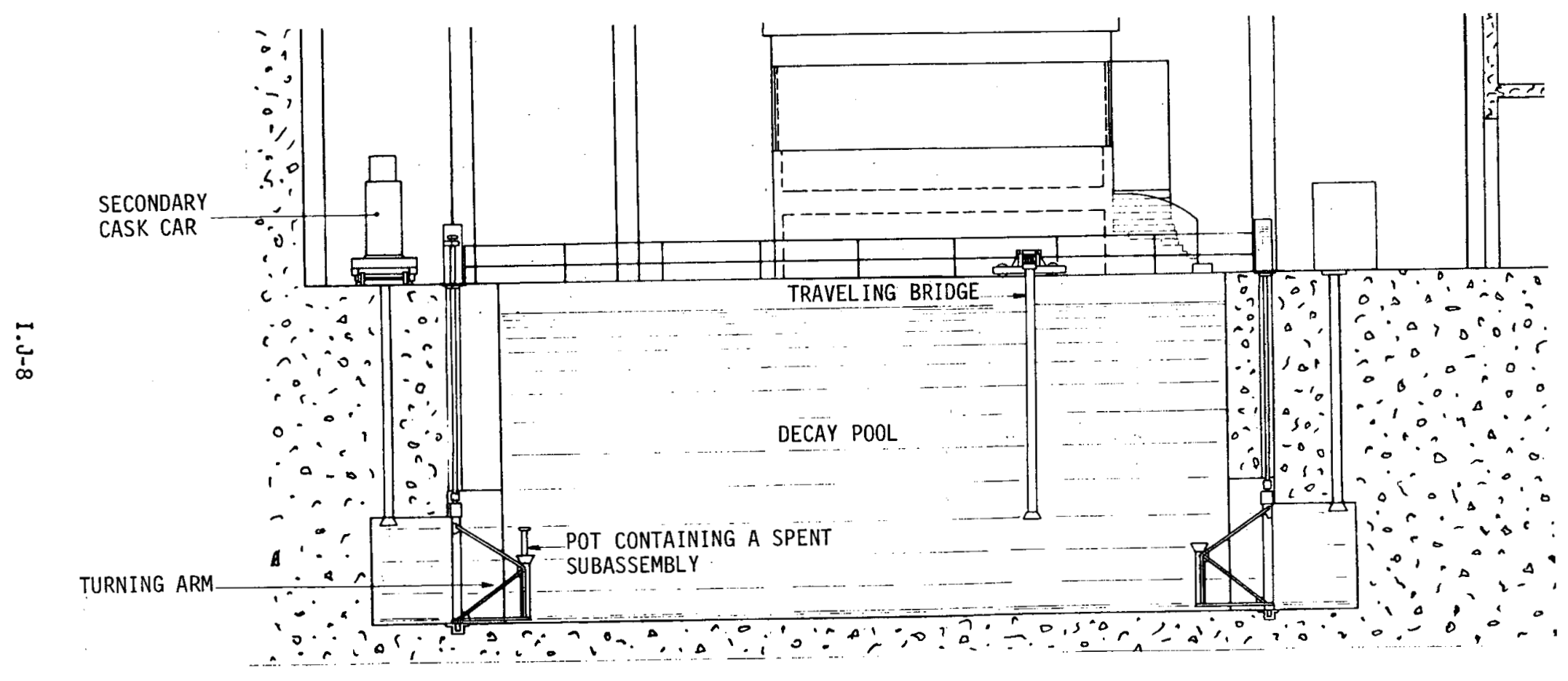

Figure I.J-7. Rapsodie Active Building Decay Pool (Ref. 2) 


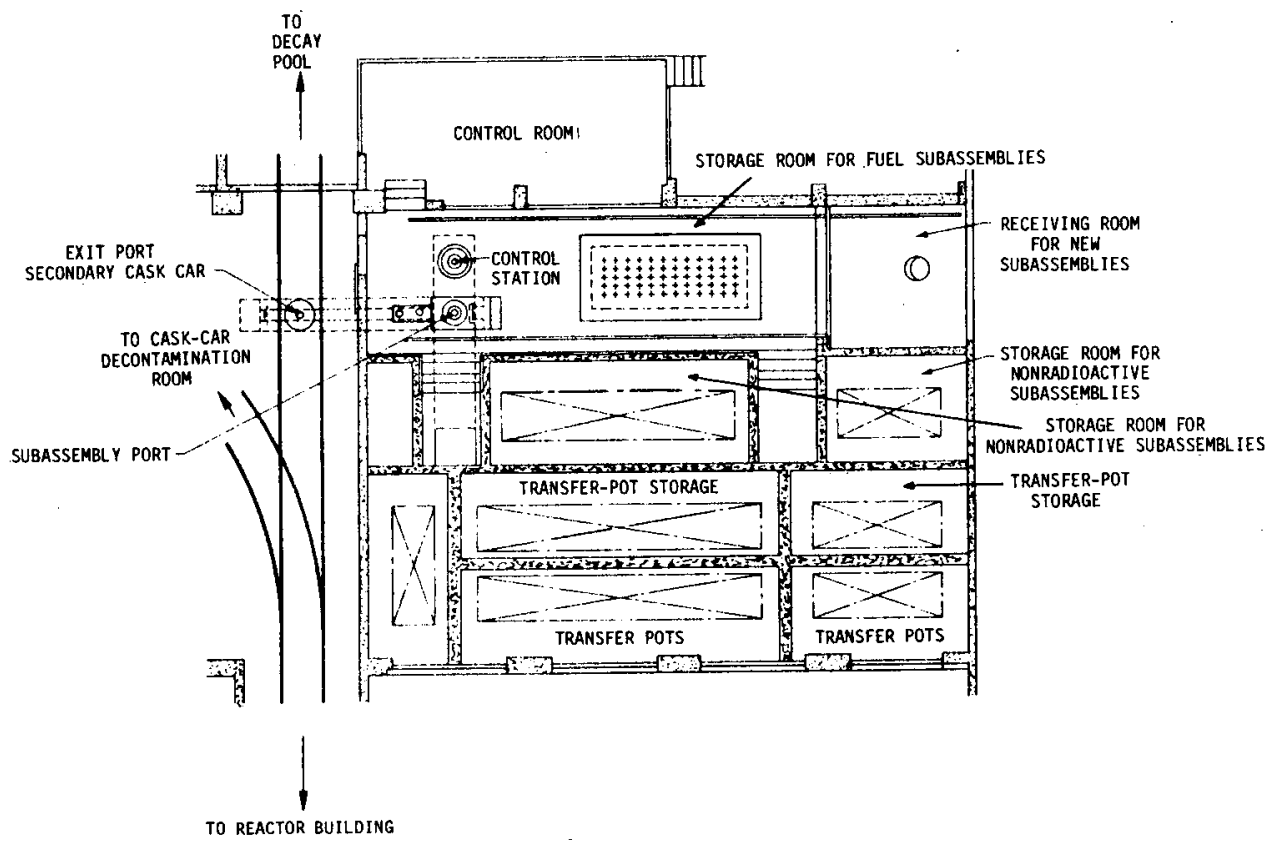

Figure I.J-8. Rapsodie New Fuel Storage Building (Ref. 5)

1.J-9 
I. K. CONTAINMENT

An air-tight vessel, 50 meters in height, houses the reactor, part of the cooling loops, the sodium purification equipment, air-conditioning system, and transfer equipment for fuel handiing. The vertical cylindrical building is steel, with a hemispherical head. The reactor is located below ground-level in a closed concrete cavity. There is a working gallery at the upper part of this cave. Two ports connect with the active building or the conventional building. There is access for large equipment. A bridge crane at a height of 14 meters serves the 23 meter diameter area.
The building is separated into two essentially independent zones by a concrete floor 1.6 meters thick at about -2.8 ground. level. Air pressure in the upper part is kept constant, at a temperature of 10 to $30^{\circ} \mathrm{C}$. In the lower zone, the atmosphere is nitrogen-enriched air at constant pressure and a temperature not above $60^{\circ} \mathrm{C}$. (Fig. I.K-I.)

The conventional building contains the control rooms and various personnel offices. (Ref. 2.) (Fig. I.K-2.)

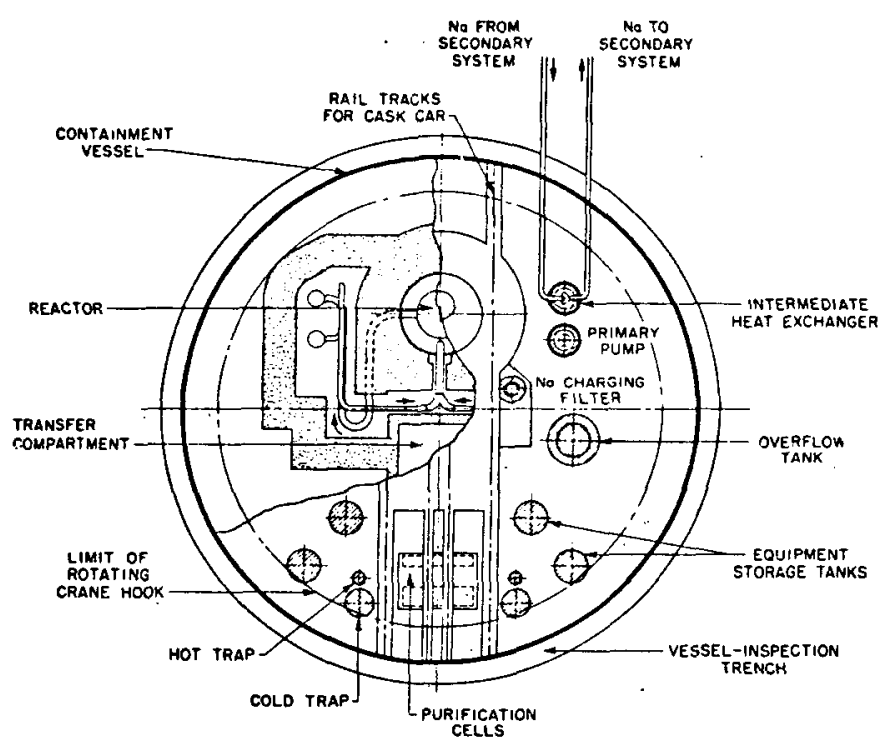

Figure I.K-1. Plan View of Rapsodie Reactor Building (Ref. 2)

\section{K-1}


RAPSODIE I.K.

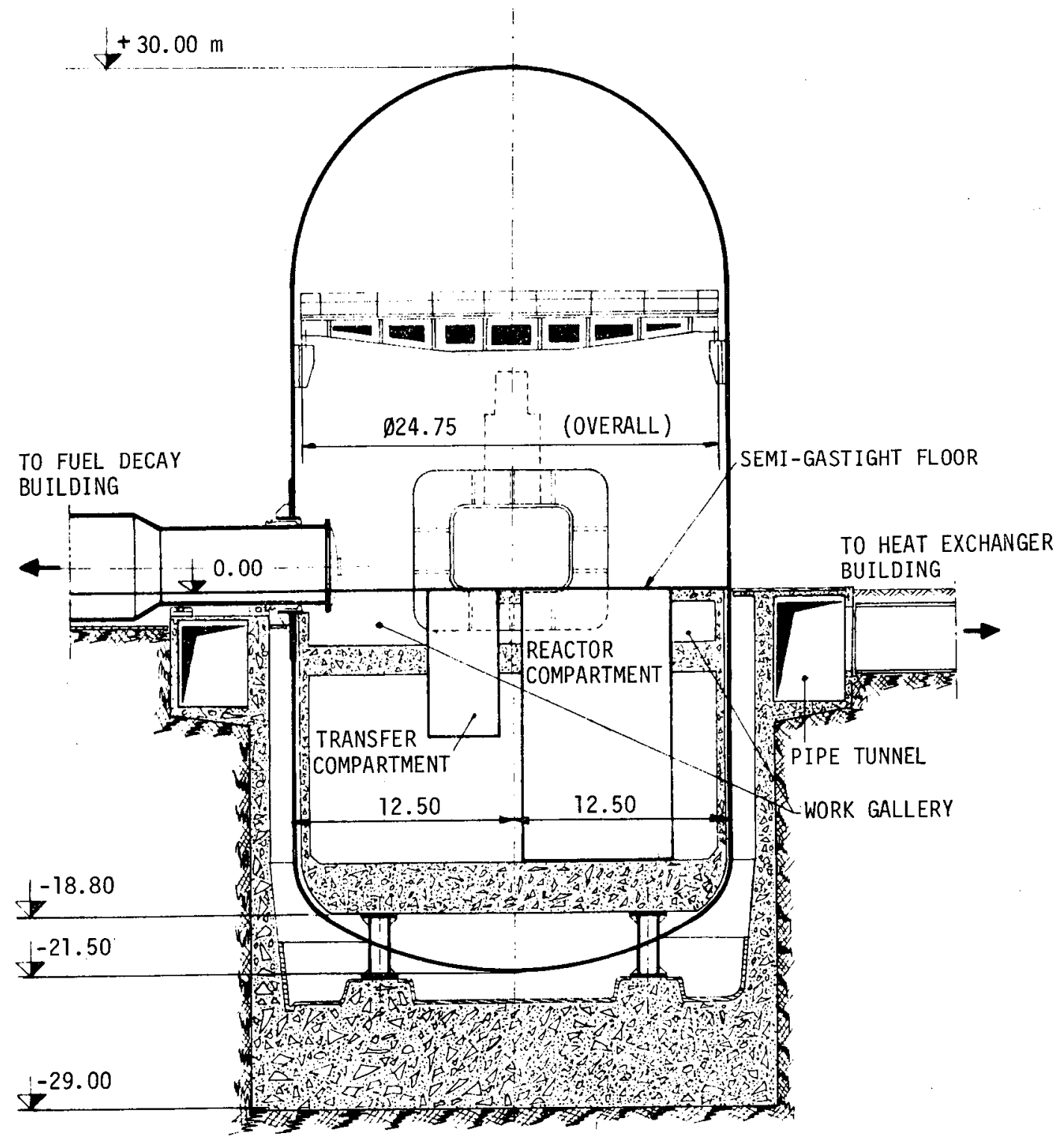

Figure I.K-2. Rapsodie Reactor Building (Ref. 2) 
RAPSODIE I.K.

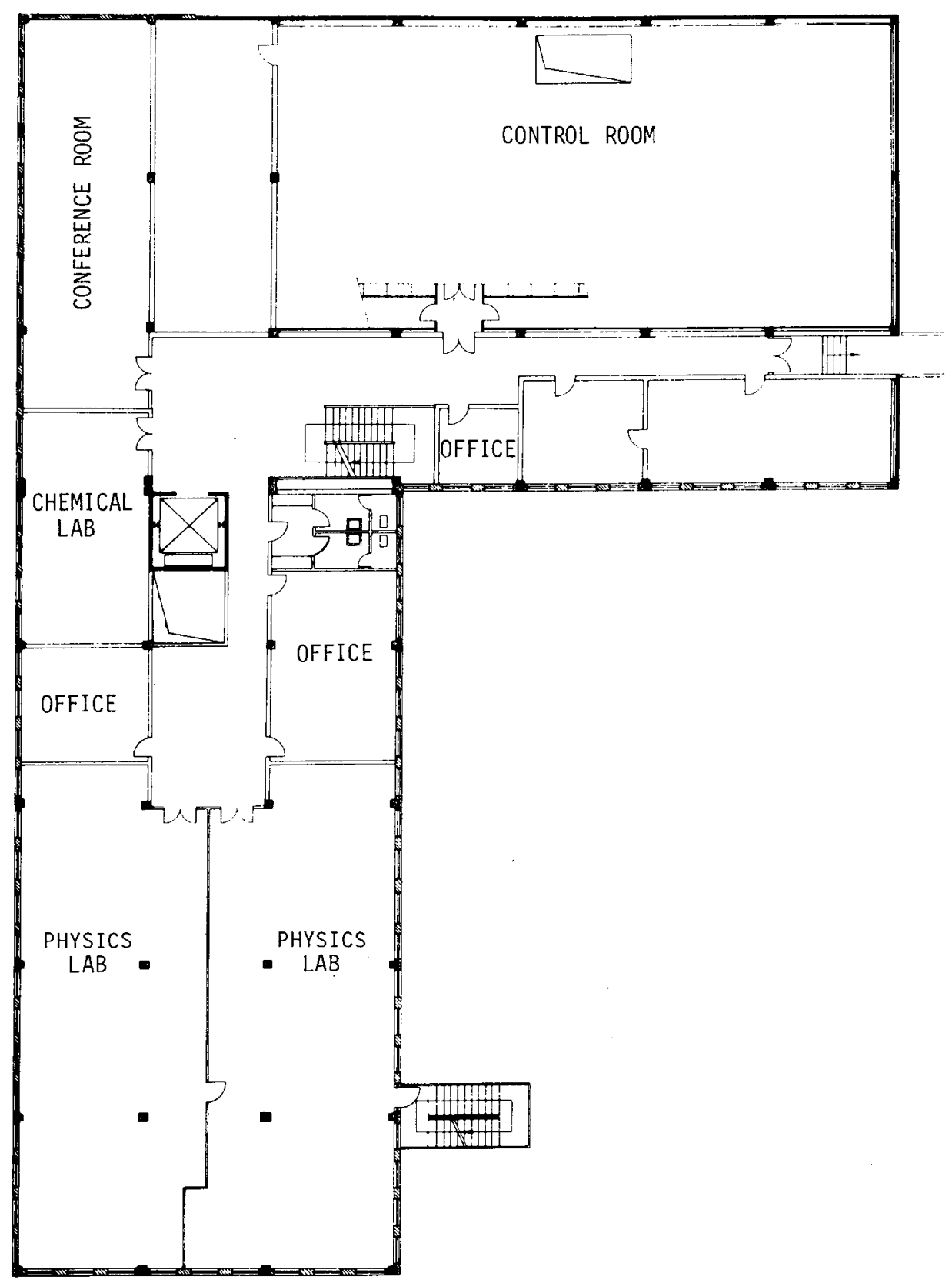

Figure I.K-3. Rapsodie Conventional Building (Ref. 2)

I. K-3 
II. PHENIX

LOCATION: Marcoule, France

(Rhone River)

\section{OPERATION: 1974}

First Nominal Power

March 12, 1974

Studies for the 250 MWe prototype fast reactor Phenix were initiated in 1967 by the French Commissariat à 1 'Energie Atomique. Construction was begun in 1968 at Marcoule, on the Rhone River. Final design and construction was placed in the hands of a team staffed with members of Technicatome, an organization formed by CEA and Electricite de France, and the Groupement Atomique Alsacienne Atlantique, a private concern. The team is directed by a CEA official. Phenix achieved criticality in August 1973 and was coupled to the grid on December 13, 1973. Fu11 power was reached in March 1974. Technicatome has developed a stretch version of Phenix rated at 450 MWe. 
INDEX

\begin{tabular}{|c|c|c|}
\hline & & Page \\
\hline REFERENC & & I I -5 \\
\hline REACTOR & ARAMETERS & I I -9 \\
\hline SECTIONS & & \\
\hline A. & CORE AND BLANKET & II.A-1 \\
\hline B. & CORE SUPPORT AND VESSEL INTERNALS & II.B-1 \\
\hline C. & REACTOR VESSELS AND SHIELDING & II.C-I \\
\hline D. & CONTROL ELEMENTS & II.D- ] \\
\hline E. & HEAT TRANSFER SYSTEMS & II.E-T \\
\hline$F$. & SODIUM PURIFICATION AND INSTRUMENTATION & II.F-1 \\
\hline G. & COVER GAS AND AUXILIARY SYSTEMS & II.G-1 \\
\hline$H$. & STEAM GENERATORS & II.H- 1 \\
\hline I. & REACTOR INSTRUMENTATION AND CONTROL & II . I - I \\
\hline J. & FUEL HANDLING & II.J-I \\
\hline K. & CONTAINMENT & I I. K- 1 \\
\hline
\end{tabular}


1. The Phenix Reactor

R. Carle, et al

Fast Reactors National Topical Meeting San Francisco April 1967

ANS-101 pp 3.39-3.58 1967

2. Engineering Components for a Sodium Cooled Fast Power Reactor

L. Vautrey, et al

Fast Breeder Reactors Proc London Conference May 1966

British Nuclear Energy Society pp 897-913 1967

3. The Place of Fast Reactors in the French Nuclear Program $G$. Vendryes, et al

Fast Breeder Reactors Proc London Conference May 1966

British Nuclear Energy Society pp 31-34 1967

4. Design Studies of Fast Reactors in France

L. Vautrey, C.P. Zaleski

Fast Breeder Reactors Proc London Conference May 1966

British Nuclear Energy Society pp 317-332 1967

5. Fast Neutron Power Reactor Phenix

R. Carle, et al

Nuclear Engineering International vol 16 pp 557-580 JuTy 1971

6. Phenix First Fast Neutron Reactor Station

R. Carle, et al

Proc Fourth International Conference Peaceful Uses of Atomic Energy 1971 Vol 5 pp 127-141 UN IAEA 1972 In French

7. The Phenix Core - Description and First Observations Made During Power Setup

M.M. Estavoyer, et al

Fast Reactor Power Stations Proc Conference London 1974

British Nuclear Energy Society pp 371-386 1974

8. Description of Phenix

J. Megy, et a1

Fast Reactor Power Stations Proc Conference London 1974

British Nuclear Energy Society pp 33-35 1974

9. Sodium Analysis and Purification Aerosols Trapping in Phenix Reactor M. Boutrais, et al

Fast Reactor Power Stations Proc Conference London 1974

British Nuclear Energy Society pp 465-480 7974

10. Special Instrumentation for Phenix

N. Lions, et al

Fast Reactor Power Stations Proc Conference London 1974

British Nuclear Energy Society pp 525-540 1974 
11. Fuel and Special Handling of Phenix Reactor Preliminary and Operational Tests

E. Benoist, et al

Fast Reactor Power Stations Proc Conference London 1974

British Nuclear Energy Society pp 577-584 1974

12. Phenix Steam Generator Development and Preliminary Operation

M.G. Robin, et al

Fast Reactor Power Stations Proc Conference London 1974

British Nuclear Energy Society pp 205-221 1974

13. Phenix

M. Rozenholc

Energie Nucleaire Vol 10 pp 65-75 March-April 1968

14. The Fast Neutron Reactor Phenix

R. Wustner

Industries Atomiques No. 7/8 pp 49-58 1969 In French

15. Prototype Fast Reactor Phenix

R. Carle, et al

Bulletin $d$ ' Inform Sci Tech No. 138 June 1969 pp 5-125 In French

16. Fuel Element for the Phenix Reactor

J.M. Dupony, et al

Proc Fourth International Conf Peaceful Uses Atomic Energy 1971

Vol 4 pp 343-361 UN IAEA 1972

17. Discussion Session 3

Fast Reactor Power Stations Proc Conference London 1974

British Nuclear Energy Society pp 383-386 1974

18. Vessels of the Phenix Reactor and Reactors With Integrated Loops G. Payan, et al

Proc Symposium on Progress in Sodium-Cooled Fast Reactor Engineering Monaco 1970

Sodium Cooled Fast Reactor Engineering pp 149-162 STI/PUB/256 IAEA 1970

19. Development in France of Steam Generators Heated by Liquid Sodium M.G. Robin, et al

Proc Symposium on Progress in Sodium Cooled Fast Reactor Engineering Monaco 1970

Sodium-Cooled Fast Reactor Engineering pp 505-525 STI/PUB/256 IAEA 1970

20. Evolution of Sodium Pumps From Rapsodie to Phenix and to the Commercial Station

W. Raczyrski, et al

Proc Symposium on Progress in Sodium-Cooled Fast Reactor Engineering Monaco 1970

Sodium-Cooled Fast Reactor Engineering pp 331-342 STI/PUB/256 IAEA 1970 
21. Incidence of Hydraulic Problems on the Concept of Sodium-Cooled Fast Reactors

J.P. Duport, et al

Proc Symposium on Progress in Sodium Cooled Fast Reactor Engineering Monaco 1970

Sodium-Cooled Fast Reactor Engineering pp 87-105 STI/PUB/256 IAEA 1970

22. The Fast Neutron Station Phenix

R. Carle, et al

Energie Nucleaire pp 172-223 May-June 1971

23. Development in France of the Technology of the Core of Fast Sodium-Cooled Reactors and Future Perspectives

J. Leduc, et al

Proc Symposium on Progress in Sodium-Cooled Fast Reactor Engineering Monaco 7970

Sodium-Cooled Fast Reactor Engineering pp 249-272 STI/PUB/256 IAEA 1970

24. Equipment Adopted for the Control of Radioactive Effluents for Fast Reactor Stations Developed in France

P. Candes

Proc Symposium on Environmental Aspects of Nuclear Power Stations

New York Aug 1970

Environmental Aspects of Nuclear Power Stations pp 159-173 STI/PUB/261 IAEA 1971

25. Emergency Cooling System for Phenix

M.J.M. Megy, et a?

Proc Int 1 Conf or Engineering of Fast Reactors for Safe and Reliable Operation Karlsruhe 1972

Gesellschaft Fur Kernforschung M.B.H. vol I pp 336-349 Karlsruhe 1973

26. Decay Heat Removal in an LMFBR

C.P. Zaleski, et al

Proc Fast Reactor Safety Meeting April 1974

Part 2 pp 785-801 Conf 740401-P2

27. Comparison of Foreign and U.S. LMFBR Plant Parameters

Office of LMFBR Programs AEC

WASH 1354 NOv 1974 
Table - 1
GENERAL PARAMETERS

Type

Pot Type

\begin{tabular}{ll} 
No. loops & 3 \\
\hline Coolant & Sodium \\
\hline Core inlet temp. & $400^{\circ} \mathrm{C}$ \\
\hline Core outlet temp. & $560^{\circ} \mathrm{C}$ \\
\hline Flow direction & Up. Velocity $7.4 . \mathrm{m} / \mathrm{sec}$. Max \\
\hline Driver fuel & $\mathrm{UO}_{2}-\mathrm{PuO}_{2}+\cup \mathrm{O}_{2}(2$ zones $)$ \\
\hline Blanket fuel & $\mathrm{UO}_{2}$ \\
\hline Core height & $850 \mathrm{~mm}$ \\
\hline Core diameter & $1394 \mathrm{~mm}$ \\
\hline Core volume & 1227 l \\
\hline No. enrichment zones in core & 2 \\
\hline Output MWe/MWt & $250 / 563$ \\
\hline Breeding ratio & 1.12 \\
\hline Neutron lifetime & $3.3 \times 10^{-7}$ \\
\hline Max. can temperature & $700^{\circ} \mathrm{C}$ \\
\hline Fuel central temperature & $2300^{\circ} \mathrm{C}$ \\
\hline Linear power, max. & $422 \mathrm{~W} / \mathrm{Cm}$ \\
\hline Neutron flux, total & $7.2 \times 10^{15}$ \\
\hline Power Density & $406 \mathrm{~kW} / \mathrm{l}$ \\
\hline No. Driver elements & $103(2$ zones $)$ \\
\hline No. Radial blanket elements & 90 \\
\hline No. In-core control elements & $6(\mathrm{vented} \mathrm{rods)}$ \\
\hline Goal burnup & $50,000 \mathrm{MWD} / \mathrm{T}$ \\
\hline
\end{tabular}


PHENIX II

Table - 2

CORE AND BLANKET

\begin{tabular}{|c|c|c|c|}
\hline & Driver zone & Axial blanket & Radial blanket \\
\hline Fuel Material & $\mathrm{UO}_{2}-\mathrm{PuO}_{2}+\mathrm{UO}_{2}$ & $\mathrm{UO}_{2}$ depleted & $\mathrm{UO}_{2}$ depleted \\
\hline Form & Sintered pellets & pellets & pellets \\
\hline Composition & 19 and $25 \% \mathrm{PuO}_{2}$ & & \\
\hline Stoichiometry & $1.94-2.00$ & lower $2.00-2.02$ & $2.00-2.02$ \\
\hline $240 \mathrm{Pu}$ & $14 \%$ & & \\
\hline Density & $80 \%$ TD & & \\
\hline Pellet od & $5.5 \mathrm{~mm}$ & $\begin{array}{l}\text { Top, } 12.6 \mathrm{~mm} \\
\text { Bottom, integral } \\
\text { with core }\end{array}$ & $12.6 \mathrm{~mm}$ \\
\hline Rod cladding & Stainless steel & Stainless steel & Stainless steel \\
\hline od & $6.55-6.6 \mathrm{~mm}$ & $\begin{array}{l}\text { Top } 13.10 \mathrm{~mm} \\
\text { Bottom integra } 1 \\
\text { core }\end{array}$ & $13.4 \mathrm{~mm}$ \\
\hline Wa11 & $0.45 \mathrm{~mm}$ & Top $0.5 \mathrm{~mm}$ & $0.9 \mathrm{~mm}$ \\
\hline Fuel-clad gap & $.15-.20 \mathrm{~mm}$ calculated & & \\
\hline Bond & $\mathrm{He}$ & & \\
\hline Column length & $850 \mathrm{~mm}$ & $\begin{array}{l}\text { Top } 260 \mathrm{~mm} \\
\text { Bottom } 300 \mathrm{~mm}\end{array}$ & $1668 \mathrm{~mm}$ \\
\hline Gas plenum & $\begin{array}{l}\text { Lower and upper chambers } \\
\text { upper containing the spring }\end{array}$ & & \\
\hline Pin length & $1793 \mathrm{~mm}$ & & \\
\hline Vented/non-vented & No & & No \\
\hline Assembly material & Stainless steel & Stainiess steel & Stainless steel \\
\hline Shape & Hexagona 1 & Hexagonal & Hexagonal \\
\hline Across flats & $126.7 \mathrm{~mm}$ & & $126.7 \mathrm{~mm}$ \\
\hline Wall thickness & $3.5 \mathrm{~mm}$ & & $3.5 \mathrm{~mm}$ \\
\hline Overall length & $4300 \mathrm{~mm}$ & & $4300 \mathrm{~mm}$ \\
\hline Weight & $\sim 200 \mathrm{~kg}$ & & $\approx 270 \mathrm{~kg}$ \\
\hline No. pins per assembly & 217 & Top 37 & 61 \\
\hline Pin spacing & $1.15 \mathrm{~mm}$ dia. wire & & $1.08 \mathrm{~mm} \mathrm{dia.} \mathrm{wir}$ \\
\hline Pin pitch & $7.7-7.75 \mathrm{~mm}$ calculated & & \\
\hline Assy. in core & 103 & & 90 \\
\hline Fuel & $36.8 \%$ & & \\
\hline Sodium & $35.0 \%$ & & \\
\hline
\end{tabular}




\section{A. CORE AND BLANKET}

The Phenix fuel assembly is $4300 \mathrm{~mm}$ high and weighs $200 \mathrm{~kg}$. The hexagonal can is extended at the bottom by an $800-\mathrm{mm}$ long section that slides into the sleeve in the support grid. It is supported at the top by an upper neutron shielding section 1300-mm high to which the 37 upper axial blanket pins are attached. The lower axial blanket is integral with the fuel pins and is located just below the fuel column. The lower fission gas chamber is below the lower breeder section. An upper chamber above the fuel column also contains a spring that holds the fuel pellets in place. Pin spacing is by a $1.15-\mathrm{mm}$ diameter wire wound helically around the cladding with a pitch of $150 \mathrm{~mm}$.

Both $\mathrm{UO}_{2}-\mathrm{PuO}_{2}$ and $\mathrm{UO}_{2}$ fuel are in the core, about half-and-half, although the arrangement is not known. There are two enrichment zones. Enrichment of the inner zone, with 55 assemblies, is $\mathrm{Pu}\left[\mathrm{PuO}_{2} \quad\left(\mathrm{PuO}_{2}\right.\right.$ $\left.+\mathrm{UO}_{2}\right)$ ] $18 \%$; the outer zone, with $4 \overline{3}$ assemblies, has $25 \%$ enrichment. Outer rings are composed of 89 radial bianket assemblies, 216 reflector elements, 41 storage positions, 175 small graphite logs, 240 large graphite bars and 240 large steel bars. The central fuel assembly has experimental access, as do two of the outer fuel assemblies. Six control assemblies are located in the inner fuel area.

(Refs. 7, 27.)

The fuel assembly (Figure II.A-1) is a hexagonal can containing fuel and axial blanket pins. The lower ends of the fuel pins are machined to run in profiled rails of varying lengths to form pin bundles. Each rail is machined to fit in two beams carried on a support beam. When the fuel bundle is assembled, it is introduced into the outer hexagonal can by displacement of the support, which then slides home into a bore at the assembly bottom. The bottom of each fuel assembly holds it upright, ensures sodium inlet flow, provides hydraulic hold-down and orients the subassembly by means of cams that bear on ramps in the heads of adjacent subassemblies. The upper portion of the assembly is a neutron shielding block supporting the upper axial blanket pins. The lower axial blanket is integral with the fuel pins; the large fission gas plenum is located in a cold area below the lower axial blanket. (Ref. 7.)

Sodium inflow to the assemblies is radial, the sodium flowing first through passages machined in the grid sleeves and then through orifices drilled in the assembiy foot. Six orifices are drilled at different levels; each sleeve includes six slots corresponding to the number of passages, varying with the position of the assembly. Depending on the desired flow rate, the assembly bottom is fitted with one or more central hole diaphragms or annular diaphragms. (Figure II.A-2)

The radial blanket assembly has the same outer geometry as the fuel assembly. Its weight is about $270 \mathrm{~kg}$. The lateral neutron shield assemblies also have the same geometry. They contain stacks of stainlesssteel-clad iron and graphite cylinders. The cylindrical "log" of an outer shield assembly is made up of cylinders of iron and graphite stacked in a $304 \mathrm{~L}$ stainless-steel tube. (Ref. 7.) 
PHENIX II.A.

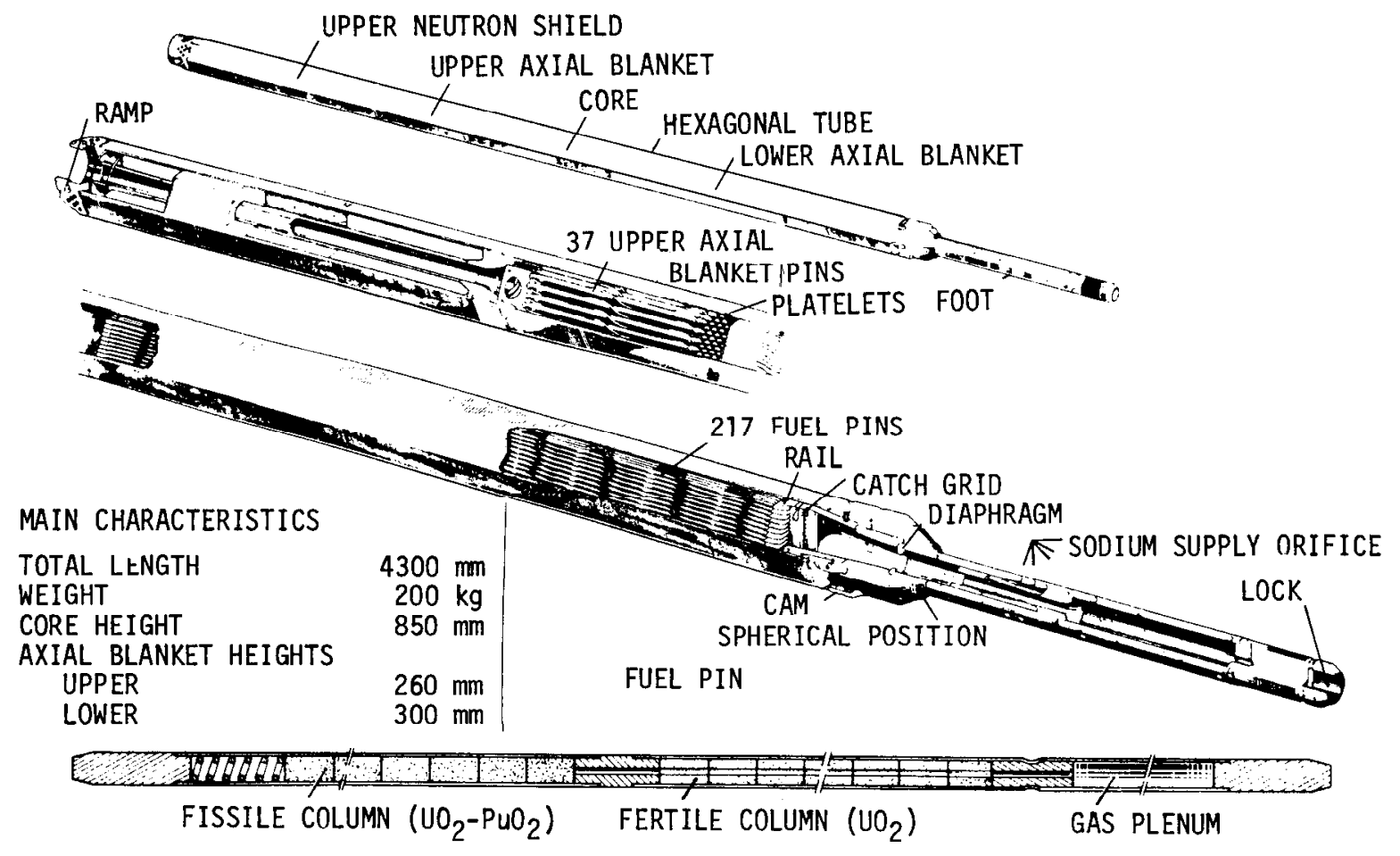

Figure II.A-1. Phentx Fuel Assembly tRoe, 27)

\section{A-2}




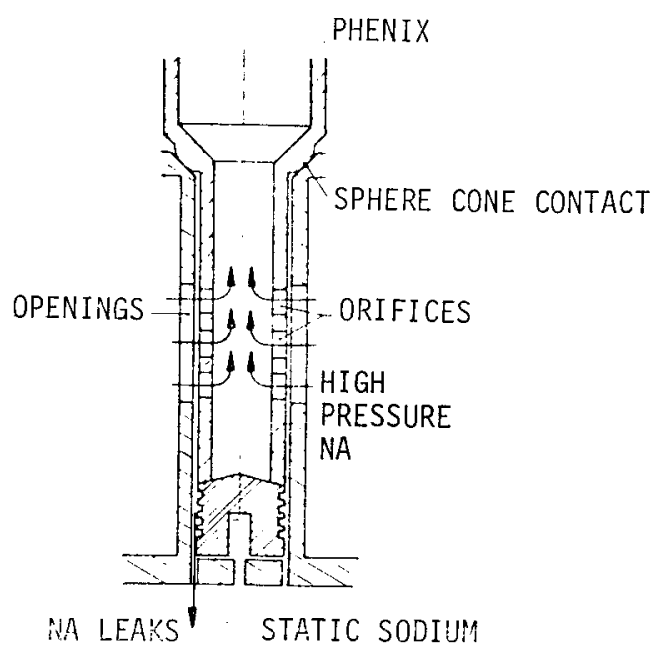

Figure II.A-2. Schematic of Phenix Assembly Foot (Ref. 21)

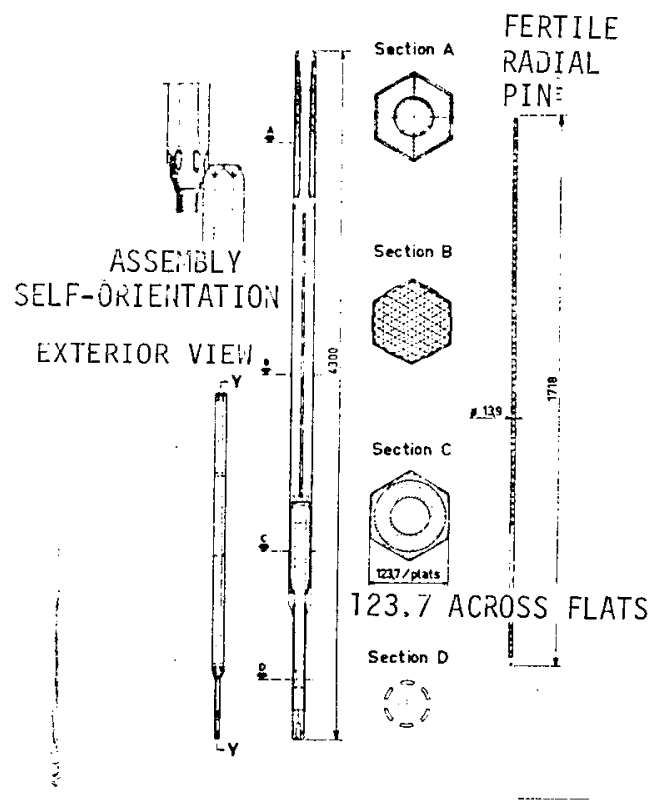

Figure II.A-3. Phenix Blanket Assembly (Ref. 14) 


\section{B. CORE SUPPORT AND VESSEL INTERNALS}

The fuel assemblies are supported by a grid plenum assembly, which also distributes sodium to the core elements, acting as an almost constant-pressure feed tank. This assembly consists of a cylindrical vessel $3500 \mathrm{~mm}$ in diameter and $965 \mathrm{~mm}$ high, the bottom and top being related by means of a series of upright tubes located according to the lattice step of the core. The free annular volumn between the sleeve and this dense tube structure acts as a calming area for the sodium. Each tube receives the foot of an assembly, with forced cooling. Distribution is to 103 fuel assemblies, 90 radial blanket assemblies, 216 or 222 stee? assemblies, 41 or 17 assemblies in storage and six control elements. The lattice tubes are attached to the bottom and top plates of the support structure by a screw piece, which serves as the tight support of the assembly at the top and the guide for the assembly foot at the bottom. The lateral surfaces of the tubes each have six drilled orifices, the lengths depending on the area of location. (Fig. II.B-1.)

A supplementary support similar to the grid assembly receives the logs of the lateral shielding. The device consists of six elements located around the grid-plenum. These elements are steel plates pierced at the lattice locations for each of the log types. (Ref. 15.)

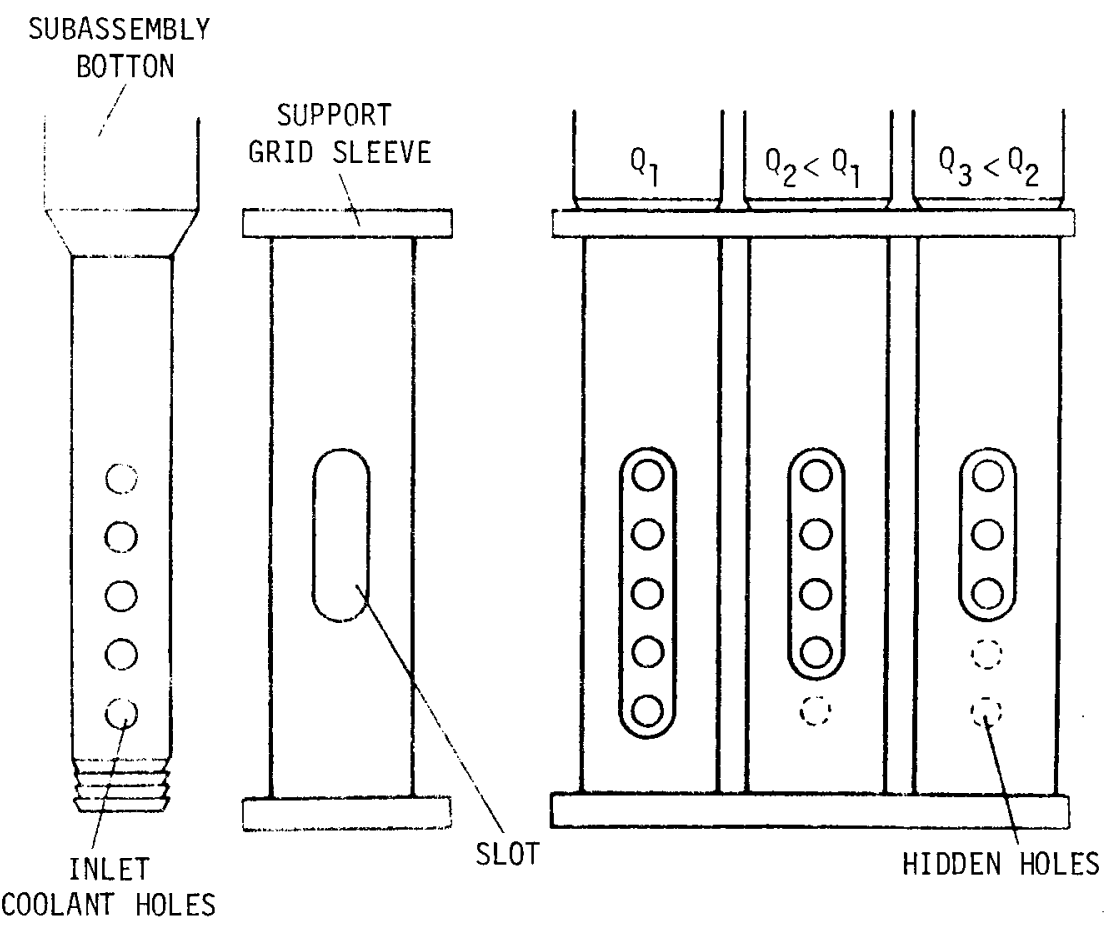

Figure II.B-1. Phenix Flow Adjus tment System (Ref. 7) 
II. C. REACTOR VESSELS AND SHIELDING

The integrated concept locates the primary loops in the immediate vicinity of the reactor vessel within the main vessel. The reactor vessel opens freely into the main tank. The grid--plenum device rests on a supporting framework at the bottom. The vessel is hung from the cover slab, which is a $60-\mathrm{cm}$ thick circular plate filled with concrete and welded to the safety vessel. The diameter of the reactor vessel is $6.7 \mathrm{~m}$.

The main vessel is $11.5 \mathrm{~m}$ in diameter and $12 \mathrm{~m}$ high. It contains a 11 of the primary sodium. It is reinforced by a ring to which suspension beams are welded. Support is from a concrete slab forming the upper part of the reactor block. The vessel is closed at the top by a flat plate (roof) with openings for the passage of pumps and heat exchangers, and connected to the sleeve of the rotating plug. Final closure is the rotating top plug.
The leak vessel is a double-wall structure surrounding the main vesset. The gap between vessels is $100 \mathrm{~mm}$.

The carbon-steel safety vessel is $12 \mathrm{~m}$ high and $14 \mathrm{~m}$ in diameter with a $25-\mathrm{mm}$ thick wall. It surrounds the other vesse1s and is located $80 \mathrm{~cm}$ from the leak vessel. It is welded to the slab and kept in a nitrogen atmosphere. The cooling circuit for the surrounding concrete can also evacuate residua] power in case of sodium loop failure. (Fig. II.C-1.) (Ref. 14; see also Section II.G.)

The final top closure for the reactor vessel is the rotating plug, a thick circular plate secured to a sleeve and filled internally with a stack of metal plates, with gas layers, insulation, and supplementary radiation shielding. Joints are liquifiable. (Ref. 14.) 
PHENIX II.C.

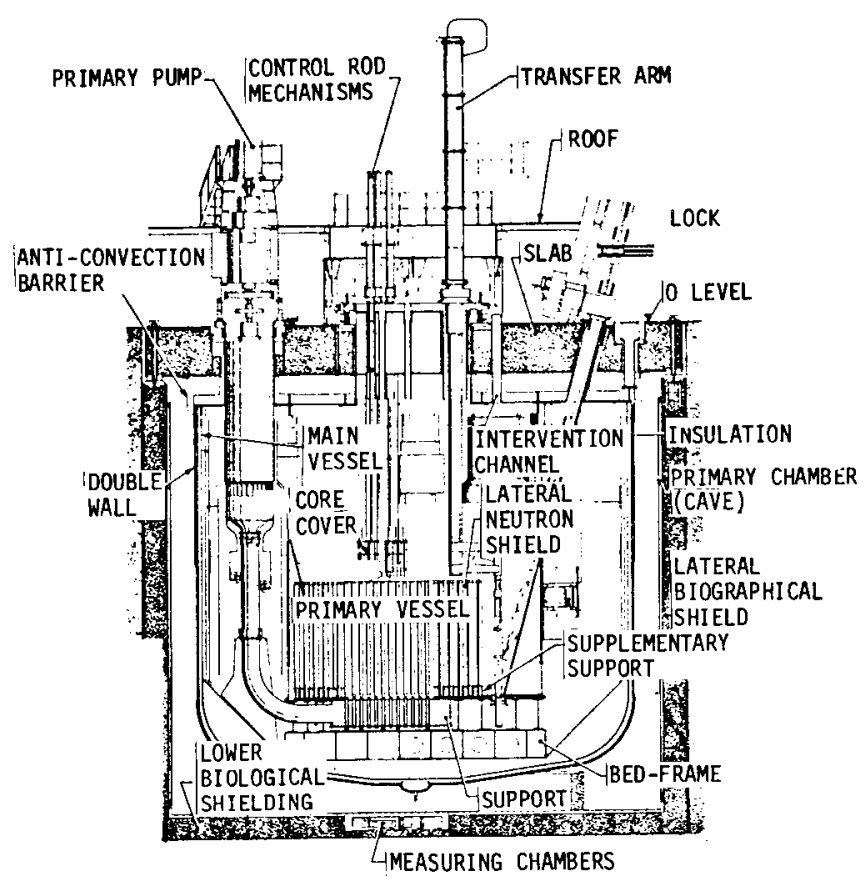

Figure II.C-1. Phenix Reactor Block (Ref. 14)

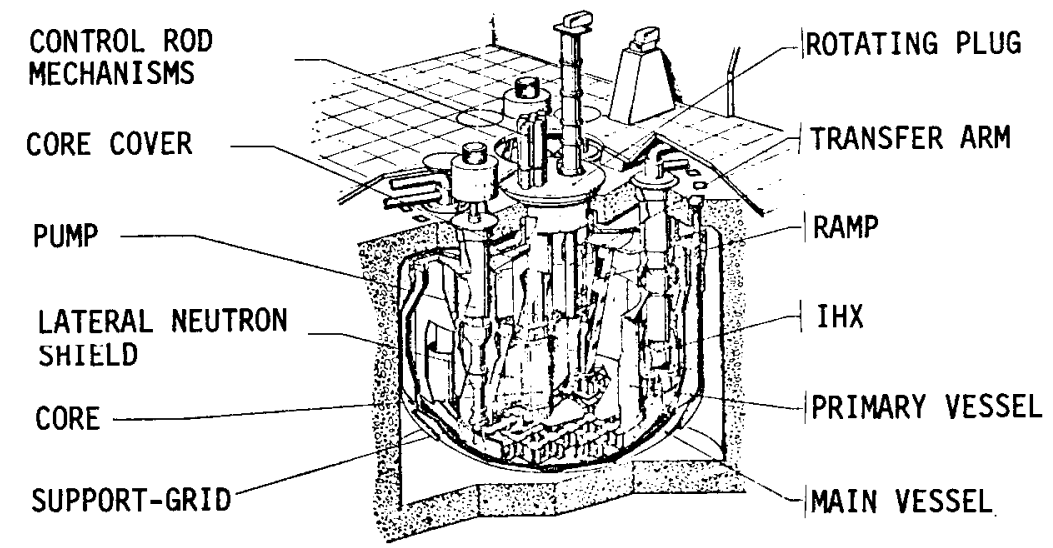

Ffgure H.C-2. Phenix Reactor Bloek Showng Top Struetures (Ref. 14)

II.C-2 


\section{D. CONTROL ELEMENTS}

Control is by six identical assemblies located at the vertices of a hexagon at the approximate midpoint of the fuel zone radius. Each assembly may be used as a shim, safety, or fine control rod. Each assembly consists of a guide thimble (a cylinder $4100 \mathrm{~mm}$ long and $113.7 \mathrm{~mm}$ in diameter) and a control rod, which are loaded separately. The bottom of the guide thimble is similar to that of the fuel assembly. The thimble body has stellite bearings for guiding the movements of the control rod. The rod is a cylindrical stainless-steel tube $95 \mathrm{~mm}$ in diameter containing seven absorbing pins. Each pin contains enriched $\mathrm{B}_{4} \mathrm{C}$ and is $28 \mathrm{~mm}$ in diameter and $1150 \mathrm{~mm}$ long. The $B_{4} C$ pellet column is $900 \mathrm{~mm}$ high. The pins are vented. (Figs. II.D-1 and II.D-2.) (Ref. 7.)

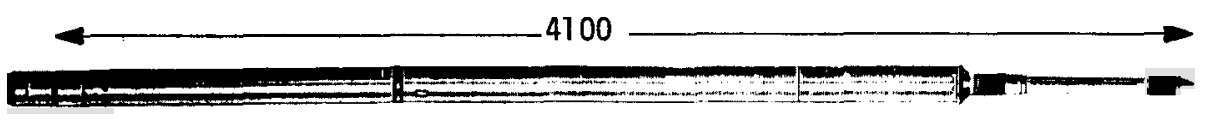

\section{REACTOR STOPPED}

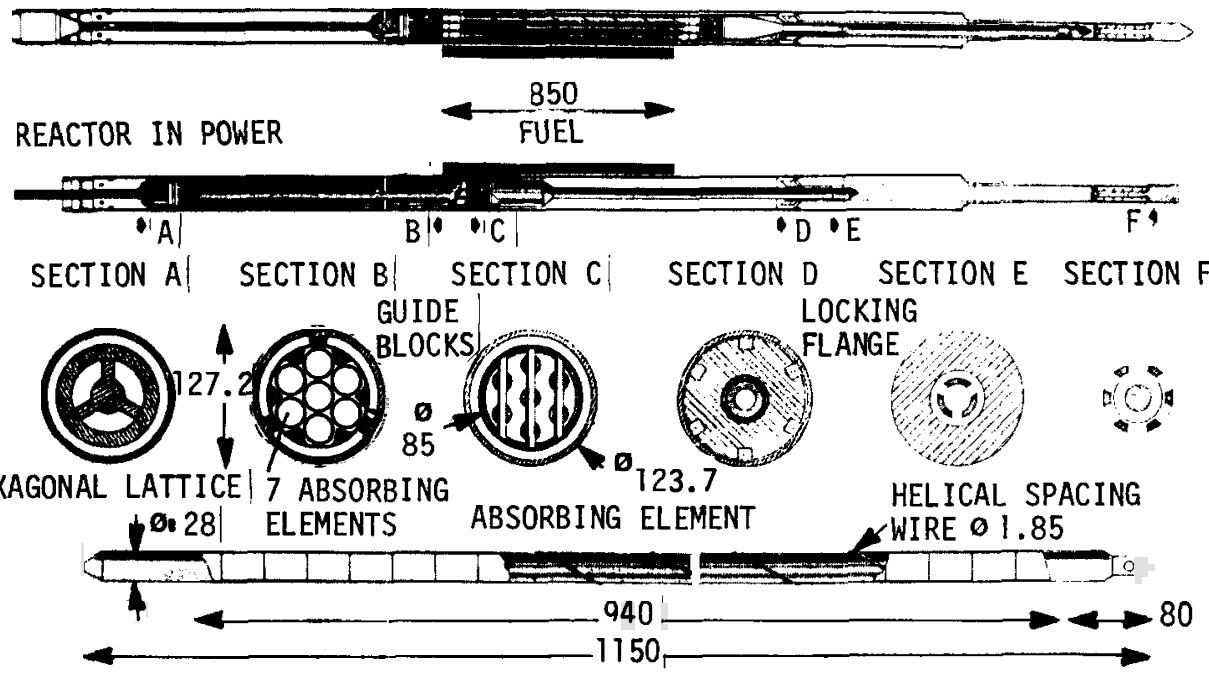

Figure II.D-1. Phenix Control Subassembly (Ref. 7)

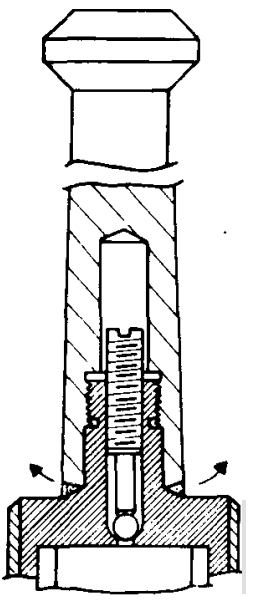

A. BALL-VALVE VENTING

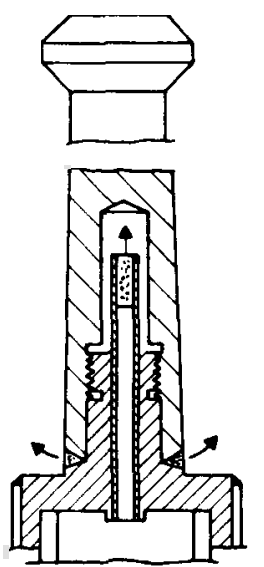

B. SINTERED METAL VENTING

Figure II.D-2. Yenting of Phenix Control Assemblies (Ref. 17) 


\section{E. HEAT TRANSFER SYSTEMS}

Phenix is pool-type reactor with core, blankets and shields, three pumps and six intermediate heat exchangers located within the main vessel, which contains about 800 tons of sodium. The blanket is argon. The intermediate heat exchangers are located in a ring around the reactor vessel. Cold sodium enters through the collectors of the assemblies at the lower part of the vessel through short pipes, which are the only pipes in the primary circuit. Flow is upward through the assemblies into the reactor vessel and into the heat exchangers. From the heat exchangers, sodium passes to the main vessel pump inlets, which direct the cold so um back to the collectors.

Each of the three independent secondary loops includes the two intermediate heat exchangers, a steam generator located between two reservoirs, a mechanical pump located in the expansion reservoir and the piping connecting this equipment. The expansion and buffer reservoirs have isolating valves and rupture disks. The steam generator has motorized isolation valves to limit the amount of sodium available to react with water during a leak and to prevent general contamination of the circuit by reaction products. The pump is at the cold point. Hot sodium leaves the intermediate heat exchanger through two 355-mm-diameter pipes, which are joined into a single 508-mm-diameter collector a short distance from the equipment in the reactor building. The sodium is directed toward the buffer reservoir; inlet is lateral and outlet is axial. The collector at the buffer reservoir outlet feeds, in parallel, the superheater and resuperheater through 457-mm-diameter pipes. on leaving this equipment, the sodium is mixed and directed through the economizer-evaporator by a 508-mm-diameter collector. Cold sodium leaves the steam generator by a 508-mm-diameter pipe and passes through the expansion reservoir. The pump takes it and returns it to the intermediate heat exchangers. (Fig. II.E-1.)
Two intermediate heat exchangers operate in parallel in each secondary loop. The unit is a thick tubular plate exchanger with straight pipes arranged in 19 concentric rings around a central pipe for secondary sodium inlet. This tube is a concentric pipe with an isolating layer of nitrogen in the annular space. Secondary flow is downward through the central pipe and upward through the IHX tubes. Primary sodium enters the unit by passing under a bell that acts as a flow guide, flows downward around the tubes and back to the main vessel where it is sucked up by the pumps. (Fig. II.E-2)

The exchanged power from six heat exchangers is $563 \mathrm{MW}$. Primary and secondary flows are 2760 and $2211 \mathrm{~kg} / \mathrm{sec}$, respectively. The heat exchanger area is $6 \times 465 \mathrm{~m}^{2}$. (Ref. 15.)

The primary pump, which is similar to the Rapsodie unit, is a vertical centrifugal pump with side suction and axial discharge. It is $10 \mathrm{~m}$ high and weiahts 20 tons. It is equipped with an inertia wheel that allows it to reach $1 / 10$ speed in $60 \mathrm{sec}$. Flow at the core inlet plenum intake is $1000 \mathrm{~kg} / \mathrm{sec}$ with a head of $76 \mathrm{~m}$ of sodium at $400^{\circ} \mathrm{C}$. Pump speed is $900 \mathrm{rpm}$. (Fig. II.E-3.)

The secondary pump is also a vertical centrifugal unit with axial discharge into a reservoir that has a free sodium surface under an argon atmosphere. There is no nonreturn valve or inertia wheel. Nominal operating flow is $0.86 \mathrm{~m}^{3} / \mathrm{sec}$ under a manometric depth of $65 \mathrm{~m}$ of sodium at $350^{\circ} \mathrm{C}$. Pump speed is $925 \mathrm{rpm}$. Estimated efficiency is 0.80. (Figs. II.E-4 and II.E-5.) (Refs. $5,15$. 


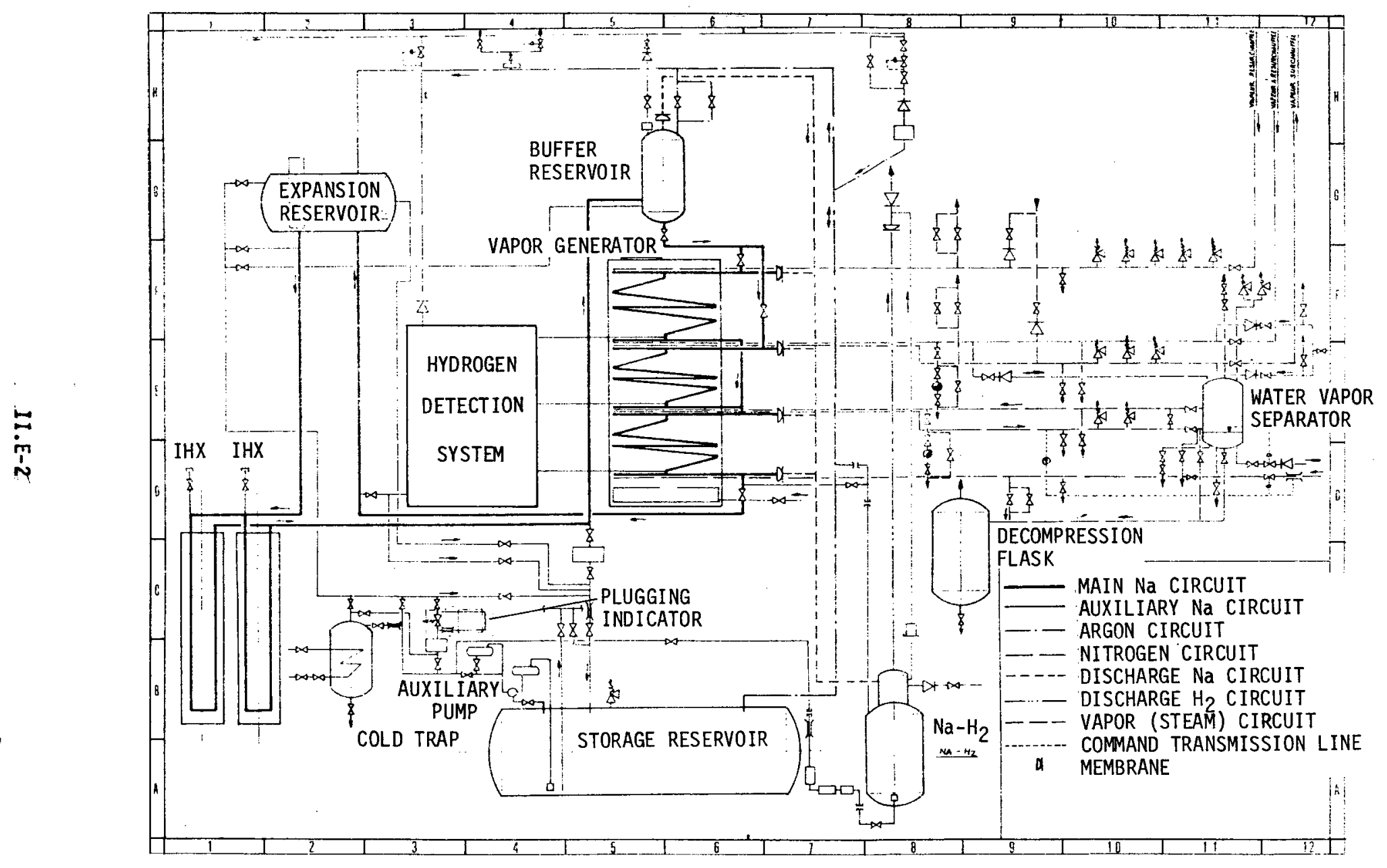

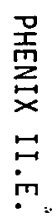

Figure II.E-1. Phenix Secondary Loop Schematic (Ref. 15) 
PHENIX II.E.

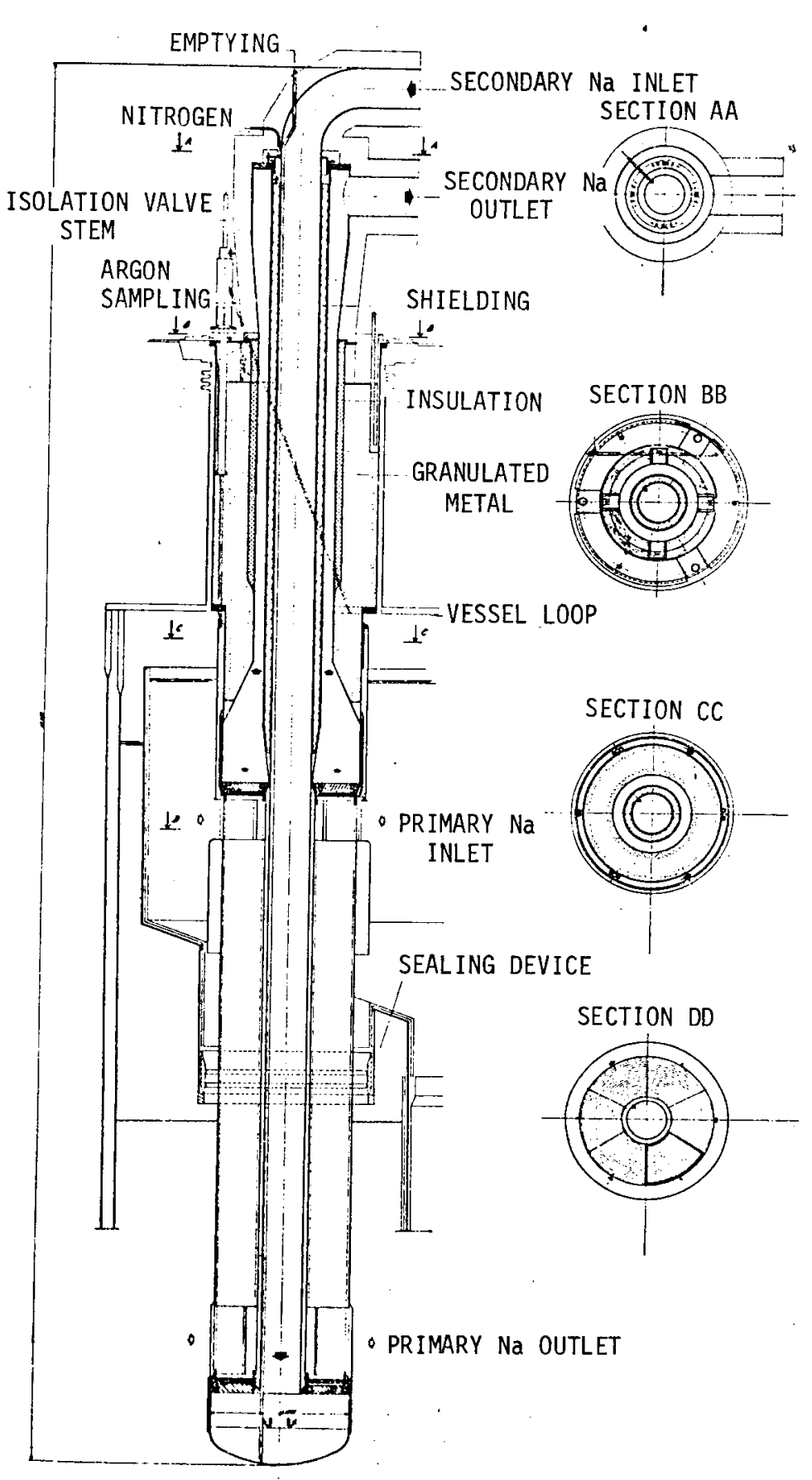

Figure II.E-2. Phenix Intermediate Heat Exchanger (Ref. 22)

II.E-3 


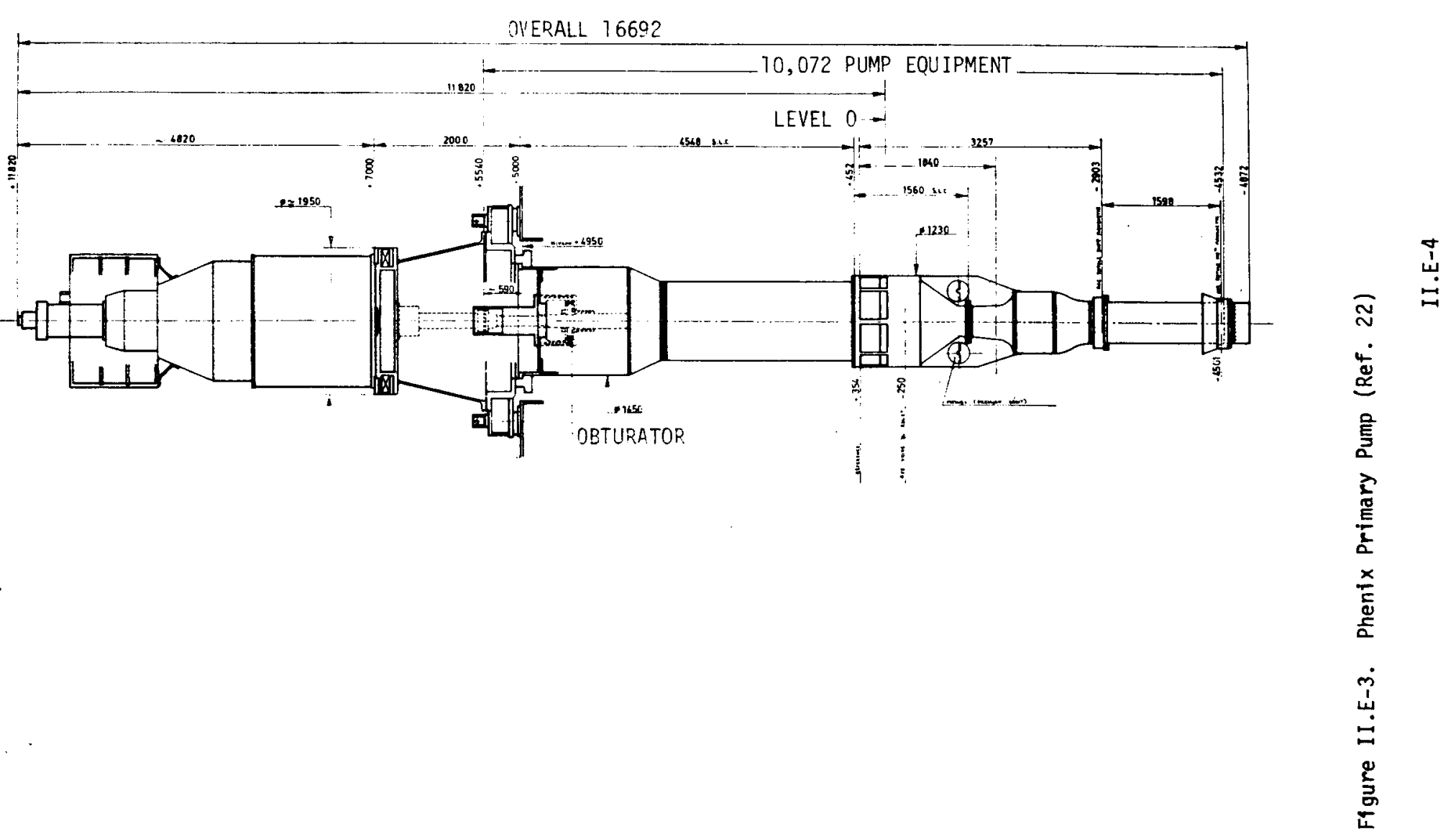




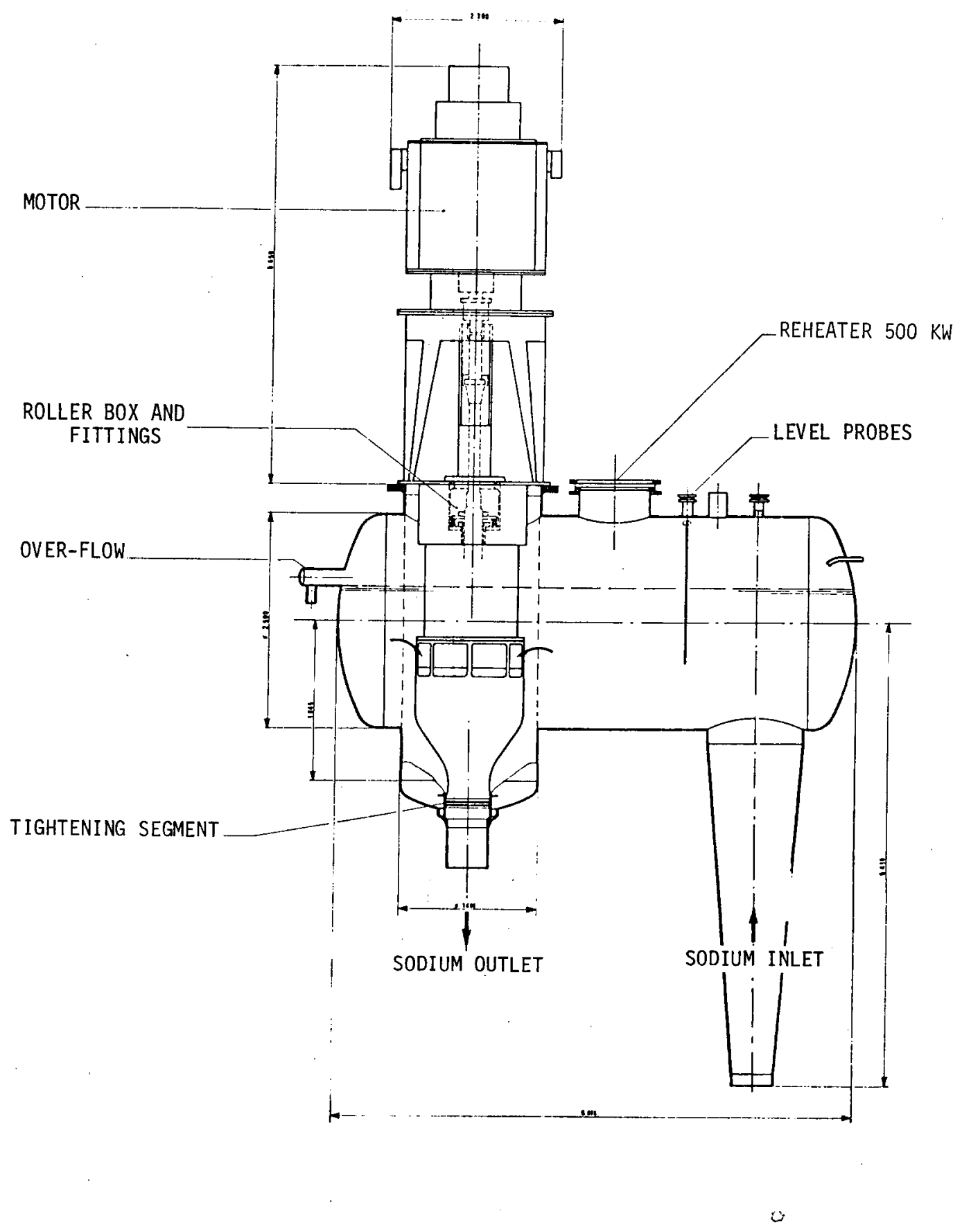

Figure II.E-4. Phenix Secondary Pump (Ref. 15)

II.E-5 
PHENIX II.E.

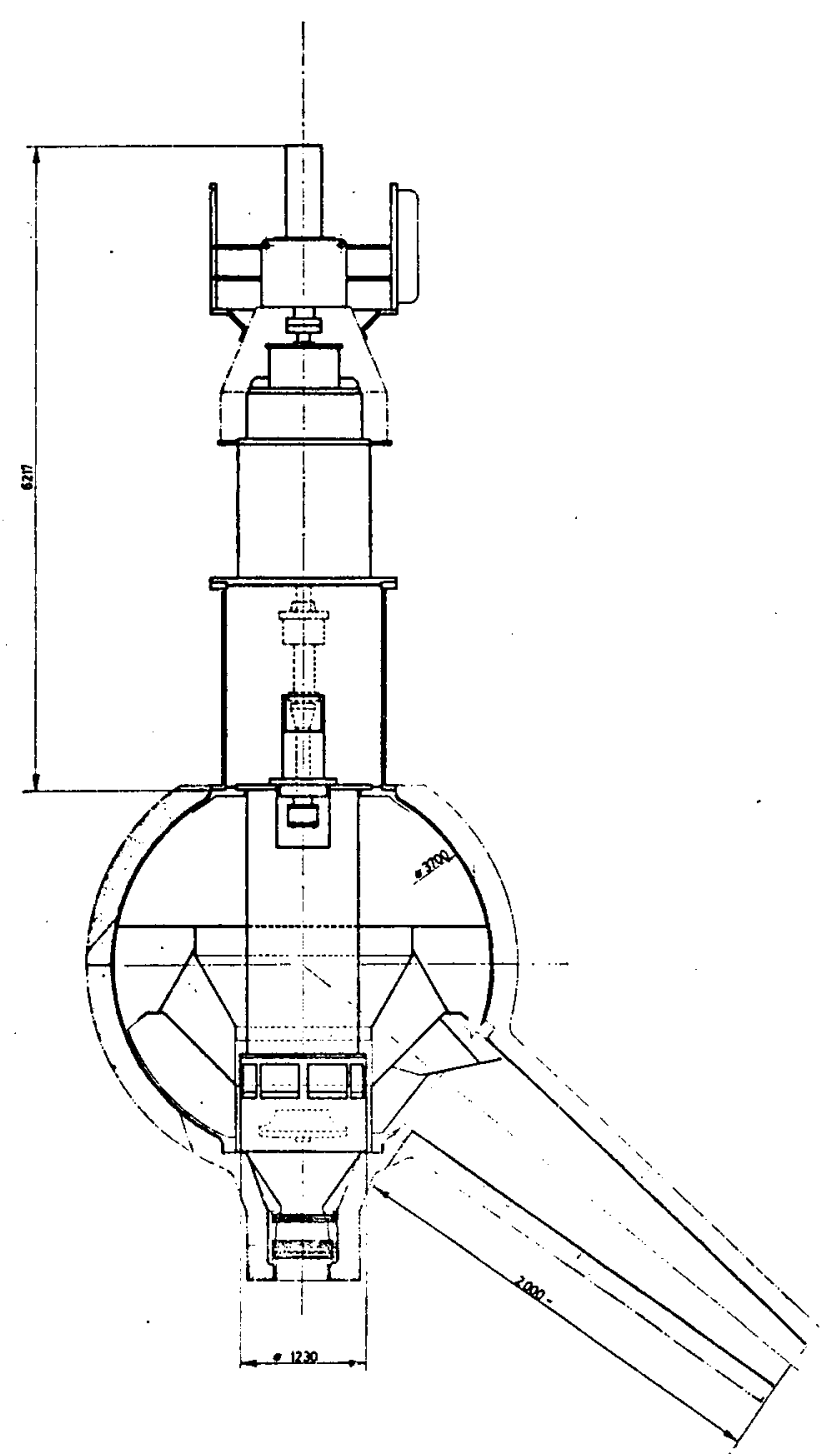

Figure II.E-5. Phenix Expansion Reservoir and Secondary Pump (Ref. 22)

II.E-6 


\section{F. SODIUM PURIFICATION AND INSTRUMENTATION}

The cold trap and the plugging meter are the primary purification components. Purification system and monitoring are part of the primary circuit.

The primary cold trap (Fig. II.F-l) is a vertical vessel surrounded by a static Nak-filled double shell cooled by an organic liquid. Sodium is cooled first in an economizer external to the trap, then in an internal economizer as it enters the trap, and finally while passing near the double shell before penetrating the mesh. Total flow is $250 \mathrm{l} / \mathrm{hr}$ minimum and $750 \mathrm{l} / \mathrm{hr}$ maximum.

Nominal operating temperature is $185^{\circ} \mathrm{C}$.

Each of the secondary loops includes a cold-trap and a plugging meter. The secondary cold trap (Fig. II.F-2) is similar to the primary trap in geometry and flow characteristics but does not have an economizer. The organic coolant flows in a coil that cools the sodium directly without the intermediate NaK double-wall device. Nominal operating temperature in the secondary trap is $160^{\circ} \mathrm{C}$.

There are two plugging meters for online sodium purity survey (Fig. II.F-3). One is operated continuousily and the other discontinuously in an automatic and cyclic mode. Nominal characteristics are as follows:

- Total minimum sodium flow -- $250 \mathrm{\ell} / \mathrm{hr}$

- Maximum sodium flow -- $750 \mathrm{\ell} / \mathrm{hr}$

- Flow in meter through channels -$200 \mathrm{l} / \mathrm{hr}$

- Differential pressure -- 150-160 mb

- Inlet temperature $--180-450^{\circ} \mathrm{C}$ depending on operating condition
Sampling devices like those used in Rapsodie were selected: the Tastena type, which dips into the sodium pool for the sample, and a bypass flow-through sampling tube. In the latter, the sampling device is located in a cell on a bypass of the purification loop. Sampling is by means of two pairs of removable parallel tubes upstream and downstream of the primary cold trap. (Fig. II. F-4.)

Flow and sodium levels are monitored by electromagnetic flowmeters and intermittent or continuous level gages. The level probes are based on the variation of the mutual inductance of two intercepted windings. Flowmeters on the primary and secondary loops are installed on large-diameter tubes.

A boiling detector to be tested in Phenix utilizes a monitoring principle based on the level of uitrasonic noise at the assembly outlets and the occurrence of boiling due to partial plugging. There are 12 boiling detectors for the reactor. Each measurement channel has a waveguide, a piezoelectric crystal, an amplifier, a highpass filter and a zero-time correlator.

Failed fuel detection is by delayed neutron monitoring of a sodium sample. All mechanisms are packed in the failed element location plug in the reactor rotating plug (Fig. II.F-5). Argon sampling is also used. Samples are taken from the reactor upper plenum and monitored for fission product $\mathrm{Kr}$ and $X e$ by means of an ionization chamber. Electrostatic precipitation counts the solid fission products $\mathrm{Rb}$ and $\mathrm{Cs}$. Tagging the fuel assemblies with gaseous $\mathrm{Kr}$ and $\mathrm{Xe}$ stable isotopes is planned to start with the second core loading. (Ref. 5.) 

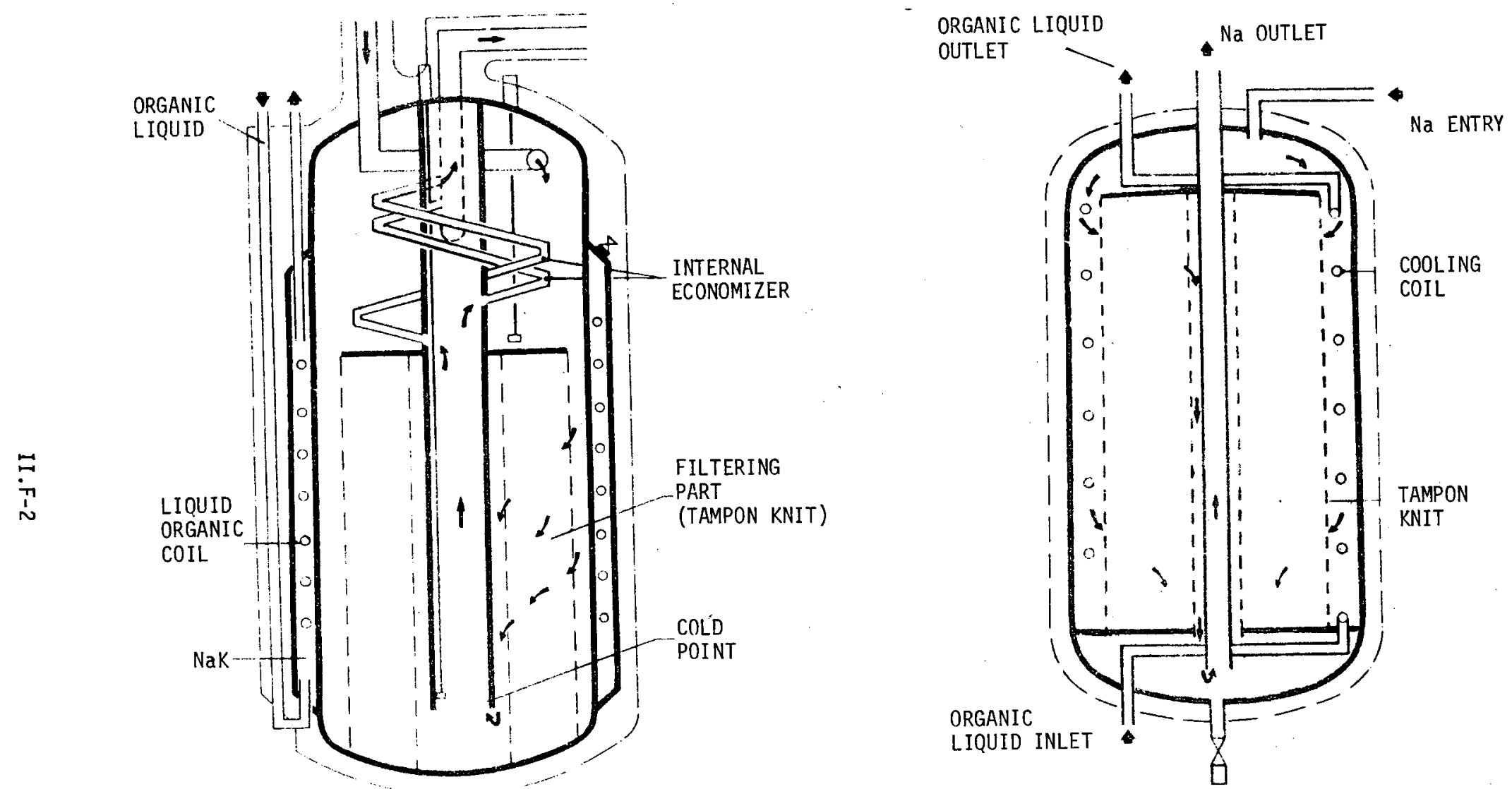

NOMINAL CONDITIONS

QNa: $30 \mathrm{~m}^{3} / \mathrm{h} \quad$ CAPACITY: $5,10 \mathrm{~m}^{3} / \mathrm{h}$

$\mathrm{BNa}:$ ( INLET) $185^{\circ} \mathrm{C}$ WEIGHT: $7,4 \mathrm{t}$

BNa: (OUTLET) $165^{\circ} \mathrm{C}$ MATERIAL: Z6CN 18.10

NOMINAL CONDITIONS

$\mathrm{QNa}=30 \mathrm{~m}^{3} / \mathrm{h} \quad$ CAPACITY $: 5 \mathrm{~m}^{3}$

$\mathrm{BNa}$ (INLET) $=160^{\circ} \mathrm{C}$ WEIGHT $=7,32 \mathrm{t}$

BNa (OUTLET) $=130^{\circ} \mathrm{C}$ MATERIAL: $26 \mathrm{CN} 1810$

Figure II.F-1. Phenix Primary Cold Trap (Ref. 9)

Figure II.F-2. Phenix Secondary Cold Trap (Ref. 9) 
C
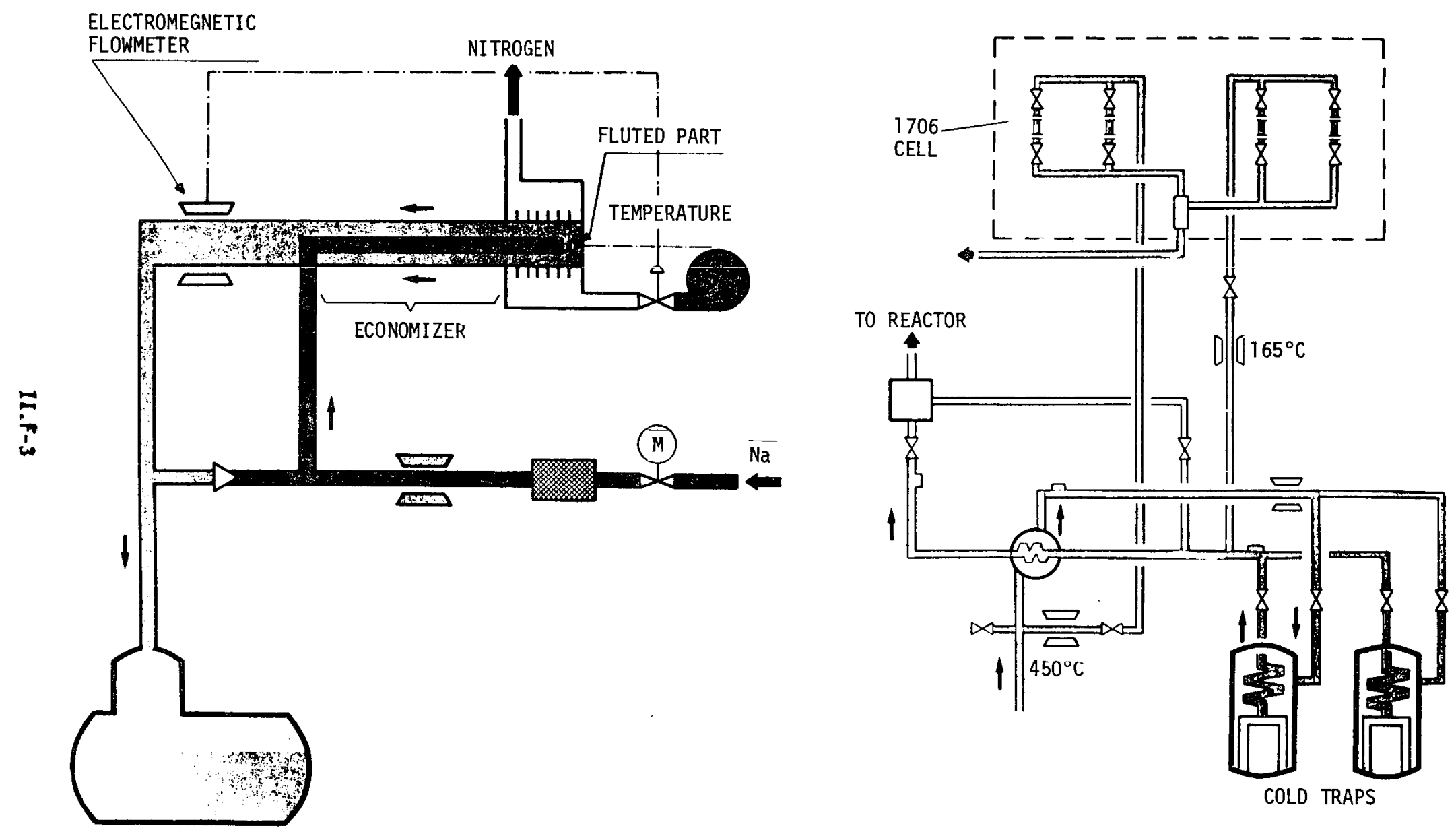

Figure II.F-3. Phenix Plugging Meter (Ref. 9)

Figure II.F-4. Phenix Sampling Cell (Ref. 9) 
PHENIX II.F.

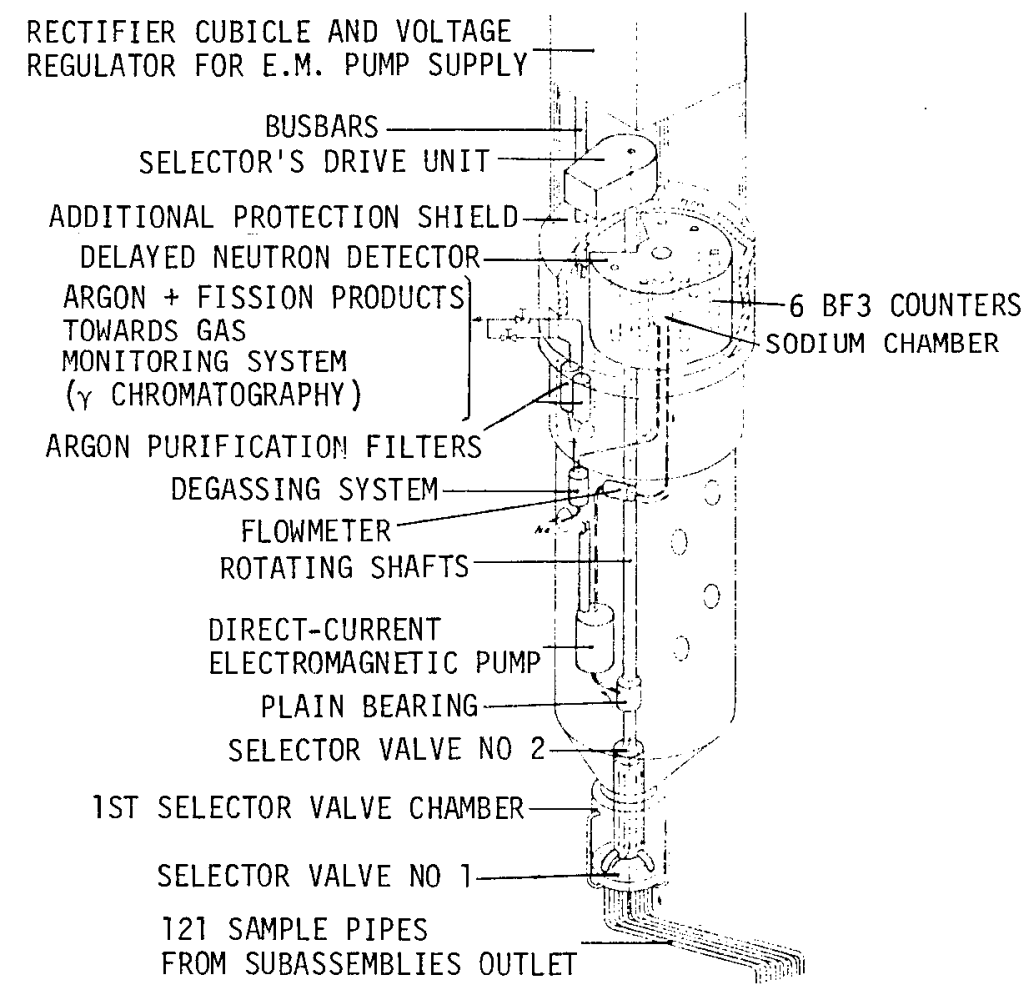

Figure II.F-5. Phenix Failed Fuel Location (Ref. 5)

II. F-4 


\section{G. COVER GAS AIID AUXILIARY SYSTEMS}

The argon circuit contains discharge reservoirs having a total volume of $600 \mathrm{~m}^{3}$ and is equipped for radioactive purification. No description of the circuit has been found.

See Section II.E for a description of sodium purification.

Emergency cooling is furnished by heat exchange (radiation and conduction) between the main vessel and the double-wall vessel and by radiation and natural convection in the double-wall insulation. The safety container and its cooling circuit constitutes a thermal shield; the water circuit protects the bottom and sleeve of the safety vessel, the slab, and the passages. Cooling is by a double network of welded tubes in the container wall. Tubes are parallel and spaced $150 \mathrm{~mm}$ apart. The flow direction is resersed and the lattice step changed in two neighboring tubes. In emergency conditions, $2100 \mathrm{~kW}$ can be evacuated. If one of the piping networks is lost, the flow still available is $70 \mathrm{~m}^{3} / \mathrm{hr}$. The circuit can be supplied directly with raw water from the Rhone River. (Figures II.G-1, II.G-2 and II.G-3.) (Ref. 25.)

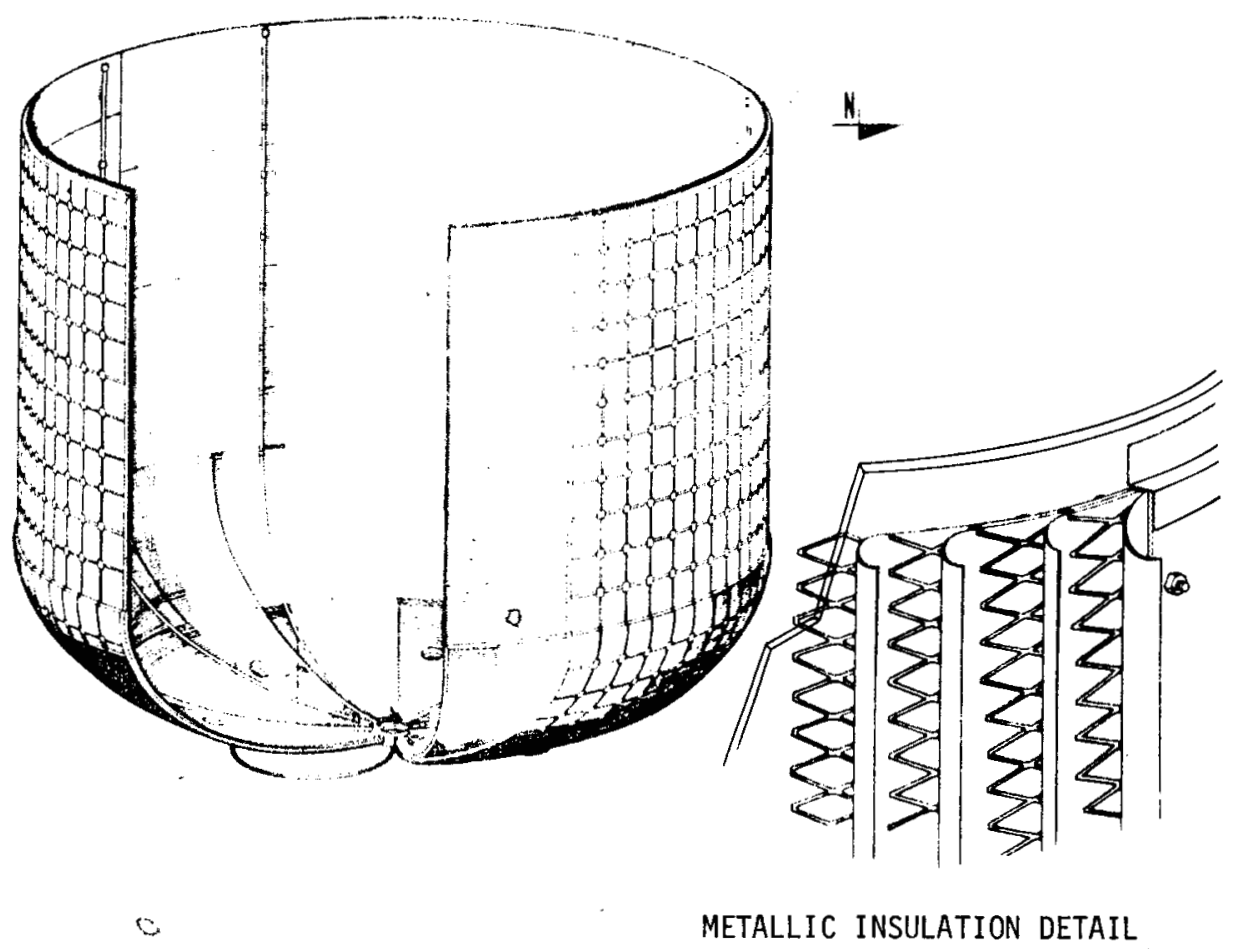

Figure II.G-1. Phenix Double-Wall Vessel Insulation (Ref. 25) 
PHENIX II.G.

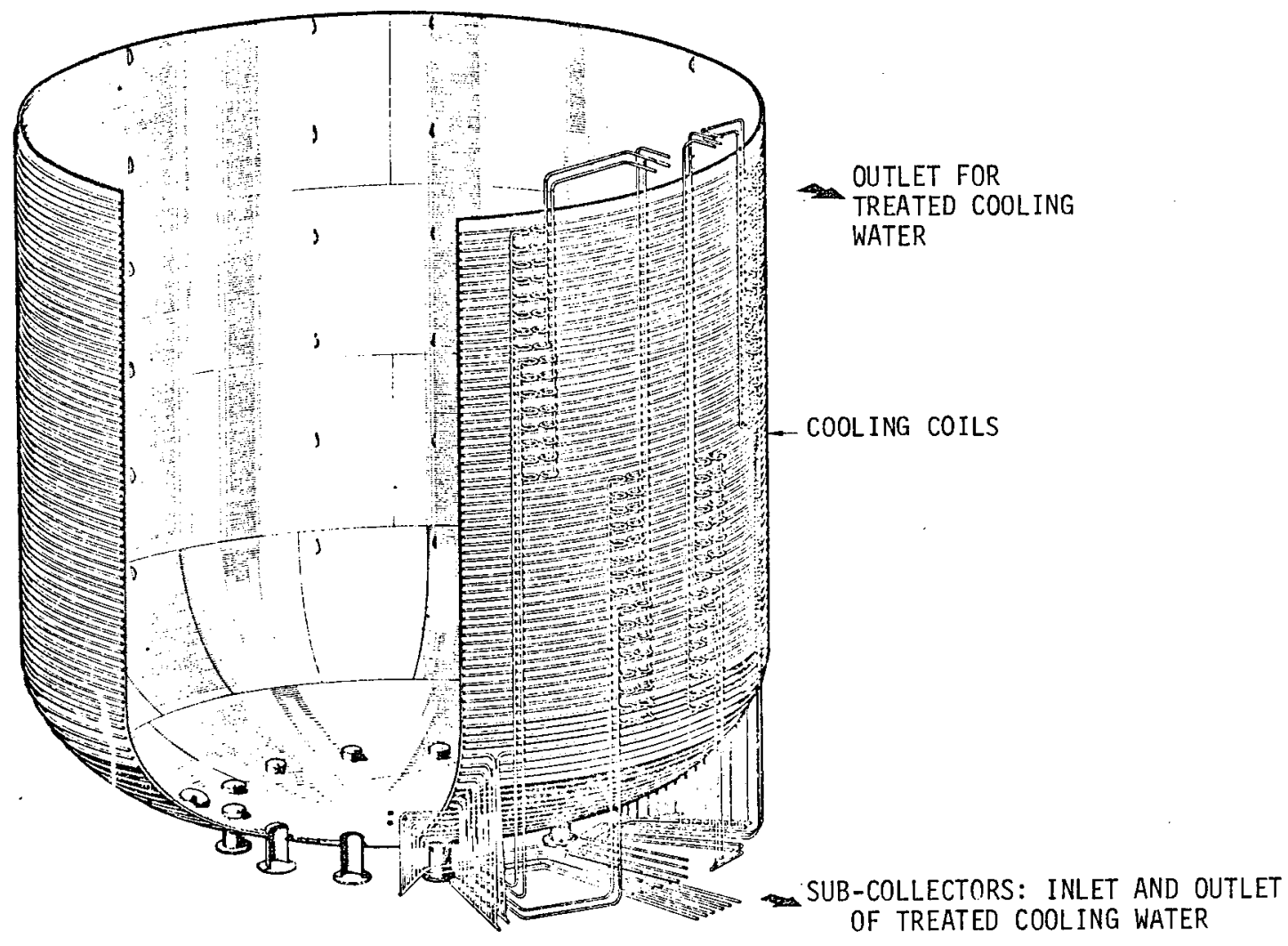

Figure II.G-2. UI timate Safety Circult, Phenix Primary Container (Ref. 25)

\section{G-2}




\section{H. STEAM GENERATORS}

The steam generator is a once-through, single-casing pipe bundle. There is no tube sheet. Each water tube bends, penetrates the shell and terminates in an outside water or steam subheader. Modules and the water and sodium headers are installed inside an insulated, self-supporting, rectangular containment box. A butterfly control valve proportions the sodium flow between superheater and reheater. A small nipple at each tube end allows for tube plugging in the event of a leak. Modules can be removed for repair or replacement. Sodium shutoff valves are located at the exit and entrance to the steam generator unit in each loop. Valves and piping can provide rapid dumping of both water/steam and sodium. (Fig. II.H-1.) (Ref. 12.)

Each generator consists of 12 economizer--evaporator modules, 12 superheater modules and 12 reheater modules. (See Table II.H-l for module specifications.) Each module is a seven-pipe bundle in an S-shaped casing for the superheater and reheater (double-s for the economizer--evaporator). Each generator has the following ancillary equipment: steam separator, decompression and nitrogen system, hydrogen detection system, exhaust air system, safety valves and fittings. (Fig. II.H-I.)

The sodium--water reaction discharge system (Fig.. II.H-2) consists of rupture disks and their discharge pipes, a $0.8 \mathrm{~m}$ discharge heater channeling reaction products to the hydrogen separator, a hydrogen separator (a vertical cylindrical tank of about $100 \mathrm{~m}^{3}$ capacity fed tangentially from the discharge header and containing an inner cyclone) and a 0.6-m ID chimney topping the separator dome and exhausting the hydrogen above the building roof. Normally, the nitrogen inside of the discharge system is maintained at a slightly positive pressure to prevent external air from leaking into the system. (Ref. 12.)

Table II.H-1. Steam generator specifications (Ref. 5)

\begin{tabular}{|c|c|c|c|}
\hline & $\begin{array}{l}\text { Economizer } \\
\text { evaporator }\end{array}$ & Superheater & Reheater \\
\hline $\begin{array}{l}\text { Steam water pipes }(\mathrm{mm}) \\
\text { Ring }(\mathrm{mm})\end{array}$ & $\begin{array}{l}\text { dia. } 28 \times 4 \\
\text { dia. } 193.7 \times 6.3\end{array}$ & $\begin{array}{r}\text { dia. } 31.8 \times 3.6 \\
\text { dia. } 193.7 \times 5.4\end{array}$ & $\begin{array}{l}\text { dia. } 42.4 \times 2 \\
\text { dia. } 193.7 \times 5.0\end{array}$ \\
\hline Exchange length per module $(\mathrm{m})$ & 60.8 & 26.9 & 21.9 \\
\hline Exchange area per module $\left(\mathrm{m}^{2}\right)$ & 26.7 & 14.5 & 18.5 \\
\hline $\begin{array}{l}\text { Exchange area of the } \\
12 \text { modules }\left(\mathrm{m}^{2}\right)\end{array}$ & 320 & 174 & 222 \\
\hline
\end{tabular}


PHENIX II.H.

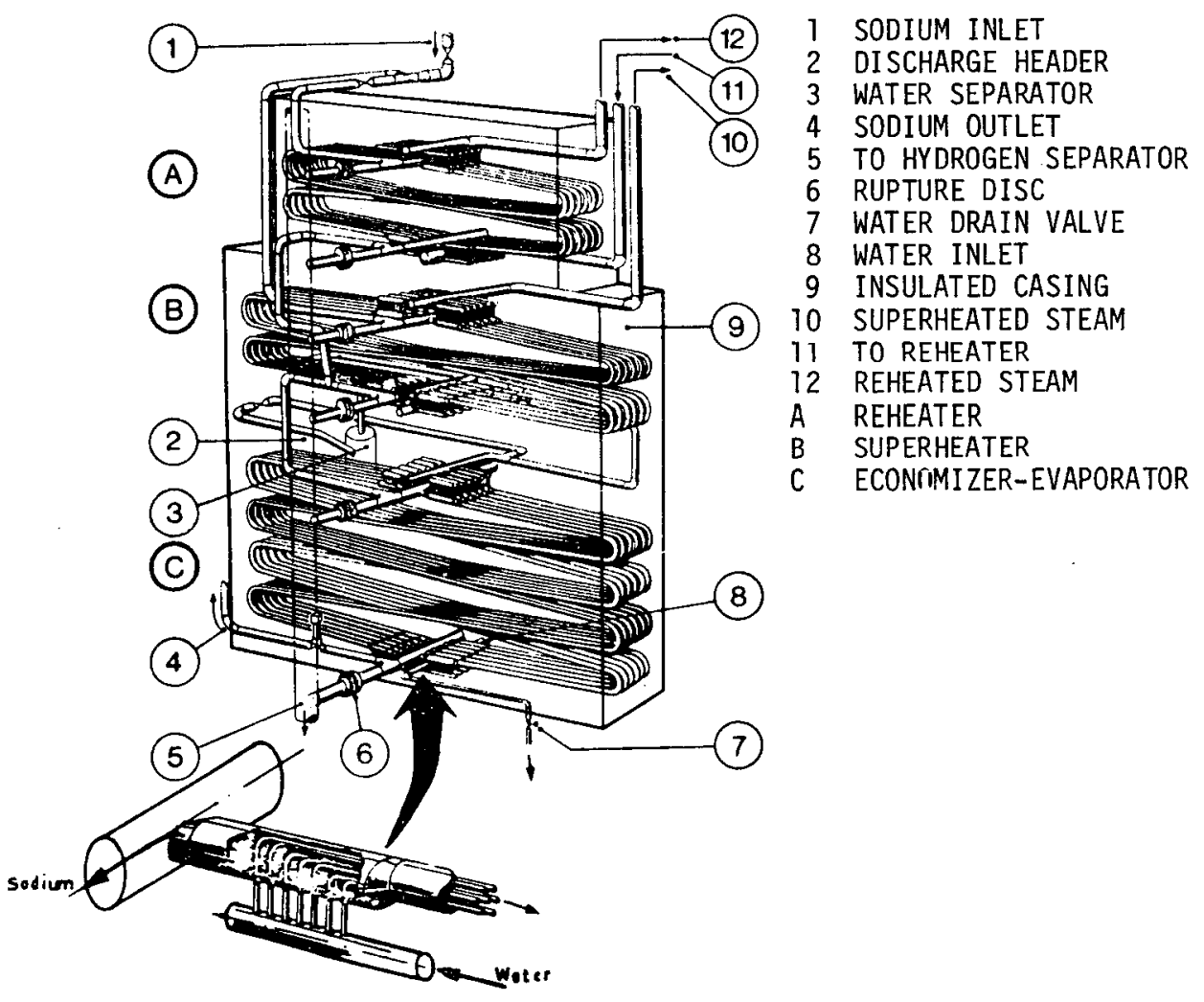

Figure II.H-1. Phenix Steam Generator (Ref. 12)

II. $\mathrm{H}-2$ 


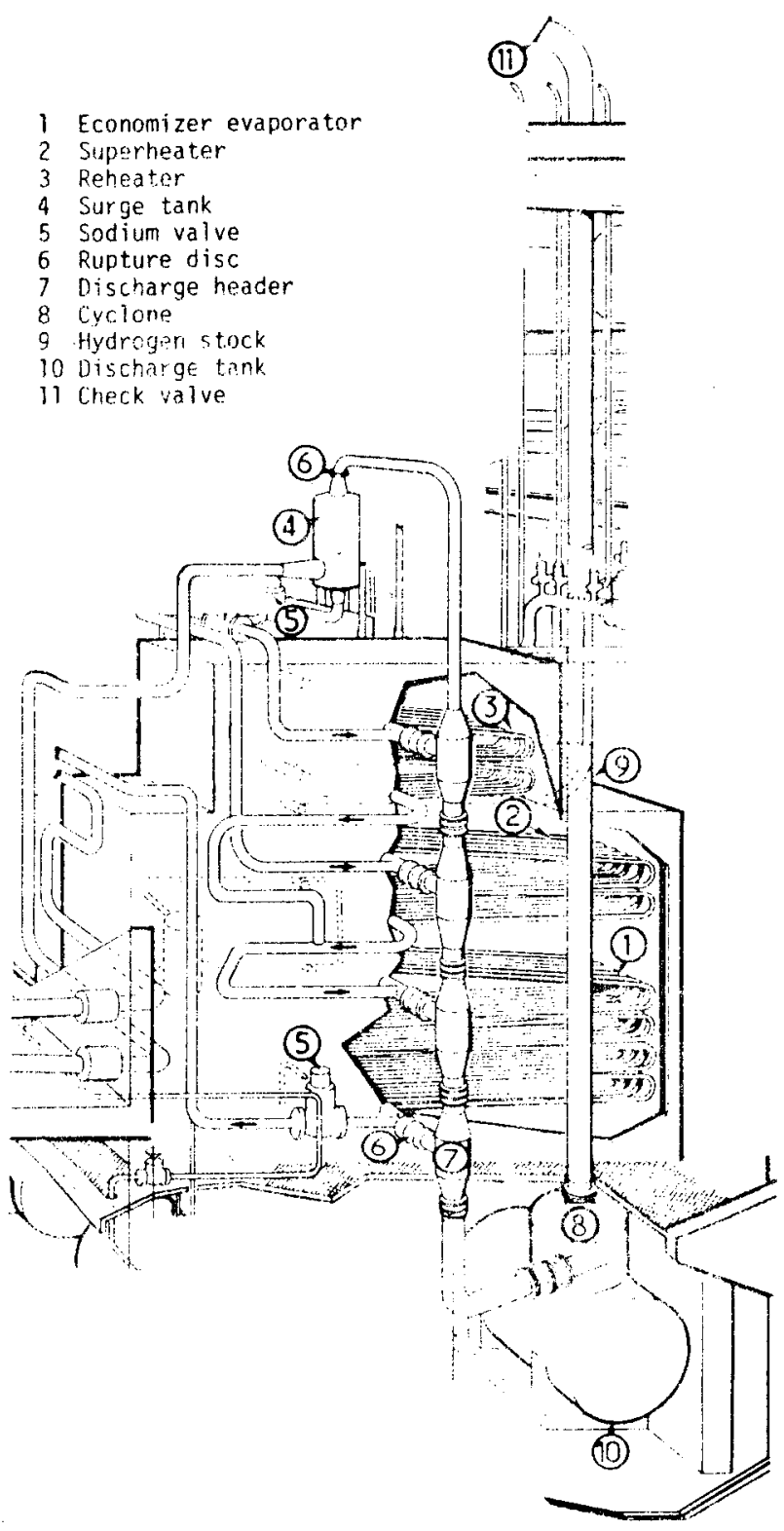

Figure II.H-2. Phenix Sodium/Water Reaction Discharge System (Ref. 12) 


\section{I. REACTOR INSTUMENTATION AND CONTROL.}

Reactor monitoring includes measurement of neutron flux over an 11 decade dynamic range. There are two pre-startup channels with $\mathrm{BF}_{3}$ detectors under the reactor vessel or high-temperature fission chambers in the vesse1. Three start-up pulse channels are associated with under-vessel boron counters. Three power channels associated with undervessel ionization chambers provide $\log$ and period measurements, a linear measurement and a reactivity measurement in the range $10^{-2}$ to 1.3 nominal power. Control measurement channels are associated with undervessel ionization chambers.

A boiling detector to be tested in Phenix utilizes a monitoring principle based on the level of ultrasonic noise at assembly outlets and the occurrence of boiling during partial plugging. There are 12 boiling detectors. Each measurement channel has a waveguide, a piezoelectric crystal, an amplifier, a high-pass filter, and a zerotime correlator.

Failed fuel detection will be by delayed neutron monitoring of a sodium sample drawn from the vessel at the IHX intake and argon sampling for detection of fission product $\mathrm{Xe}$ and $\mathrm{Kr}$. Electrostatic precipitation will be used to count solid fission products $\mathrm{Rb}$ and Cs. (See Section II.F for a description of sodium instrumentation.)
Two computers operating separately are used for central data processing. They individually monitor the nuclear boiler circuitry and the electric generator plant circuitry. They do not share in the automatic system except for the failed fuel detection system. (Ref. 5.)

An ultrasonic under-sodium scanning device has been tested for use as an obstacle detector. An ultrasonic projector operated by an electronic transmission system transmits wave trains to a vertical waveguide. The wave guide is filled with a liquid having acoustical properties similar to those of sodium. There is a 90-deg elbow with a reflector towards the lower end for deflecting the ultrasonic beam horizontally through an acoustic window. Echos reflected by obstacles are captured by an identical waveguide system that terminates at a transducer at the top. The transducer is connected to a receiver. The scanning system is rotated and vertically controlled by a suitable mechanism. uisplay is by means of a CRT. The height and bearing of the object is reproduced and the coordinates and shape of the object can be determined. (Fig. II.I-'])

There is no general automatic startup or shutdown feature and no general regulating system to adjust the power level to the grid. The reactor does not have load-following capability. (Refs. 5, 10.) 
PHENIX II.I.

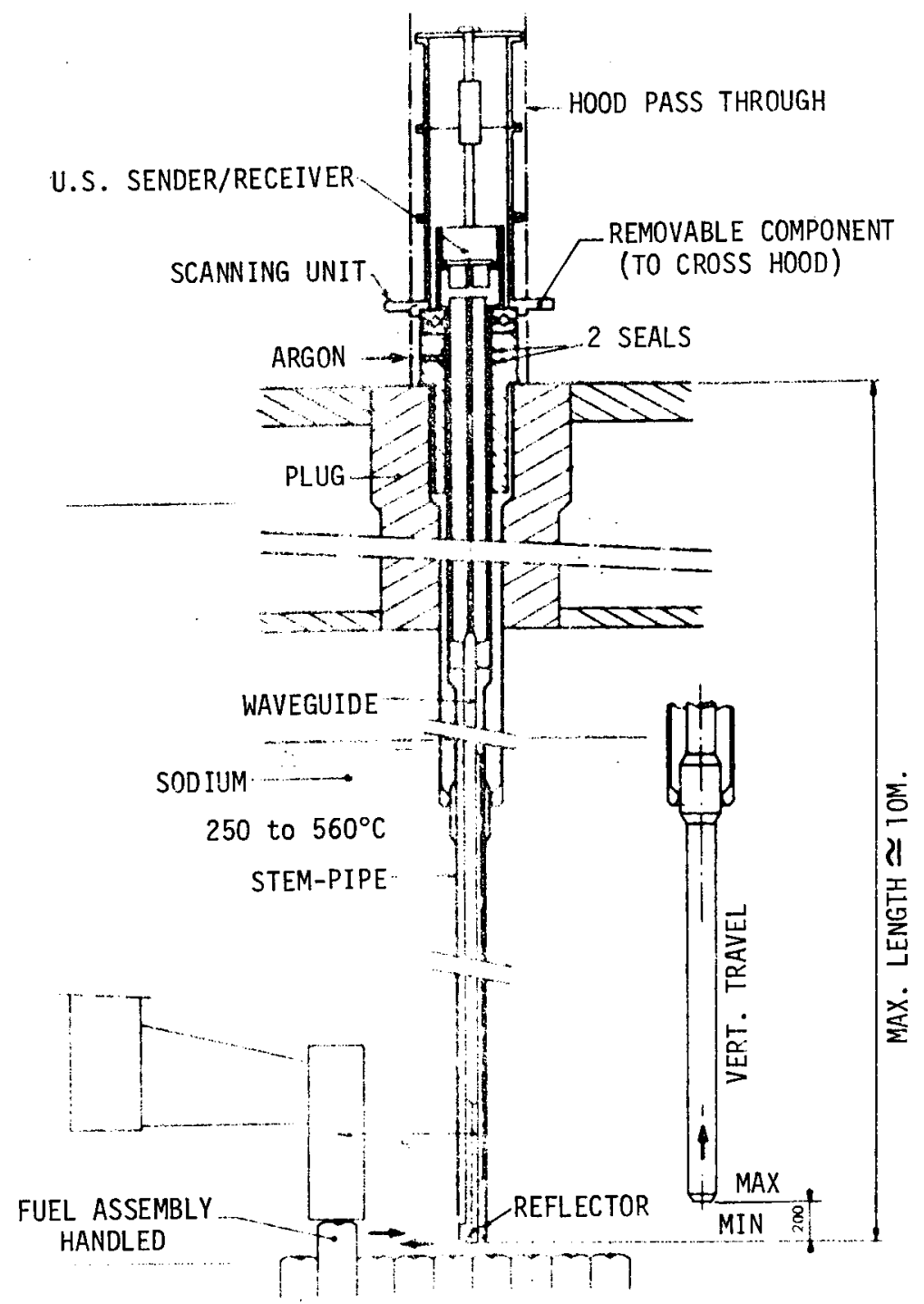

Figure II.I-1. Phenix Under-Sodium Viewing (Ref. 10)

II. I-2 


\section{J. FUEL HANDLING}

Facilities for handiing fuel assemblies include (1) a new element line, (2) a fixed argon-leak-tight assembly for transferring the element from one housing to another within the reactor by means of the rotating plug and transfer arm and (3) a spent element line where elements are processed in a nitrogen-filled hot cell after storage outside the reactor. After handling, spent elements are transported to the reprocessing plant or to solid-wastes storage. (Fig. II.J-1). Loading and unloading is done six times yearly, about 15-17 fuel assemblies and 8-11 fertile assemblies being unloaded during a handling period. The fuel assemblies release a heat power of $6.5 \mathrm{MW}$ or less; fertile assemblies release 1.2 MW at end of life. During transfer, the fuel assembly releases $40 \mathrm{~kW}$ maximum residual power. The assembly is kept immersed in sodium and its maximum can temperature is below $550^{\circ} \mathrm{C}$. In the core storage housings, the heat power of each assembly is below 120 $\mathrm{kW}$ (fission and gamma radiation) when the reactor is operating. The fuel elements are placed in the rotor of the storage drum when being unloaded.

In the spent elements cell (Fig. II.J-2), the elements are extracted from the drum by means of a blower grapple. Nitrogen flow cooling is used. Fuel and fertile pins are placed in cans for transport to the reprocessing plant. The neutral atmosphere transport cask carries eight cans containing pins from four assemblies and dissipates 10 $\mathrm{kW}$ of heat. Reactor elements are taken to the storage drum by the carriage via argon lock and ramps.

The L-shaped new element line (Fig. II.J-3) is inside the handling building. One leg includes the assembly storage rooms; the other includes the assembly inspection area and the zone of transfer to the storage drum. On arrival, new elements are located in a storage area consisting of 156 housings placed $300 \mathrm{~mm}$ apart and shielded by $30 \mathrm{~cm}$ of concrete.

Components handled include primary pumps, intermediate heat exchangers, control rod mechanisms, experimental fuel stringers, the in-reactor part of the transfer arm with its oral plug, secondary pumps, cold traps and drum auxiliaries. There are two special flasks for processing large components handled by the traveling crane in the reactor building. The special handling transfers them to the handling building by the traverser. A storage pit is partly in the reactor building and partly in the handling building. There are wash-down and decontamination pits; a pit for assembling, servicing, and repairing components; a dismentling cell for working on very active components; and a station for component testing. (Figs. II.J-4 and II.J-5.) (Refs. $5,15$. 
PHENIX II.J.

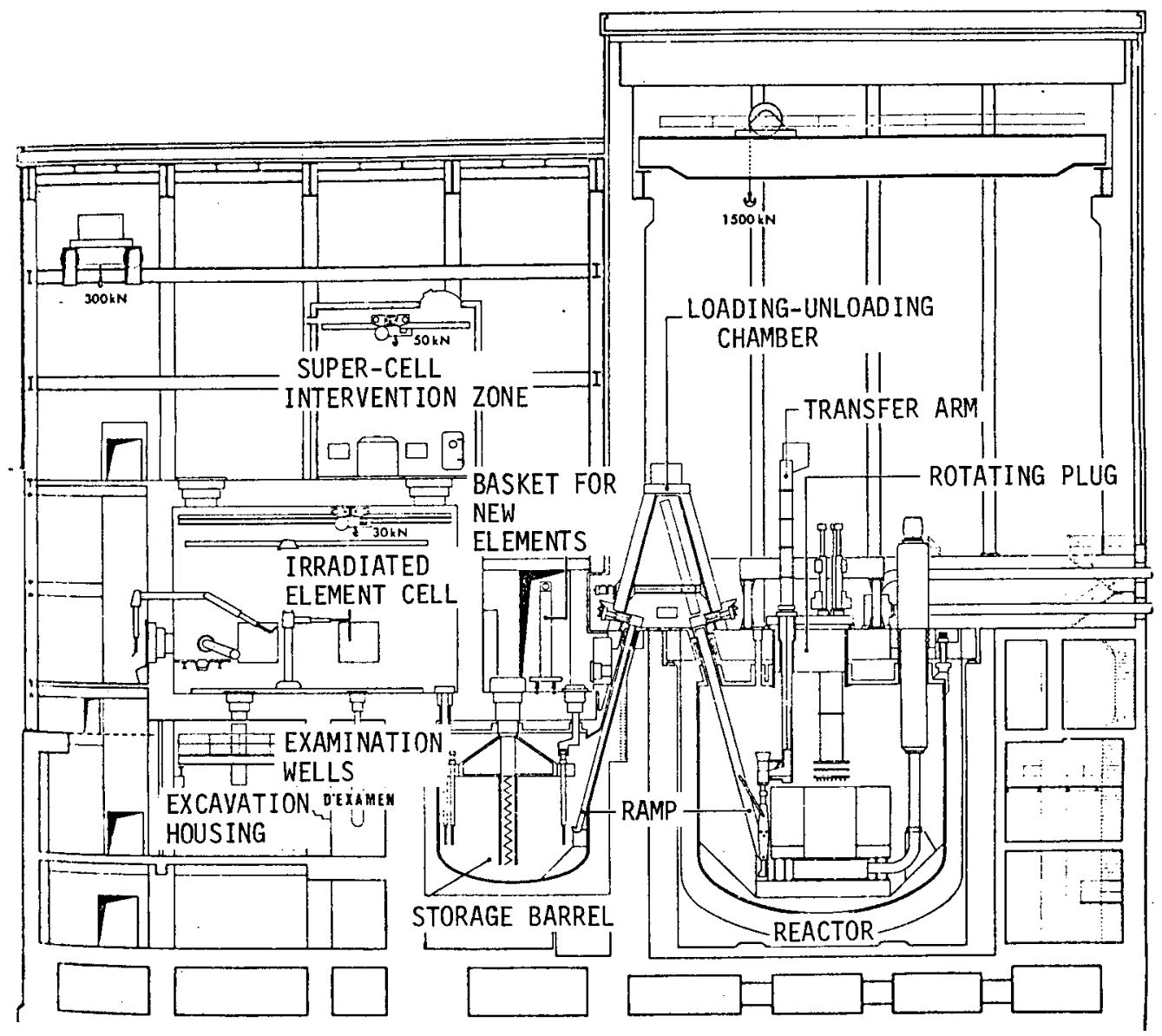

Figure II.J-1. Phenix Fuel Handling Line (Ref. 15)

II.J-2 
PHENIX II.J.

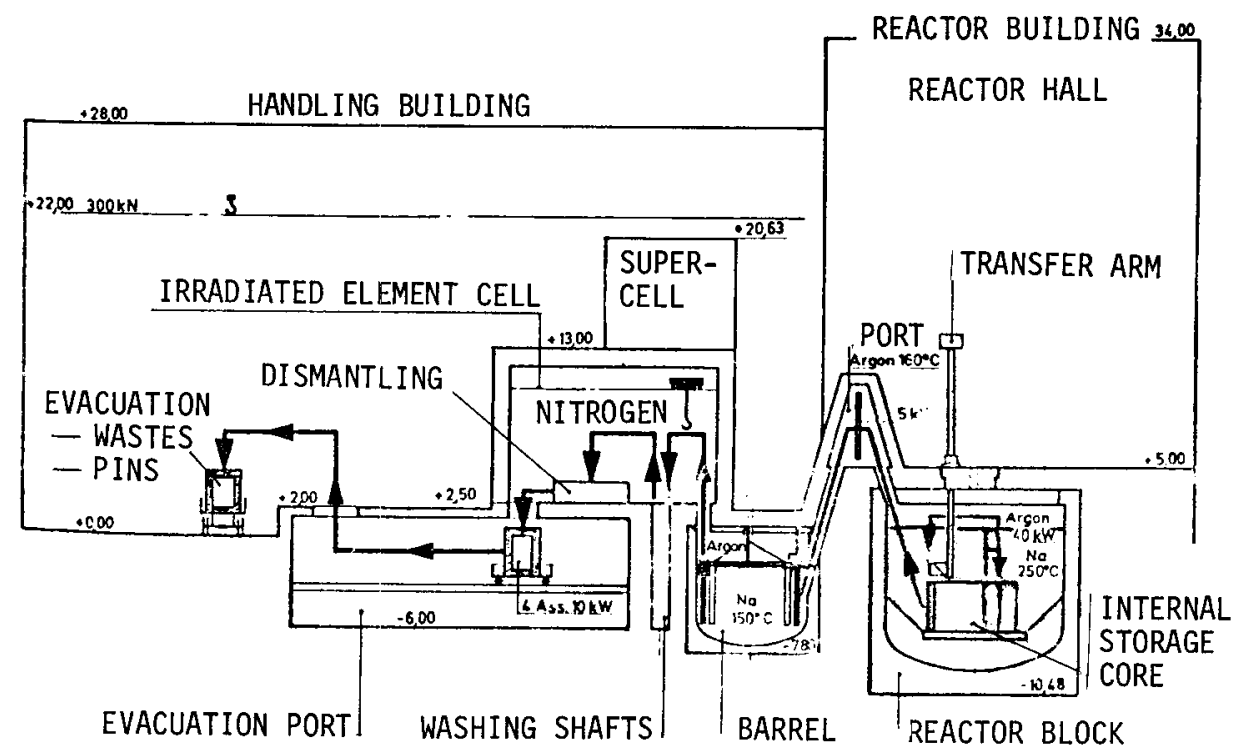

Figure II.J-2. Phenix Spent Element Line (Ref. 15)

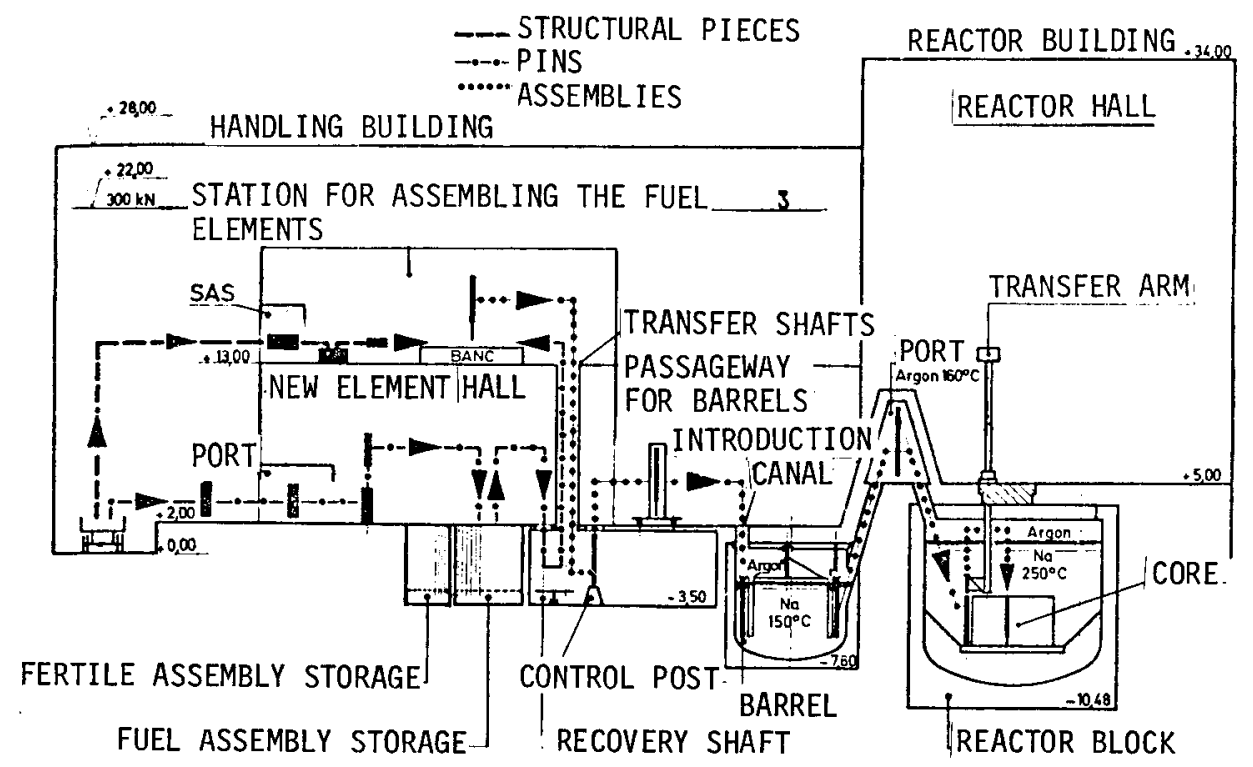

Figure II.J-3. Phenix New Element Line (Ref. 15)

\section{J-3}


PHENIX II.J.

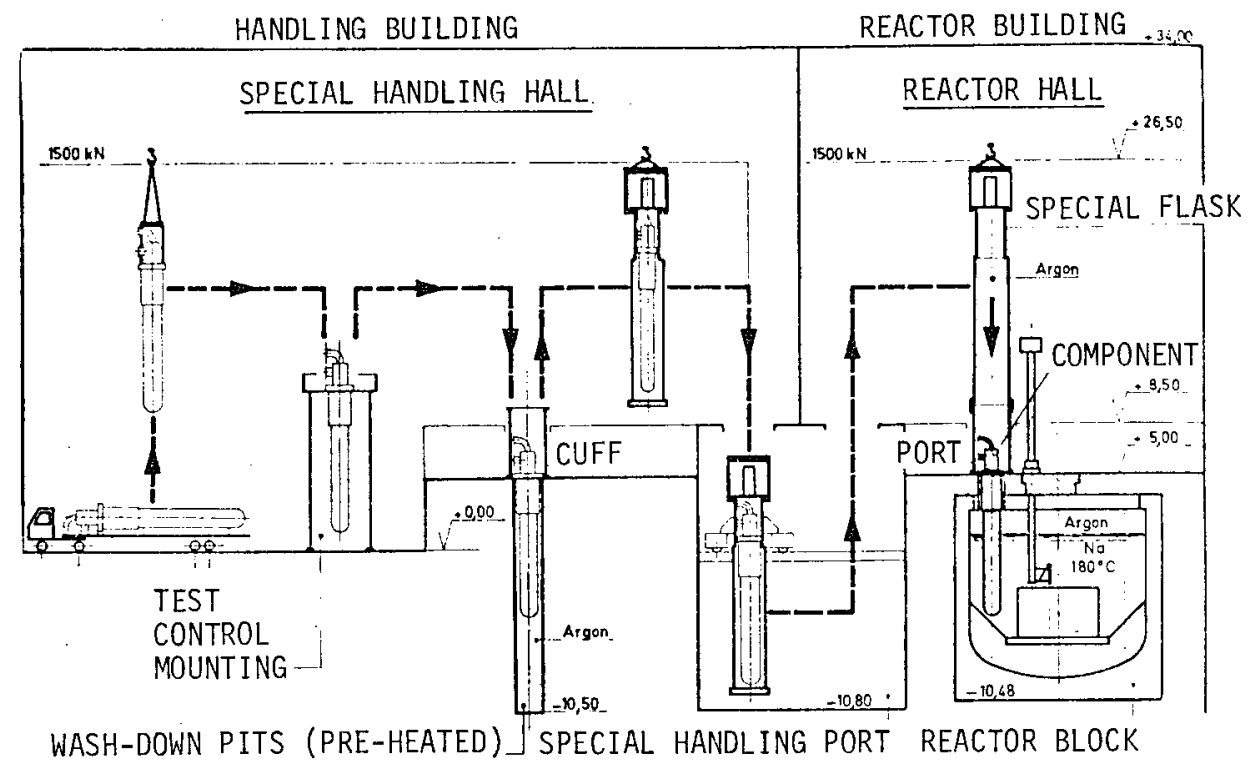

Figure II.J-4. Circulation of New Equipment (Ref. 15)

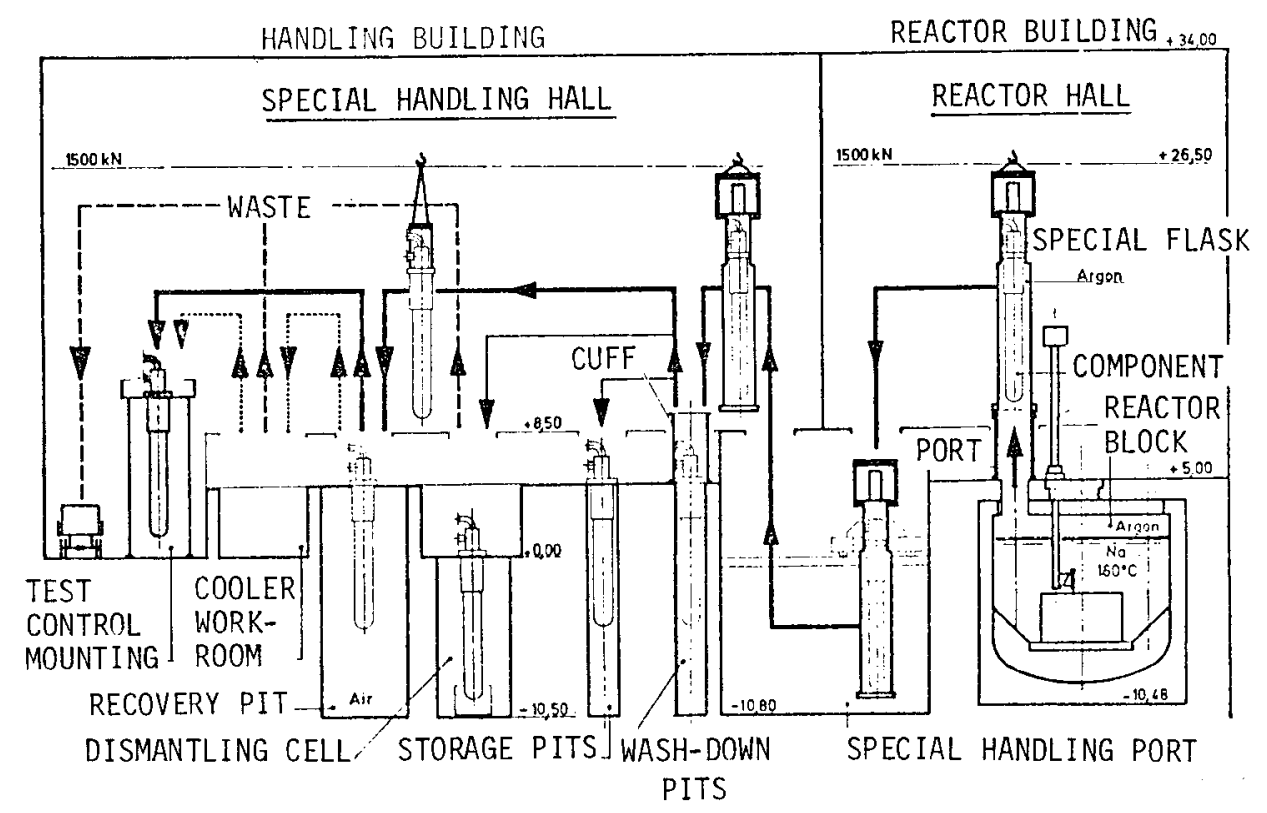

Figure II.J-5. Circulation of Irradiated Equipment (Ref. 15) 


\section{K. CONTAINMENT}

The reactor containment system is a combination of a highly leak-tight envelope and a secondary envelope with underpressure and filter trapping. High-efficiency filters serve the reactor hall and air is released through a 70-ft stack. The base of the stack and the reactor hall are monitored and an alarm is given in case of accident or failure in the ventilating system.

The controlled leakage reactor building is kept at an underpressure of a $5 \mathrm{mbar}$ and can resist a 40-mbar overpressure. The underground part of the structure is of welded steel plates. (The bottom plate is $10 \mathrm{~mm}$ thick and the side plates are $5 \mathrm{~mm}$ thick.) Cement and resin injections were used to ensure sealing of all seams. The superstructure outer walls are prefabricated panels secured to concrete posts cast in place (the structure is prestressed). The floor of the lower stage is at the -10.50 level, which is the level of the base of the reactor cave.
The handling building, annexed to the reactor building, has two main sections. One section is reserved for handling core elements, with storage drum, dismantling cell, and hall for preparation, storage, and testing of new assemblies. The second section; the special handling hall, is reserved for reactor equipment, with cells for dismantling and examination, storage pits, washdown areas, testing areas, etc. This building has a special ventilation supply with absolute filters. Air is rejected to the stack. The building is at a slight underpressure.

The steam generator building is alongside the main building. No special tightness or ventilation is required. The only portion underground is that which contains steam generators supplied with sodium reservoirs, sodium/hydrogen separators, auxiliary sodium loops, etc.

The machine ha 11 and control buildings are standard. (Refs. 5, 15, 25.) 
III. SUPER-PHENIX

$\begin{aligned} \text { LOCATION: } & \text { Crey's-Malville } \\ & \text { France } \\ & \text { (Rhone River) }\end{aligned}$

CONSTRUCTION TARGET: 1975

OPERATION TARGET: $1979-1980$

Super-Phenix, a 1,000 MWe commercial fast reactor, will be built at Crey's-Malville on the Rhone River. Official designation for the station is Creys-1. The French government has authorized the formation of the Societé Centrale Nucleaires Européene Neutrons Rapides SA (NERSA) for construction and operation. Members are Electricité de France (51\%), Italian ENEL (33\%), and West Germany's RWE (16\%). The French CEA is preparing the preliminary safety analysis report. Construction target is 1975 and projected date of operation 1979 or 1980. A German version to be built by NERSA will be under way about 1981 . 


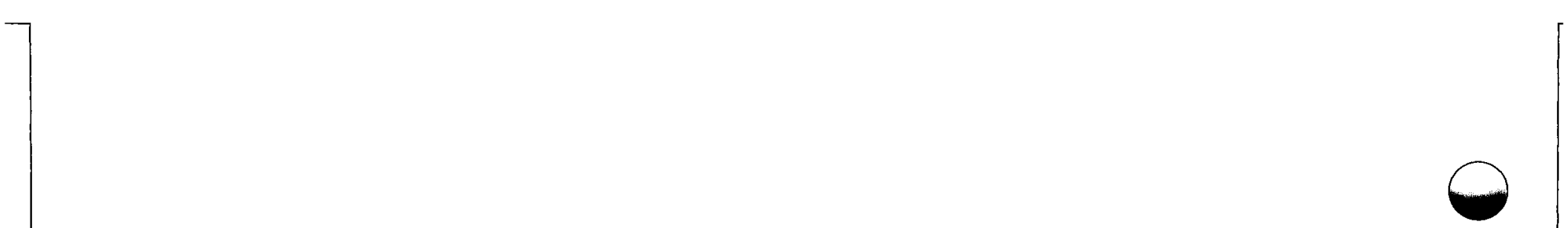

-

0 
INDEX

REFERENCES

$\underline{\text { Page }}$

I I -5

SECTIONS

A. CORE AND BLANKET III.A-T

B. CORE SUPPORT AND VESSEL INTERNALS III.B-1

C. REACTOR VESSELS AND SHIELDING III.C-1

D. CONTROL ELEMENTS III.D-1

E. HEAT TRANSFER SYSTEMS

F. SODIUM PURIFICATION AND INSTRUMENTATION SEE SECTION III.E

G. COVER GAS AND AUXILIARY SYSTEMS

SEE SECTION III.E

H. STEAM GENERATORS

SEE SECTION III.E

I. REACTOR INSTRUMENTATION AND CONTROL NO DATA

J. FUEL HANDLING

III.J-1

K. CONTAINMENT

III. K-I 
REFERENCES

1. Super-Phenix Preliminary Safety Analysis. General Related Criteria and Main Features J. Megy, et. al.

Fast Reactor Safety Meeting-Apri 1974 Proceedings. Part 1

CONF-740401-PL, p.29-50

2. Toward Commercial Fast Reactors; the First 1200 MWE Unit

M. Banal, R. Carle

Vittel Conference, Sept. 1973

CEA-CONF-2641, p. 3-11

3. The French Fast Breeder Program

Jean-Paul Crette

Kerntechnik Vol. 16, No. 11 (Nov. 1974), p. 481-482

4. Future Programs and Plans for Prototype and Prospects for CFR's

R. Carle, et. al.

Fast Reactor Power Stations, Proc. Conference March 1974, p. 605-609

5. Decay Heat Removal in an LMFBR

C.P. ZaTeski, et. al.

Fast Reactor Safety Meeting Apri] 1974 Proceedings, Part 2,

CONF-740401-P3, p. 785-801

6. Comparision of Foreign and U.S. LMFBR Plant Parameters

Office of LMFBR Programs, U.S. AEC,

WASH-1364 (Nov. 1974)

7. Steam Generators Developed in France for Super-Phenix

M.G. Robin

ERDA-TR3 (1974)

8. Super-Phenix Fuel Element llesign.

J. Leclere, et. at.

Nuclear Energy Maturity, Proc. 1st Conf., European

inclear Society, France Apri1 1975, p. 308-311

ANS Trans. Vol. 20, April 1975.

9. Creys-Malville Plant-Options and Descriptions

B. Saitcevsky, et. al.

NucTear Energy Maturity, Proc. 1st. Conf., European

Nuclear Society, France Apri1 1975, p. 130-131

ANS Trans. Vol. 20, Aprit 1975 
III. A. CORE AND BLANKET

Driver fuel is $\mathrm{UO}_{2}-\mathrm{PuO}_{2}$ in stainless steel cladding; blanket material is depleted $\mathrm{UO}_{2}$. There are two enrichment zones in the core.

The core assemblies resemble those of Phenix, with the exception that the upper and lower axial blanket pellets are inserted in the fuel pin. Neutron shielding is incorporated at the top. (Fig. III, A-1)

Both the fuel pins and the fuel assembly are larger. There is no core clamping, but the hexagonal cans are fitted with pads that are in contact when the reactor reaches a pre-determined temperature. Lateral neutron shielding has been designed to impart good rigidity.

\section{Parameters}

Core height $\sim 1$ meter

No. driver assemblies ( 2 regions) $196+162$

Pins/assembly 271

Hex. can, distance between flats

(internal) $163.8 \mathrm{~mm}$

Fuel pellet od $7 \mathrm{~mm}$

Fuel clad (stainless steel) od $8.65 \mathrm{~mm}$

Gas plenum (bottom) $850 \mathrm{~mm}$

Pin length 2,700 mm

Spacer: helical wire wrap

Subassembly overall height $5,400 \mathrm{~mm}$

Max. cladding temperature $620^{\circ} \mathrm{C}$

Max. Linear power $450 \mathrm{w} / \mathrm{cm}$

BU 70,000 MWD/T

(Ref. 1,8)

\section{III.A-1}




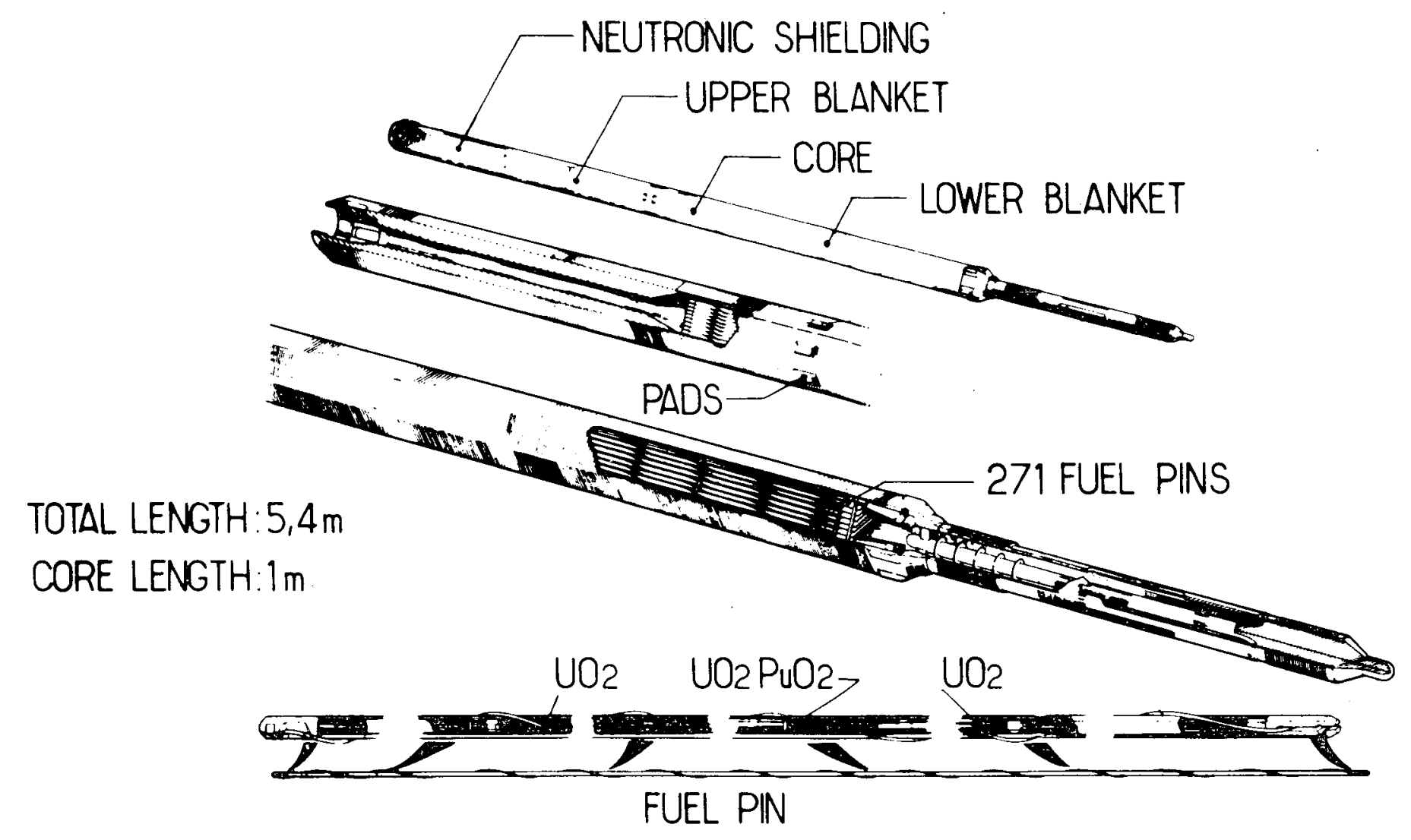

Figure III.A-1. Super-Phenix Fuel Subassembly (Ref. 1) 
III. B. CORE SUPPORT AND VESSEL INTERNALS plates.

Subassemblies are held by two support

Room is provided under the core support grid for a core-catcher assembly, built of metal plates. This assembly is still under study. (Fig. III B-1) Alternately, the main vessel bottom would serve as core catcher. (Ref. 1,5)

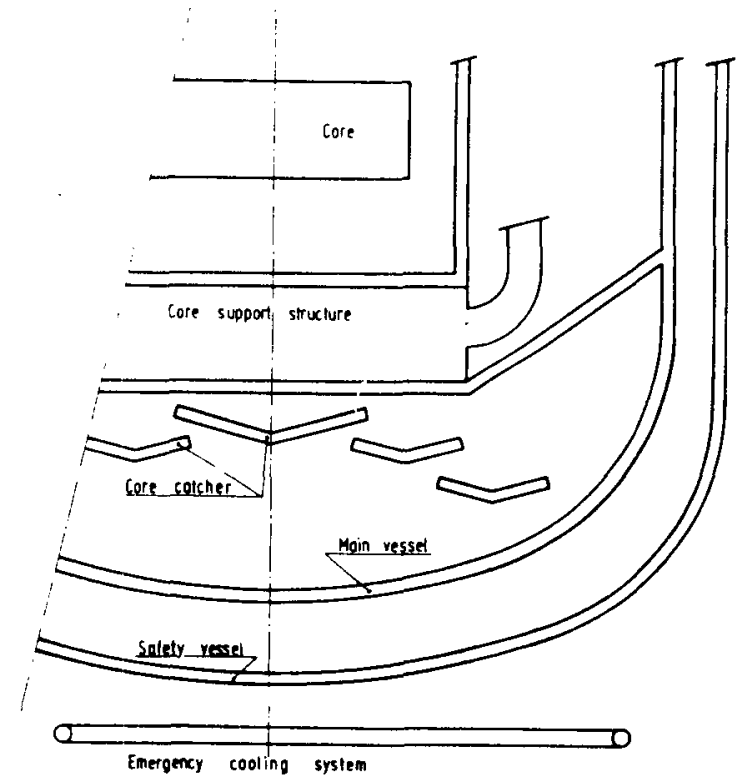

Figure III.B-1. Super-Phenix Possible Design for Core Catcher (Ref. 5) 
III. C. REACTOR VESSELS AND SHIELDING

The reactor vessel is closed by a bottom-insulated slab, with the insulation set in the argon cover gas. The vesse? is cooled by a sodium flow. The main vessel is surrounded by a safety vessel, which serves as a leak-proof vessel and is part of the primary containment. The primary containment is completed by a metallic dome surmounting the reactor. It is slightly larger than the safety vessel. (Fig. III C-1)

Two circulating water loops around the safety vessel serve as an emergency circuit for decay heat removal. (Fig. III C-2) Circulation of water to these loops is handled independently. (Ref. 1,5)

III.C-I 


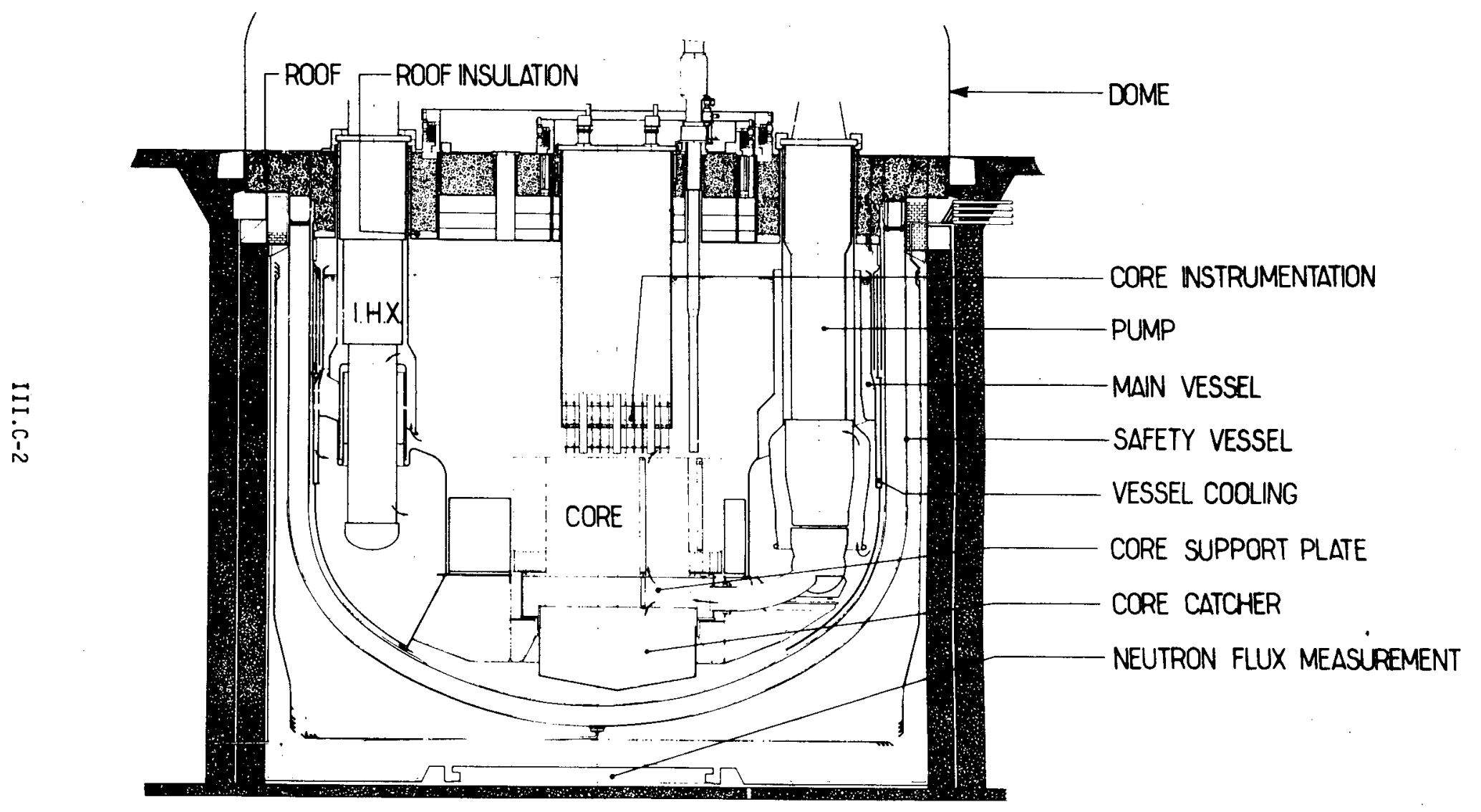

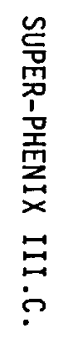

Figure III.C-1. Super-Phenix Reactor (Ref. 1) 

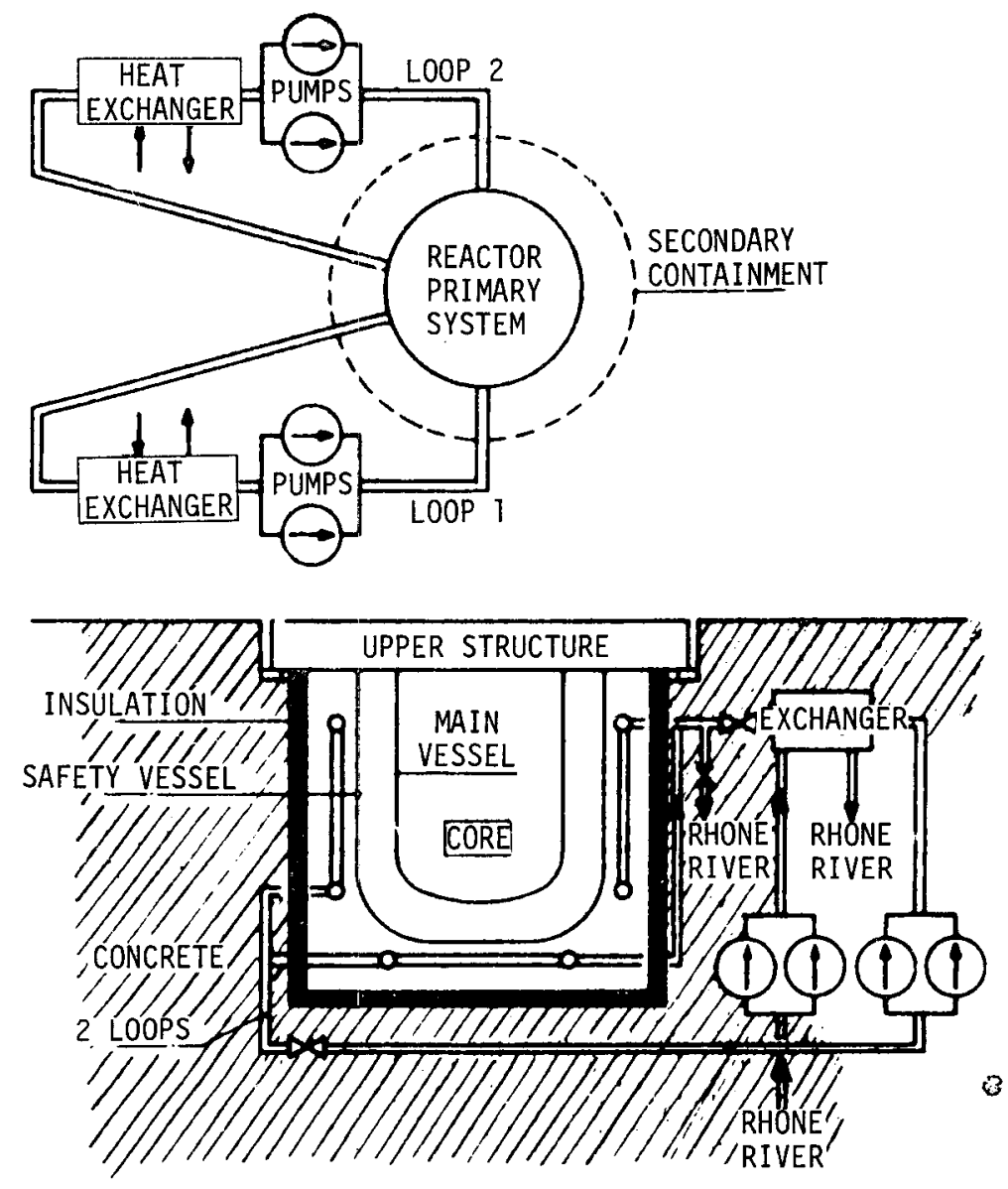

$\varnothing$

Figure III.C-2. Super-Phenix Emergency Cooling System (Ref. 5)

III.C-3 
SUPER-PHENIX III.D.

III. D. CONTROL ELEMENTS

The core includes control rods of two types. The primary shutdown system, has twenty-four rods of the Phenix type set over two subassembly rows. The standby shutdown system, under development, will probably consist of three rods actuating only reactor shutdown. (Ref. 1) 


\section{E. HEAT TRANSFER SYSTEMS}

Super-Phenix is a pool-type system. There are four sodium pumps and eight intermediate heat exchangers, closely resembling Phenix equipment. Pump check valves have been replaced by built-in valves allowing for pump operation even if one has stopped. The intermediate heat exchanger also has built-in valves. Primary pumps are driven by frequency shift generators, with a flywheel ensuring $1 / 2$ the flow rate after 50 seconds of electrical power failure. Pumps are located at the cold point. (Fig. III $E-1)$

Auxiliary sodium-argon loops are not unusual except for primary sodium purification. Two cold traps are located in the main vessel, with special nitrogen cooling and plugging indicators.

Core equipment includes thermocouples located above each core assembly, equipment for fuel clad failure detection, subassembly sodium sampling, sonic detection, and a neutron flux measuring unit below the main vessel.

A monotubular helical-tube steam generator has been under investigation by Babcock-Atlantique. The module is formed by a vertical cylindrical shell of austenitic stainless steel, $2.9 \mathrm{~m} \mathrm{dia}$ and $22 \mathrm{~m}$ high. It contains a group of 357 helical tubes $25 \times 2.6 \mathrm{~mm}$, made of Incoloy-800. Each tube penetrates individually into the shell by means of a thermal collar, and exits from one of the tube plates of the four steam chests arranged in the upper part of the she11. Full length of each tube is $87 \mathrm{~m}$. Heat exchange surface is $1920 \mathrm{~m}^{2}$. Sodium enters at the top through two systems of pipes, flows downward, and exits through a single pipe at the bottom. Water enters from. four outside water chests, circulates in cross counter flow into the tubes, and exits as superheated steam into the upper chests.

Stein Industrie has developed a modular straight tube steam generator, each module consisting of a vertical tube nest with 1389 tubes for the evaporation and 583 tubes for the superheater. The module is connected at its ends to two tube plates forming the bottom of the water and vapor collectors. The tube nest is housed in a slim, vertical cylindrical shell, with a diameter of 2.27-2.37 $\mathrm{m}$ and an overall height of $27.5 \mathrm{~m}$. Economizer and superheater are in series. Sodium enters near the center of the module, rises into the ring shaped space between the shell and the jacket of the nest, passes into the tubular nest below the free level, flows down between tubes to the thermal screen protecting the lower tube plate, rises again to the ring-shaped space as far as the outlet at the mid-section of the shell. Water enters from the lower water chest of the economizer, rises into the tubes and exits as slightly superheated steam into the upper chest. Steam goes through a separator and into the lower chest of the superheater, passes through the tubes and out into the upper chest.

Both generators have been dimensioned for the Super-Phenix steam cycle. They are both single-wall and gravity-drained.

(Ref. 7) 


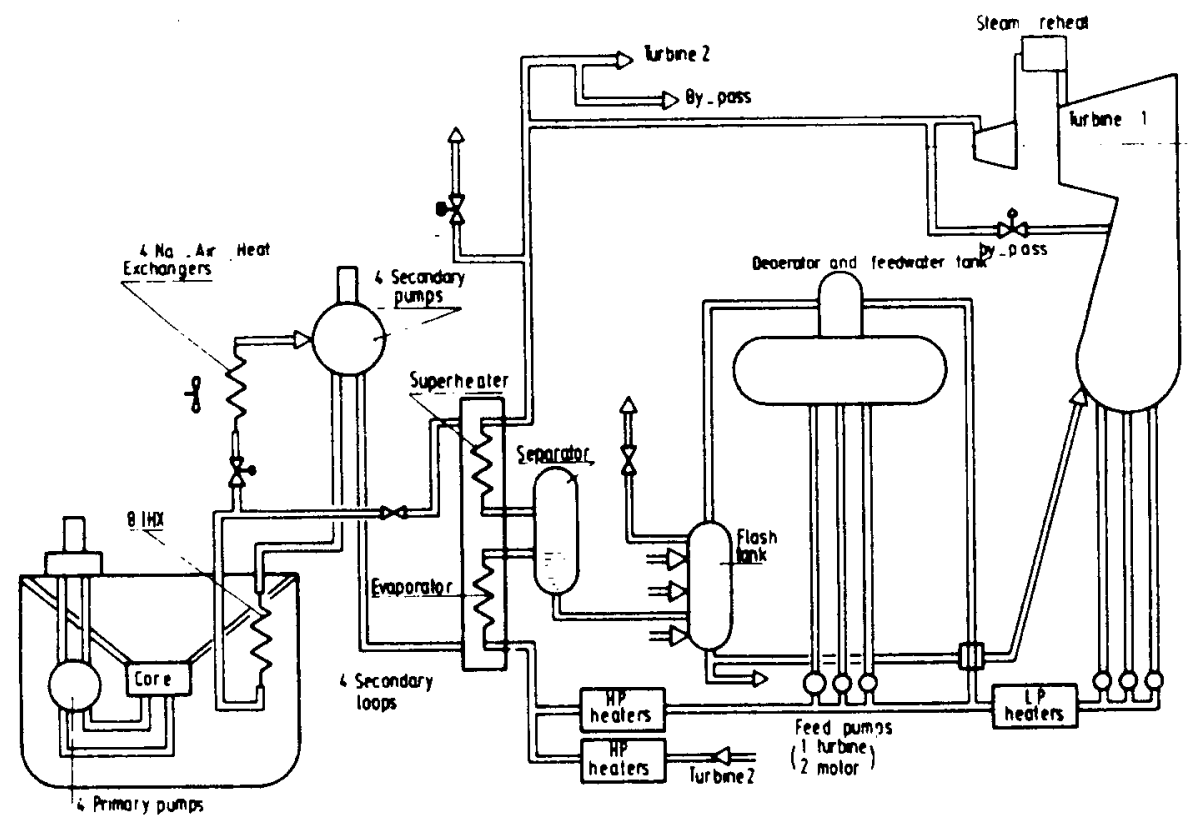

Figure III.E-1. Super-Phenix Primary, Secondary, Steam-Water Loops (Ref. 5)

$$
\text { III.E-2 }
$$




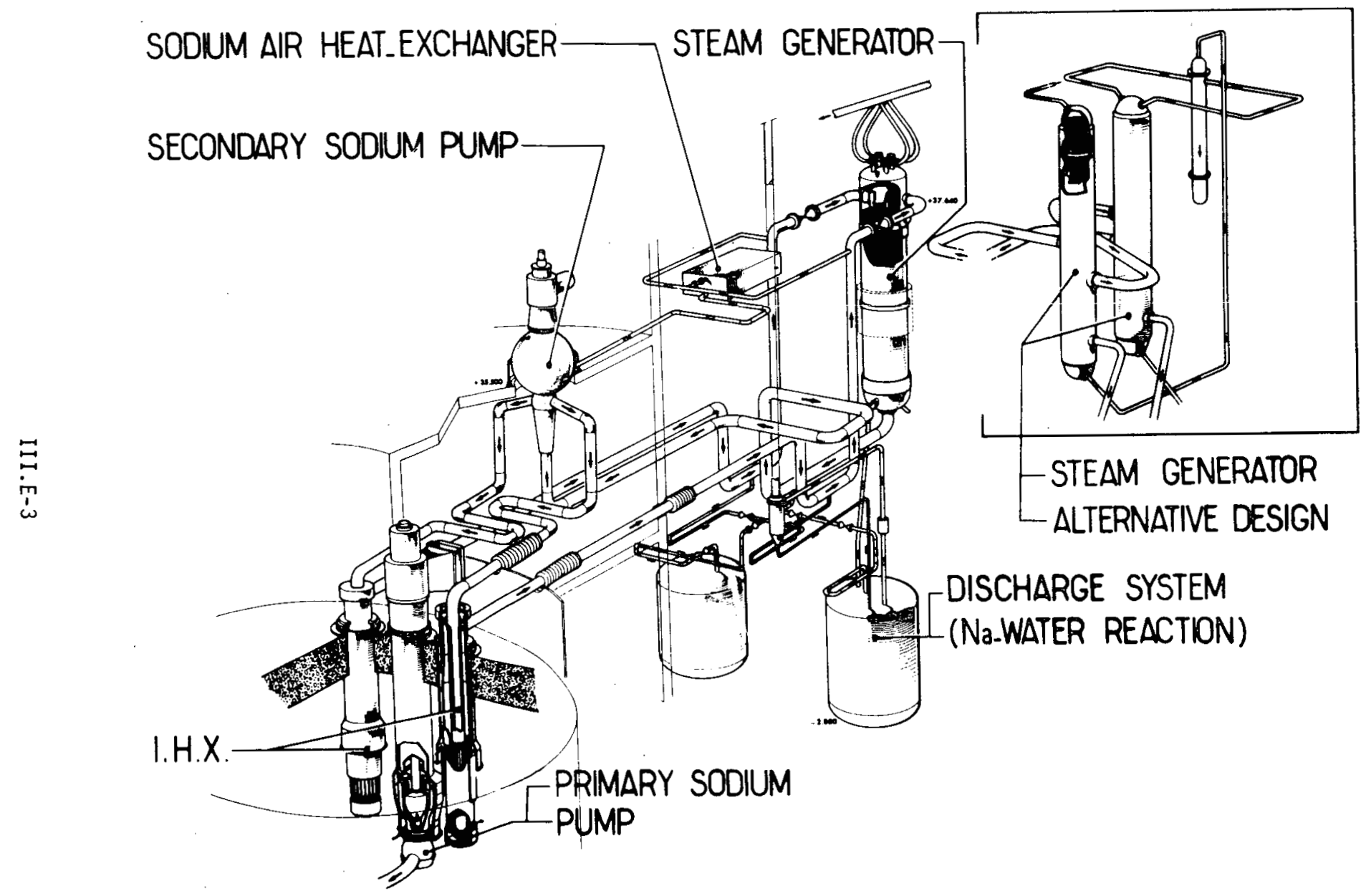

Figure III.E-2. Super-Phenix Secondary Sodium Loop and Steam Generator (Ref. 1) 
III. J. FUEL HANDLING

Handling is by means of two rotating plugs. The small plug bears the transfer machine for shifting assemblies in the reactor. Subassemblies are removed from the reactor in sodium pots, transported by a carriage over a ramp, and lowered into rotating storage by another ramp. No internal storage is provided. After outer storage cooling, the subassemblies are transported in sodium-filled pots to the reprocessing plant. (Fig. III J-1) (Ref. I) 


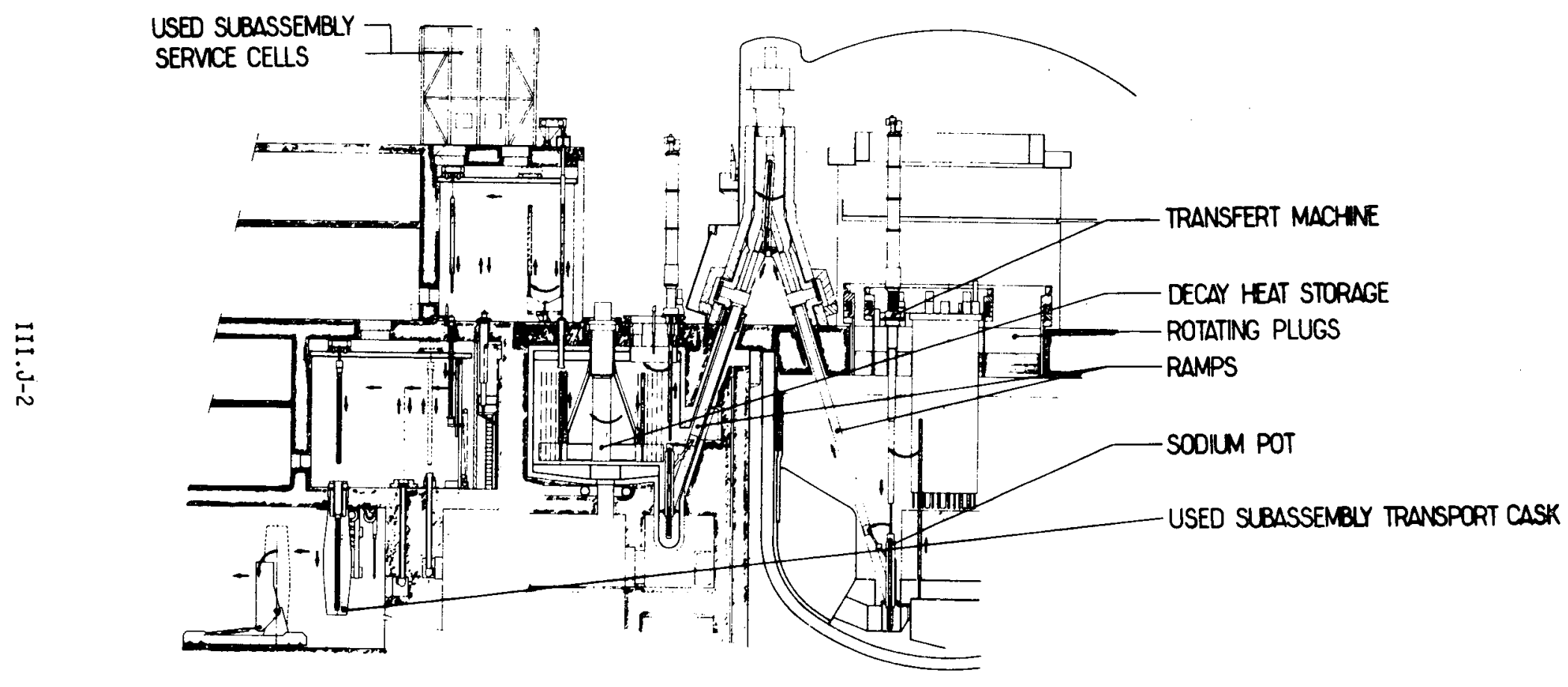

Figure III.J-1. Super-Phenix Subassembly Loading System (Ref. 1) 
III. K. CONTAINMENT

The reactor building, as designed, is a cylindrical concrete structure, of the kind used for light water reactors. Four buildings housing four steam generators will be located around it. Between these buildings, others housing auxiliary water and ventilating circuits, organic circuits, etc. will be located. (Fig. III K-1, III K-2)

(Ref. 10) 


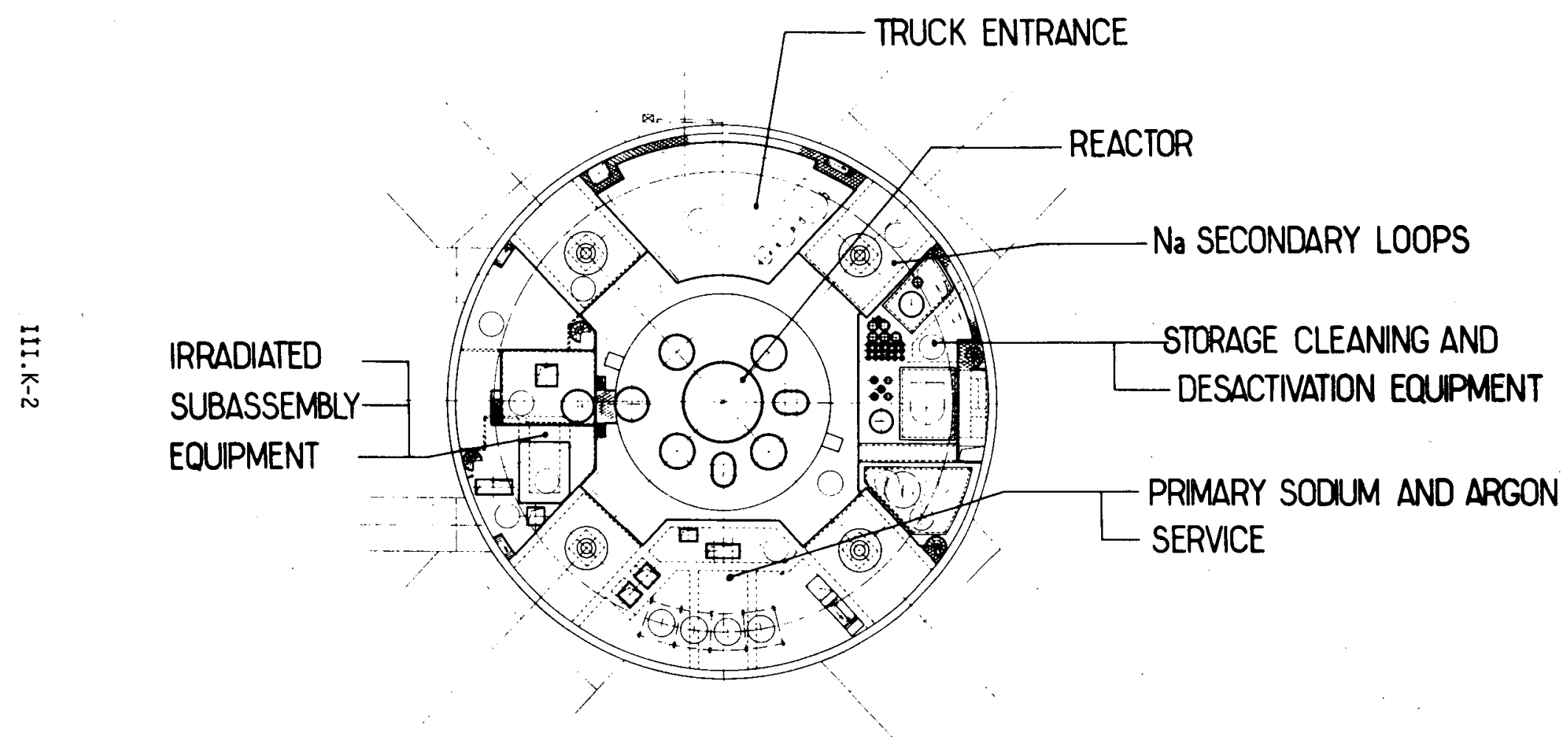

Figure III.K-1. Super-Phenix Reactor Building (Ref. 1) 


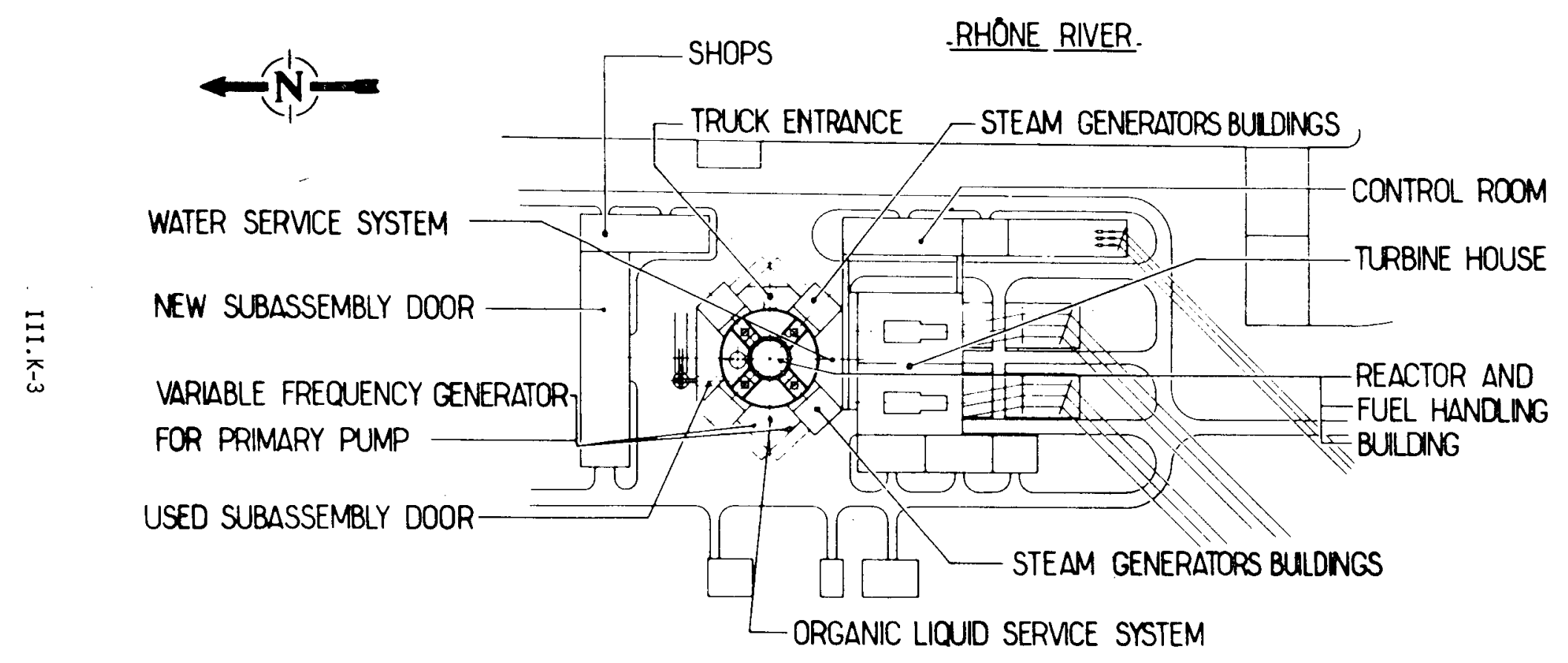


IV. $B R-5 / B R-10$

LOCATION: Obninsk, USSR

OPERATION: 1959

Peconstruction, BR-10, 1972

In 1956, the USSR decided to construct the BR-5 reactor, both to gain experience in operating a multi-loop, liquid-metal-cooled reactor and to test fuel elements and equipment for future fast reactors. The reactor was assembled within the biological shielding of the dismantled BR-2, a small, 1iquid-mercury-cooled critical facility. The BR-5 $\mathrm{PuO}_{2}$ core achieved criticality in January 1959; on July 21, it reached its design power of 5 MWt.

Due to signs of leaking fuel elements, the reactor was shut down from September 1961 to March 1962 for examination of the fuel and to clean up the primary loop components. The reactor continued to operate through 1963 with leaking elements in the core. In November 1964, BR-5 was shut down to load a new UC core and started up with the new core in May 1965. Rated power was achieved in June 1965. In 1972, the reactor was modified for 10-MWt operation and a new $\mathrm{PuO}_{2}$ core was loaded. Criticality was reached in March 1973. The installation has since been known as BR-10. 
$\odot$

- 
INDEX

\section{REFERENCES}

REACTOR PARAMETERS

SECTIONS
Page

IV -5

IV -7

A. CORE AND BLANKET

IV.A- 1

B. CORE SUPPORT AND VESSEL INTERNALS

IV.B- 1

C. REACTOR VESSELS AND SHIELDING

IV. C- 1

D. CONTROL ELEMENTS

IV.D-1

E. HEAT TRANSFER SYSTEMS

IV.E-T

F. SODIUM PURIFICATION AND INSTRUMENTATION

G. COVER GAS AND AUXILIARY SYSTEMS

H. STEAM GENERATOR AND FINAL HEAT TRANSFER

I. REACTOR INSTRUMENTATION AND CONTROL

J. FUEL HANDLING

K. CONTAINMENT
IV.F-1

IV.G-I

IV.H- 1

IV.I -1

IV.J- 1

IV. K -1 


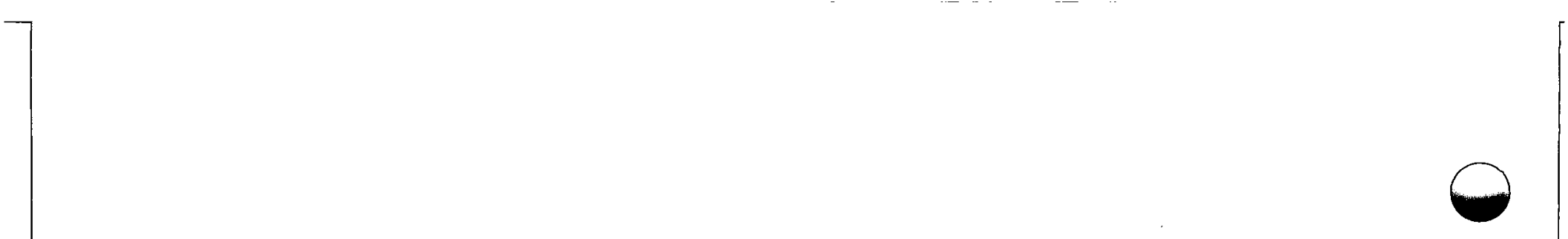

$\bullet$

$\bullet$

$\longrightarrow$

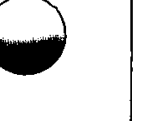


REFERENCES

1. Fast Reactor Technology: Plant Design

J. G. Yevick, editor

A. Amorosi, assoc. editor

MIT Press 1966

2. Soviet Fast Reactor $B R-5$

R.R. Matthews

Nuclear Engineering Vol. 4 p. 359-60 (Oct. 1959)

3. CEMA Symposium on Atomic Power Stations with Fast Reactors, USSR

JPRS-48330 (July 1969) Vol. 1, p. 238-251

4. Experience Gained from Operation of the BR-5 Reactor, 1964-1965

A.I. Leipunski $i$, et.al.

Fast Breeder Reactors, Proc. London Conference on

Fast Breeder Reactors, BNES, May 1966, p. 171-185

Pergamon Press 1967

5. Soviet Power Reactors 1970. Report of the U.S.A. Nuclear

Power Delegation Visit to USSR June 15-Ju1y 1, 1970.,

WASH-1175 (1970)

6. Technical Problems of Fast Reactors

Yu. Ye. Bagdasarov, et. al.

Atomic Energy Publishing House, Moscow, 1966

Given to the U.S. Nuclear Power Reactor Delegation .

WASH- 1179

7. Experimental Fast Reactors in the Soviet Union

A.I. Leipunskii, et. al.

Proc. Intl. Conf. Peaceful Uses of Atomic Energy, Geneva 1958

Vol. 9 p. 348-57

United Nations 7958

8. Operating Experience with the BR-5 Reactor Over the 1959-1966 Period.

A.I. Leipunskii, et. al.

Soviet Atomic Energy Vol. 23, p. 1270-1278 (1967) Translation of Atomnaya Energiya

Pergamon Press 


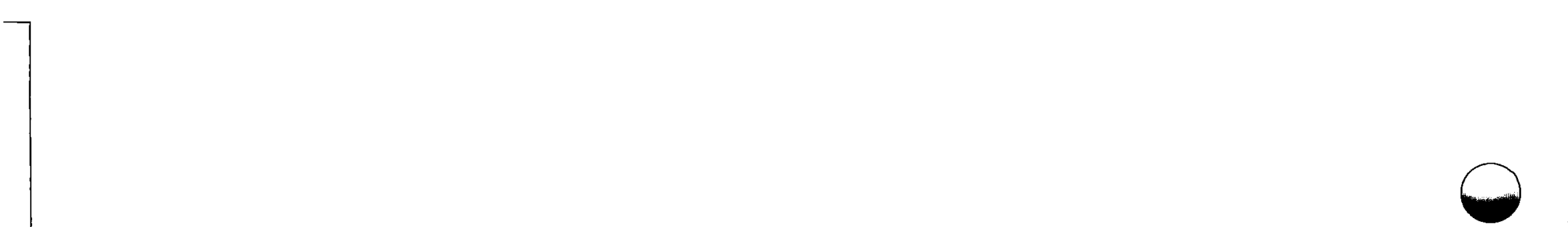

-

○

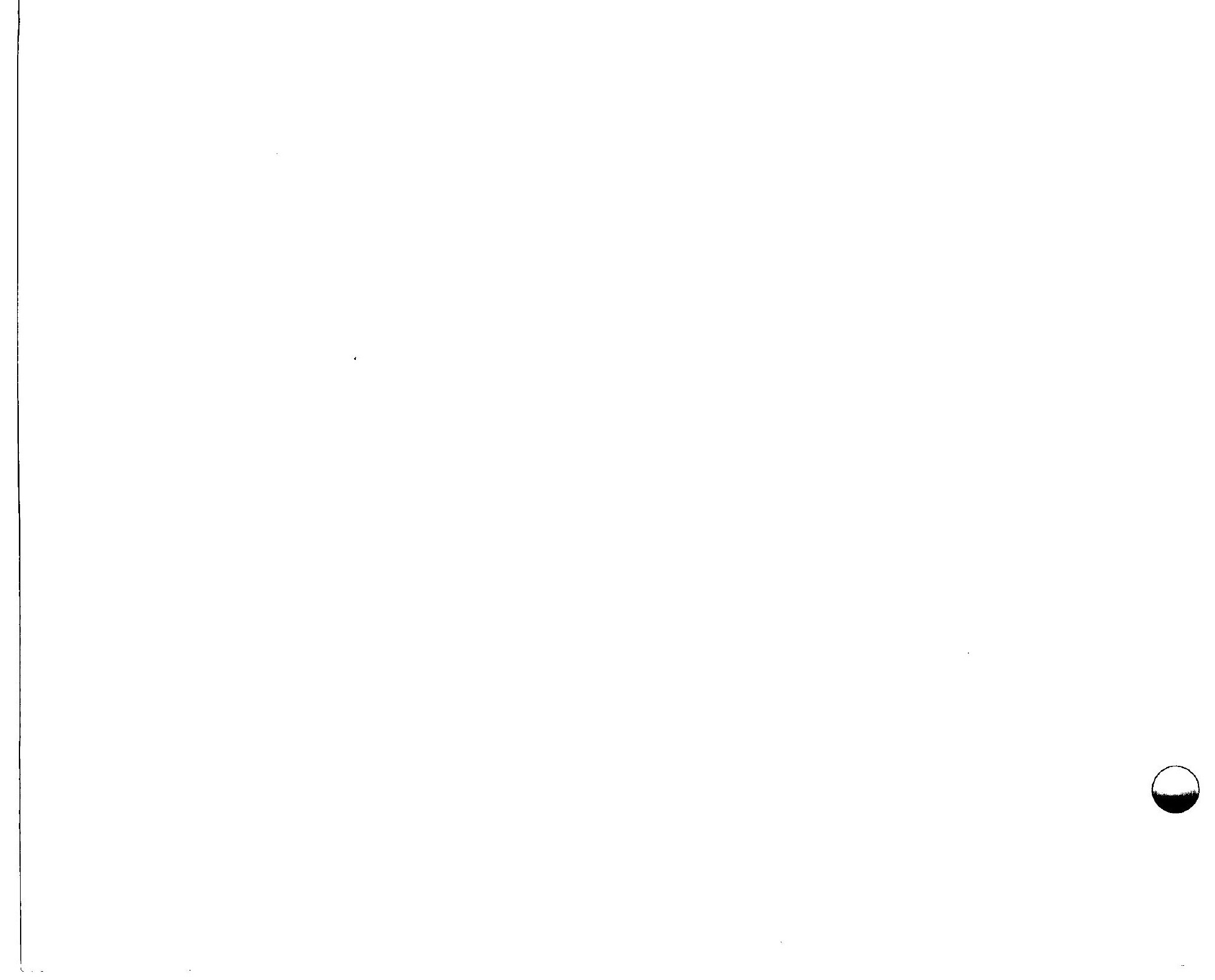


IV $B R-5 / B R-10$

Table 1

GENERAL PARAMETERS

\begin{tabular}{|c|c|c|c|}
\hline & \multirow{2}{*}{\multicolumn{2}{|c|}{$B R-5$}} & \multirow{3}{*}{ BR-10 } \\
\hline & & & \\
\hline & CORE-1 & CORE -2 & \\
\hline Type & Loop & Loop & Loop \\
\hline No. loops & 2 & 2 & 2 \\
\hline Coolant & $\mathrm{Na} / \mathrm{Nak}$ & $\mathrm{Na} / \mathrm{Nak}$ & $\mathrm{Na}$ \\
\hline Core inlet temp. & $430^{\circ} \mathrm{C}$ & $360^{\circ} \mathrm{C}$ & \\
\hline Core outlet temp & $500^{\circ} \mathrm{C}$ & $500^{\circ} \mathrm{C}$ & \\
\hline Flow direction & Upward & & Upward \\
\hline Driver fuel & $\mathrm{PuO}_{2}$ & $U C$ & $\mathrm{PuO}_{2}$ \\
\hline Blanket fuel & U & $U$ & \\
\hline Core Diameter & $280 \mathrm{~mm}$ & & \\
\hline Output MWe/MWt & $5 \mathrm{MWt}$ & $5 \mathrm{MWt}$ & $10 \mathrm{MWt}$ \\
\hline Breeding ratio & 1.9 & & \\
\hline Delayed neutron fraction & 0.25 & 0.67 & \\
\hline Max. can temperature & $600^{\circ} \mathrm{C}$ & $670^{\circ} \mathrm{C}$ & \\
\hline $\mathrm{CL}$ temperature & $1300^{\circ} \mathrm{C}$ & $2200^{\circ} \mathrm{C}$ & \\
\hline Neutron flux, Max. & $1 \times 10^{15}$ & $4.8 \times 10^{14}$ & $2 \times 10^{15}$ \\
\hline Doppler $(\Delta \mathrm{K} / \mathrm{K}) /{ }^{\circ} \mathrm{C}$ Total & Negative & Negative & \\
\hline Power Density (Max) & $500 \mathrm{kw}(\mathrm{t}) / \mathrm{\ell}$ & $285 \mathrm{kw} / \mathrm{l}$ & \\
\hline No. Driver elements & 80 & 80 & \\
\hline No. Radial blanket elements & 40 & 40 & \\
\hline No. In-core control elements & * & & \\
\hline \multicolumn{4}{|l|}{ Test positions } \\
\hline Burnup achieved & $7 \%$ & & \\
\hline
\end{tabular}


IV BR-5/BR-10 :

Table 2

CORE AND BLANKET

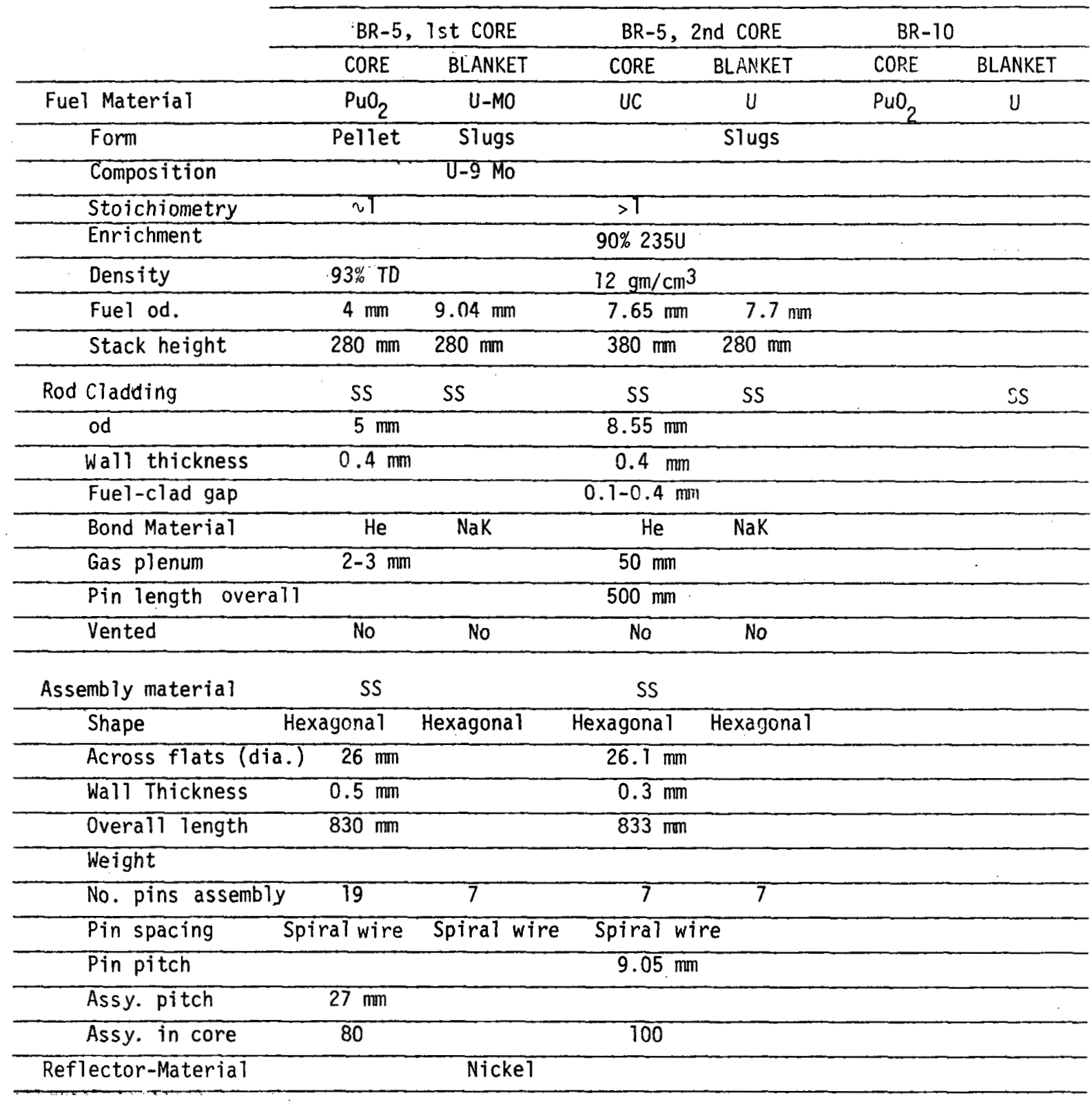


IV. A. CORE AND BLANKET

The first BR-5 core contained eighty hexagonal fuel assemblies, each with a 19pin bundle of stainless-steel clad $\mathrm{PuO}_{2}$ pins. Pellets were loaded into the cladding and the pin sealed after charging with helium. Pins were rigidly fixed to the top and bottom of the assembly. Alternate pins were wound spirally with stainless-steel wire. The lower part of the assembly ended in a cylindrical split bushing with a central hole for feeding coolant into the assembly. This bushing was also used to $f i x$ the assembly in the bottom support plate. Grooves along the sides of this tail-piece allow coolant to be removed from the core. (Fig. IV.A-1.)
The inner radial blanket contained forty assemblies, each with seven pins $9 \mathrm{~mm}$ in diameter and $280 \mathrm{~mm}$ high. Each pin contained two U-9Mo alloy pellets.

The carbide core had the same general dimensions, each assembly having seven larger diameter pins. A gas plenum was provided above the fuel core.

The core for 10-MWt operation, loaded in 1972, is $\mathrm{PuO}_{2}$. (Ref. 6) 
BR-5/BR-10 IV.A.

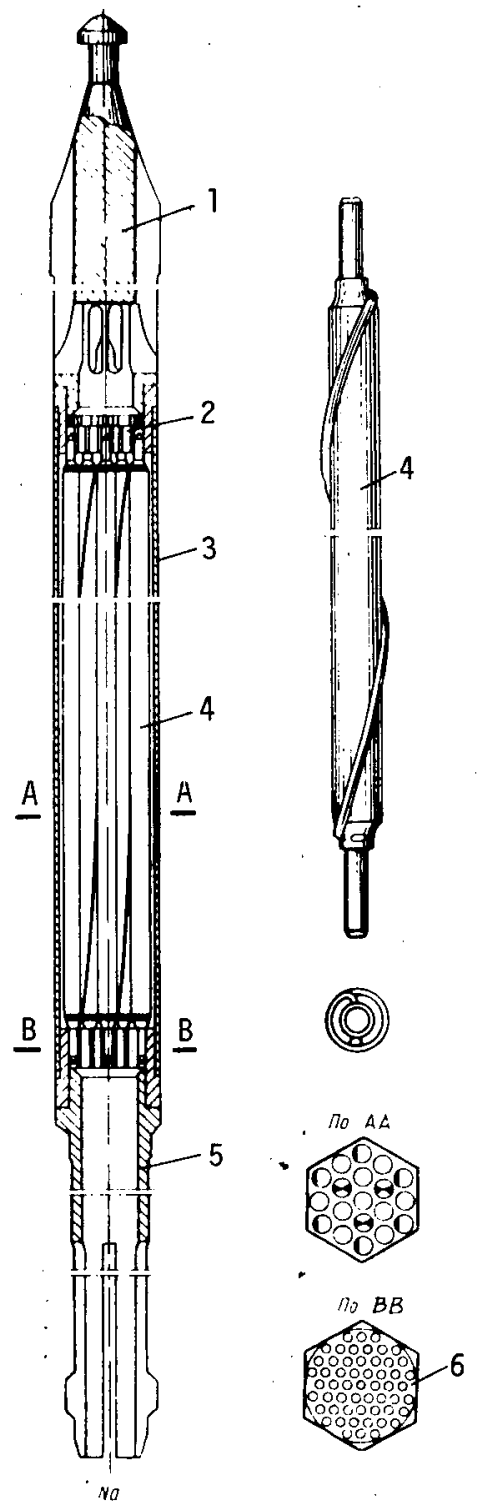

1. UPPER END PIECE

2. UPPER SPACING LATTICE

3. HEXAHEDRAL CASING

4. FUEL ELEMENT

5. LOWER END PIECE

6. LOWER SPACING LATTICE

Figure IV.A-1. BR-5 Fuel Assembly (Ref. 6) 
IV. B. CORE SUPPORT AND VESSEL INTERNALS

The assemblies are supported at the bottom by a perforated plate. The fuel assembiy has a bottom conical nozzle that centers it in a certain support grid hole. Hydraulic hold-down is provided by a groove prepared in the lower plate, a band with beveled sides and four lengthwise grooves in the collar of the fuel assembly.

(Fig. IV.B-1.)
The bottom support structure is made of nickel and comprises a 370-mm thick lattice that serves as a lower end shield, a ring with bayonet catch and twelve expeliers.

No lateral restraint is provided and there is no top grid plate. (Ref. 1,6)

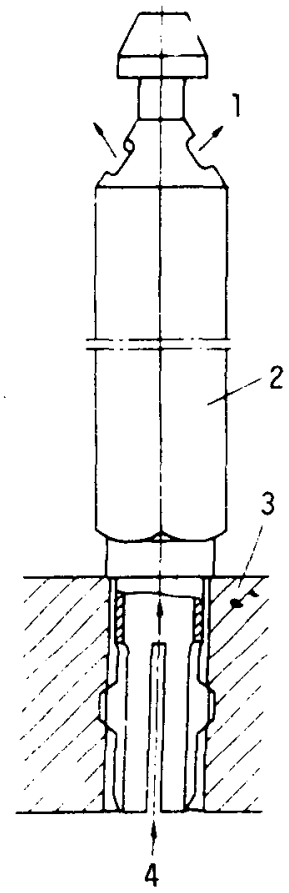

1. OUTLET OF THE MAIN STREAM OF THE COOLANT

2. PACKET

3. COLLECTOR PLATE

4. INPUT OF THE MAIN STREAM OF THE COOLANT

Figure IV.B-7. BR-5 Hold-Down Arrangement (Ref. 6)

IV. B-1 
IV. C. REACTOR VESSELS AND SHIELDING

The central part of the structure is a stepped pipe $330 \mathrm{~mm}$ in diameter that contains the fuel and uranium elements. The central pipe has a double wall. The annular gap between the inner and outer walls is used both to warm the reactor prior to sodium filling and to maintain the shut-down reactor in a warm state by a pumped circulation of hot air through the gap.

The side reflector is a nickel cylinder $975 \mathrm{~mm}$ in diameter and $900 \mathrm{~mm}$ high installed in a special metal tank within the water shield tank. The part of the reflector adjacent to the central tube consists of two coaxial movable cylinders that act as reactivity compensators and safety elements. The moving and fixed parts of the reflector are cooled by air from an upper distribution chamber.

Side shielding is provided by a $500 \mathrm{~mm}$ thick layer of water enclosed in $400 \mathrm{~mm}$ thick cast iron and surrounded by an $1100 \mathrm{~mm}$ thick layer of heavy concrete. The water shield is in the form of an annular tank with the inner cavity containing the central part of the reactor and the reflector. Top shielding consists of three plates, the cast-iron lower and middle plates and the concrete upper plate. A removable plate of paraffin and boron carbide is located over the central pipe of the shield. Lower shielding is provided by a layer of water, $400 \mathrm{~mm}$ of cast iron and removable paraffinboron carbide plates. There is a gastight hood over the central pipe.

A horizontal graphite column penetrates one side of the shield to permit horizontal and vertical experimental location.

When the hood of the central pipe is removed, fuel reloading proceeds by means of special mechanisms placed on a small rotating plate. (Fig. IV.C-l.) (Refs. 1,6) 


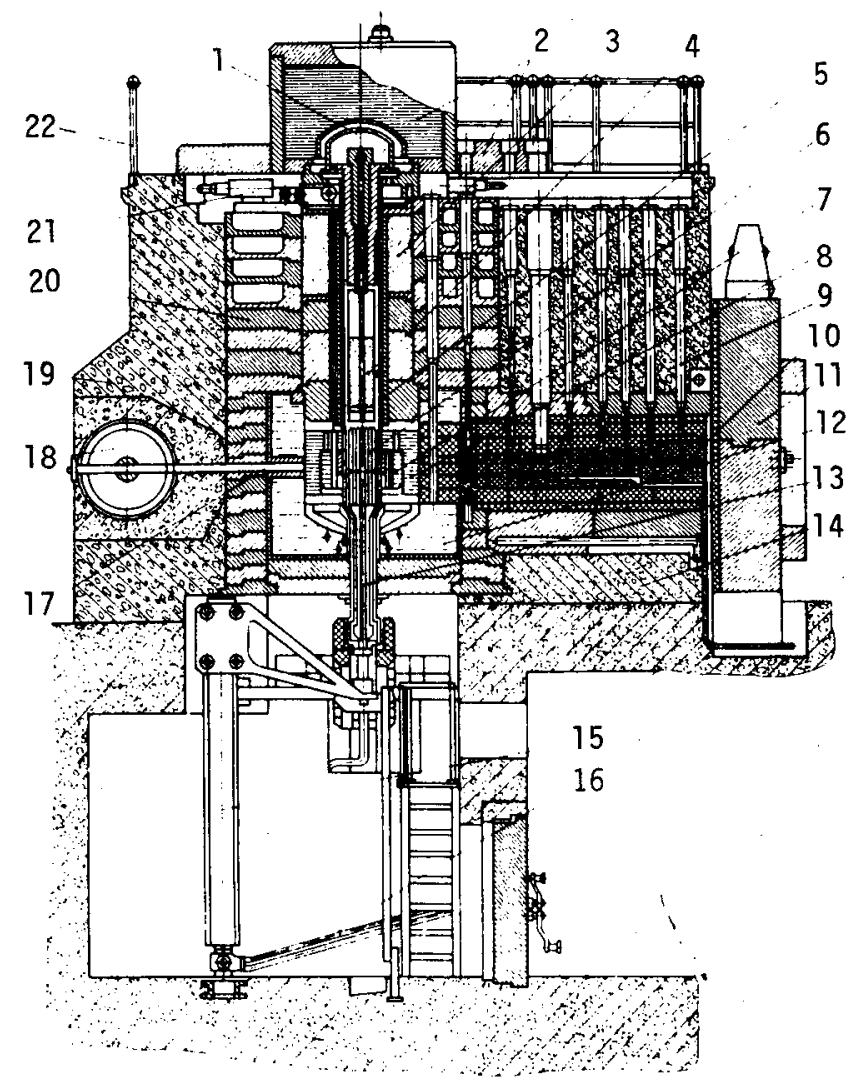

1. GASPROOF HOOD OF THE CENTRAL PIPE

2. UPPER SHIELD

3. CONCRETE PLATE

4. ROTATABLE PLATE

5. CENTRAL PIPE (VESSEL)

6. CORE

7. MOBILE SCREEN

8. FIXED SCREEN

9. VERTICAL EXPERIMENTAL CHANNEL

10. GRAPHITE (THERMAL) COLUMN

11. GATE VALVE OF THE THERMAL COLUMN

12. WATER TANK

13. CENTRAL EXPERIMENTAL LOOP

14. LOWER SHIELD

15. LOADING-UNLOADING MECHANISM

16. CONTROL OF THE CENTRAL LOOP MECHANISM

17. NEUTRON BEAM CHANNEL

18. GATE VALVE OF THE NEUTRON BEAM CHANNEL

19. SIDE SHIELD (HEAVY CONCRETE)

20. CAST IRON SIDE SHIELD

21. DRIVE OF THE MOBILE SCREEN

22. RAILING

Figure IV.C-1. BR-5 Reactor Structure (Ref. 6) 
IV. D. CONTROL ELEMENTS

$B R-5$ is controlled by moving the inner layers of the nickel reflector. The compensating layer, located just behind the casing of the central tube, is a cylinder $50 \mathrm{~mm}$ thick and $340 \mathrm{~mm}$ high. The second moving layer of the reflector, the shield compensator, is placed behind the first layer. It is $105 \mathrm{~mm}$ thick, $475 \mathrm{~mm}$ high, and has an outside diameter of $710 \mathrm{~mm}$. Two automatic regulating rods are located on its inner surface in opposite grooves. Each rod is $30 \times 40 \mathrm{~mm}$ in cross-section and $400 \mathrm{~mm}$ long. The control units are cooled by air from an upper distribution chamber.

The total rectivity introduced by the control elements is as follows:

- Compensating cylinder: $63 \times 10^{-3}$

- Shield compensator: $28 \times 10^{-3}$

- Automatic rods: $0.9 \times 10^{-3}$

(Ref. 6,7) 


\section{E. HEAT TRANSFER SYSTEMS}

The primary heat transfer fluid is sodium (NaK was originally used for the intermediate loops). Sodium enters at the bottom of the central tube and flows upward, leaving the tube through two $110-\mathrm{mm}$ diameter tubes into two similar loops. Each loop has an $\mathrm{Na}$-NaK. intermediate heat exchanger and a pump that returns the sodium to the central tube. Non-return valves are located in each loop. All primary sodium pipes outside hermetically sealed locations are provided with protective sleeves filled with argon. The sealed caves in which primary loop equipment is located have nitrogen atomospheres. These areas are observed by means of television. The intermediate heat transfer fluid was changed to sodium when the modifications for 10-MWt operation were undertaken.

An air heat exchanger is installed in one of the intermediate NaK loops, heat being removed by air flow from a fan. An evaporator is installed in the other 10op. The heat is being used to generate steam. oxide traps are fitted to the liquid-metal loops for sodium and NaK cleaning.

(Fig. IV. E-1.) (Ref. 7)

The $\mathrm{Na}-\mathrm{NaK}$ intermediate heat-exchanger (Fig. IV.E-2) is a U-shaped tube bundle. Branches of the bundle are included in their own cylindrical shells and are arranged at a small angle with respect to one another. The bend of the bundle is enclosed in a drum connecting both halves of the heat exchanger into one unit. Flow is countercurrent, with primary sodium in the inter-tube space. Heat exchange surface is $1120 \mathrm{~m}^{2}$. Sodium inlet and outlet temperatures are 500 and $300^{\circ} \mathrm{C}$, respectively. NaK inlet and outlet temperatures are 273 and $453^{\circ} \mathrm{C}$, respectively.
The NaK-to-air heat exchanger installed in one intermediate loop is a vertical shell with $U$-shaped bundles inserted in it (Fig. IV.E-3). During modification for 10 MWt operation, two additional sodium-air heat exchangers were added. (Refs. 3,6)

The BR-5 primary pump is a centrifugal, hermetically-sealed, submerged-type pump with a vertical shaft. The hydraulic part and the electric motor are located on the same shaft. This design has been a drawback since it makes it impossible to install or remove a pump without cutting the sodium pipeline and draining the loop. Also, it is necessary to unseal the loop to replace the electric motor (Fig. IV.E-4). Up-dated pumps were installed in 1967.

A spiral electromagnetic pump operating on radioactive NaK was used in an experimental loop. Its jacket was watercooled. (Ref. 6)

During modification for 10 MWt operation, the pumps were replaced by electromagnetic pumps.

Bellows-type valves and non-return valves are used in the BR-5 sodium and NaK loops (Fig. IV.E-5, IV.E-6). The valves are hermetically sealed, welded structures. The large bellows valves on the main pipelines of the primary loop have an electric drive with a duplicating distance control, and manual control on the circulation pipelines and drain lines of the second loop. 


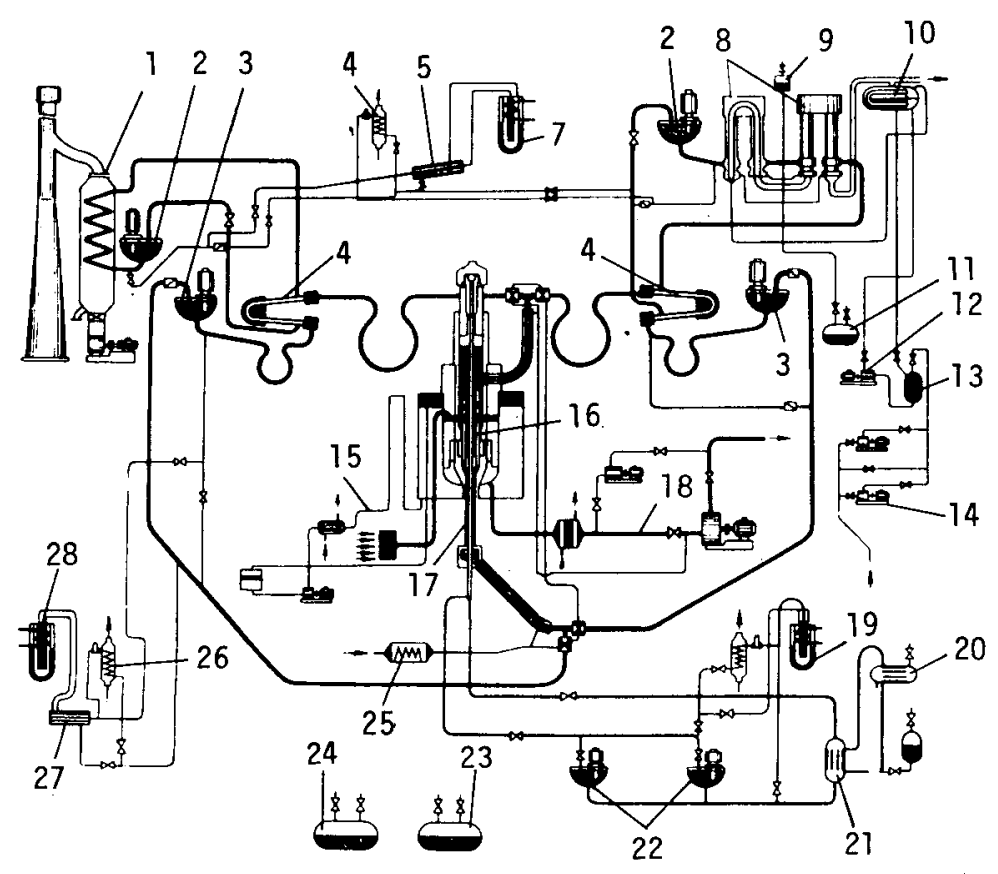

1. AIR HEAT EXCHANGER

2. CIRCULATION PUMP OF THE SECOND CIRCUIT

3. CIRCULATION PUMP, OF THE FIRST CIRCUIT

4. INTERMEDIATE HEAT EXCHANGER

5. OXIOE INDICATOR OF THE SECOND CIRCUIT

6. RECUPERATOR

7. COLD TRAP FOR OXIDES OF THE SECOND CIRCUIT

8. STEAM GENERATOR

9. EXPANSION TANK OF THE MERCURY SYSTEM

10. CONDENSER-HEATER

11. MERCURY DUMP TANK

12. DISTILLATE PUMP

13. FEED TANK

14. CONDENSATE PUMPS

15. COOLING SYSTEM OF THE WATER SHIELD

16. REACTOR

17. CENTRAL LOOP CHANNEL

18. COOLING SYSTEM FOR THE ACTUATING ELEMENTS OF THE LOOP CHANNEL COOLING SYSTEM

19. COLD TRAP AND OXIDE INDICATOR OF THE LOOP CHANNEL COOLING SYSTEM

20. DOWTHERM YAPOR CONDENSER

21. DOWTHERM EVAPORATOR

22. PUMP OF THE LOOP CHANNEL COOLING SYSTEM

23. DUMP TANK FOR THE SODIUM OF THE FIRST CIRCIIT

24. DUMP TANK FOR THE SODIUM-POTASSIUM ALLOY. OF THE SECOND CIRCUIT

25. REACTOR PREHEATING SYSTEM

26. OXIDE INDCATOR OF THE FIRST CIRCUIT

27. RECUPERATOR

28. COLD TRAP FOR OXIDES OF THE FIRST CIRCUIT

Figure IV.E-1. BR-5 Heat Removal Scheme (Ref. 6)

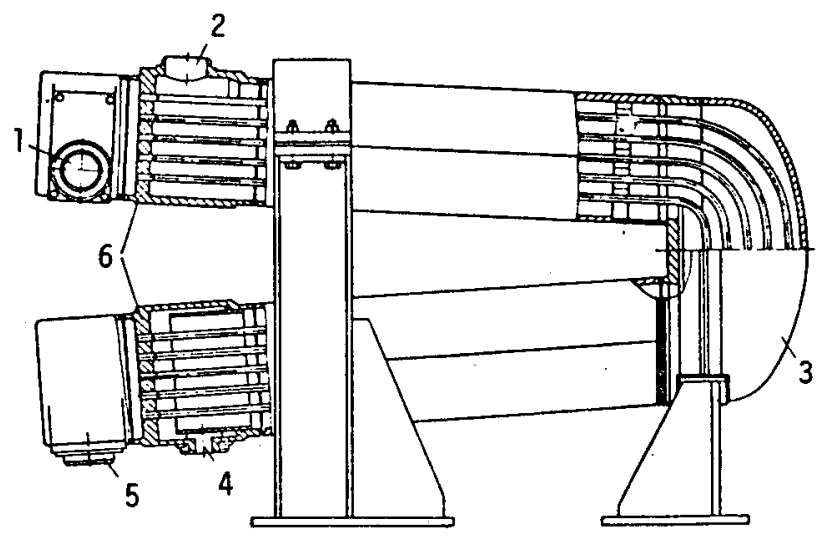

1 and 5 SODIUM INLET AND OUTLET

2 and 4 SODIUM-POTASSIUM ALLOY INLET AND OUTLET

3 - - DRUM

6 - PIPE PANELS

Figure IV.E-2. BR-5 Intermediate Heat Exchanger (Ref. 6) 


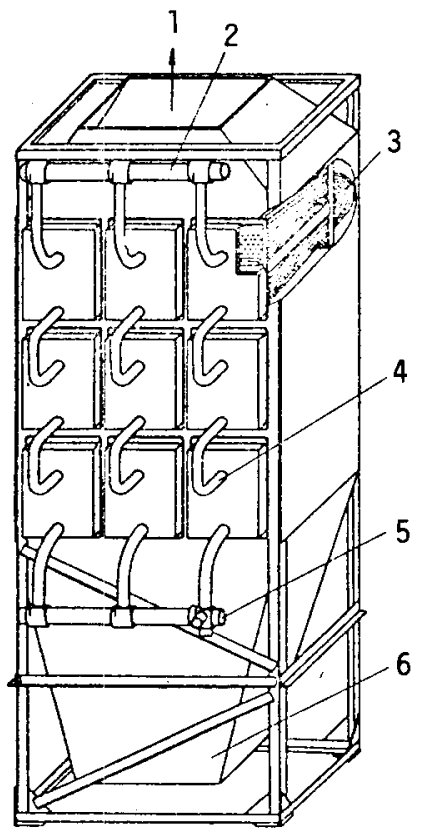

1 and 6 OUTLET AND INLET OF AIR

2 and 5 NaK ALLOY INLET AND OUTLET HEADERS

3 - - TUBE BUNDLE

4 - - BYPASS PIPES FOR NaK ALLOY

Figure IV.E-3a. BR-5 NaK-Air Heat Exchanger (Ref. 6)

(b) AIR HEAT EXCHANGER

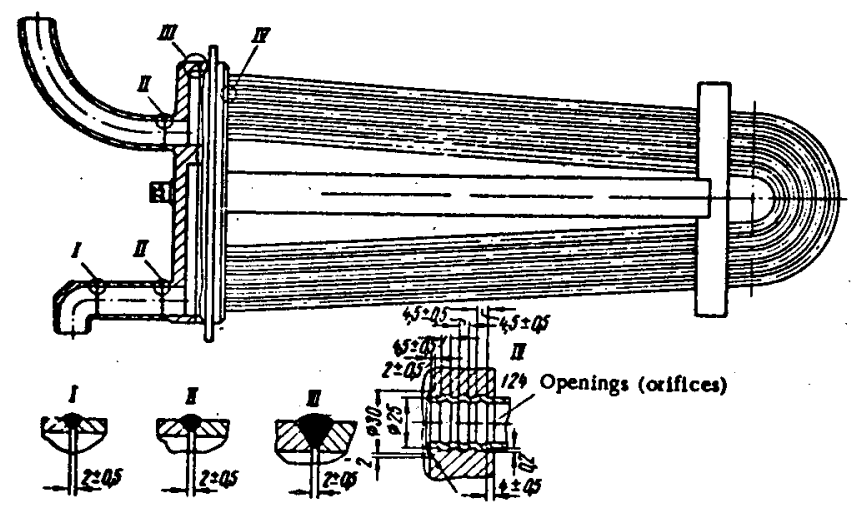

Figure IV.E-3b. BR-5 NaK-Air Heat Exchanger (Ref. 8)

IV.E-3 


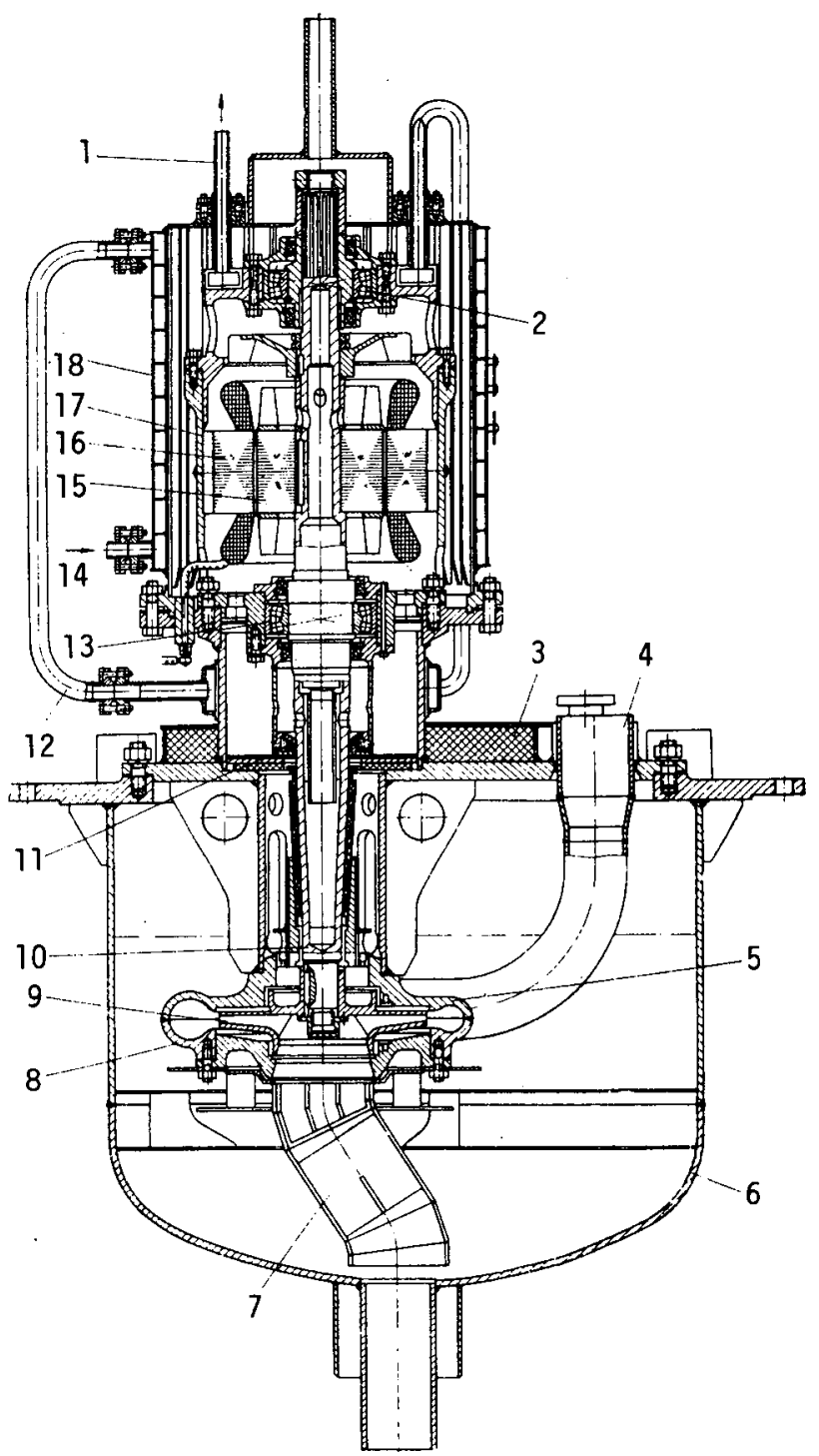

1. WATER FROM THE CONLING SYSTEM OF THE UPPER BEARING

2. UPPER ROLLLER BEARING

3. THERMAL INSULATION

11. FLOUROPLAST SEAL

12. WATER LINE FOR COOLING THE CAVITY OF THE LOWER BEARING

4. DISCHARGE NOZZLE

5. PUMP HOUSING

6. PUMP TANK

7. SUCTION NOZZLE

8. SPIRAL

9. IMPELLER

10. PUMP SHAFT

13. LOWER ROLLER BEARING

14. WATER TO THE JACKET TO THE ELECTRIC MOTOR

15. 16 and 17 ROTOR, STATOR AND HOUSING OF THE ELECTRIC MOTOR RESPECTIVELY

18. COOLING JACKET OF THE ELECTRIC MOTOR

Figure IV.E-4. BR-5 Primary Pump (Ref. 6) 

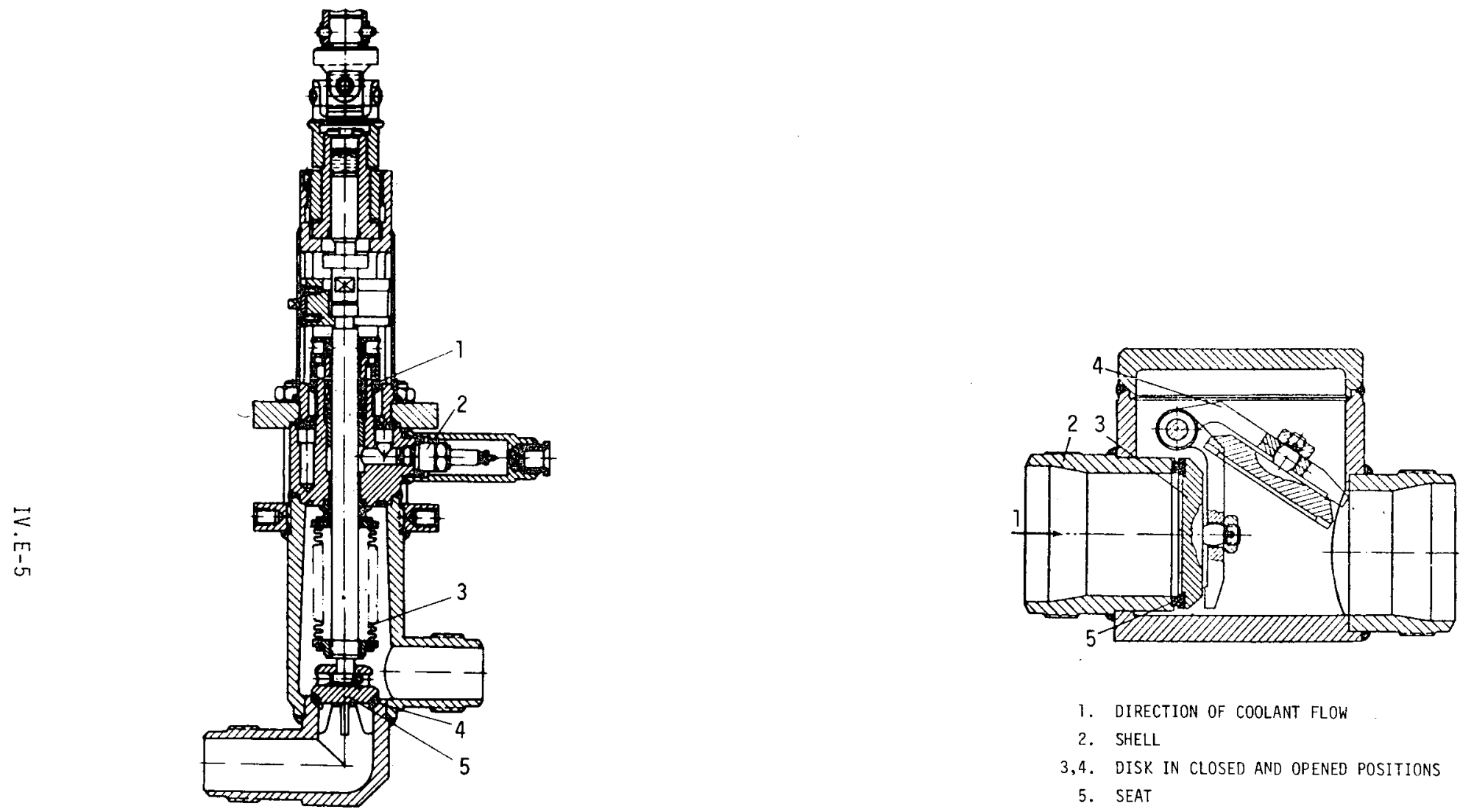

1. DIRECTION OF COOLANT FLOW

2. SHELL

3,4. DISK IN CLOSED AND OPENED POSITIONS

5. SEAT

1. PACKING

2. SIGNALING DEVICE FOR LEAKAGE THROUGH

BELLOWS

3. BELLOWS

4. STELLITE WELDING

5. VALVE 
IV. F. SODIUM PURIFICATION AND INSTRUMENTATION

Each loop contains a cold trap

(Fig. IV.F-1) cooled by toluene. In this cold trap, sodium enters the recuperator and passes into the outer cavity of the trap to a settling basin and is cooled to 120 to $2300 \mathrm{C}$. It enters the cavity filled with stainless-steel shavings, passes from the trap to the recuperator and back to the loop.

The sodium impurity content is monitored by plugging indicators (one in each loop). (Fig. IV.F-2.) (Ref. 6)

Sodium level is monitored by potentiometer-type level gages. The detecting element is a steel pipe divided into several sections of equal resistance. A stainlesssteel wire lead from each section is fed by a low-voltage transformer. When the level touches the lower end of the section, the supply current passes through all sections and voltage proportional to the value of the supply current and the resistance of the sections is released. (Fig. IV.F-3)

A Soviet-developed radio-interference level gage was also installed in BR-5. It works on the principle of fixing the position of the minimum of a standing wave that forms as a result of the addition of the incident wave and the wave reflected from the liquid. Automatic monitoring is possible with differential data units consisting of two detectors and coupling coils in which voltage is induced. The detecting element receives its power from an amplitudemodulated, high-frequency generator.

(Ref. 6)

Coolant flow in $\mathrm{Br}-5$ is measured by magnetic flowmeters. A potentiometer is used as a secondary instrument of the detecting element assembly. The detecting element is a horse-shoe magnet with a base plate of armco iron. (Fig. IV.F-4)

The BR-5 uses membrane manometers as pressure transmitters. The detecting element is a shell containing a coil with plunger and the elastic sensitive element (membrane and lower and upper flanges).

The BR-5 has six membrane units. (Fig IV.F-5.) (Ref. 6)

Temperature is monitored by Chrome 1Alumel and Chromel-kopel thermocouples. Communication to the secondary instrument is by a single wire insulated with porcelain beads. (Ref. 6) 

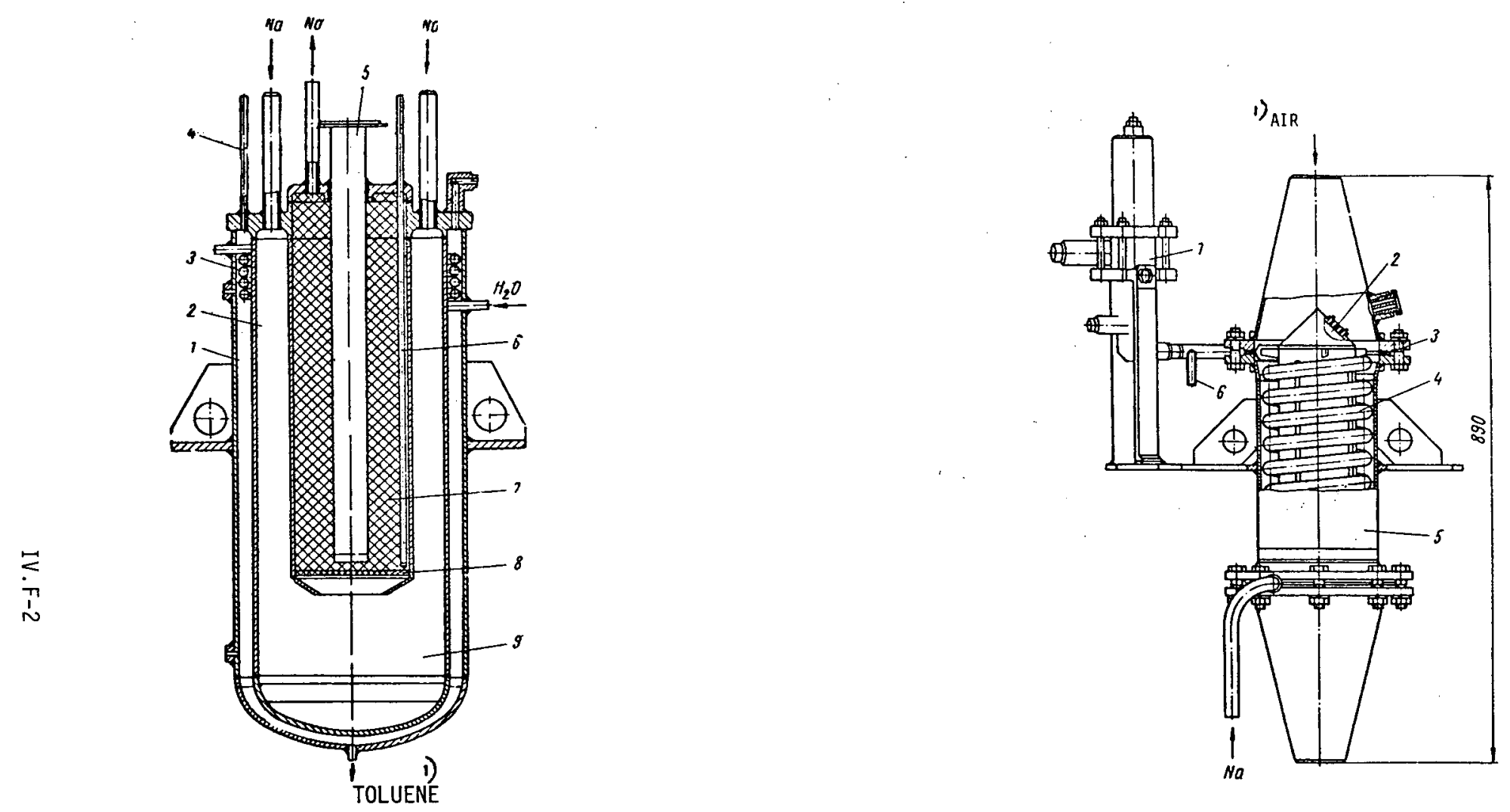

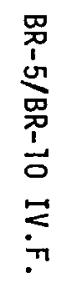
1. TOLUENE CAVITY
2. COOLING ZONE
3. TOLUNE VAPOR CONDENSER
4. PULSE TUBE FOR MEASURING PRESSURE
5. HEATER CAVITY
6. THERMOCOUPLE POCKET
7. FILTRATION ZONE
8. GRID
9. SETTLING TANK
LEGEND: 1) TOULUENE
1. VALVE WITH SLOTS ON THE VENT
2. DISPLACER
3. SEALING FILLER
4. COILED PIPE
5. CASING OF THE SODIUM-AIR HEAT
EXCHANGER
6. THERMOCOUPLE POCKET

Figure IV.F-1. BR-5 Cold Trap (Ref. 6)

Figure IV.F-2. BR-5 Plugging Indicator (Ref. 6) 


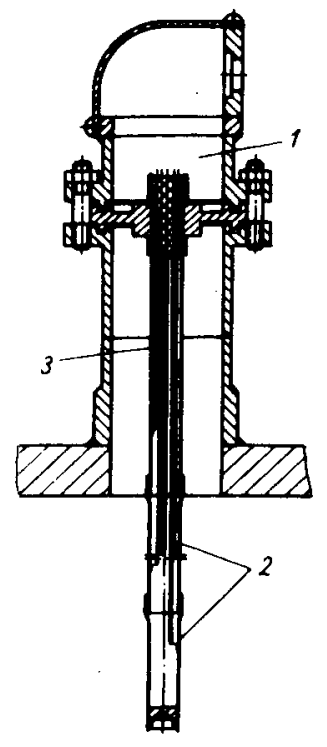

1. POTENTIAL OUTLETS

2. MEASURING TUBES

3. SUPPLY TUBE

Figure IV.F-3. Potentiometer-Type Level Gauge (Ref. 6)

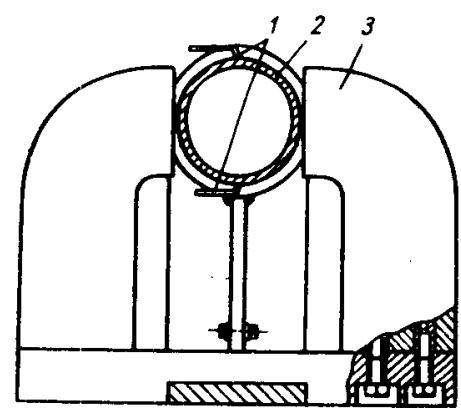

1. SIGNAL ELECTRODES

2. PIPE

3. MAGNETIC SYSTEM

Figure IV.F-4. BR-5 Magnetic Flowmeter (Ref. 6)

IV. F-3 


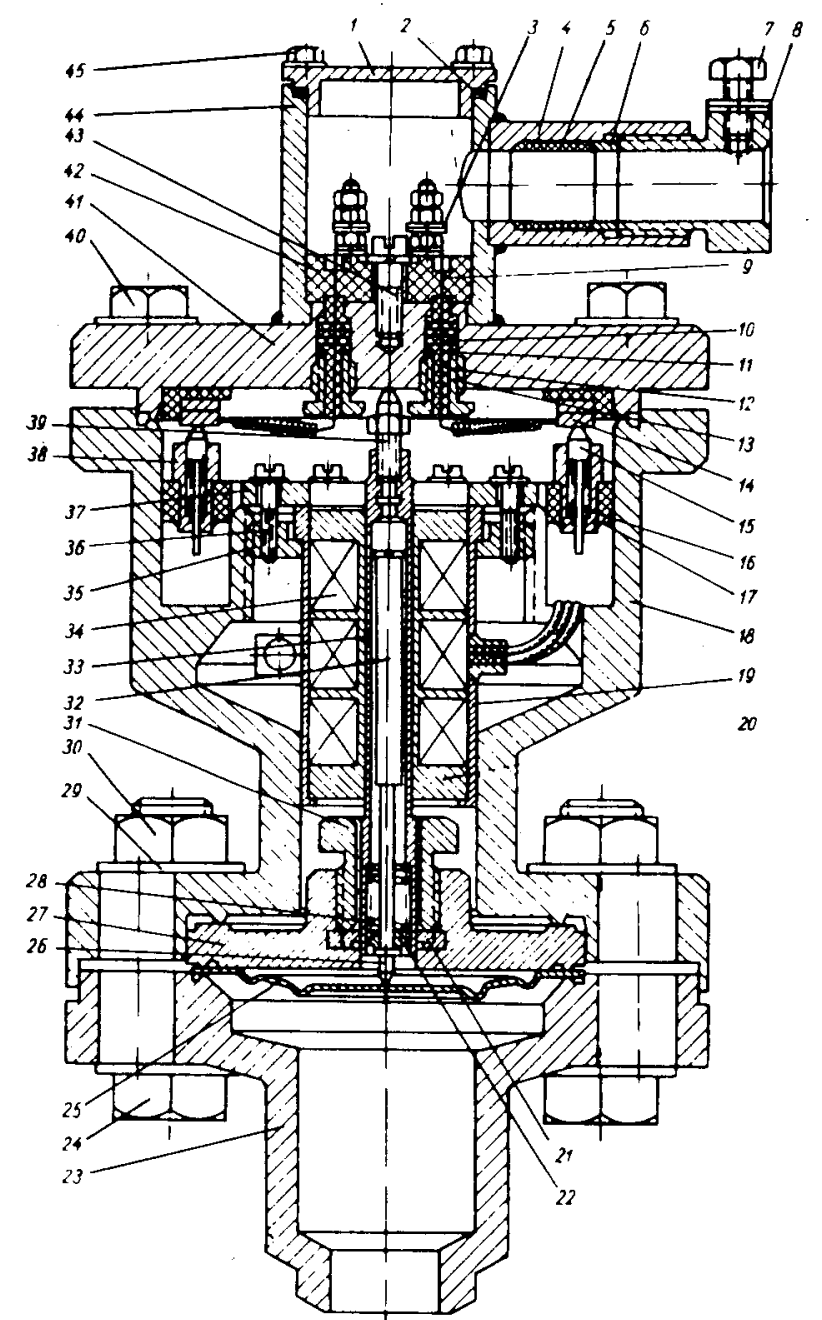
1. LID
11. WASHER
22. WASHER
2. TEFLON LINING
12. TEFLON BUSHING
23. LOWER FLANGE
3. WASHER
13. CONNECTING PIECE
24. BOLT
4. LUG
14,15. CONTACTS
25. MEMBRANE
5. INTERL INING
16. SPRING
26. ROD
5. BOTTOM
17. TERMINAL PANEL
26. ROD
7. BOLT
18. SHELL
8. CONNECTING PIECE
19. SCREEN
28. SPRING
9. CONDUCTOR
20. FRAME
29. WASHER
10. TEFLON LINING
21. RING
30. NUT
37. CONNECTING PIECE

Figure IV.F-5. Pressure Transmitter of the Type Used in BR-5 (Ref. 6) IV.F-4 
IV. G. COVER GAS AND AUXILIARY SYSTEMS

A number of auxiliary circuits are provided for cooling and heating the reactor elements, shielding reflectors, water-shield tank, thermal column, experimental loop and water loop of the experimental channel.

The nickel reflectors are cooled by filtered air, which flows downward along cooling channels and is ejected to the atmosphere through a tall pipe. Heat released from the water-shield tank and the experimental channel is removed by forced circulation of distillate along the closed circuit, the heat being transferred to running tap water in the jacket-and-pipe heat exchanger. The distillate is pumped back to its tank and returns to the pump intake through a buffer reservoir along an overflow pipe.
The gas heating system of the central reactor tube is a disconnected heating loop. Air passes through an electric heat radiator and goes to the heating system of the central tube and the first loop gate valves where it mixes with air from the reflector cooling system and is ejected with it. (Fig. IV.G-1.) (Refs. 1,6)

Argon cover gas is circulated continuously through a silica-gel drier and through copper-coated silica gel heated to $250^{\circ} \mathrm{C}$.

Preliminary sodium purification is by vacuum distillation. The main unit of the BR-5 system is the evaporator, which is equipped with an electric furnace and a condenser, with distillation under vacuum. (Fig. IV.G-2.) (Ref. 6) 


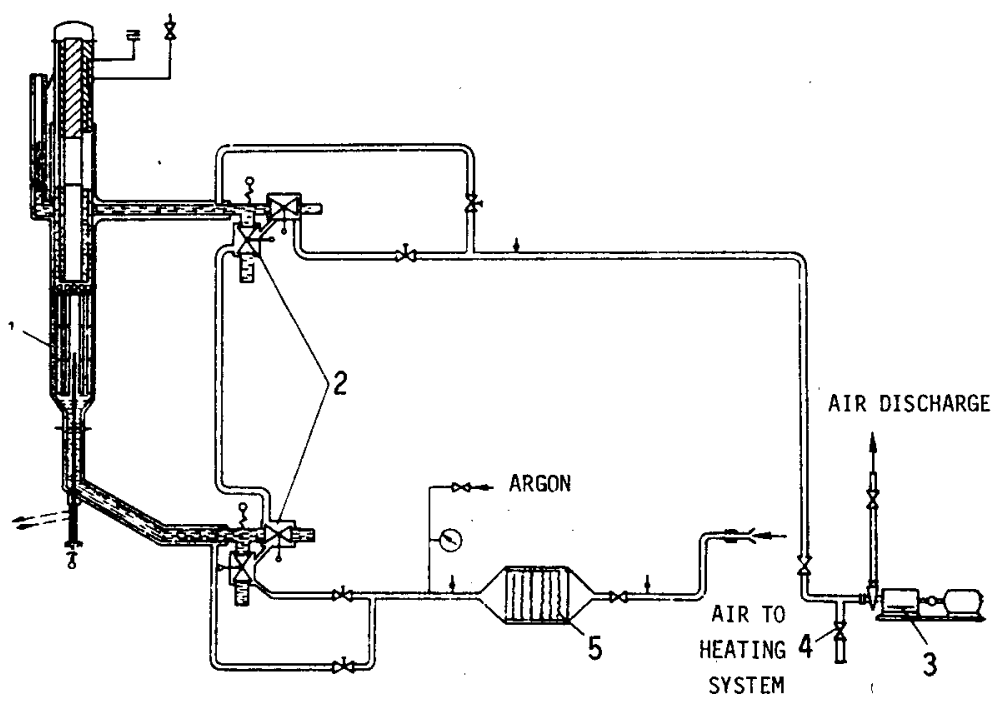

1. REACTOR

2. VALVES OR CUTTING OFF THE LOOPS OF THE FIRST CIRCUIT

3. GAS BLOWER

4. AIR FROM THE SCREEN COOLING SYSTEM

5. ELECTRIC HEAT RADIATOR ( $75 \mathrm{~kW})$

Figure IV.G-1. Diagram of the BR-5 Gas-Heating System (Ref. 6)
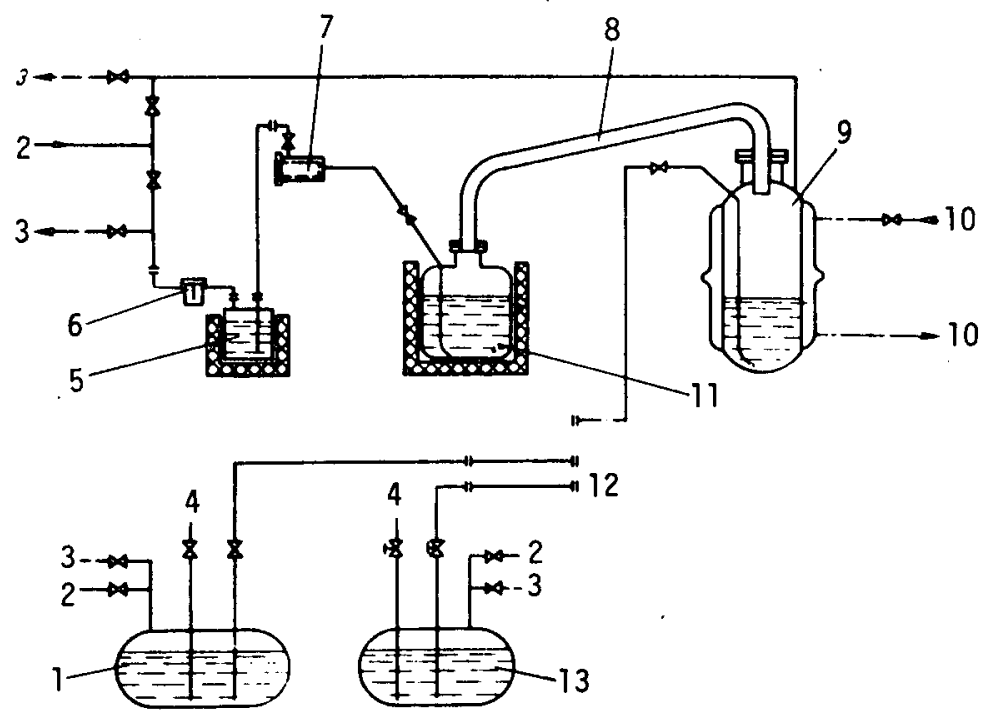

1. DUMP TANK OF THE FIRST CIRCUIT

2. PURE INERT GAS SUPPLY

3. CONNECTION OF THE VACUUM LINE

4. LINE FOR DELIVERING LIQUID METAL INTO THE CIRCUIT

5. TRANSPORT TANK

6. PARAFFIN VAPOR TRAP

7. MECHANICAL MESH FILTER

8. STEAM PIPELINE $100 \mathrm{~mm}$ IN DIAMETER

9. CONDENSER

10. FEED AND REMOVAL OF STEAM COOLING THE CONDENSER

11. EVAPORATOR

12. REMOVABLE SECTIONS OF THE PIPELINE

13. DUMP TANK DF THE SECOND CIRCUIT

Figure IV.G-2. BR-5 Sodium Distillation System (Ref. 6)

IV.G. -2 
IV. H. STEAM GENERATOR AND FINAL HEAT TRANSFER

The BR-5 steam generator is a vertical shel1 unit with 61 coaxial tubes inserted in it. Outer straight pipes are welded at their ends to an upper tube plate and into the plate of a mercury chamber located in the upper part of the she11. Inner, inverted U-shaped tubes are fastened into lower tube plates. Mercury fills the annulus of the double-wall tubes and the space between the tube plates. Pressure in this cavity is lower than the steam pressure and higher than the NaK pressure.

The generator consists of two shells connected in series. Circulation on the water-steam side is by a once-through

circuit with no separators. Steam and water flows through the inner tubes countercurrent to the NaK (Figs. IV.H-1 and IV.H-2). At the end of 1960 , the steam generator was replaced by a NaK-air heat exchanger. (Refs. 6, 8)

The NaK-air heat exchanger consists of nine sections arranged in the casing, which is $1.5 \times 1.5 \times 2 \mathrm{~m}$. Each section is a cluster of $62 \mathrm{U}$-shaped tubes, each $25 \mathrm{~mm}$ in diameter with $1.5 \mathrm{~mm}$ thick walls. The staggered arrangement is sealed into the tube plate of the chamber section. NaK passes into the upper collector and is distributed along three parallel threesection tubes and is carried out of the heat exchanger through the lower collector. Cooling air flows from the bottom to the top. Heat exchanger sections are fabricated of stainless steel. (Ref. 8) 
BR-5/BR-10 IV.H.

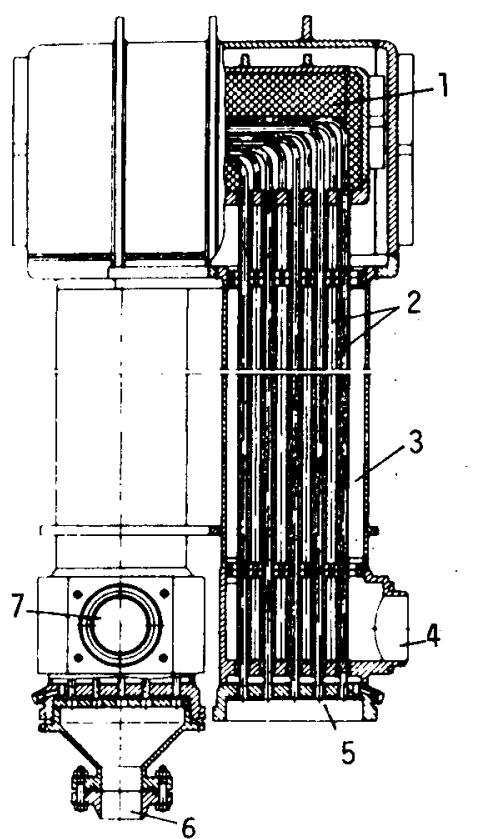

1. MERCURY CAVITY

2. WATER TUBES $16 \times 1.5 \mathrm{~mm}$ IN DIAMETER

3. ALLOY CAVITY

4,7. SODIUM POTASSIUM ALLOY INLET AND OUTLET

5. STEAM-WATER MIXTURE OUTLET

6. WATER INLET

Figure IV.H-1. BR-5 Steam Generator (Ref. 6)

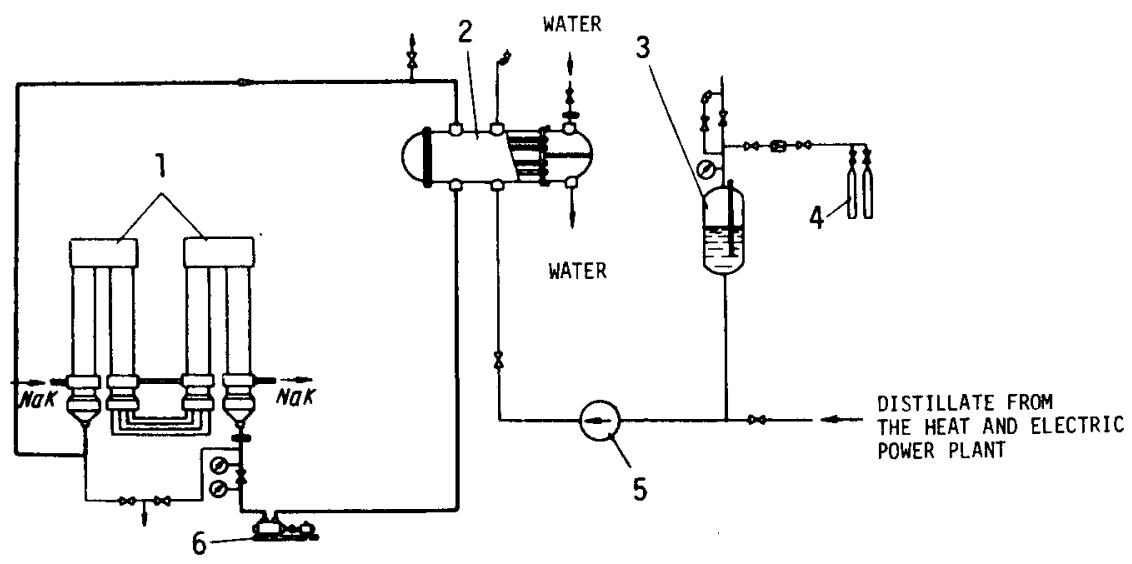

1. STEAM GENERATOR

2. CONDENSER

3. FEED TANK

4. CYLINDERS WITH NITROGEN

5. FEED PUMP INCLUDED IN THE CIRCUIT DURING THE PERIOD OF ADJUSTMENT OF THE SGU

6. CIRCULATION PIJMP OF THE THIRD CIRCUIT

Figure IV.H-2. BR-5 Design Diagram of the Steam Generator Unit (Ref. 6)

IV.H-2 
IV. I. REACTOR INSTRUMENTATION AND CONTROL

Two $\mathrm{BF}_{3}$ counters are located in the water-shield tank to measure flux level at startup. There are eleven ionization chambers for use when the reactor is at power. These boron chambers are fitted with a boroncoated steel cylinder. The thickness of the boron coating increases linearly with the length of the cylinder so that chamber sensitivity varies with reactor power.

Monitoring the fuel element cladding leak-tightness provides both a continuous check for damaged fuel elements and constant monitoring of the activity level of fission products in the primary loop. (Ref. 3)

The activity of gases sampled from gas spaces in the central reactor tube and the primary loop pumps is monitored by means of a spectrometer recorder. One of the primary pumps is equipped with a recirculation line with a sealed gas blower, by means of which gas from the gas space of this pump is recirculated over the spectrometer recorder. (Ref. 4)

Delayed-neutron monitoring of the coolant is accomplished by special sensors using corona discharge counters. Six sensors are installed directly on the heat insulation of the primary piping. Secondary installations on a central board record the averaged data from all sensors on a chart. (Ref. 3)

The reactor is controlled by nickel reflector cylinders suspended on steel rods and connected by cable to servodrives in the upper box of the reactor by means of electromagnets. In scram situations, they drop by their own weight. Two automatic regulating rods located in grooves in the shield compensator cylinder furnish shim control .

(Ref. 6) 


\section{J. FUEL HANDL ING}

With the hood of the central reactor tube removed, special handling mechanisms are mounted on the small rotating plate above the core. The gas cavity of the central tube communicates through locks with the gas cavities of the mechanisms. The channel in the small rotating plate is aligned with the assembly to be removed, and further operations are done with a reloading container suspended from an overhead crane. The reloading container is a cylindrical body filled with lead $200 \mathrm{~mm}$ thick. The inner part has a vertical cylindrical pipe containing a rod with tongs that pulls the assembly into the container. A conical ground cock in the lower part closes the channel tightly. Inert gas can be circulated in the container. The inner channel connects with the channel of the small plate. The surface of the plate is sealed to the lower surface of the container by a rubber ring. After removing the fuel assembly and sealing the container, the space between the cocks is blown with pure gas and the container moved to the assembly storage tank by the overhead crane. New assemblies are loaded in reverse order. (Fig. IV.J-1.) (Ref. 6)

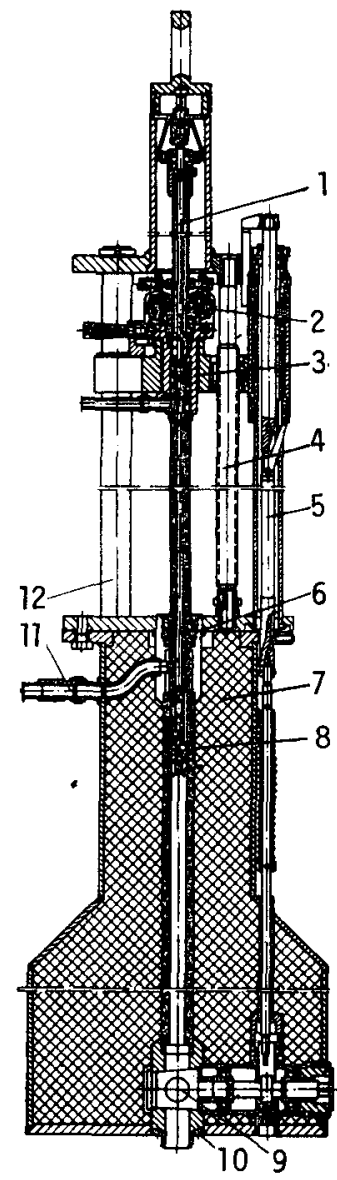

1. ROD WITH TONGS

2. DRIVING ROLLERS

3. CARRIAGE

4. SCREW OF CARRIAGE DRIVE

5. CRANE CONTROL MECHANISM

6. SEAL OF THE ROD

7. CONTAINER

8. TONGS

9. COCK

10. GASKET RING

11. GAS INLET

12. CARRIAGE GUIDE

Figure IV.J-1. BR-5 Reloading Container (Ref. 6) 


\section{K. CONTAINMENT}

BR-5 has no outer containment building.

Both the massive concrete structure around the water-shield tank and the water tank itself serve as biological shielding. Primary loops are housed in separate concrete cells and the secondary loop equipment is in a single compartment.

Additional shielding to protect operating personnel was provided during modification for 10-MWt operation. 
V. $B O R-60$

LOCATION: Near Melekess, USSR

OPERATION: March 1970

BOR-60 is an experimental loop-type fast reactor. Design started at the end of 1963 and construction in May 1965. The reactor went dry critical in December 1968 and reached criticality with sodium in December 1969. Unti1 the end of 1970, the reactor operated at $60 \mathrm{MW}$ with air-dump heat exchangers. A steam generator was installed in 1970. A second steam generator of different design was installed and put into service in 1973. 
INDEX

Page

REFERENCES

$V-5$

REACTOR PARAMETERS

V-7

SECTIONS

A. CORE AND BLANKET V.A-T

B. CORE SUPPORT AND VESSEL INTERNALS V.B-1

C. REACTOR VESSELS AND SHIELDING V.C-1

D. CONTROL ELEMENTS V.D-1

E. HEAT TRANSFER SYSTEMS V.E-1

F. SODIUM PURIFICATION AND INSTRUMENTATION V.F-1

G. EXPERIMENTAL FACILITIES V.G-1

H. STEAM GENERATORS V.H-1

I. REACTOR INSTRUMENTATION AND CONTROL V.I-T

J. FUEL HANDLING V.J-1 
REFERENCES

1. The BN-350 and BOR Fast Reactors

A.I. Leipunskii, et. al.

Soviet Atomic Energy, Vol. 21, pp. 1146-1157, December 1966

2. The $B N-350$ and $B 0 R$ Fast Reactors

A.I. Leipunskii, et. al.

Proc. London Conference on Fast Breeder Reactors, May 1966, pp. 243-274,

Pergamon Press, 1967

3. The BOR Experimental Reactor and its Empirical Basis

A.I. Leipunskii, et. al.

CEMA Symposium on Atomic Power Stations with Fast Reactors, 1969,

JPRS-48330, Vol. 1, pp. 228-237, July 1969

4. Soviet Power Reactors - 1970

Report of the USA Nuclear Power Reactor Delegation Visit to the USSR, June 1970, WASH-1175, 1970

5. The Experimental Reactor BOR

E.V. Borisiouk, et. al.

Energie Nucleaire, Vol. 12, pp. 33-38, January-February 1970

6. Fast Breeder Reactor Development in the USSR

J.J. Taylor.

Combustion, pp. 6-11, July 1972. (See also American Power Conference, pp. 98-109, 1972)

7. Investigation of BOR-60 Reactor Fuel and Absorbing Elements

N.V. Krasnoyarov

Proc. Conference on Fast Reactor Power Stations, London, March 1974, pp.319-324, British Nuclear Energy Society, 1974

8. Four Years Operating Experience on the Experimental BOR-60 Nuclear Power Station V. M. Gryatzev, et. al.

Proc. Conference on Fast Reactor Power Stations London, March 1974, pp. 21-26, British Nuclear Energy Society, 1974

9. Technical Problems of Fast Reactors

Yu. Ye. Bagdasarov, et. al.

Atomic Energy Publishing House, Moscow, 1966. (Given to the USA Nuclear Power Reactor Delegation).

WASH- 1179

10. Investigation of the Temperature Distribution and Coolant Flow Rate in the Core Assemblies of the BOR-60 Reactor

V.M. Gryatsev, et. aT.

Kernenergie, Vol. 17, No. 6, pp. 164-170, 1974. (Translation: BNWL-TR-134, 1974.)

11. The Behavior of BOR-60 Reactor Control and Safety Rods During Their Operation S.N. Votinov, et. aT.

Absorbing Materials and Control Rods for Fast Reactors, Papers Presented at the Meeting of the International Working Group for Fast Reactors, June 1973, Dimitrovgrad, USSR,

JPRS-59863, August 1973

12. Emergency Conditions in the Operation of the BOR Reactor

I.A. Kutznetsov, et. al.

Proc International Conference on the Safety of Fast Reactors, Aix-en-Provence, France, September 1967, Edited by G. Denielou, pp. III.7-1-III.7-15, CEA, France. 
Table 1

Type

No. loops

Coolant

Core inlet temp.

Core outlet temp.

Flow direction

Driver fuel

Blanket fuel

Core height

Core diameter

Velocity in core

No. enrichment zones in core

Output MWe/MWt

Max. can temp.

Linear power, max.

Neutron flux, total

Power density

No. Driver elements

No. Radial blanket elements

No. In-core control elements

Goa 1 burnup

*It was reported in Nuclear Engineering for May 1974 that BOR-60 was operating with 113 fuel

assemblies in the core.
GENERAL PARAMETERS

Loop-type, enriched $U 0_{2}$ fuel

Sodium

$360-480^{\circ} \mathrm{C}$

$500-600^{\circ} \mathrm{C}$

Upward

$\mathrm{UO}_{2}$, fully enriched

$\mathrm{UO}_{2}$, depleted

$40 \mathrm{~cm}$

$40.4 \mathrm{~cm}$

$8 \mathrm{~m} / \mathrm{sec}(\max .10 \mathrm{~m} / \mathrm{sec})$

1

$60 \mathrm{MWt}$

$750-800^{\circ} \mathrm{C}$

$500 \mathrm{w} / \mathrm{cm}$

$3.7 \times 10^{15} \mathrm{n} / \mathrm{cm}^{2} / \mathrm{sec} .(\max$.

$16.7 \mathrm{kw} / \mathrm{ft} . \max$.

80 initial load*

$158-178$

7 (Sealed $\mathrm{B}_{4} \mathrm{C}$ )

$10 \%$ 
BOR $-60 V$

Table - 2

CORE AND BLANKET

\begin{tabular}{|c|c|c|c|}
\hline & Driver zone & Axial blanket & Radial Blanket \\
\hline Fuel material & $\mathrm{UO}_{2}$ & depleted $\mathrm{UO}_{2}$ & depleted $\mathrm{UO}_{2}$ \\
\hline Form & Annular pellet & Annular pellet & pellet \\
\hline $235 \mathrm{U}$ inner zone & $90 \%$ & depleted & depleted \\
\hline Density & $10.2 \mathrm{~g} / \mathrm{cm}^{3}$ & $\therefore$ & \\
\hline Pellet od & $\begin{array}{l}5.1 \mathrm{~mm} \\
\text { Central hole } 1.7 \mathrm{~mm} \text { dia. }\end{array}$ & & \\
\hline Pellet length & $10 \mathrm{~mm}$ & & \\
\hline Rod cladding & Stainless steel & Stainless steel & Stainless steel \\
\hline od & $6 \mathrm{~mm}$ & & $14.5 \mathrm{~mm}$ \\
\hline Wall thickness & & & $0.35 \mathrm{~mm}$ \\
\hline Fuel-clad gap & $0.1-0.2 \mathrm{~mm}$ & & \\
\hline Column length & $400 \mathrm{~mm}$ & $100 \mathrm{~mm} \times 2$ & $900 \mathrm{~mm}$ \\
\hline Gas plenum length & $\begin{array}{l}150 \mathrm{~mm} \text { top } \\
100 \mathrm{~mm} \text { bottom }\end{array}$ & & \\
\hline Vented/non-vented & No & & \\
\hline Assembly material & Stainless steel Integral & with fuel core & Stainless steel \\
\hline Shape & Hexagonal & & Hexagonal \\
\hline Across flats & $44 \mathrm{~mm}$ & & $44 \mathrm{~mm}$ \\
\hline Wall thickness & $1 \mathrm{~mm}$ & & \\
\hline Overall length & $1495 \mathrm{~mm}$ & & \\
\hline No. pins/assembly & 37 & $37 \times 2$ & 7 \\
\hline Pin spacing & Spiral wrap, oval wire & & \\
\hline Pin pitch & $6.7 \mathrm{~mm}$ & 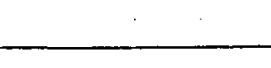 & $1.5 .2 \mathrm{~mm}$ \\
\hline Assy. pitch & $45 \mathrm{~mm}$ & & \\
\hline Assy. in core & $80-1000$ & & $158-178$ \\
\hline
\end{tabular}


V. A. CORE AND BLANKET

The BOR-60 core consists of hexagonal assemblies loaded with a pitch of $6.7^{\circ} \mathrm{mm}$ for the fuel and $15.2 \mathrm{~mm}$ for the radial blanket assemblies. Pin cladding is a USSR-modified type 316 stainless stee 1 $(16 \mathrm{Cr}-15 \mathrm{Ni}-3 \mathrm{Mo}-0.8 \mathrm{Nb})$. Pin spacing is by a spiral wrapping of oval stainless-steel wire. The axial blanket pins are loaded into the top and bottom of the hexagonal can. A gas plenum at the top is $150 \mathrm{~mm}$ high. The bottom plenum $(100 \mathrm{~mm})$ contains a spring to hold the fuel column. Although the cladding is sealed, vented elements will be tested. The fuel assembly has an upper head that provides a gripping area for the reloading machine and a lower end piece for positioning in the throttle socket of the grid-plenum assembly. The shafts of the driver assemblies have lateral inlets 5 to $5.5 \mathrm{~mm}$ in diameter for the delivery of sodium from the high-pressure plenum. Spiral seals are used to reduce leakage. The radial assembly shafts have similar equipment to take sodium flow from the low-pressure plenum. (Figs. V.A-l, V.A-2 and V.A-3 (Refs. $4,19,10$ )

The design called for an initial core loading of 80 driver elements. Criticality was reached with 68 elements. In the May 1974 issue of Nuclear Engineering International, it was reported that BOR-60 was operating with 113 fuel assemblies in the core.

Assemblies containing experimental specimens can be placed in the active zone. Some radial blanket assemblies can also be used for irradiation.

The cover gas is argon. 


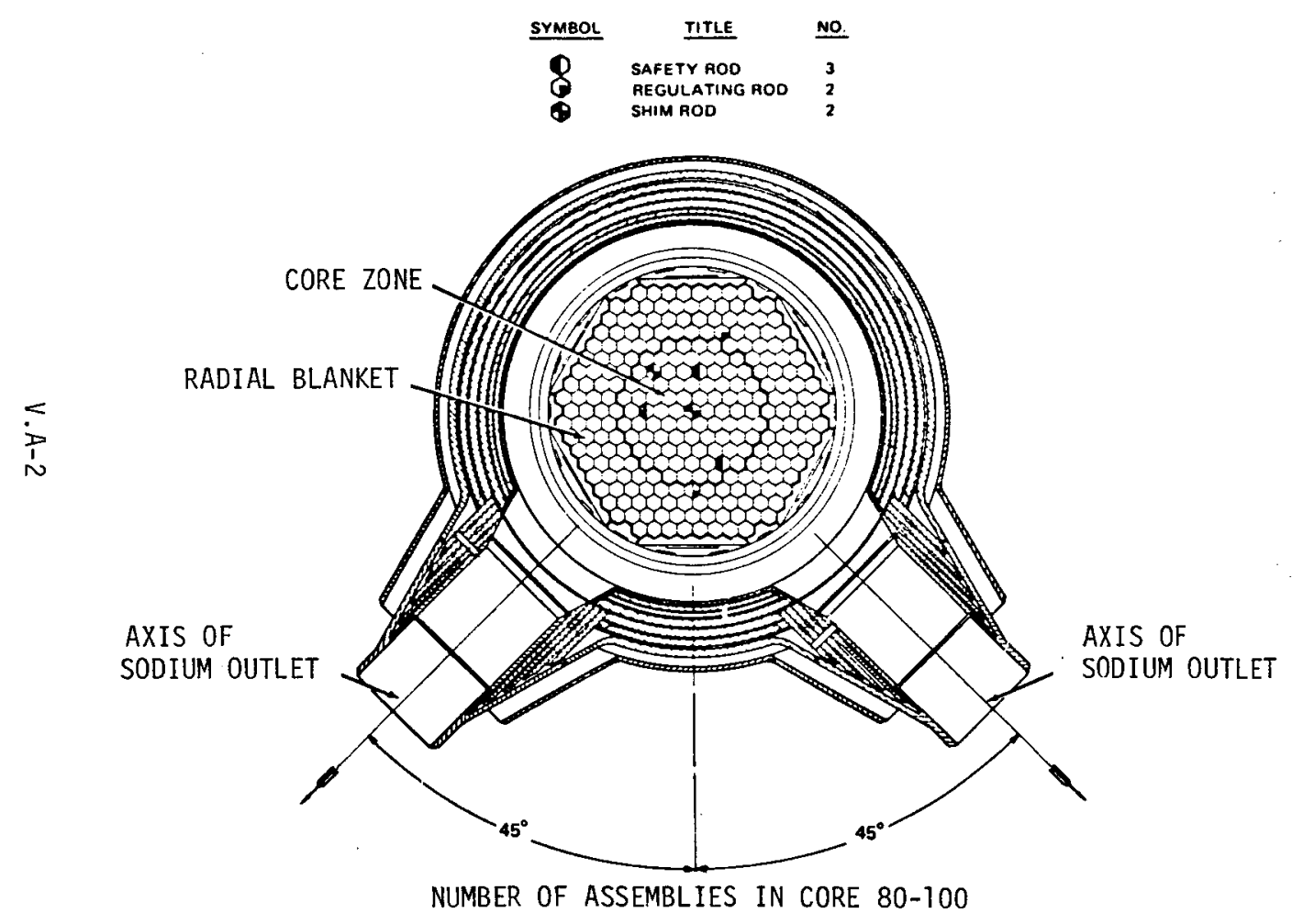

NUMBER OF ASSEMBLIES IN CORE AND RADIAL BLANKET 158-178

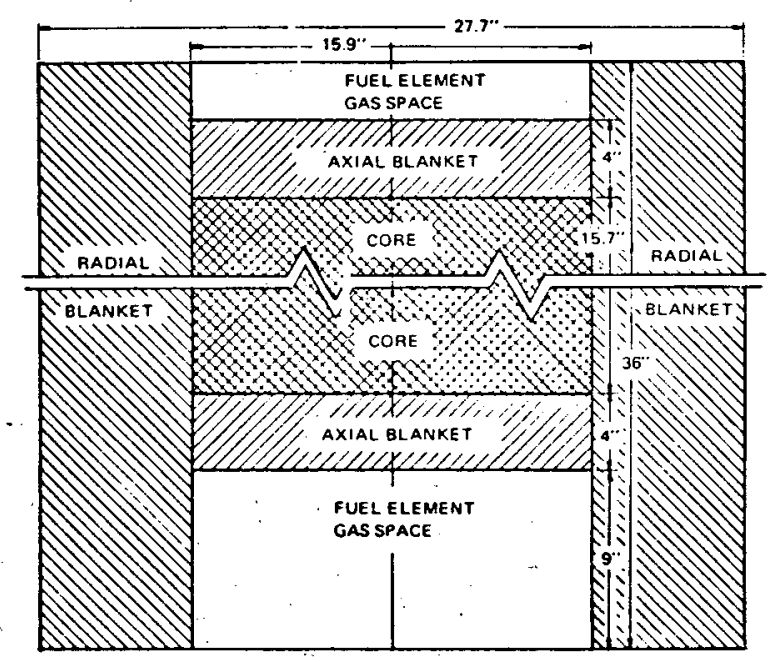

Figure V.A-1. BOR-60 Core Design (Ref. 4) 


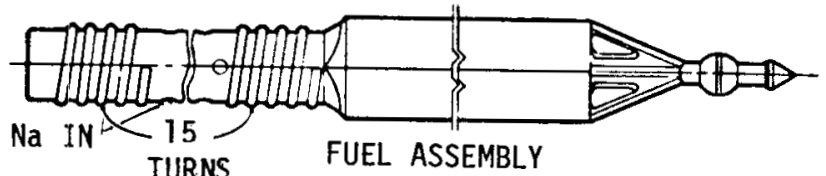

ORIFICE FOR FLOW CONTROL

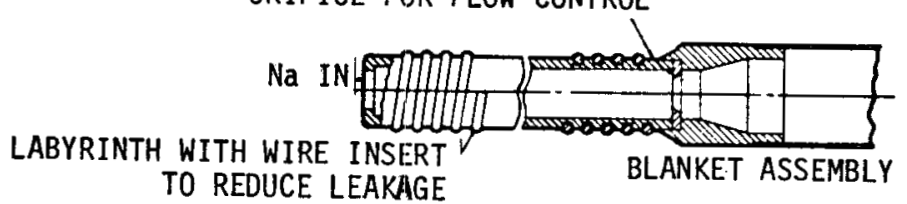

TO REDUCE LEAKAGE

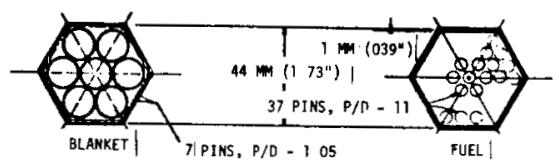

Figure V.A-2, BOR-60 Fuel and Blanket Assemblies (Ref. 4)

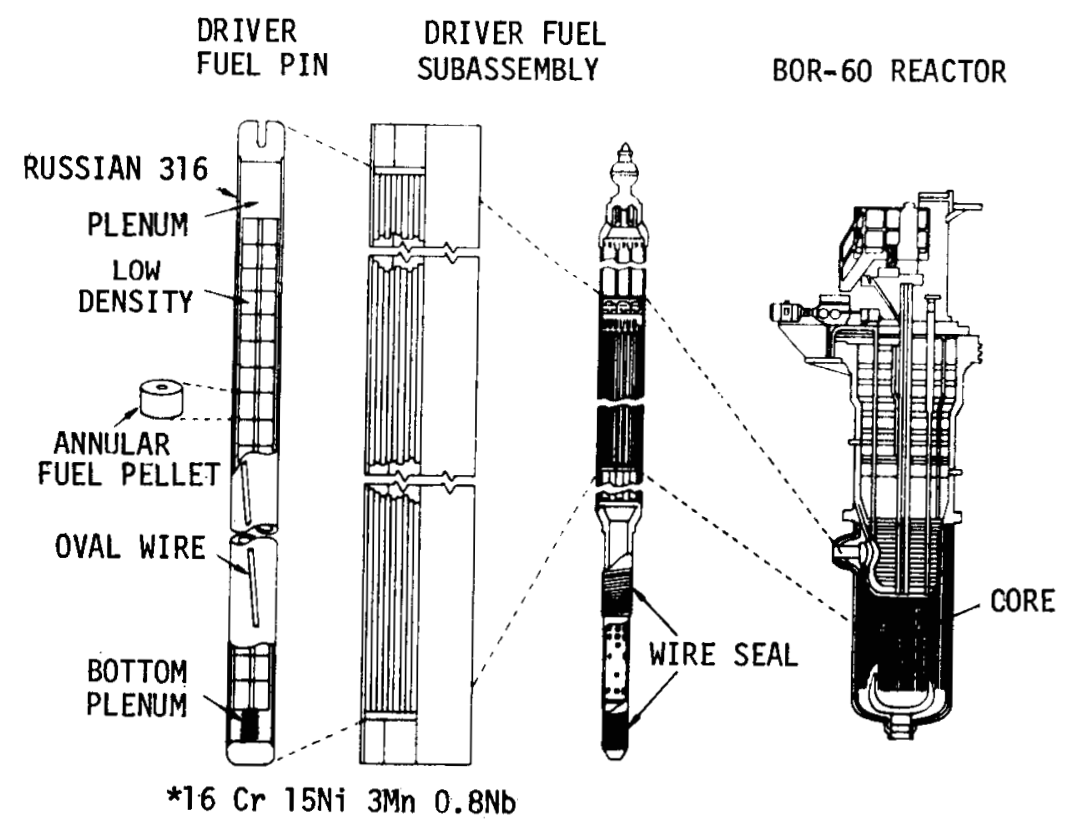

Figure V.A-3. BOR-60 Fuel System (Ref. 4) 
V. B. CORE SUPPORT AND VESSEL INTERNALS

The grid-plenum assembly supports for the fue 1 and blanket assemblies and distributes sodium into the core. The bottom ends of the assemblies are fastened to the grid plates while the top ends are free. Radial restraint is by core clamping. The plenum is suspended from the core "basket", a stepped cylinder resting on the upper flange of the vesse?.

The inlet plenum is divided into highpressure and low-pressure zones. The high- pressure zone is the area between the $50 \mathrm{~mm}$ thick upper and lower support plates. These plates are joined by nozzles into which the driver and radial assemblies are positioned. The cavity between the lower plate and the bottom of the reactor vessel is the lowpressure zone. This zone acts to reduce the upward force on both the core assemblies and the plenum zone that feeds the blanket elements, thermal shield and reactor vessel wall. (Figs. V.B-I and V.B-2 (Refs. 2,4) 
BOR-60 V.B.

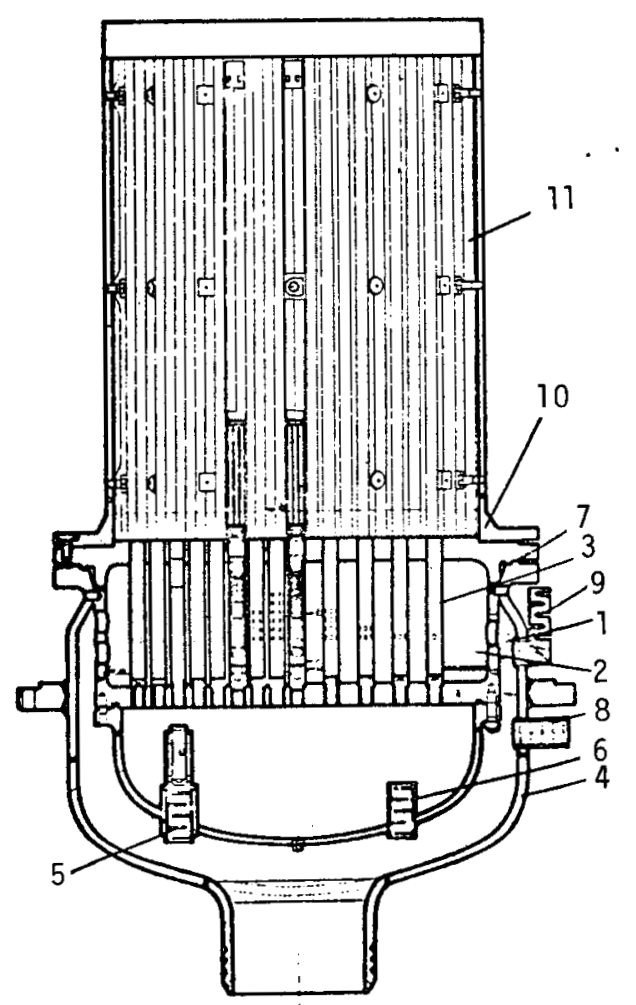

1. HIGH-PRESSURE DISTRIBUTION HEADER

2. HIGH PRESSURE PLENUM

3. SUBASSEMBLY FLOW REGULATOR

4. INTAKE-MANIFOLD STRUCTURE

5. PRESSURE-DROP REGULATOR FOR COOLING CONTROL ROD

6. PRESSURE-DROP REGULATOR FOR LOW PRESSURE PLENUM

7. GASKET

8. PRESSURE-FLOW REGULATOR FOR VESSEL WALL COOLANT

9. PRESSURE-FLOW REGULATOR FOR SHIELD COOLANT

10. FLANGE FOR RADIAL RESTRAINT

11. CORE CLAMP (RADIAL RESTRAINT)

Figure V.B-1. BOR-60 Core Support Structure (Ref. 4)

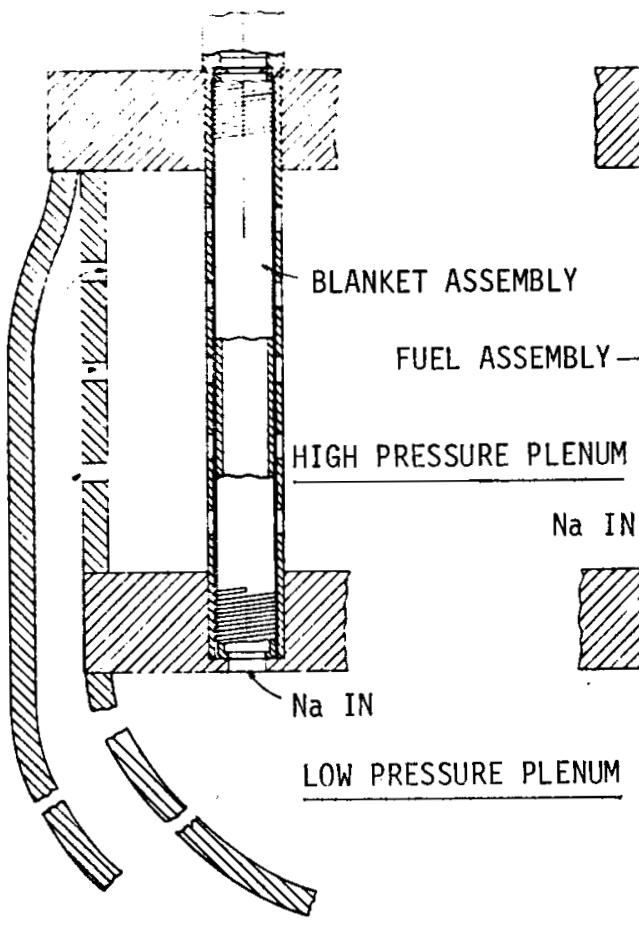

Figure V.B-2. BOR-60 Sodium Inlet Plenum (Ref. 4) 
V. C. REACTOR VESSELS AND SHIELDING

The reactor vessel is a vertical cylindrical structure $6500 \mathrm{~mm}$ high with a wall thickness of 16-22 mm. The vessel diameter at core level is $1100 \mathrm{~mm}$; maximum diameter is $1500 \mathrm{~mm}$. It is enclosed in a leaktight secondary vessel. The space between the vessels is used for warming the reactor with gas. There is a $300 \mathrm{~mm}$ inlet duct welded into the elliptical bottom head and two $300 \mathrm{~mm}$ outlets located above the tops of the assemblies. The internals are removable, the thermal sleeve of the outlet pipes being split to accommodate removal. (Fig. V.C-1.)

The radial thermal shield consists of concentric steel cylinders located between the core and the reactor vessel. The total thickness of the radial thermal shield is $24 \mathrm{~cm}$. Shielding below the core consists of the lower fuel assembly extensions. Upper biological shielding is supplied by the alternate layers of steel and borated graphite of the double rotating plugs. Gastight sealing of the plugs is obtained by the use of freeze seals fitted with a bismuth-tin alloy. Drives for the control elements, and the fuel-transfer-tank connection, are on the small rotating plug.

The side biological shielding is fabricated of layers of steel, ferrous oxide and concrete. (Fig. V.C-2.)

There is no core-catcher device provided. (Ref. 4.) 


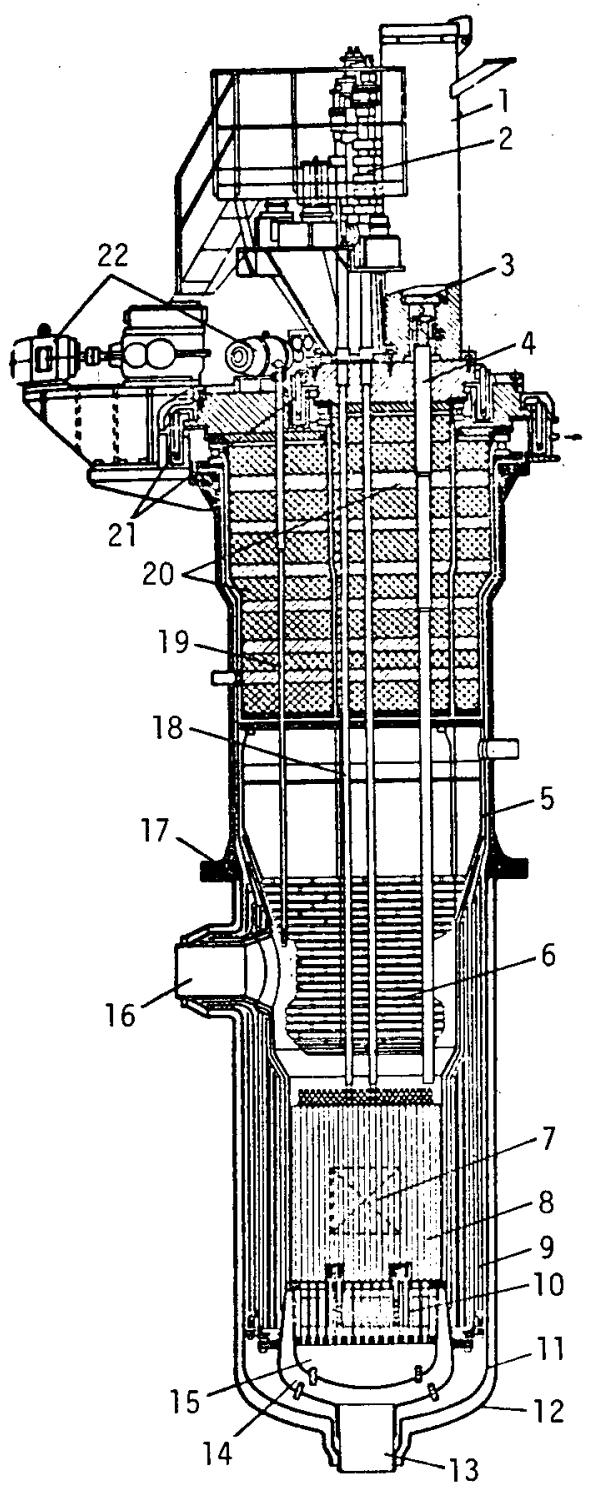

1. FUEL EXCHANGE CASK

2. DRIVE FOR THE CONTROL ROD SYSTEM

3. GATE OF FUEL EXCHANGER CASK

4. FUEL EXIT PORT OF FUEL EXCHANGER CASK

5. BASKET SUPPORT FOR CORE

6. STEEL SHIELDING

7. CORE

8. REFLECTOR

9. PLATES FOR THE GAMMA HEAT SHIELD

10. HIGH PRESSURE PLENUM

11. REACTOR VESSEL

12. SECONDARY CONTAINMENT

13. SODIUM INLET

14. HIGH-PRESSURE INLET ZONE

15. LOW-PRESSURE INLET ZONE

16. SODIUM OUTLET DUCT

17. SUPPORTING FLANGE

18. CONTROL ROD

19. THERMOCOUPLE

20. ROTATING PLUGS

21. DIP SEAL

22. ROTATING PLUG DRIVE MECHANISMS

Figure V.C-1. BOR-60 Reactor (Ref. 4) 


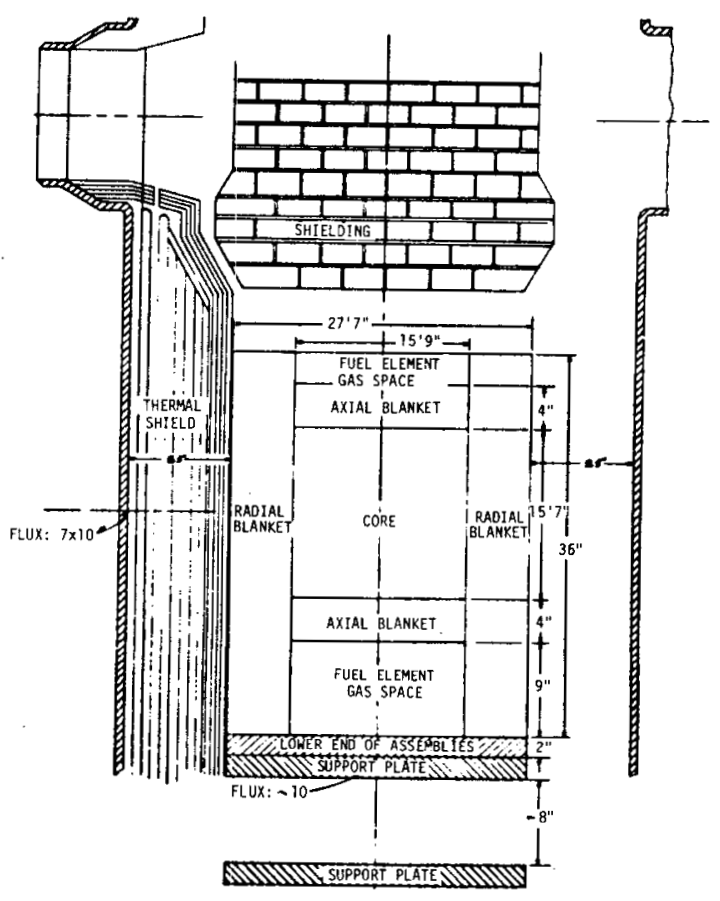

Figure V.C-2. BOR-60 Reactor Vessel Shielding (Ref. 4)

V.C -3 
The BOR-60 is controlled by three safety rods and two shim rods located in the core and two regulating rods in the radial blanket. Ali elements are similar in design and consist of bundles of rods containing boron. The elements are connected with servodrives installed on the rotating plug. During reloading, the elements are lowered and disconnected from the drives.

The rods are composed of bundles of pins containing pellets of boron carbide enriched $80 \%$ in ${ }^{10} \mathrm{~B}$. Pin cladding is a modified 316 stainless steel. The pin is sealed with a bottom plenum equal in volume to the volume of $\mathrm{B}_{4} \mathrm{C}$. The plenum is connected to the junction by a filter. The rod bundie is in a cylindrical guide tube that moves within a hexagonal outer duct. Pin design for all rods is similar and varies only in the number of pins per element. (Ref. 11.)

For a maximum thermal power output of $60 \mathrm{MW}$ the efficiency of the control system is reported to be as follow:

- Efficiency of three scram (safety) rods:

- Efficiency of temperature compensating rod:

$1.0 \%$

- Efficiency of burnup compensator:

- Efficiency of two control (regulating) rods: $0.48 \%$

The reactivity temperature coefficient is $-4 \times 10-5\left({ }^{\circ} \mathrm{C}\right)-{ }^{1}$; the reactivity power coefficieni is $1.5 \times 10^{-4}$ (MW) - . (Refs. 1,4.) 


\section{E. HEAT TRANSFER SYSTEMS}

The primary circuit includes, for each loop, the reactor, hot piping with valve, intermediate heat exchanger, cold piping and a pump. The secondary loop includes the intermediate heat exchanger, a steam generator with buffer tank and a circulation pump. An air heat exchanger is mounted in by-pass in the steam generator; it can evacuate $50 \%$ of the reactor power and can be connected with either of the two secondary 1oops.

Sodium enters through a 300-mm diameter inlet duct welded to the elliptical bottom head of the reactor. The flow from the high-pressure zone passes into the zone between the support plates where it is directed into the core assemblies and to the low-pressure zone below the lower support plate. Flow through the core is upward to two $300-\mathrm{mm}$ diameter outlet ducts above the tops of the assemblies. Flow to each assembly is controlled by means of slots in the throttling sleeves of the inlet plenum, covering a given number of side holes in the bottom ends of the assemblies. Flow through the blanket elements is supplied from the low-pressure inlet plenum and is controlled by an orifice located at the bottom of the assembly.
Primary piping is doubly contained out to the stop valves, with bellows to accomodate differential thermal expansion.

$$
\text { (Refs. 4, 5.) }
$$

A11 piping in the secondary circuit is $200 \mathrm{~mm}$ in diameter. The use of bellows in the secondary piping permits compact piping arrangement in the steam generator rooms. Bellows are used only on vertical runs of hot-leg piping. They are formed of U-span type. (Fig. V. F-1.) (Ref. 4.)

Both primary and secondary pumps are vertical centrifugal units. The primary pump is submerged with a bottom radial hydrostatic bearing operating in the sodium, a top journal thrust oil bearing and a gastight oil seal on the shaft. The pump is fitted on the upper cover of the primary loop box and the motor is accessible for servicing during operation without breaching the primary piping. Pumps are single stage, single suction. Speed is controlled at 350 to $1500 \mathrm{rpm}$ by an ac-dc motor generator system. There are no pony motors for emergency cooling. All pumps are installed in cold legs. (Table V. E-1.) (Ref. 4.)

TABLE V. E-1. Pump Characteristics (Ref. 5.)

\begin{tabular}{lcc}
\hline \multicolumn{1}{c}{ Characteristic } & First Loop & Second Loop \\
\hline Nominal production, m3/hr & 600 & 830 \\
Nominal water column height, $m$ & 85 & 60 \\
Inert gas pressure in gas cavity, & & 0.5 \\
$\mathrm{~kg} / \mathrm{cm}^{2}$ & $0.1-0.5$ & 1500 \\
Nominal rpm & 1500 & 200 \\
Minimum rpm & 200 & 250 \\
Nominal shaft power, kw & 250 & 330 \\
Continuous current, $V$ & 330 & 17,300 \\
Weight (dry), kg & 20,300 & 0 \\
Biological shield thickness, mm & 700 & 2 \\
\hline
\end{tabular}


The intermediate heat exchanger (IHX) (Fig. V. E-2) is a vertical cylindrical vessel containing a tube bundle with a floating lower head. Primary sodium flows in the space between the tubes from top to bottom and secondary sodium flows upward in the tubes. The IHX is mounted on the top cover of the primary loop boxes and can be removed without breaching the primary piping. The central down-comer tube for secondary sodium inlet uses a bellows in the lower end to accommodate differential expansion. There are no baffles on the shell side. The IHX is blanketed with nitrogen. (Ref. 4.)
A gate valve, similar to the $\mathrm{BN}-350$ gate vaive, is used for the primary loop intake lines. It was designed for possible removal of the working elements by remote control for servicing or replacement without cutting the pipelines and has a bult-in biological shield in the valve lid. (Fig. V.E-3) Bellows-type valves are used in the pressure lines of the first loop and on all other liquid-metal systems of the unit. They are analogous to the BR-5 fittings. (Fig. V.E-4.) (Ref. 9.)

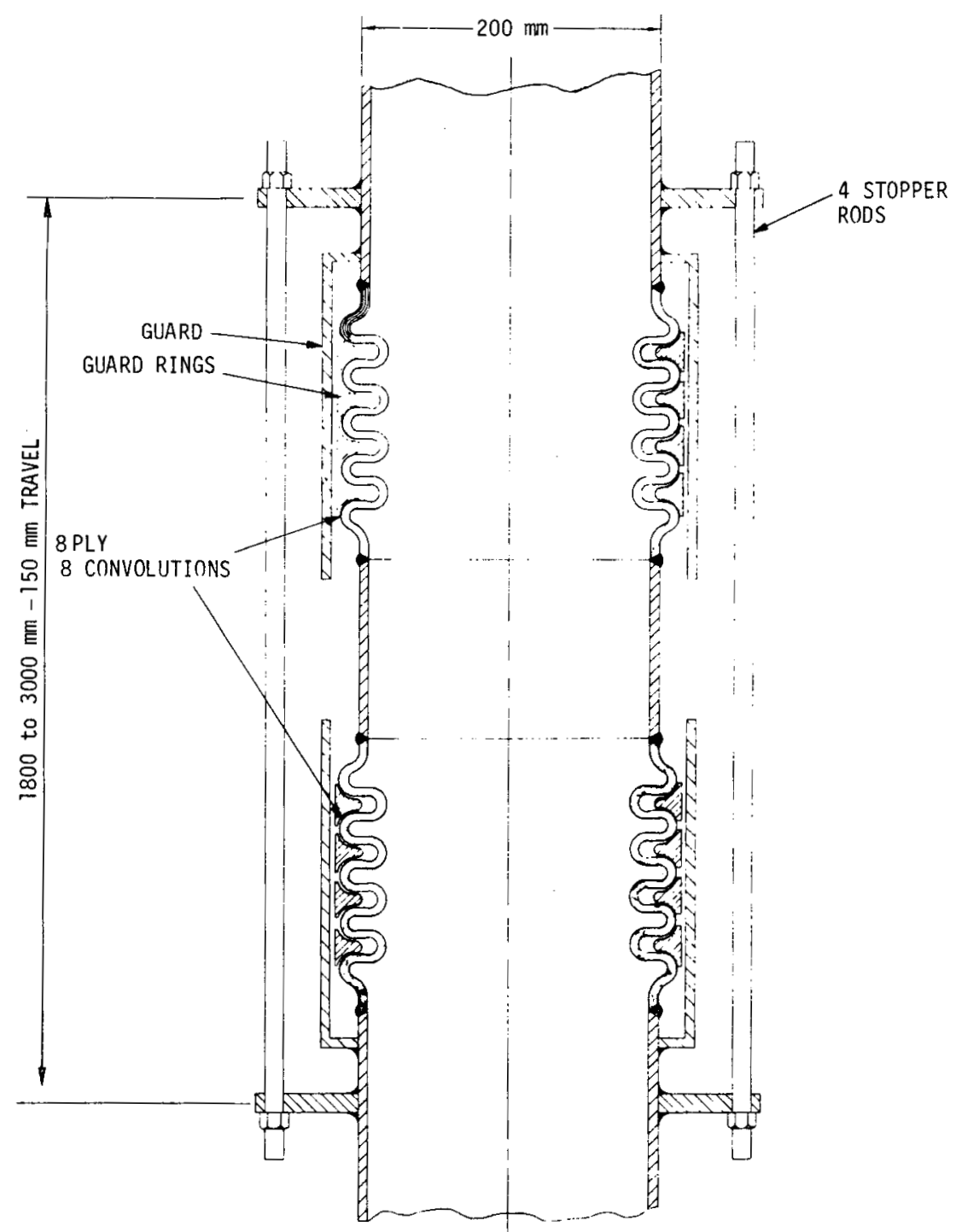

Figure V.E-i. BOR-60 Secondary Piping Expansion Bellows (Ref. 4) 


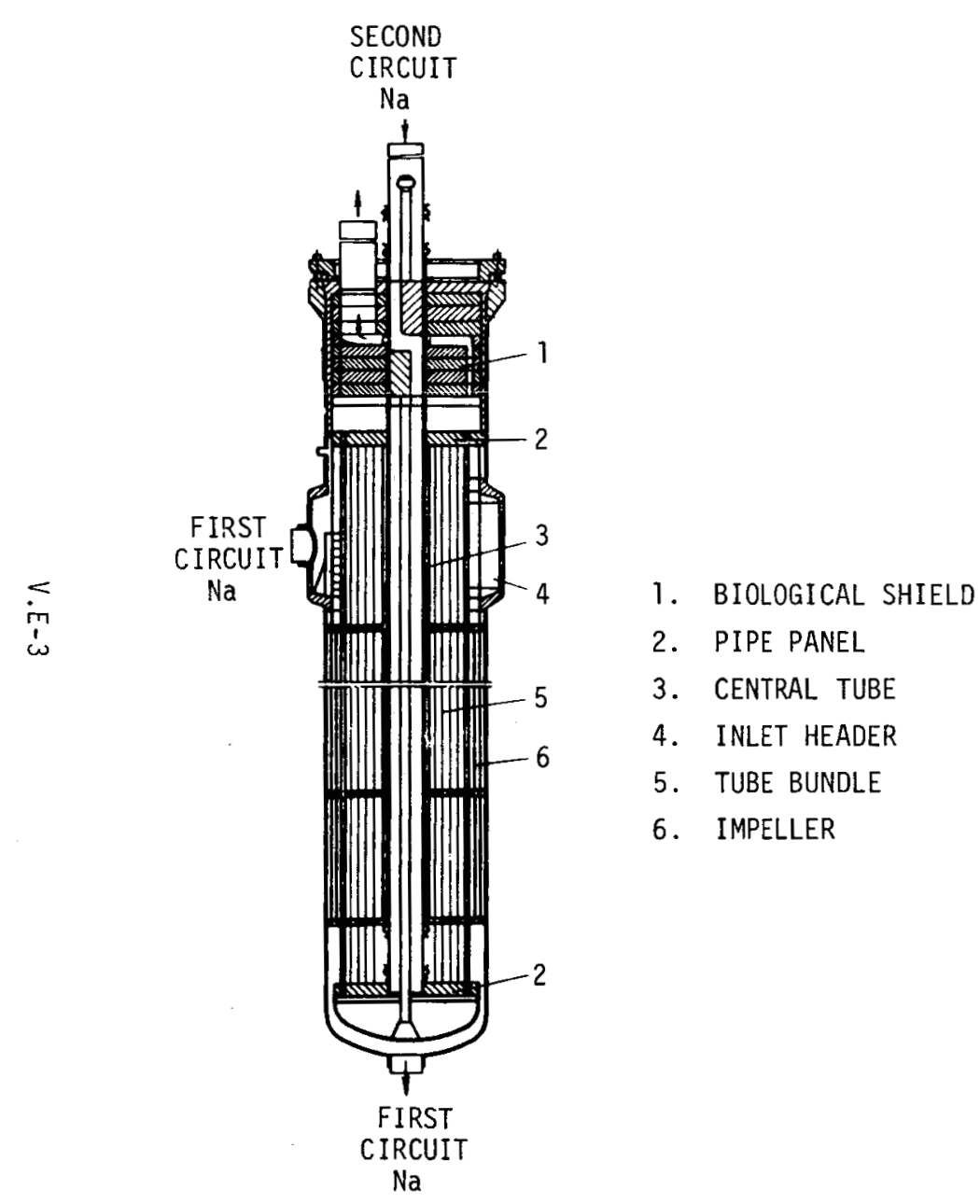

Figure V.E-2. BOR-60 Intermediate Heat Exchanger (Ref. 9)

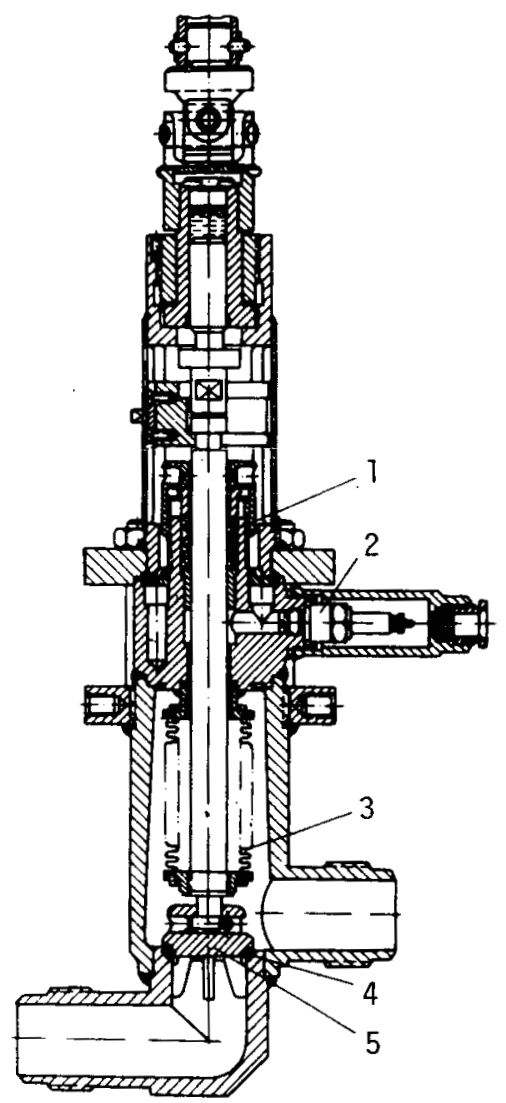

1. PACKING

2. SIGNALING DEVICE FOR LEAKAGE THROUGH BELLOWS

3. BELLOWS

4. STELLITE WELDING

5. VALVE

Figure V.E-3. Bellows-Type Valve of the Kind Used in BOR-60 (Ref. 9) 
V. F. SODIUM PURIFICATION AND INSTRUMENTATION

The BOR-60 cold trap is a conventional design but is steam or water cooled. Lowpressure steam is used to keep the sodium molten and to provide fine control on the trapping temperature. A low melting-point, lead-base alloy is used as a thermal bond between the steam vessel and the cold-trap vessel. In addition, two metal walls separate the steam and water from the sodium (Fig. V.F-T). Both the primary and secondary circuits are equipped with cold traps. (Refs. 4, 5.)

Chromel-Alumel thermocouples are installed at the outlets of individual fuel assemblies to indicate sodium temperature. Not all of the assemblies are monitored.
Instruments for fuel failure detection based on delayed-neutron monitoring are located on the outlet pipe of the IHX. The activity of the coolant is measured after the test loops have been cut off from the main circuit by means of valves. One of the test loops has its own pump and is supplied with an oxide trap, sampler and isotopic dosimeter. There are two loops for monitoring fission product pollution. (Ref. 5.)

Coolant flow rate through the core assemblies is measured by a special flowmeter consisting of an 8-m long rod with a measuring pipe fastened to one end. The measuring pipe has two pickups, one magnetic and one electromagnetic. (Fig. V.F-2.)

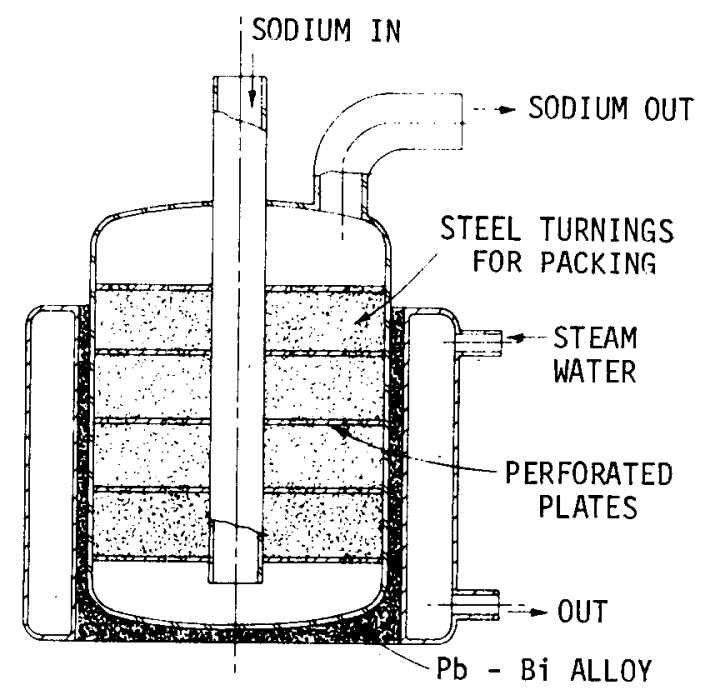

Figure V.F-1. BOR-60 Cold Trap (Ref. 4)

$$
\text { V.F-1 }
$$


BOR-60 V.F.

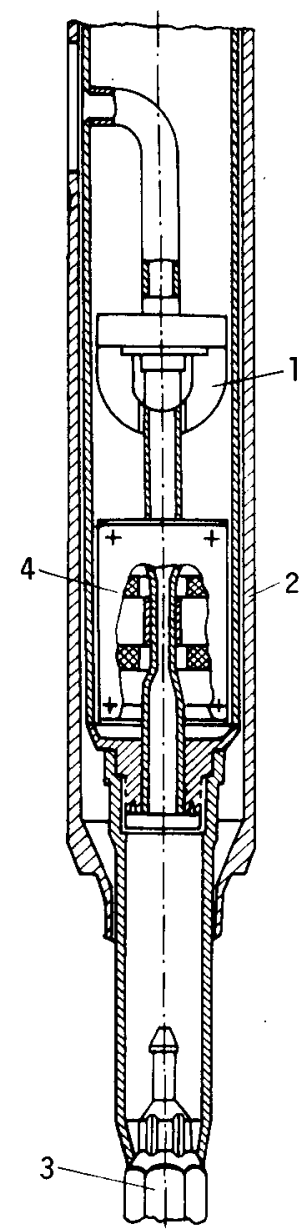

1. PICKUP WITH PERMANENT MAGNET

2. PIPE FOR OVERFLOW PASSAGE

3. ASSEMBLY HEAD

4. ELECTROMAGNETIC PICKUP

Figure V.F-2. BOR-60 Flowmeter (Ref. 10)

$$
\text { V.F-2 }
$$


V. G. EXPERIMENTAL FACILITIES

A special channel near the center of the core is provided for studying fuel element operation. The channel is an assembly externally identical to the other assemblies but fitted with various indicators and fastened to a rod containing the leads for the indicators. During discharge, the assembly is removed from the core and rotates with the plugs.
There are four horizontal bundles for physics investigations and ten vertical uncooled channels, including some $300 \mathrm{~mm}$ in diameter. A large number of assemblies with experimental specimens can be loaded into the core at the same time. (Ref. 2.) 


\section{H. STEAM GENERATORS}

BOR-60 began operating as a power station in December 1970 when the first steam generator was installed in one of the two loops. This unit is a once-through coil steam generator consisting of two cylindrical frames, each with a diameter of about $1 \mathrm{~m}$. The evaporator tube bundle has sixty coils and the superheater has ninety coils. The steam generator is fitted with means for control and protection in the event of either tube leakage or water or steam entering the sodium (Fig. V.H-l)
The second steam generator, developed and manufactured in Czechoslovakia, was installed and started up in 1973. This 30-MW unit has eight separate modules. The individual units are small. Fault location is possible in the modules. The double tube plate design prevents water from contaminating the sodium in the event of leakage through the weld between tubes and plate. (Ref. 8) 
BOR-60 V.H.

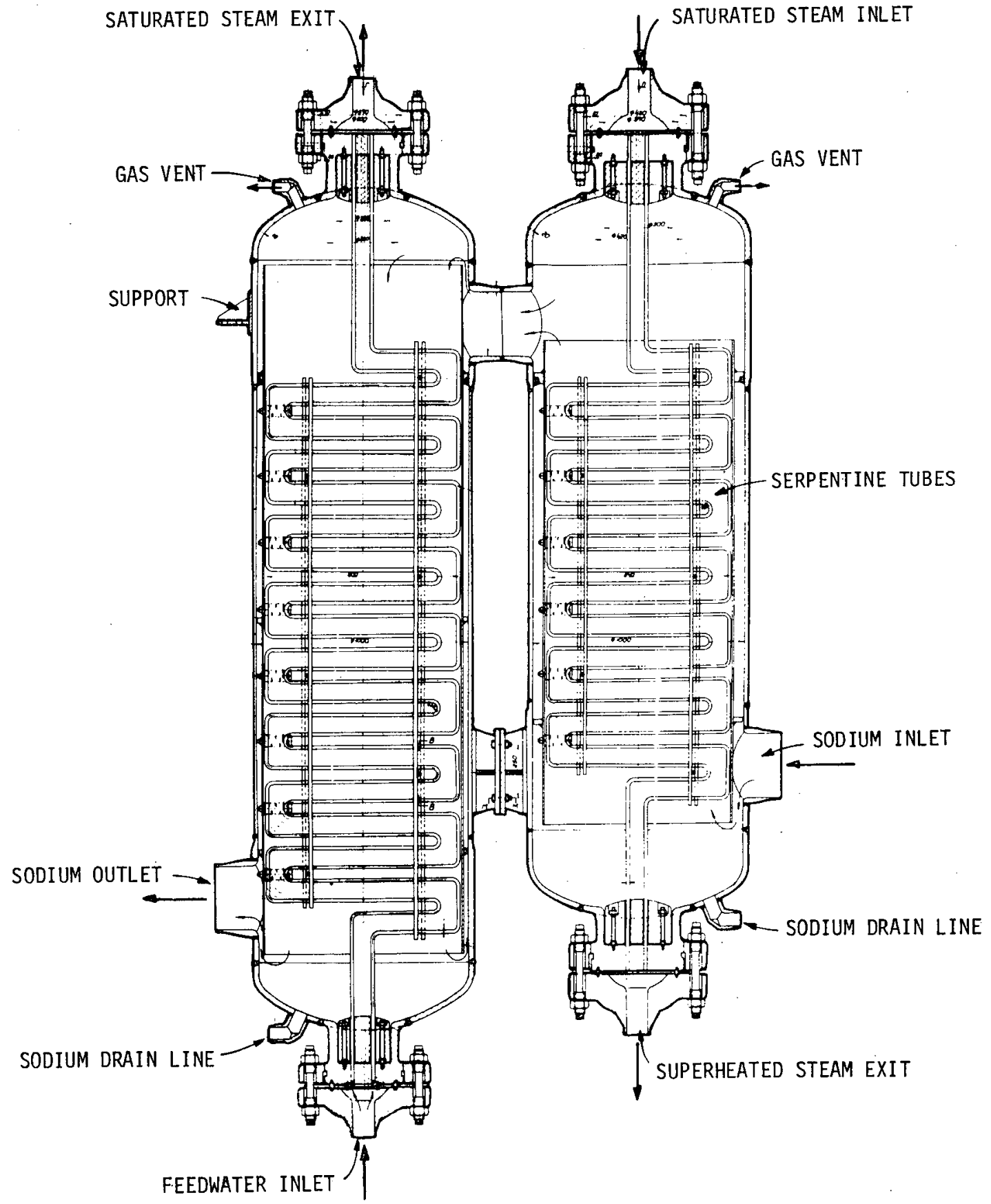

Figure V.H-1. BOR-60 Steam Generator (Ref. 4)

V. $\mathrm{H}-2$ 
V. I. REACTOR INSTRUMENTATION AND CONTROL

The automatic control system is designed to maintain a given power level and coolant outlet temperature. A temperature controller, accepting signals from a temperature-setting device and sensors, controls the power setting device by moving it to a position so that the coolant outlet temperature coincides with the set temperature. The temperature-sensor time constant is v10 sec.
The safety system shuts down the reactor in the event of either an unacceptable deviation from preselected parameters or when hazardous disruptions occur in the heat transfer systems.

Delayed-neutron detection instruments for detecting fuel failures are located at the IHX outlet pipe. Fission-gas detectors capable of detecting ${ }^{13} \mathrm{Xe}$ and ${ }^{85} \mathrm{Kr}$ are located in the cover gas. (Refs. 4, 12.) 
V. J. FUEL HANDLING

Fuel is handled by means of double rotating plugs. All charging and discharging operations are conducted through a special port in the small rotating plug, which contains all of the connections. The fuel charge-discharge machine (Fig. V.J-1) is brought into place and sealed to the port by a small plug. The machine, a coffin with a gripping device, is mounted on a gantry crane and is able to move along coordinate axes. The assembly is raised into the coffin in an inert atmosphere and transferred in the coffin to external storage. Charging and discharging are carried out by the same machine. Assemblies to be loaded are first heated to $300^{\circ} \mathrm{C}$ in an electric furnace. A closed gas circuit in the charge-discharge machine removes decay heat (estimated at about $5 \mathrm{~kW}$ ) from discharged elements. The fuel is cleaned by steam and nitrogen in the transfer coffin. (Ref. 4.)

Experience with the fuel-handling devices has shown that it is better to distribute refueling operations among separate simple machines rather than to utilize a single all-purpose machine. Some changes have been made to simplify operation and improve control of the procedure. Also, a system for inspecting the assembly inside the coffin by television has been installed. (Ref. 8.)

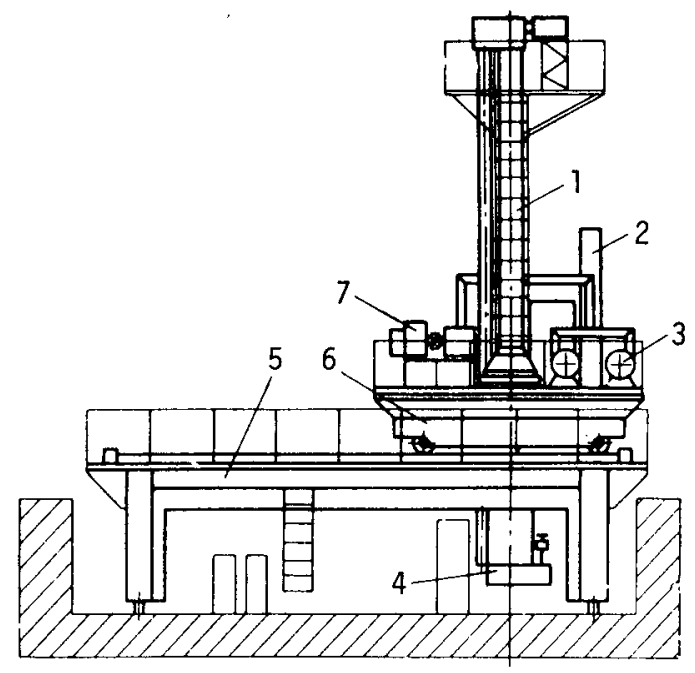

1. CONTAINER

2. ARGON-AIR HEAT EXCHANGER

3. AIR BLOWER

4. CLOSURE OF CONTAINER

5. BRIDGE

6. CARRIAGE

7. COMPRESSOR

Figure V.J-1. BOR-60 Fuel Handling Machine (Ref. 4) 
BN-350. VI

LOCATION: Shevchenko, USSR

OPERATION: JUTY, 1973

BN-350 was brought into operation in July 1973 at Shevchenko, in the Kazakh SSR. Actual work on the project was begun in 1964. The reactor supplies 150 MWe to the grid, and power for the distillation of seawater. By the end of 1973 the station was operating at 20-30\% capacity. Delays in further development were due to water leakages to the sodium and to the steam generator evaporators.

Construction is based on the design and experience from BR-5 operation. It is adaptable to loadings with various fuels. First core loading was enriched $\mathrm{UO}_{2}$. Later cores will probably be mixed oxide. 
$$
\text { . }
$$ 
INDEX

Page

REFERENCES

VI-5

REACTOR PARAMETERS

VI-7

SECTIONS

A. CORE AND BLANKET VI.A-T

B. CORE SUPPORT AND VESSEL INTERNALS VI.B-1

C. REACTOR VESSELS AND SHIELDING VI.C-1

D. CONTROL ELEMENTS VI.D-1

E. HEAT TRANSFER SYSTEMS VI.E-1

F. SODIUM PURIFICATION AND INSTRUMENTATION VI.F-I

G. COVER GAS AND AUXILIARY SYSTEMS VI.G-1

H. STEAM GENERATORS VI.H-1

I. REACTOR INSTRUMENTATION AND CONTROL VI.I-1

J. FUEL HANDLING VI.J-1

K. CONTAINMENT VI.K-1 
1. The BN-350 and BOR Fast Reactors

A. I. Leipunskii, et. al.

Fast Breeder Reactors, Proc. London Conference, BNES, May 1966, p. 243-274

British Nuclear Energy Society 1967

2. Nuclear Power Plant BN-350

A. 1. Leipunskii, et. al.

Fast Reactor Technology, Proc. ANS National Topical. Meeting, Detroit, April 1965

Supplement, p. 15-26, ANS-100

American Nuclear Society

3. Soviet Power Reactors 1970

Report of the USA Nuclear Power Reactor Delegation Visit to the USSR

June 15-JuTy 1, 1970, AEC, DRDT, WASH-7175 (1970)

4. Development of Fuel Elements for Fast Power Reactors

I. S. Golornin, et. al.

Soviet Atomic Energy Voi., p. 196-202 (Sept. 1973)

5. The $B N-350$ Reactor

W. Mitchell III

Reactor and Fuel Processsing Technology 12:323-34 (Fal1 1969)

6. The BN-350 Atomic Electric Power Plant

A. I. Leipunskij, et. a1.

CEMA Symposium, Atomic Power Stations with Fast Reactors, Vol. 1, p. 123-150 (1969), JPRS-48330 (1969)

7. Design and Pre-Reactor Testing of Control Units of the BN-350 Reactor

V. 1. Yevseyev, et. al.

Absorbing Materials and Control Rods for Fast Reactors, Papers presented at the meeting of the International Working Group for Fast Reactors, Omitrovgrad, 1973, JPRS-59863 (Aug. 1973), p. 31-37

8. Technical Problems of Fast Reactors

Yu. Ye. Bagdasarov, et. al.

Atomic Energy Publishing House, Moscow, 1969,

WASH-1179 (1969), Given to the U.S. Nuclear Power Reactor Delegation 1970

9. Heat Exchange Equipment for the $B N-350$ Reactor

A. I. Leipunskii, et. a?.

CEMA Symposium, Atomic Power Stations with Fast Reactors, Vo1. 1, p. 269-286 (1969), JPRS-48330 (1969)

10. Systems of Monitoring and Measuring Instruments for Fast Reactors

A. N. Mitropol'skiy, et. al.

CEMA Symposium, Atomic Power Stations with Fast reactors, Vol. 1., p. 312-333 (1969), JPRS-48330 (1969)

11. Sodium Technology and Equipment for the BN-350 Installation

A. I. Leipunskii, et. a1.

Fast Breeder Reactors, Proc. London Conf., BNES, May 1966, p. 797-808,

British Nuclear Energy Society 1967

12. The BN-350 Atomic Electric Plant

A. I. Leipunskii, et. a).

CEMA Symposium, Atomic Power Stations with Fast Reactors, Vo1. 1, p. 123-15 (1969), JPRS-48330 (1969) 
-

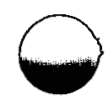




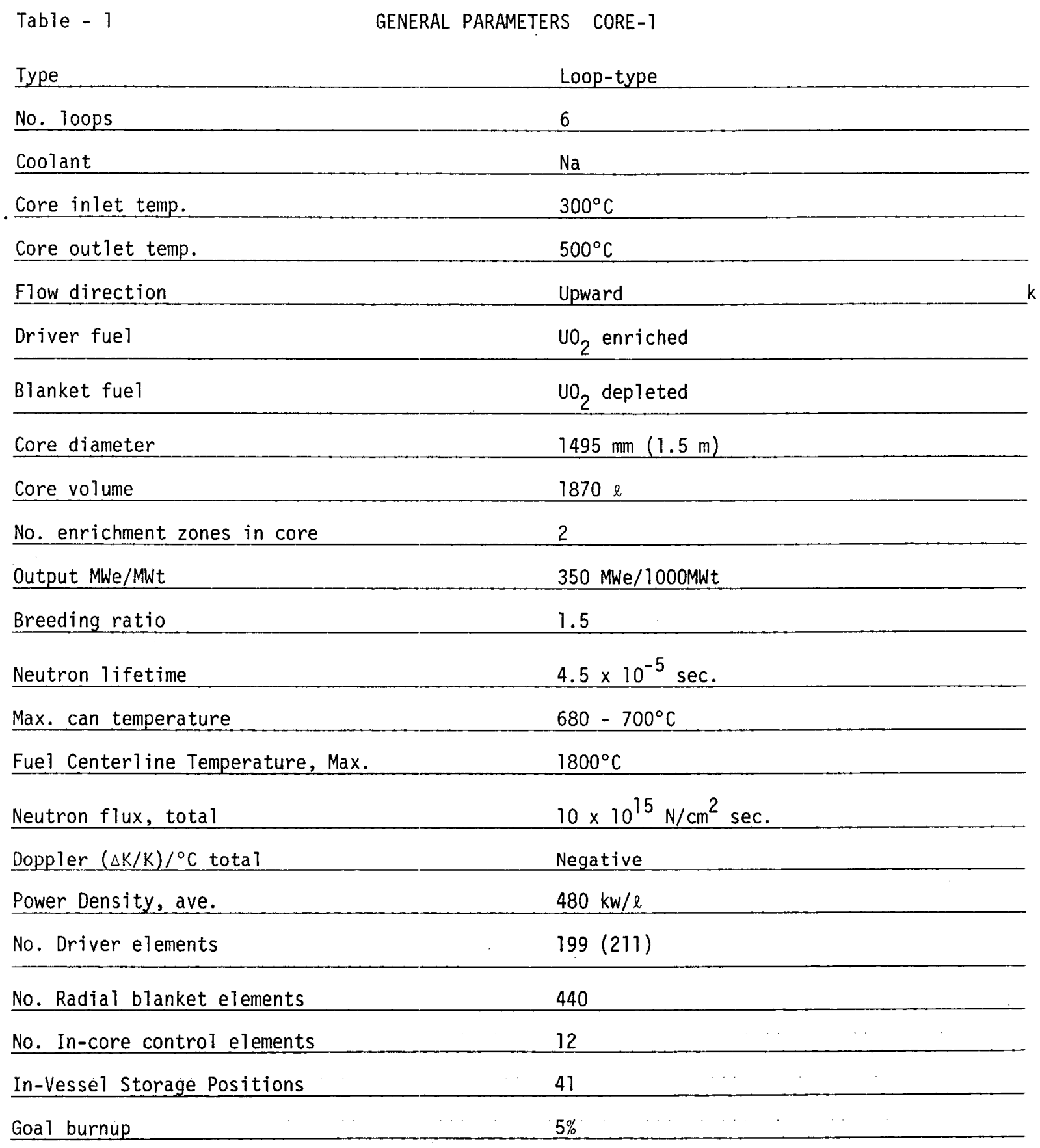




\begin{tabular}{|c|c|c|c|}
\hline \multirow[t]{2}{*}{ Table -2} & \multicolumn{3}{|c|}{ CORE AND BLANKET CORE- 7} \\
\hline & Driver zone & Axial blanket & Radial blanket \\
\hline Fuel material & $\mathrm{UO}_{2}$, enriched & $\mathrm{UO}_{2}$, depleted & $\mathrm{UO}_{2}$, depleted \\
\hline Form & Annular pellet & & \\
\hline $235_{U}$ inner zone & $26 \%$ & & \\
\hline outer zone & $17 \%$ & & \\
\hline Density (effective) & $8 \mathrm{~g} / \mathrm{cm}^{3}(75 \%$ TO $)$ & $9.5 \mathrm{~g} / \mathrm{cm}^{3}$ & \\
\hline Pellet od & $4.28 \mathrm{~mm}$ & & \\
\hline Rod cladding & stainless steel & stainless steel & stainless steel \\
\hline od & $6.7 \mathrm{~mm}$ & $12 \mathrm{~mm}$ & $14.2 \mathrm{~mm}$ \\
\hline Wall thickness & $0.35 \mathrm{~mm}$ & $0.4 \mathrm{~mm}$ & $0.5 \mathrm{~mm}$ \\
\hline Fuel-clad gap & $0.6 \mathrm{~mm}$ & & \\
\hline Column length & $1060 \mathrm{~mm}$ & $600 \mathrm{~min} \times 2$ & \\
\hline Gas plenum length & $20-25 \%$ of volume & & \\
\hline Pin 1ength & $1140 \mathrm{~mm}$ & & \\
\hline Vented/non-vented & No & & \\
\hline Assembly material & stainless steel & stainless steel & stainless stee? \\
\hline Shape & Hexagonal & Hexagonal & Hexagonal \\
\hline Across flats (dia. & $96 \mathrm{~mm}$ & & $96 \mathrm{~mm}$ \\
\hline Wall thickness & $2 \mathrm{~mm}$ & & $2 \mathrm{msn}$ \\
\hline Overali length & $3500 \mathrm{~mm}$ & & $3500 \mathrm{~mm}$ \\
\hline No. pins/assembly & 169 & $37 \times 2$ & 37 \\
\hline Pin spacing & $\begin{array}{l}\text { Spiral wire, alternate } \\
\text { pins, wire dia. } 0.85 \mathrm{~mm} \text {, } \\
\text { spiral pitch } 100 \mathrm{~mm}\end{array}$ & & \\
\hline Pin pitch & $7.0 \mathrm{~mm}$ & & $14.8 \mathrm{~mm}$ \\
\hline Assy. pitch & $98 \mathrm{~mm}$ & & $98 \mathrm{~mm}$ \\
\hline Assy. in core & $199(211)$ & (with core assembly) & 440 \\
\hline Volume fraction & & & \\
\hline Fuel & $44.7 \%$ & $44.7 \%$ & $60.8 \%$ \\
\hline Steel & $24.2 \%$ & $24.2 \%$ & $17.6 \%$ \\
\hline Sodium & $31.1 \%$ & $31.1 \%$ & $21.6 \%$ \\
\hline
\end{tabular}


VI. A. CORE AND BLANKET ASSEMBLIES

$\mathrm{UO}_{2}$ was decided upon for the first loading. There are two enrichment regions in the core, the elements differing in the design of the end fittings. The radial blanket elements are reportedly interchangeable to provide for adjusting the critical size of the core. (Ref. 5.)

The driver assembly is a stainless steel hexagonal can containing the fuel and fertile pins. Spacing is by spacer pads, for a close-packed core. (Fig. VI.A-l)

Fuel pins are $6.1 \mathrm{~mm}$ diameter, with a cladding wall thickenss of $0.55 \mathrm{~mm}$. The fuel pin bundle is made up of 169 pins. Spacing is by helical wire wrapping of alternate pins to give a pin pitch of $7.0 \mathrm{~mm}$. Fuel pins are welded at the bottom to a spacer grid; upper are free ends. The cans are sealed at the end by argon arc welds. There is practically no gas plenum. The free volume consists of the central hole formed by the annular fuel pellets and a 20-25 $\mathrm{mm}$ space at the upper end of the element. Fuel-clad gap is 0.1-0.5 mm. (Fig. VI.A-2)

Axial blanket pins are $12 \mathrm{~mm}$ diameter with a wall thickness of $0.4 \mathrm{~mm}$. They are physically separated from the fuel pins. There are two 37-pin bundles, at the top and bottom of the core subassembly. (Ref. 4.)
For the second loading, the hexagonal can will contain 127 pins, $6.9 \mathrm{~mm}$ in diameter, with a gas space in the lower, colder, part of the element. The lower blanket is combined with the fuel core in a single jacket. The lower $230 \mathrm{~mm}$ of the core directly joining the end blanket will consist of solid rather than annular pellets. The effective density of this portion is $86 \%$ TD(from 75\% TD). (Fig. VI.A-2.)

An alternate design provides for the incorporation of both end blankets into a single jacket. (Ref. 4.)

The upper head of the core subassembly is designed to accommodate the reload manipulators. The lower ends are shanks which fit into the support grid. Lateral openings in the bottom shank admit sodium which leaves through a port in the top head. At the end of the bottom shank and in its upper section there are spiral seals to reduce sodium leakage. Throttling devices in the subassembly shanks and in the support grid distribute sodium flow. In the shank, this device consists of a number of holes in the closed-end tube. (Fig. IV.A-4.) (Ref.6.)

The radial blanket element differs in shank design from the core subassemblies to locate them correctly in the support grid.

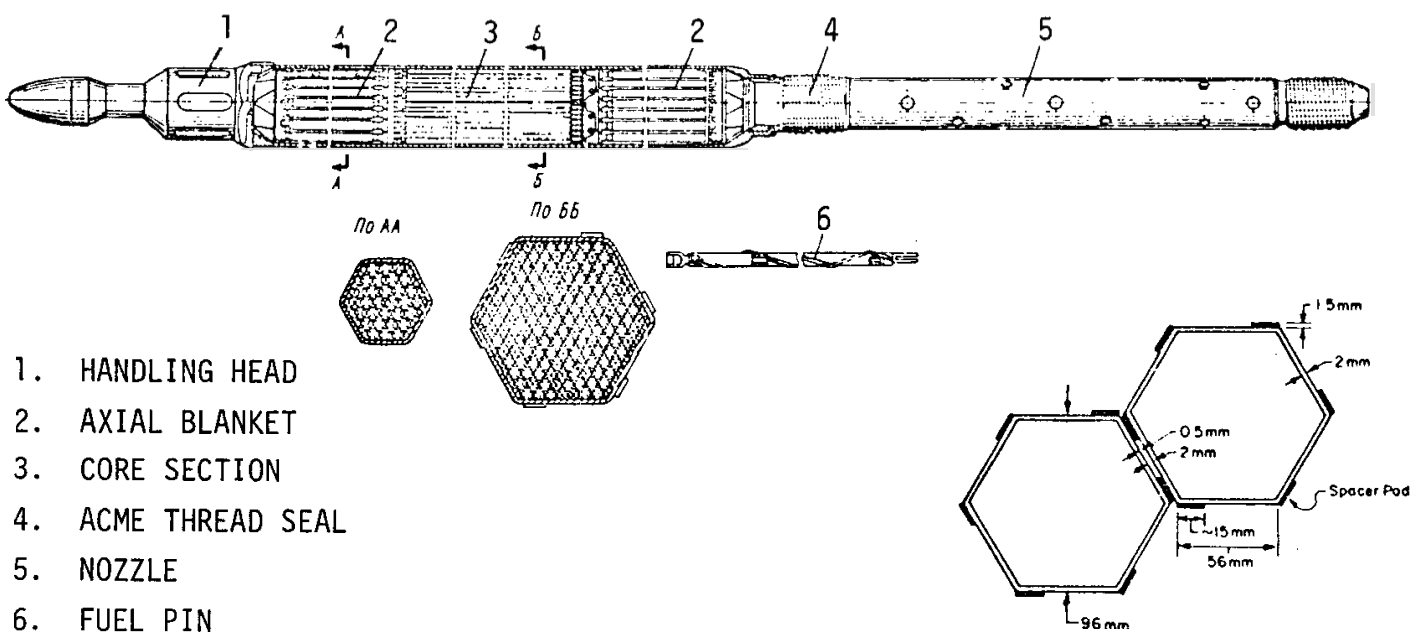

Figure VI.A-I BN-350 Core Subassembly' (Ref. 3) 
BN-350 VI.A.

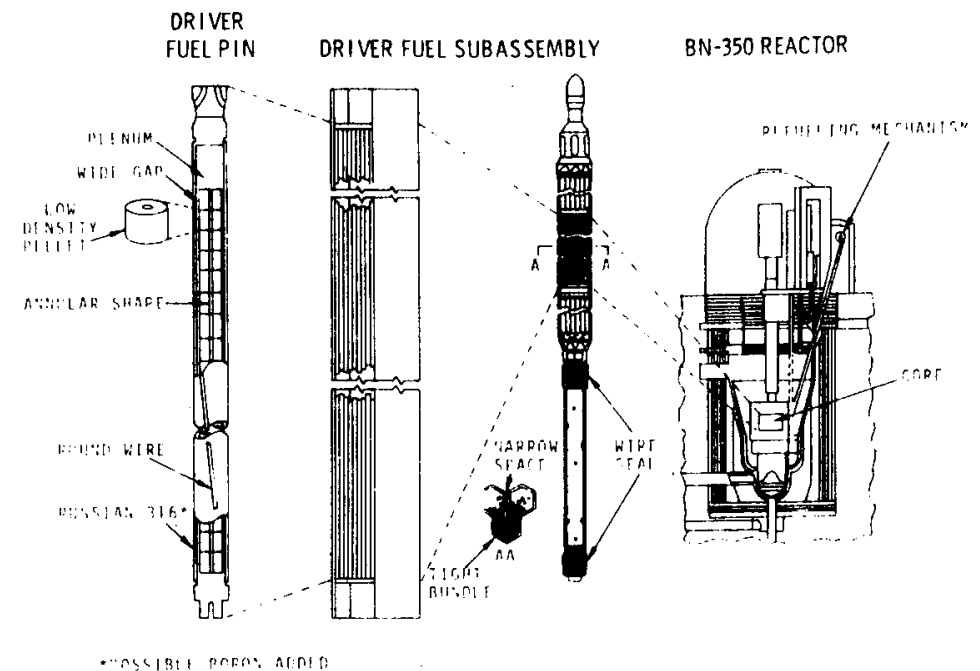

Figure VI.A-2 BN-350 Fuel Assembly and Fuel System (Ref. 3)

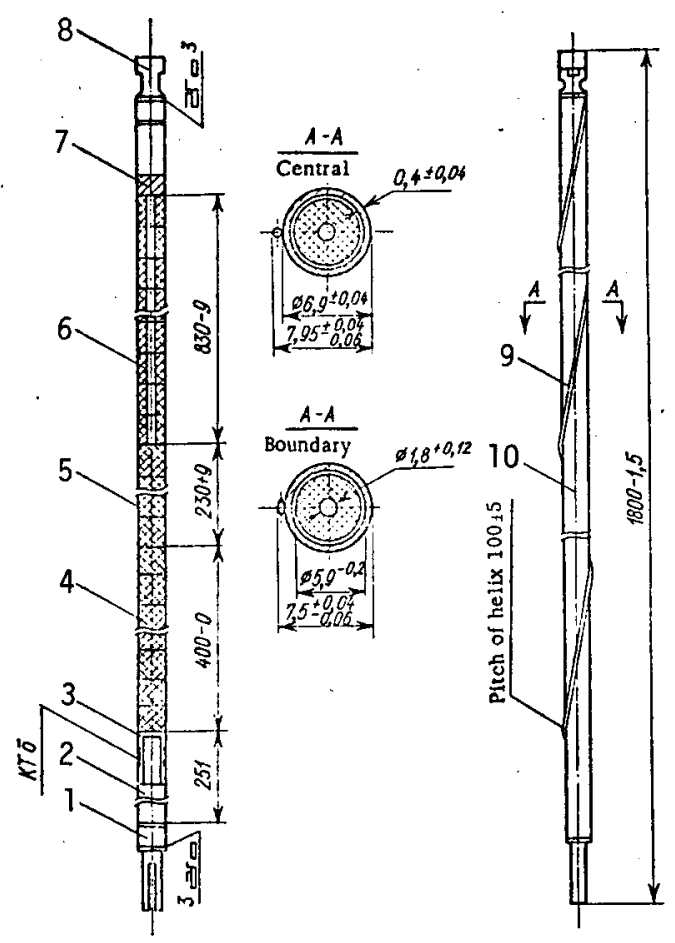

1. LOWER CAP

2. GAS SPACE

3. CAN

4. LOWER END SHIELD BRIQUET

5. CORE BRIQUET

6. SLEEVE

7. POROUS PLUG

8. UPPER CAP

9. SPACING WIRE (TAPE)

10. CLADDING

Figure VI.A-3 Fuel Element Design for Second Loading of BN-350

VI. A-2 
BN-350 VI.A.

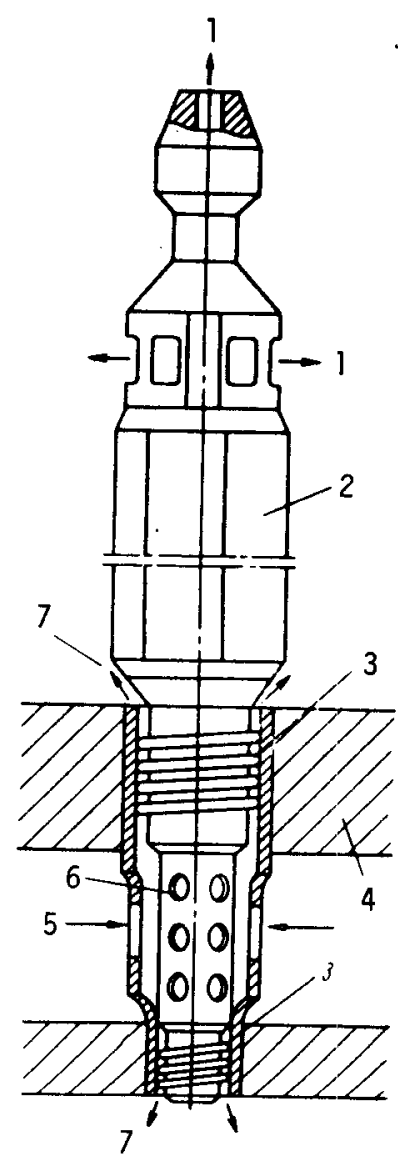

1. FLOW OUTLET

2. SUBASSEMBLY

3. SEAL (ACME THREADS)

4. UPPER SUPPORT PLATE

5. COOLANT INLET TO BUSHING

6. COOLANT INLET TO SUBASSEMBLY

7. LEAK-THROUGH SEAL

Figure VI.A-4 BN-350 Seals for Controlling Leakage in the Core Subassembly (Ref. 3)

VI. A-3 
$B N-350$ VI.B.

VI. B. CORE AND BLANKET ASSEMBLIES

Core restraint is provided by the core support structure. There is no lateral restraint provided except for the subassembly cans, radial blanket assemblies, and radial shielding. The subassemblies are free at the top.

The support structure is a pressure header consisting of an upper and lower plate, forming a high-pressure section. Openings

in the top plate accommodate the lower bends of the subassemblies, which fit into the lower plate. Leak-proof seals are located on the assembly shank. (See Section VI.A, Fig. VI.A-4.) Throttling devices in the pressure header and in the subassembly shank regulate coolant flow.

The header is supported on flanges inside the vessel. (Fig. VI.B-T, B-2.) (Ref. 3.)

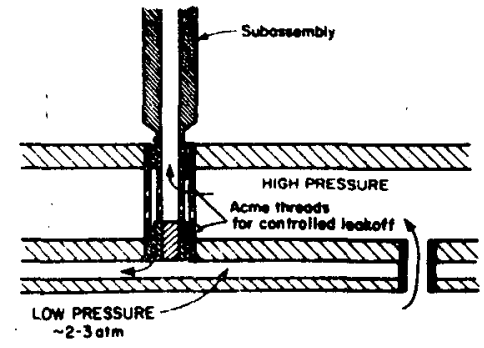

HIGH PRESSUAE INLET PLERIUN

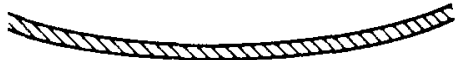

Figure VI.B-1 BN-350 Fuel Assembly Hydraulic Holddown (Ref. 3)

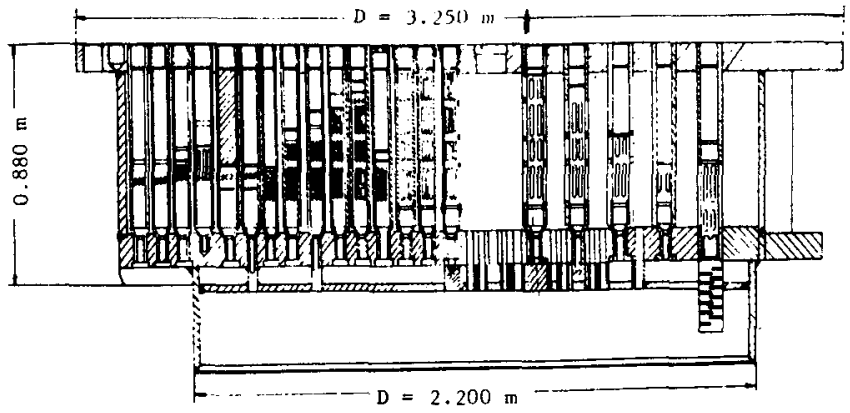

Figure VI.B-2 BN-350 Pressure Header (Ref. 2)

VI.B -1 


\section{C. REACTOR VESSELS AND SHIELDING}

The core, blanket, refueling mechanism, and other components are enclosed in a sodium-filled vessel of changing diameter. The vessel is steel-lined stainless steel, $2.2 \mathrm{~m}$ to $6 \mathrm{~m}$ in diameter. Overall height is $13 \mathrm{~m}$, with $300 \mathrm{~mm}$ thick walls. There are six inlets for the primary sodium near the bottom. Inlet piping is $500 \mathrm{~mm}$ in diameter. Outlet piping, located above the core, is $600 \mathrm{~mm}$ in diameter. (Fig. VI.C-1.) Secondary sodium containment is provided by a $10 \mathrm{~mm}$ thick envelope around the vessel. (Ref. 5.)

The reactor vessel support was originally by means of a flange at mid-height, with support columns (Fig. VI.C-2). This has apparently been changed, with a cylinder or flexible plates being used. (Ref. 3.)
A thermal shield consisting of $60 \mathrm{~mm}$ thick stainless steel forms an annular gap around the reactor vessel. Two per cent of the total sodium flow is directed into this space to cool the reactor vessel to $420^{\circ} \mathrm{C}$. Internal radiation shielding is provided around the blanket and the upper region of the vessel. Two rotating plugs are supported by the upper part of the vessel. The reactor cave is formed by $2 \mathrm{~m}$ of concrete.

The rotating plugs rotate on ball bearings. A low-melting point tin-bismuth eutectic alloy is used in an electrically heated seal during rotation. It is solid during operation. There is a rubber seal for back-up during normal operation. (Ref. 3, 5.)

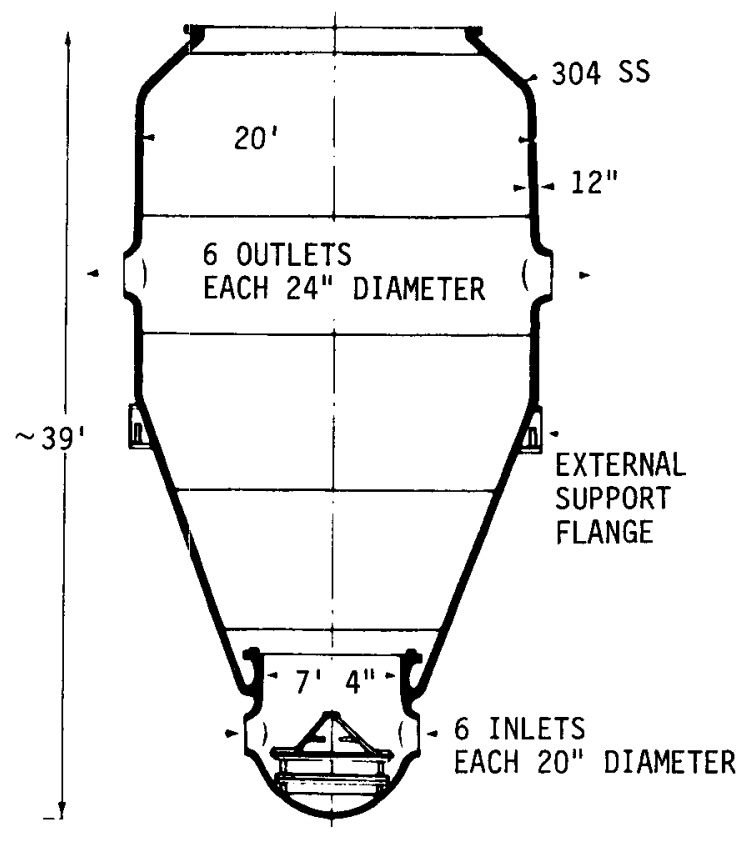

Figure VI.C-1 BN-350 Reactor Vessel (Ref. 3)

VI.C-1 
$B N-350$ VI.C.

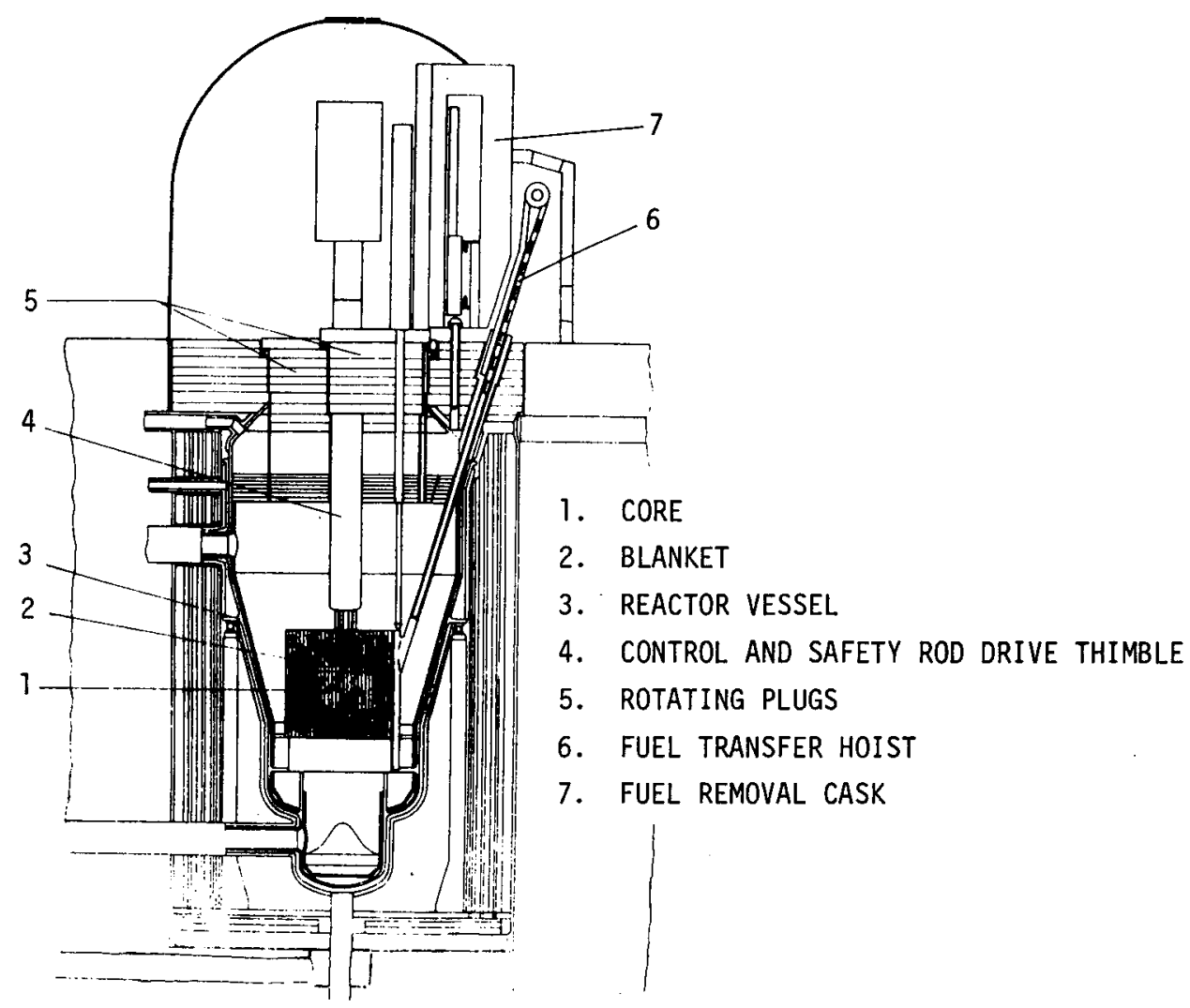

Figure VI.C-2 BN-350 Reactor Showing Vessel Support (Ref. 2)

$$
\text { VI.C-2 }
$$




\section{D. CONTROL ELEMENTS}

A sealed design was adopted for $\mathrm{BN}-350$ control rods. For the regulating, compensating and safety rods the absorbing material is boron carbide enriched in ${ }^{10} \mathrm{~B}$. In rocis to compensate for fuel burnup, the material is the same as for the core. Stainless steel is the jacketing material. There is no jacketing on the operating length of the automatic and safety rods, and none in the upper operating link of the compensating rod. Rods are arranged in vertical guide bushings in the core; they are cooled directly with the primary sodium. Free volumes are provided for collection of helium.

There are two automatic control rods, three safety rods, and a total of seven power and temperature compensating and burnup compensating assemblies; six of the compensating rods are fueled units. Drop time for the safety rod is 0.7 second, speed of motion is $1.3 \mathrm{~mm} / \mathrm{second}$, with a stroke of $1260 \mathrm{~mm}$. (Fig. VI.D-1.) (Ref. 7.)
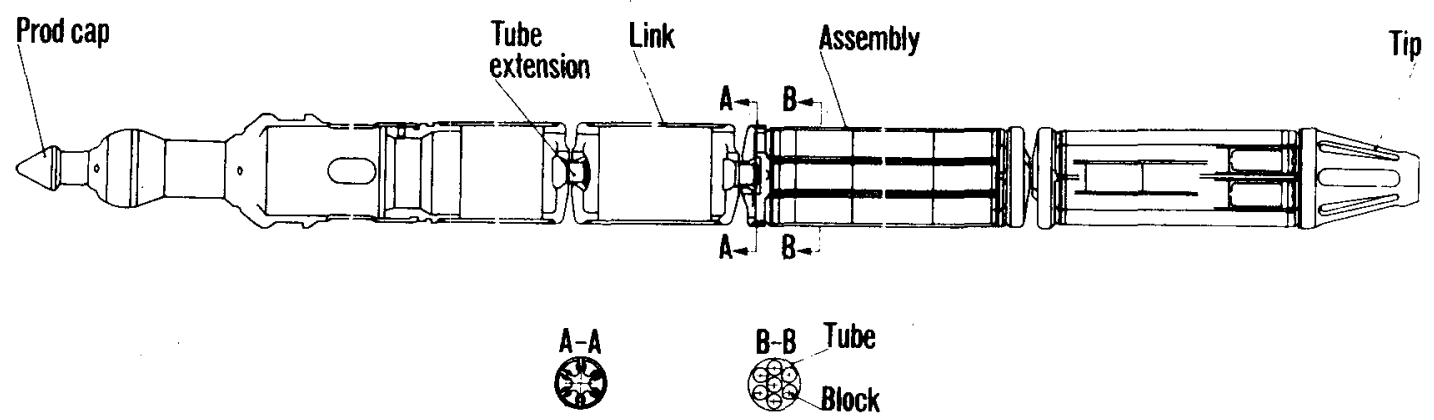

(a) Safety rod

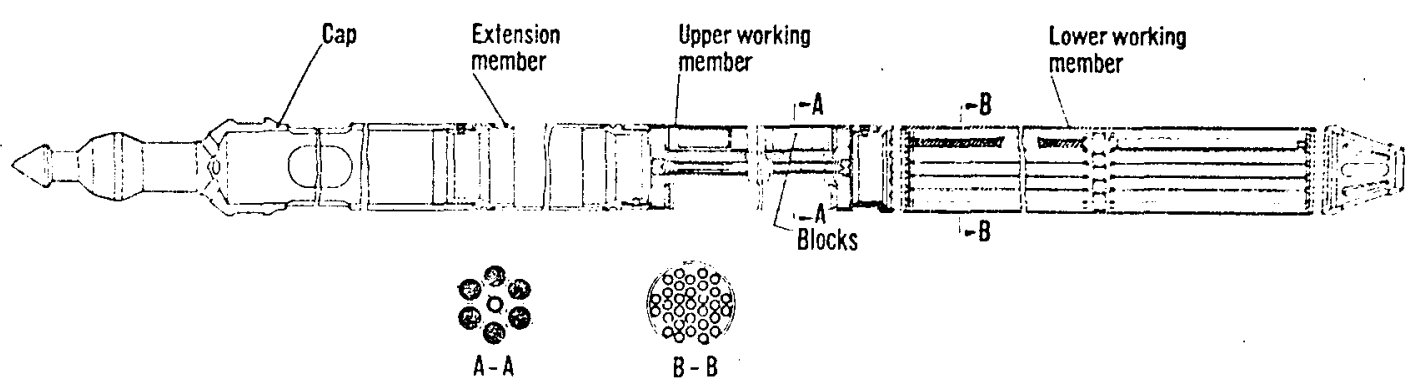

COMPENSATOR ROD (TEMPERATURE)

(b) Temperature compensating rod

Figure VI.D-1 BN-350 Control Assemblies (Ref. 1)

VI.D-1 


\section{E. HEAT TRANSFER SYSTEMS}

Primary sodium enters at the bottom of the reactor vessel through six inlet pipes, $500 \mathrm{~mm}$ diameter. It is distributed by a pressure header to the core subassemblies, flowing upward through the core to six outlet pipes above the core. These pipes are $600 \mathrm{~mm}$ in diameter.

There are six parallel primary loops, five being used during operation and one held in reserve. Each primary loop contains an intermediate heat exchanger, a pump, a check valve, and two gate valves with freeze seals. Auxiliary equipment of the primary loops includes drain tanks and cold traps. Sodium inlet temperature is $300^{\circ} \mathrm{C}$, outlet $500^{\circ} \mathrm{C}$. Flow is upward through the core at the rate of 14,150 metric tons/hour. A1l primary loops and components are located in sealed, steel-1ined cells.

The intermediate circuit consists of six loops, five in use at rated power and one on standby. The circuit transfers heat to the steam-water system, sodium from the heat exchanger entering the superheater section of the steam generator at $453^{\circ} \mathrm{C}$. It leaves at $416^{\circ} \mathrm{C}$ and passes through an evaporator section where the temperature is reduced to $273^{\circ} \mathrm{C}$. The intermediate sodium is then pumped back to the heat exchanger. Primary loop and components are in sealed cells under nitrogen atmosphere.

(Fig. VI.E-1) (Ref. 5)

The intermediate heat exchanger is composed of two sections connected in parallel. Each section is a horizontal tank in which three heat-transfer bundles are immersed. Each bundle contains 343 $U$-shaped tubes mounted in sets. A flowsmoothing baffle is located in the shell (primary) side before the first tube bundle. Secondary sodium enters the U-tube bundles from above, primary sodium at the ends of the horizontal tank, creating a cross-flow heat removal regime. The tube bundles are removable, and the heads have biological shielding. (Fig. VI.E-2)
Basic IHX Characteristics

$\begin{array}{lc}\text { Thermal power capacity } & 200 \mathrm{MW} \\ \text { Primary Na, inlet } & 500^{\circ} \mathrm{C} \\ \text { outlet } & 300^{\circ} \mathrm{C} \\ \text { Intermediate } \mathrm{Na} \text {, inlet } & 273^{\circ} \mathrm{C} \\ \text { U-tube dimensions } & 453^{\circ} \mathrm{C} \\ & 28 \mathrm{~mm} \mathrm{dia.,} \mathrm{wall} \\ & \text { thickness } 2 \mathrm{~mm}, \\ & \text { spacing (square } \\ \text { lattice) } 35 \mathrm{~mm} \\ \text { Material } & \text { 18-9 stainless } \\ & \text { steel }\end{array}$

Heat exchange surface

$1120 \mathrm{~m}^{2}$

(Ref. 5, 9)

Primary pumps are sealed, single-stage centrifugal units with vertical shafts, located in the cold leg. The pump shaft is mounted on one radial bearing and one radial thrust bearing. The lower bearing does not operate in sodium. Rated capacity is $3200 \mathrm{M}^{3} / \mathrm{hr}$., rated head $110 \mathrm{M}$, shaft speed 250-1000 rpm. (Fig VI.E-3)

The secondary pump has an overhung impeller with complex shaft bearing and cooling arrangements. The shaft is short. It has a Nak freeze seal.

Capacity is $3850 \mathrm{M}^{3} / \mathrm{hr}$., sodium head $70 \mathrm{~m}$, shaft speed $250-1000 \mathrm{rpm}$.

Maximum rating is 1100 kwc. (Ref. 1)

Gate valves and check valves are used in each loop. The gate-valves are bulky, forged bodies: bored-out forgings; cylinder forged down to $\sim 1-i n$. flats on outside. Double-disk wedge gates have provisions for draining between the disks, watercooled stem freeze seals are backed up by mechanical packing in the primary and secondary system. Diameter is $600 \mathrm{~mm}$. Gate valves are electrically operated.

(Fig VI. E-4)

Check valves are easily removable, $600 \mathrm{~mm}$ diameter units. There is hydraulic damping of the valve-disk closing, pin and bearing materials, and provision for low-pressure drop during natural circulation. (Ref. 3) 
NB-350 VI.E.

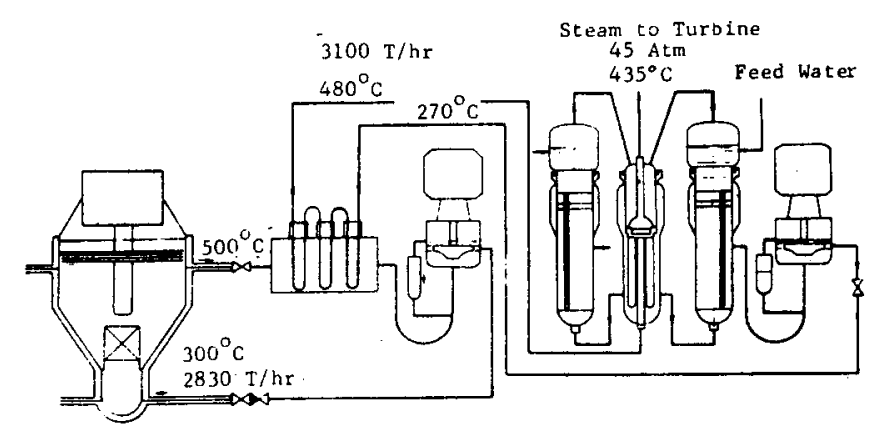

Figure VI.E-1 BN-350 Reactor Flow System (Ref. 2)

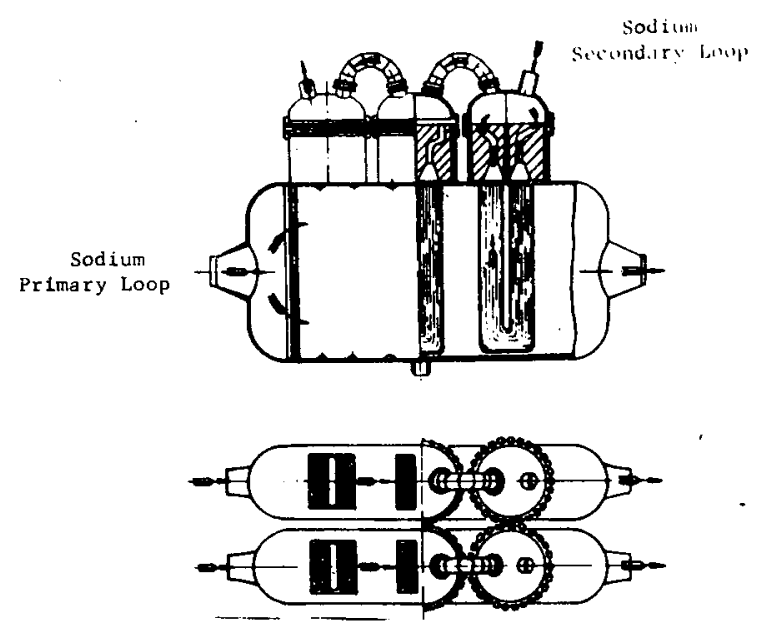

Figure VI.E-2 BN-350 Heat Exchanger (Ref. 2)

VI.E-2 


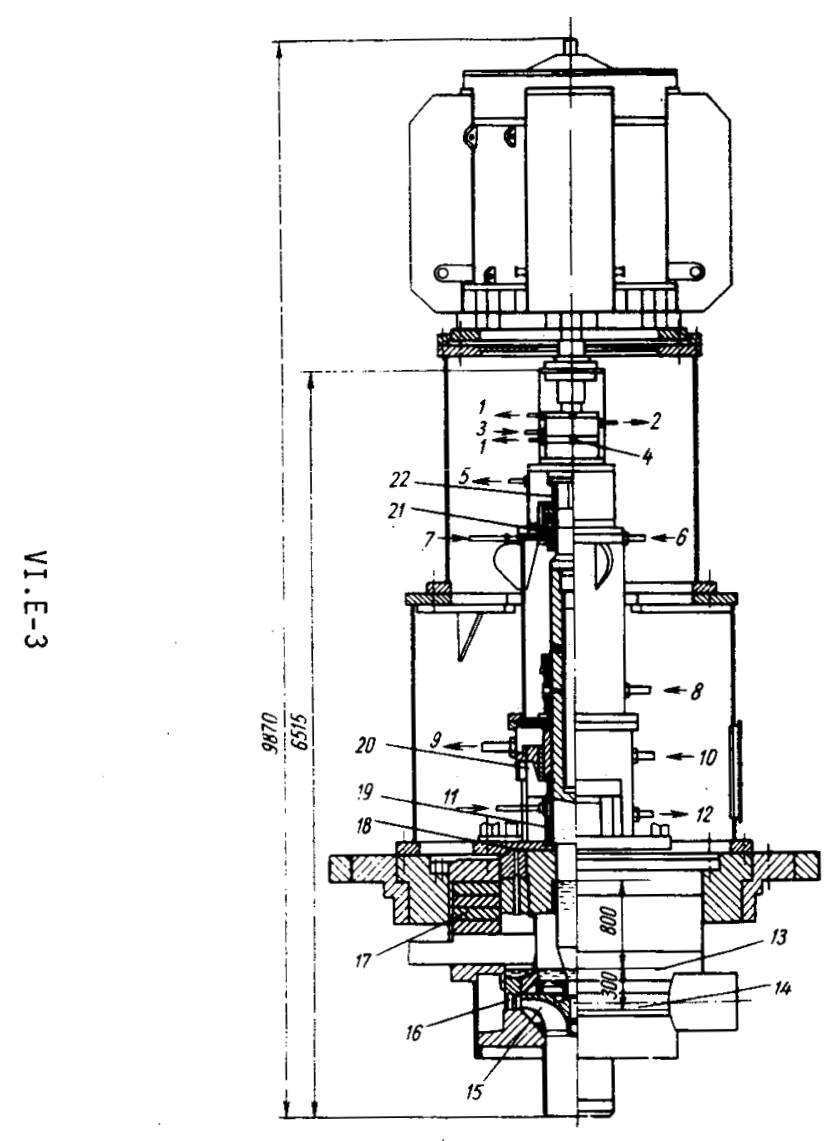

1. LEAKAGE OF OIL FROM THE GAS SEAL ASSEMBLY OF THE SHAFT

2 \& 3. OUTLET AND INLET RESPECTIVELY OF THE COOLING WATER FROM THE SEAL ASSEMBLY OF THE SHAFT

4. OIL TO THE SEAL

5. GAS FOR BLOWING

6. OIL TO UPPER BEARING

7. OIL TO PIVOT

8. OIL FOR COOLING THE SHAFT

9. OIL FROM THE PIVOT UPPER BEARING AND THE SHAFT

10. OIL TO THE LOWER BEARING

11. SODIUM-POTASSIUM ALLOY FOR COOLING THE SHAFT

12. OIL FROM THE LOWER BEARING

13. MAXIMUM LEVEL OF SODIUM LOADING

14. INITIAL SODIUM LEVEL OF THE PUMP

15. IMPELLER

16. GUIDING DEVICE

17. BIOLOGICAL SHIELD

18. SHELL

19. COOLING BELT

20. RADIAL BEARING

21. THRUST BEARING

22. SHAFT 
BN-350 VI.E.

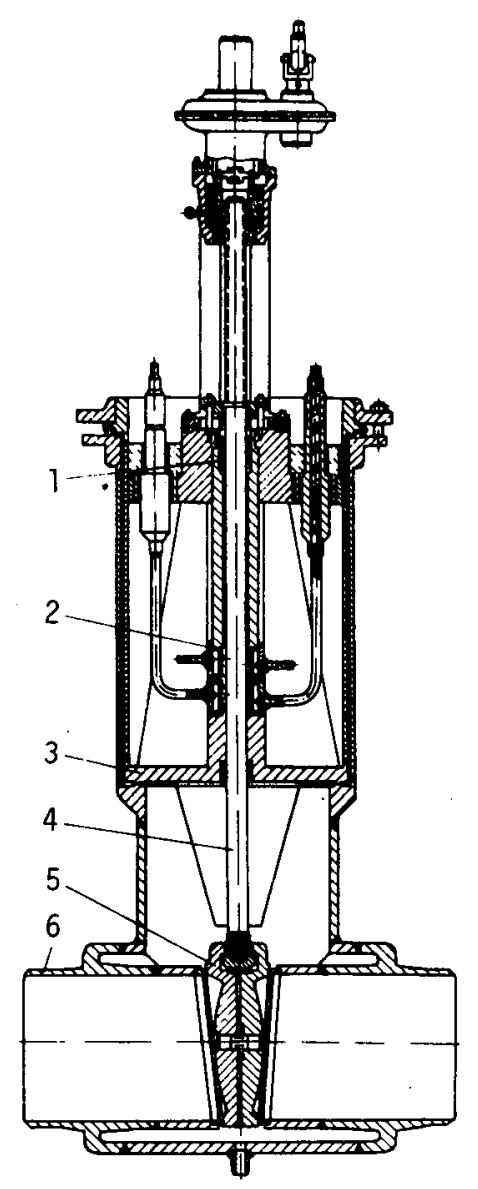

1. PACKING

2. COOLING CHAMBER WITH A DOUBLE WALL

3. REMOVABLE PART

4. STEM

5. WEDGE PLUG

6. CASE

Figure VI.E-4 BN-350 Gate Valve 
VI. F. SODIUM PURIFICATION AND INSTRUMENTATION

Sodium arrives at the site in drums. It is heated in electric furnaces and recirculated through cold traps to less than 50 ppm of oxygen by weight. (Fig. VI. F-1) on-line oxygen is checked by plugging meters.

There are six Nak-cooled cold traps in the primary circuit, with two to four in operation at one time. Housing is a singlewall cylindrical vesse $16 \mathrm{~m}$ high and $1 \mathrm{~m} \mathrm{dia.}$ Nak circulates through coiled pipes located in the cooling zone. An additional coiled pipe is situated in the settling tank. Heat is evacuated by electromagnetic pumps to two Nak-air heat exchangers mounted on the wall of the main reactor room. These exhaust through the wall directly to the outside. (Fig. VI. F-2) (Ref. 3, 8.)

A special manometer was developed for measuring the coolant pressure. It has a pickup device which consists of three basic units: intake tube with lower diaphragm, housing, and upper flange with upper diaphragm, induction coil and lead-out cable. (Ref. 8.)
Magnetic flow-meters measure coolant flow in $\mathrm{BN}-350$. The magnetic system includes two permanent magnets and magnetic circuit, pole and end pieces forming an air-gap. It is arranged with respect to the pipelines so that the electrodes welded to the measuring section are perpendicular to the magnetic flux in the gap. In most cases, emergency shielding and interlock systems will be activated by the flow-meters in the primary circuit. (Fig VI. F-4)

Level measurement is by means of induction level gages. A discrete inductance level meter which operates by relay determination of the presence or absence of a signal has been developed. Pickup is a set of coaxial inductance coils.

Temperature is measured by chromelalumel thermocouples and resistance thermometers. These are mounted in a protective sleeve.

Detection of leaks in the steam generators is by the detection of hydrogen in the sodium. (Ref. 9, 10.) 


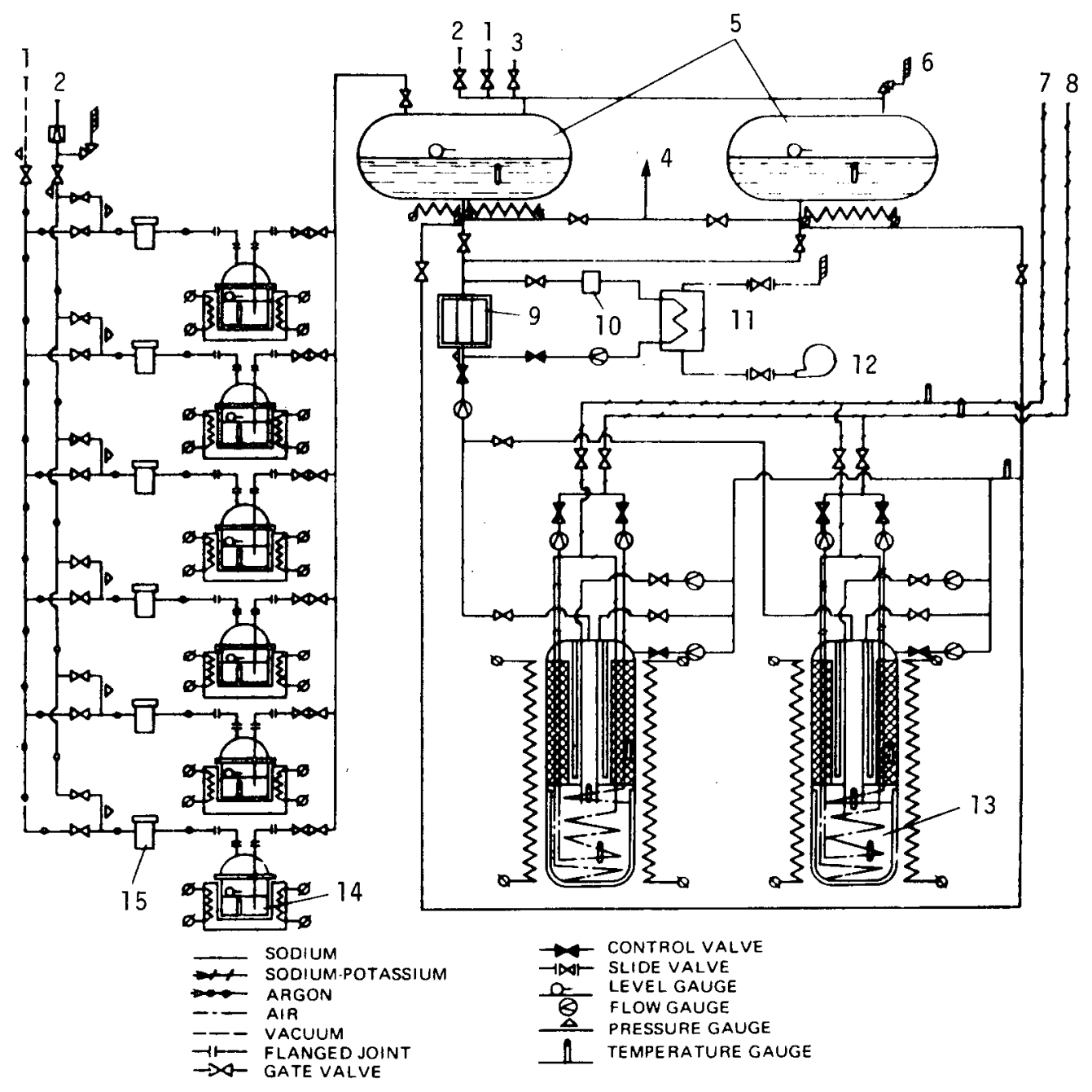

1. TO VACUUM

2. GAS OUTLET

3. GAS INLET

4. TO SECONDARY SYSTEM DRAIN

5. SECONDARY SYSTEM DRAIN TANKS

6. TO ATMOSPHERE

7. NaK OUTLET

8. NaK INLET
9. ELECTROMAGNETIC PUMP

10. OXIDE PLUGGING INDICATOR

11. PLUGGING-INDICATOR HEAT EXCHANGER

12. AIR BLOWER

13. COLD TRAP

14. TRANSPORT CONTAINER

15. STEAM TRAP

Figure VI.F-1 BN-350 Sodium Receiving System (Ref. 3)

$$
\text { VI . F-2 }
$$




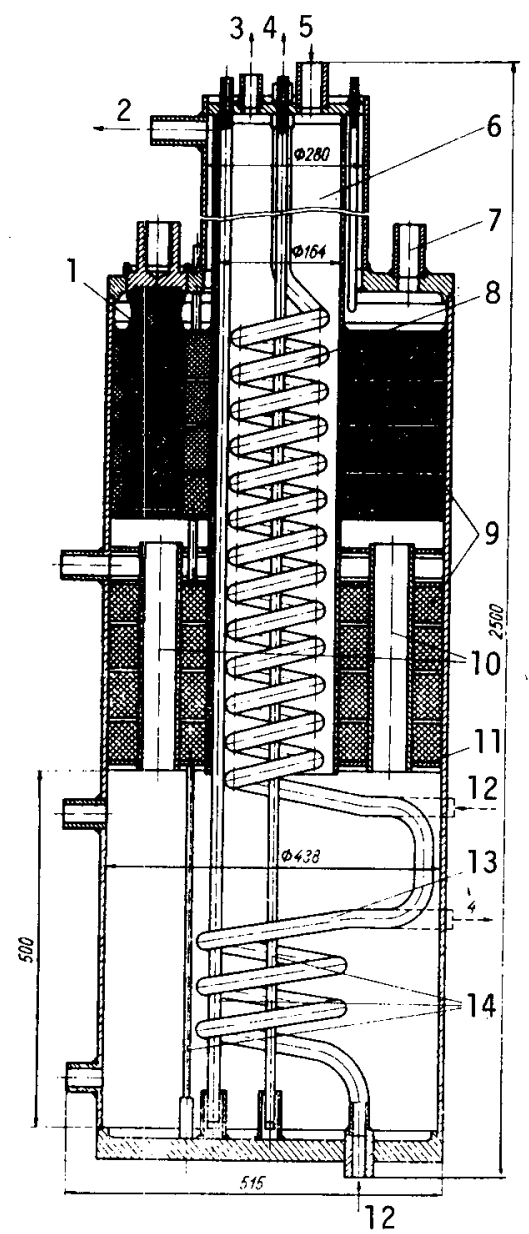

1. CONTROL INSERT

2. SODIUM EXIT

3. DISCHARGE OF SODIUM WITH GAS

4. EXIT OF SODIUM-POTASSIUM ALLOY

5. SODIUM INLET

6. RECUPERATOR

7. RECUPERATOR BYPASS

8. COILED PIPE OF THE COOLING ZONE

9. FILTRATION ZONE

10. OVERFLOW PIPES

11. GRILLSS

12. INLET OF SODIUM POTASSIUM ALLOY

13. COILED PIPE OF THE SETTLING TANK

14. THERMOCOUPLE POCKETS

Figure VI.F-2 Type of Trap Used in BN-350 (Ref. 8)

$$
\text { VI.F-3 }
$$


BN-350 VI.F.

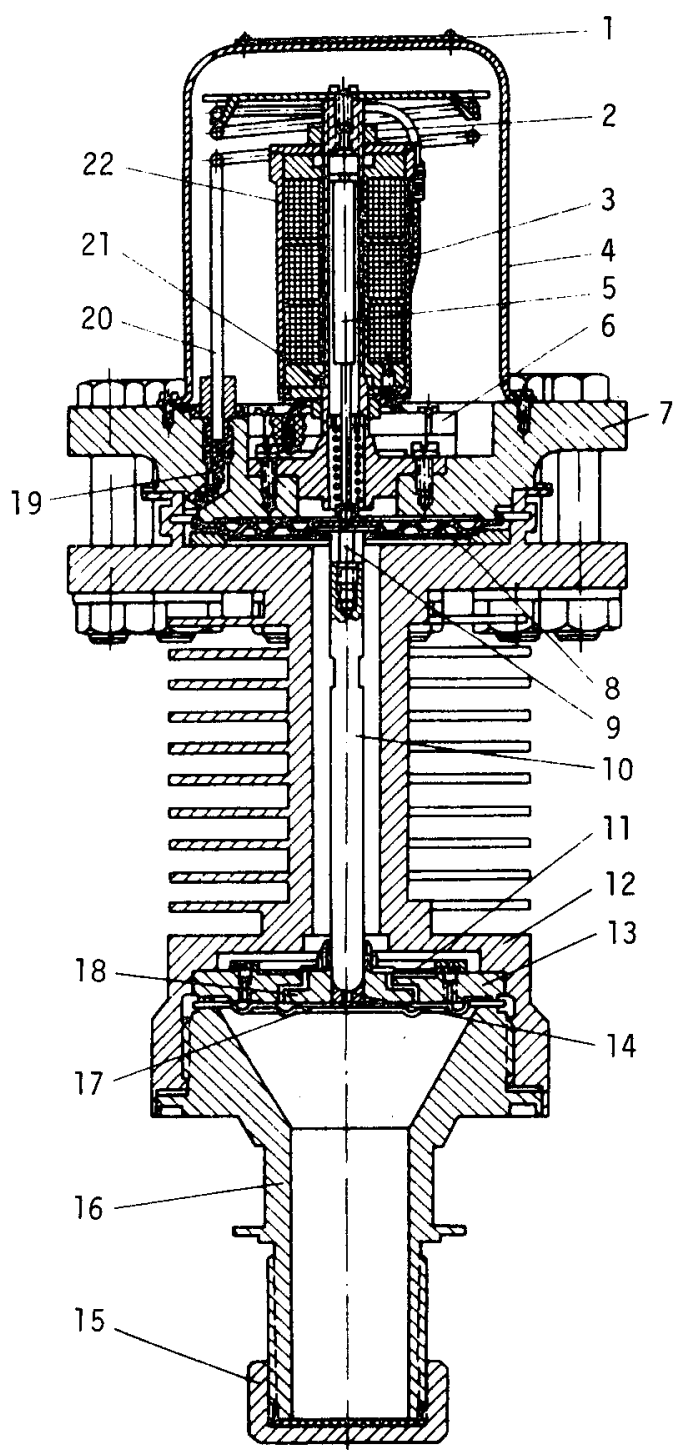

1. SPECIFICATIONS OF THE INSTRUMENT

2. WASHER

3. INDUCTION COIL

4. CASING

5. PLUNGER

6. FLUOROPLAST BLOCK

7. FLANGE

8. UPPER MEMBRANE

9. UPPER FLAT DISK CENTER

10. ROD

11. CENTERING WASHER

12. CASING

13. GROOVED PAD

14. CENTRAL INSERT

15. PROTECTIVE COVER

16. RECEIVING NOZZLE

17. LOWER MEMBRANE

18. LOWER FLAT DISK CENTER

19. SIGNAL WIRE

20. CAPILLARY

21. DIA-MAGNETIC TUBE

22. SCREEN

Figure VI.F-3 BN-350 Sodium Pressure Transmitter (Ref. 8) 


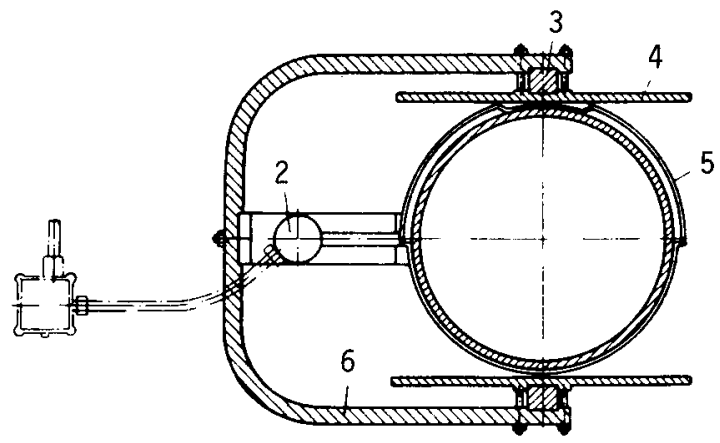

1. TERMINAL BOX

2. CONNECTIVE BOX

3. MAGNET

4. POLE END PIECE

5. ELECTRODE

6. MAGNET

Figure VI.F-4 BN-350 Detecting Element for Flow Gage (Ref. 8)

$$
\text { VI.F-5 }
$$


VI. G. COVER GAS AND AUXILIARY SYSTEMS

$$
\text { Sodium purification and instrumentation: }
$$
See Section VI. F.

Cooling of the seals and fittings of the pumps is provided by an independent Nak system.

Drainage tanks of the primary circuit can drain the sodjum from the whole circuit; ten tanks of $50 \mathrm{M}^{3}$ each are provided. They are connected in pairs to hold gas and metal respectively, each pair being located in a separate box. In an individual box there are two such tanks connected to the gas cavity of the reactor; these keep fluctuations in gas pressure with changes in volume or temperature of the sodium within acceptable limits.

Drainage tanks of the secondary circuit can drain any two loops simultaneously; there are four tanks of $50 \mathrm{~m}^{3}$ each.
Primary and seconaary circuits are filled from the drainage tanks by linear electromagnetic pumps. Primary circuit pumps also pump the coolant through the cold traps.

Cover gas for the reactor is argon.

(Ref. 11.)

The upper section of the rotating plugs is cooled by air blown through special ventilating ducts. Air is discharged through a special system. The reactor vessel is heated with gas circulated between the vessel and the secondary containment. Sealed, steellined cells in which primary piping and equipment are housed are cooled by between-wall cooling; cell atmosphere is nitrogen. 


\section{H. STEAM GENERATORS}

$B N-350$ has six steam generators, each with two parallel evaporator sections, two parallel superheater sections, and a surge tank. The sections are connected by long runs of piping. Sodium from the IHX enters the superheater section at $453^{\circ} \mathrm{C}$ and leaves at $416^{\circ} \mathrm{C}$. It passes through the evaporator section, where the temperature is lowered to $273^{\circ} \mathrm{C}$. The secondary sodium is then pumped back to the IHX. (Fig. VI. H-I)

The evaporator section has bayonet tubes closed at the bottom end, with a concentric downcomer tube inside each tube. A single tube sheet holds the upper ends of the outer tubes, separating the sodium in the lower portion of the shell from the water and steam above. Above the tube sheet and evaporator section, there is a space for natural separation of water and steam, the steam rising and passing through the pipe to the superheater section. Water is recirculated downward to the evaporator tubes, and feedwater added by a header below water level.

The superheater is a counter-flow shelland-tube heat exchanger with sodium on the shell side and water inside the single-wall tubes. The surge tank is a cylindrical vessel serving as part of the cover-gas system of the steam generator during normal operation. (Ref. 5.)

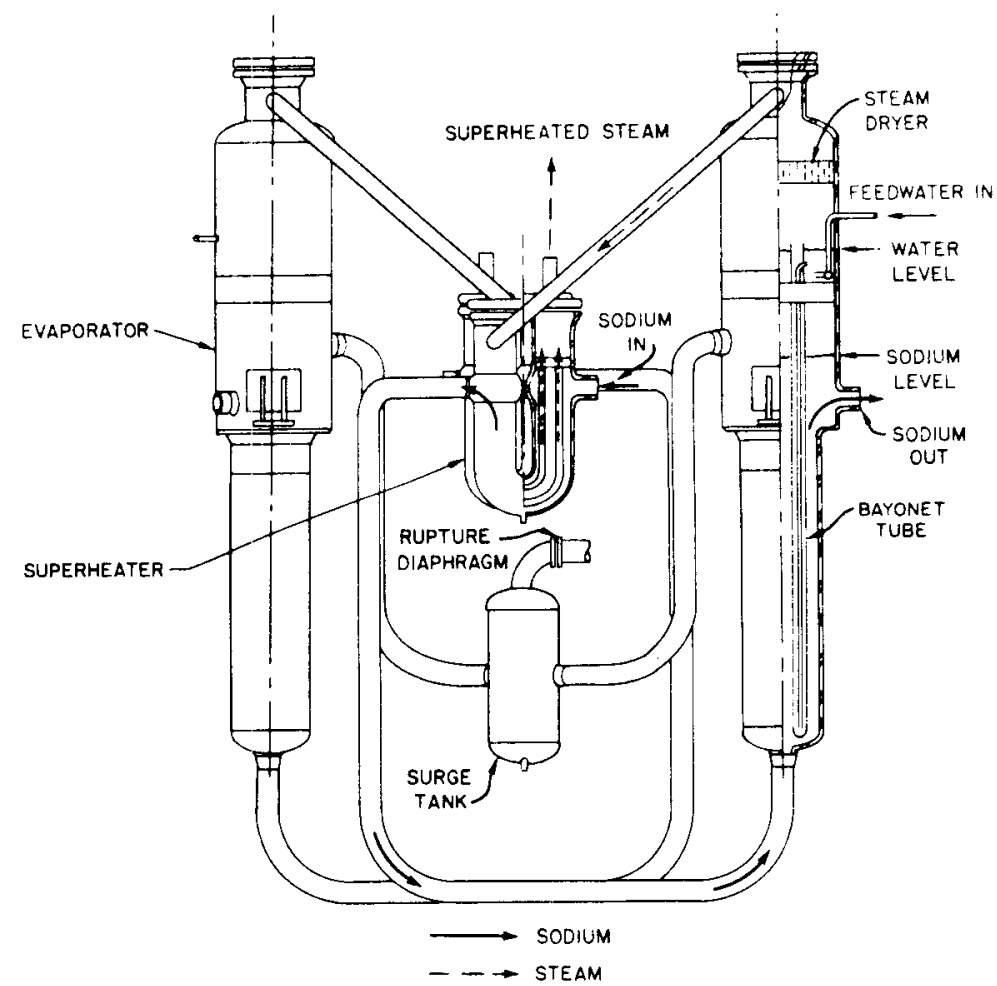

Figure VI.H-1 BN-350 Steam Generator (Ref. 5) 
VI. I. REACTOR INSTRUMENTATION AND CONTROL

The overall centralized control system for $\mathrm{BN}-350$ includes measurement and control of reactor power and period, automatic control system, reactivity change compensating system, and the reactor safety system.
An emergency shutdown cooling system makes it possible to calculate the temperature field of the reactor, the IHX, the steam generator, and the liquid metal circuits. Rapid operation occurs only in exceptional cases. Most of the signals go to the slow emergency system which reduces the power by a factor of 2.7 in 100 seconds. (Ref. T.) 
VI. J. FUEL HANDLJNG

The refueling system consists of double rotating plugs with drives; an invessel fuel handling machine; two inclined elevators for moving fuel between the reactor and position below the refuelingcell handling-machine gripper; an exit port to a shielded refueling cell; a refueling cell transfer machine for pickup and deposit and translation along the refueling cell; two transfer rotors cooled by Nak for interim transfer storage; a fuel-handling transfer machine in a shielded cell above wash stations; an exit port to the decaystorage water pool; and the water pool. (Fig. VI. J-1) (Ref. 3.)

Provision is made for reloading the reactor every six weeks to two months. Core elements which have reached their predetermined burn-up are transferred to a storage pit located at the periphery of the radial blanket region and fresh core elements installed.

Refueling is dore with the reactor shut down. (Ref. 12.)

The in-vessel fuel handling machine can 1 ift and rotate and has a hold-down. elevator is inclined $17^{\circ}$ to the vertical and consists of a guide, a pot, a carriage, a drive rod, and a chain transmission. The carriage travels $16.5 \mathrm{ft}$. at $10 \mathrm{ft} / \mathrm{min}$. and requires a $0-83 \mathrm{kw}$ drive. (Fig. VI. J-2)

The refueling elevator contains a transfer pot at the bottom of the elevator. The pot is always filled with sodium and is always in a vertical position as it travels upward. The head of the fuel assembly is grasped by the transfer machine above sodium level. (Ref. 3.)

The refueling cell is a narrow box-like sealed compartment tangential to the reactor. It has an argon atmosphere. The feed mechanism in the transfer cell moves the assembly to the channel of the drum for spent elements and drops it into one of the receptacles. Reverse order is used in loading fresh fuel. The spent element is transferred from the drum to a receptacle in the wash box, and after washing it is moved to the holding tank.

A11 operations are automatic by command from a control panel. (Ref. 12.) 
BN-350 VI.J.

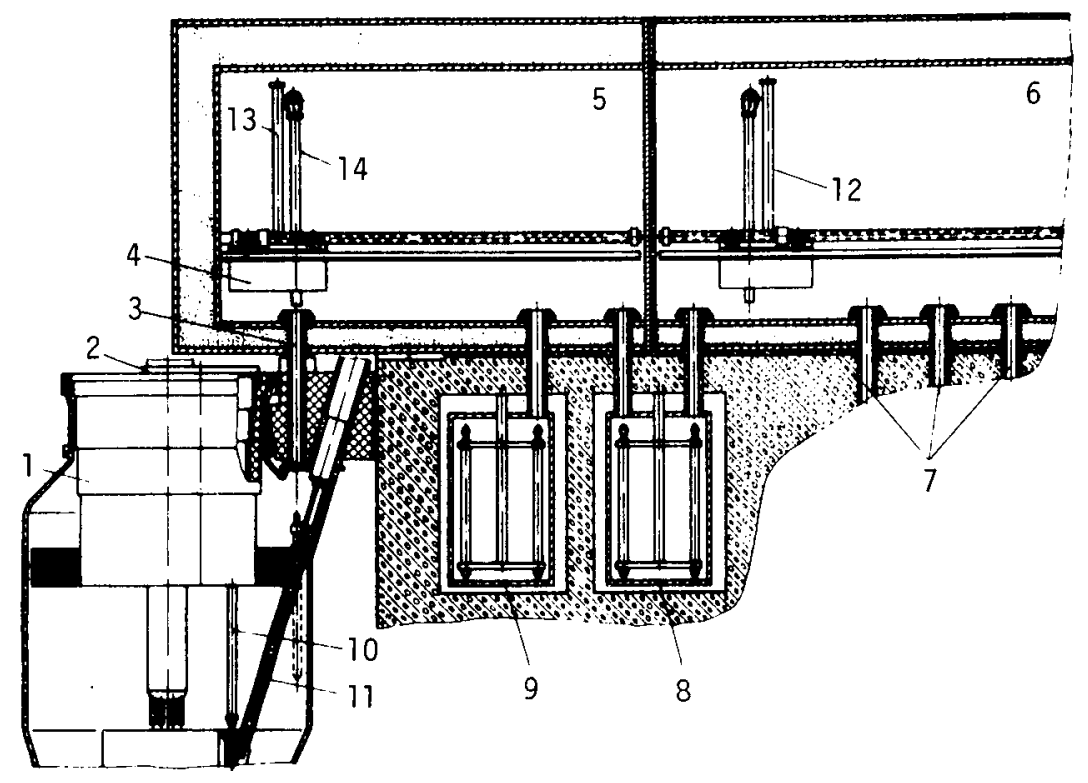

1. LARGE ROTATING PLUG

2. SMALL ROTATING PLUG

3. REACTOR EXIT PORT

4. REFUELING-MACHINE CARRIAGE

5. REFUELING CELL

6. WASH CELL

7. WASH PORTS

8. USED ASSEMBLY TRANSFER ROTOR

9. FRESH ASSEMBLY TRANSFER ROTOR

10. IN-VESSEL FUEL TRANSFER MACHINE

11. ELEVATOR

12. WASH-CELL FUEL TRANSFER MACHINE

13. NEW FUEL POT

14. REFUELING-CELL FUEL TRANSFER MACHINE

Figure VI.J-1 BN-350 Refueling System (Ref. 3)

VI.J-2 
BN-350 VI.J.

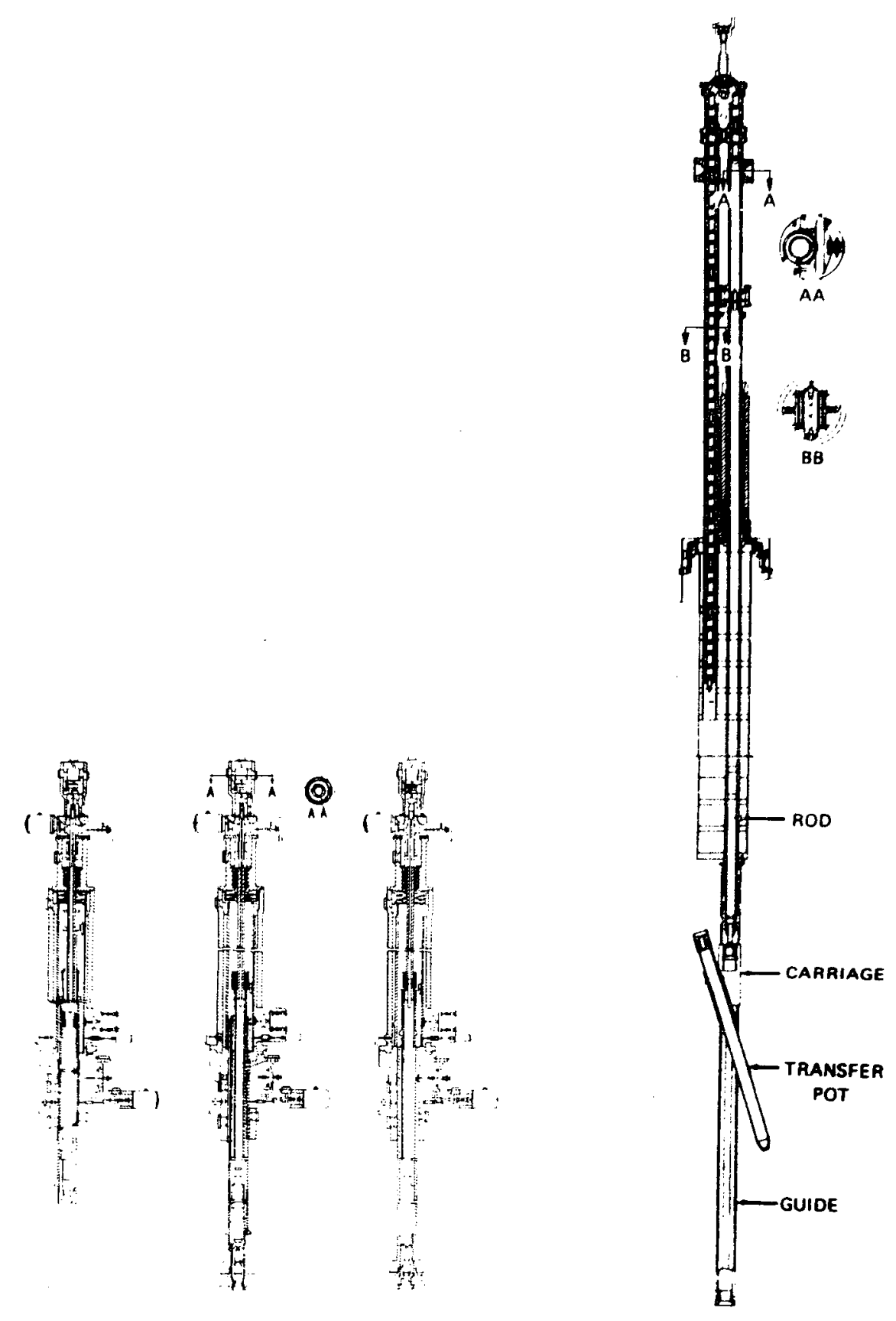

Figure VI.J-2 BN-350 In-Vessel Fuel Handling Machine and Refueling Elevator (Ref. 3)

VI.J-3 


\section{K. CONTAINMENT}

The reactor and basic auxiliary systems are located in an industrial type building. The building is divided into structural units consisting of a section for control rooms, electrical and electronic information equipment, general ventilating equipment etc.. A reactor area includes loops of the primary and secondary circuits, steam generators and auxiliary systems; a section accommodating the transport system including water tanks for storage of depleted fuel, the hot cell, and the gas systems equipment. There is also a section accommodating the technological ventilating systems. Rooms of the reactor section are metal-1ined, and contain a pit for the reactor. (Fig. VI. K-1) (Ref. 12.)

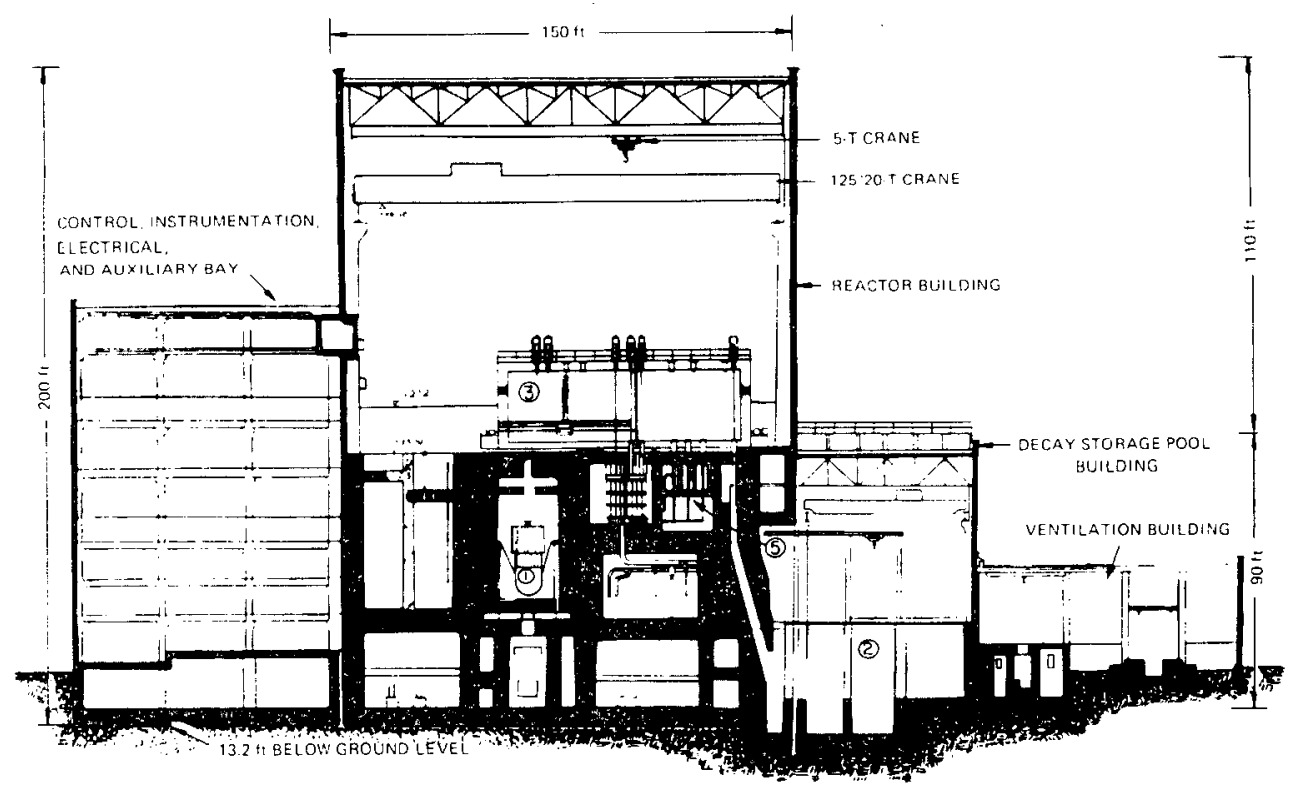

1. REACTOR

2. WATER POOL FOR FUEL DECAY AND STORAGE

3. REFUELING CELL

4. TWO TRANSFER ROTORS

5. FUEL WASH STATIONS

Figure VI.K-1 Vertical View of $\mathrm{BN}-350$ 
VII. $B N-600$

$$
\begin{aligned}
& \text { LOCATION: Beloyarsk, USSR } \\
& \text { OPERATION: } 1975 \text { (Target) }
\end{aligned}
$$

The $\mathrm{BN}-600$ reactor is an integral, pot-type system. Construction, begun in 1968, is scheduled for completion in 1975. The nominal electrical power rating of the $\mathrm{BN}-600$ reactor is $600 \mathrm{MWe}$; the thermal power is $1470 \mathrm{MWt}$. The first core, which is somewhat flattened, will use uranium dioxide canned in stainless stee1. Target burnup is 10\%. The $\mathrm{BN}-600$ reactor is designated Unit 3 of the Kurchatov station. 
INDEX

REFERENCES

Page

REACTOR PARAMETERS

VII -5

VII -7

SECTIONS

A. CORE AND BLANKET

VII.A-1

B. CORE SUPPORT AND VESSEL INTERNALS

VII.B-1

C. REACTOR VESSELS AND SHIELDING

VII.C- 1

D. CONTROL ELEMENTS

VII.D- 1

E. HEAT TRANSFER SYSTEMS

VII.E-1

F. SODIUM PURIFICATION AND INSTRUMENTATION

VII.F-1

G. COVER GAS AND AUXILIARY SYSTEMS

(NO INFORMATION)

H. STEAM GENERATORS

VII.H-1

I. REACTOR INSTRUMENTATION

(NO INFORMATION)

J. FUEL HANDLING

VII.J-1

K. CONTAINMENT

VII.K-I 
REFERENCES

1. The $B N-600$ Reactor, A. I. Leipunskii, et. a1., NUCLEX-69 Vol. 2, Section $4 / 5$ International Nuclear Industires Fair, Basel, Switzerland, October 1969 NUCLEX, Base1, Switzerland.

2. Soviet Power Reactors 1970.

Report of the USA Nuclear Power Reactor Delegation Visit to the USSR, June-1970 AEC, DRDT

WASH- 1175 (1970)

3. Experience in Fast Reactor Operation and Design in USSR.

A. I. Leipunskii, et al.,

Proc. Fourth Int1. Conf. on the Peaceful Uses of Atomic Energy, Geneva, 1971, Vol. 5. D. 37-51

IAEA, Vienna, 1972

A/CONF. $49 / \mathrm{p} / 750$

4. Fast Breeder Reactor Development in the USSR.

J. J. Taylor et. al.,

Combustion,

Vol. 44 p. 6-11 July 1972 
Table - 1

Type

No. loops

Coolant

Core inlet temp.

Core outlet temp.

Flow direction

Driver fuel

Blanket fue

Core height

Core diameter

No. enrichment zones in core

Output MWe/Mwt

Breeding ratio

Max. can temperature

Fuel Centerline temperature

Doppler $(\Delta k / k) /{ }^{\circ} \mathrm{C}$ total

Specific power

Power Density

No. Driver elements

No. Radial blanket elements

No. In-core control elements

In-Vessel Storage Positions

Goal burnup
GENERAL PARAMETERS CORE- 1

Pot-type integral design

3

Sodium

$380^{\circ} \mathrm{C}$

$550^{\circ} \mathrm{C}$

Upward

(First core) $\mathrm{UO}_{2}$

$\mathrm{UO}_{2}$, depleted

$0.7 \mathrm{~m}$

$2.048 \mathrm{~m}$

2

$600 \mathrm{MWe} / 1470 \mathrm{MWt}$

(1st core: operation as converter) $690^{\circ} \mathrm{C}$ $2500^{\circ} \mathrm{C}$

$-1.64 \times 10^{-5} \% /^{\circ} \mathrm{C}$

$840 \mathrm{kw} / \mathrm{\ell}$ (peak), $550 \mathrm{kw} / \mathrm{l}$ (ave)

$16.1 \mathrm{kw} / \mathrm{ft} .(\max )$

397

37

27

126

$10 \%$ (Ist core $5 \%$ ) 


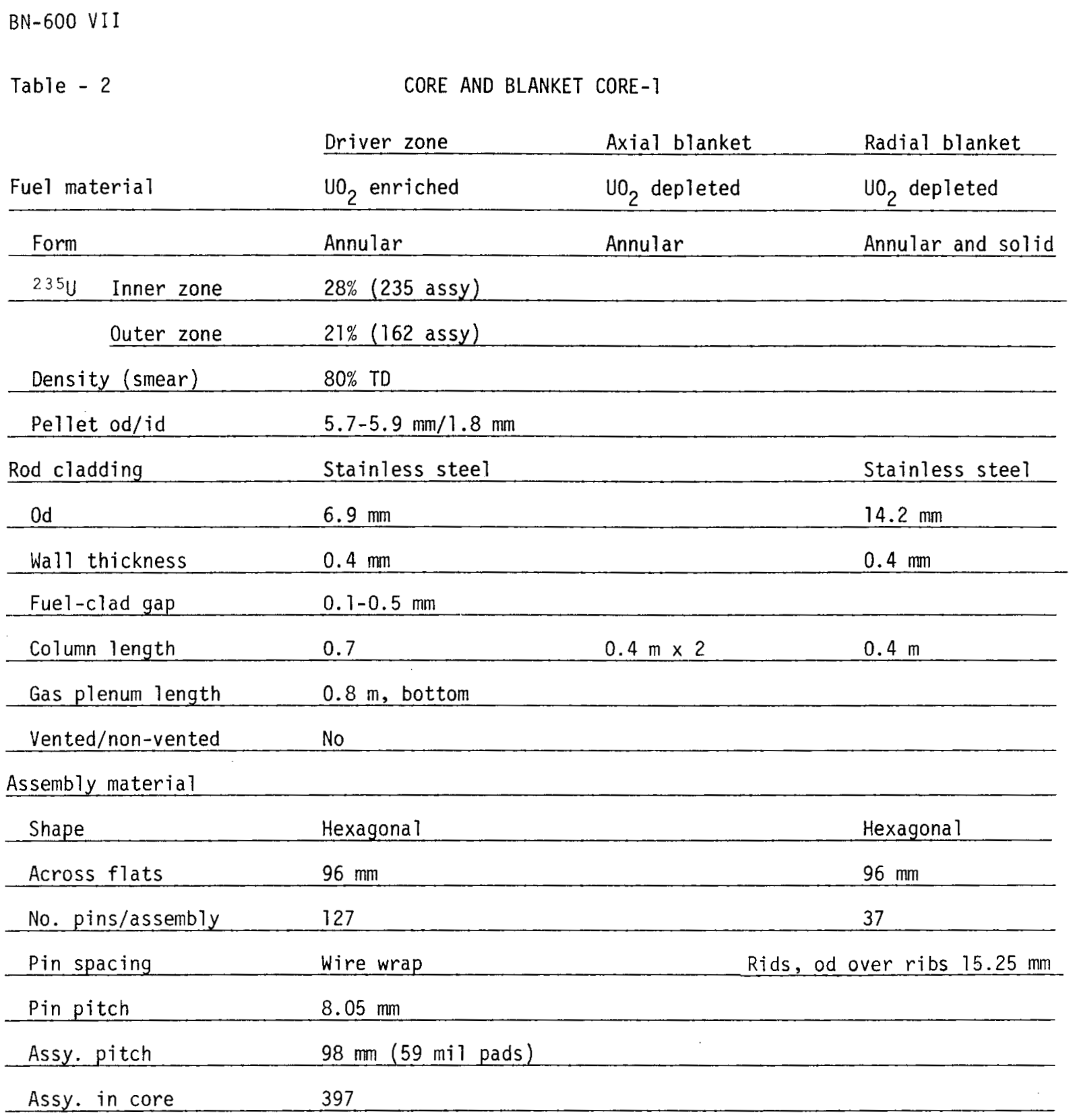


VII. A. CORE AND BLANKET

The first BN-600 core, which uses enriched $\mathrm{UO}_{2}$ as fuel, will contain sealed fuel elements. Vented elements are under consideration for use in future mixed-oxide cores. With the exception of the addition of a large gas plenum, the fuel assembly is very similar to that of the $B N-350$. Both the upper and lower blanket pellets in the pin have been incorporated into the same jacket with the fuel pellets. The pellets are annular with a smear density of about $80 \%$ TD. The pins are spaced by radiallywrapped wire. (Fig. VII.A-1).

The first two rows of radial blanket assemblies also contain annular pellets while the outer assemblies contain solid pellets. Stainless-steel 3-rib-tubes (rib diameter $=15.25 \mathrm{~mm}$ ) are used for cladding. Radial blanket assembly geometry is similar to fuel assembly geometry.

Throttles in the assembly tails distribute the sodium coolant. The sodium inlet is radial and provides hold-down. The assemblies are combined into four, five and seven assembly modules fixed to bushings in the outlet plenum structure. No radial restraint is provided.

There are 126 fuel storage positions outside the radial blanket. (Refs. 1,2.) 

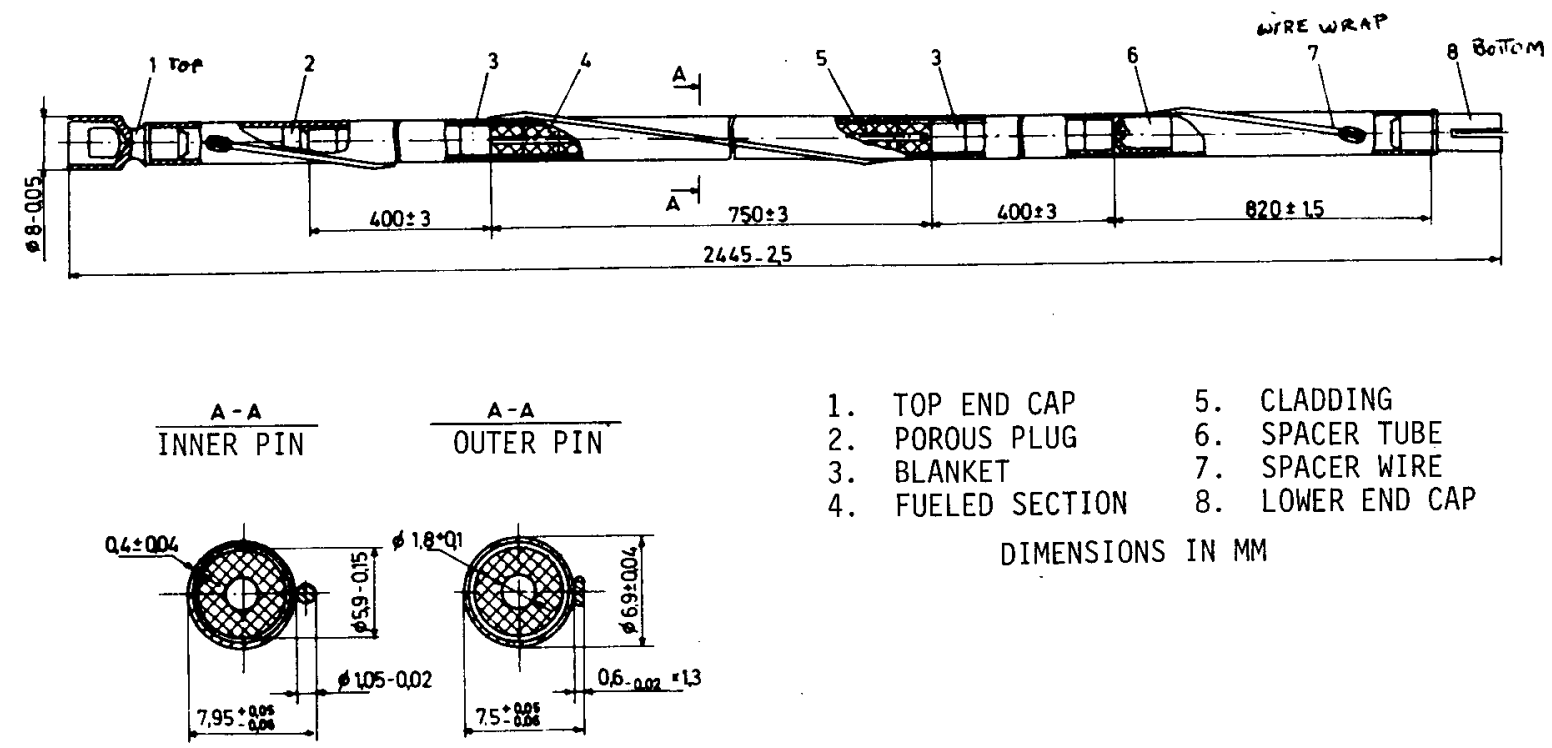

1. TOP END CAP

2. POROUS PLUG

3. BLANKET

4. FUELED SECTION DIMENSIONS IN MM
5. CLADDING

6. SPACER TUBE

7. SPACER WIRE

8. LOWER END CAP

Figure VII.A-1a BN-600 Fuel Assembly (Ref. 3)

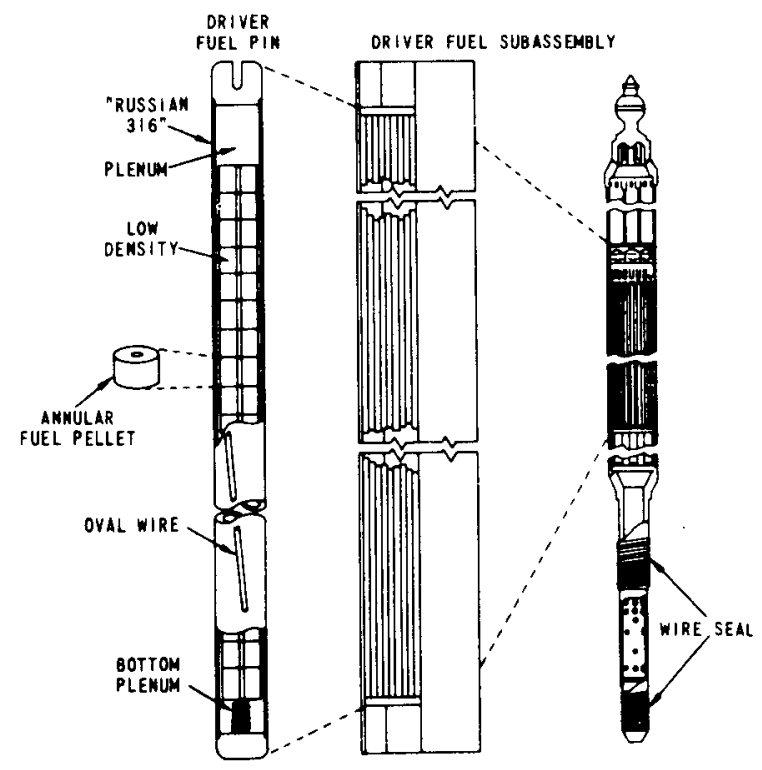

Figure VII.A-1b BN-600 Fuel System (Ref. 3) 
BN-600 VII.B.

VII. B. CORE SUPPORT AND VESSEL INTERNALS

The reactor tank is supported by a ring girder that also supports a bridgetruss structure spanning the bottom of the tank. The reactor core intermediate heat exchangers, radial shielding and pump she11s are all supported by the truss structure. A primary flow shroud nests the radial blanket and shielding.

(Ref. 2.) 


\section{C. REACTOR VESSELS AND SHIELDING}

The reactor vessel contains both the core and all of the components of the primary circuit. It is a cylindrical tank $12.8 \mathrm{~m}$ in diameter with a tapered upper part and an elliptical bottom. Its height is $12.6 \mathrm{~m}$; the wall thickness is $30 \mathrm{~mm}$ for the cylindrical and bottom part and $50 \mathrm{~mm}$ for the upper tapered part. All components except the rotating plugs are mounted on a support girdle, which in turn is mounted on a support ring that forms an integral part of the vessel. The rotating plugs are supported on the upper, tapered part of the vessel. The vessel is enclosed in a tight jacket extending above sodium level, the gap between vessels being filled with inert gas at a slight over-pressure. Sodium leak warning devices are mounted in the gap. There are six cavities for heat exchangers and three for pumps in the upper part of the vessel; the difference in thermal expansion between the vessel and components is compensated by means of bellows. A "top-hat" structure encloses control and instrumentation mechanisms.

The reactor is mounted on a concrete base. A cylindrical supporting shell is welded to the lower part of the vessel. This shell rests in two roller supports mounted on the base beam. The vessel is kept from turning by four radial keys. The rollers and their guides are cooled by air entering for reactor vessel cooling. (Fig. VII.C-1.) (Ref. 1.)

Intravessel shielding consists of a set of steel plates adjacent to the core and several rows of vertical steel tubes filled with graphite at the periphery of the shielding.

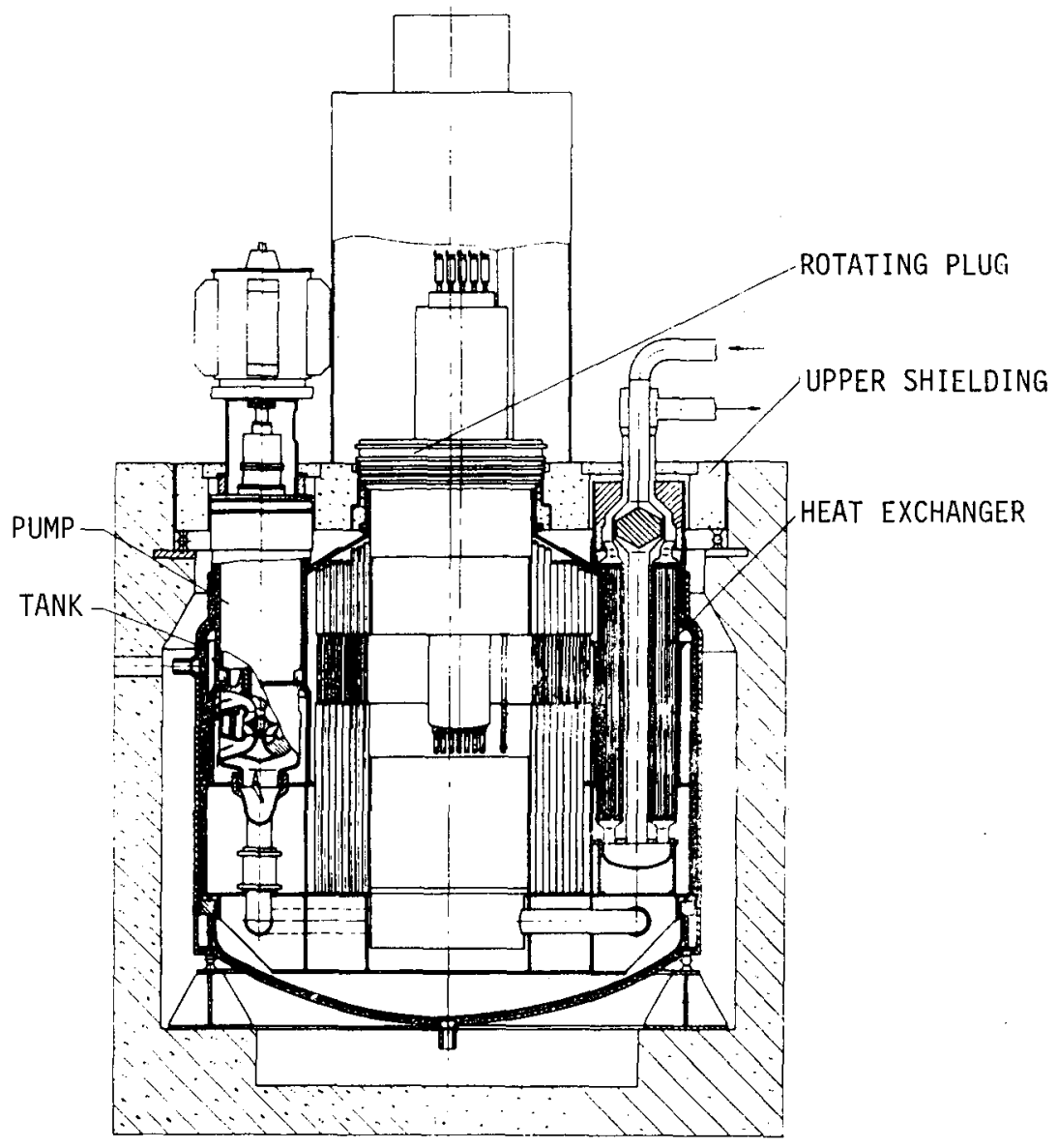

Figure VII.C-1 BN-600 Reactor (Ref. 3) 
VII. D. CONTORL ELEMENTS

There is a total of 27 safety and control elements in BN-600. Of these, two are automatic control rods, 19 are burnup and temperature compensators and six are safety elements. $\mathrm{B}_{4} \mathrm{C}$ is the absorbing material for the automatic control rods and the safety elements. The burnup and temperature compensators will contain $\mathrm{B}_{4} \mathrm{C}$ or tantalum. The automatic safety system occupies two cells in the central part of the low-enrichment zone. The assemblies are sealed.

(Refs. 1,2.) 


\section{E. HEAT TRANSFER SYSTEMS}

Two pressure pipes deliver the primary circulating sodium into the distribution chamber of the primary tank. From there it is directed among the fuel and blanket assemblies. Part of the incoming flow is used to cool the reactor vessel, the assembly storage points and the inner shield. Sodium enters the assemblies radially, flows upward and, at a temperature of $550^{\circ}$, exits to the six intermediate heat exchangers through an annular gap in the shielding around the core. The primary sodium flows downward in the shel1-side of the heat exchangers and exits at a temperature of $380^{\circ} \mathrm{C}$. It then enters three overflow chambers where it is fed to pumps that deliver it back to the reactor. Secondary sodium flows upward through the tube side of the IHX and downward in the economizer-evaporator section of the steam generator.

The IHX is a vertical tube-and-shell unit. Pressure in the secondary sodium side exceeds pressure in the primary side. There are six IHX's.
Pumps circulating primary and secondary sodium are mounted in cold-legs. They are immersible, single-stage, double-suction units with a fixed coolant level in the pump tank. Sodium-lubricated hydrostatic bearings are used at the impeller end and oil-lubricated radial and thrust-bearings are used outside the sodium and sodium-vapor space. Rotating gas seals retain the inertgas blanket over the sodium pool. Pump capacity is $32,000 \mathrm{gpm}$.

Check valves are installed inside the pump casings below the impeller in the discharge. There are no stop valve in the primary or secondary circuits, a loop being shut down by closing the check valve in the pump of that 1oop. (Refs. 1, 2.) 
BN-600 VII.F.

VII. F. SODIUM PURIFICATION AND INSTRUMENTATION

Cold traps are used to maintain satisfactory oxygen concentration. The BN-600 cold-trap design is similar to the $\mathrm{BN}-350$ trap. It is cooled with NaK and only one metal wall separates the coolant from the sodium.
Information on other sodium monitoring and instrumentation systems is not available. In-sodium hydrogen diffusion meters are being studied and development is proceeding on other on-line monitors, e.g., electrochemical oxygen meters and carbon diffusion cells. (Ref. 2.)

VII.F-1 
VII. H. STEAM GENERATORS

The reference design for $B N-350$ steam generation is for three once-through, singlewall steam generators. Each has two $3.6 \mathrm{~m}$ diameter units. The economizer and evaporator are located in one $12 \mathrm{~m}$ high unit. The second unit, $17 \mathrm{~m}$ high, contains the main and reheating steam superheaters. Secondary sodium passes through the superheater and evaporator sections in succession. Each unit has a free sodium level with the space above the sodium filled with argon at a slight over-pressure. The generators are provided with a special system to ensure the discharge of sodium-water reaction products in the event of water leakages into the sodium. This system consists of $250-\mathrm{m}^{3}$ separators in series mounted on top of the steam generator room for each of the three secondary loops. A fast-response stop valve on the feed-water line is provided in case of leakage in a steam generator. Steam at $505^{\circ} \mathrm{C}$ and 140 ATM is directed from the steam generators into three turbo-generators. Thermal capacity per set is $480 \mathrm{MWt}$. A startup steam separator would be passed during normal power operation.

A modular version of the steam generation system is under consideration.

(Refs. 1,2.)

VII.H-1 
VII. J. FUEL HANDLING

The fuel handling system is similar to that of the $\mathrm{BN}-350$. It includes two rotating plugs, two handling devices, two elevators, a handling casket for assembly transport, and two fuel-handling drums. The large rotating plug is mounted on the tapered part of the reactor vessel with the small one placed eccentrically on it. Loading and unloading follows the same sequence as in BN-350. (Fig. VIII.J-1.) (Refs. 1, 2.)

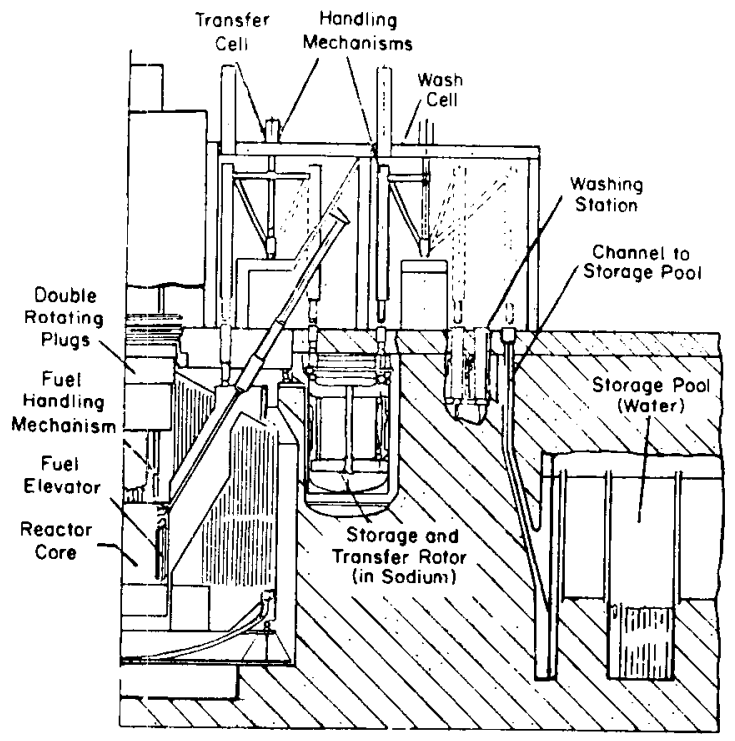

Figure VII.J-1 BN-600 Fuel Handling System 
BN-600 VII.K.

VII. K. CONTAINMENT

The reactor building is a conventionaltype bulding about $47 \mathrm{~m}$ high. A steel-lined concrete cell contains the main reactor tank. The steam generator and auxiliary building, and the turbine building, are separate, adjacent structures. (Ref. 2.) 
VIII. JOYO

LOCATION: 0-Arai Center, Japan

Joyo is an experimental fast sodium-cooled reactor. Construction was begun in 1971 at the 0-Arai Engineering Center, Japan. First step power will be 50 MWt. Final design power is 100 MWt. The project is being conducted by the Power Reactor and Nuclear Fuel Development Corporation of Japan. Joyo is a two loop system.

The preliminary design was done in 1964, and the first conceptual design was begun in August 1967 and completed in May 1968. In October 1967, the Power Reactor and Nuclear Fuel Development Corporation (PNC) was established. PNC has assumed responsibility for design, $R \& D$, construction and operation of the reactor. PNC gave contracts to five industrial consortia for the third conceptual design, which was submitted to PNC in March 1969. Application for a construction permit was filed in June, 1969. As of July 1974 construction was nearly completed. It was reported that fuel assemblies were being installed, and blanket assemblies were being assembled, while instrumented assemblies were still under design. 


\section{INDEX}

\begin{tabular}{|c|c|c|}
\hline & & Page \\
\hline REFERENC & & VIII -5 \\
\hline REACTOR & ARAMETERS & VIII-7 \\
\hline SECTIONS & & \\
\hline A. & CORE AND BLANKET & VIII.A-1 \\
\hline B. & CORE SUPPORT AND VESSEL INTERNALS & VIII.B-1 \\
\hline C. & REACTOR VESSELS AND SHIELDING & VIII.C-I \\
\hline D. & CONTROL ELEMENTS & VIII.D-I \\
\hline E. & HEAT TRANSFER SYSTEMS & VIII.E-1 \\
\hline $\mathrm{F}$ & SODIUM PURIFICATION AND INSTRUMENTATION & VIII.F-1 \\
\hline G. & COVER GAS AND AUXILIARY SYSTEMS & VIII.G-1 \\
\hline$H$. & $\begin{array}{l}\text { STEAM GENERATORS (NO POWER TAKE-OFF. } \\
\text { SEE SECTION E) }\end{array}$ & \\
\hline I. & REACTOR INSTRUMENTATION AND CONTROL & VIII.I-1 \\
\hline J. & FUEL HANDL ING & VIII.J-1 \\
\hline K. & CONTAINMENT & VIII.K-1 \\
\hline
\end{tabular}




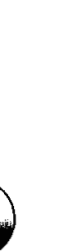

-

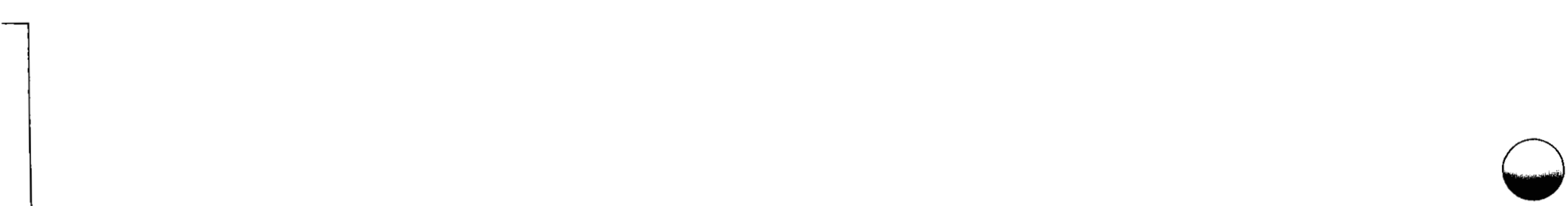

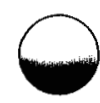

. 
REFERENCES

1. JAERI's Conceptual Design of the Japan Experimental Fast Reactor

Parts 1 and 2

Japan Atomic Energy Research Institute

JAERI-1177, 1177-B (1969)

2. Outline of the Japan Experimental Fast Reactor JoYo.

Power Reactor and Nuclear Fuel Development Corp.

JAPFNR-29 (Trans. PNC-N-24.1-72-15) (1972)

3. Fue] Design of JoYo.

Power Reactor and Nuclear Fuel Development Corp.

PNC-N-141-72 (1) (Apri1 1972) JAPFNR-31

4. A Survey Study of the Joyo Mark II Core.

PNC, Sumimoto Electrical Industries, Mitsubishi Atomic Power Industries, 'Inc.

PNC-N-141-72-1 (18) (Apri1 1972)

5. Uranium-Plutonium Mixed-0xide Fuel Fabrication for the Experimental Fast Reactor JoYo in Japan

J. Akutsu, K. Matsumoto

Fuel and Fuel Elements for Fast Reactors, Proc. Symp., Brussels 1973

Vol. 2 p.441-464

STI/PUB/346. (IAEA, 1974)

6. Development of the Mechanical Sodium Pump

Y. Oda, others

Sodium Cooled Fast Reactor Engineering, Proc. Symposium, Monaco, March 1970, p. $375-395$

IAEA, STT/PUB/256 (1970)

7. Program and Present Status of Fast Breeder Reactor Development in Japan A. Oyama et al

Proc. Fourth Inter National Conf. Peaceful Uses of Atomic Energy, Geneva 1971 Vol. 5 p. 101-114

Un, IAEA, (1972) 


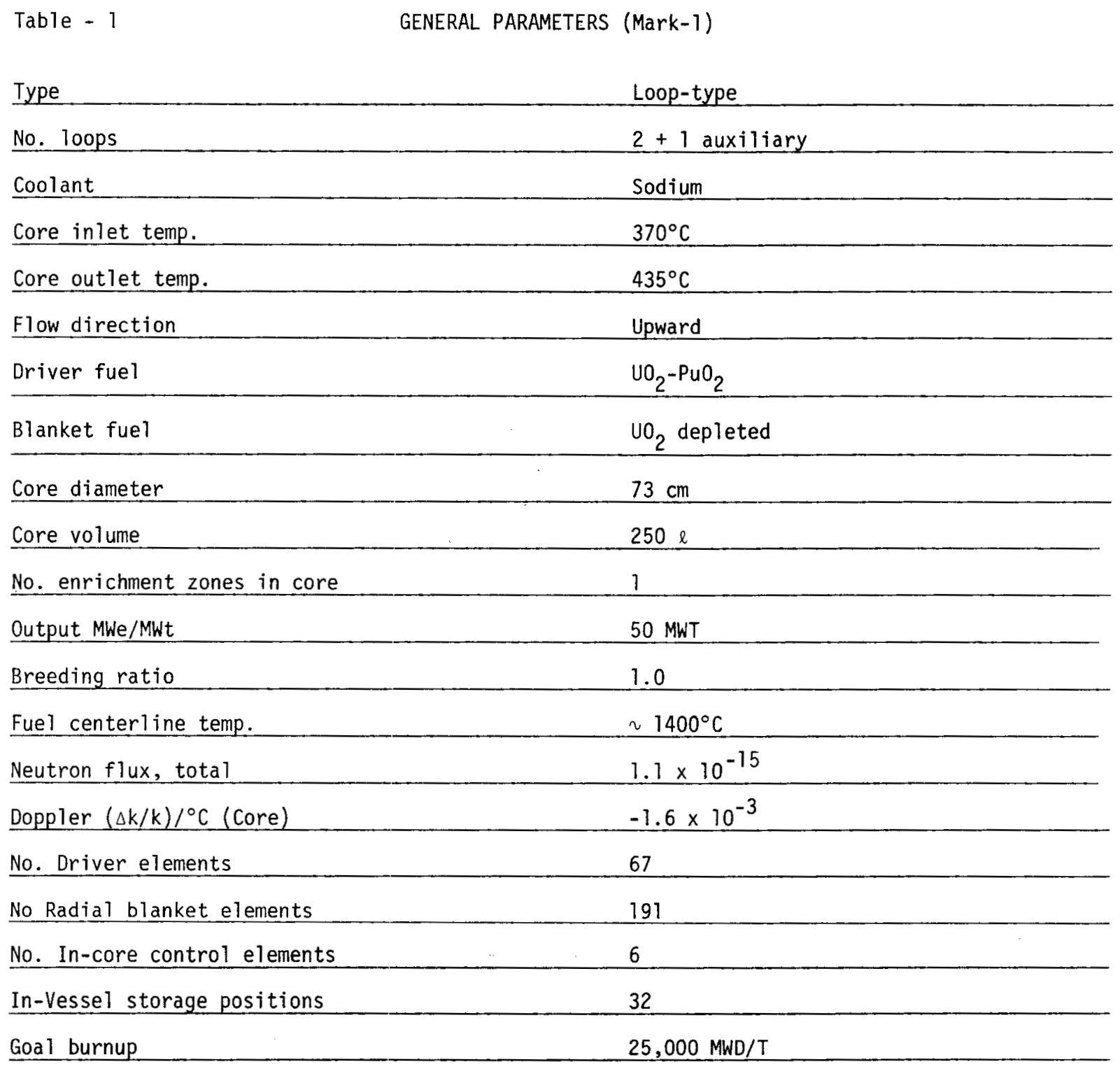




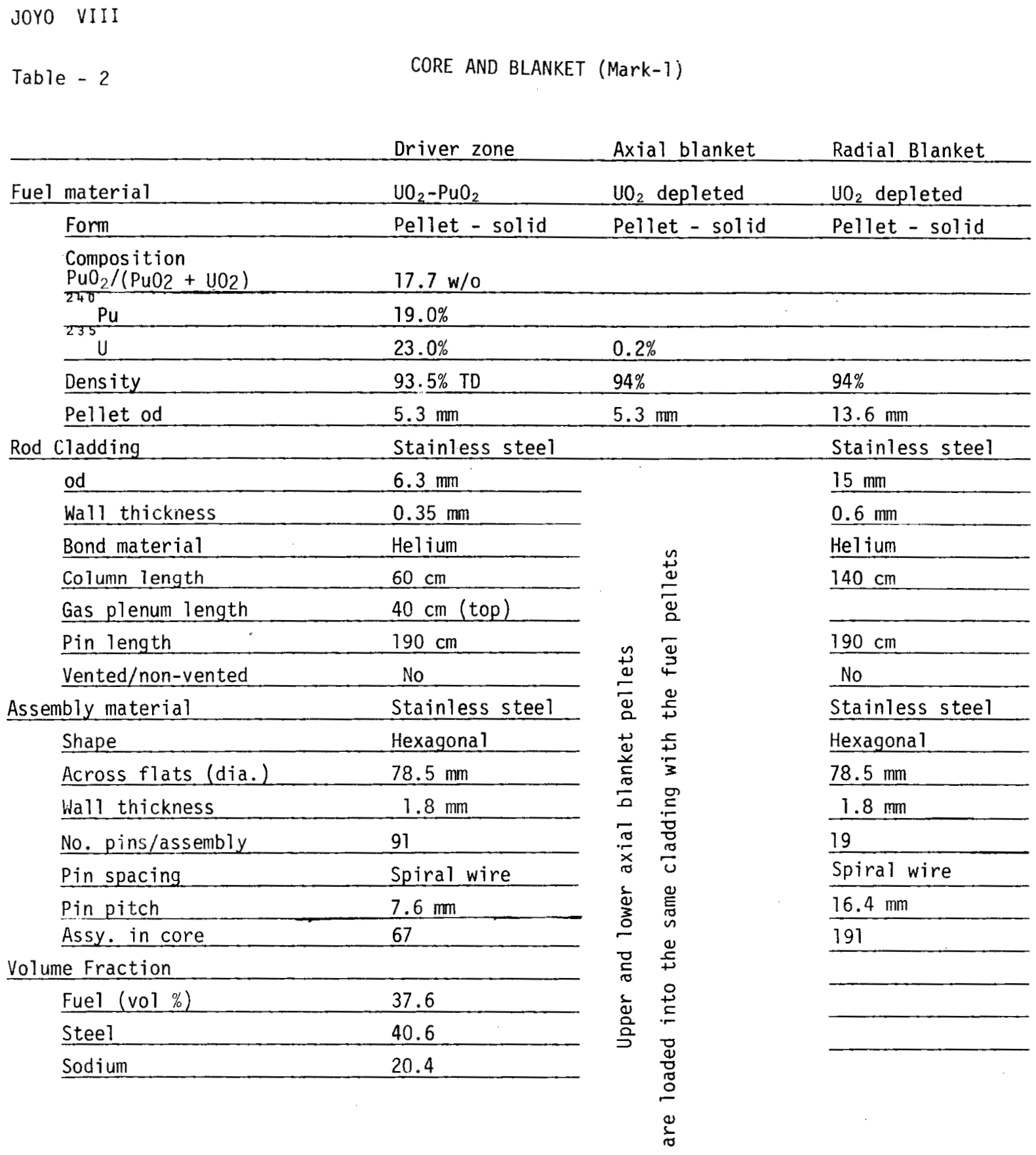


VIII. A. CORE AND BLANKET

Core fuel pins have sintered pellets of mixed oxide fuel, with axial blanket pellets of depleted $\mathrm{UO}_{2}$ loaded above and below in the same can. A top plenum is provided to contain the fission gases. Wires, $1.2 \mathrm{~mm}$ dia., are wrapped spirally around the pins to provide a pitch of $7.6 \mathrm{~mm}$. The plenum sleeve and plenum spring are loaded into the gas plenum space to prevent the fuel column from moving up and down. The hexagonal assembly holds 91 pins, and is connected to a handling head at the upper end and to an entrance nozzle at the lower end. A fixing-box and knock-bars at the lower end hold the fuel pins in place. Two spacer pads are provided on the side walls of the assembly. The radial assembly has the same shape and size as the core assembly.
It holds 19 pins of greater diameter. Spacing is by spiral wire wrap to give a pin pitch of $16.4 \mathrm{~mm}$. (Fig. VIII.A-1)

Reflectors are stainless steel hexagonal rods. (Ref.5.)

The MARK-2 core prel iminary surveys have been done by Sumimoto Electric Industries and Mitsubishi Atomic Power Industries. Design studies are continuing. The preferred solution seems to be a two-region core with $32.5 \sim 27.7$ w/o plutonium enrichment. Pellet diameters from 4.5 to $5.0 \mathrm{~mm}$ were investigated. The MARK-2 core is to have an output of 100 MWt and a maximum neutron flux $>5 \times 10^{15} \mathrm{n} / \mathrm{cm}^{2} \mathrm{sec}$. (Ref. 4.) 
JOYO VIII.A

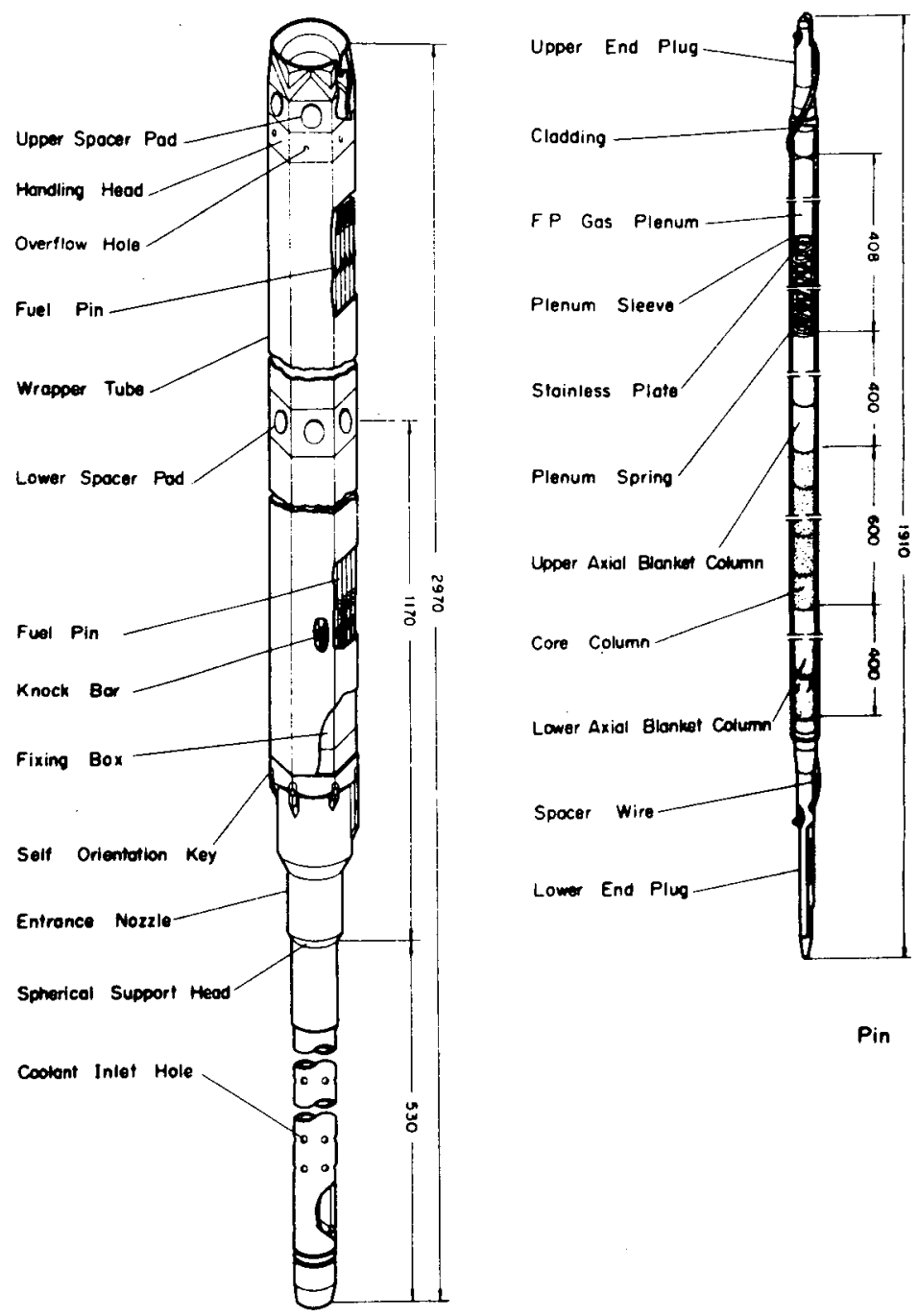

Figure VIII.A-1 JOYo Fuel Assembly (Ref. 5)

VIII.A-2 
VIII. B. CORE SUPPORT AND VESSEL INTERNALS

A grid-plenum structure supports the core and serves as a high-pressure plenum for the inlet sodium. The support grid is a sandwich-type structure composed of two $50 \mathrm{~mm}$-thick perforated plates spaced $350 \mathrm{~mm}$ apart by connecting tubes and a surrounding cylinder. The high-pressure plenum is between the plates and supplies sodium to the fuel and inner blanket regions. The low pressure plenum'is below this structure, between the lower plate and a supporting structure for the grid-plenum assembly.
This supporting structure is bolted to a support lug in the reactor. A flow guide pipe attached to it directs the sodium from the spherical plenum to the supporting structure. The bottom of this pipe has a labyrinth connection. (Fig. VIII.B-2)

The core barrel consists of six cylindrical sleeves held apart by spacers. It serves as shielding around the core.

(Fig. VIII.B-1) (Ref. 1) 
JOYO VIII.B
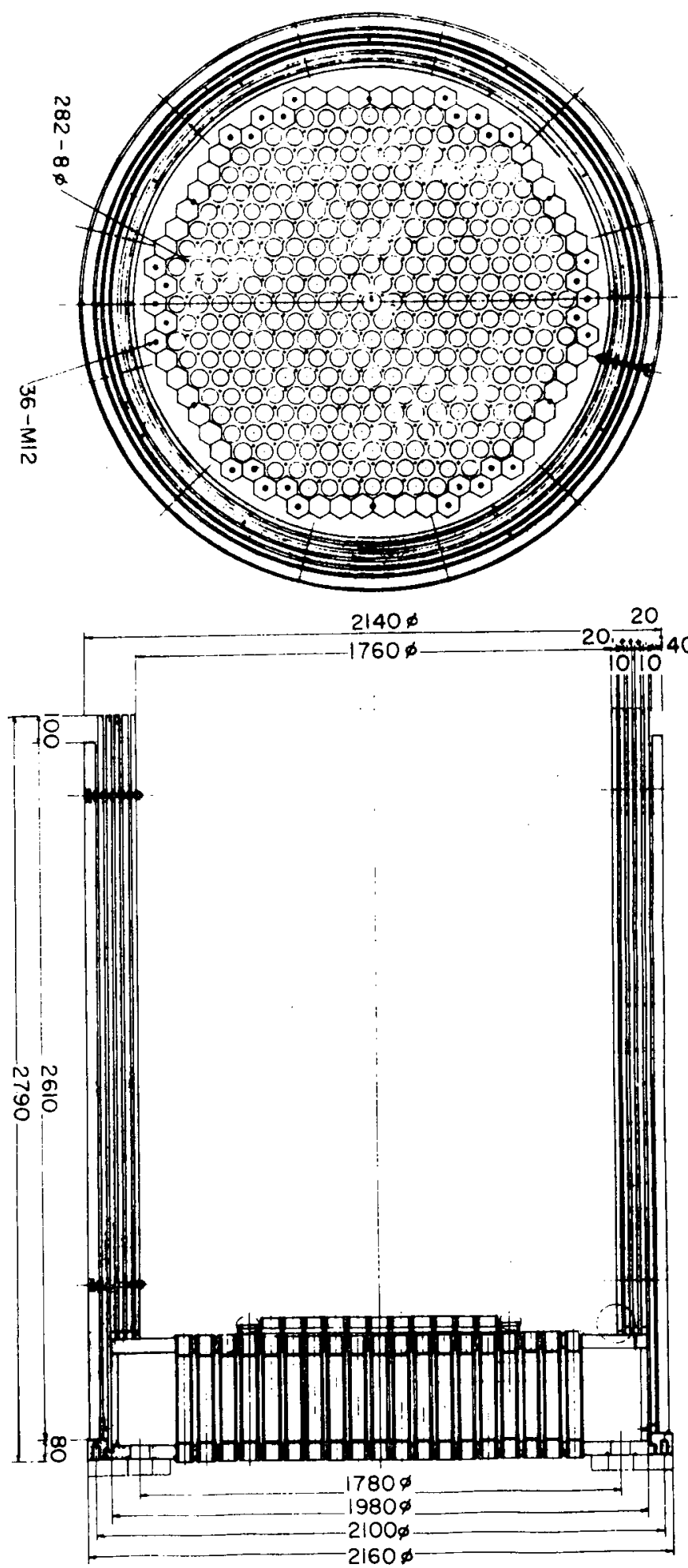

Figure VIII.B-1 JoYo Core Support and Barrel (Ref. 1)

VIII.B-2 


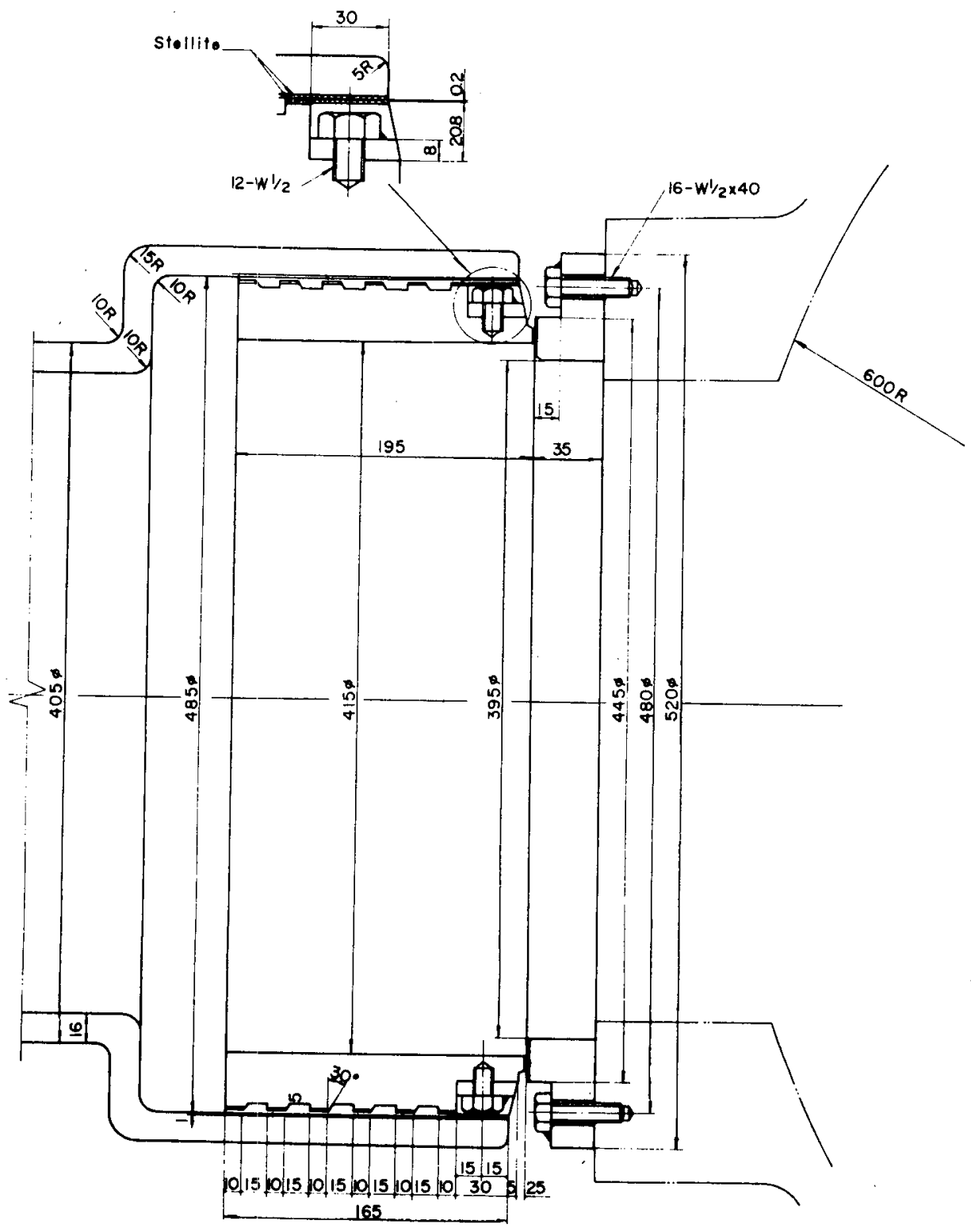

Figure VIII.B-2 Joro Labyrinth Structure (Ref. 1) 
VIII. C. REACTOR VESSELS AND SHIELDING

The reactor vessel is a stainless steel, double-walled cylindrical structure approximately $3.6 \mathrm{~m}$. id and $10.5 \mathrm{~m} \mathrm{high}$. Nitrogen gas fills the annular space. Two inlet nozzles are located at an angle of $90^{\circ}$ to each other in the base, with outlets in the upper part. An inlet for emergency cooling sodium is just below the main outlets, with an outlet for the emergency sodium on the opposite wall. There are also nozzles for a liquid sodium over flow system, an argon gas system, and other systems in the upper part. There is a spherical bottom plenum. (Fig. VIII.C-1, C-2, C-3) (Ref. 2)
The vessel encloses the core, rotating fuel storage racks, core support structures, material monitoring racks etc. Top closure consists of two rotating plugs, each with its own drive mechanism. They consist of layers of stainless steel, carbon steel, and graphite, with a thickness of about $2.5 \mathrm{~m}$. Cooling is by internal circulation of nitrogen gas. All mechanisms are installed in the small plug. (Fig. VIII.C-3) The vessel is hung by a top flange. (Ref. 2)

A graphite shield, one meter thick, serves as a safety vessel. Concrete biological shielding surrounds the vessel and shield. (Ref. 2) 


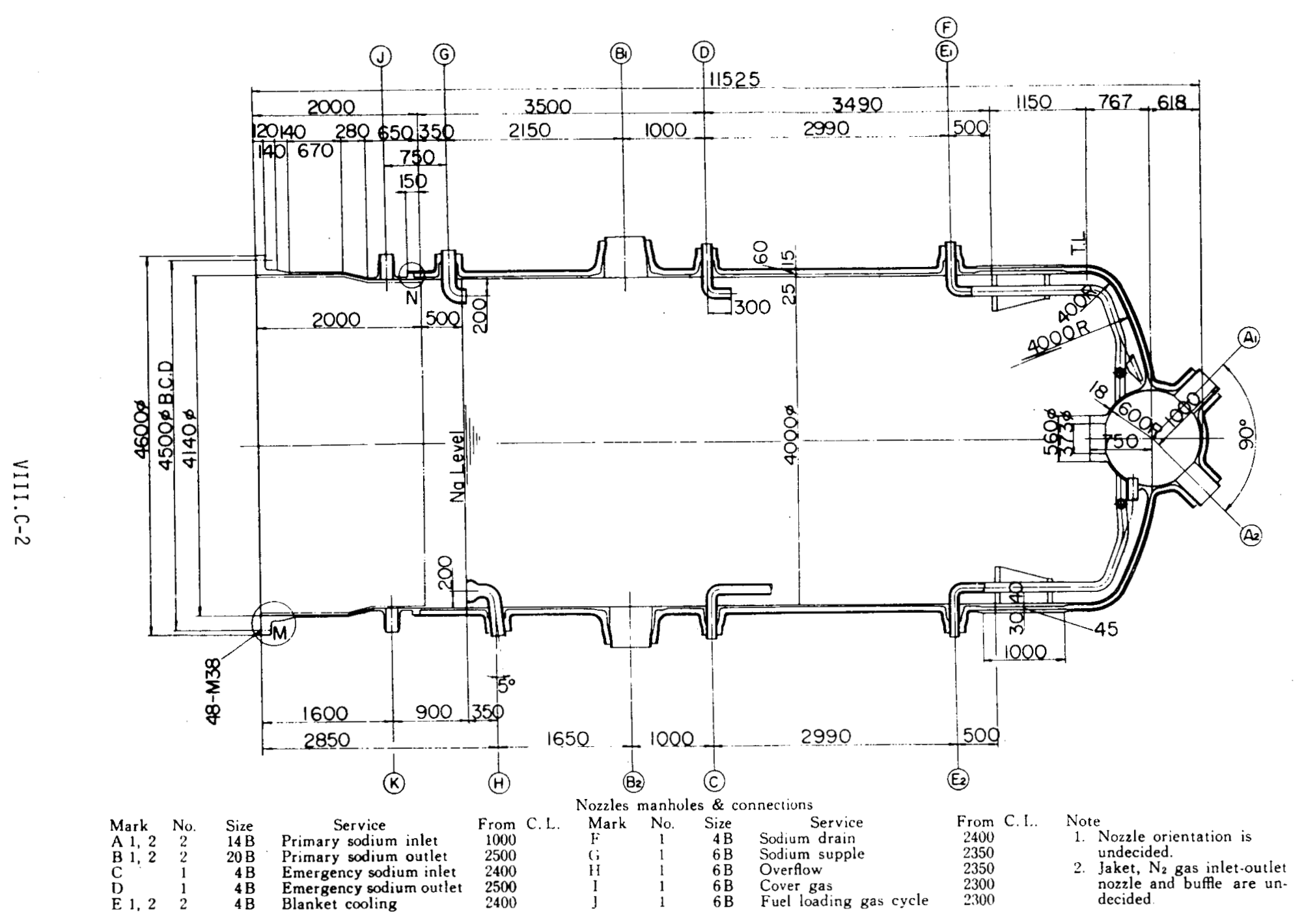

Figure ViII.C-1 Joro Vessel Showing Nozzles (Ref. 1) 


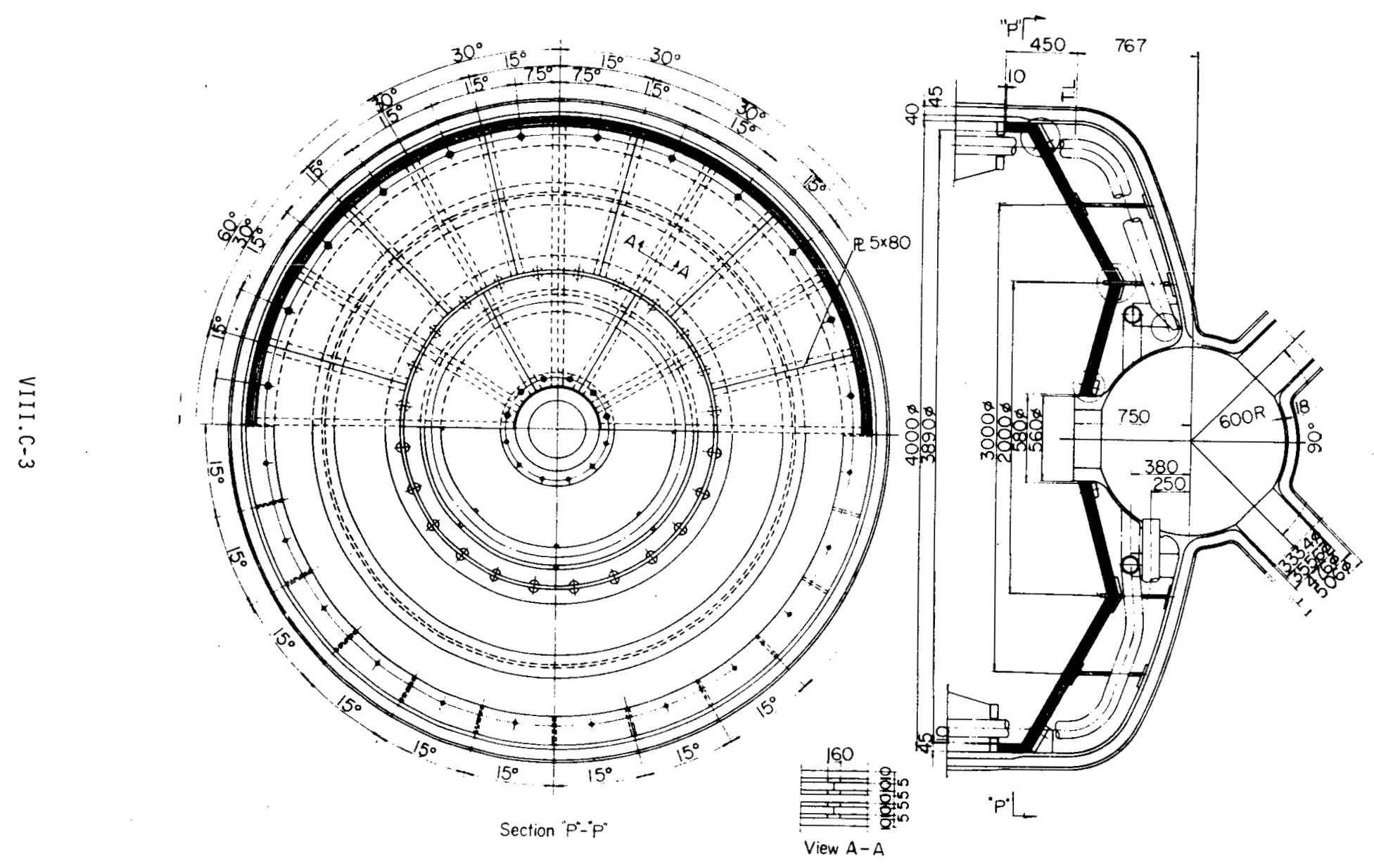

Figure VIII.C-2 JOY0 Reactor Lower Shell (Ref. 1) 
JoYo VIII.C

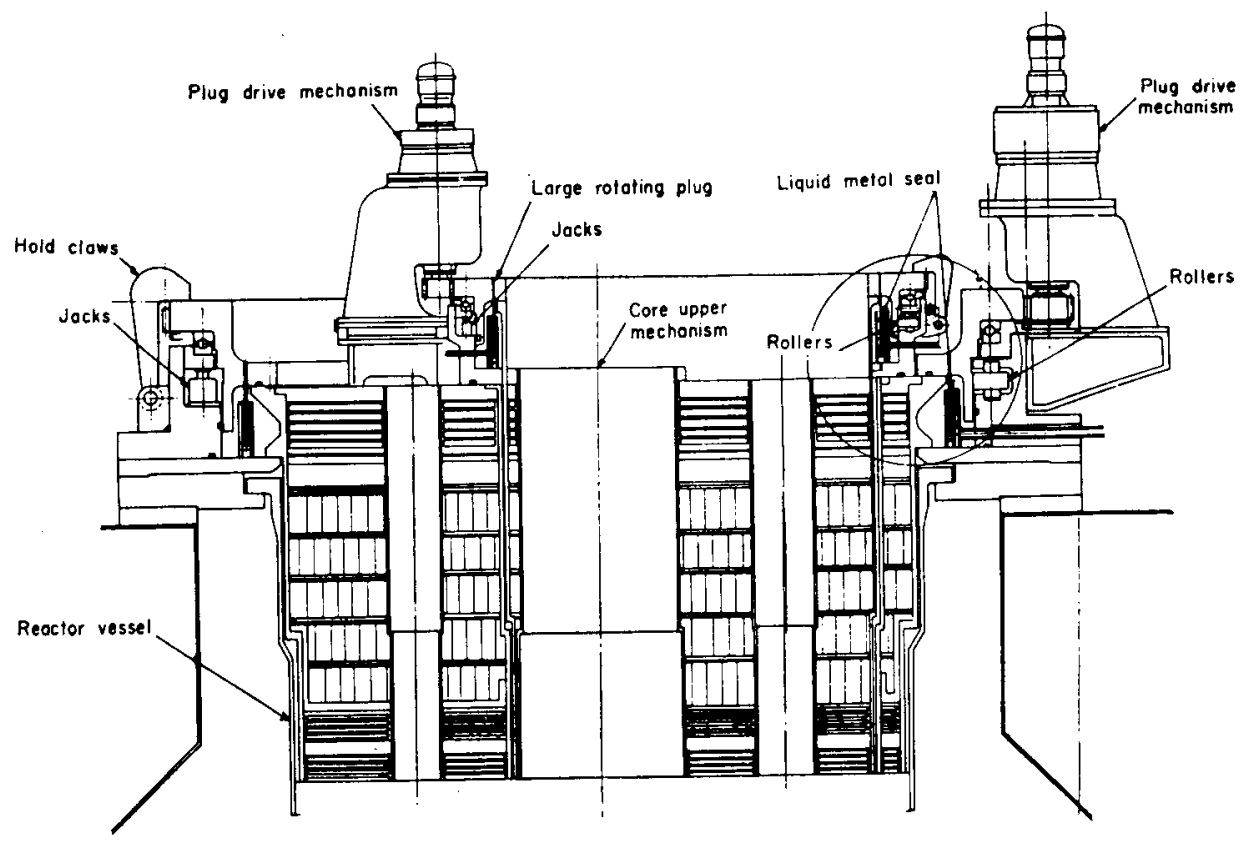

Figure VIII.C-3 Joro Rotating Plugs (Ref. 1)

VIII.C-4 


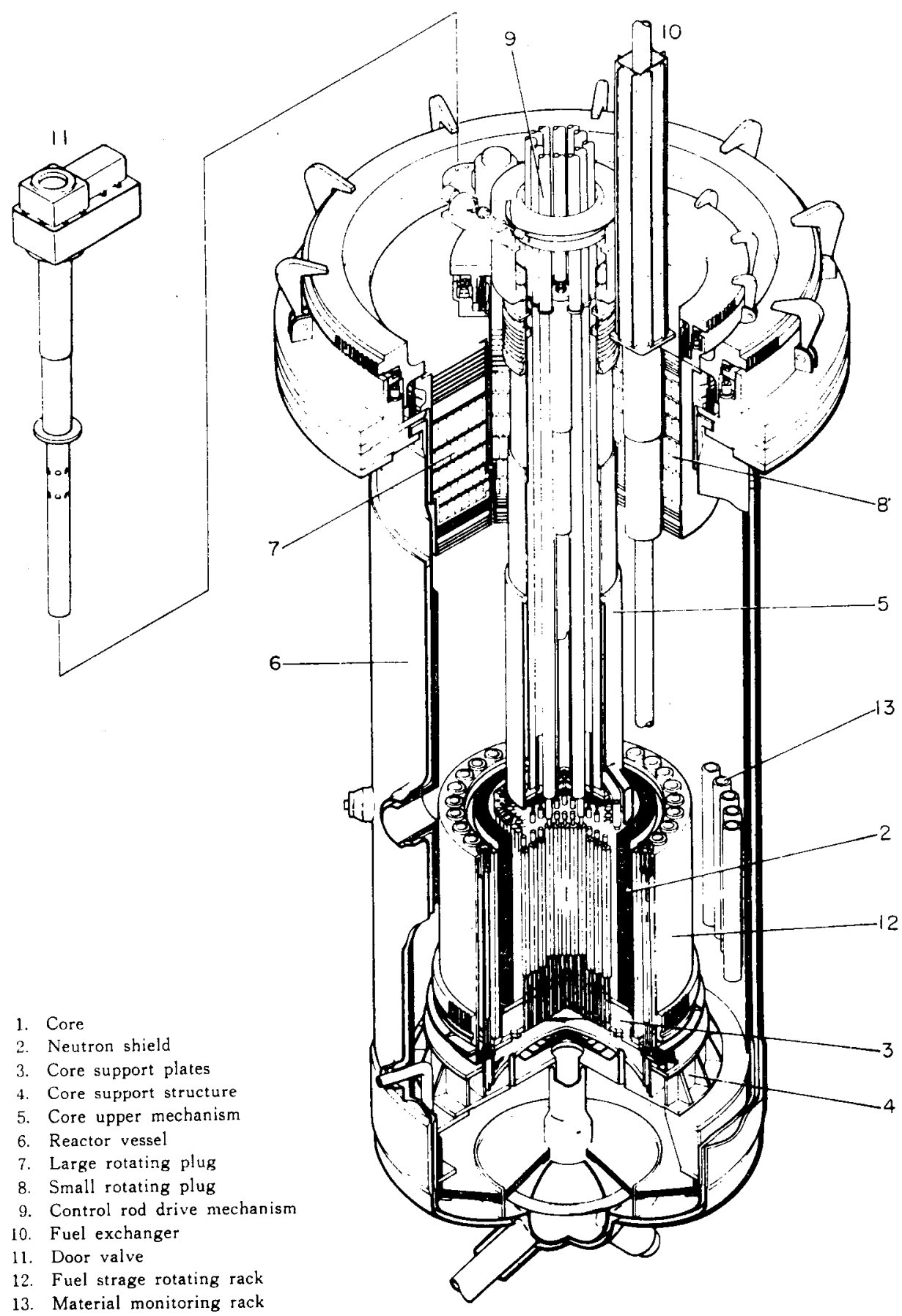

Figure VIII.C-4 Joro Reactor Structures (Ref. 1) 
VIII. D. CONTROL ELEMENTS

Reactor control is by means of four control rods and two safety rods, arranged symmetrically in the core region. Rods consist of seven elements, $70 \mathrm{~cm}$ long, containing $\mathrm{B}_{4} \mathrm{C}$ pellets enriched in ${ }^{10} \mathrm{~B}$. Containment is a stainless steel tube. Travel distance is about $90 \mathrm{~cm}$. They are driven by a ball-nut screw mechanism, with springs to accelerate insertion into the core.

(Ref. 1)

VIII.D- ] 


\section{E. HEAT TRANSFER SYSTEMS}

Joyo has a two-loop heat transfer system. All primary system piping is double walled. The space between the walls is filled with nitrogen gas. Each main loop includes an intermediate heat exchanger and a pump. In the secondary system heat is rejected by means of an air-cooled heat exchanger. Pumps are in cold legs. The system includes cold traps and a plugging meter.

Sodium enters the fuel assembly from the high pressure plenum through lateral orifices in the assembly, and flows upward through the core. In the blanket region, sodium from the high-pressure plenum enters the low-pressure plenum through orifices in the ends of the reflectors and flows into the blanket assemblies at the bottom ends. Flows merge into one above the core in the reactor vessel and are led to the heat exchangers through the outlet nozzles and the hot leg piping. Primary sodium flow is downward through the IHX to the main pump, which returns it to the reactor. An overflow system maintains the sodium level constant. Cover gas is argon. Dip plates prevent surface ripples.

The main pipes have the following parameters:

$\begin{array}{lr}\text { Reactor to IHX } & 0.484 \mathrm{~m} \mathrm{dia} . \\ \text { IHX to pump } & 0.391 \mathrm{~m} \mathrm{dia} . \\ \text { Pump to reactor } & 0.340 \mathrm{~m} \mathrm{dia} . \\ \text { Straight pipe distance } \\ \text { Reactor to IHX }\end{array}$

Secondary system sodium circulates at a higher pressure than in the primary system. Pipina is single-walled. Heat is rejected by means of a sodium-air heat exchanger, which is a finned, multitube, forced air cooled unit. (Fig. VIII.E-I) Four such units are installed in the secondary loops. (Ref. 1)

Primary and secondary pumps are vertical, free-surface, centrifugal units, with a hydrostatic bearing operating in sodium and double mechanical seals in the top part. (Fig. VIII.E-2) The auxiliary cooling system uses 1 inear induction type electromagnetic pumps.

The IHX is a vertical, free-surface, shell-and-tube unit. Sodium surface is covered by argon gas. Primary sodium flows downward through the shell side, and secondary sodium circulates in the tubes. Inlet temperature of the primary sodium to the IHX is $\sim 420^{\circ} \mathrm{C}$, outlet about $355^{\circ} \mathrm{C}$.

(Fig. VIII.E-3)

The emergency heat-transfer system is a separate system, with a primary and secondary loop and its own intermediate heat exchanger and air-dump heat exchanger. Heat transfer fluid is NaK. (Fig. VIII.E-4, E-5) (Ref. 1) 


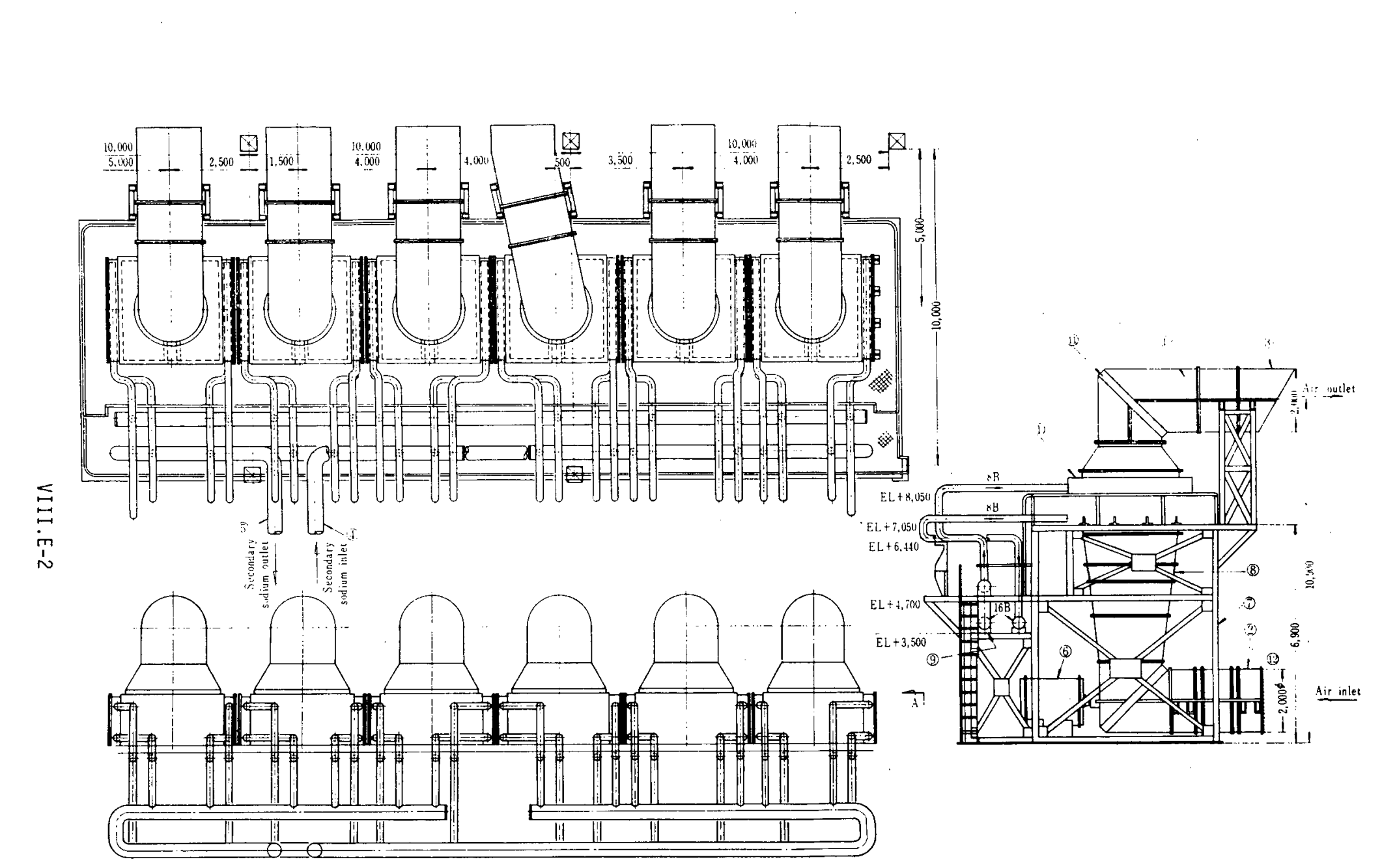

응
$\vdots$
学

Figure VIII.E-1 Joro Main Air Cooler (Ref. 1) 


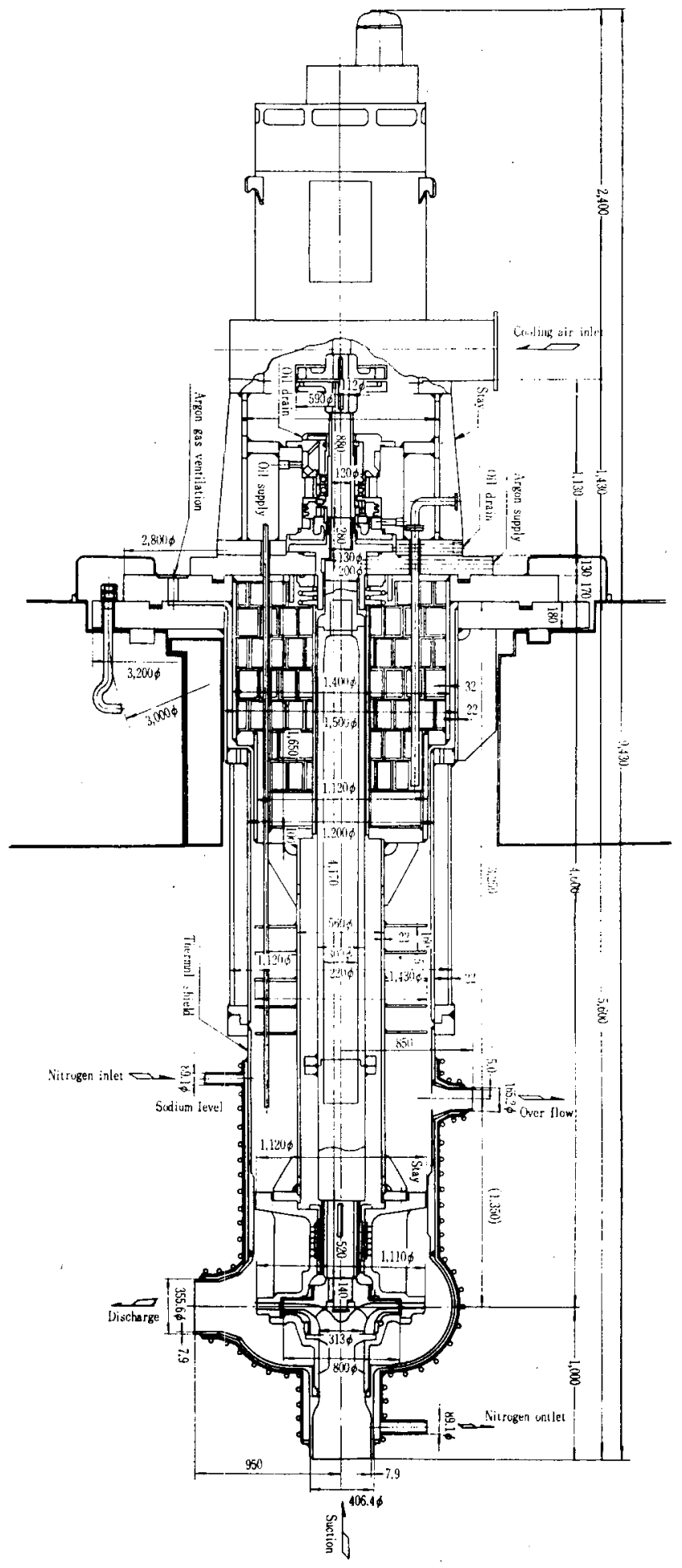

Figure VIII.E-2 JOYO Primary Pump (Ref. 1)

VIII.E-3 
JOYO VIII.E

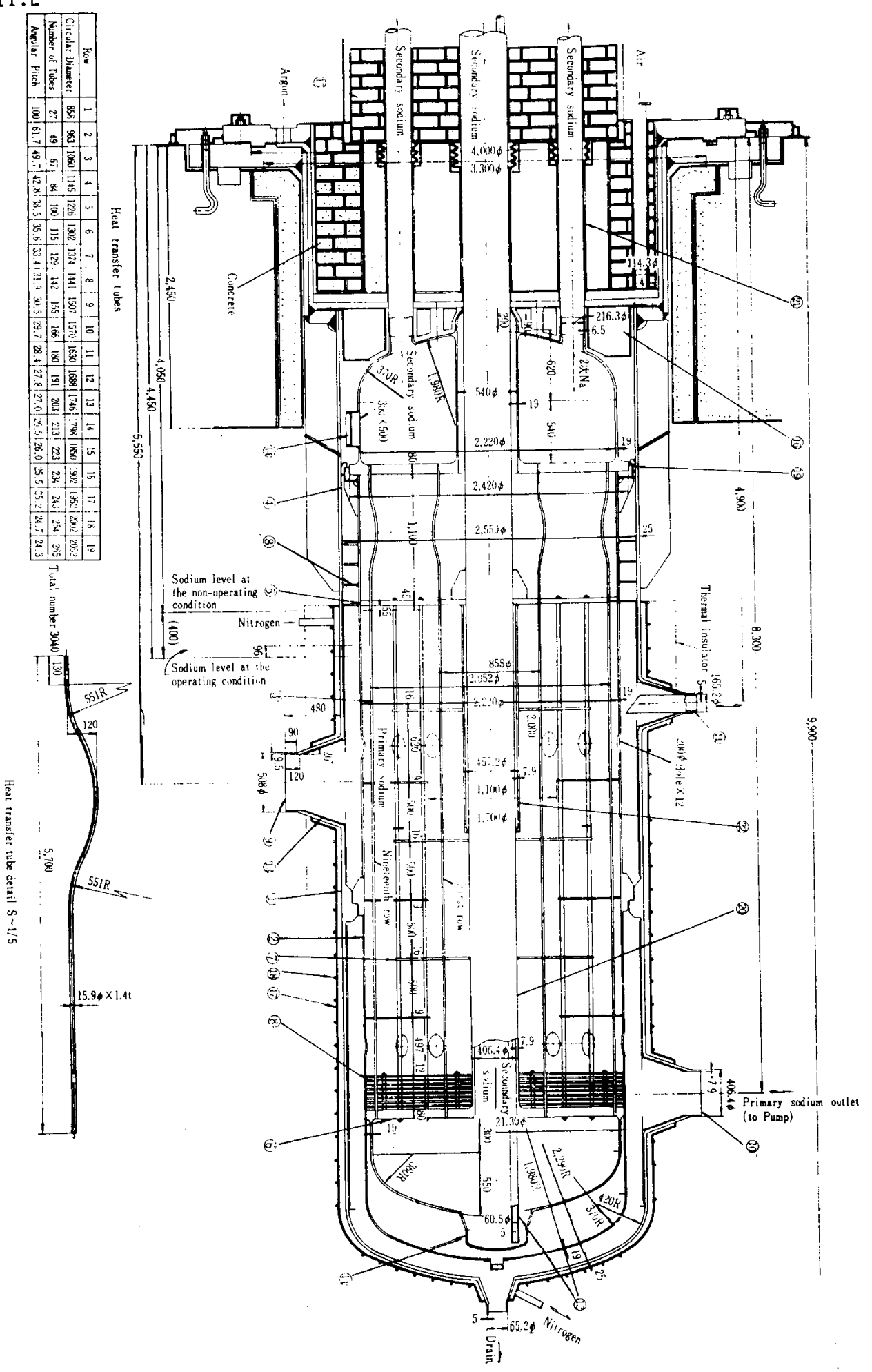

Figure VIII.E-3 JoYo Intermediate Heat Exchanger (Ref. 1)

VIII.E-4 


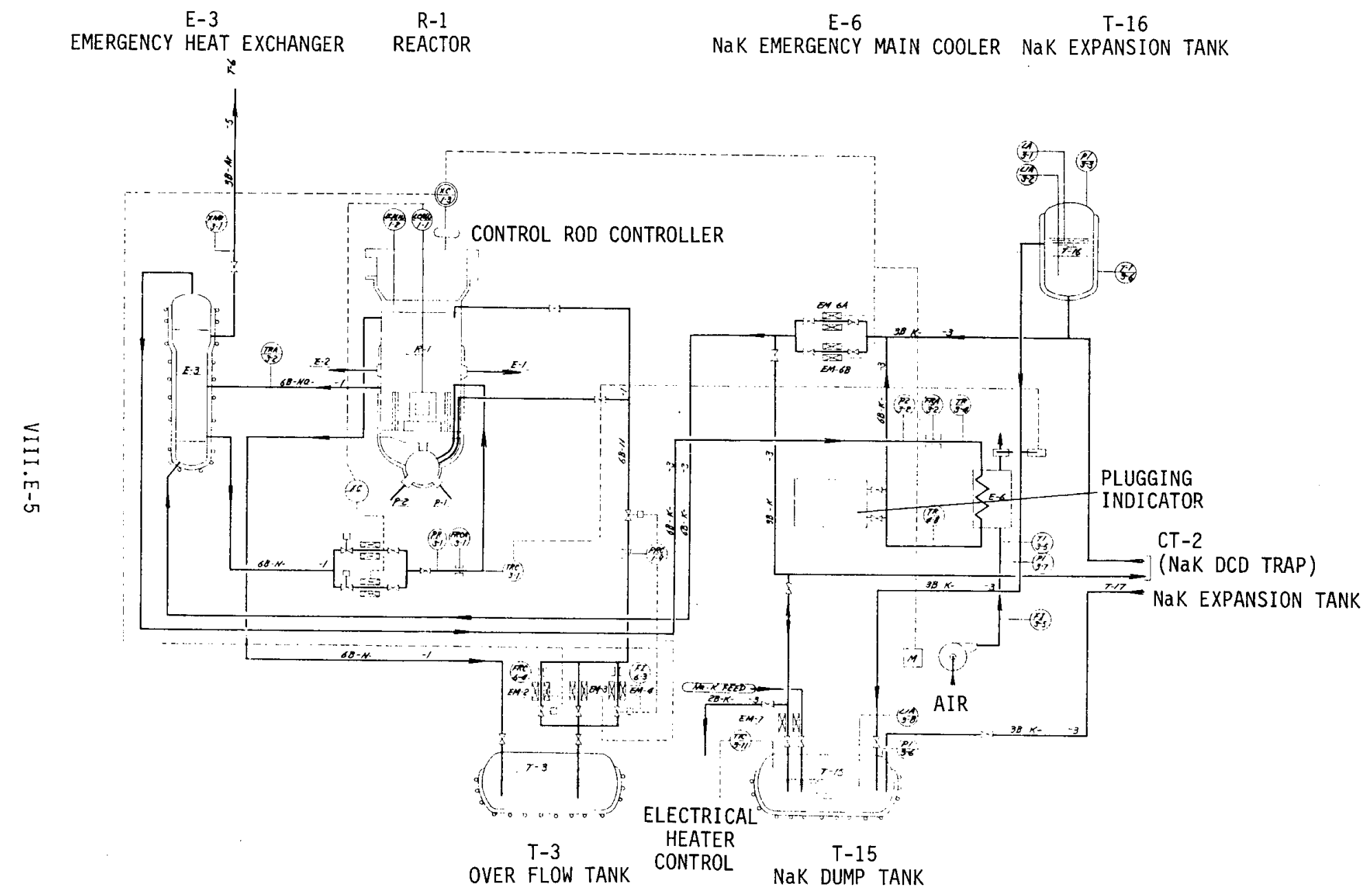

Figure VIII.E-4 JOY0 Emergency Cooling System Flow Design (Ref. 1) 


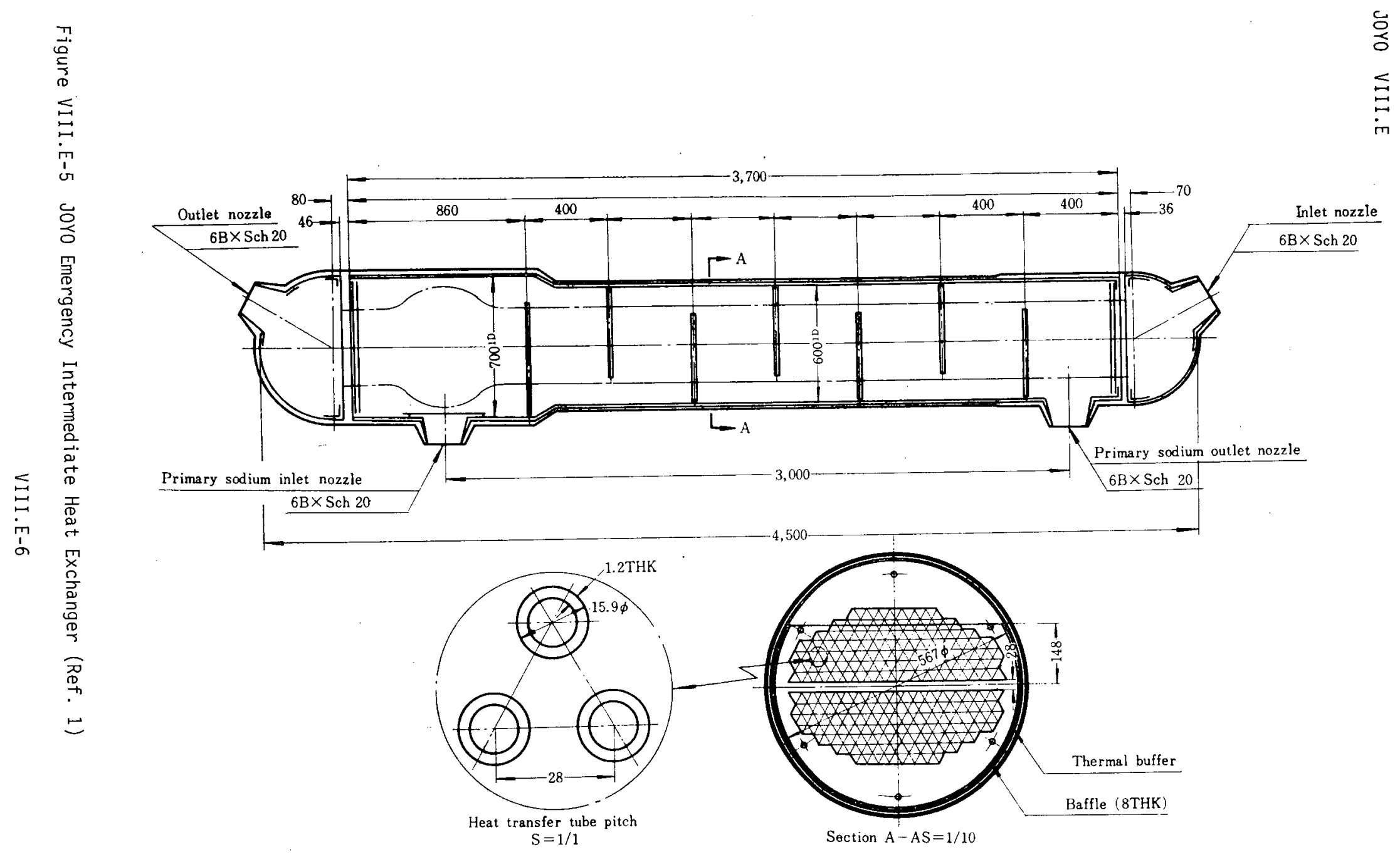


VIII. F. SODIUM PURIFICATION AND INSTRUMENTATION

Primary sodium purification is performed by cold traps, with oxygen concentration being maintained at less than $10 \mathrm{ppm}$. The purification system is connected both to the main loop and to the overflow tank. Sodium for purification is provided by an electromagnetic pump from the suction line of the main pump. After purification, sodium is returned to the shell side of the IHX. Cold-traps can be by-passed when monitoring for oxygen indicates a satisfactory level. The purification loop has one electromagnetic pump, one sampling pot, three plugging sets, one cold trap economizer, two cold traps (one is a spare), and an Nak/air heat exchange unit. (Fig. VIII.F-1)
The secondary purification system is provided by an air-cooled cold trap. It has two loops, with electromagnetic pumps, plugging meter sets, sampling pots, cold traps.

The NaK which is used for the auxiliary cooling system and for cooling the primary loop cold traps is purified by an air-cooled cold trap in a one-loop system. (Ref. 1)

VIII.F-1 
6. Coolant System
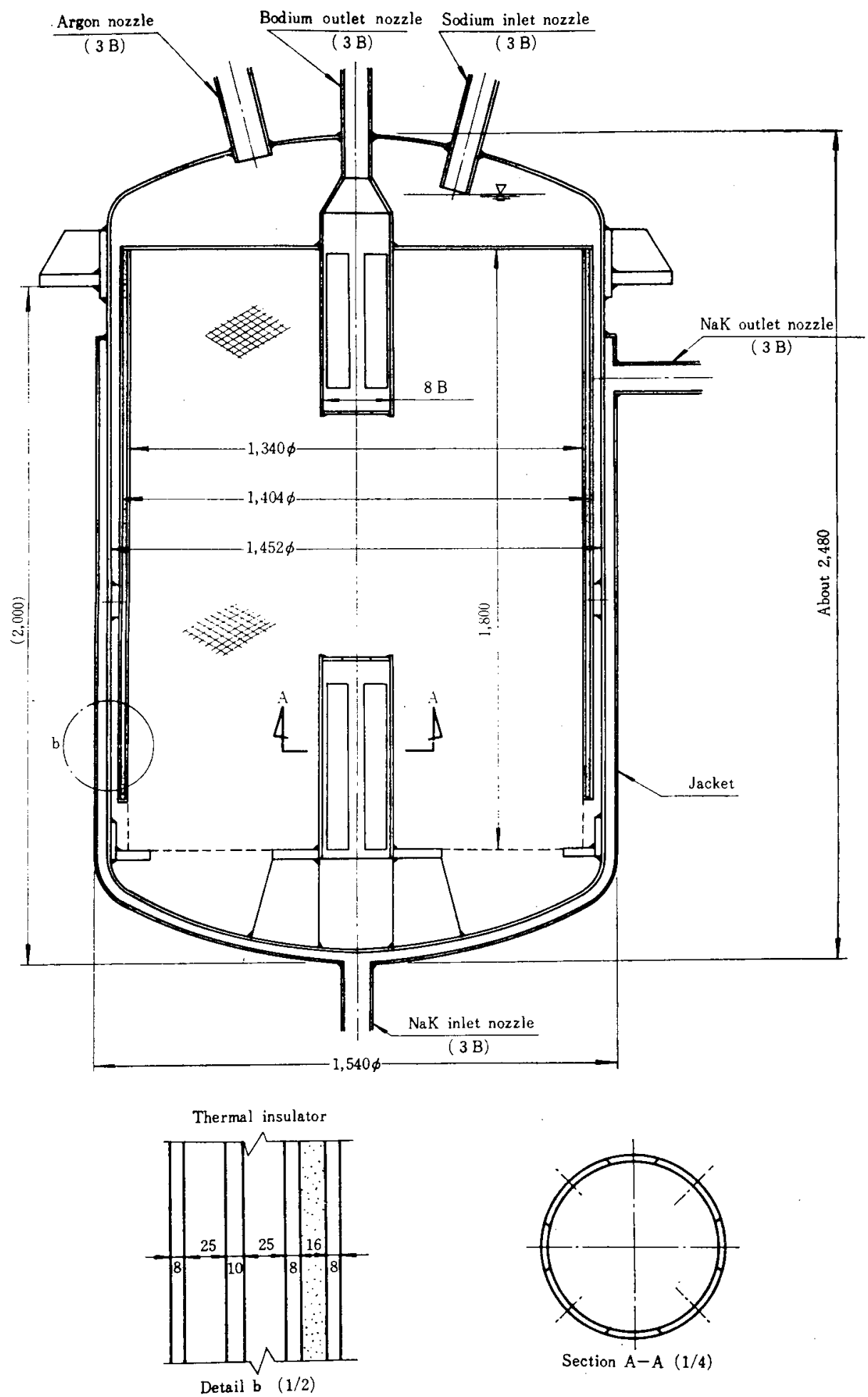

Figure VIII.F-1 JoYo Primary Cold Trap (Ref. 1) VIII. F-2 
VIII. G. COVER GAS AND AUXILIARY SYSTEMS

The primary argon, which is radioactive, is provided by a recirculating system consisting of a buffer tank, pressure reguiating tank, vacuum tank, sodium vapor trap, mist catcher, and compressor. Purge argon used in operation of the refueling machine, blow -down argon for the control rods, and sealing argon for the rotating plugs is supplied from the buffer tank. The secondary, non-radioactive argon is supplied from a secondary argon supply tank. Pressure of the secondary system argon is higher than primary blanket argon pressure. (Fig. VIII.G-1) (Ref. 1)

Nitrogen is used in the spaces in jackets and in the piping annuli. The shield tank and rotating plugs are cooled by forced flow of nitrogen. (Fig. VIII.G-2) 
JOYO VIII.G

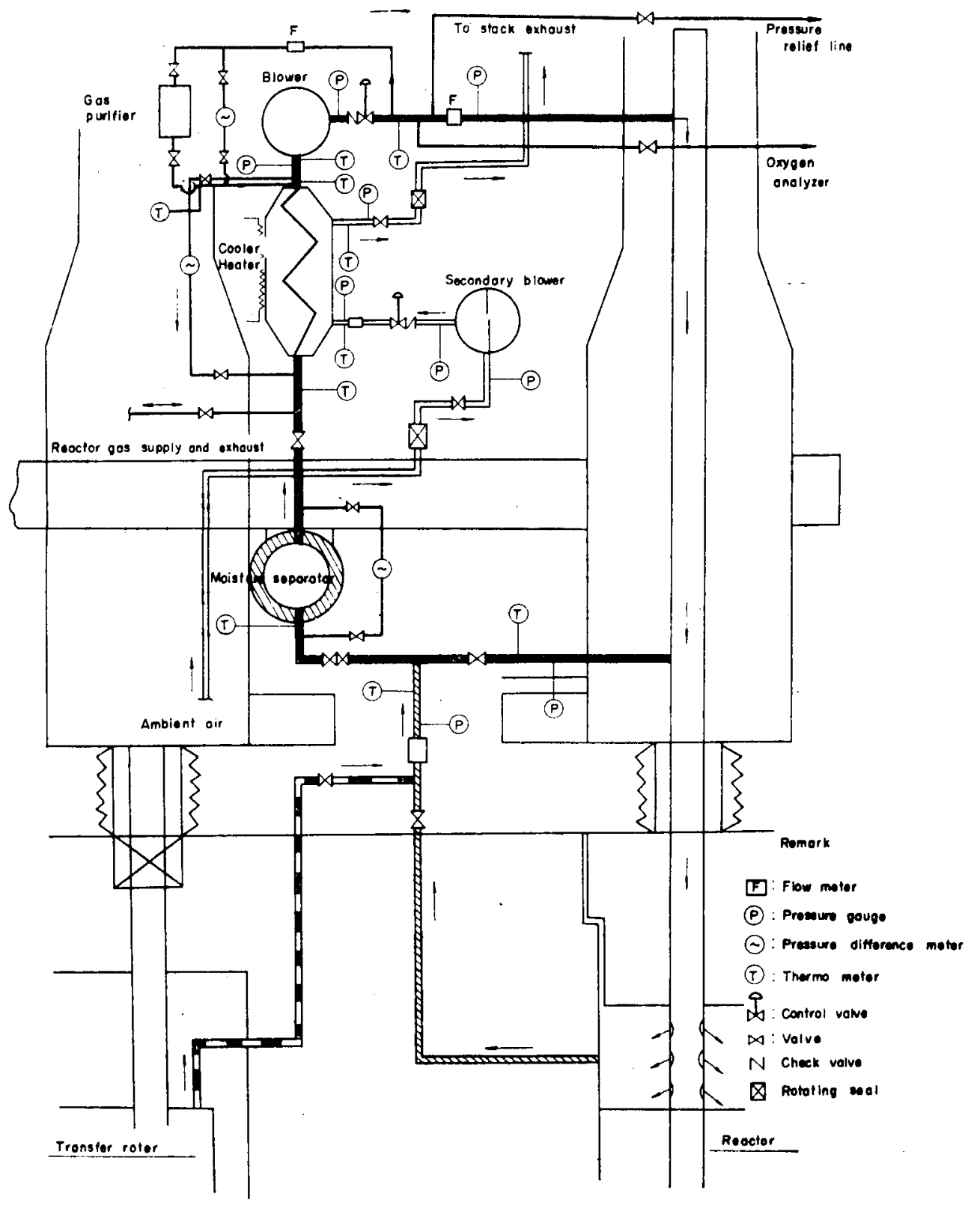

Figure VIII.G-1 JOYO Argon Gas System (Ref. 1)

VIII.G-2 


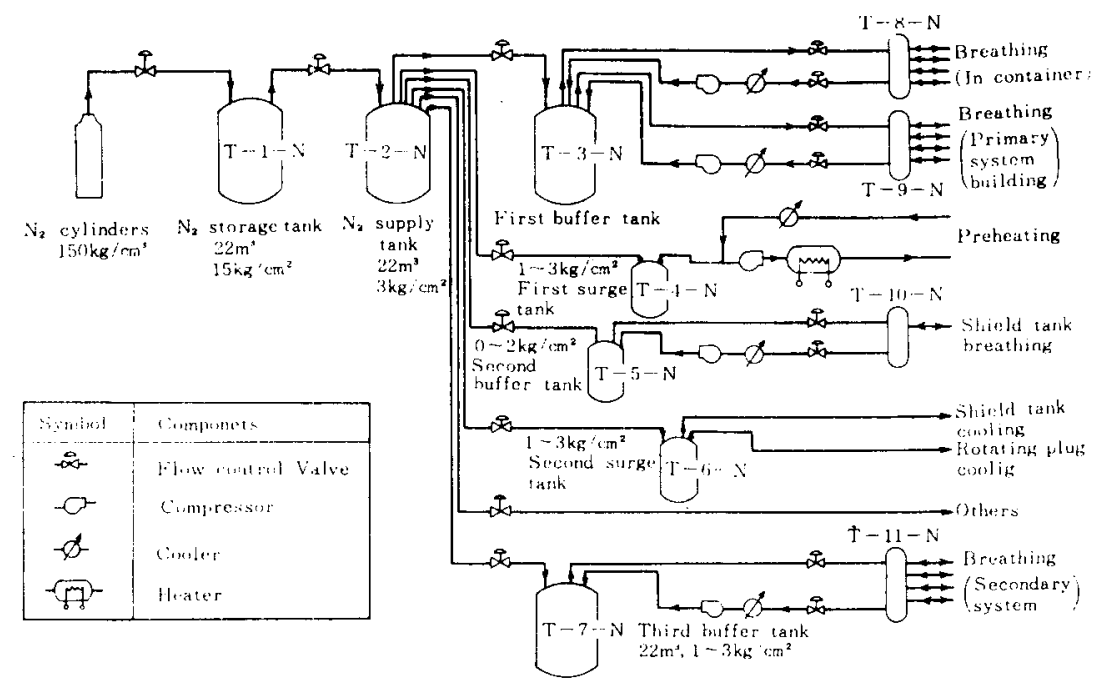

Figure VIII.G-2 JOYO Nitrogen Systems (Ref. 1)

VIII.G-3 
VIII. I. INSTRUMENTATION AND CONTROL

For sodium instrumentation see Section

F.

Reactor power is manually controlled. The plant control system keeps the inlet sodium coolant temperature constant by changing the air flow rate of the main aircooled heat exchanger. This system is automatically or manually controlled by the signal from the inlet temperature monitor. Neutron monitoring systems monitor neutron flux level and reactor period during startup, operation, and shut-down. There are two startup channels, three intermediate power channels, and three linear power channels. Process-instrumentation systems monitor plant performance by measuring temperature, pressure, and flow-rates of sodium and argon gas. Ordinary thermocouples measure the temperature. Electromagnetic flow meters measure sodium flow. Sodium leak detectors are located at many points.
The reactor protection system has automatic functions of shut down by insertion of control rods, and reactor containment isolation by closing valves of pipes and ducts penetrating the enclosure. It also has an interlock system to prevent reactor malfunction.

Delayed neutron monitoring of the sodium coolant, and measurement of fission gases released to the argon cover gas, are used for failed fuel detection.

Instrumentation and control systems are centralized in a control room in the reactor building. (Ref. 2) 
VIII. J. FUEL HANDLING

A refueling machine is used to move the fuel assembly from its core position to an in-vessel storage rack. This machine is set on top of the double rotating plug for the exchange. It can hang any fuel or blanket assembly, and can move it between the core and the storage rack in a liquid sodium environment. The storage rack is used to relay new and spent fuel, and to cool the spent fuel. (Fig. VIII.J-l)
To introduce assemblies into the vessel or to remove them, a charge-discharge machine is used. This machine moves along a rail or a bridge. It moves fuel between the reactor vessel and a transfer rotor. (Fig. VIII.J-2) The transfer rotor can be used for temporary storage of new fuel or for temporary cooling of spent fuel. Fuel is moved between transfer-rotor and new-fuel or spent-fuel storage by a self-driven cask car.

Spent fuel is stored and cooled in a water-pool after washing. 


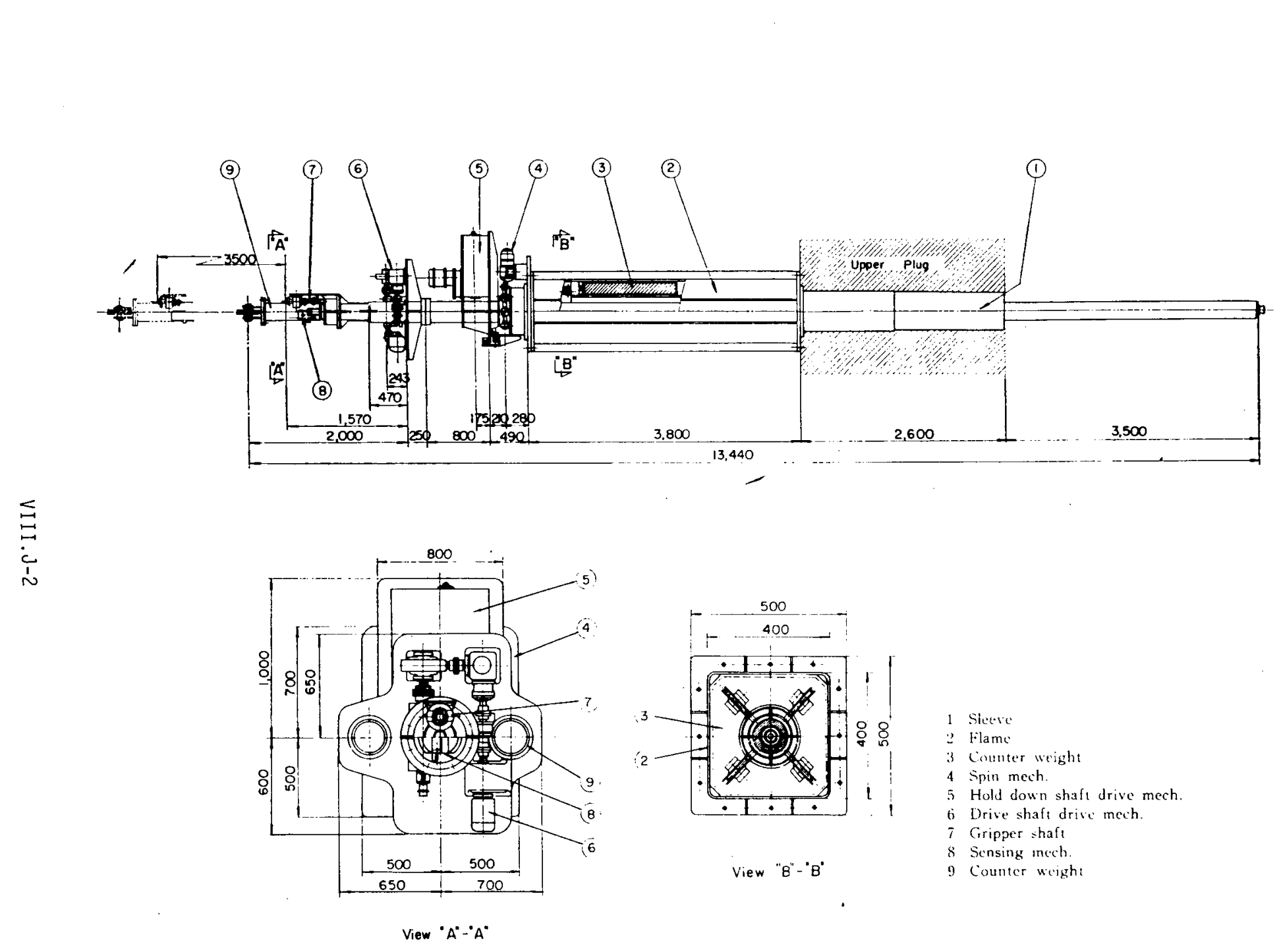

Figure VIII.J-1 JoYo Fuel Transfer Machine (Ref. 1) 

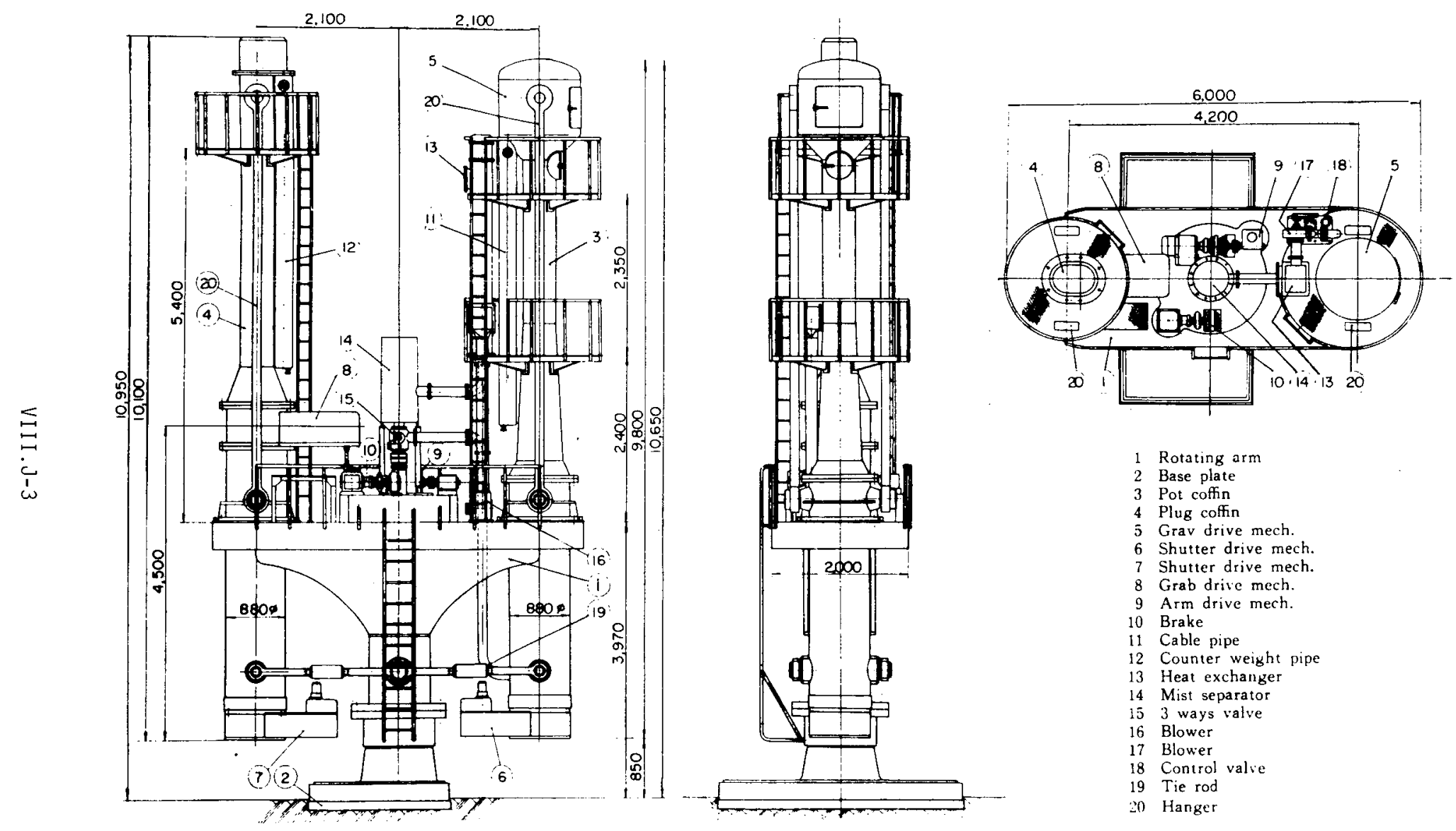

Figure VIII.J-2 JoYo Charge-Discharge Machine (Ref. 1) 


\section{K. CONTAINMENT}

The containment vessel is a steel cylinder with a hemispherical top and semi ellipsoidal bottom. Total height is about $60 \mathrm{~m}$, with $30 \mathrm{~m}$ above ground. Inside diameter is about $28 \mathrm{~m}$. The cylindrical part is surrounded by a concrete wall, with the space between vessel and wall at negative pressure. Air-tight doors are at all. accesses. Separation valves are installed in pipes and ducts between the containment vessel and the annex building.

The operating floor is at ground level. The space above the floor contains atmospheric air. The space below the floor is normally filled with nitrogen gas. A polar crane is installed to handle heavy equipment within the containment vessel. The reactor vessel is located a little north of center. The fuel handling facility is within the containment structure. The intermediate heat exchangers, primary pumps etc. are installed near the reactor vessel.
An annex building partly surrounding the containment vessel has a fuel handling facility, a central control room, a blowerroom, waste-gas tank room etc. In another part of the annex building, an emergency diesel generator room, battery room, secondary system rooms and rooms for air-conditioning, liquid waste etc. are located. Secondary cooling systems are in a maincooling building. The maintenance building is for maintenance and repair of equipment. In the waste disposal building, liquid waste tanks and solid-waste storage are in the basement, and waste-treatment facilities are on the ground floor. (Fig. VIII.K-1) (Ref. 2)

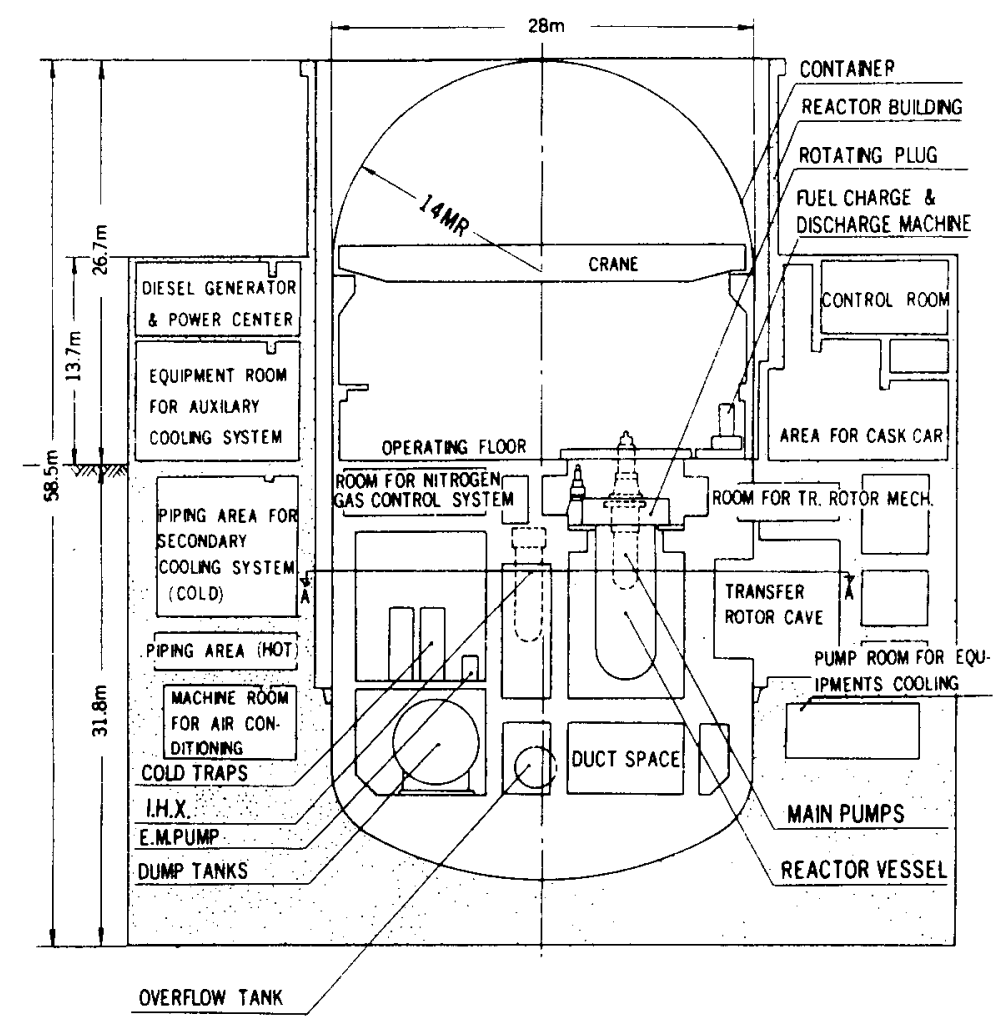

Figure VIII.K-1 JoYO Reactor Building (Ref. 7)

VIII.K- 1 


\section{MONJU IX}

LOCATION: Japan

Monju is a 300 MWe prototype fast reactor. It uses a loop-type configuration. Single-wall piping will be used instead of the double-wall piping called for in the first design studies. Safety analysis reports were continuing in 1974, and critical mockup experiments of the Monju core are being conducted. Sites are being considered for construction of the station. 
0

$\bullet$ 


\section{INDEX}

$\begin{array}{lc} & \underline{\text { Page }} \\ \text { REFERENCES } & \text { IX }-5 \\ \text { REACTOR PARAMETERS } & \text { IX }-7 \\ \text { SECTIONS } & \end{array}$

A. CORE AND BLANKET IX.A-T

B. CORE SUPPORT AND VESSEL INTERNALS IX.B-1

C. REACTOR VESSELS AND SHIELDING IX.C-I

D. CONTROL ELEMENTS IX.D-1

E. HEAT TRANSFER SYSTEMS IX.E-1

F. SODIUM PURIFICATION AND INSTRUMENTATION (NO INFORMATION)

G. COVER GAS AND AUXILIARY SYSTEMS IX.G-1

H. STEAM GENERATORS IX.H- I

I. REACTOR INSTRUMENTATION AND CONTROL (NO INFORMATION)

J. FUEL HANDLING IX.J-1

K. CONTAINMENT IX.K-1 


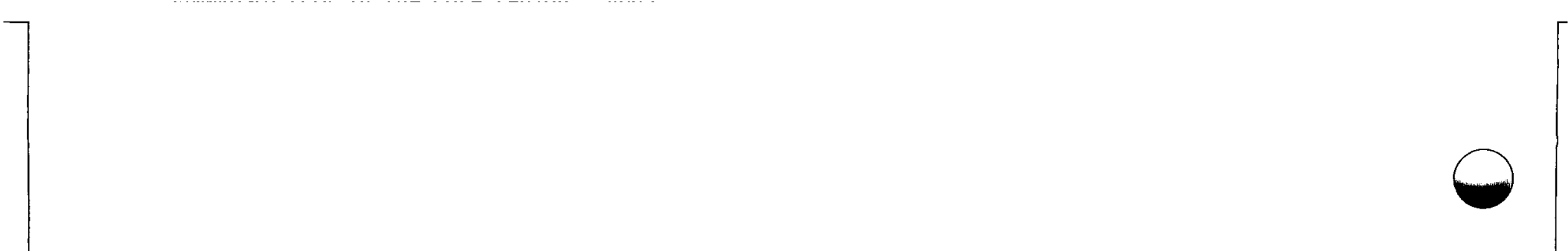

0

0 


\section{REFERENCES}

1. Selection of Safety Design Bases for Monju

K. Terata, et. al.

Proc. Conf. Fast Reactor Safety, Beverly Hills April 1974

Part 1 p. 51-71

CONF-740401-P]

2. Design Basis for Monju Fuel Pin

Power Reactor and Nuclear Fue1 Development Corp.

JAPFNR-32 (1972) From PNC-N-141-72-1-2

3. Present Status of Monju (The Prototype Fast Reactor in Japan). Power Reactor and Nuclear Fuel Development. Corp. JAPFNR-52 (1972) From PNC-N-141-72-1-23

4. Program and Present Status of Fast Breeder Reactor Development in Japan.

P. Oyama, et. al.

Proc. Fourth Int1. Conf. Peaceful Uses Atomic Energy, Geneva 1971 , Vo1. 5 p. 101-114

UN/IAEA, 1972

5. MONJU Heat Transport System

Y. Nakai, et. al.

Fast Reactor Power Stations, Proc. Conf., BNES, London

March 1974, p. 387-392

British Nuclear Energy Society, 1974

6. Reactor and Fuel Handling on PNC Prototype Fast

Breeder Reactor Plant MONJU

Y. Nakai, et. al.

Fast Reactor Power Stations, Proc. Conf., BNES, London

March 1974, p. 597-599

British Nuclear Energy Society, 1974

7. Brief Description of Planned Prototype FBR MONJU of Japan.

R. Miki, et. al

Fast Reactor Power Stations, Proc. Conf., BNES, London March 1974

p. 101-1n4

British Nuclear Energy Society, 1974

8. Steam Generators for the MONJU Power Plant.

Y. Nakai, et. al.

Fast Reactor Power Stations, Proc. Conf., BNES, London, March 1974

p. $157-156$

British Nuclear Energy Society, 1974 


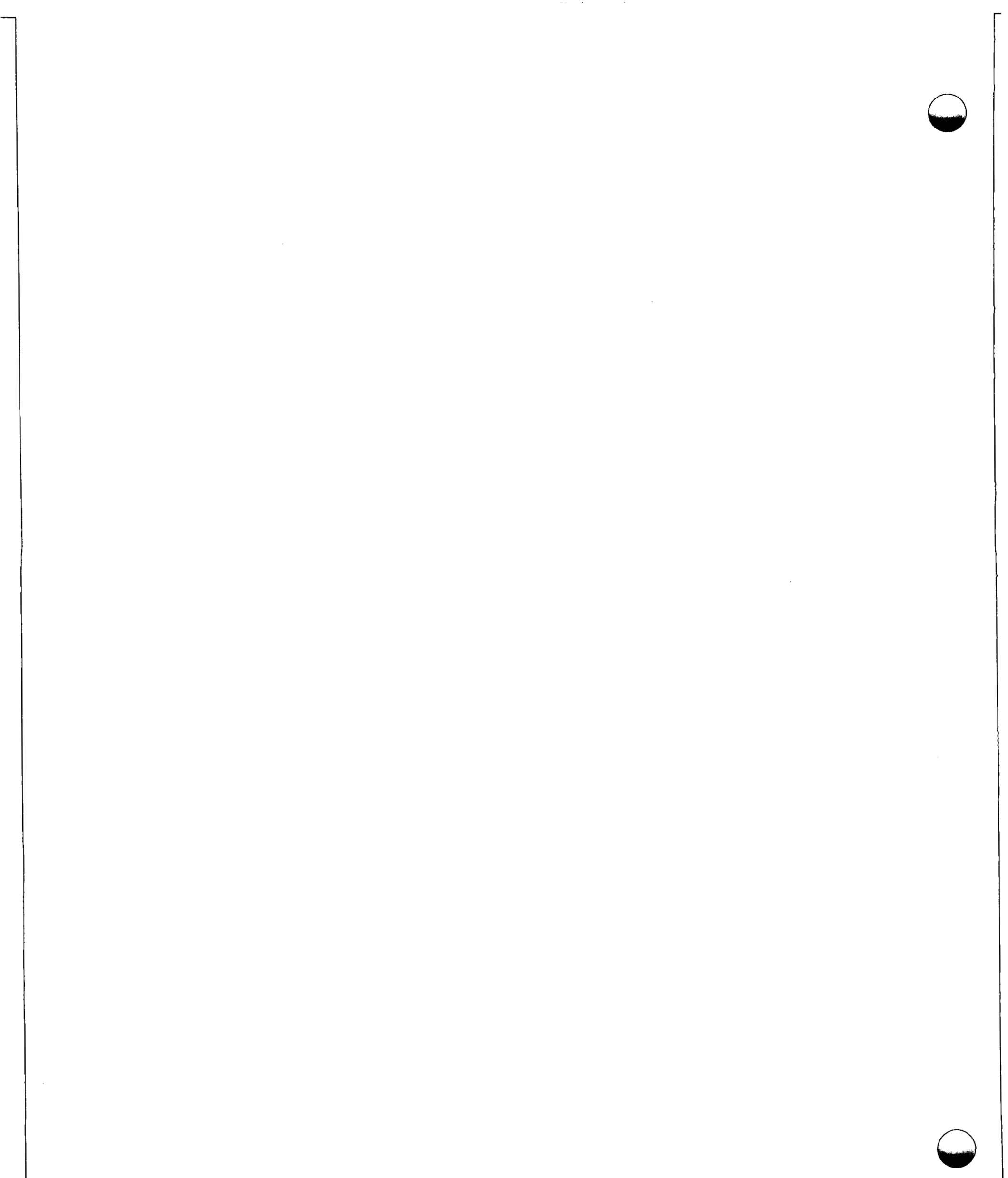


Table - 1

Type

No. loops

Coolant

Core inlet temp.

Core outlet temp.

Flow direction

Driver fuel

Blanket fuel

Core diameter (equivalent)

Core volume

No. enrichment zones in core

Output MWe/MWt

Breeding ratio

Max. can temperature

Linear power, max.

Neutron flux, total

Power Density

No. Driver elements

No. Radial blanket elements

No. In-core control elements

In-Vessel storage positions

Goal burnup
GENERAL PARAMETERS

Loop-type

3

Sodium

$390^{\circ} \mathrm{C}$

$540^{\circ} \mathrm{C}$

Upward

$\mathrm{UO}_{2}-\mathrm{PuO}_{2}$

$\mathrm{UO}_{2}$ depleted

$1780 \mathrm{~mm}$

$2230 \ell$

2

$300 \mathrm{MWe} / 714 \mathrm{MWt}$

ข. 2

$<700^{\circ} \mathrm{C}$

$457 \mathrm{~W} / \mathrm{cm}$

$4 \times 10^{15} \mathrm{n} / \mathrm{cm}^{2} \mathrm{sec}$. (ave.)

$292 \mathrm{KW} / 2$

196

174

19

80

$280,000 \mathrm{MWD} / \mathrm{T}$ 
MONJU IX

Table - 2

CORE AND BLANKET

\begin{tabular}{|c|c|c|c|}
\hline & Driver zone & Axial blanket & Radial blanket \\
\hline Fuel material & $\mathrm{UO}_{2}+\mathrm{PuO}_{2}$ & $\mathrm{UO}_{2}$ depleted & $\mathrm{UO}_{2}$ depleted \\
\hline Form & Sintered pellet & Sintered Pellet & Sintered Pellet \\
\hline Composition & Inner $16 \mathrm{v} / \mathrm{O}^{\mathrm{PuO}}$ & & \\
\hline- & Outer $22 \mathrm{v} / \mathrm{O}_{2} \mathrm{PuO}_{2}$ & & \\
\hline${ }^{235} \mathrm{U} / \mathrm{U}$ & $0.2 \mathrm{w} / 0$ & & \\
\hline $\mathrm{PuO}_{2} /\left(\mathrm{PuO}_{2}+\mathrm{UO}_{2}\right)$ inner & $22.64 \mathrm{a} / \mathrm{o}$ & & \\
\hline outer & $31.0 \mathrm{a} / 0$ & & \\
\hline $240 \mathrm{Pu}$ & $25 \%$ & & \\
\hline Density & $85 \%$ TD & $93 \%$ TD & $93 \%$ TD \\
\hline Pellet od & $5.4 \mathrm{~mm}$ & & \\
\hline Rod cladding & Stainless steel (316) & & Stainless steel \\
\hline od & $6.5 \mathrm{~mm}$ & & $11.6 \mathrm{~mm}$ \\
\hline Wall thickness & $0.45 \mathrm{~mm}$ & & $0.5 \mathrm{~mm}$ \\
\hline Bond material & Helium & & \\
\hline Column length & $900 \mathrm{~mm}$ & $350 \mathrm{~mm} \times 2$ & $1600 \mathrm{~mm}$ \\
\hline Gas plenum length & $1130 \mathrm{~mm}$ Top & & \\
\hline Vented/non-vented & No & & No \\
\hline Assembly material & Stainless steel & & Stainless steel \\
\hline Shape & Hexagonal & \multirow{12}{*}{ 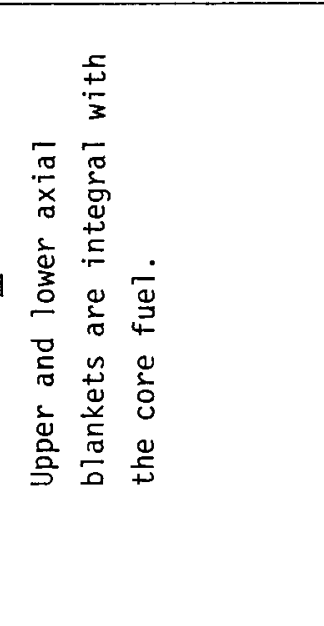 } & Hexagonal \\
\hline Across flats (dia.) & $110.6 \mathrm{~mm}$ & & $110.6 \mathrm{~mm}$ \\
\hline Wall thickness & $3 \mathrm{~mm}$ & & $3 \mathrm{~mm}$ \\
\hline Overall length & $4200 \mathrm{~mm}$ & & $4200 \mathrm{~mm}$ \\
\hline No. pins/assembly & 169 & & 61 \\
\hline Pin spacing & wire or honeycomb grid & & wire \\
\hline Pin pitch & $7.9 \mathrm{~mm}$ & & $13.1 \mathrm{~mm}$ \\
\hline Assy. pitch & $115.6 \mathrm{~mm}$ & & \\
\hline Assy. in core & 196 & & 174 \\
\hline Fuel $\left(\mathrm{UO}_{2}+\mathrm{PuO}_{2}\right)$ & $32.8 \%$ & & \\
\hline Steel & $23.4 \%$ & & \\
\hline Sodium & $41.3 \%$ & & \\
\hline
\end{tabular}

IX -8 
IX. A. CORE AND BLANKET

The Monju core has 196 fuel assemblies with 2-region enrichment, 174 blanket assemblies arranged in three rows around the fuel core, nineteen control assemblies, and four rows of stainless steel reflectors. Assemblies are sealed. In the fuel assembly the upper and lower axial blanket pins are integral with the fuel core. Control assemblies have $\mathrm{B}_{4} \mathrm{C}$ as an absorber.
Each fuel assembly has three grid supports for the pins. Pin pitch is maintained over the length of the element by a $1.3 \mathrm{~mm}$ od stainless steel wire spacer or a honeycomb grid spacer. Radial blanket pins are spaced by stainless steel wire. Fixed orifices, in the bottom of the assembly, control sodium distribution to the core. 
MONJU IX.B

IX. B. CORE SUPPORT AND VESSEL INTERNALS

A core support structure is above the sodium inlet plenum. The plenum has a hydraulic holddown arrangement for the assemblies. A core restraint mechantsm applies restraining force against radial motion and positions the core during refueling.
The support grid consists of upper and lower plates with openings for the assembly feet. The outer core-clamping mechanism is similar to mockup experiments for FFTF and AI demonstration reactors. An inner clamping system applies to laterally movable pads on central control or fuel assembly surrounded by six assemblies. 


\section{C. REACTOR VESSELS AND SHIELDING}

The reactor vessel is a double-walled vertical cylinder, with three 26-in. diameter inlet nozzles at the base and three 32-in. diameter nozzles above the core. Upon completion of the third design, it was decided to incorporate a leak-tight barrier around the reactor and primary system. The space between vessels will be filled with nitrogen gas. The addition of this leak or guard vessel has made it possible to use single-wall piping rather than double-wall piping for the primary loops. The reactor vessel is about $6.3 \mathrm{~m}$ in diameter and $16.0 \mathrm{~m}$ high. It is closed at the top by a double shield plug, which has only one rotating piece. The vessel is hung by a device on the upper part. These vessels are housed in a safety vessel which is inside the concrete biological shield structure.

(Fig. IX.C-1)

The fixed plug has a diameter of $\sim 8 \mathrm{~m}$. The rotating plug diameter is about $41 / 2 \mathrm{~m}$. Overall thickness is $2-3 \mathrm{~m}$. Freeze seals are used. Ref. $(4,7)$

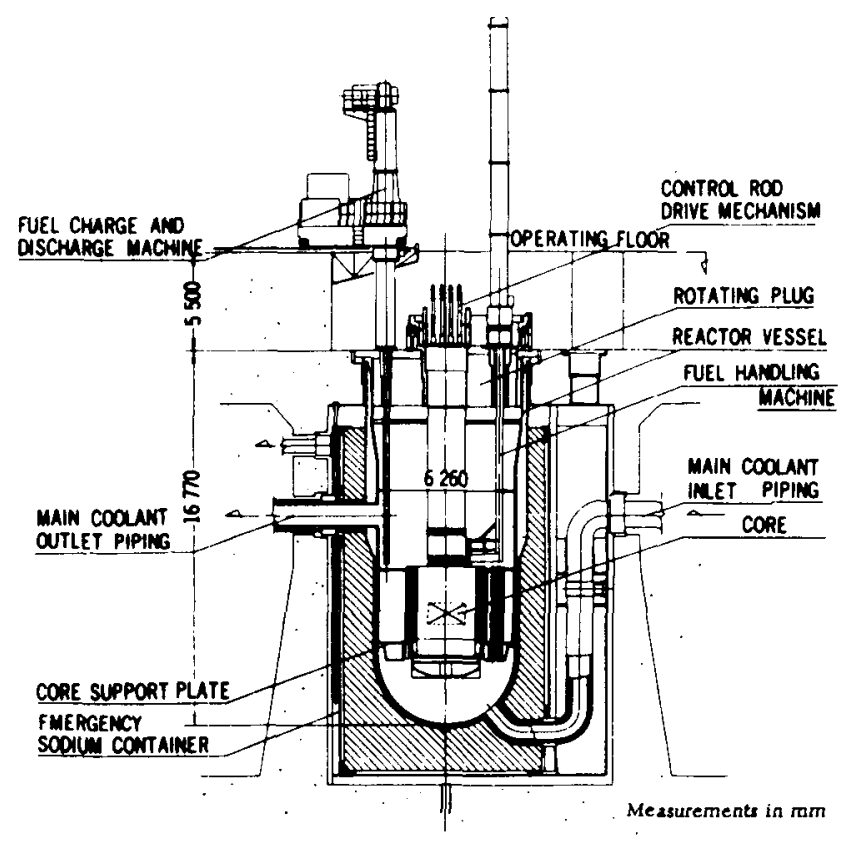

Figure IX.C-1 MONJU Reactor Structure (Ref. 4) 
MONJU IX.D

IX. D. CONTROL ELEMENTS

There are nineteen control elements, consisting of three regulating rods, nine: shim rods, four safety rods, and three back-up shut down rods. $\mathrm{B}_{4} \mathrm{C}$ is the poison material.

IX.D-1 


\section{E. HEAT TRANSFER SYSTEMS}

There are three primary and three secondary loops. Each primary loop includes an intermediate heat exchanger, pump, check valves and piping. The secondary loop includes flow control and stop valves, a steam generator set, pump and piping. pumps are located in cold legs. All piping is single-walled. With adoption of the single-pipe system, a siphon-breaker system included in earlier designs has been dropped. All primary heat transport systems are placed in guard vessels, which let the primary system act in an auxiliary coolant mode in case of sodium leakage. (Fig. IX.E-1)

When the primary system is utilized as an auxiliary or emergency core cooling system, primary sodium flows from the reactor vessel across the auxiliary heat transfer coil, which is contained in the same shell (IHX) as the main heat transfer section. The auxiliary section is a coiled type tube heated outside the shroud. The main section of the IHX is a straight vertical type tube with no free sodium surface. Each auxiliary coolant section feeds to its own, independent secondary system, with heat rejected by air coolers. Electromagnetic pumps move the fluid in these auxiliary loops. (Fig. IX.E-2)
The primary pumps are long-shaft centrifugal units with free sodium surface. Internals are removable. They are equipped with cyclic converter type controllers. The same controller is used in case of auxiliary mode operation at $15 \%$ of the maximum operational speed. Overflow is a simple overflow type column type with the overflow piped back to the suction of the pump. The pump is operable with the sodium level inside the reactor at approximately $4.5 \mathrm{~m}$ below normal level. Pump design is still under development.

Monju has an auxiliary 3 MW loop driven by an electromagnetic pump which can lower the sodium level to inspect the tops of fuel assemblies. Each assembly has flow-holes near the upper end which allow a small sodium flow to be maintained.

A major development program for valves is in progress. Two globe-type twelve inch valves, one with a bellows seal and one with a freeze seal, are first in the program. Twenty-two inch gate valves and twenty-six inch check valves have been manufactured and tested. Butterfly valves are under construction. A thirty-two inch valve is being considered for primary system use. Cold traps and flow-meters are being studied. (Ref. 5)

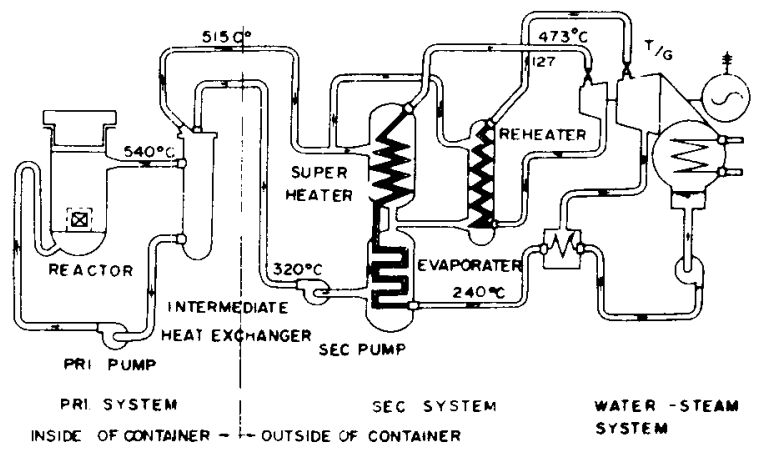

Figure IX.E-1 MONJU Flow System (Ref. 7)

$$
\text { IX.E-T }
$$




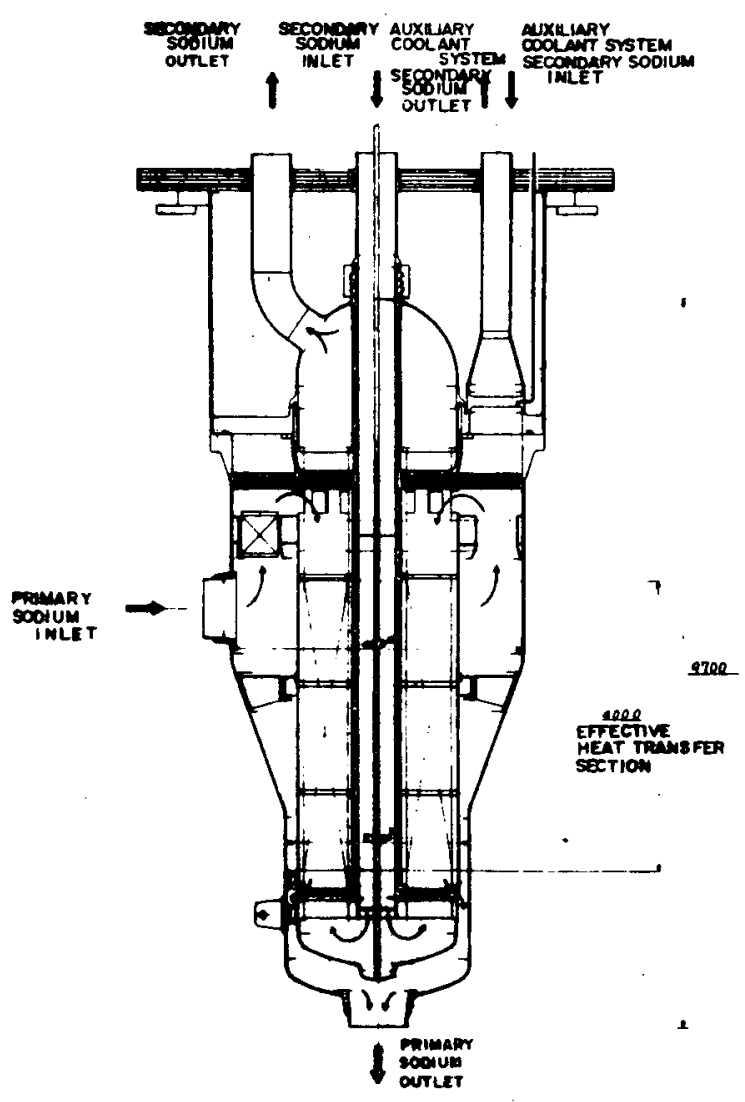

Figure IX:E-2 MONJU Intermediate Heat Exchanger (Ref. 5)

$$
\text { IX.E-2 }
$$


IX. G. COVER GAS AND AUXILIARY SYSTEMS

\section{(Emergency auxiliary cooling system.} See Section E)

Cover gas is argon. The circulation system is closed-cycle and pressure of the cover gas is about $0.3 \mathrm{~kg} / \mathrm{cm}^{2} \mathrm{~g}$. Reactor cover gas can be closed off in case of primary sodium leakage. There is a ful 1flow gas cleaning system of the nitrogen cooled fractionating type.
The preheating system for the primary system is under investigation. The system being considered is a combination of electric resistance heaters, inner argon preheating system, and outer nitrogen preheating system. (Ref. 5) 
IX. H. STEAM GENERATORS

Each secondary loop includes one steam generator set. The system consists of an evaporator, a reheater, and a superheater. Thermal output for full load is $238 \mathrm{MW}$ per 10op. The generators have been designed for a series-parallel reheat cycle, with an evaporator and a superheater operating in series, and a superheater-reheater operating in parallel. Monju will operate down to $30 \%$ partial load. At full load the generators will operate as a once-through unit, but this may be changed to recirculation operation, depending on the outcome of studies.

Sodium at $515^{\circ} \mathrm{C}$ from the IHX separates and flows into the superheater and reheater. Flow ratio is regulated by a flow control valve and fixed orifices at locations in the secondary system. The sodium is then recombined before entry into the evaporator. Temperature at this time is about $454^{\circ} \mathrm{C}$. It leaves the evaporator at $320^{\circ} \mathrm{C}$ and is sent back to the IHX.

On the water side, slightly superheated steam extracted from turbine flow goes through a water-steam separator located between evaporator and superheater. Outlet steam flows into the superheater and exits at $487^{\circ} \mathrm{C}$ and $133 \mathrm{~kg} / \mathrm{cm}^{2} \mathrm{~g}$ to the high pressure turbine. Low pressure steam from the turbine returns to the preheater to generate reheated steam.

Cover gas and sodium are monitored for hydrogen to detect sodium-water reactions. A relief system is provided which includes a reaction product separator. The hydrogen gas after separation is blown out to the atmosphere via a check valve.

(Fig. IX, H-3)

The steam generator is a helical coil type with downcomers and a free sodium surface. The top head is assembled with the lower shell and bolted flanges. The tube support bundle is supported from the top head and is removable. Tube sheets are sodium. A stainless steel liner is installed between the helical coil bundle and the main shell. An overflow and a sodium makeup nozzle are installed. No such nozzles are s used for the superheater or reheater.

(Fig. IX.H-1, H-2) (Ref. 3) 
MONJU IX.H

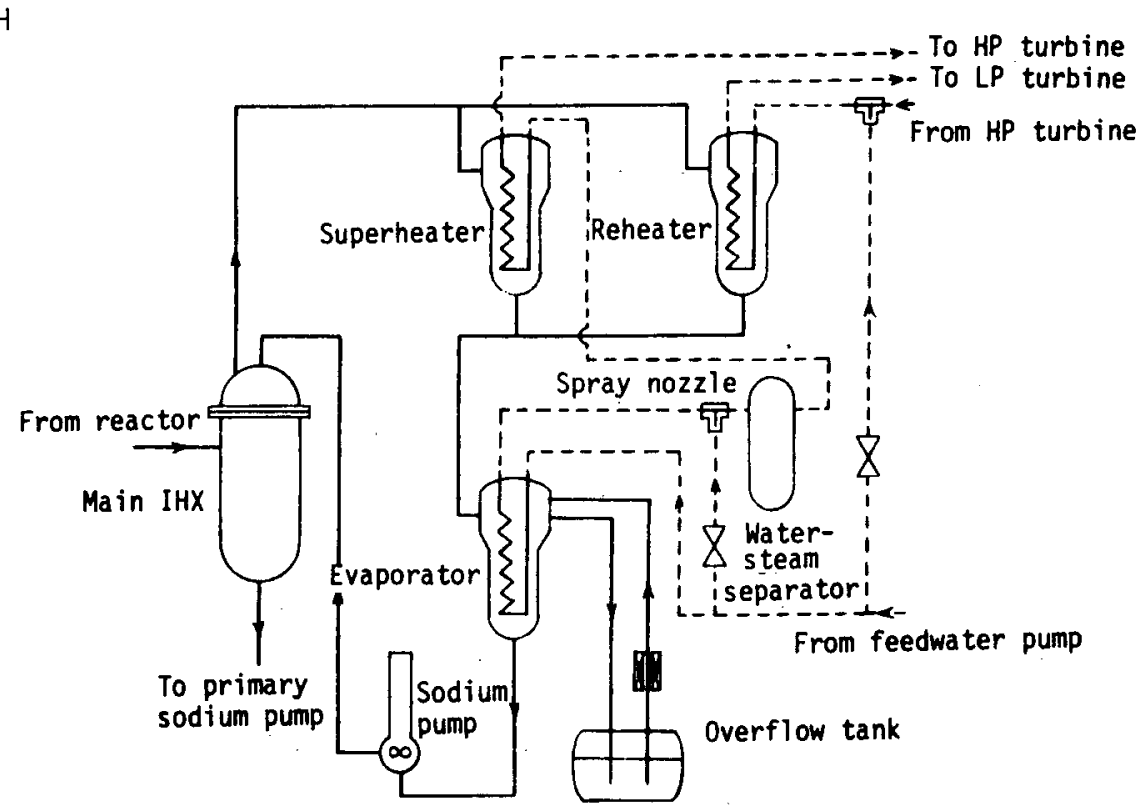

Figure IX.H-1 MONJU Steam Generator Flow Diagram (Ref. 8)

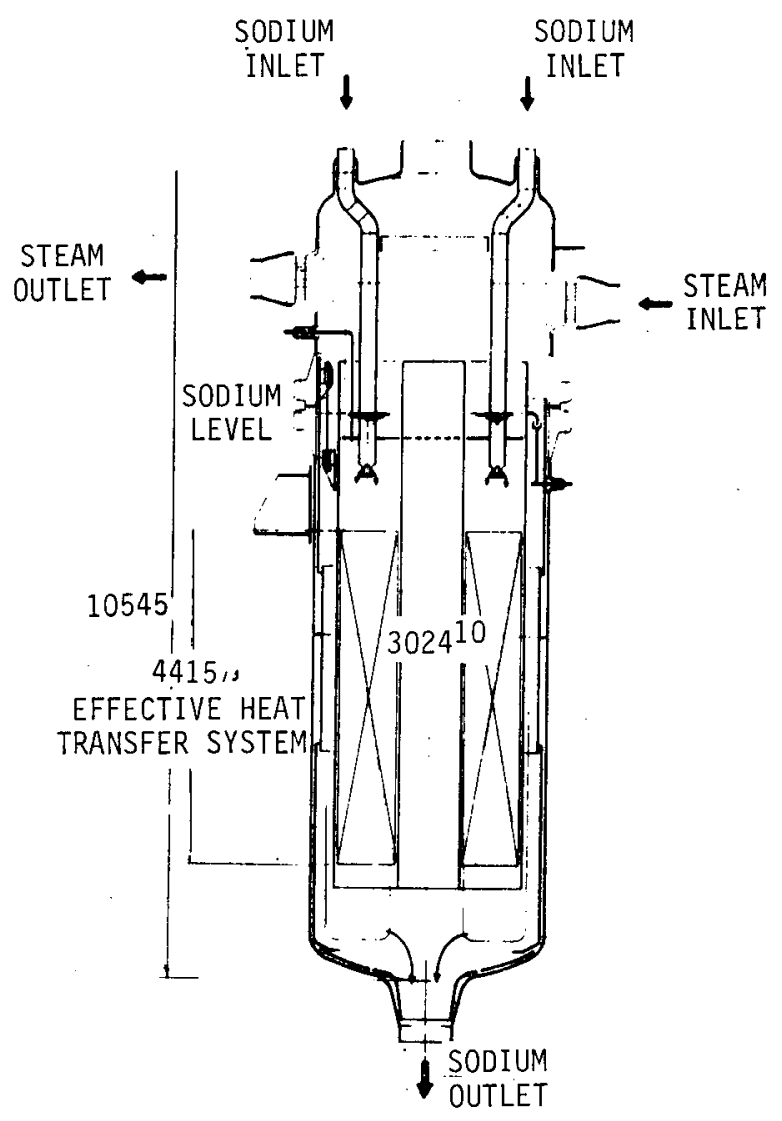

Figure IX.H-2 MONJU Steam Generator (Evaporator) (Ref. 8)

IX.H-2 


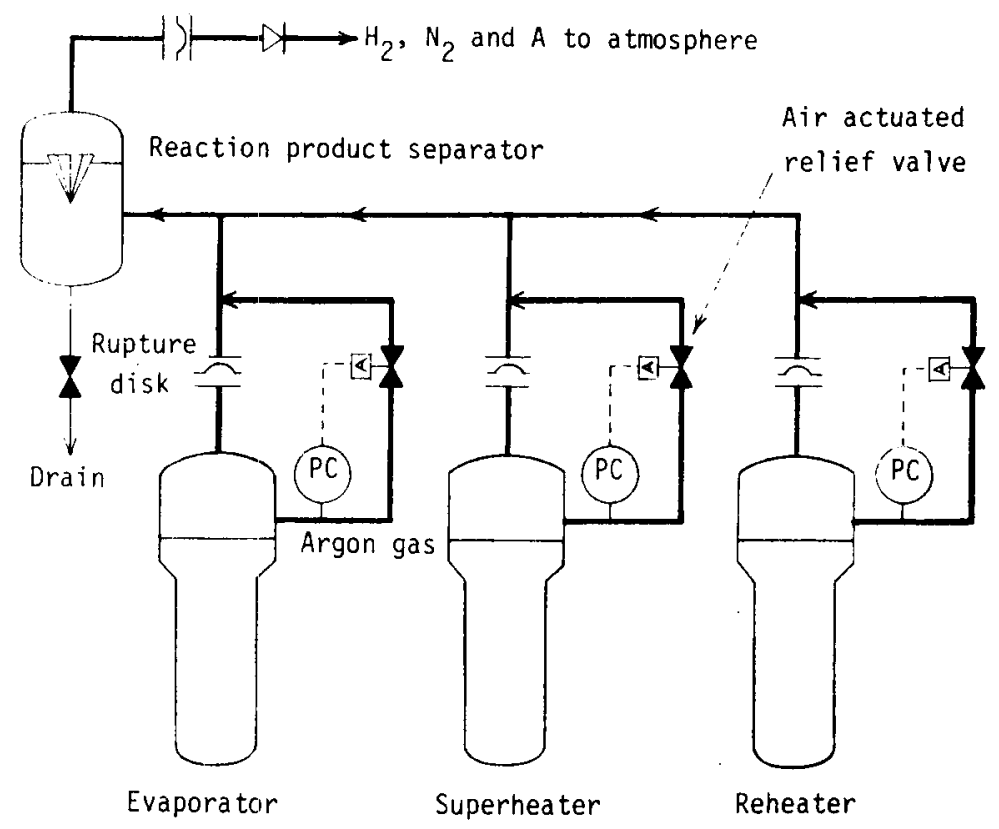

Figure IX.H-3 MONJU Typical Relief System (Ref. 8)

IX. H-3 
MONJU IX.J

IX. J. FUEL HANDLING

An under-the-plug-system by means of a single rotating plug and a rotating arm fuel handling machine is designed for

Monju. Spent fuel is transferred from the core position to an in-vessel storage rack. There are eighty storage positions available. A charge-discharge machine transfers the element to an ex-vessel transfer machine. A cask-car is used to transfer the element to a spent fuel storage tank. A cleaning facility and a spent fuel water pool

complete the sequence. After inspection, new fuel follows this path from a new fuel storage position to the core or blanket position. From forty to forty-two fuel assemblies and twenty-three blanket assemblies are exchanged at approximately six month intervals.

IX.J-1 
IX. K. CONTAINMENT

The reactor vessel is a low-leakage steel structure. A reactor pit contains

the reactor, and a reactor access pit.

Equipment cells are kept in an atmosphere of nitrogen. The cylindrical steel containment structure is located in the center of a rectangular reactor building.

(Fig. IX.K-1) (Ref. 7) 


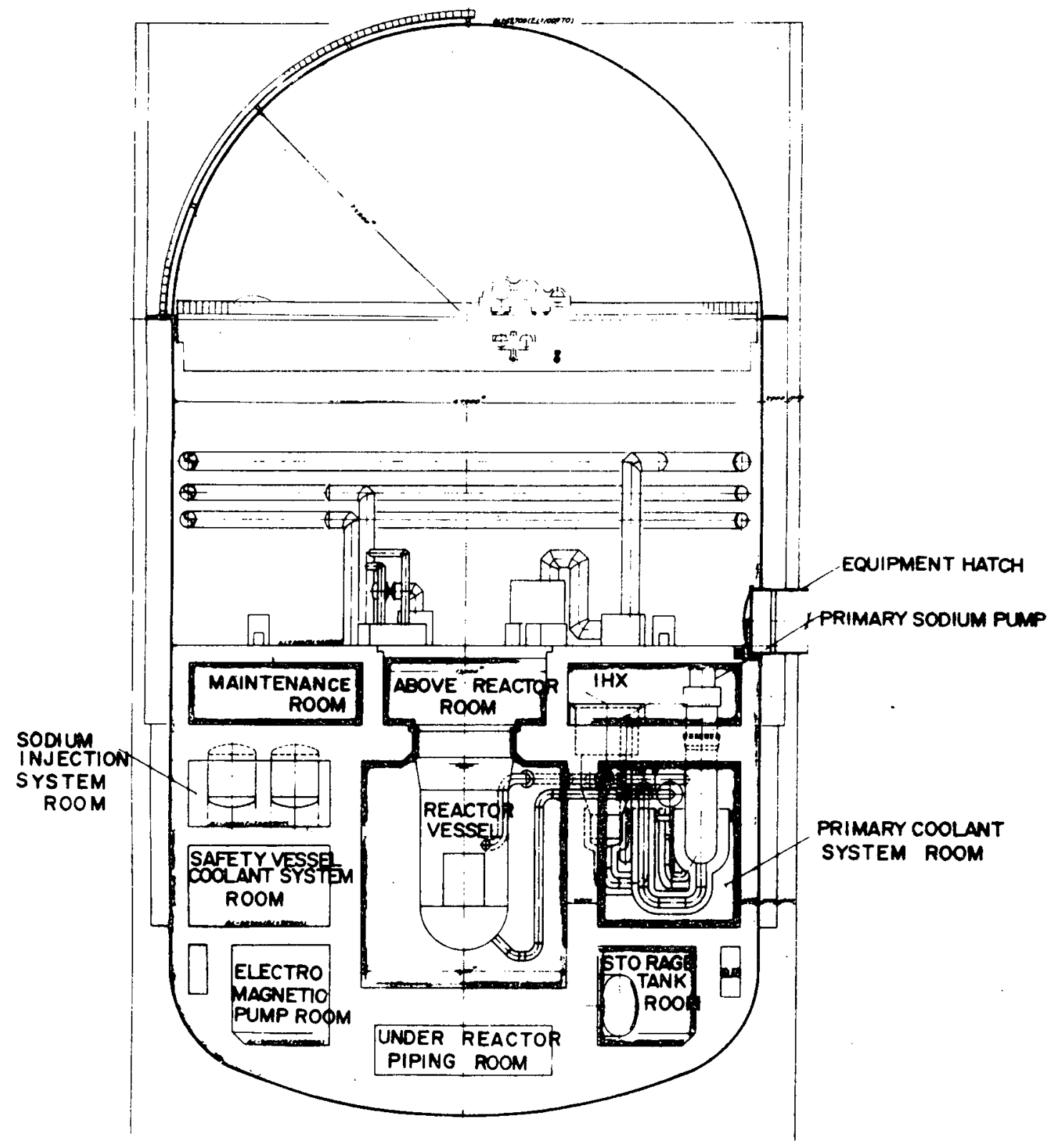

Figure IX.K-1 MONJU Reactor Building (Ref. 4)

IX.K-2 
$x$ KiNk

$$
\begin{aligned}
& \text { LOCATION: Karlsruhe, Germany } \\
& \text { OPERATION: August, } 1971
\end{aligned}
$$

The KNK reactor was designed by Interatom in 1964 as a prototype sodiumcooled, zirconium hydride moderated reactor for energy production. It has been decided to introduce a fast core, which is targeted for operation in 1975. KNK-1 began operation in August 1971. The fast-core system is known as KNK-2. It will serve as a test bed for fast reactor fuel elements. 
INDEX

Page

REFERENCES

$x-5$

REACTOR PARAMETERS

$x-7$

SECTIONS

A. CORE ASSEMBLIES X.A-1

B. CORE SUPPORT AND VESSEL INTERNALS X.B-1

C. REACTOR VESSELS AND SHIELDING X.C-1

D. CONTROL ELEMENTS X.D-1

E. HEAT TRANSFER SYSTEMS X.E-T

F. SODIUM PURIFICATION AND INSTRUMENTATION (NO INFORMATION)

G. COVER GAS AND AUXILIARY SYSTEMS

(NO INFORMATION)

H. STEAM GENERATORS X.H-1

I. REACTOR INSTRUMENTATION AND CONTROL (NO INFORMATION)

J. FUEL HANDLING

X.J-1

K. CONTAINMENT X.K-1 

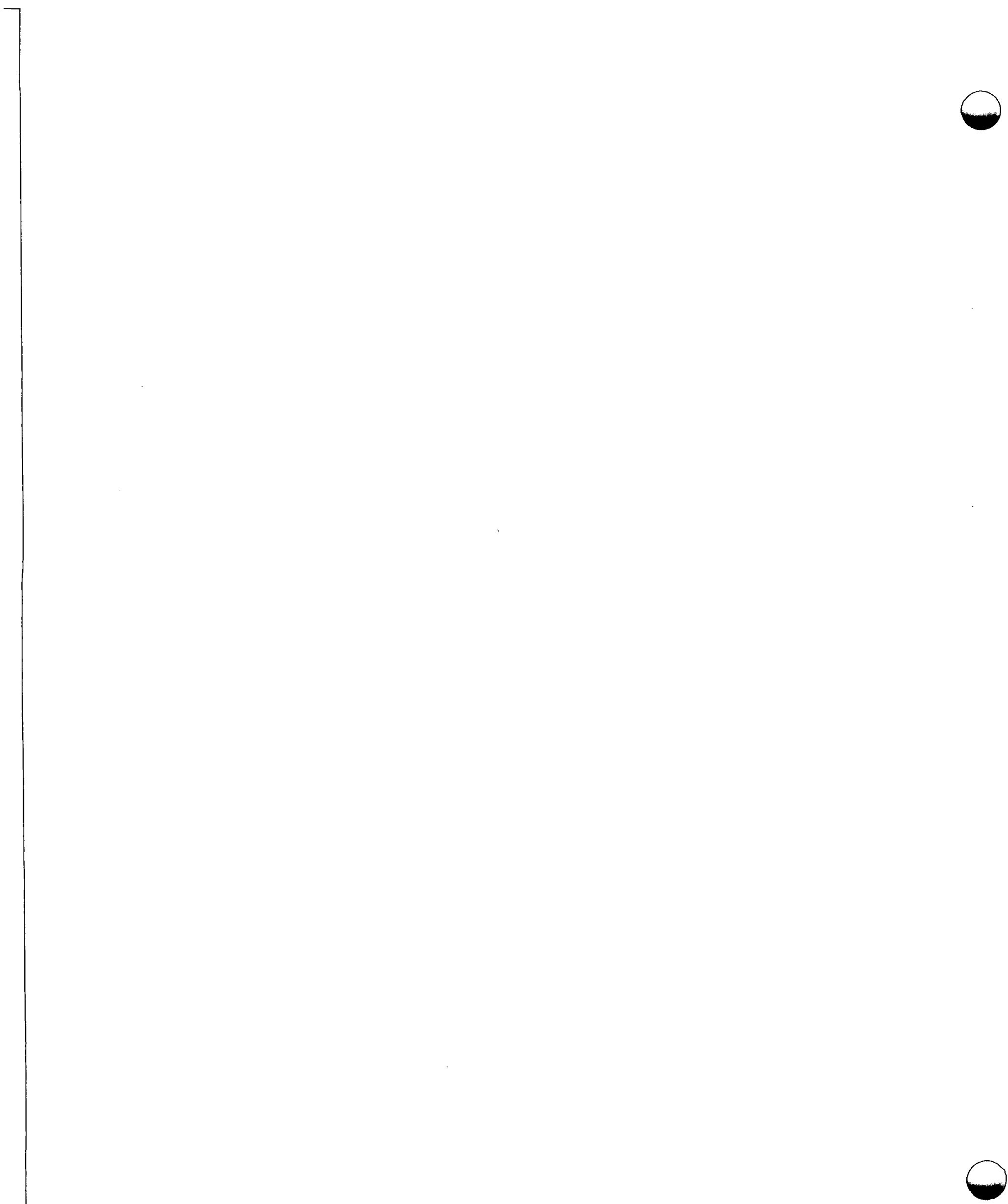


\section{REFERENCES}

1. A Sodium-Cooled Power Reactor Experiment Employing Zirconium-Hydride Moderator R. Harde, K. W. Stohr Proc. Third Intl. Conf. Peaceful Uses of Atomic Energy, Geneva 1964 Vol. 6 p. 353-361 UN. 1965

2. Safety Aspects of the Experimental Power Station KNK Nuclear Engineering Vol. 10p. 335-337 (Sept. 1965)

3. KNK (Kompakte Natriumgekuhlte Kerneaktoranlaze). Directory of Nuclear Reactors Vol. 7 p. 319-326 (1968) IAEA, ST1/PUB/174 (1968)

4. Physics Considerations in the Design of, and Mockup Experiments in SNEAK, for KNK-2

D. Eitner, et. al.

Physics of Fast Reactor Operation and Design, Proc. Int1. Conf., London, June 1969 p. 201-212

British Nuclear Energy Society, 1969

5. The Role of the KNK-2 Facility for the Development of SNR Fuel Subassemblies H. Mayer, H. Andres Proc. American Nuclear Society Topical Meeting, Irradiation Experimentation in Fast Reactor, Jackson Lake Wyoming, Sept, 1973, p. 166-185 ANS, 1973

6. Operating Experience with the KNK Reactor and Preparations for a Mixed-0xide Core (KNK-2) G. Brudermuller, et. al. Fast Reactor Power Stations, Proc. Conf., BNES, London, March 1974 p. 111-118 British Nuclear Energy Soc. 1974

7. Diverse Shutdown Systems for KNK-1, KNK-2, and SNR-300 Reactors.

F. H. Morgenstern, et. al.

Proc. Fast Reactor Safety Meeting, California, Apri1 1974

Part 3, P. 1349-1369

CONF-740401-P3 (1974)

8. Tests of Tube-in-Tube Sodium-Heated Steam Generator

E. Buscher, et. al.

Proc. Intl. Conf. Sodium Technology and Large Test Reactor

Design, Nov. 1968

ANL-7520 Part 1 p. $335-344$

9. Status of Sodium-Water Reaction Test Work at Interatom K. Dumm, et. al.

Proc. Int1. Conf. Sodium Technology and Large Test Reactor Design, Nov. 1968 ANL-7520 Part I p. 374-383

10. Experience with Handling Core Subassemblies in Sodium-Cooled Reactor KNK and Test Rigs D. Althaus, et. al.

Fast Reactor Power Stations, Proc. Conf. BNES, London, March 1974 p. 545-554

British Nuclear Energy Soc. 1974

11. Directory of Nuclear Reactors

Vol. VII. p. 320 Section A-A

International Atomic Energy Agency 
KNK-1 $\times$

Table - 1

Type

No. loops

Coolant

Core inlet temp.

Core outlet temp.

Flow direction

Driver fuel

Core diameter

No. enrichment zones in core

Output MWe/MWt

Linear power, max.

Doppler $(\Delta k / k) /{ }^{\circ} \mathrm{C}$ tota $]$

Power Density Ave.

No. Driver elements

No. In-core control elements

Test positions

Goal burnup
GENERAL PARAMETERS

$\mathrm{ZrH}$ moderated thermal reactor, loop-type 2 $\mathrm{Na}$ $410^{\circ} \mathrm{C}$ $560^{\circ} \mathrm{C}$ Upward $\mathrm{UO}_{2}$ $1292 \mathrm{~mm}$ 1 20 MWe $/ 58$ MWt $500 \mathrm{~W} / \mathrm{cm}^{2}$ positive $33 \mathrm{MWt} / \mathrm{T}$ 66 9 14 $10,000 \mathrm{MWD} / \mathrm{T}$ 
KNK- $1 \quad X$

Table - 2

CORE AND BLANKET

Driver Zone

Fuel material

$\mathrm{UO}_{2}$

\begin{tabular}{|c|c|c|}
\hline Form & Pellet & \\
\hline $235 U$ & $6.8 \mathrm{a} / 0$ & - \\
\hline Pellet od & $8.7 \mathrm{~mm}$ & \\
\hline Rod cladding & Stainless steel & \\
\hline od & $9.5 \mathrm{~mm}$ & \\
\hline Wall thickness & $0.3 \mathrm{~mm}$ & \\
\hline Bond material & $\mathrm{He}$ & \\
\hline Column length & $1045 \mathrm{~mm}$ & \\
\hline Assembly material & Stainless steel & \\
\hline Shape & Cylindrical & \\
\hline Diameter & $\approx 128 \mathrm{~mm} \mathrm{od}$ & \\
\hline No. pins/assembly & 44 & \\
\hline Pin spacing & Lower grid & . \\
\hline Assy. pitch & $129 \mathrm{~mm}$ & \\
\hline Assy. in core & 66 & \\
\hline \multicolumn{3}{|l|}{ Volume fraction } \\
\hline Fuel Vol.\% & 18.3 & \\
\hline Steel & 6.0 & \\
\hline Sodium & 34.9 & \\
\hline $\mathrm{ZrH}$ & 40.4 & \\
\hline
\end{tabular}

$x-8$ 
Table - 3

GENERAL PARAMETERS

Type Loop

No. loops 2

Coolant Sodium

Core inlet temp. $360^{\circ} \mathrm{C}$

Core outlet temp. $594^{\circ} \mathrm{C}$

Flow direction Upward

Driver fuel

$\mathrm{UO}_{2}$

Test zone fuel

$\mathrm{UO}_{2}-\mathrm{PuO}_{2}$

Blanket (axial) fuel

$\mathrm{UO}_{2}$ depleted

Core dia., effective $\sim 80 \mathrm{~cm}$

Core volume Driver zone 240 e

No. zones in core

2. Inner zone serves as test bed

Delayed neutron fraction $6 \times 10^{-3}$

Doppler (normal operation) $-1.7 \times 10^{-6} /{ }^{\circ} \mathrm{C}$

Neutron 1 ifetime $4.3 \times 10^{-7} / \mathrm{sec}$

Max. can temp. $\sim 685^{\circ} \mathrm{C}$

No. driver elements 22

No. test zone elements

7. Central element is SNR-type bundle

In-core control elements $6+2$ independent shutoff rods

Test positions 6

Linear power, max. $460 \mathrm{~W} / \mathrm{cm}$

Goal burnup $90,000 \mathrm{MWD} / \mathrm{T}$ 
KNK-2 X

Table -4

CORE AND BLANKET

Driver Zone

Test Zone + Axial Blanket

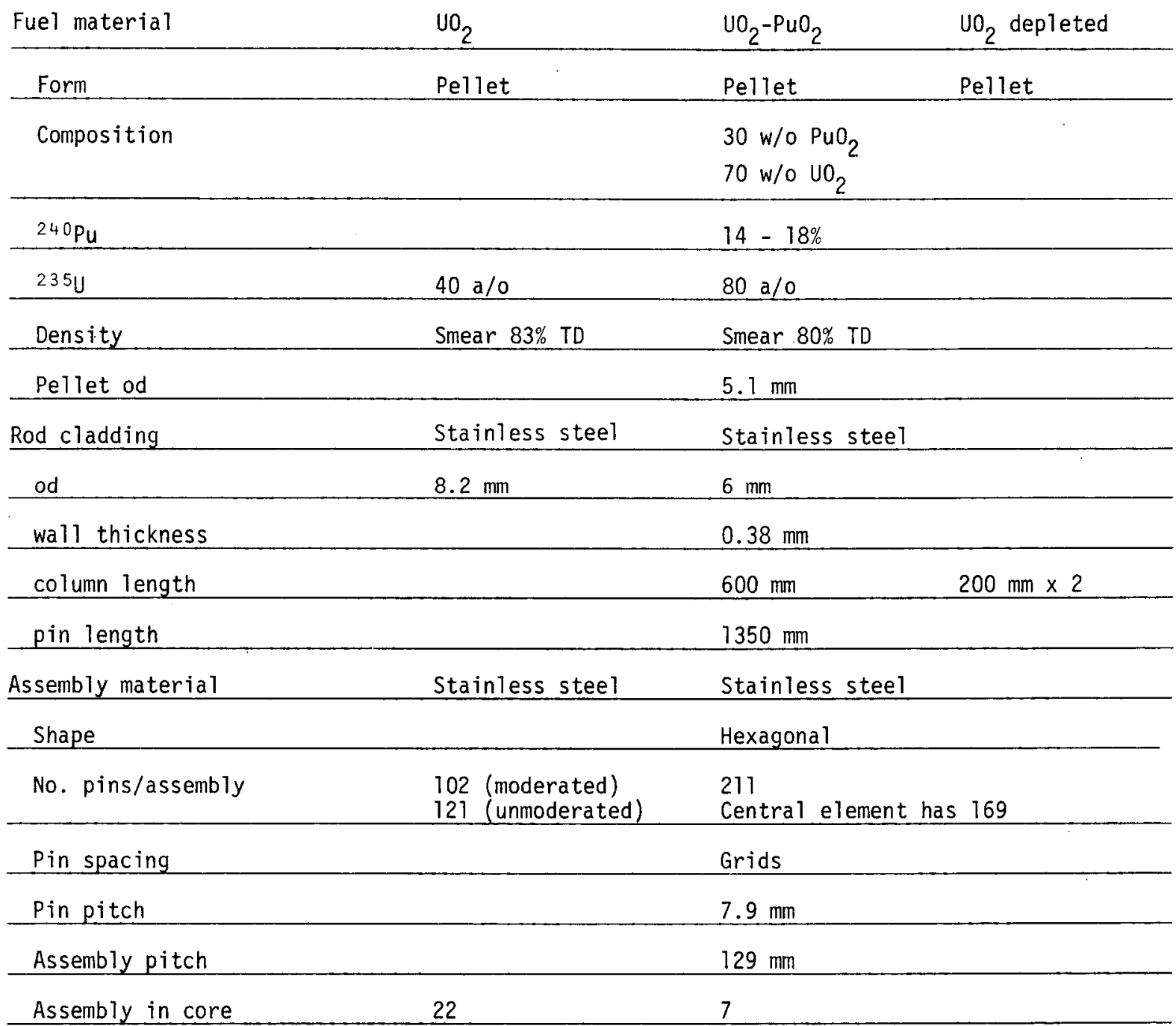

$x-10$ 


\section{A. CORE ASSEMBLIES}

KNK-1 had a thermal core composed of sixty-six $\mathrm{UO}_{2}$ fuel elements moderated by zirconium hydride. The assembly was round or ring-shaped, with two rings of fuel rods enclosed between a central cylinder of stainless steel - clad $\mathrm{ZrH}$ and an outer $\mathrm{ZrH}$ cylinder. The inner, centrally bored moderator was about $55 \mathrm{~mm}$ od, the outer ring about $12 \mathrm{~mm}$ thick and $128 \mathrm{~mm}$ od. Pin cladding was stainless steel, $9.5 \mathrm{~nm}$ od with a wall thickness of $0.3 \mathrm{~mm}$. Each assembly had forty-four pins, with an active fuel length of $1045 \mathrm{~mm}$. All voids were filled with sodium. (Fig. X.A-1) The thermal core became critical in August 1971. (Ref. 1, 5)

KNK-2 will have two zones - a driver zone consisting of $\mathrm{UO}_{2}$ fuel elements, and a test zone with $\mathrm{UO}_{2}-\mathrm{PuO}_{2}$ elements. There are two types of fuel elements in the test portions. Six of the elements have rounded edges of the wrappers and an extra row of fuel pins (211), and six tie rods in the corners. (Fig. X.A-2)

The central element has SNR geometry, except for active and overall length.

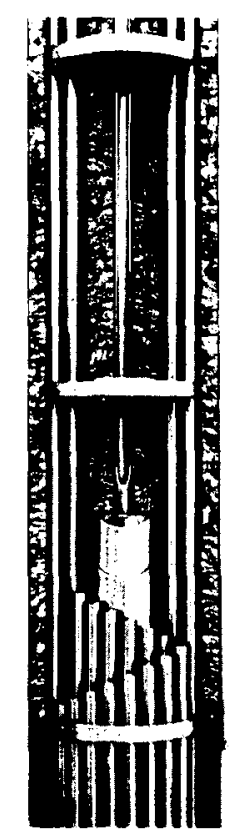

Figure X.A-1 KNK-1 Fuel Assembly (Ref. 5)
Assemblies in the test zone have an upper and lower axial blanket section. Pins are spaced by grids. Grid types to be tested are honeycomb spot welded grids, brazed ferrule spacers attached to the wrapper tube, and spark-eroded spacers attached to the six tie rods. Eight spacer grids per bundle are used. The head has a mixing device. Steel/ZrH reflector elements form an outer ring around the core. Steel and blanket elements are located inside this ring. (Ref.5)

The test zone has seven fuel assemblies. The central one is instrumented. The driver zone contains twenty-two fuel elements, six on an inner ring in contact with the test elements. Reflector assemblies surround the driver zone. Blanket elements for testing can be inserted into these positions, or the reflector elements can be replaced by additional driver elements. Driver elements may also be replaced by reflector elements. To improve the Doppler coefficient ZrHx will be incorporated into the driver. Some assemblies containing ZrHx pellets are canned in steel tubes similar to the fuel rods. Radial reflector assemblies will be cylindrical since they touch on the outer reflector segments. The wrapper tube for these assemblies will be filled with an undetermined number of single pins. Radial reflector assembly od is $129 \mathrm{~mm}$. (Ref. 4) (Fig. $X . A-3)$ 
KNK X.A
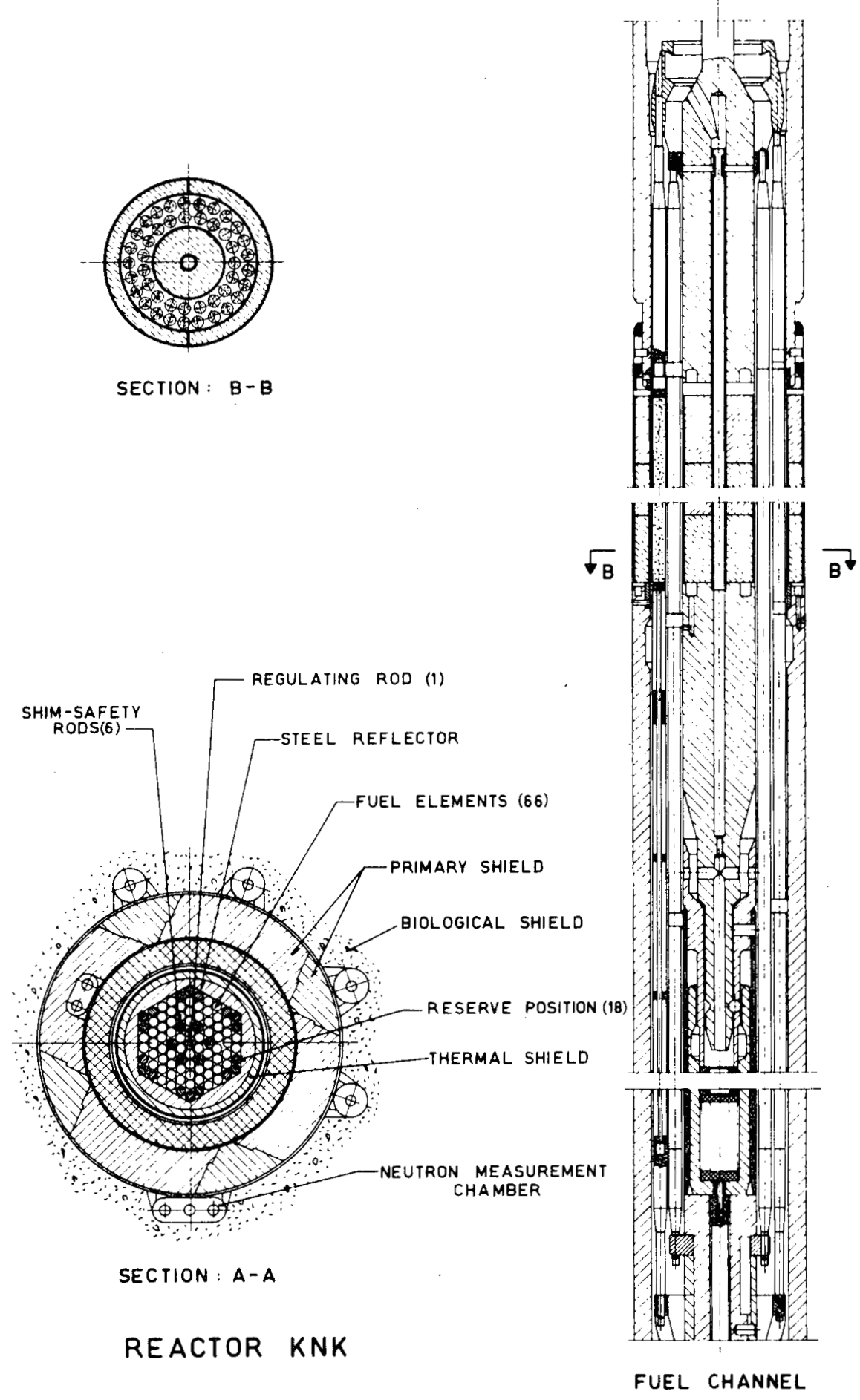

Figure X.A-2 KNK-1 Core Cross-section (Ref. 11)

$$
\text { X.A-2 }
$$


KNK X.A
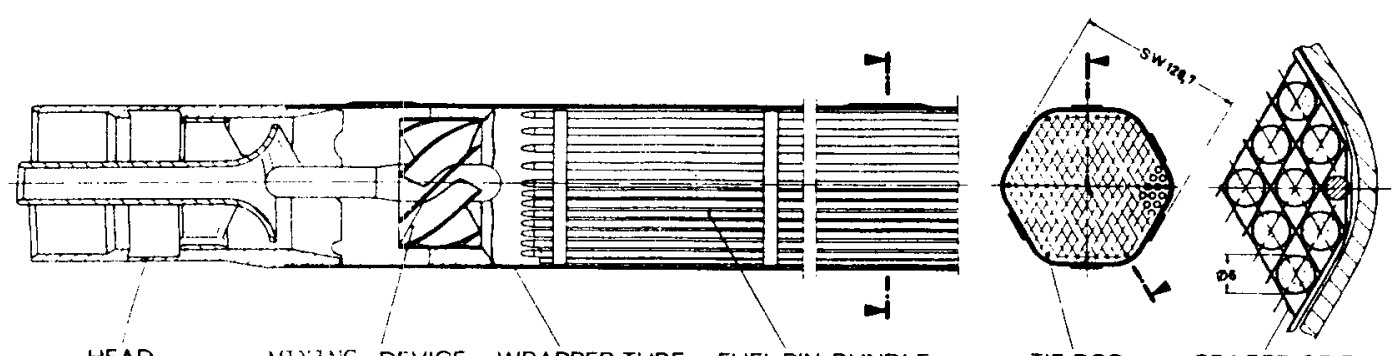

HEAD

MIXING DEVICE WRAPPER TUBE FUEL PIN BUNDLE

TIE ROD

SPACER GRID
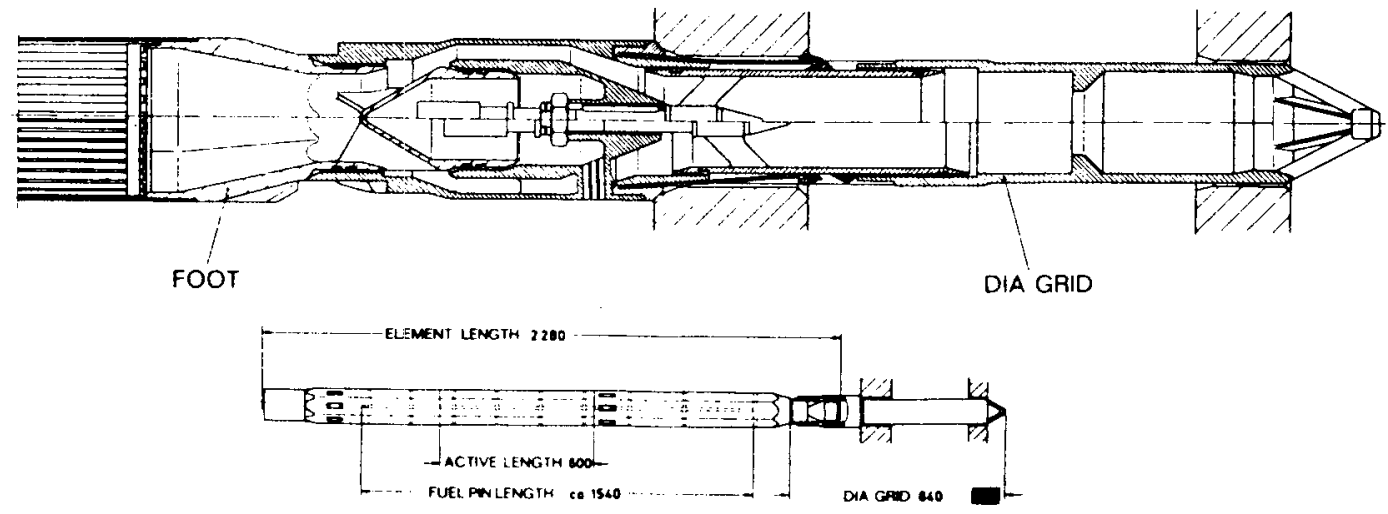

Figure X.A-3 KNK-2 Fuel Assembly, Test Position (Ref. 5)

\section{CORE CROSS SECTION KNK II}

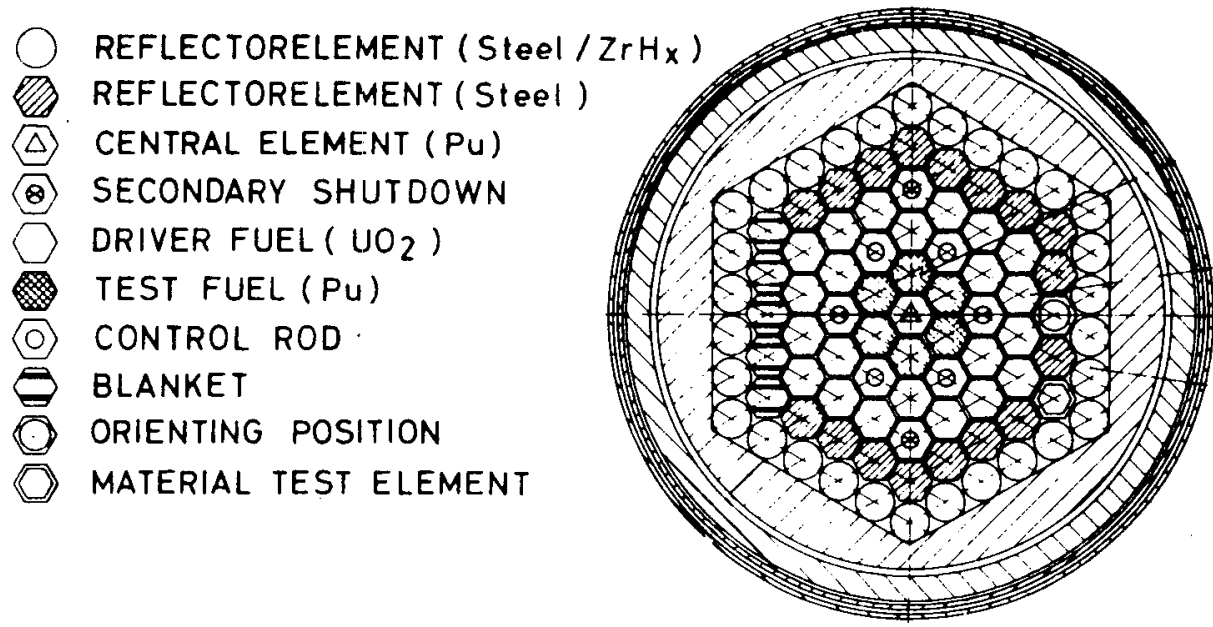

Figure X.A-4 KNK-2 Core Cross-section (Ref. 5) 


\section{$X . \quad C$. REACTOR VESSELS AND SHIELDING}

The reactor vessel is a cylindrical structure $10.5 \mathrm{~m}$ high and 1.9 dia., filled with sodium. The free surface has an argon blanket. A rotating cover $2.8 \mathrm{~m}$ thick is made of heavy concrete which protects a fully accessible operating room. An outer tank is provided as a leak-vessel. The annulus between the two vessels is filled with nitrogen gas. The biological shield is of high density concrete, which is nitrogen-cooled. The reactor tank is supported from above by a flange located in the cold area. (Fig X.C-1.)
The rotating shield plug system consists of a large rotating plug centered over the reactor vessel, and a smaller rotating plug off-set within it. Each plug contains, from bottom to top, 38 steel plates, $2 \mathrm{~mm}$ thick with $7.8 \mathrm{~mm}$ separation, a flat for forced cooling by nitrogen, shielding of basalt granules and high density concrete, a steel plate to support the bearings. Inflatable seals with buffer gas monitoring are used. Ball bearings support and center the plugs. (Fig. X.C-Z) (Ref. 10.)

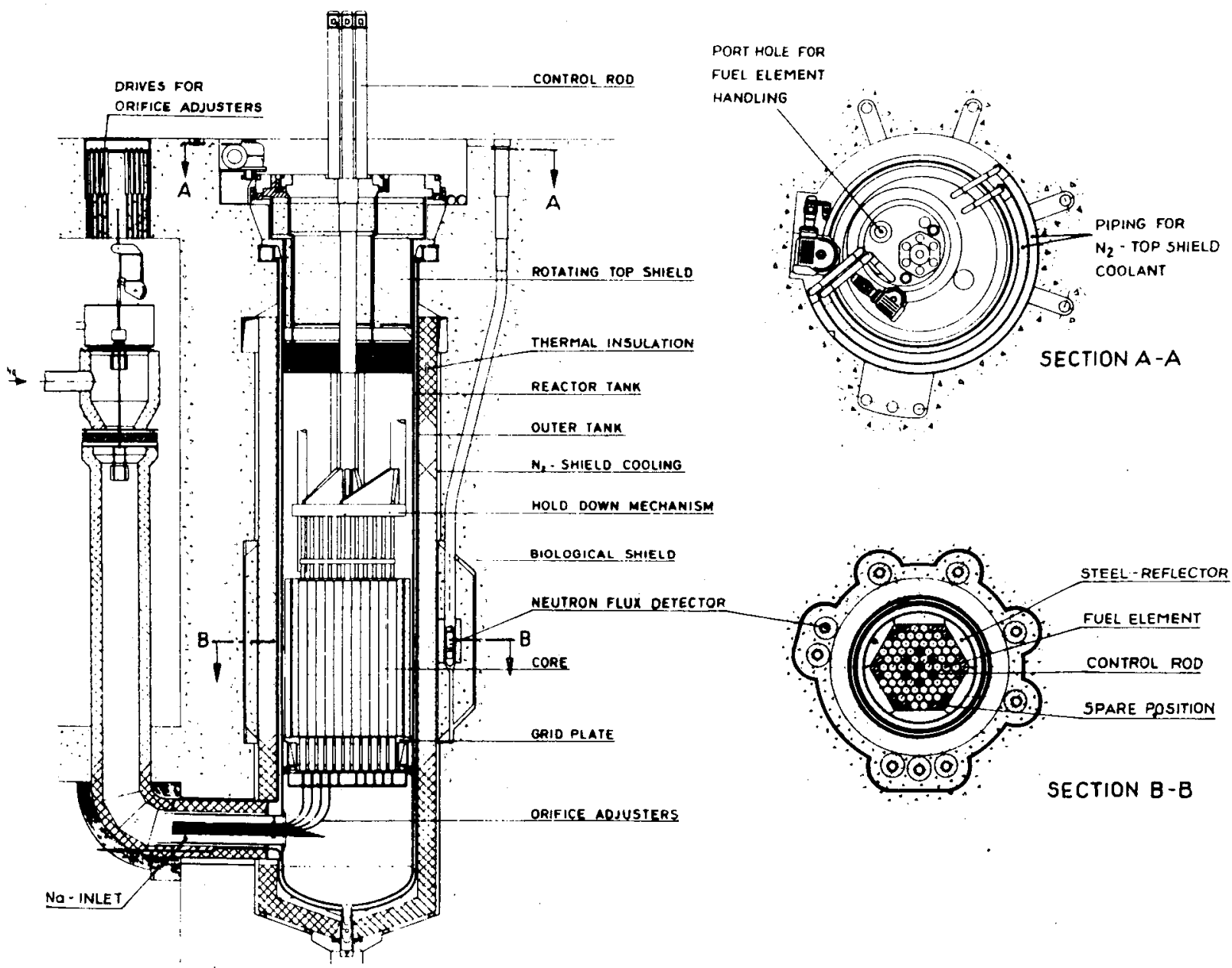

Figure X.C-1 KNK Reactor Vessel and Structures (Ref. 1) 
KNK X.C

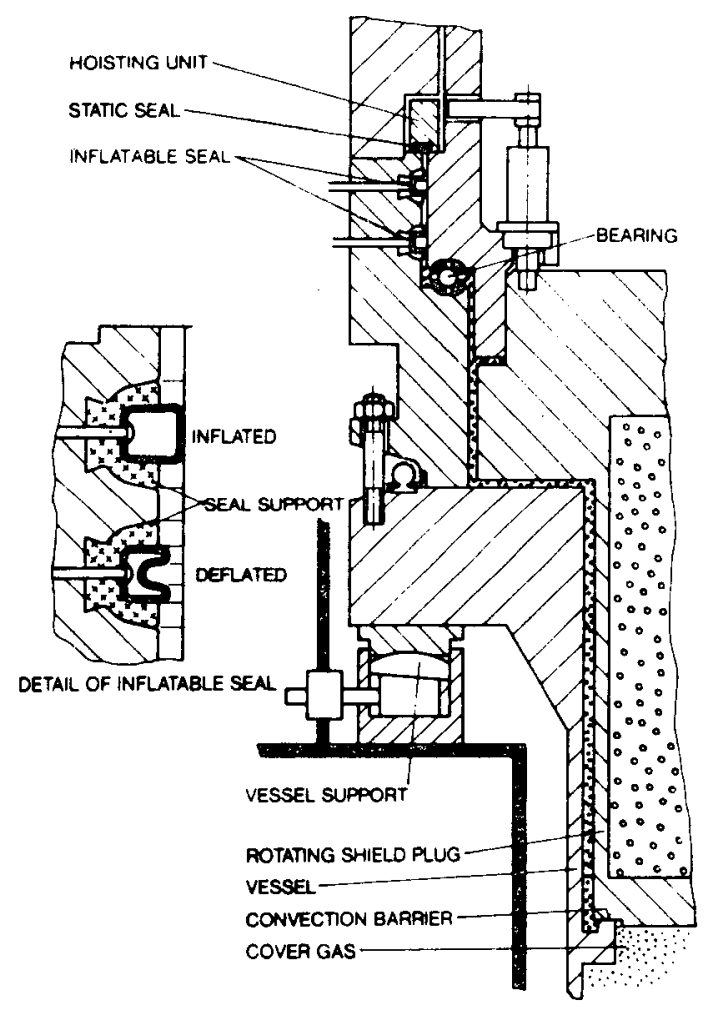

Figure X.C-2 KNK Detail of Rotating Shield System (Ref. 10)

X.C-2 
X. D. CONTROL ELEMENTS

KNK control elements contain $\mathrm{B}_{4} \mathrm{C}$ enriched in $2{ }^{\circ} \mathrm{B}$ as an absorber. The first system for KNK-1 consisted of rigid rodbundles positioned above the core. At the end of 1966 the licensing authorities required a second fast-acting, independent system for the reactor. This second system consisted of an absorber chain of articulated rods, also positioned above the core. Three of these elements were lacated around the core. On order to scram, the absorber chain was released to drop into an annulus formed by a guide tube and a central Be0 displacement rod. Absorber chains were in shutdown condition during fuel handling. The first and second systems were electrically connected via a lag-time relay. (Fig. X.D-1.)
KNK-2 control rod system consists of six combined shim-safety rods postioned above the boundary between the two zones, and two independent shut-off rods positioned at the outer edge of the core. Absorbing material is $\mathrm{B}_{4} \mathrm{C}$ with $60 \% 10 \mathrm{~B}$ enrichment. Reactivity requirements for the central shim rods will be $10 \% \mathrm{k} / \mathrm{k}$ and for the shutoff rods $2.4 \% \Delta k / k$. Release time will be $250 \mathrm{sec}$. maximum and drop time $2600 \mathrm{msec}$. (Ref. 7.) 
KNK X.D

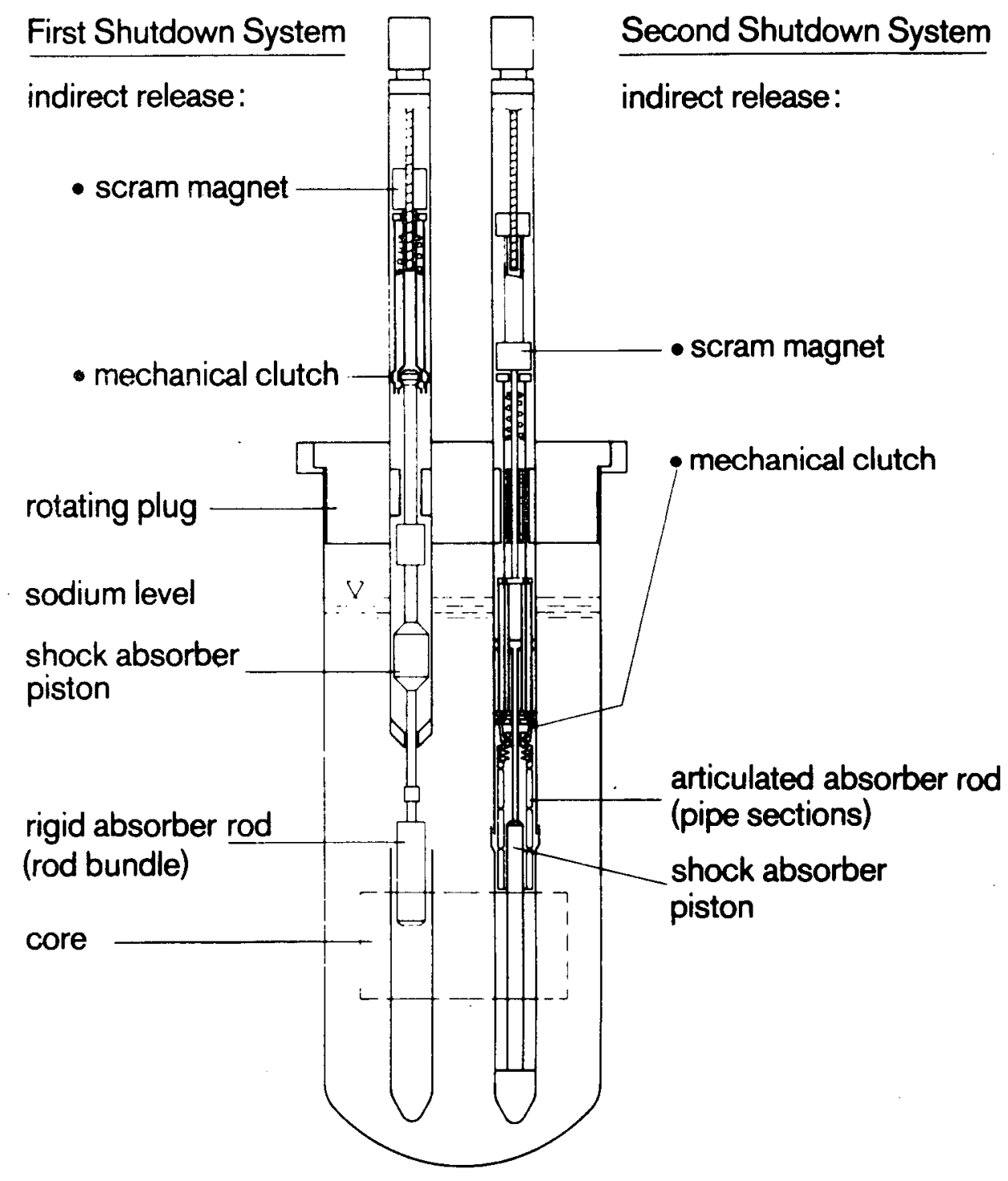

Figure X.D-1 KNK-1 Shutdown Systems (Ref. 7) 
KNK X.E

X. E. HEAT TRANSFER SYSTEMS

There are two primary and two secondary heat transfer loops. Low alloy ferritic steel is used. The intermediate heat exchangers are cylindrical shell and helical-tube structures. Flow is countercurrent. Inlet temperature at the IHX is $306^{\circ} \mathrm{C}$, outlet is $539^{\circ} \mathrm{C}$. Pumps are centrifugal units. Cold traps and plugging meters are provided.
Primary sodium flows upward through the core. Pressure in the primary system is $4.5 \mathrm{~atm}$. In the secondary loops it is $8.3 \mathrm{~atm}$. The primary systems are in nitrogen-filled compartments, kept above atmospheric pressure.

Cover gas is argon. It is monitored by gas chromatography. (Ref. 2, 8.) 


\section{$X$. H. STEAM GENERATORS}

The KNK steam generator is a concentric tube-in-tube system. Two units consist of twenty eight tubes each, with a maximum $1 \mathrm{MW}$ per tube. Feed water at $200-235^{\circ} \mathrm{C}$ flows up the central tubes, and superheated steam at $570^{\circ} \mathrm{C}$. Sodium flows downward in the annulus. The pressure-relief system consists of shutoff devices at entrances to the sodium tubes, a depressurizer, a rupture disc, the pressure-relief line, the reactor products separation tank, and fast shutoff valves at both sides of the sodium heaters. The generator is a once-through type. (Ref. 8.)

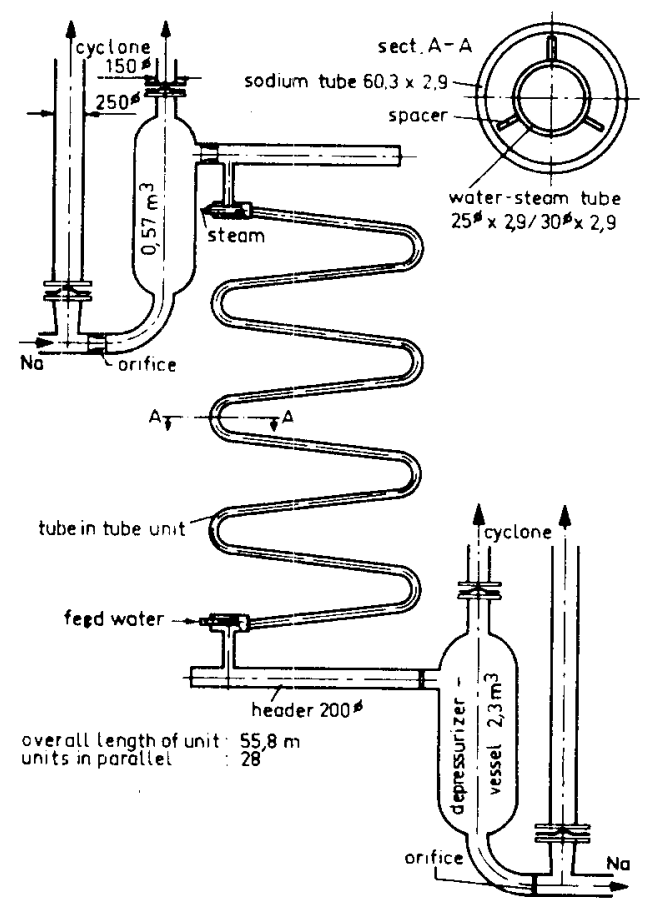

Figure X.H-1 KNK-1 Steam Generator Concept (Ref. 9) 


\section{J. FUEL HANDLING}

KNK fuel handling equipment includes a fuel handling machine with a gas-cooling circuit, an uncooled component handling device, a sodium-filled nitrogen-cooled storage tank for fuel assemblies, an inspection station, and a subassembly transport flask for transporting new and irradiated subassemblies. (Fig.X.J-1.)

The fuel handling machine consists of a superstructure and an undercarriage, a refuelling flask with bottom gate valve and an over-head hoisting unit, control and interlock devices. Its working area is bounded by its circular path around the stationary turning column and by the translational motion of the superstructure. The refuelling cask is sealed by a bottom gate valve with inflatable seals flanged to the flask. A sealing skirt provides a leak-tight connection with the shield plug transfer tube. The control panel is on top of the superstructure, with TV supervision. The machine is connected via the rotating column to argon cooling loops installed beneath the floor. Four different grippers can be coupled to the upper gripper assembly. (Fig.X. J-2.)
The large rotating plug is centered over the reactor vessel, with the smaller rotating plug positioned eccentrically within it. The fuel storage tank is closed at the top by a stationary plug. A rotating "LazySusan" fuel assembiy storage system is suspended from this plug. Each position can be served by one of six loading holes.

The transport flask for irradiated assemblies is a cylindrical vessel with a manually driven hoist unit on top. It transports assemblies to the inspection station and to stations located outside the containment. The inspection station is a shielded leak-tight cell in which components can be disassembled and inspected. Spent assemblies can be shipped to the reprocessing plant in a shipping flask after about ninety days decay. The fuel storage tank has a capacity of up to seventy-six subassemblies. (Ref. 10)

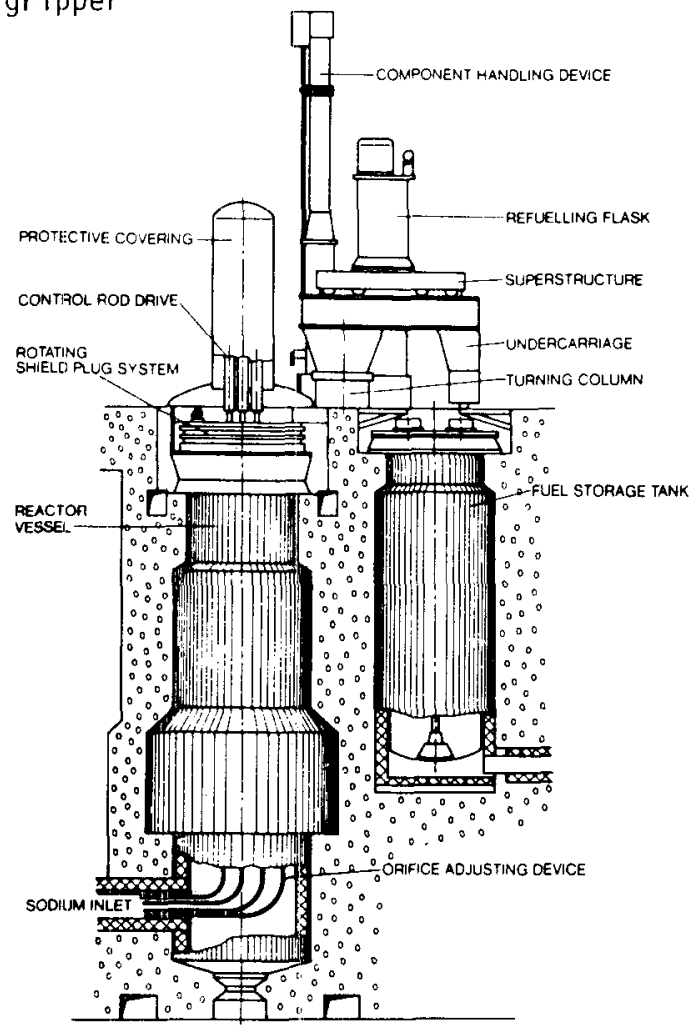

Figure X.J-1 KNK Schematic of Vessel, Storage Tank, and Fuel Handling Machine (Ref. 10) 
KNK $\quad X . J$

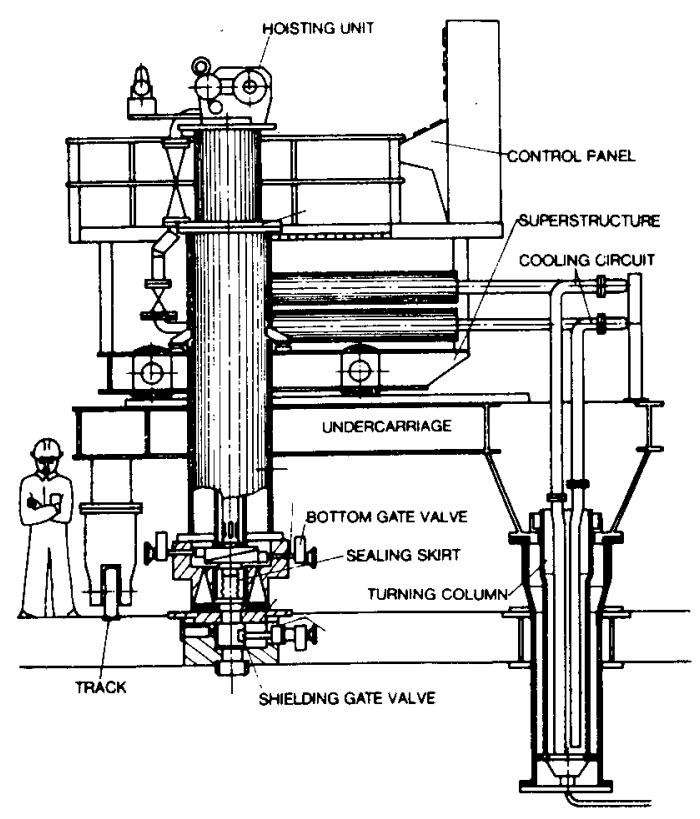

Figure X.J-2 KNK Fuel Handling Machine (Ref. 10)

$\mathrm{X} . \mathrm{J}-2$ 
KNK X.K

X. K. CONTAINMENT

KNK safety containment is provided by a cylindrical steel structure $17 \mathrm{~m}$. dia, with a hemispherical head. A concrete containment structure is outside. The structure holds the reactor and primary system compartments, handling equipment and nitrogen systems. Auxiliary systems such as air-cooling, rad-waste, laboratories and radiation monitoring stations are in an annex. Separate buildings house steam generators with the secondary sodium plant and argon system; turbine-generator plant, control switchboard, supplies and offices; and workshops, emergency power supply and feed water preparation. 
$X I . \quad$ SNR -300

LOCATION: Kalkar, Germany

OPERATION: Target, 1979

In 1966, an industrial consortium was formed by Siemens/Interatom for long-term cooperation on fast reactor projects. The consortium made a study of a sodium-cooled fast breeder reactor, NR-2, which was a first approach to the SNR design. In 1968 the firms Belgonucleaire (Belgium) and Neratoom (The Netherlands) were added. Design of the SNR-300 has been done by Interatom. Participation in the project by the German, Netherlands, Belgium interests is about 70-15-15 percent respectively.

SNR-300 is a loop-type system using mixed oxide fuel. Construction was started in 1973 near Kalkar on the lower Rhine River. Operating target is 1979 . 
INDEX

\begin{tabular}{|c|c|c|}
\hline & & Page \\
\hline REFERENCE & & $X I-5$ \\
\hline REACTOR P & ARAMETERS & $X I-9$ \\
\hline SECTIONS & $\cdot$ & \\
\hline A. & CORE AND BLANKET & $X I . A-1$ \\
\hline B. & CORE SUPPORT AND VESSEL INTERNALS & $X I . B-1$ \\
\hline C. & REACTOR VESSELS AND SHIELDING/CORE CATCHER & $X I . C-1$ \\
\hline D. & CONTROL ELEMENTS & $X I .0-1$ \\
\hline E. & HEAT TRANSFER SYSTEMS & $X I . E-1$ \\
\hline $\mathrm{F}$ & SODIUM PURIFICATION AND INSTRUMENTATION & $X I . F-1$ \\
\hline G. & $\begin{array}{l}\text { COVER GAS AND AUXILIARY SYSTEMS } \\
\text { (NO INFORMATION }\end{array}$ & \\
\hline $\mathrm{H}$ & STEAM GENERATORS & $X I . H-1$ \\
\hline I. & $\begin{array}{l}\text { REACTOR INSTRUMENTATION AND CONTROL } \\
\text { (NO INFORMATION) }\end{array}$ & \\
\hline J. & FUEL HANDLING & $X I . J-1$ \\
\hline K. & CONTAINMENT & $X I . K-1$ \\
\hline
\end{tabular}




\section{REFERENCES}

1. NA-2 Design. The 300 MWe German FCR

K. Gast, et. al.

Fast Reactors National Topical Meeting, San Francisco, 1967

ANS-101 p. 3-23 to 3-38

American Nuclear Society 1967

2. Fast Sodium-Cooled Reactor $N A-2$

K. Gast, E.G. Schlechtendahl

KFK-660 (1967)

EURFNR-462 (1967)

3. Design Considerations and Experimental Program for the Common Development of a 300 MWe Sodium-Cooled Fast Breeder Prototype SNR by a BelgianDutch-German Consortium

R. Harde

Proc. Intl. Conf. Sodium Technology and Large Fast Reactor Design

Nov. 1968, p. 130-146

ANL-7520 Part 2, (1968)

4. Out-of-Pile Experiments with Prototype Fuel Elements for SNR-300

W. Jansing, et. al.

Fuel and Fuel Elements for Fast Reactors, Proc. Symposium, Brussels, July 1973, Vol. 1 p. 311-328

STI/PUB/346

IAEA, 1974

5. The Reactor Tank of the SNR-300

M. Kohler, H. Rothfuss

Kerntechnik 15 No. 2, 1973, p. 75-79

6. Design of the Reactor Vessel of the SiNR Prototype

M. Kohler, H. Rothfuss

Sodium Cooled Fast Reactor Engineering, Proc. Symposium,

Monaco, March 1970, p. 139-148

STI/PUB $/ 256$

IAEA, 1970

7. Construction and Operation Description of the Fast Reactor Core-Catcher.

H. Friedrich, H. Krape

Interatom Memo 43/7947/8 (Aug. 1974)

AEC-TR-759]

8. The Safety Related Criteria and Design Features for SNR

H.J. Hube 1

Proc. Fast Reactor Safety Meeting, California April 1974

CONF-74040]-PT, p. 3-28

9. SNR-300

A. Brandstetter, et. al.

Fast Reactor Power Stations, Proc. Conf. BNES, London March 1974

p. 105-110

British Nuclear Energy Society, 1974

10. Steam Generator and Intermediate Heat Exchanger Development

W.J. C. deClercq, N.J. vanhlaveren

Sodium Cooled Fast Reactor Engineering, Froc. Conf., Monaco,

March 1970, p. 433-453

STI/PUB $/ 256$

IAEA, 1970 
11. 6000 Hours Testing of a Ful1-Scale Prototype Sodium Pump R.H. Fakkel, et. al. Nuclear Engineering Int]., Vol. 18, Dec. 1973, p. 949-951

12. Design and Requirements for SNR Pipework

K. Bieniussa, et. al.

Nuclear Engineering Int]. Vol. 19, Feb. 1974, p. 94-96

13. Diverse Shutdown Systems for KNK-1, KNK-2, and SNR-300 Reactors

F. H. Morgenstern, et. al.

Proc. Fast Reactor Safety Meeting, California, April 1974

Part 3, p. 1349-1369

CONF-740401-P3 (1974)

14. The Role of the KNK-II Facility for the Development of

SNR Fuel Subassemblies

H. Mayer, H. Andrae

Proc. ANS Topical Meeting, Irradiation Experiments in

Fast Reactors, Sept. 1973, p. 166-185

ANS, 1973

15. Operational Experience with Main Circuit Components for the SNR Power Plant.

A.J.H. Mante, et. al.

Fast Reactor Power Stations, Proc. Conf., BNES, London

March 1974, p. 157-171

British Nuclear Energy Society, 1974

16. The Development of Sodium-Heated Steam Generators in the Netherlands

W.J.C. LeClerc, et. al.

Fast Reactor Power Stations, Proc. Conf. BNES, London, March 1974, p. 173-187

3ritish Nuclear Energy Society, 1974

17. Design Criteria, Description and Test Program of the SNR Prototype Fuel-Handling System.

D. Althaus, et, al.

Sodium-Cooled Fast Reactor Engineering Proc. Symposium,

Monaco 1970, p. 771-786

STI/PUB/256. IAEA, 1970

18. Development of Honeycomb Spacer Grids for the SNR-300

Fast Reactor

J. Dewandeleer, et. al.

Nuclear Energy Maturity, Proc. Ist Conf., European Nuclear

Soc., Paris, Apri] 1975

ANS Trans., Vol 20, April 1975, p. 304-305

American Nuclear Society, European Nuclear Society 1975

19. Status and Further Development Targets of the SNR Fuel

Element Development

G. Karsten

KFK-2110 (Nov. 1974)

20. SNR-300 Primary and Secondary Loop Valves

D. Markfort

International Working Group on Fast Reactors, Specialists

Meeting on Operating Experience and Design Criteria of

Sodium Valves, Richland Wash. Sept. 1974.

p. 115-121 and SNR-300 Bellows Seal Valves

Ibid p. $130-134$ 
21. SNR-300 Bellow Seal Valves

International Working Group on Fast Reactors, Specialists Meeting on Operating Experience and-Désign Criteria of Sodium Valves,

Richland, Wash. Sept. 1974. Summary Report., p. 130-134

CONF-740964

22. SNR Emergency Cooling - Heat Transfer Calculations on In-Tank Natural Circulation with Blanket Backflow

F. Timmermann, H. Vossebrecker

Engineering of Fast Reactors for Safe and Reliable Operation, Proc. Int].

Conf., Karlsruhe Oct. 1972, Vol. 1, p. 322-335

Geselischaft fur Kernforschung Mbtt, Karlsruhe 1973

23. General Characteristics of Fast Reactor Fuel Pins

K. Kummerer

Nuclear Energy Maturity, Proc. 1st Conf., European Nuclear Soc., Paris, April 1975

ANS Trans. Vol. 20, April 1975, p. 301-304

American Nuclear Soc., European Nuclear Soc., 1975

24. Control Rod Worth and Power Distribution Measurements in the SNR

Mock-Up Sneak Assembly 9 A

M. Pinter, et. al.

KFK-2077 (Nov. 1974)

EURFNR-1235

25. Instrumentation Specific to the SNR-300 Liquid Metal Fast

Breeder Reactor

R. Hans, H. Mausbeck

Kerntechnik 17, No. 3, p. 113-118 (March 1975)

26. Handling the Core Elements of the Reactor SNR-300

D. Al thaus

Kerntechnik 15, No. 3, p. 105-113 (March 1973)

27. Fast Breeder Project Status Report 1974

KFK-2003 (May 1974)

Translation EURFNR-1182

28. Technical and Economic Aspects of the Fuel Elements for SNR:

State of the Art and Future Prospects.

J. Hoche 1, W. Stoll

ITB 73.5 (Feb. 1973)

29. Neratoom.

Brochure, March 1975

B.V. Neratoom 


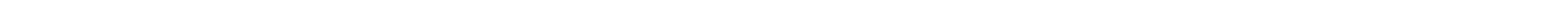


Table - 1

GENERAL PARAMETERS MÄRK- 1 CORE

\begin{tabular}{ll} 
Type & Loop \\
\hline No. loops & $3+$ emergency loop \\
\hline Coolant & Sodium \\
\hline Core inlet temperature & $377^{\circ} \mathrm{C}$ \\
\hline Core outlet temperature & $546^{\circ} \mathrm{C}$ \\
\hline Flow direction & Upward \\
\hline Driver fuel & $\cup 0_{2}-\mathrm{Pu} 0_{2}$ \\
\hline Blanket fuel & $\cup 0_{2}$ \\
\hline No. enrichment zones & 2 \\
\hline Output MWe/MWt & $300 / 762$ \\
\hline Max. can temperature & $685^{\circ} \mathrm{C}(\mathrm{midline})$ \\
\hline Fuel centerline temnerature & $2400^{\circ} \mathrm{C} \mathrm{Max.}$ \\
\hline Linear Power & $354 \mathrm{n} / \mathrm{cm} \mathrm{max.}$ \\
\hline Neutron flux & $6.4 \times 10^{15} \mathrm{n} / \mathrm{cm}^{2}$ sec. max. \\
\hline No. driver elements & 205 \\
\hline No. radial blanket elements & $96+186$ steel reflectors \\
\hline No. in-core control elements & 12 \\
\hline In-vessel storage bositions & 0 \\
\hline Goal burnup. max. & $90,500 \mathrm{MWD} / \mathrm{T}$ \\
\hline
\end{tabular}




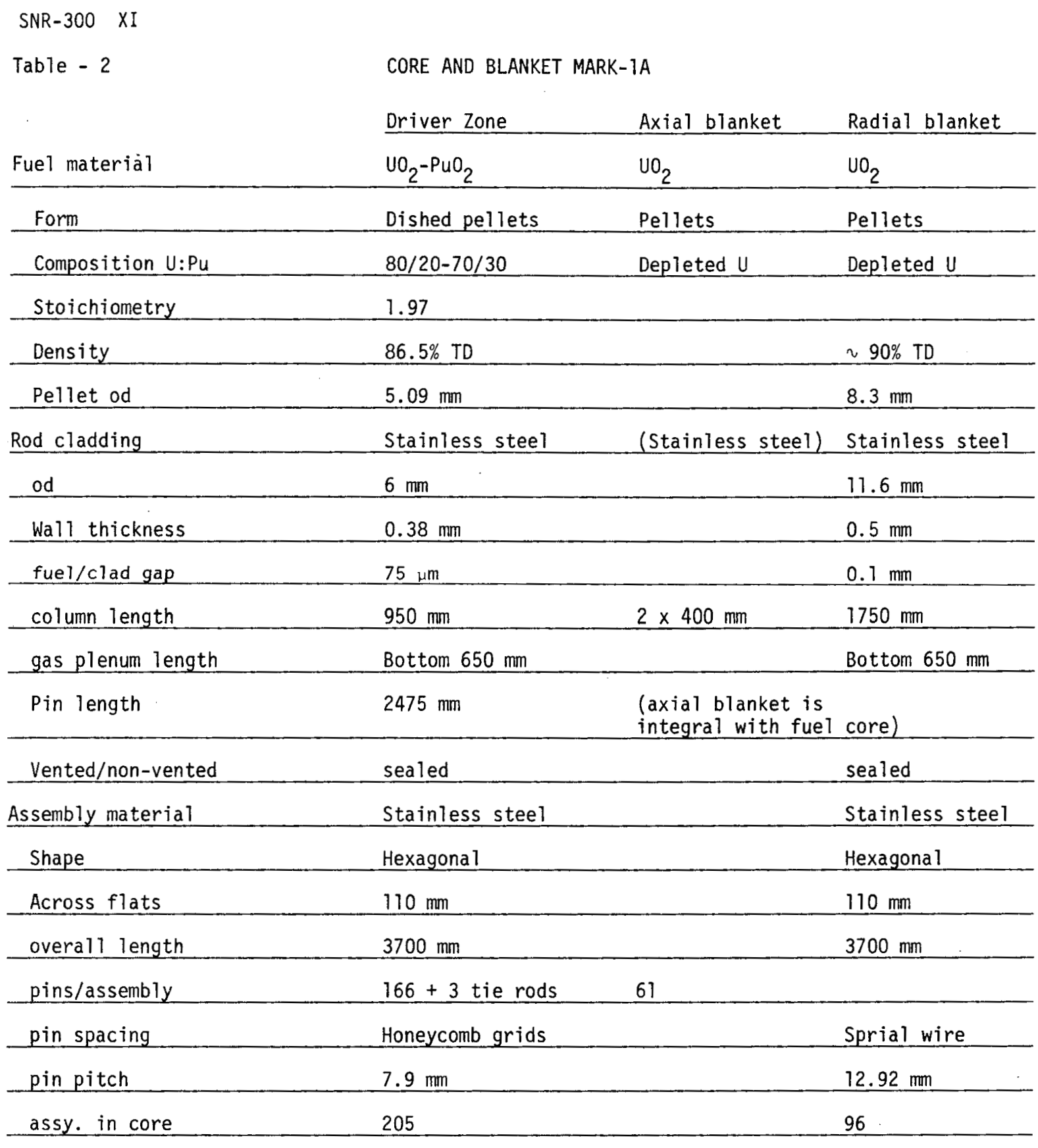




\section{A. CORE AND BLANKET}

SNR-300 has been developed by Interatom. The Mark $1 \mathrm{~A}$ core will have 205 driver assemblies, 96 radial blanket assemblies, 12 control rods, and 186 reflector assemblies. (Fig. XI.A-1)

The fuel assembly is a hexagonal stainless steel can $110 \mathrm{~mm}$ across the flats, containing a bundle of 166 fuel pins and three tie rods, located in the can by means of a honeycomb grid or egg-crate structure. Head and foot structures are welded to the wrapper can. The head contains a coolant mixing device. Overall length is $3700 \mathrm{~mm}$.

The fuel pin is a $6 \mathrm{~mm}$ od stainless steel tube, with a wal1 thickness of 0.38 $\mathrm{mm}$. It contains a $950 \mathrm{~mm}$ high stack of $\mathrm{UO}_{2}-\mathrm{PuO}_{2}$ pellets, dished at both ends. The pellet-clad gap is $75 \mu \mathrm{m}$. Above and below the fuel core there is a $400 \mathrm{~mm}$ stack of $\mathrm{UO}_{2}$ pellets forming the axial blankets. At the bottom, there is a $650 \mathrm{~mm}$ gas plenum. Pin spacing within the assembly can is by means of honeycomb grids, which give a pin pitch of $7.9 \mathrm{~mm}$. There is an anchor plate at the lower end of the bundle. Fourteen or fifteen spacer grids are supported axially by tie rods located in lattice positions. The tierods are solid, with the same dimensions as the fuel pins. The grid is assembled from stainless steel strip shaped and spot-welded to form a lattice of single hexagonal cells, except at the periphery where the cells are pentagonal. At the grid mid-plane, each cell has three ovoid dimples located $120^{\circ}$ apart to provide contact points with the fuel pin. The gap between pin and dimple is about $1 \mathrm{~mm}$. Centering pads are provided on each of the six lateral faces of the structure. (Fig. XI.A-2, XI.A-3) (Ref. 4, 19)

Radial blanket assemblies have 61 pins spaced by spiral wrapped wire. Pin diameter is $11.6 \mathrm{~mm}$, and the pin-pitch is $12.92 \mathrm{~mm}$. The hexagonal wrapper tube has the same dimensions as those of the fuel assembly.

The Mark-II core will have pins 7.6 $\mathrm{mm}$ od, with cladding wall thickness 0.50 $\mathrm{mm}$. The assembly will contain 127 fuel pins. Spacers will be by grids. Pitch/ diameter will be 1.16. The core will have 205 driver elements. (Ref. 9, 27)

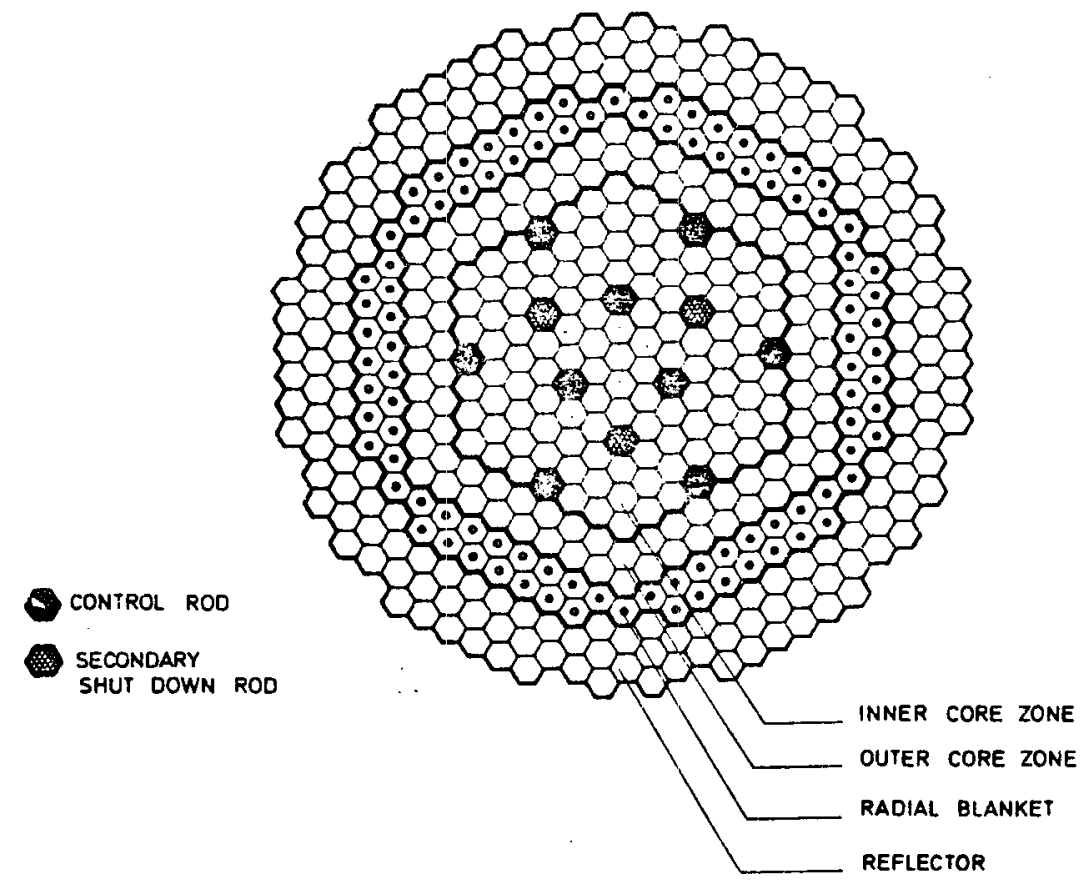

Figure XI.A-1 SNR-300 Mark-1A Core (Ref. 24) 


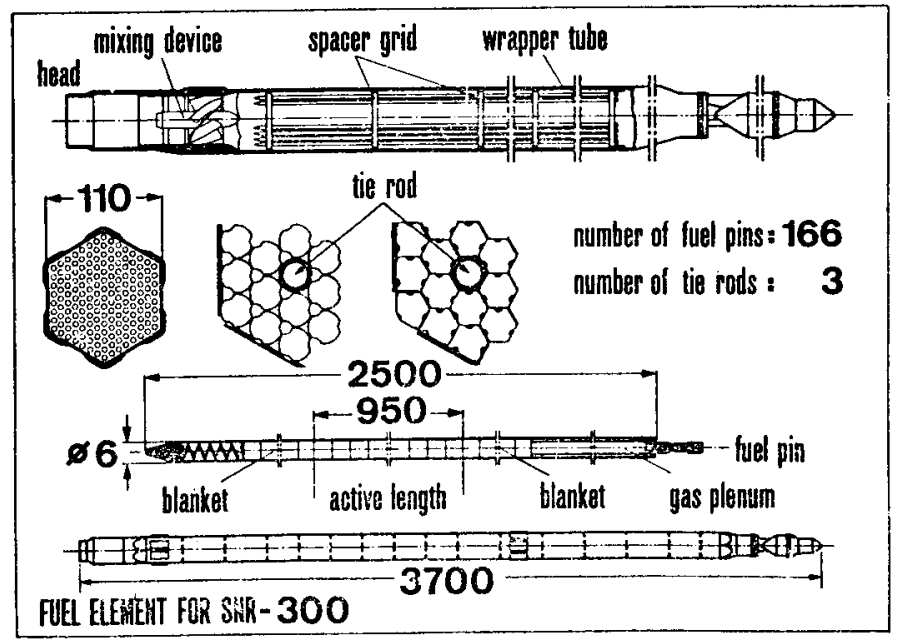

Figure XI.A-2 SNR-300 Fuel Assembly (Ref. 14)

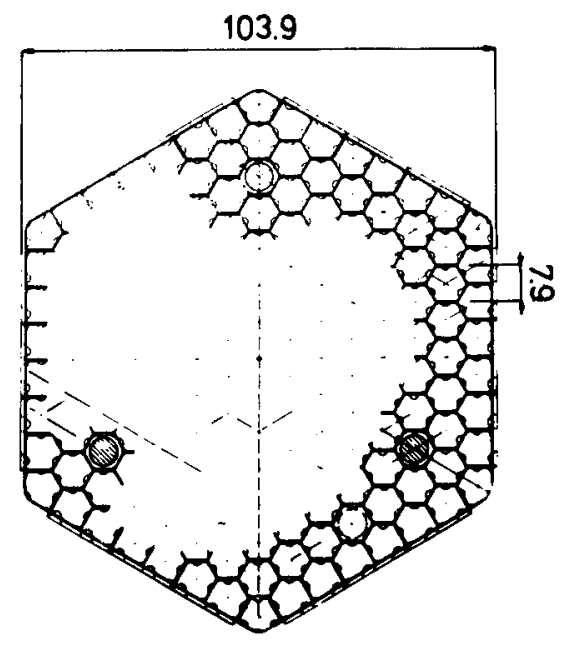

Figure XI.A-3 SNR-300 Honeycomb Spacer Grid (Ref. 19)

$X I . A-2$ 
XI. B. CORE SUPPORT AND VESSEL INTERNALS

The core of SNR is supported below the fission zone on a support plate surrounded by a shroud. A second plate is located above the active core. The plates are fabricated of ferritic steel, so that the differential thermal expansion between the ferritic rings and shroud and the austenitic structural material of the core affords the loosening required during refueling, when reactor temperature is lowered. The upper and lower plates are rigidly connected by struts. Plates are about $100 \mathrm{~mm}$ thick. The structure is supported at the vessel wall by a conical skirt. A grid-plenum structure below the core support and shroud directs inflowing sodium to the core, blanket, and reflector assemblies. The cold sodium penetrates by inlet lines through the hot tank wall, in the gas space between normal sodium level and the tank cover, via a conical transition sleeve. The inlet pipes carry the sodium down to the collector vessel, and are welded to it. This lower plenum tank has a gas separating device to prevent large gas bubbles from passing through the fuel region. Sodium heated by passage through the core enters an outlet collector space formed by a cylindrical outlet skirt and an upper dip plate, exits through openings in the outlet skirt into an outer annular space to three outlet pipes. (Fig. XI.B-I)

(Ref. 15,9)

A passive core restraint system is used, consisting of two ferritic stee? rings located above and below the core. The arrangement is tight below the core, and provides a $6 \mathrm{~mm}$ clearance in the upper plane. (Fig. XI.B-2) (Ref.1) 
SNR-300 XI.B

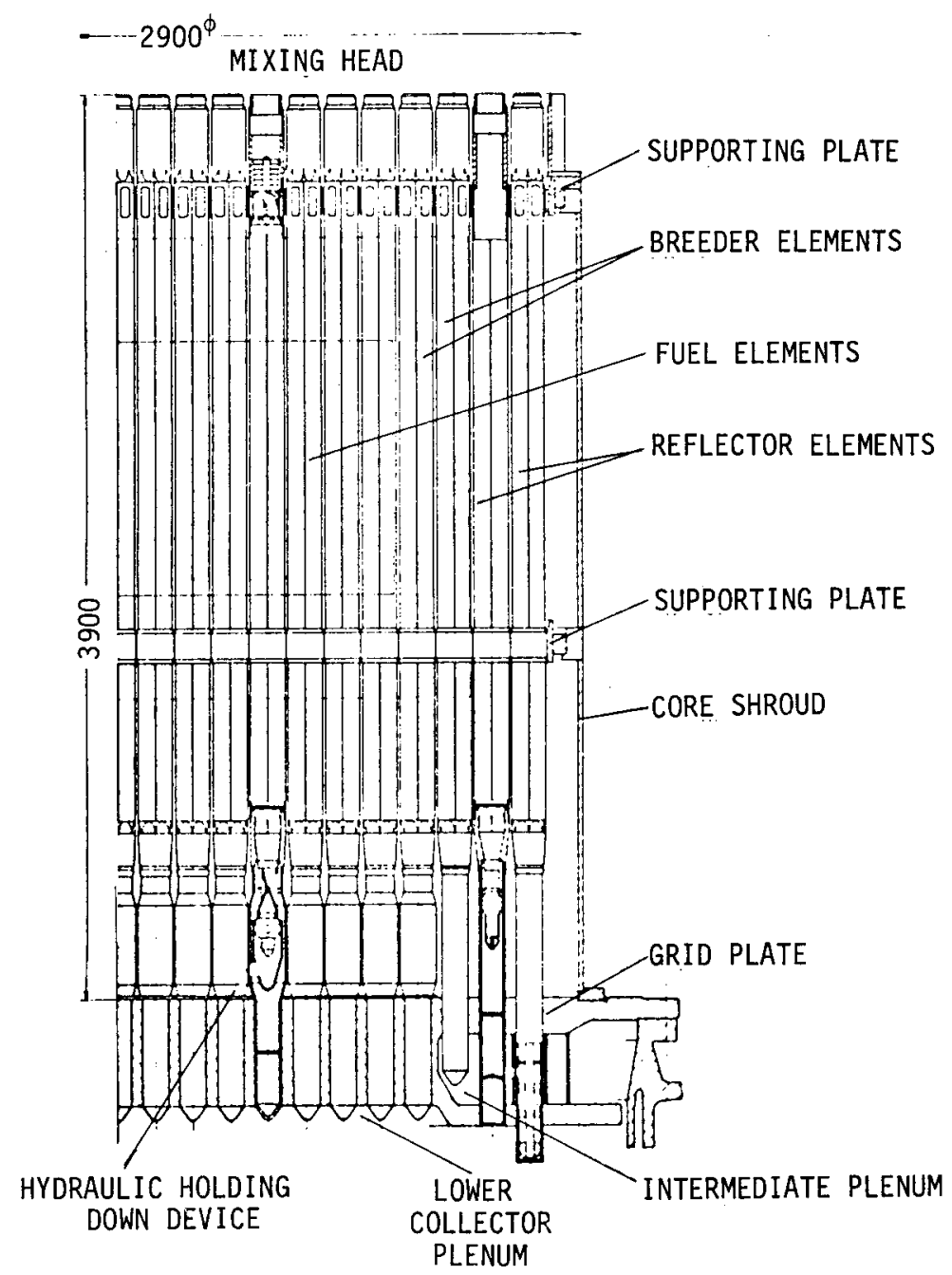

Figure XI.B-1 SNR Core Support and Grid Structure (Ref. 5)

XI.B-2 
XI. C. REACTOR VESSELS AND SHIELDING

The cylindrical stainless stee? reactor tank is $6.2 \mathrm{~m}$ in diameter, with $40 \mathrm{~mm}$ thick walls. It is surrounded by a stainless steel safety vessel. The gap between the vessels is about $300 \mathrm{~mm}$, providing a space into which TV cameras can be introduced during shutdown for inspection of the vessel walls. The reactor vessel wall, in contact, with sodium, has a thermal lining. All pipework lines are accommodated below the emergency sodium level, entering at the top of the vesse 1 and dropping down to the bottom collector vessel. The pipes are welded to the bottom collector vessel, which is supported on the bottom of the reactor tank. The reactor vessel is supported by a top flange and supporting girders. A dip plate serves as instrument carrier and holddown. The tank wall is protected from pressure surges by a perforated inner enclosure, which consists of the bottom collector vessel, the shield tank, and the upper dip plate. Structural connection between the dip plate and the bottom collector vessel is through the reactor tank wall. The wall thickness of the inner pressure enclosure is $50 \mathrm{~mm}$. (Fig. XI.C-T) (Ref. 5)

The top closure is a system of three rotating plugs, nested eccentrically into each other. Each cover has a lower arrangement of austenitic steel sheets acting as heat reflector, a shield zone filled with granular basalt, and an upper cast steel plate, which is $600 \mathrm{~mm}$ thick. Individual covers are held down by bearing rings, and the whole system is bolted down to carrier beams. Sealing is by means of two consecutive inflatable seals, with the space between them filled with an inert gas. The covers are centered and carried by ball bearings. (Ref. 2)

An ex-vessel cooling system, to protect the containment system against melt-through and to maintain long-term confinement of fuel immersed in sodium, consists of a large collecting tank located below the safety vessel and inside the biological shield. It is designed for the assimilation of 582 tons of sodium at $900^{\circ} \mathrm{C}$, corresponding to a volume of $790 \mathrm{~m}^{3}$. The tank is lined with inner insulation to keep the wall temperature $\leq 520^{\circ} \mathrm{C}$. This insulation consists of fused cast press stones made of $\beta$-alumina. An additional protective wall is in front of these stones. The catch-tank wall is enclosed in a $5 \mathrm{~cm}$ wide cooling slot, with nitrogen distribution from pressure-relief channels. The upper edge of the catch tank is of conical construction. The whole base is filled with steel granulate. A base cooler between the fuel catching shell and the base of the sodium catch tank consists of hairpin tubes running parallel and connected to two circumferential connectors. These contain circulating NaK. The contact medium between the fuel catching shell and the cooling tubes is the sodium which enters the sodium catch tank, passing under the fuel catching sheil during melting of the reactor tank and the safety tank. The catch shell is provided with small boreholes to prevent the formation of an insulating gas buffer.

Diameter of the fuel catching shell is $5.4 \mathrm{~m}$. It has a protective coating. It is located on a support grating, which in turn is located on the base of the catch tank. Dynamic forces and pressure vaves originating from falling parts or from fuel/sodium interactions are. transmitted to a concrete foundation and to the containment concrete. A conical, truncated fuel directional spreader is located in the center of the fuel catching shel1. The sodium catch tank is located on a $0.85 \mathrm{~m}$ high base of temperature resistant concrete. The outer reactor tank is located on the conical shell within the sodium catch tank. (Fig. XI.C-2) (Ref. 7) 


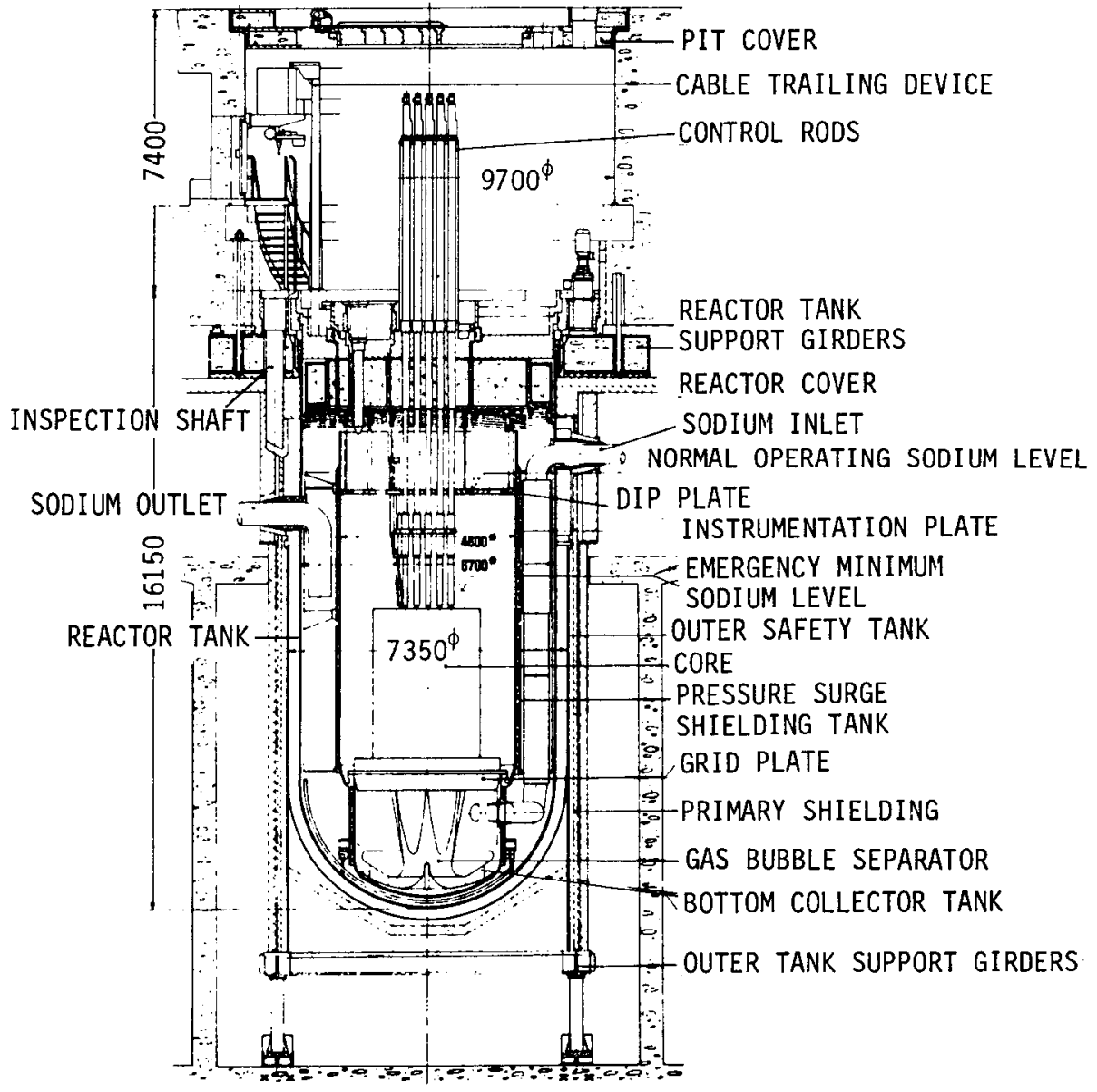

Figure XI.C-1 SNR-300 Reactor Vessel (Ref. 5)

$X I . C-2$ 


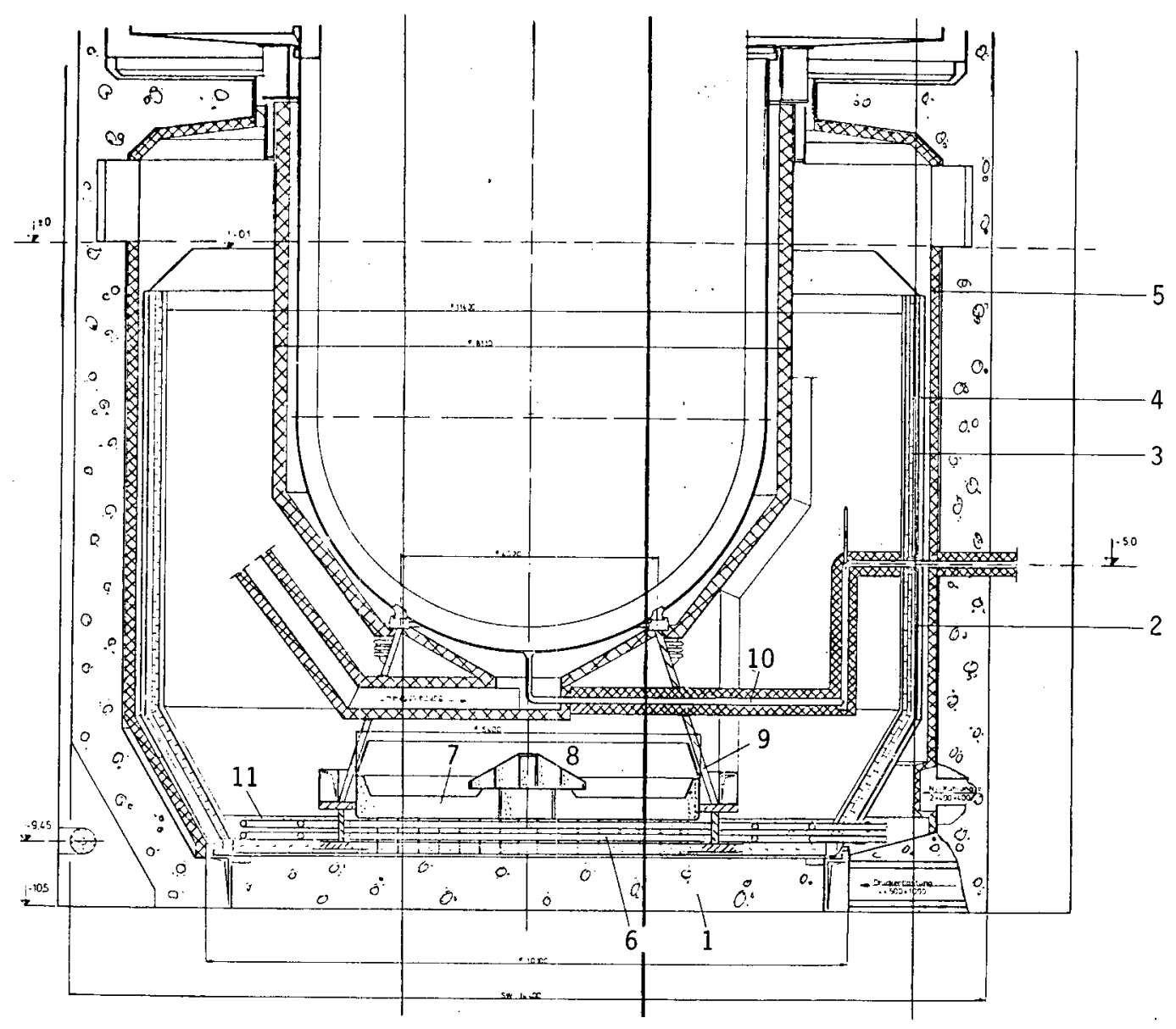

1. CORE CATCHER SOCKET

2. Na - CATCH PAN

3. INNER INSULATION

4. COOLING GAP

5. OUTER INSULATION

6. NaK - COOLING DEVICE

7. CORE - CATCH PAN

8. DISTRIBUTION DEVICE

9. GUARD VESSEL SUPPORT

10. GUARD VESSEL DRAIN

11. STEEL GRANULATE

Figure XI.C-2 SNR-300 Core Catcher (Ref. 7) 
XI. D. CONTROL ELEMENTS

The SNR-300 has twelve control assemblies in the core. Three of these form the auxiliary or emergency shut-down system. Enriched $\mathrm{B}_{4} \mathrm{C}$ is the absorbing material. At the beginning of life, surplus reactivity will be compensated by diluent rods in some of the fuel element positions.

The nine elements of the first system are composed of nineteen-pin bundles enclosed in a movable circular guide tube. The outer duct is hexagonal. The control elements are suspended above the core and drop into place. The absorber pins are sealed, with finned spacers. Studies have been done on vented pins using porous plugs.

In the second, or emergency system, the absorber is a flexible chain of three rod bundles containing highly enriched $B_{4} C$. During normal operation these elements are kept in the lowest position below the core by a scram magnet above the core, which tensions the accelerating spring. On scram signal, the inductor current to the magnet is interrupted and the released armature plate is pushed upward. A transfer rod connected to the plate pulls the absorber into the core on a fast stroke. The transfer rod has a shock absorption piston which enters a shock cylinder after $30 \%$ of the 1 ift stroke. During this operation the acceleration spring is re-tensioned. The second system does not operate at every scram, but only if the primary system fails. During refueling, the connecting rods must be disconnected and the three safety elements left below the core.

(Fig. XI.D-1) (Ref. 13)

Al1 nine of the compensating rods represent a total reactivity of about $7.5 \%$. The safety rods provide a further $3.6 \%$. (Ref. 24) 


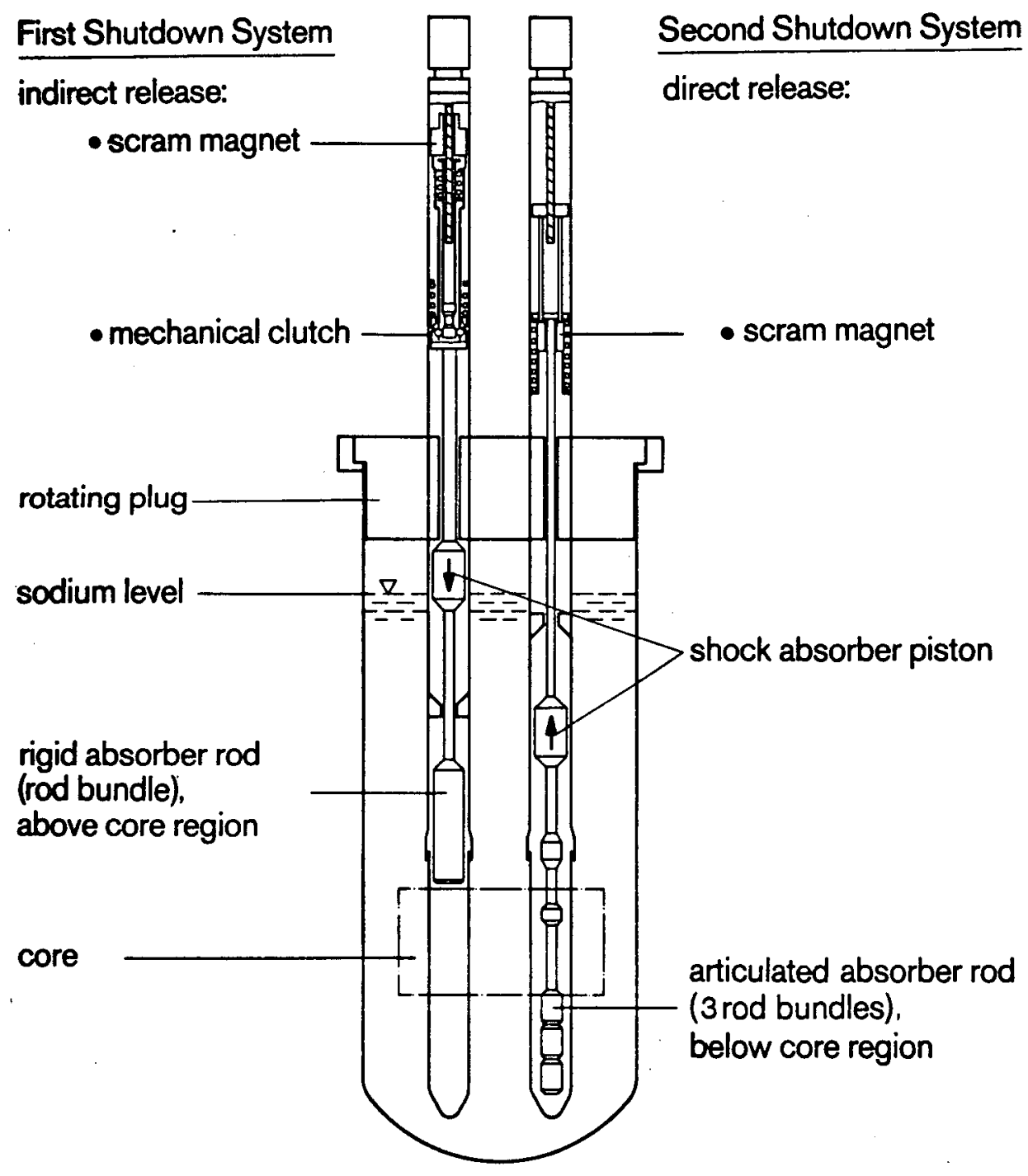

Figure XI.D-1 SNR-300 Shutdown Systems (Ref. 13)

XI.D-2 


\section{E. HEAT TRANSFER SYSTEMS}

SNR-300 has three primary and three secondary loops, plus a separate emergency cooling system. Arrangement of the system allows for natural circulation. The primary system has no isolation valves, but a throttle valve in each primary loop reduces thermal shock after shutdown. Primary pumps are located in hot legs, secondary pumps in cold legs. Each primary loop includes the shell sides of three intermediate heat exchangers. All piping is single-wall. All nozzles and nearly all sections of the primary piping are located above the emergency sodium level in the reactor vessel. Parts located below this level are surrounded by limited-volume guard vessels to avoid unacceptable loss of coolant in case of a leak. Diameters of the primary and secondary pipework vary between $300 \mathrm{~mm}$ and $600 \mathrm{~mm}$, and wall thicknesses between $6 \mathrm{~mm}$ and $14 \mathrm{~mm}$. Operating pressure of the secondary system is greater than pressure in the primary system. (Ref. T2)

The intermediate heat exchanger is an $85 \mathrm{MW}$ straight tube unit with a bottom floating head. The vessel is placed on a skirt which is outside the insulation. Primary sodium enters at the upper level and flows downward in the shell side. Secondary sodium enters at the top and flows down through a central downcomer to the lower tube plate, from which it is directed upward through the tubes. Each of the three loops will include three intermediate heat exchangers, for a total of nine. The unit can be removed and replaced if necessary. (Fig. XI.E-1) (Ref. 10, 27)

The SNR-300 prototype pump is a vertical, free-surface type with a singlestage radial flow impeller. The shaft is supported by a sodium-lubricated hydrostatic bearing near the impeller, and an oil-lubricated roller bearing at the top. Anti-vortex baffles are provided in the upper part of the pump, and air-cooled therma] baffles keep the temperature of the biological shield, the sealing, and the upper bearing under $80^{\circ} \mathrm{C}$. The three SNR primary pumps and three secondary pumps have been ordered. The main pumps have $5300 \mathrm{~m}^{3} / \mathrm{hr}, 140 \mathrm{~m}$ head, and $73 \mathrm{~m}$ NPSH. (Fig. XI.E-2) (Ref. I1)
There are six butterfly type isolation valves in the primary and secondary loops, one valve located at the suction side of each pump. The valve is a special design selected to control flow at after-heatremoval conditions, flow in the secondary loop with loss of the primary loop, stop reverse flow under conditions of pump failure. The valve has an eccentric axle. Pipe diameter is $609.6 \mathrm{~mm}$. The freeze seal is cooled by forced convection. The guide tube carries a bushing with brazed cooling fins. There is a safety gasket with an intermediate gas seal. (Fig. XI.E-3) (Ref. 20)

Auxiliary loops will be equipped with bellows seal valves up to a maximum width of $100 \mathrm{~mm}$. These have a forged housing, with upper and lower parts connected by welding. Cones are connected to the shafts by flexible joints. Three bores at the circumference of the shaft head connect the bellows cavity with the main duct. Drive is electro-mechanical.

(Fig. XI.E-4) (Ref. 21)

In addition to the main system, a separate emergency cooling system is provided. When in use, heat is removed from the core coolant by six coolers immersed in the sodium between the shield tank and the reactor vessel. Each immersed cooler has its own secondary sodium system which transfers the heat to two groups of air coolers. In the emergency case, the radial blanket serves as the connection between the upper plenum and the pressure region for sodium backflow to establish natural convection stream paths. The higher power density in the core results in a temperature difference between core and blanket sodium. Core sodium rises, and on reaching the sodium level, may be distributed radially to the six immersion coolers. Because of a temperature differential in the sodium column on both sides of the shield vessel--due to refrigeration in the immersion coolers--a sodium current will stream downward in the outer annulus, and enter the inner annulus through holes in the shield vessel. The inner sodium column is heated by heat transferred from the blanket. The flows are connected in the upper part of the blanket where cold sodium from the coolers enters the blanket elements radially through perforations. During normal 
operation about $10 \%$ of the total flow

passes through the blanket. In the

emergency case, total flow passes through

blanket and core, in series. Special

blanket throttles called cascade diodes

are planned. (Fig. XI.E-5) (Ref. 22,

27)
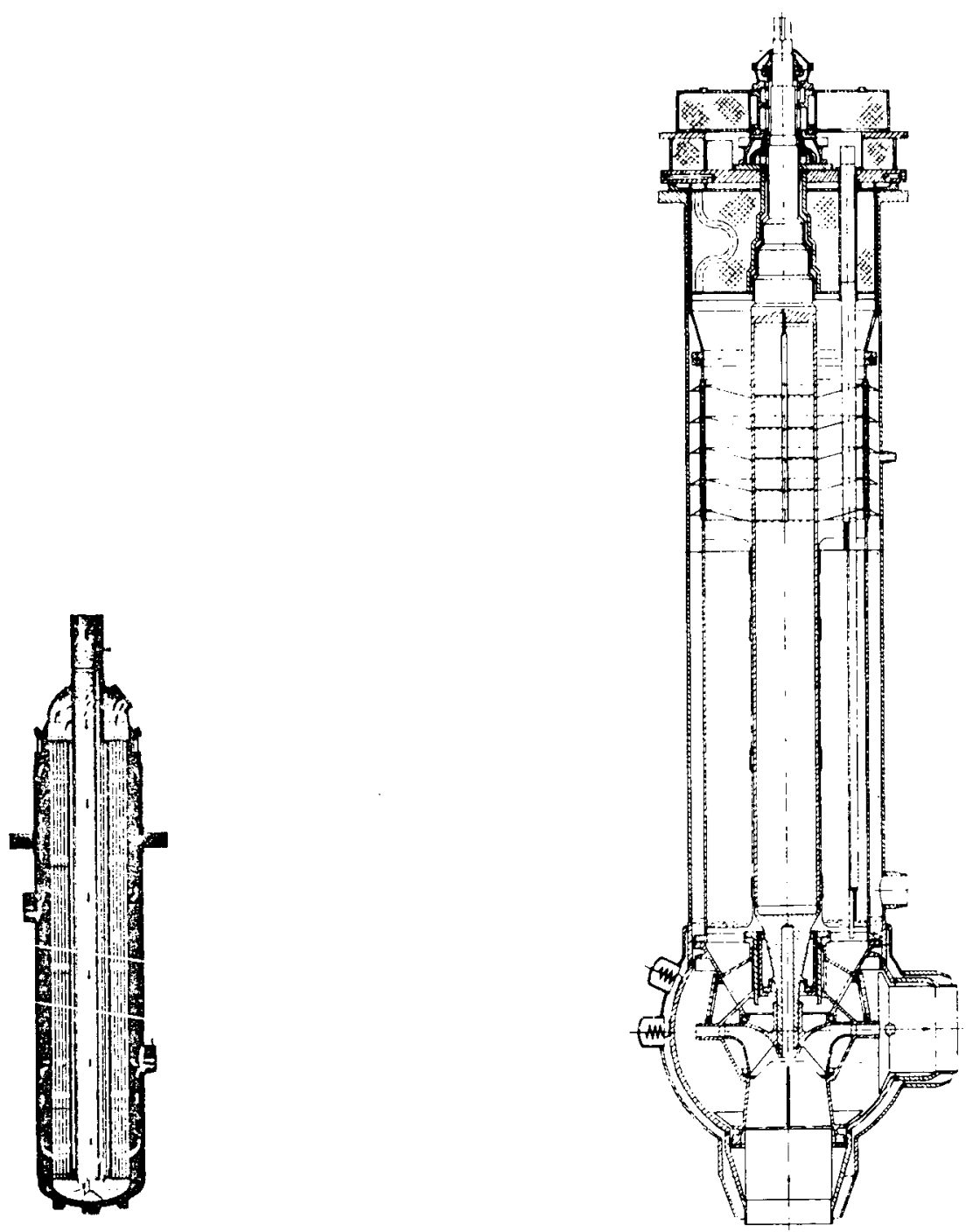

Figure XI.E-1 SNR-300 Intermediate Heat Exchange (Ref. 15)

Figure XI.E-2 SNR-300 Primary Pump (Ref. 11) 


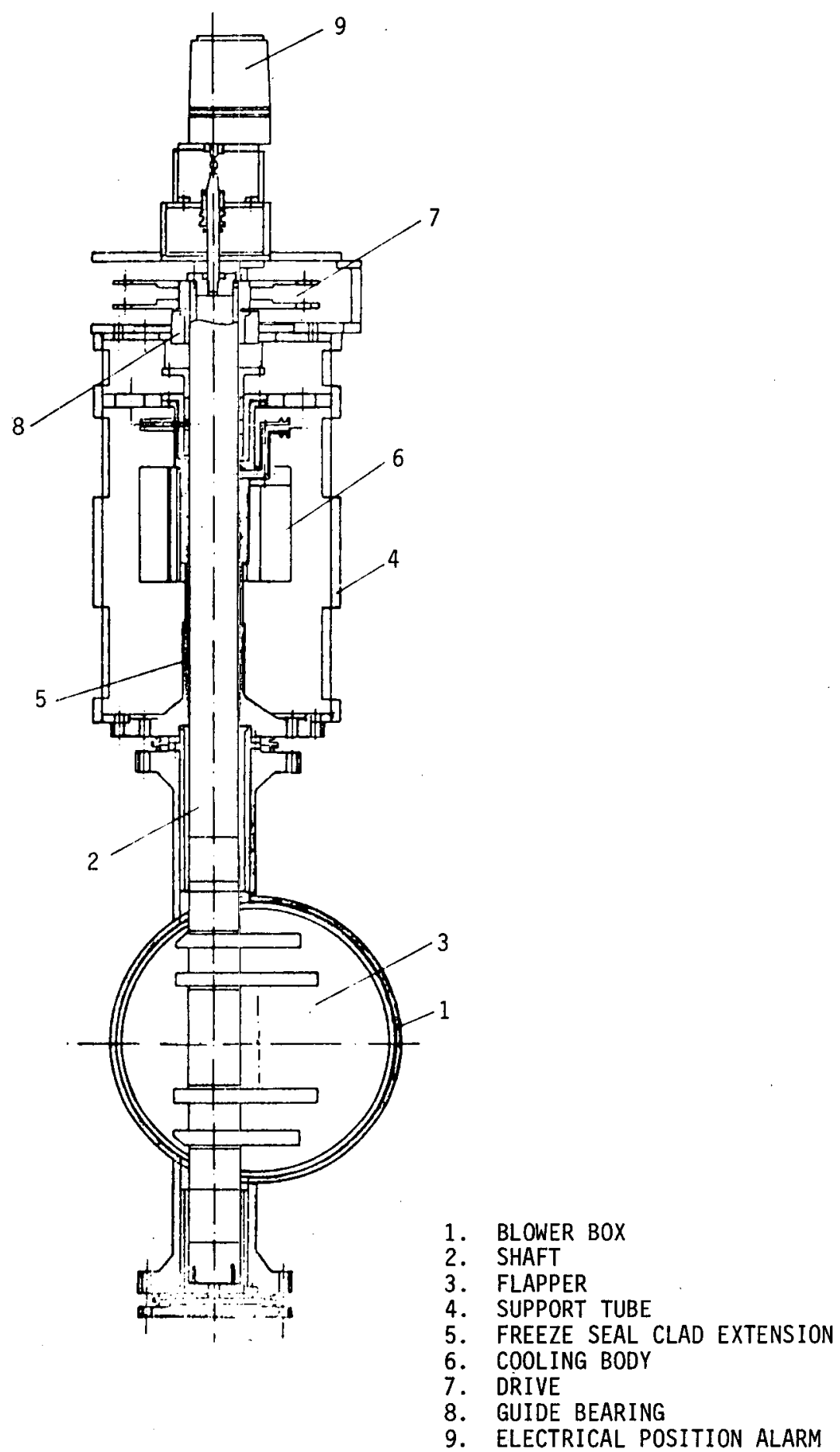

Figure XI.E-3 SNR-300 Butterfly VaTve and Armature (Ref. 20)

XI.E-3 
SNR-300 XI.E

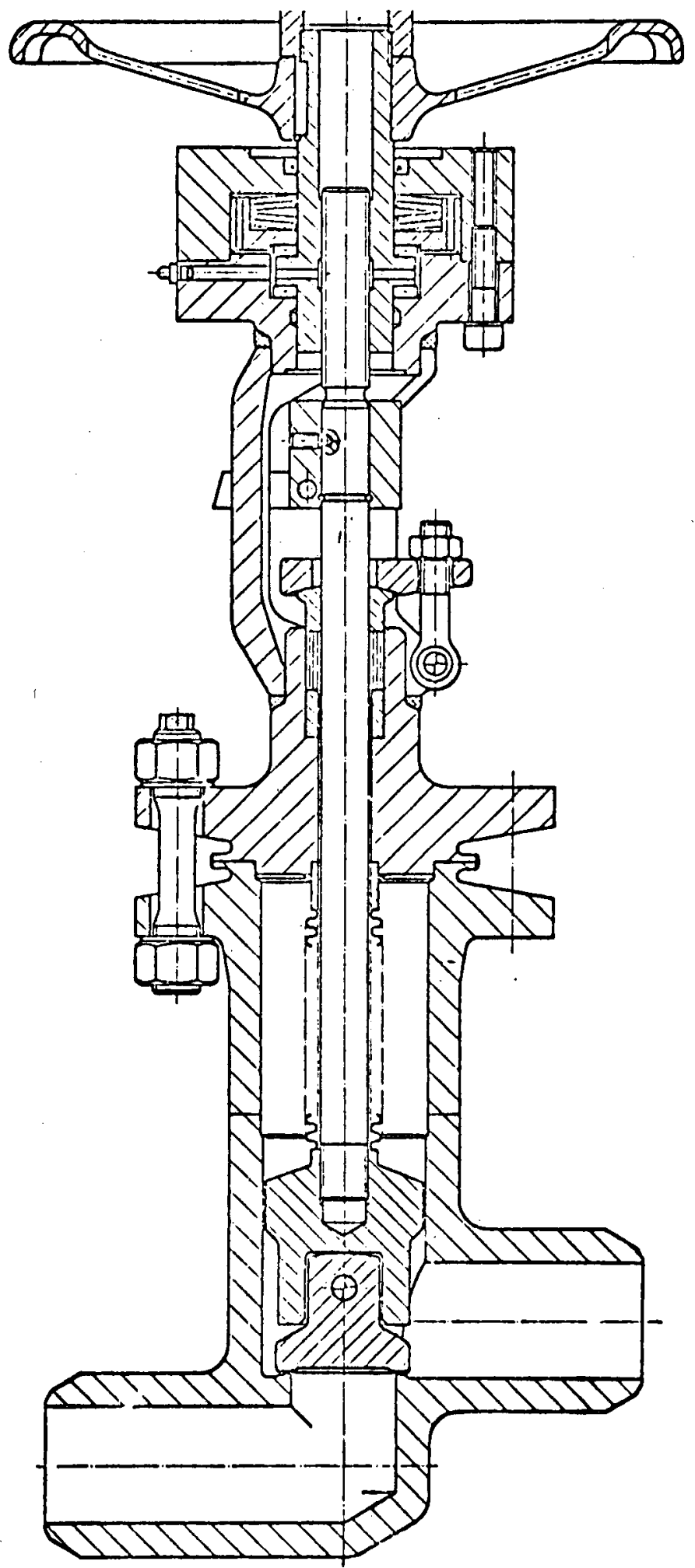

Figure XI.E-4 SNR-300 Bellows Seal Valve (Ref. 21)

$$
\text { XI.E-4 }
$$


SNR-300 XI.E

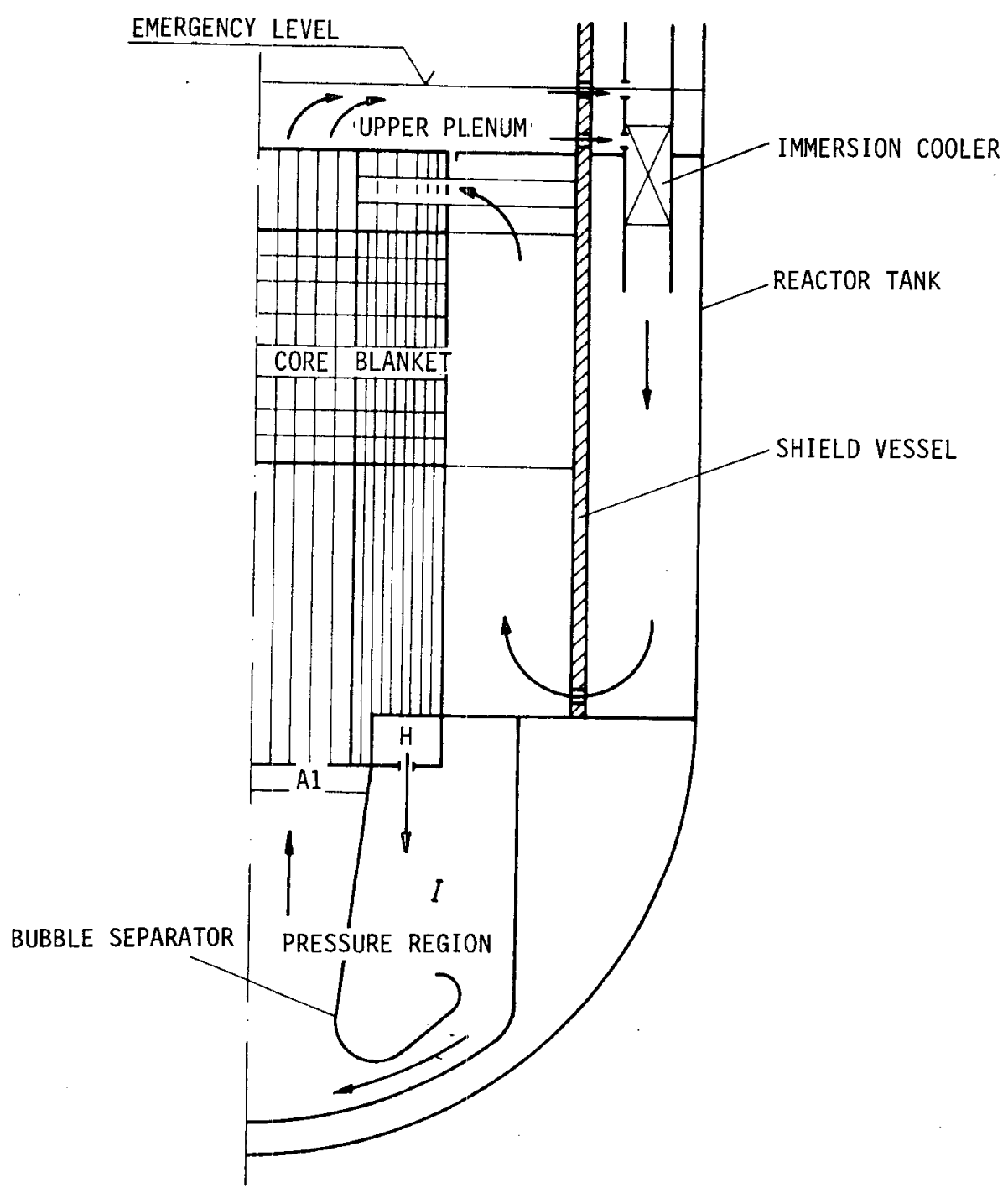

Figure XI.E-5 SNR-300 In-Tank Natural Circulation Stream Paths (Ref. 8)

XI.E-5 


\section{F. SODIUM PURIFICATION AND INSTRUMENTATION}

Level measuring techniques consist of continuous and discontinuous probes, operating on the induction principle. The cladding tube can be welded into the vessels to be monitored. Functions extend from monitoring of normal operation to direct shutdown criteria for the first and second shutdown systems. For Targe leakage measurements under the reactor tank and level monitoring of vessels with highly radioactive sodium, a discontinuous flexible level probe with a maximum of two measuring points and a possible insertion length of $25 \mathrm{~m}$ has been developed. (Fig. XI.F-l)

The permanent magnet method of flow metering has been selected for the SNR-300. The measuring device is mounted on the closed pipe carrying the sodium, and can be mounted and removed wi thout opening the system. A uniform family of magnet systems up to a pipe diameter of $100 \mathrm{~mm}$ has been developed. Permanent magnets are also used on pipe diameters up to $600 \mathrm{~mm}$. These require special mechanical supports. Flow measuring functions extend from monitoring the main lines with switching into the reactor protection system, and the measurement of practically all pipes carrying sodium to measurement components of instrumentation devices, such as plugging meters. About forty-five flow meters will be used.

Pump head for required coolant flow and the inert gas pressures, and sodium system pressures, are monitored by absolute pressure and differential pressure transducer systems. The high temperature resistant liquid for the transducer system is NaK eutectic.

Plugging meters are used to monitor sodium purity. Sodium to be monitored passes through a cooling section and a narrow point, upstream of which the sodium is measured simultaneously with the flow rate. When saturation temperature is reached, impurities precipitate at the narrowed point and the flow rate drops, the plugging temperature being that at which the decreased flow begins. Measuring can be manual or at intervals automatically. (Fig. XI.F-2)
Cold traps are used for sodium purification. Cooling of the traps is by nitrogen gas in the primary system and air in the secondary system. The traps include separate economizers. (Fig. XI.F-3)

In the case of a leak in the singlewall sodium/water steam generator, hydrogen is formed in a sodium-water reaction, and the increase in hydrogen concentration in the sodium is an indication of the leakage and its size. The SNR-300 hydrogen detection system is based on the use of a pure nickel membrane, which is selectively permeable to hydrogen. An ion atomizing pump is installed. At constant suction capacity the ion current is proportional to the hydrogen partial pressure in the sodium and thus to the hydrogen concentration. The instrument was designed to contain all components allowing operation regardless of the state of the plant. (Fig. XI.F-4)

Sodium samples are taken from the plant in crucibles and brought in a transport chamber to the laboratory, where oxygen and carbon are determined or complete analys is done. (Fig. XI.F-5)

Chromel-alumel sheathed thermocouples are used to monitor fuel element, and some breeder element, outlet temperatures. Four thermocouples are provided for each measurement. A probe has been developed, into the point of which the four thermocouples are brazed, and passed over a total length of $8 \mathrm{~m}$ in a leak-proof welded steel sheath to the collector. A heating element is installed at the upper end, and radial seals are provided in the cover zone.

Soolant flow rate is measured in four fuel elements by eddy-current flowmeter.

A combined inductive and measuring device is placed into the change tube of the in-vessel fuel transfer machine, by which direct observation of the fuel transfer process is possible. It is located about $200 \mathrm{~mm}$ above the sodium level. By manipulation of the gripper rod system, the core element position can be determined. Distinction between different fuel element types is also possible. (Fig. XI.F-6) (Ref. 25) 


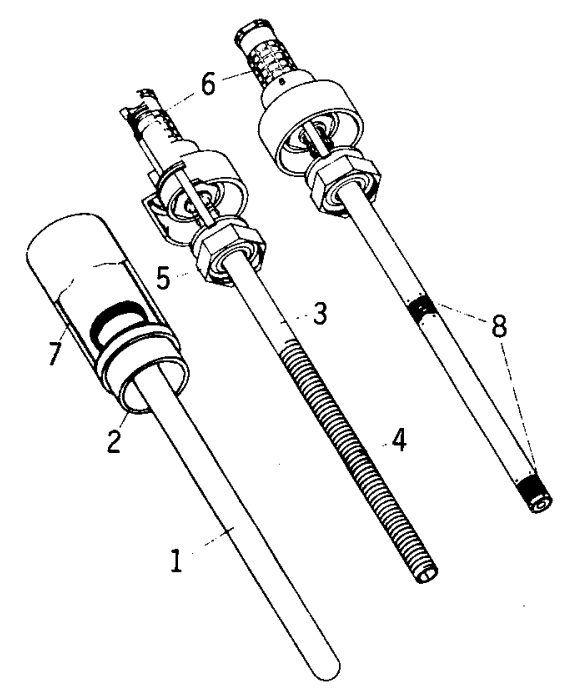

1. CLADDING TUBE

2. WELDING FLANGE

3. REPLACEABLE MEASURING DEVICE INSET

4. COIL SUPPORT (CONTINUOUS PROBE)

5. BOLTING

6. PLUG CONNECTION

7. PROTECTIVE HOOD

8. TWO MEASURING POINTS (DISCONTINUOUS PROBE)

Figure XI.F-1 SNR-300 Sodium Level Measuring Device (Ref. 25)

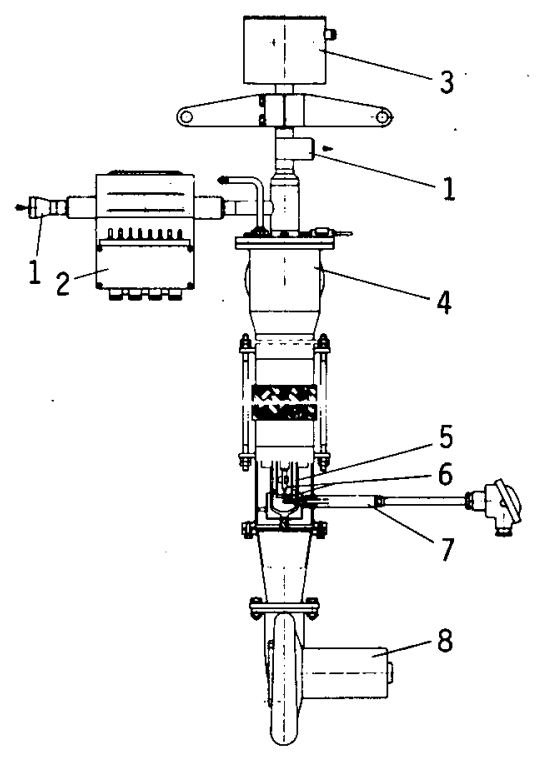

1. SODIUM INLET/OUTLET

2. FLOW METER

3. LIFT MAGNET

4. COOLING JACKET

5. HEAT EXCHANGER

6. NEEDLE AND SUPPORT PLATE

7. TEMPERATURE GAUGE

8. COOLING BLOWER

Figure XI.F-2 SNR-300 Plugging Meter (Ref. 26)

$X I . F-2$ 


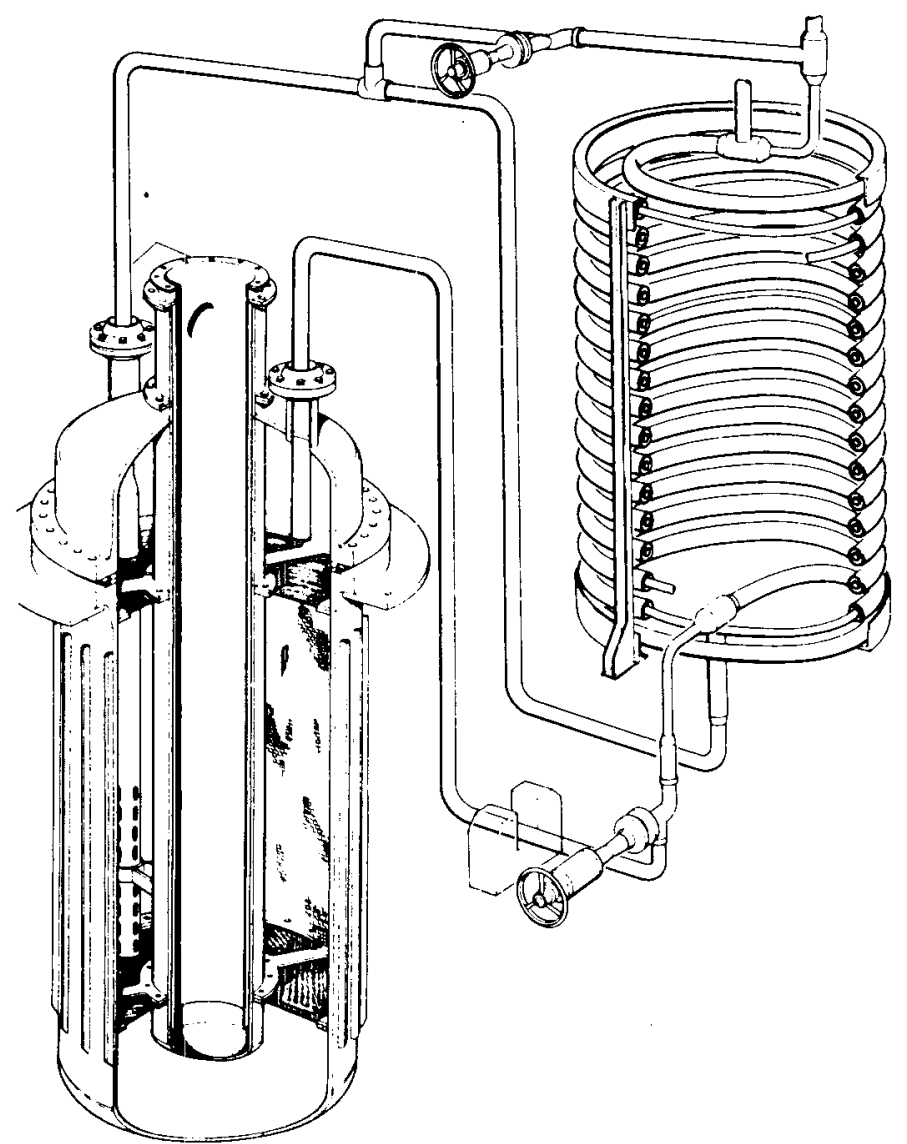

Figure XI.F-3 SNR-300 Cold Trap (Ref. 15)

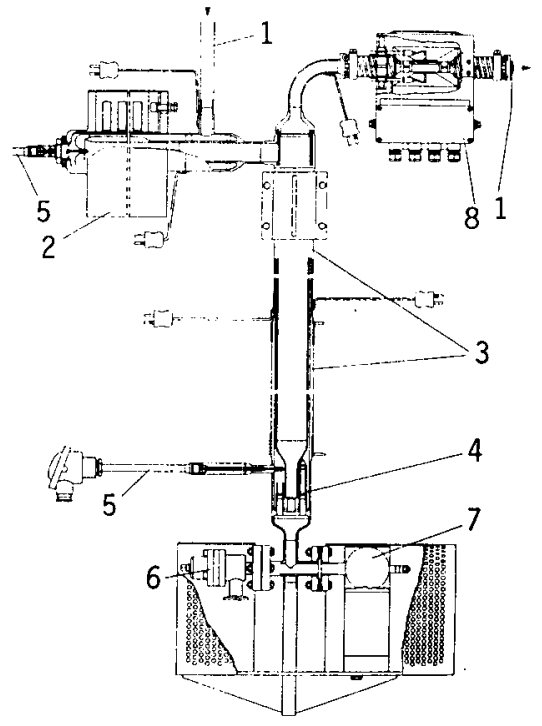

1. SODIUM INLET/OUTLET

2. INDUCTION PUMP

3. HEAT EXCHANGER AND HEATED SECTION

4. Ni MEMBRANE

5. TEMPERATURE GAUGE

6. VACUUM PUMP CONNECTION

7. ION ATOMIZER PUMP

8. FLOW METER

Figure XI.F-4 SNR-300 Hydrogen Detection System (Ref. 26)

$X I . F-3$ 


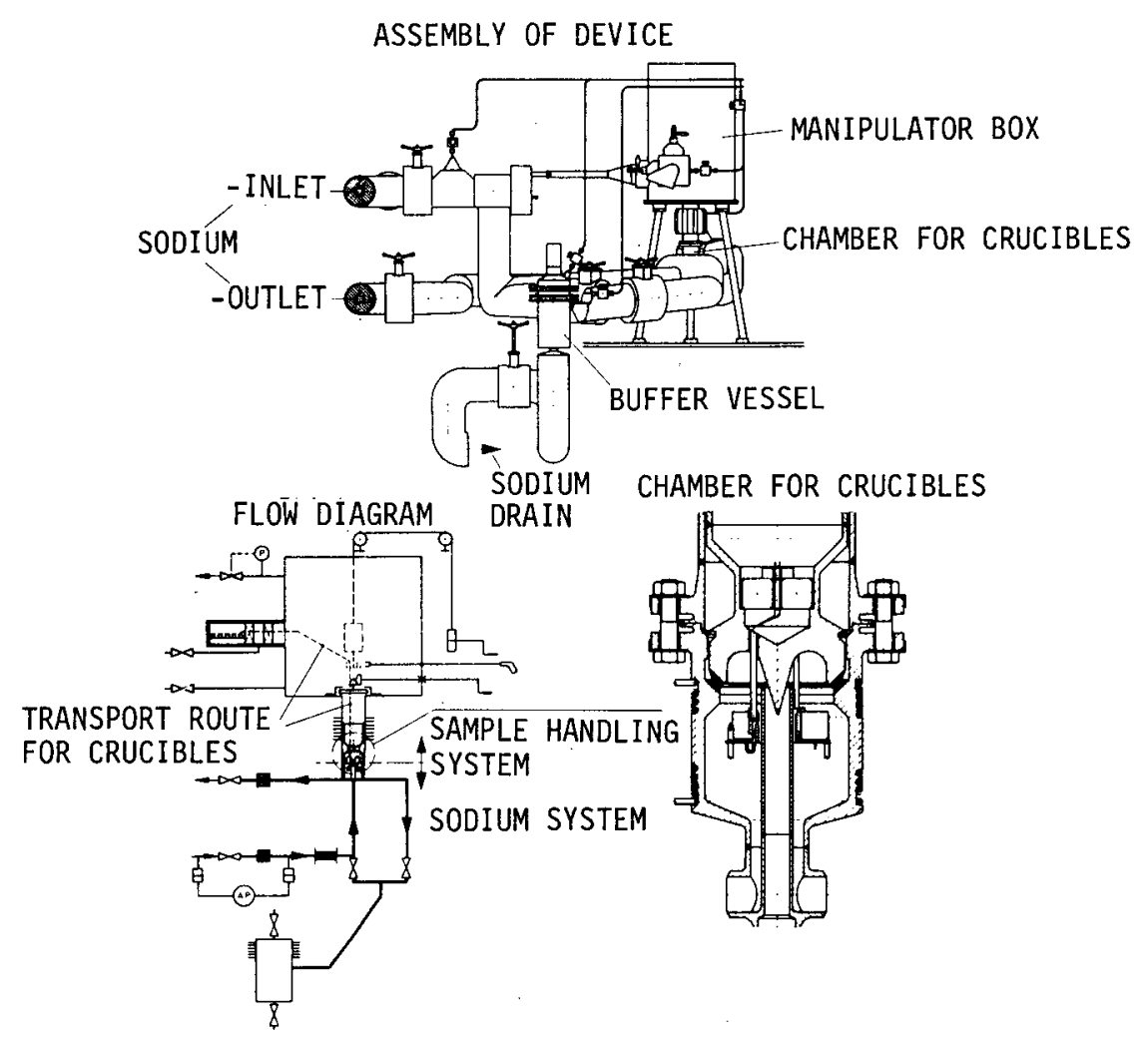

Figure XI.F-5 SNR-300 Sodium Sampling System (Fig. 25)

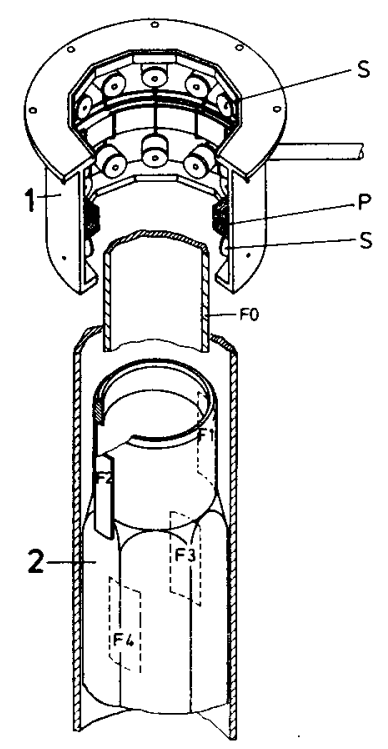

1. MEASURING DEVICE

2. FUEL ELEMENT HEAD

Figure XI.F-6 SNR-300 Core Element Positioning Device (Ref. 25)

$$
\text { XI.F-4 }
$$


$X I$. H. STEAM GENERATORS

The steam generating system will consist of three steam generator cells, two equipped with straight-tube generators and one with a helical-tube generator. The steam generator consists of an evaporator and a superheater, each cell will have three evaporators and three superheaters installed.

The steam generator with helically coiled tubes can be operated in parallel with the straight tube generator, and is interchangeable with it. The tube bundle comprises a number of concentrically fitted helically coiled tubes, which pass the vessel shell individually via thermal sleeves and come together at a central header. Water/steam flows upward from a ring header through the tubes. Sodium enters radially at the upper part of the cylindrical vessel, flows downward around the tubes, and leaves radially. Uniform distribution of the sodium is created by a flow skirt around the bundle and by cylindrical and annular circular plates above and below the bundle. A by-pass sodium flow is devised inside the vessel for hydrogen detection. Rupture disks are positioned near the sodium inlet and outlet. The evaporator and superheater units are identical in design. (Fig. XI.H- I)

In the straight tube version, evaporator and superheater are essentially the same in design. There is no reheater in the SNR-300 set. The unit consists of straight tubes between tube sheets. The shell is provided with a bellows to allow temperature differences between tube and shel1. Support grids are provided along the tubes. A dodecagonal flow skirt closely surrounds the tube bundle. Sodium inlets and outlets are annular chambers followed by a perforated

cylinder. Pressure relief systems at the sodium inlet and outlet are connected to two nozzles. Sodium flow is downward, water/steam flow upward. Thermal shielding is provided at the tube sheet region and at the point where the tube sheet is connected to the shell.

(Fig. XI.H-2) (Ref. 16) 
SNR-300 XI.H

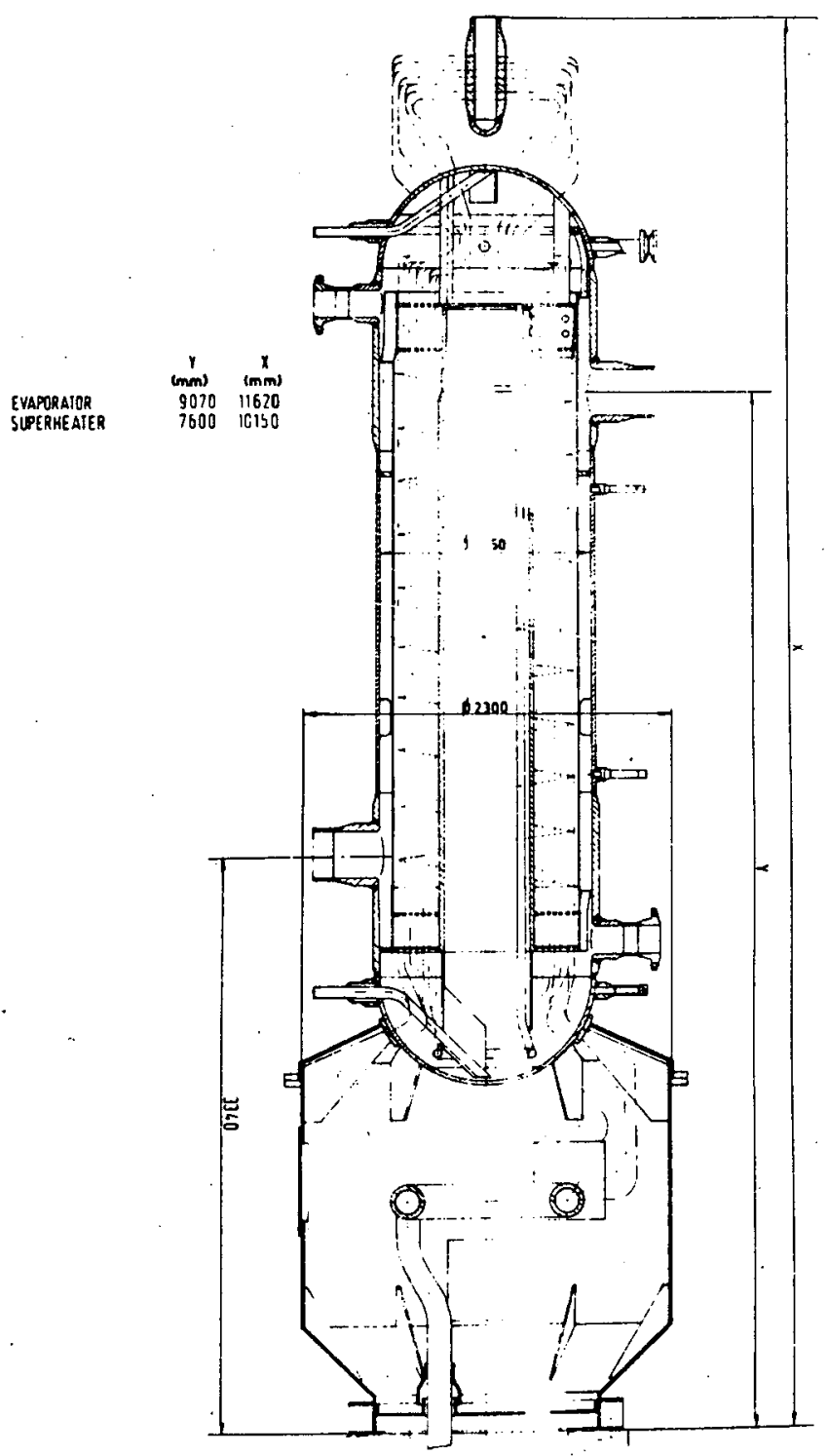

Figure XI.H-1 SNR-300 Steam Generator, Helically Coiled Tubes (Ref. 16) $X I . H-2$ 


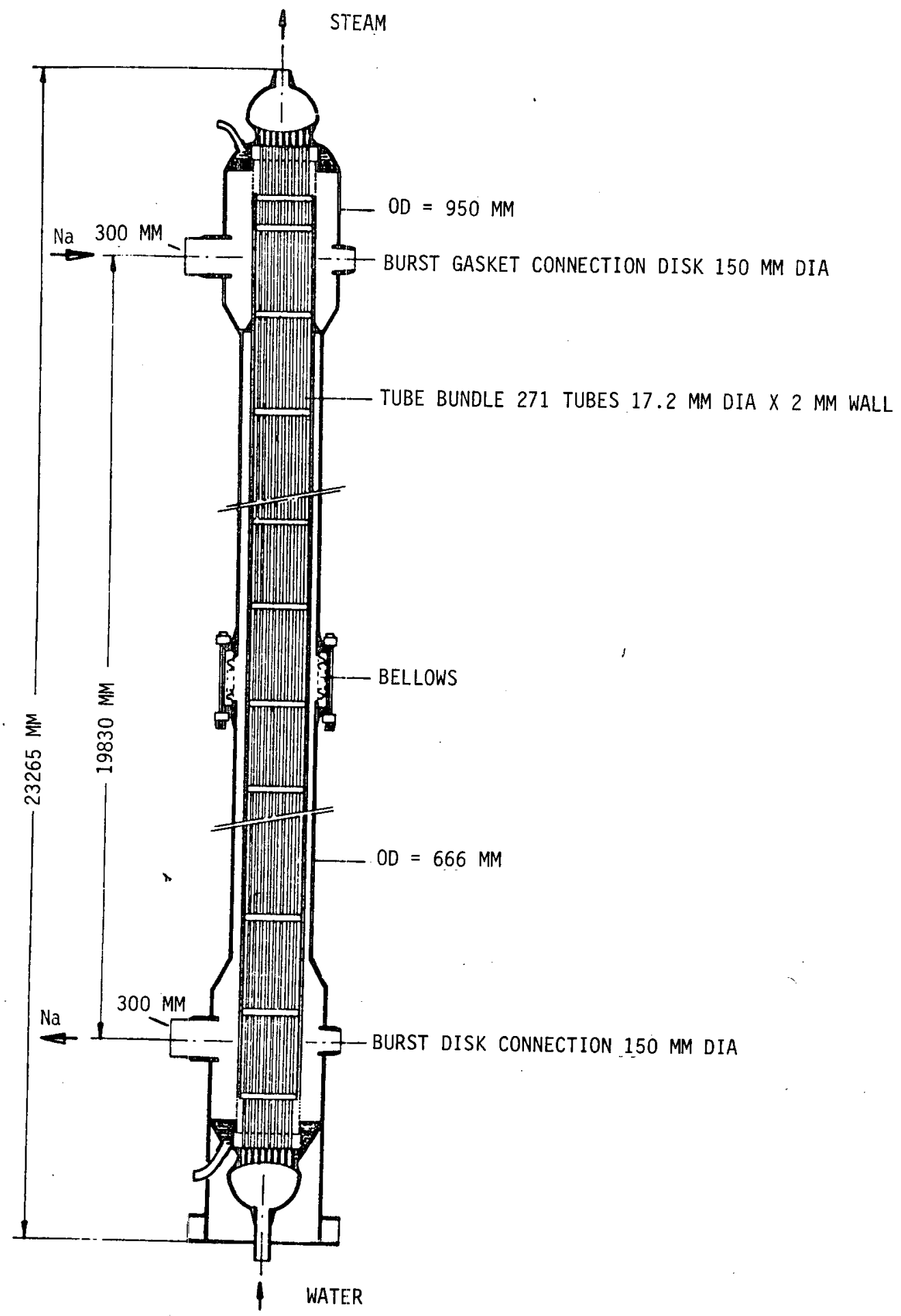

Figure XI.H-2 SNR-300 Straight Tube.Steam Generator

$$
\text { XI.H-3 }
$$


$X I . \quad J$. FUEL HANDLING

Under-plug refueling with the triple rotating plug was selected for SNR-300. Transfer from reactor vessel to ex-vessel storage is by a shielded, gas-cooled machine. Ex-vessel storage and other handling equipment are installed in special handling cells. Spent fuel transfer through the wall is by a gate which is removable only when the reactor is down, eliminating the need for an airlock and a second handling machine. There is no in-vessel storage of irradiated fuel. (Fig. XI.J-1, XI.J-2) (Ref. 9)

The ex-vessel handling machine is a shielded cask, moving on a bridge and equipped with a forced circulation gascooling system. Spent and new fuel is transported in sodium-filled canisters. Fuel storage is in a sodium-filled vessel with sodium circulation and nitrogen cooling. Emergency coolant loops are provided, which circulate the sodium to air coolers.

The in-vessel handling machine is positioned on the rotating plug, and can be positioned over any fuel, blanket, control or reflector assembly. The grab rod allows both up and down and rotational movement of the assemblies. (Fig. XI.J-2)

An auxiliary handling machine is provided for refueling preparation and post-refueling operations on the reactor, manipulation of control rod actuators and instrumentation, transport of contaminated material, etc. It is a shielded, gastight cask handled by the building cranes in the reactor building, and between buildings by a special gantry. (Ref. 9,17) 


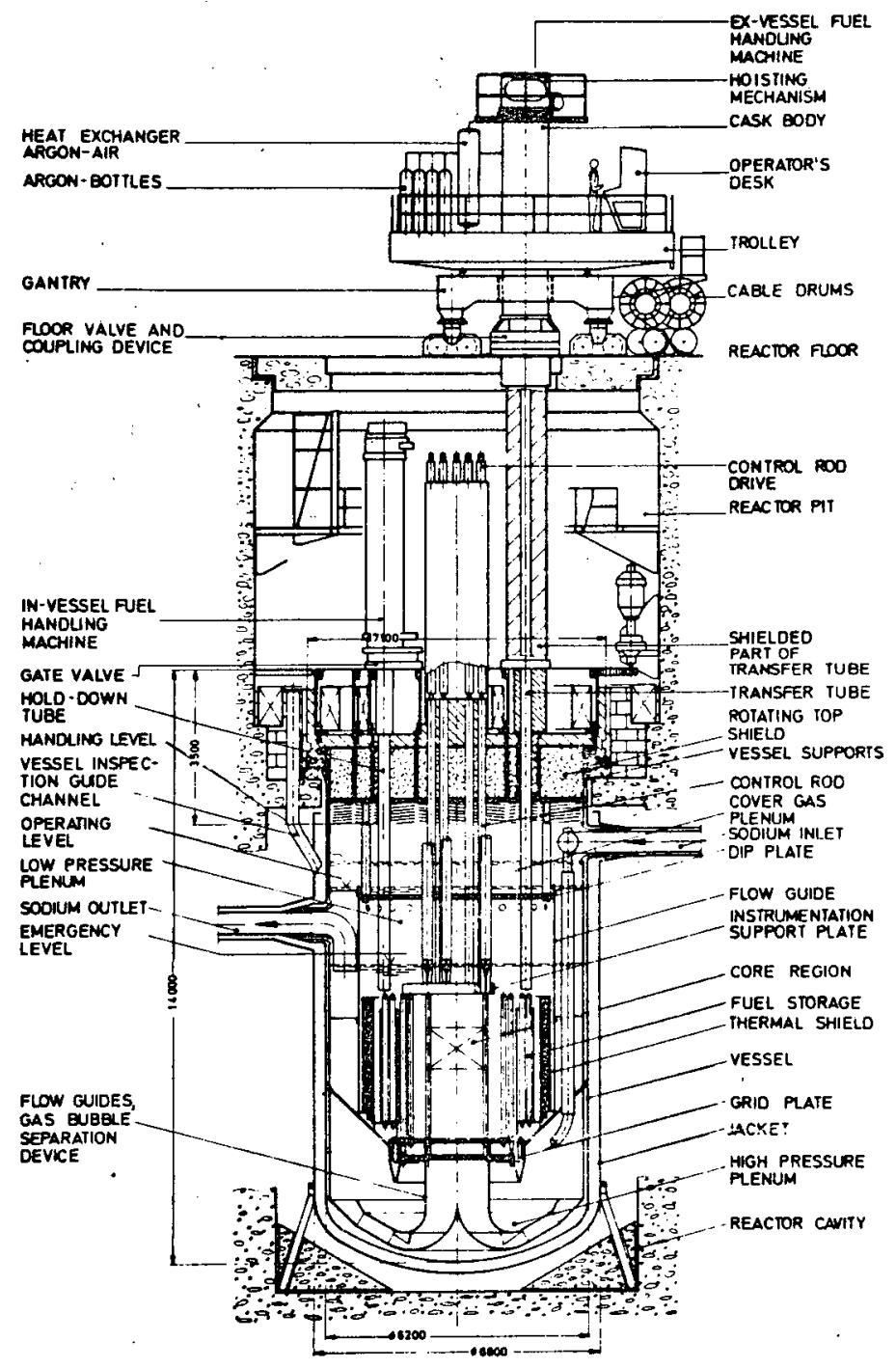

Figure XI.J-1 SNR-300 Arrangement of Refueling Equipment (Ref. 17)

$X I . J-2$ 


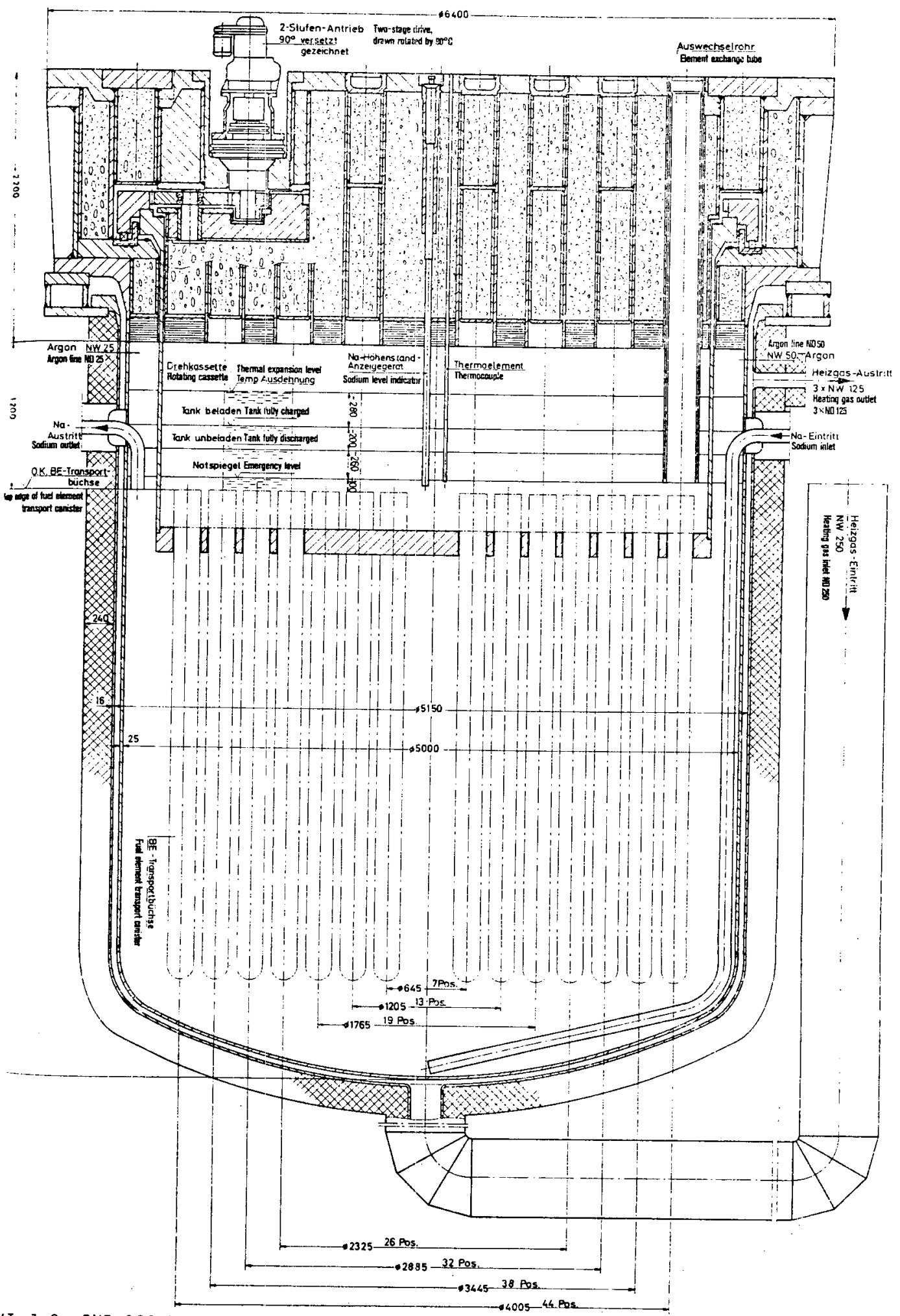

Figure XI.J-2 SNR-300 Decay Tank for Irradiated Elements (Ref. 26) 
SNR-300 XI.J

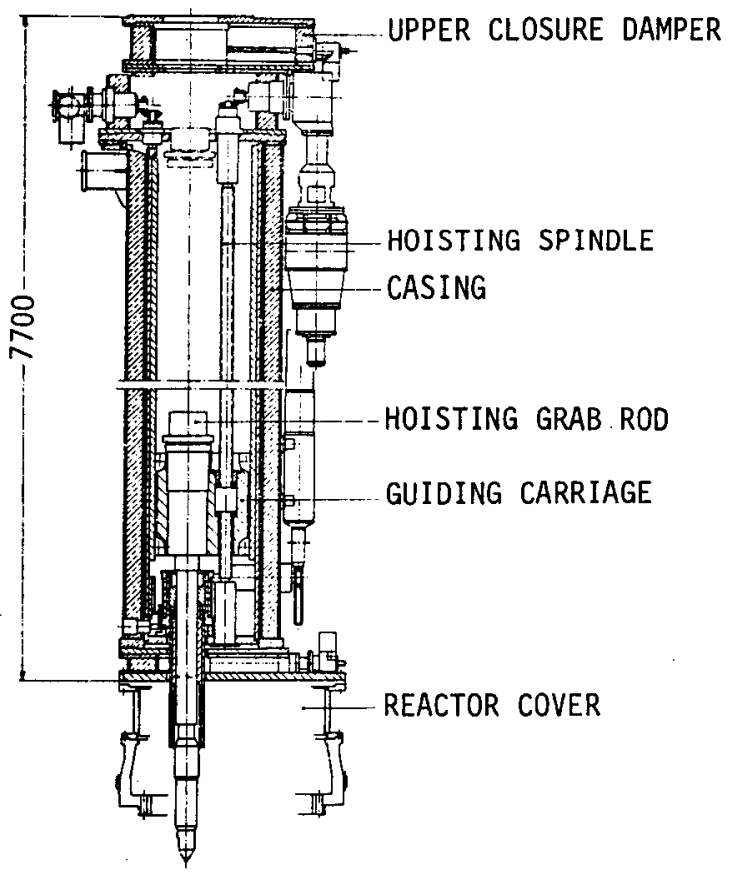

Figure XI.J-3 SNR-300 In-vessel Handling Machine (Ref. 17)

$X I . J-4$ 


\section{K. CONTAINMENT}

Containment is divided into two main zones. The inner contains the reactor and primary system. An additional volume, the pressure-relief room, is located at an elevated position within the inner containment. This volume limits the pressure peak and provides a flat temperature profile by natural convection of the containment atmosphere in case of an excursion. A low oxygen concentration is maintained in the inner containment during operation. The foundation below the reactor vessel is protected by a structure ensuring low temperatures of the containment boundary in case of a molten core penetrating the reactor vessel and guard vessel. An NaK cooling system is installed in the lower part of this structure. See Section C.

The outer containment includes the fuel handling area, the primary sodium auxiliary systems, nitrogen systems and operating floor. Its boundary is a steellined concrete wall. The gap between the concrete wall and the steel liner is connected to a reventing system to insure zero leakage directly after an accident. The gap between the reactor building and the outer containment is about $2 \mathrm{~m}$, and is used for the installation of cables and piping. (Fig. XI.K-T) (Ref. 9)

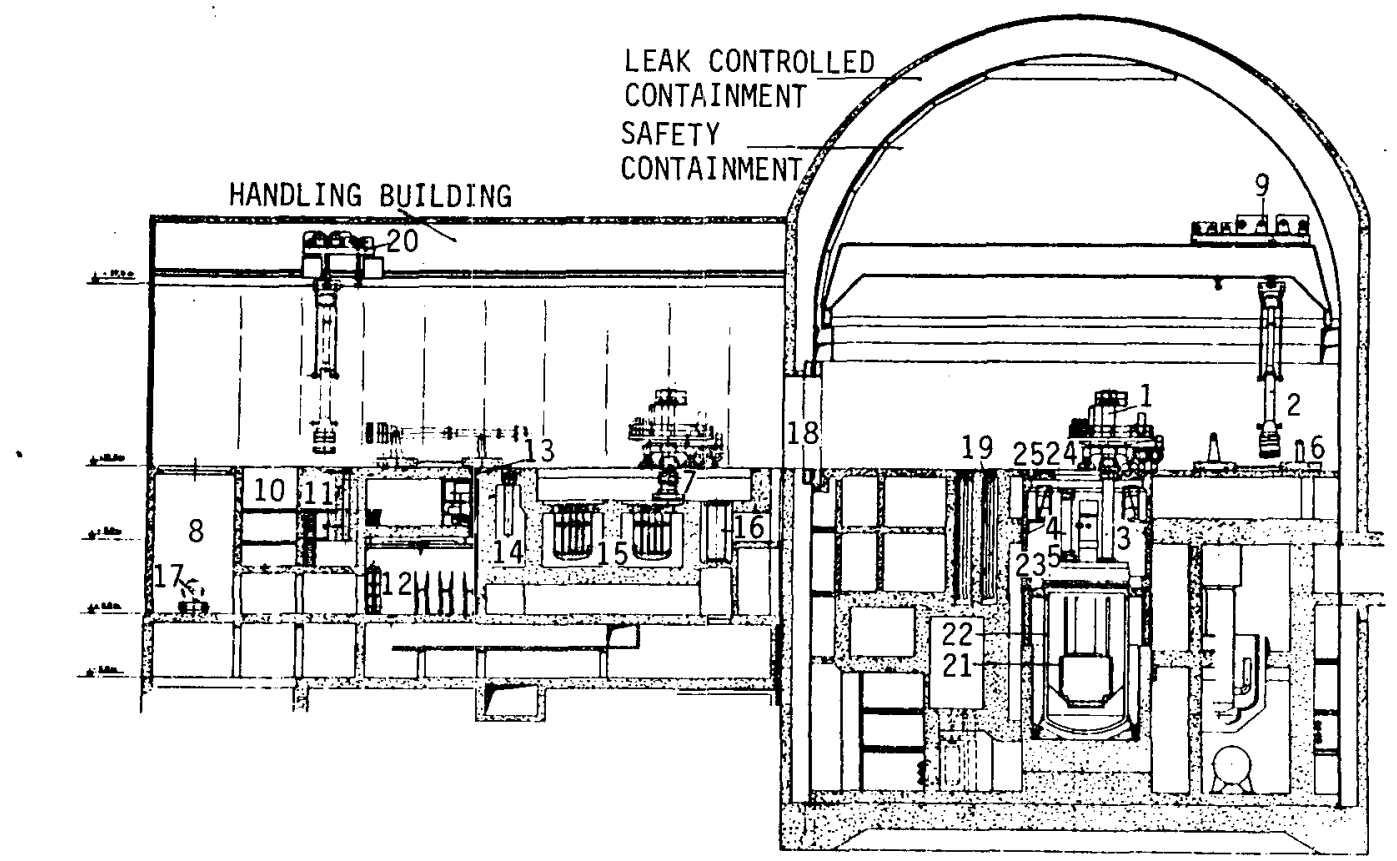

1. EX-VESSEL FUEL HANDLING MACHINE (EVFHM)

2. AUXILIARY HANDLING MACHINE (AHM)

3. SHIELDED TRANSFER TUBE

4. IN-VESSEL FUEL HANDLING MACHINE (IVFHM)

5. SHIELDED GATE VALVE

6. GANTRY OF AHM (2)

7. PLUG HANDLING MACHINE

8. LORRY ENTRY

9. SAFETY CONTAINMENT CRANE

10. HANDLING MACHINE MAINTENANCE PIT

11. SPENT FUEL INSPECTION CELL

12. FRESH FUEL STORAGE

13. FUEL ASSEMBLY PREHEATING CELL
14. FUEL ASSEMBLY WASH CELL

15. SPENT FUEL EX-VESSEL STORAGE

16. SHIPPING CONTAINER (CHARGE POSITION)

17. SHIPPING CONTAINER (SHIPPING POSITION)

18. SAFETY CONTAINMENT TRANSFER GATE

19. STORAGE OF CORE COMPONENTS AND SODIUM CONTAMINATED HANDLING EQUIPMENT

20. HANDLING BUILDING CRANE

21. IN-VESSEL STORAGE

22. REACTOR VESSEL

23. ROTATING PLUG TOP SHIELD

24. REACTOR PIT

25. OUTER REACTOR PIT CLOSURE PLUG

Figure XI.K-1 SNR-300 Reactor and Handling Building (Ref. 17) 


\section{DOUNREAY}

LOCATION: Dounreay, Scotland OPERATION: 1959

Full Power, 1963

Consideration of the engineering of a fast breeder reactor in the United Kingdom dates from 1951. Original work involved physics, engineering, metallurgy, heat transfer, fuel and sodium technology. A zeroenergy facility, Zephyr, was built and operated at Harwell from 1954 to 1958. The zero-energy facility Zeus followed, with a core using enriched uranium and closely related to the core design for Dounreay. Construction of Dounreay began in 1955, and the reactor became critical November 14, 1959. Since July 1963 Dounreay has operated at its full power level using redesigned fuel elements.

Dounreay uses enriched uranium fuel and $\mathrm{NaK}$ as coolant. It is a multi-loop system, with coolant flow downward through the core. Fuel elements are of the vented design. 


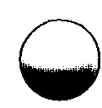

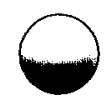

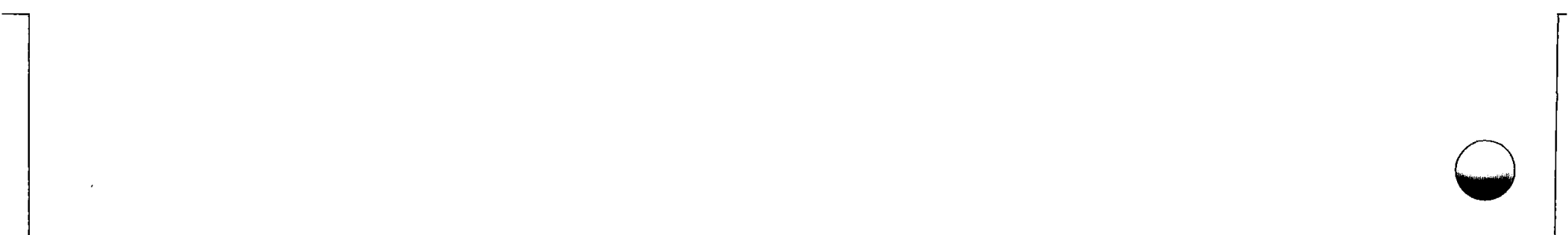


INDEX

Page

REFERENCES XII-5

REACTOR PARAMETERS

XII-7

SECTIONS

A. CORE AND BLANKET XII.A-1

B. CORE SUPPORT AND VESSEL INTERNALS XII.B-1

C. REACTOR VESSELS AND SHIELDING XII.C-1

D. CONTROL ELEMENTS XII.D-1

E. HEAT TRANSFER SYSTEMS XII.E-1

F. COOLANT PURIFICATION AND INSTRUMENTATION XII.F-1

G. COVER GAS AND AUXILIARY SYSTEMS XII.G-1

H. FINAL HEAT REJECTION XII.H-1

I. REACTOR INSTRUMENTATION AND CONTROL XII.I-T

J. FUEL HANDLING XII.J-7

K. CONTAINMENT XII.K- 


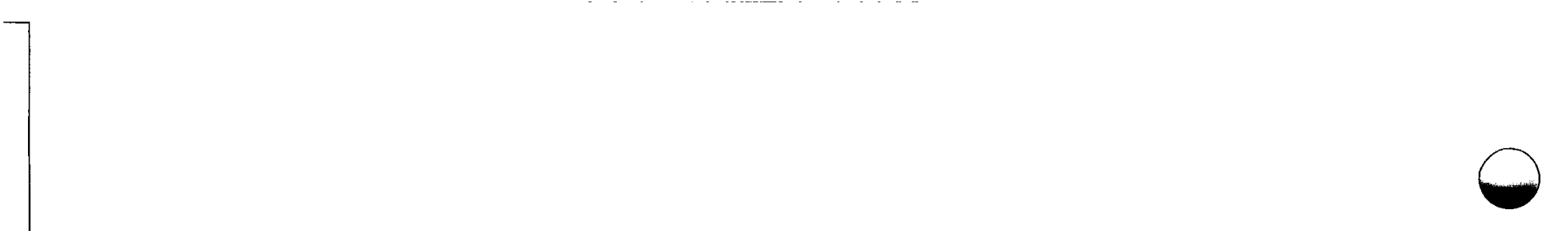

$\bullet$

- 


\section{REFERENCES}

1. Design and Construction of the DFR Core, Reactor Vessel Fuel Handling Equipment and Shielding

J. Tatlock, et. al.

British Nuclear Energy Conference J. Vol. 6 p. 166-188

July 1961 (Symposium on the Dounreay Fast Reactor)

2. Design and Construction of the DFR Heat Transfer Circuits Steam Generating Plant and Reactor Control System.

R. R. Matthews, et a 1 .

British Nuclear Energy Conference J. Vol. 6 p. 189-210

July 1961 (Symposium on the Dounreay Fast Reactor)

3. Dounreay Fast Reactor Modifications

J. L. Phillips

Nuclear Engineering Vol. 12, January 1967 p. 40-43

4. Development and Performance of Dounreay Fast Reactor Metal Fuel

S. A. Cottrel1, et. a 7 .

Proc. 3rd. Int1. Conf. Peaceful Uses of Atomic Energy, 1964, Vo1. 10 p. 151-160 United Nations 1965

5. Performance and Operation of the Dounreay Fast Reactor

R. R. Matthews, et. al.

Proc. 3rd. Intl. Conf. Peaceful Uses of Atomic Energy, 1964, Vol. 6 p. 23-32

United Nations 1965

6. A Review of the Operation of the Dounreay Fast Reactor

K. J. Henry, A. G. Edwards

Fast Breeder Reactors, Proc. BNES London Conf. May 1966 p. 153-169

British Nuclear Energy Society, 1967

7. Minimizing the Hazards Associated With the Use of the Dounreay Fast Reactor

As an Irradiation Facility

J. L. Phillips

Proc. Int1. Conf. Safety of Fast Reactors, Aix-en-Provence, 1967

p. Va. 4-1 to Va. 4-12

8. The Design of Irradiation Experiments for DFR and PFR

J. 0. Pounder

ANS Topical Meeting, Irradiation Experiments in Fast Reactors

Jackson Lodge Wyoming, 1973, p. 21T-228

American Nuclear Soc. 1973

9. Fast Reactor Technology Plant Design

J. G. Yevick, editor

MIT Press, 1966

10. Full Power Operation of the Dounreay Fast Reactor

J. L. Phillips

Fast Reactor Technology, ANS National Topical Meeting

Detroit, April 1965, p. 7-24

ANS -100

American Nuclear Society, 1965 


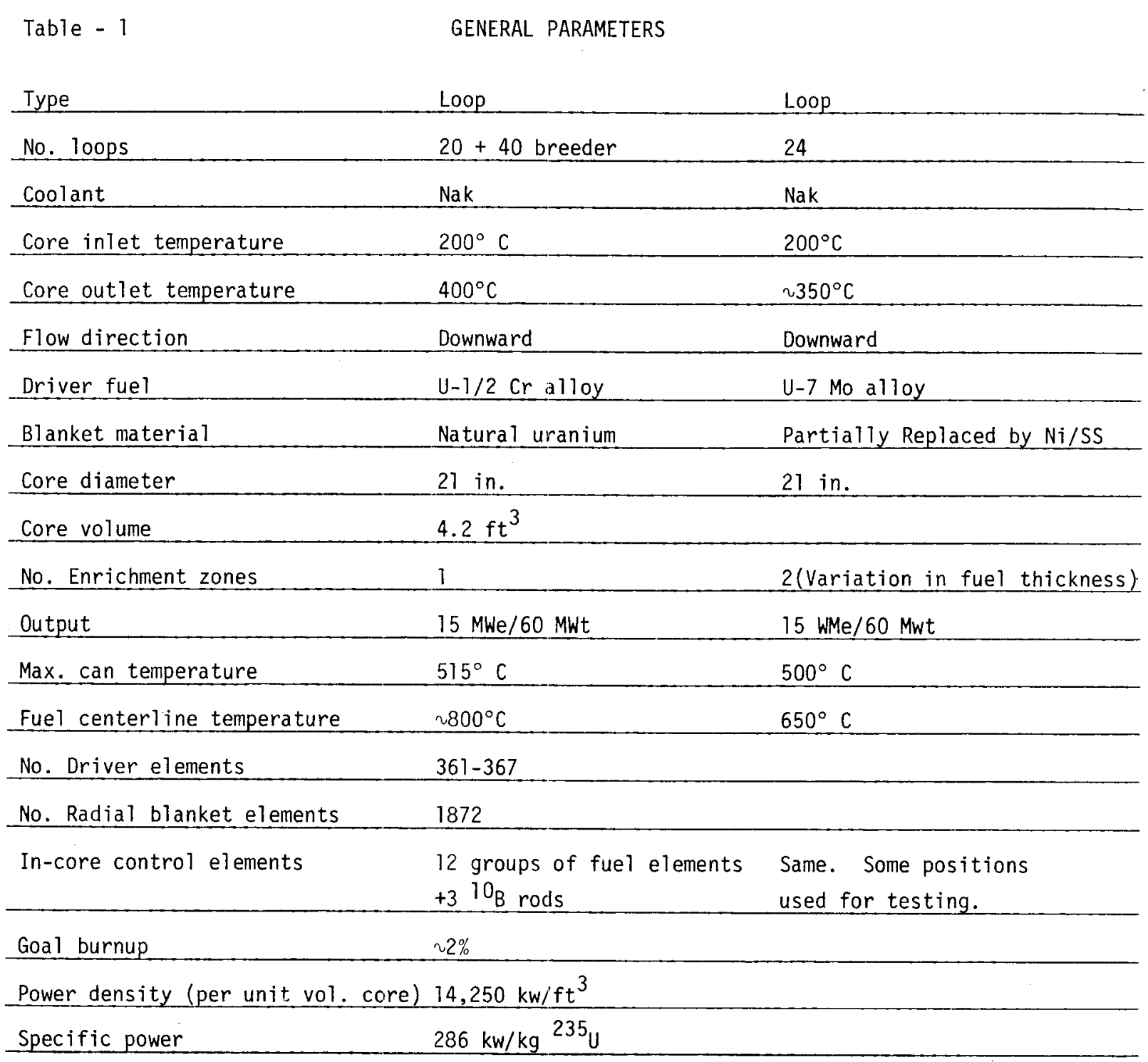


DOUNREAY XII

Table - 2

CORE AND BLANKET

1st Core

Mark - III

\begin{tabular}{|c|c|c|}
\hline Fuel material & \multicolumn{2}{|l|}{ Uranium a1loy } \\
\hline Blanket material & \multicolumn{2}{|l|}{ Uranium alloy (Magnox) } \\
\hline Composition & $\mathrm{U}-1 / 2 \mathrm{Cr}$ & $\mathrm{U}-7$ Mo \\
\hline${ }^{235} \mathrm{U}$ core & $30 \%$ & $75 \%$ \\
\hline blanket & \multicolumn{2}{|l|}{ Natural } \\
\hline Fuel form & Hollow rod & Hollow rod \\
\hline Blanket material form & \multicolumn{2}{|l|}{ Solid rod } \\
\hline \multirow[t]{2}{*}{ Fuel thickness } & & Inner zone 0.1 in. \\
\hline & & Outer zone 0.13 in. \\
\hline Fuel od/id & 0.698 in. $/ 0.316$ in. & Both zones 0.65 in. od \\
\hline \multirow{2}{*}{ Cladding-fuel } & Outer $\mathrm{Nb}$ tube & Outer Nb tube \\
\hline & Inner $v$ tube & Inner $V$ tube \\
\hline od & \multicolumn{2}{|l|}{ Nb 0.752 in. } \\
\hline & \multicolumn{2}{|l|}{ V $0.298 \mathrm{in}}$. \\
\hline \multirow[t]{2}{*}{ Fuel-clad gap } & \multicolumn{2}{|r|}{$\mathrm{U}-\mathrm{Nb} \quad 0.028 \mathrm{in}}$. \\
\hline & \multicolumn{2}{|r|}{ U-V 0.004 in. } \\
\hline Cladding-radial blanket & Stainless steel & Partially replaced \\
\hline Bond material & Sodium & Sodium \\
\hline Fuel length & 21 in. & $21 \mathrm{in.}$ \\
\hline Radiation blanket length & & Partially replaced \\
\hline Axial blanket length & 5.6 in. & (Replaced) \\
\hline Vented/non-vented & Vented to coolant & Vented to coolant \\
\hline Assembly & $\begin{array}{l}\text { Element components are the } \\
\text { end-piece, breeder end } \\
\text { pieces, } 7 \text { hollow fuel } \\
\text { slugs (stacked), adapter } \\
\text { washer, inner and outer } \\
\text { cladding tubes, top and } \\
\text { bottom fittings. Elements } \\
\text { are located in groups of } 7 \\
\text { in a core tube nest. }\end{array}$ & $\begin{array}{l}\text { General design essentially } \\
\text { unchanged. For core } \\
\text { modifications see Section } A \text {. }\end{array}$ \\
\hline
\end{tabular}




\section{XII.A. CORE AND BLANKET}

Core fue1 elements consist of a breeder end piece of natural uranium solid rods, the fuel section composed of seven interlocking hollow slugs forming a 21 -inch length, with cladding and support furnished by an inner vanadium can and an outer niobium can. The top plug has vent holes for venting to the coolant, the bottom plug is solid. The outer niobium can has integral spiral fins. Top end plugs of stainless steel locate the element in the top core plate. Ejght radial holes in the fitting allow coolant to pass through the plate. The bottom end fitting serves to guide the fuel element into position and locate it in the bottom end plate. Fuel-clad bonding is NaK. The fuel elements are located by groups of seven in a core tube nest. (Fig. XII.A-1a, XII.A-1b)

The original fuel was a $\mathrm{U}-1 / 2 \mathrm{Cr}$ alloy. After early power runs this was replaced by a $45 \%$-enriched U-20 Mo alloy. Mark III elements, loaded in 1963, have an enrich- ment of $75 \%$ and are fabricated of a U-7 Mo alloy. The fuel pieces are not interlocked. A two-zone core is used, differing in the thickness of the fuel. There is a large radial fuel-can gap. The axial blanket has been replaced by stainless steel and the first three rows of the radial blanket by nickel, with the first row mainly devoted to experiments. The central hexagonal block of the core has been replaced by two rhomboid blocks containing slightly modified standard elements, and the first experimental assembly containing $77 \mathrm{UO}_{2}-\mathrm{PuO}_{2}$ pins loaded into the third rhomboid block. The central space of these blocks can be used for instrumented experiments. These may also be located in four of the twelve control rod carrier center positions. DFR center flux is $2.5 \times 10^{15} \mathrm{n} / \mathrm{cm}^{2} / \mathrm{sec}$. dropping off to $1.9 \times 1015 \mathrm{n} / \mathrm{cm}^{2} / \mathrm{sec}$. at the core edge. (Fig. XII.A-2) (Ref. 5, 8) 


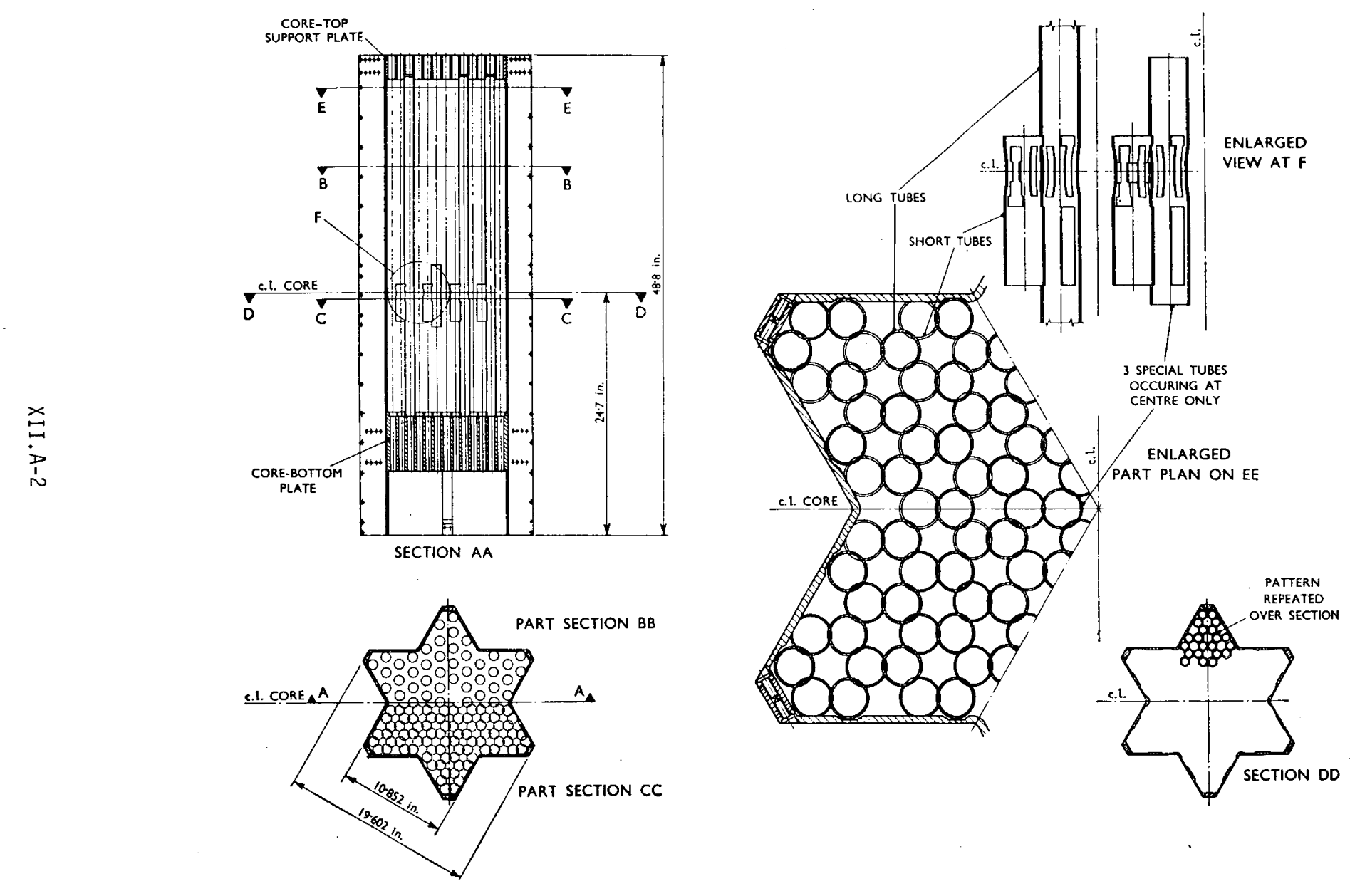

嵩

Figure XII.A-1a Dounreay Core Tube Next (Ref. 1) 


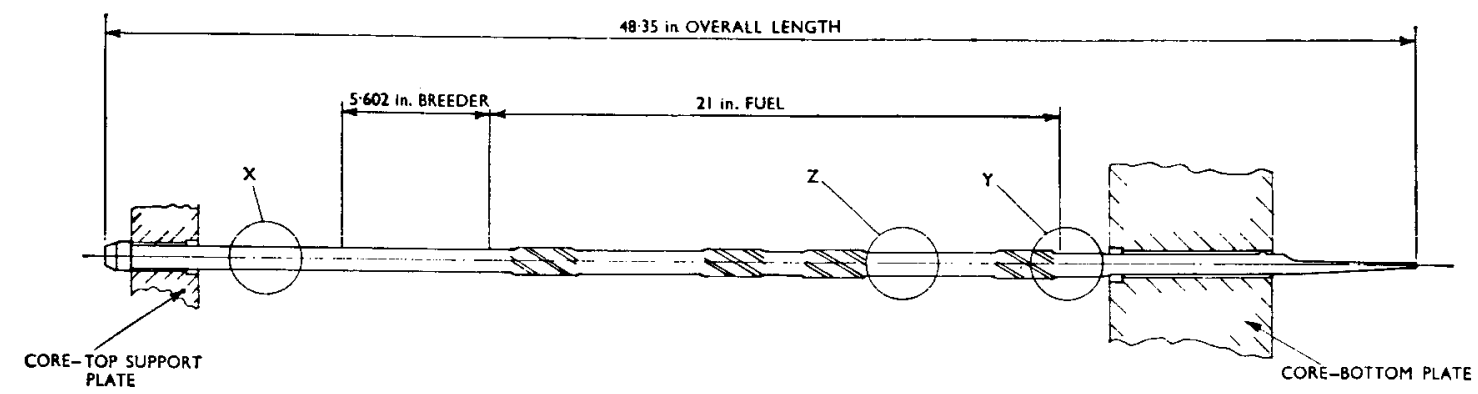

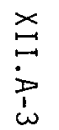

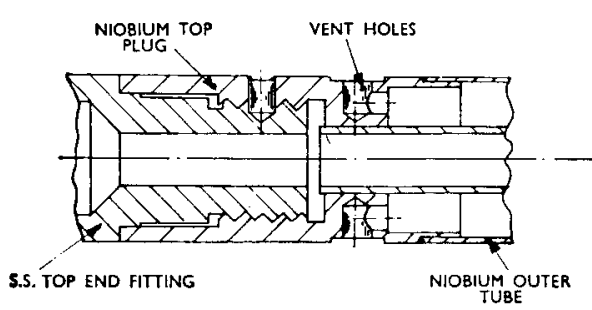

INTERLOCKING
FUEL PIECES

SODIUM FILING NOBNT BOTTOM
POINT

.

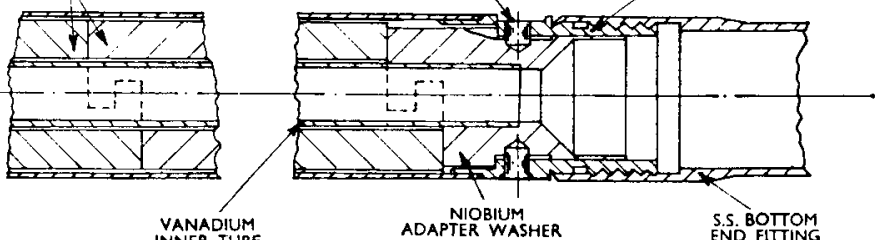

ENLARGED VIEW AT $X$

ENLARGED VIEW AT $z$

ENLARGED VIEW AT Y 


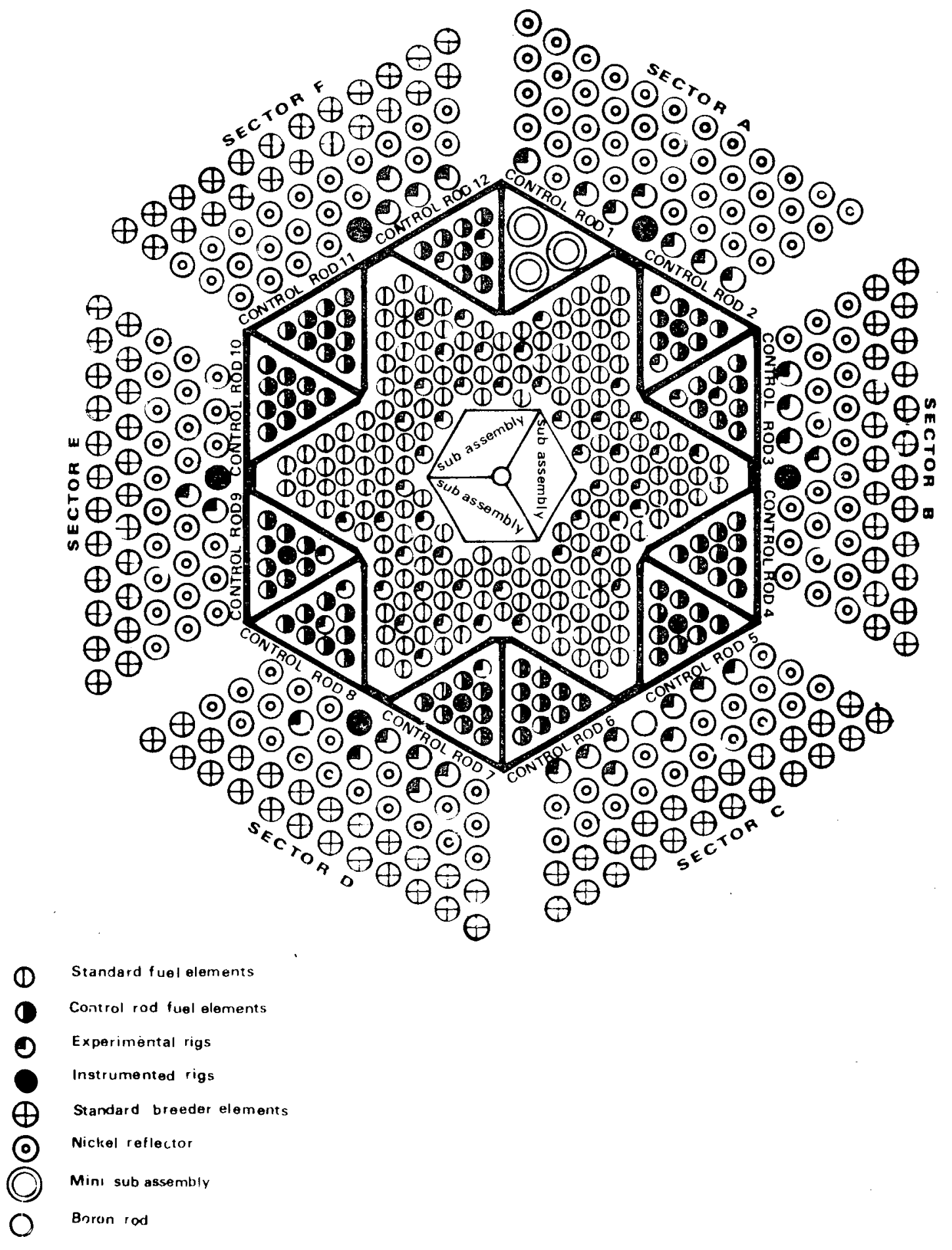




\section{XII.B. CORE SUPPORT AND VESSEL INTERNALS}

The breeder support box is the main structural member supporting the core and breeder, and acts as a header box for the breeder outlet coolant. It has a series of T-section ribs with continuous circular plates covering the top and bottom of the box. The top plate has holes for breeder coolant flow. The bottom end of the breeder element can be changed to control flow through these holes. The bottom plate slopes for drainage to coolant cutlet pipes. There are circumferential stiffeners adjacent to the hexagonal hole in the center of the box.

The inner breeder assembly is a vertically mounted skirt of hexagonal cross-section. It encloses the five inner rows of breeder elements. It consists of six sides bolted together, with plates fitted at top and bottom and a spacer plate midway between them. Spacer tubes with continuous spiral fins on the bore and outside diameter are fitted in counterbores in the plates in the second and fourth row. Al1 breeder rods in this section have a $1.63 \mathrm{in}$. equilateral pitch.

The outer breeder support consists of two plates, the bottom plate mounted on the breeder support box and the upper plate mounted on the inner breeder skirt

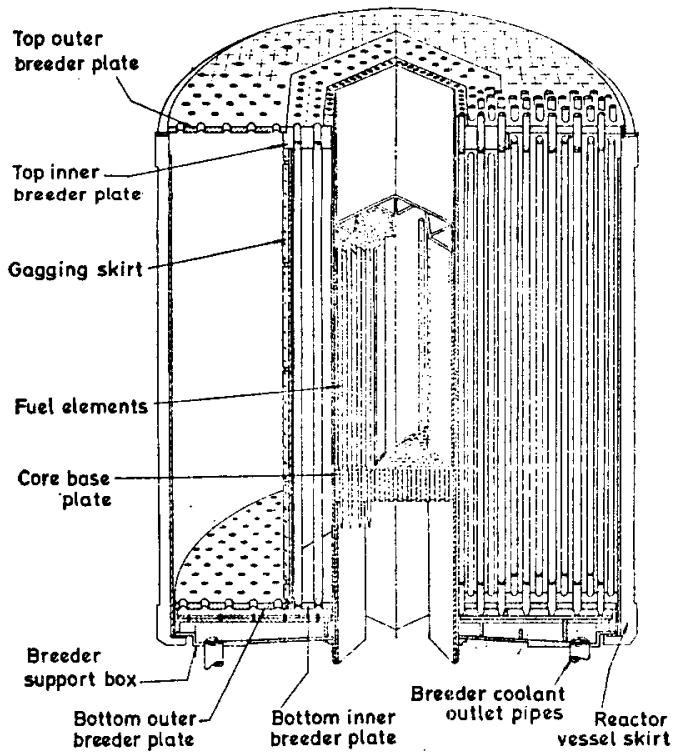

assembly at the inside, and the reactor vessel at the outside. Elements in the first two rows have a pitch of 1.55 in., all others 1.507 in. The outer section forms an annular blanket varying from nine to fourteen rows.

The core skirt is a fabricated, hexagonal tube which hangs vertically from a flange located on the top plate of the inner breeder assembly and passes through the breeder support box at the lower end. The skirt acts as a duct for coolant flow through the core and supports the core tube nest. It also provides bearing tubes for control rod carriers.

A support location for the core tube nest is provided just above the bottom of the skirt.

The core tube nest is built up from a series of long and short interlocking tubes, the long tubes located in counter-bores in the top and bottom plates. Side plates enclose the tube nest, and the whole is positioned within the core skirt as one complete unit. The tubes are circular, but machined to a hexagonal cross-section at the core centerline. They are built together to form a continuous diaphragm at the core center. The tube in the center of each group of seven fuel elements is omitted. (Ref. I) (Fig. XII.B-1)

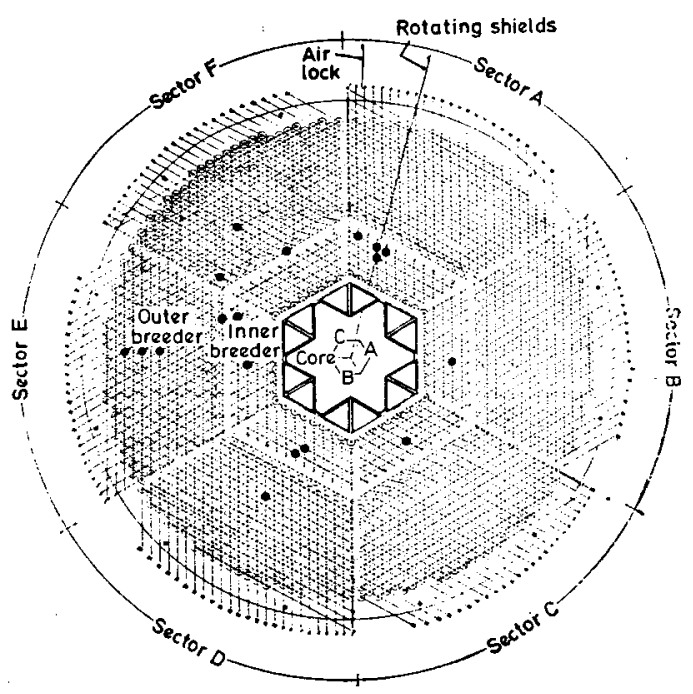

Figure XII.B-1 Dounreay Core Support Structures (Ref. 3) 


\section{XII.C. REACTOR VESSELS AND SHIELDING}

The reactor vessel is a stainless steel cylindrical structure $20 \mathrm{ft}$. high and $10 \mathrm{ft} .6 \mathrm{in}$. internal diameter. It is closed at one end and open at the other, with an outer casing of stainless steel forming a leak jacket. The lower ma in shell is designed as a coolant-retairing stressfree casing with no external laads of perforations. Main reactor loads from the core and breeder are carried by an internal cylindrical skirt to the top flange. The skirt forms an outer annulus over $2 / 3$ of the vessel depth into which tubes for control mechanisms, thermocouples and heaters are built. A thin inclined jilate at the bottom of the skirt seals the annulus between skirt and vessel. At the top of the skirt another plate connects vessel and skirt and acts as a seal between the interior of the vessel and the top flange. A support ring around the base of the skirt carries the load of breeder and core assembly.

The top of the vessel is joined to a thick fabricated ring with an od greater than that of the vessel. The ring rests on rollers on support columns. The top face of the support flange receives the outer and inner rotating shields with their auxiliaries. The inner shell of the support flange extends down into the vessel and is joined to the top of the skirt.

An outer casing surrounds the sides and bottom of the vessel, and extends at the stub pipes to form an annulus around the pipes. This space is filled with nitrogen gas, and is connected to a liquid-metal leak detector.
Support consists of two sets of columns, 24 per set, one set on a 24-ft. pitch circle diameter and the other on a $211 / 2 \mathrm{ft}$. pitch circle diameter. The columns are about $32 \mathrm{ft}$. high and are interconnected at the $11-\mathrm{ft}$. level and at the top. The vessel is supported from the top of the inner columns. The weight of the vesse? and internals is transferred to the top of the upper flat plate through a stainless steel block bolted to the underside of the vessel flange. The column structure also forms a support for the inner neutron shield. (Fig. XII.C-1)

The two rotating shields form the top closure of the reactor vesse 1 , and orient the charge and discharge machine. They are lowered and rotated only after the reactor is down. Sealing is by mechanical bolted seals and by liquid metal dip seals. The outer casing is the boundary of the coolant circuit, the inside being sealed from the coolant and vented to the atmosphere. The inner shield fits eccentrically into. the outer shield.

A thermal shield consisting of $4 \mathrm{ft}$. of graphite with a small amount of boron surrounds the reactor vessel. Shielding above the core is built into the rotating plugs. There is a $2 \mathrm{ft} .9$ in. plug, and above this a layer of thermal insulation. Loose concrete blocks are fitted around the reactor top, and a removable, thick steel shield covers the reactor top. (Fig XII.C-3) (Ref. 1) 


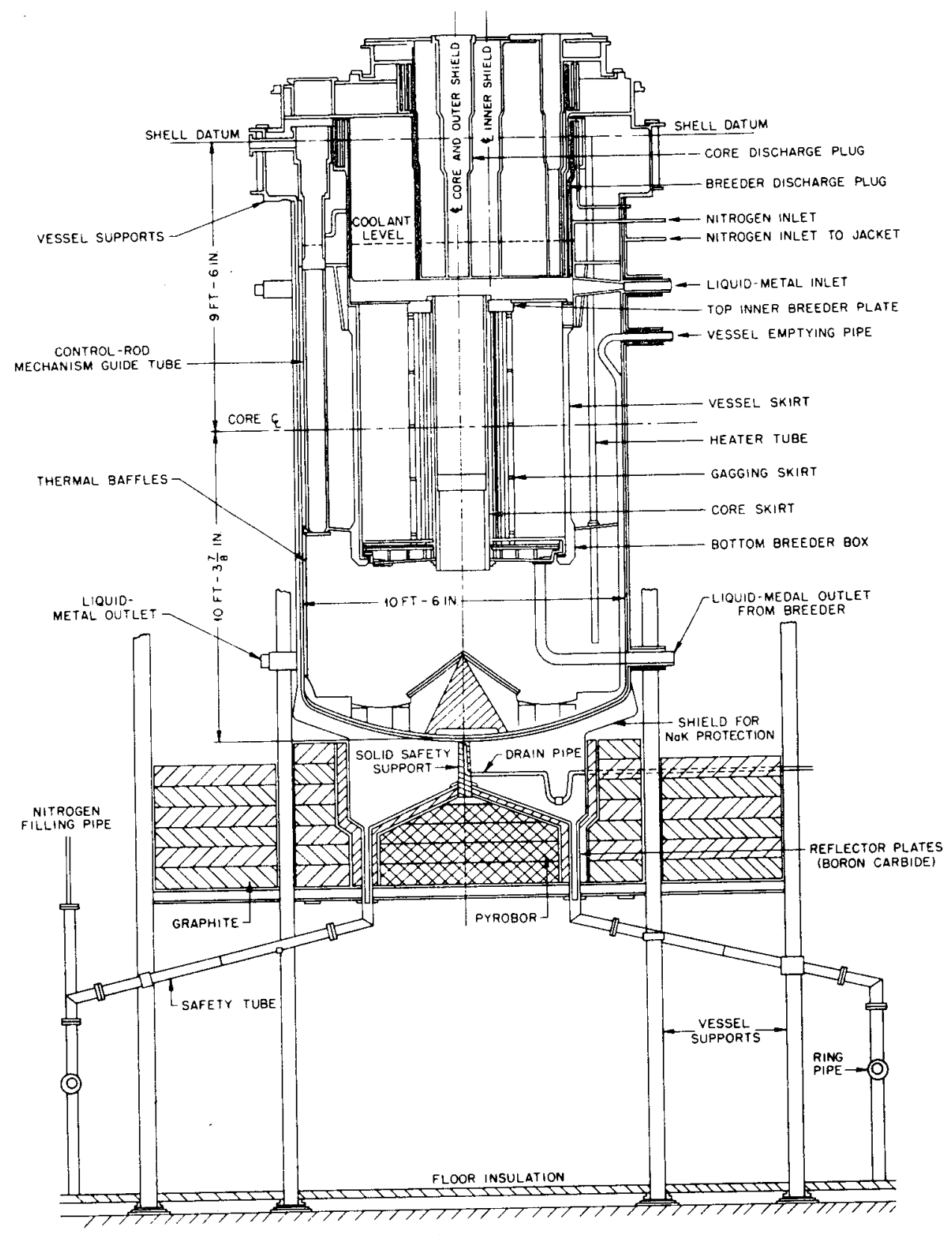

Figure XII.C-1 Dounreay Reactor Vesse1 and Support Structure (Ref. 9) 


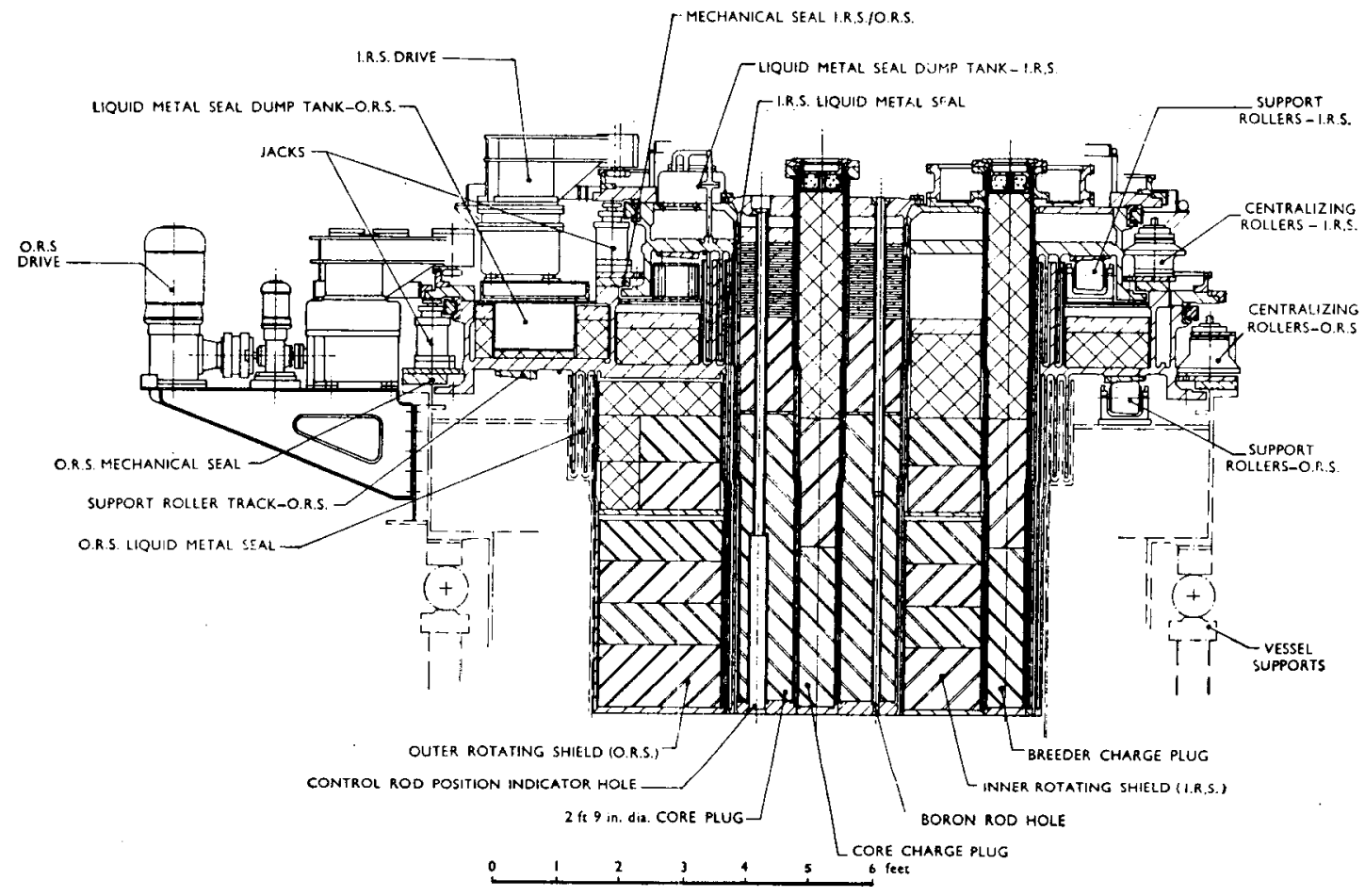

Figure XII.C-2 Dounreay Section through Rotating Shields (Ref. 1) 


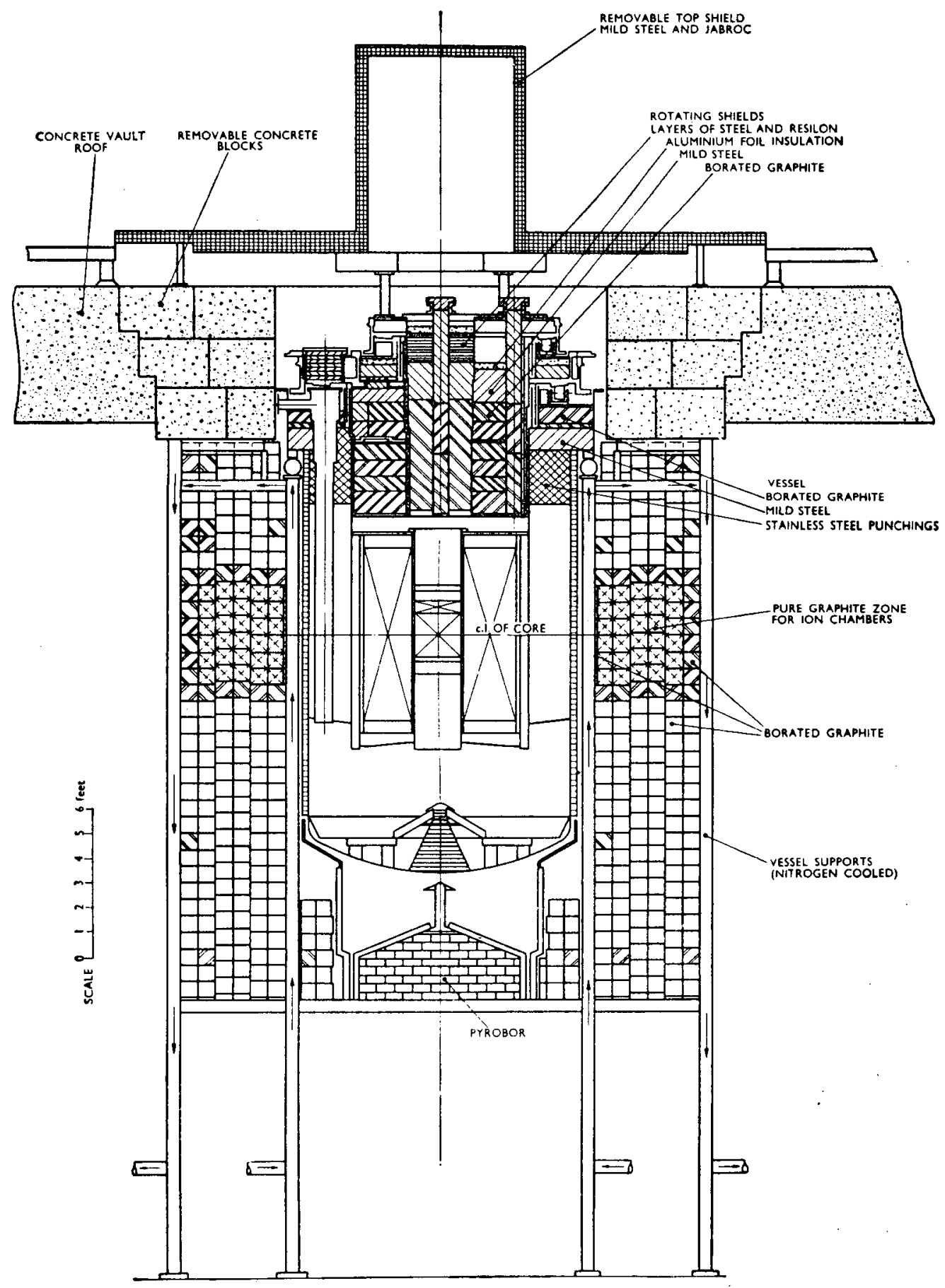

Figure XII.C-3 Dounreay Radiation Shielding (Ref. 1) 


\section{XII.D. CONTROL ELEMENTS}

Dounreay has twelve control and safety elements, and three ${ }^{1}{ }_{B} \mathrm{~B}$ rods provided as spares. The elements consist of groups of ten fuel elements divided into two safety rods, six control rods, and four shutoff rods. Control is manual by the operator. Startup and control consists of insertion of safety, shutoff, and control groups, with interlocks provided to ensure this sequence. The $10 \mathrm{~B}$ shutoff rods can be dropped by gravity into the inner breeder. The control unit is offset, with the drive located outside the rotating shields. An electromechanical drive is used. The reactivity controlled by the control group is $3.6 \%$, by the shutoff group $2.4 \%$, and by the safety group $1.2 \%$. Three speeds were available: slow-in, slow-out at 0.003 in./sec. and fast-out at $0.15 \mathrm{in.} / \mathrm{sec}$. Maximum rate of reactivity addition was $2 \times 10^{-4} \% / \mathrm{sec}$. (Fig. XII.D-1)

Subsequent modifications to the drive mechanism has provided a very simple single speed output which permits reactivity addition at ten times the original rate, and the rod selector switch has been modified to prevent the movement of more than one rod at a time. (Ref 1,6$)$ 
DOUNREAY XII.D.

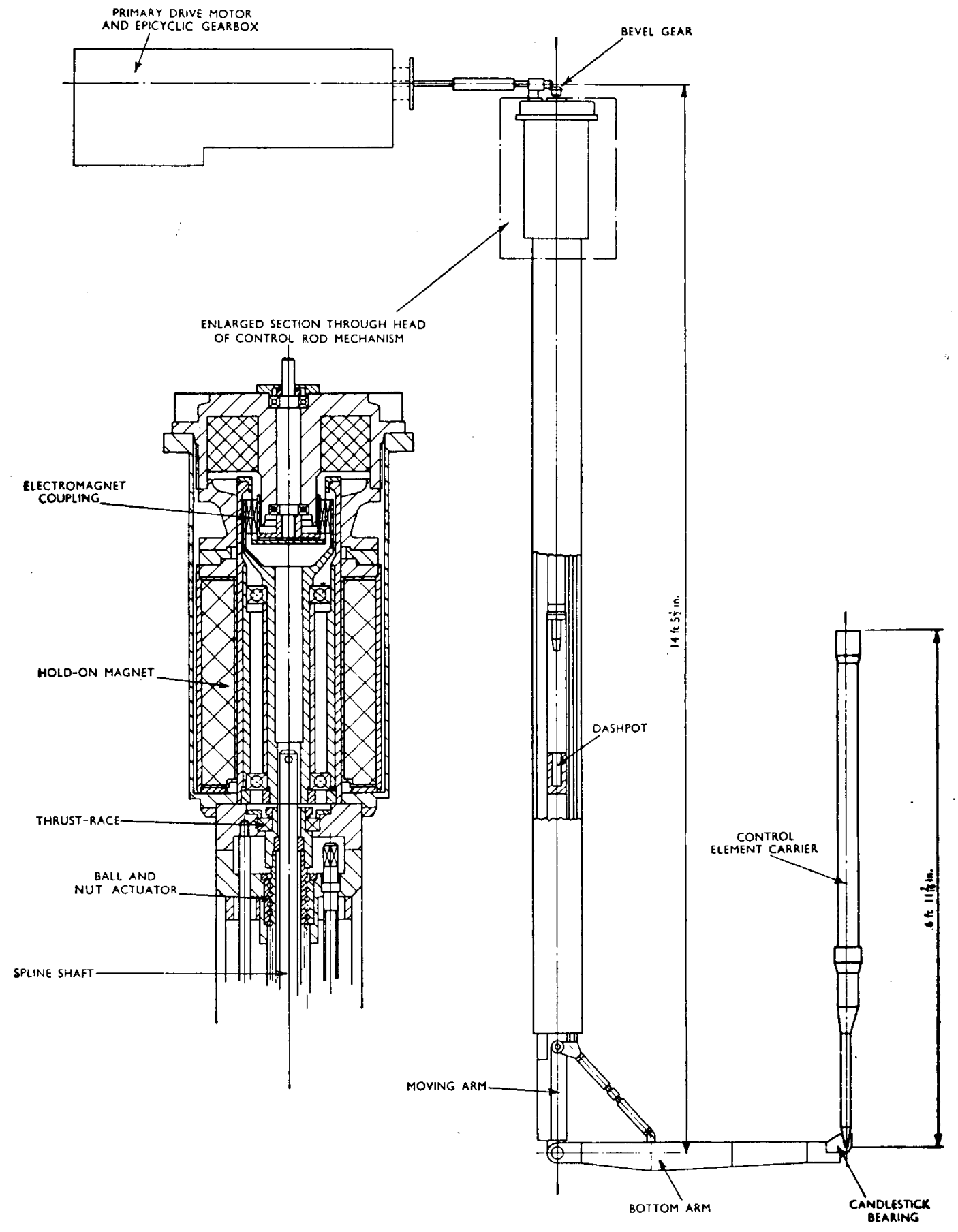

Figure XII.D-1 Dounreay Control Rod Mechanism (Ref. 1)

XII.D-2 


\section{XII.E. HEAT TRANSFER SYSTEMS}

The primary circuit consists of 20 core loops and four breeder loops, all designed for the same heat transfer conditions. Each loop includes an intermediate heat exchanger and a cold-leg electromagnetic pump. Expansion tanks are fitted to the primary circuit. Four of these have leve1indicators and six have blanket gas pressure transmitters. Cold traps and hot traps are used. The whole of the primary circuit is enclosed in a 5-ft. thick concrete vault. Cold and hot traps, pump windings, level indicators and flow-meters are installed at the top of the primary circuit and supported from the vault roof with access through roof liner tubes closed by shielded plugs. Each primary circuit and the vessel are enclosed in a leak jacket. A11 pipework is hung from a network of steel supports on the underside of the vault roof. (Fig. XII.E-1)

Nak coolant leaves the bottom of the reactor, after flowing downward through the core, at $350^{\circ} \mathrm{C}$, passes through the IHX, an electromagnetic pump, and a thermal siphon heat exchanger before reentering the vessel at about $200^{\circ} \mathrm{C}$. The thermal siphon unit in a small heat exchanger fitted to the top leg of each primary loop and connected to the natural-draft aircooled heat exchangers located in the stack outside of the containment sphere. There are four of these air-dump units. They can remove $1.8 \mathrm{MW}$ of decay heat 30 minutes after shut-down from a power level of $60 \mathrm{MWt}$. Piping is 4-in. in diameter contained within a 6-in. guard pipe.

There are twelve secondary loops, each serving two of the primary loops. Nak coolant circulates through the IHX to a Nak-water heat exchanger. Each loop has two electromagnetic pumps installed in parallel in the cold leg. Two cold traps are installed in by-pass loops in parallel with the main loop at the top of each loop, with an expansion tank in series. Free surfaces are blanketed with an inert gas. The loops include flowmeters, level indicators, and pressure transmitters. Loops are constructed of 6-in. diameter stainless steel pipe with mineral-wool insulation.

The intermediate heat exchanger has a heat-transfer duty of $3 \mathrm{MW}$. It consists of an inner stainless steel pipe $300 \mathrm{ft}$. long and 4 in. diameter. surrounded by an outer, 6-in. diameter stainless steel pipe, formed into seven complete loops. Spiders hold the inner and outer pipes in place. Secondary coolant flows through the annulus, entering at $180^{\circ} \mathrm{C}$ and exiting at $330^{\circ} \mathrm{C}$. Primary sodium flows in the inner pipe, entering at $350^{\circ} \mathrm{C}$ and leaving at $200^{\circ} \mathrm{C}$. Flow is counter-current. (Fig. XII. E-2)

Pumps are electromagnetic flat-linear induction pumps, consisting of a flat thinwall pump tube with a clamped linear stater on either side. There are no moving parts. The pump tube is welded into the loop. Each primary pump operates within a deep steel pressure vessel forming a leak jacket. Secondary pumps are of similar design and construction, but have no shielding plugs. (Fig. XII.E-3)

Expansion tanks fitted to the primary loops are constructed of two cylinders, the inner one of stainless steel. The outer cylinder is mild steel and forms a leak jacket. Each tank has a stand-pipe near the reactor vessel end, which passes vertically upward through the vault roof to terminate in a flange. Four of these flanges carry level indicators and six carry pressure transmitters. (Fig. XII.E-4) (Ref. 1)

Modifications to the original design include the installation of a separately pumped cold trap 10op and improved cold traps in three of the primary circuit bypass loops. 


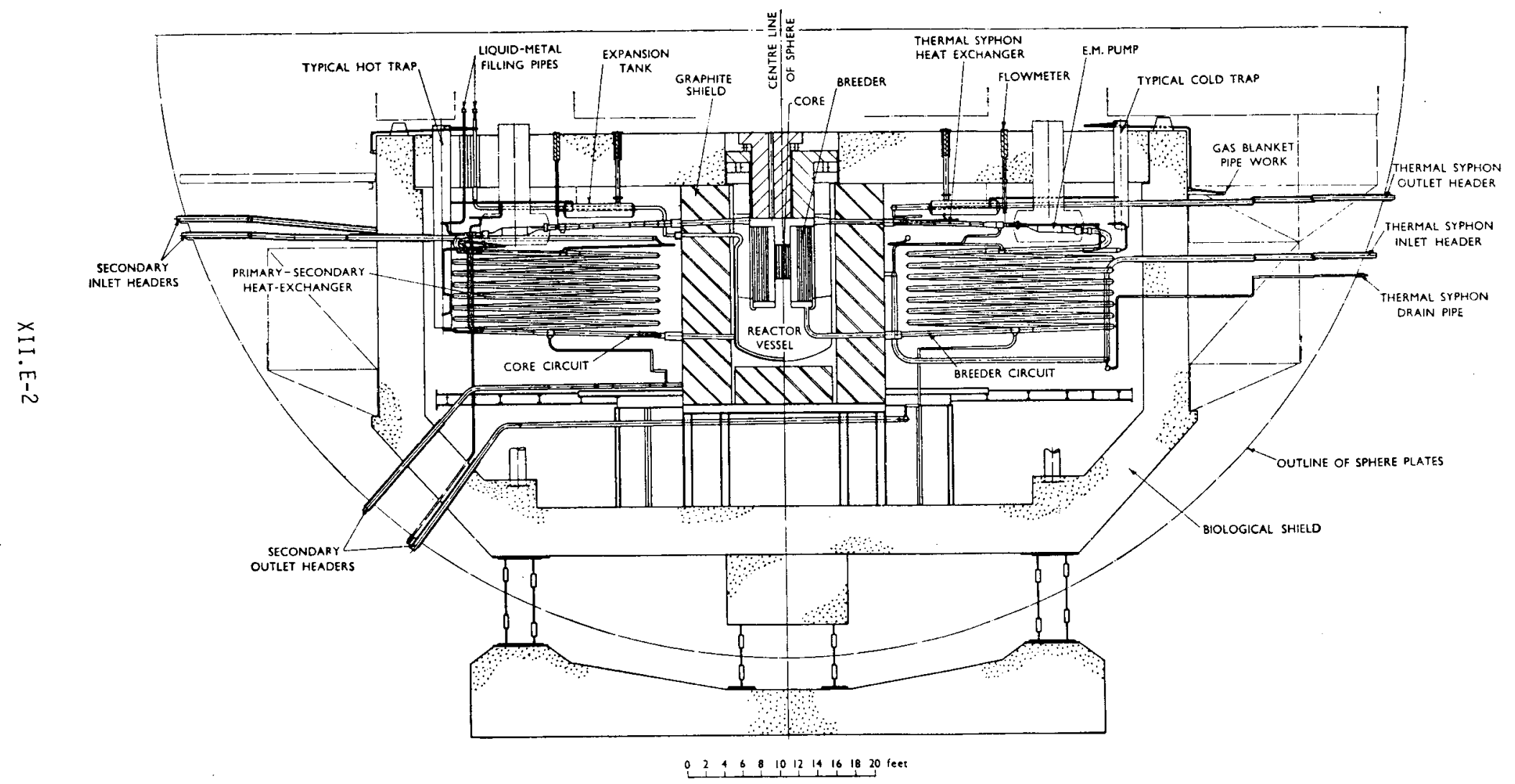

Figure XII.E-1 Dounreay Primary Loop Pipe-Work (Ref. 1)

O 

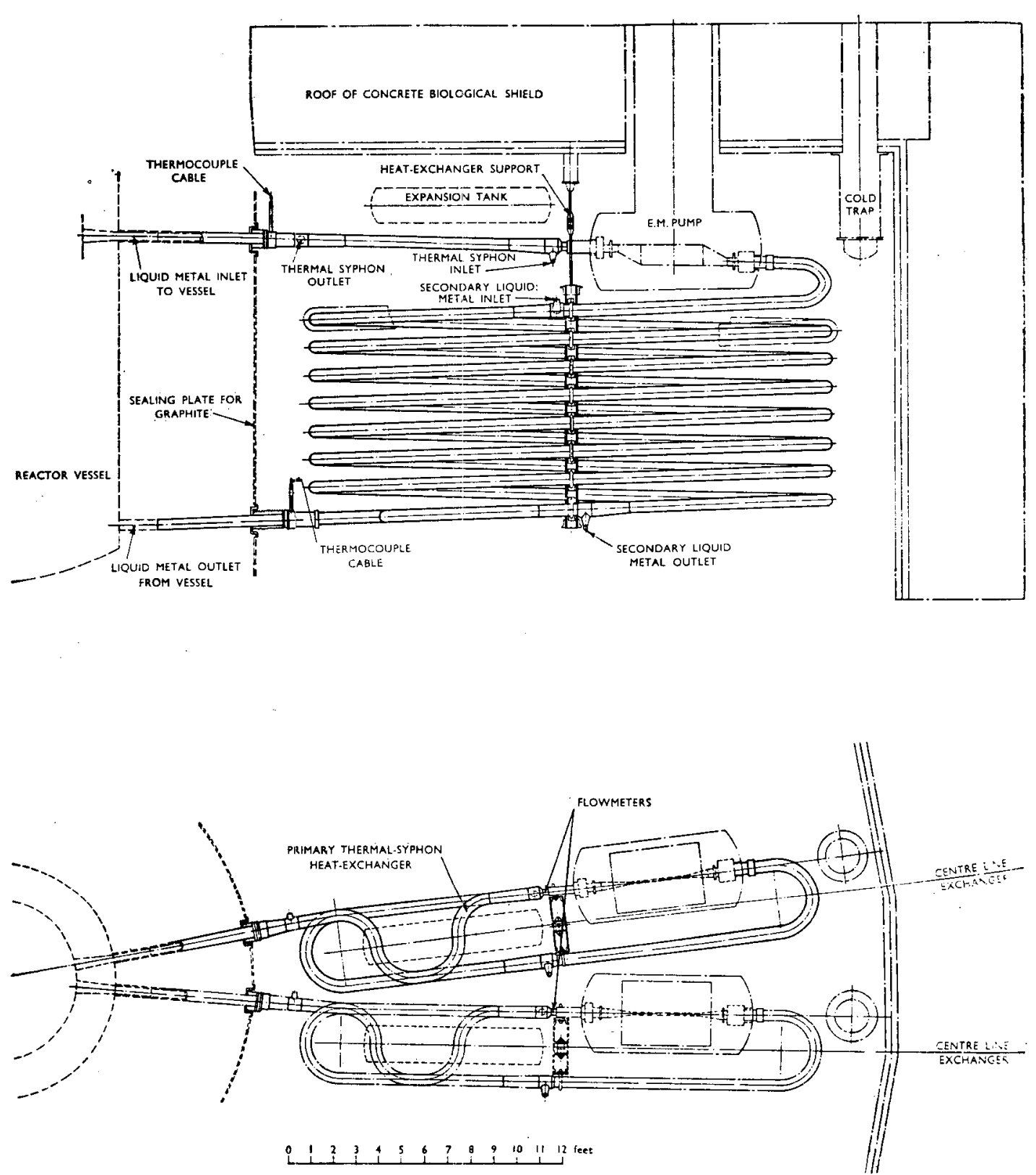

Figure XII.E-2 Dounreay Intermediate Heat Exchanger (Ref. 1)

XII.E-3 


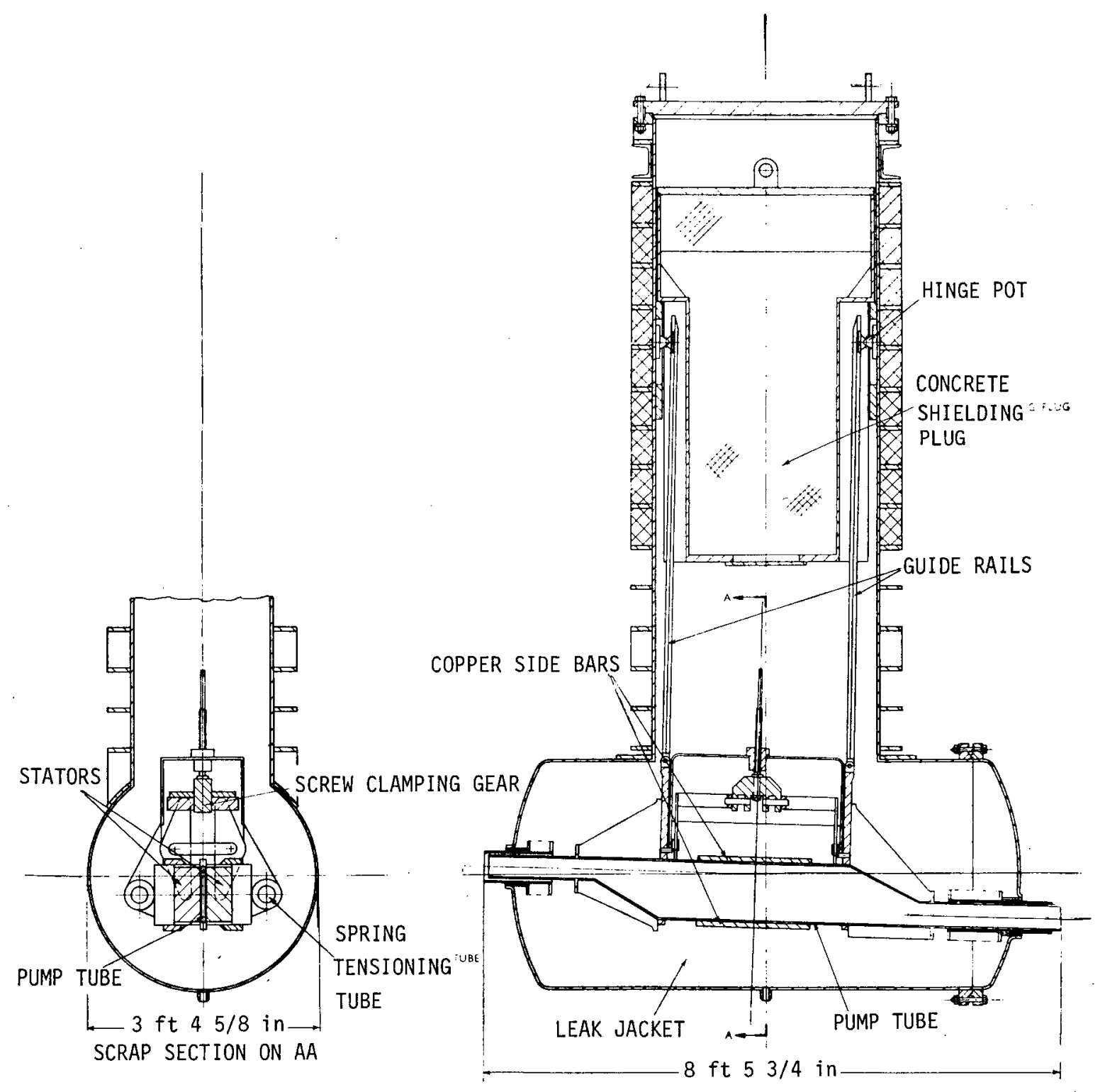

Figure XII.E-3 Dounreay Primary Pump (Ref. 1) 

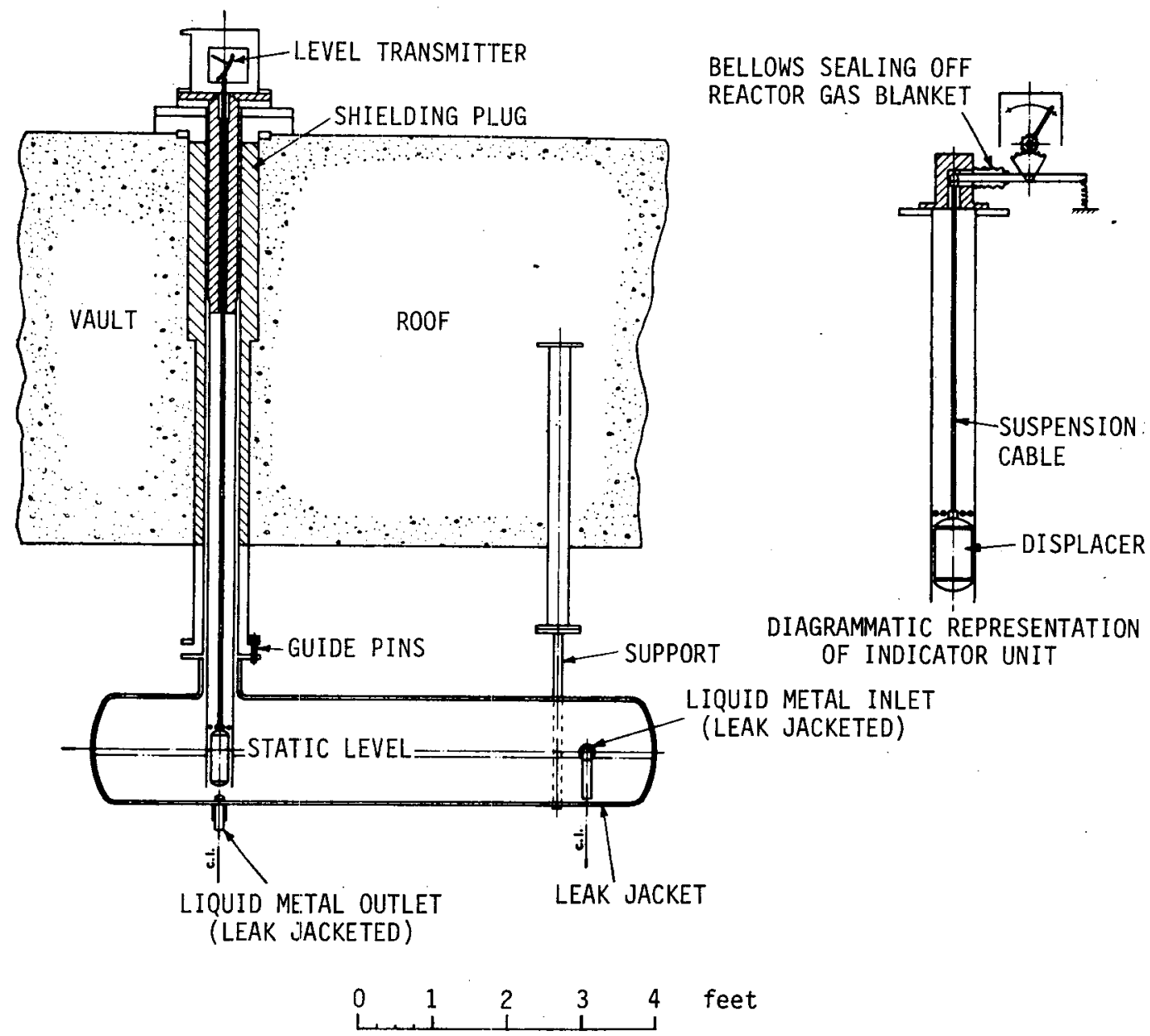

Figure XII.E-4 Dounreay Expansion Tank (Ref. 1) 


\section{XII.F. COOLANT PURIFICATION AND INSTRUMENTATION}

The primary cold trap is a vessel with single wall construction in the upper section and double wall construction in the lower part to just above the highest coolant level. A section of the double wall interface sandwiches a layer of aluminum, with machined grooves in the aluminum to provide a leak path down to the leak jacket. A finned bronze sleeve is shrunk on the outside of this compound tube. Nak at $200^{\circ} \mathrm{C}$ enters the trap at the bottom and flows upward through a central tube and down through the tubes of a regenerative heat exchanger, leaving at $125^{\circ} \mathrm{C}$. Flow is then upward through the compound tube where it is cooled by air drawn from the biological shield cooling system, and enters a basket containing stainless steel rings at $115^{\circ} \mathrm{C}$. After $5 \mathrm{~min}$. residence time in the basket, the Nak enters the shell side of the regenerative heat exchanger and leaves the exchanger and the cold trap vessel at $195^{\circ} \mathrm{C}$. A $1-i n$. bypass loop connects the trap to the pump outlet, with return connected via an expansion tank to the main loop at the reactor vessel inlet.

(Fig. XII.F-T)

Secondary cold traps are similar in design. In this case two traps are installed in a bypass loop in parallel with the main loop, with an expansion tank in parallel with the two cold traps.

The hot trap vessel is $22 \mathrm{ft}$. high and $1 \mathrm{ft} .3 \mathrm{in}$. in diameter. A shell-and- tube regenerative heat exchanger in the lower section heats the incoming Nak from $200^{\circ} \mathrm{C}$ to $580^{\circ} \mathrm{C}$. The coolant then passes over the 7 in. diameter heater container tube and is heated to $600^{\circ} \mathrm{C}$. Flow is then downward through a container of zirconium foil onto stainless steel bobbins which are 8 in. in diameter. Nak is cooled by a heat exchanger to $200^{\circ} \mathrm{C}$ before leaving the hot trap. A return connection to a low pressure section of the loop is by means of a $3 / 4 \mathrm{in}$. diameter pipe. (Fig. XII.F-2)

Hot traps are used only in the primary circuit.

Primary and secondary 1oop instrumentation includes electromagnetic flow meters, chromel-alumel thermocouples, coolant level indicators which operate on the buoyancy principle, and blanket gas pressure transmitters fitted on top of expansion tank tubes above the tank roof. 0xide corrosion meters, oxide sampling units, and resistivity meters are installed in hot and coldtrap vessels of the primary loop. A rhometer in the primary circuit measures coolant resistivity. (Ref, 2)

Sub-assembly monitoring by thermocouples located in the coolant outlet stream beneath the element was instituted when assemblies containing multiple pins were inserted for test operation. Other methods developed for sub-assembly monitoring are thermal noise analysis at coolant outlet thermocouples, acoustic monitoring, or the incorporation of tracers in the experimental pins and blanket gas sampling. (Ref: 7) 


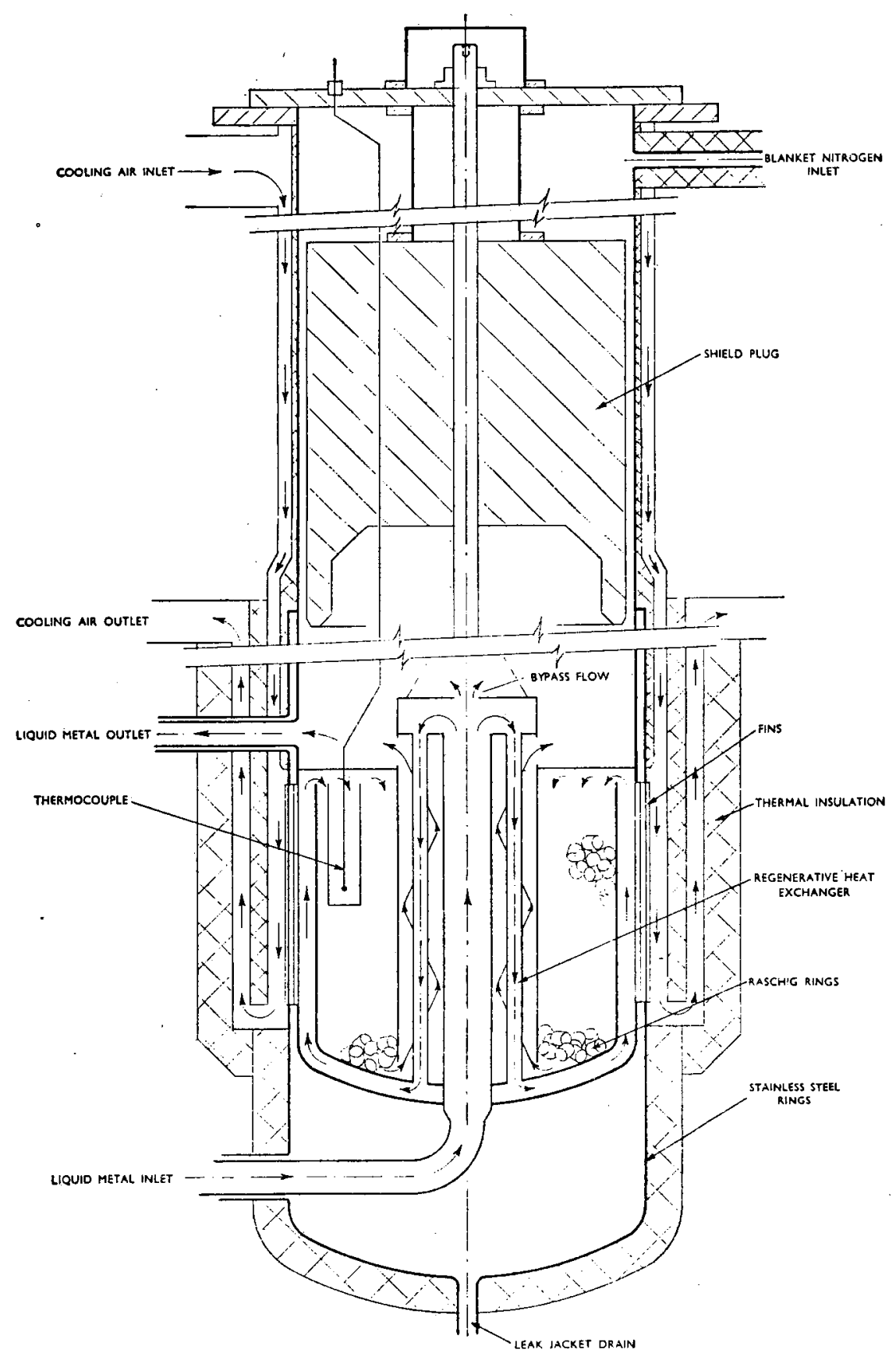

Figure XII.F-1 Dounreay Cold Trap (Ref. 1) 


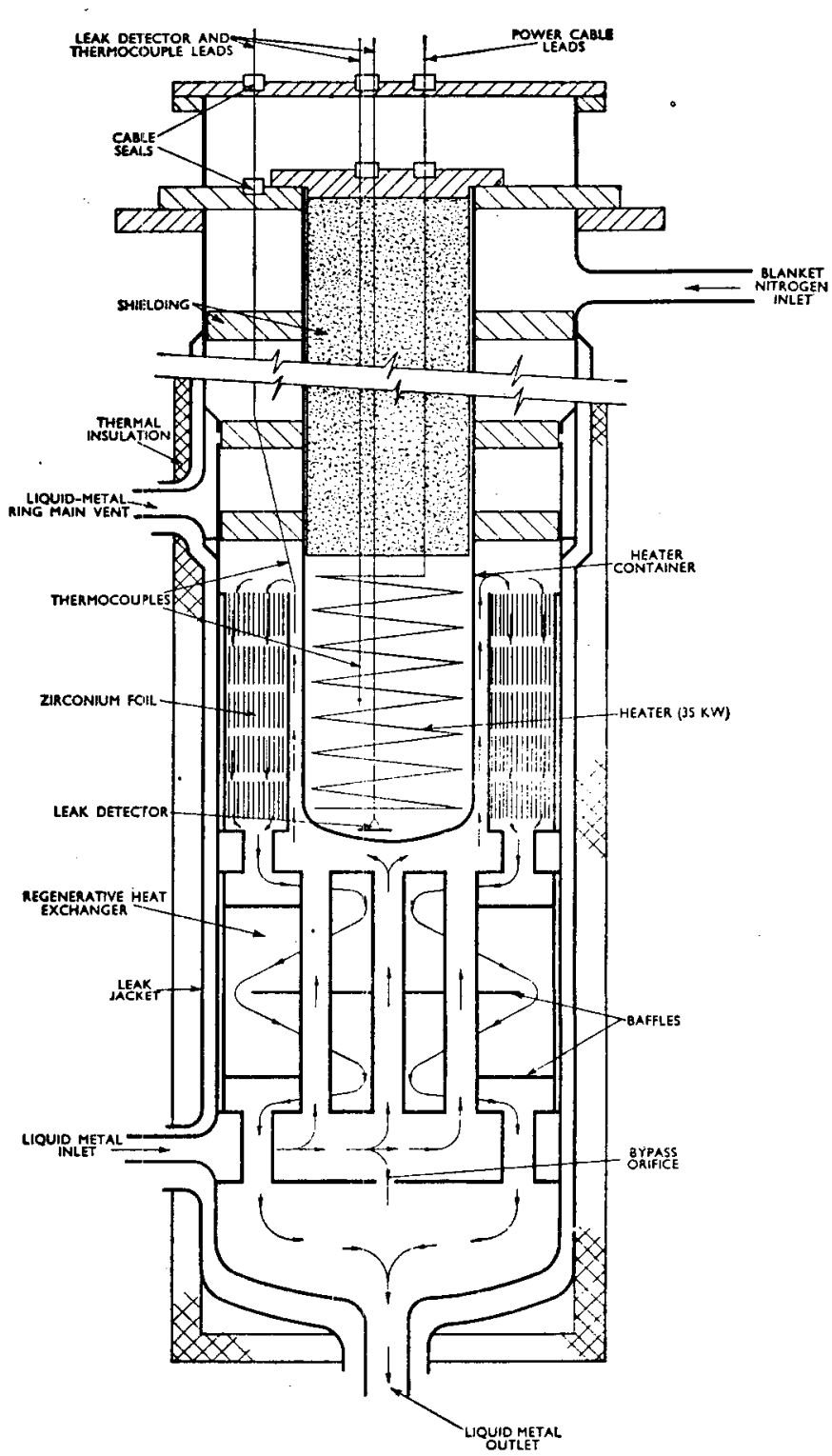

Figure XII.F-2 Dounreay Hot Trap (Ref. 1) 
DOUNREAY XII.G

XII.G. COVER GAS AND AUXILIARY SYSTEMS.

The DFR originaliy used a nitrogen blanket over the primary coolant, but it has since been converted to an argon cover gas system. Because of the use of vented elements, the external gas bianket pipes have been shielded. 
X. B. CORE SUPPORT AND VESSEL INTERNALS

Fuel elements fit into a lower grid plate and are locked from above by means of a hold-down device. No alterations to the reactor vessel or grid-plate assembly are necessary for conversion to KNK-2.
The grid plate structure subdivides the tank volume into a lower pressurized plenum and an upper plenum with a free sodium surface. The fuel elements are held in a tightly-packed triangular lattice within the hexagonal boundary formed by the steel reflector. (Fig. X.B-1.)

(Ref. 1.) 


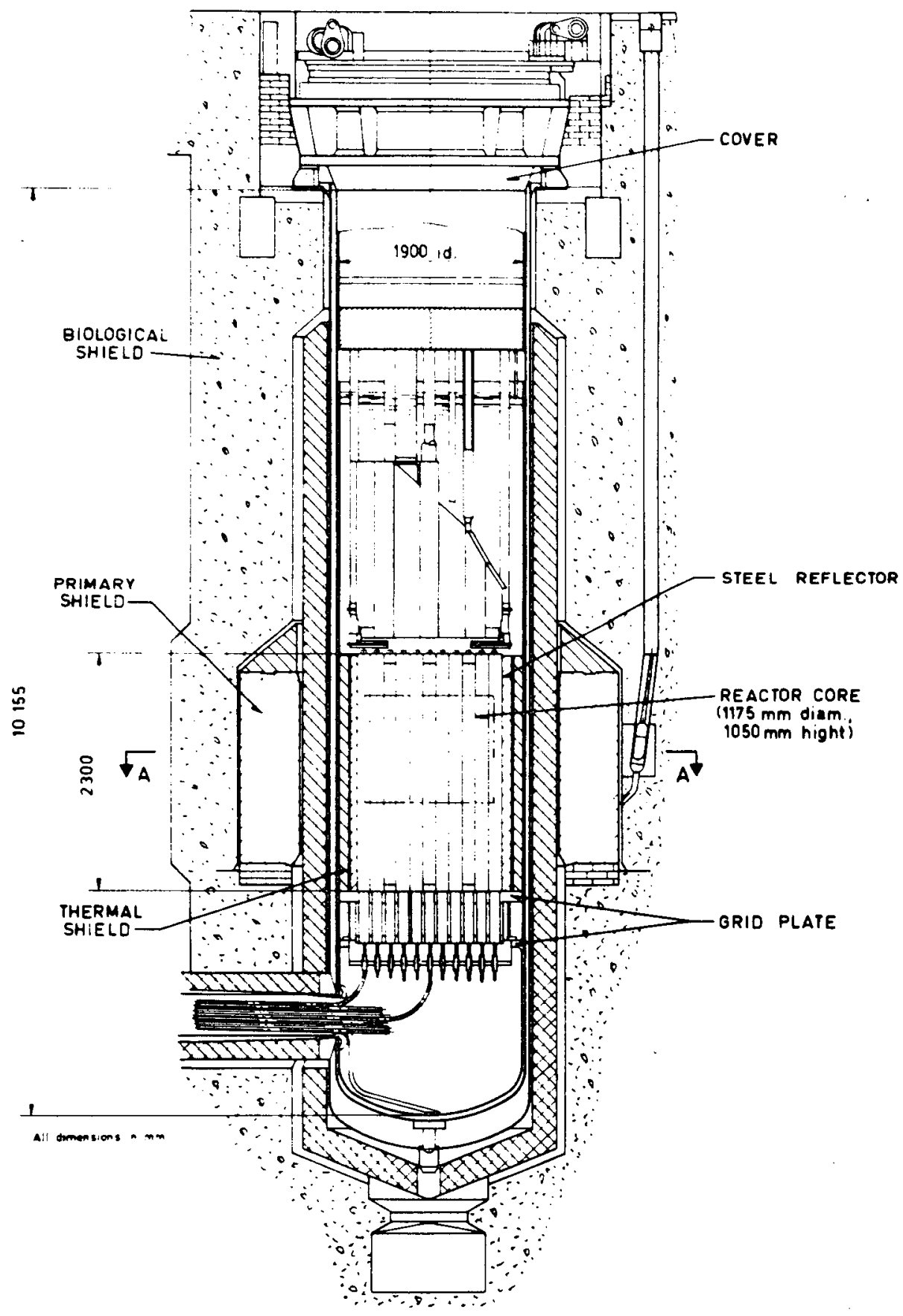

Figure X.B-1 KNK Reactor Structure (Ref. 1) 


\section{XII.H. FINAL HEAT REJECTION}

Nak coolant circulates from the intermediate heat exchanger through a Nakwater/steam heat exchanger. These $6 \mathrm{MW}$ units consist of thirteen rows of twenty heattransfer elements in each row. The elements were constructed of copper-laminated stainfrom bottom to top, and on the steam/water side connections are made to the economizer, evapor, and superheater sections of the boiler plant. Heat exchangers are lodged in cubicles made of thick steel packed with mineral wool insulation and having penetration for the Nak, steam, and water pipes and heat-exchanger support rods. The bottom of the cubicle has deflector plates to guide Nak leakage into a tray. This less steel tubes. Nak flows in the tubes

tray has a leak detection element. The cubicle is also fitted with fire-fighting equipment, with external connections for portable equipment. (Fig XII.H-7)

A Lamont forced circulation boiler is arranged conventionally with an economizer, evaporator, and superheater. When not in use as a steam generator, only a section of the evaporator is used. Dump condensers were designed to fulfill the function of pressurized water coolers, with simple conversion to steam condensers at a later stage. (Ref. 2)

Electric power was first generated in October 1962.
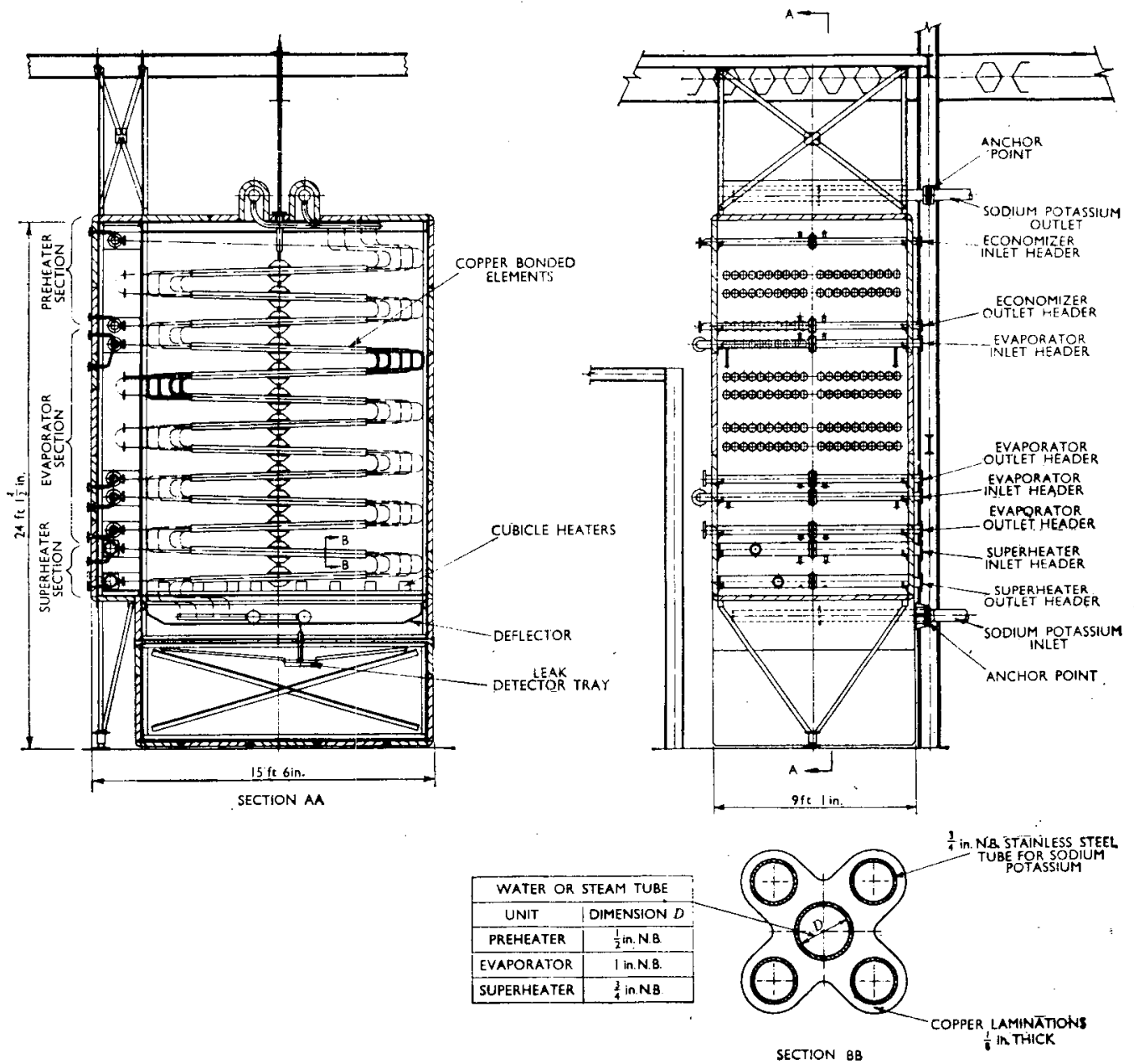

Figure XII.H-1 Dounreay NaK/Water-Steam Heat. Exchanger (Ref. 1) 
XII.I. REACTOR INSTRUMENTATION AND CONTROL

The reactor control room is located outside of the containment sphere. All controls and measurements are installed on a central desk, and measurements which require only periodic checking are displayed on panels around the room. These panels also contain alarm and reactor trip circuits, with one panel allocated to oscillator controls and instruments for analyzing reactor stability.

Thermal neutron detectors provide information on power level, drift, and doubling time. Three groups of instruments measure neutron flux in three ranges: $50 \mathrm{~mW}-100 \mathrm{~W}, 2 \mathrm{~W}$ and $2 \mathrm{MW}$, $1 \mathrm{MW}$ and 100MW. The radium-beryllium neutron source in use can be withdrawn from the reactor, with withdrawal and insertion controlled from the reactor control room. The neutron detectors are installed in 12 holes in an equatorial belt of pure graphite contained within the neutron shield around the reactor vessel. The detectors are gas-cooled. There are three $235 \mathrm{U}$ coated fission chambers for low-power channels, two ion chambers for intermediate-power channels, one ion chamber for use with the oscillator, and eight ion chambers for high power channels. All detectors, except the latter, are retractable.

Reactor operating conditions are controlled by moving control rods and by controlling the temperature and flow-rates of the coolant. Control rods are manualiy operated by switches at the control desk. Primary and secondary flow-rates can be altered by increase or decrease switches. Pumps can be adjusted in pairs or in groups. (Ref. 2) 
XII.J. FUEL HANDLING

Fuel-loading is done with the reactor shut down. Access to the core is through holes in the eccentric rotating plugs. Two charge machines, each handling single elements, are used. The machine is positioned over the reactor and sealed in it through an adapter-door valve. A snout is driven into the core by a rack and chain through a rack tube; in the retracted position the fuel element and the snout are completely within the tube in the charge machine body. As the element is being withdrawn from the core it is continuousiy cooled. Valves are closed and the machine is moved to the canning station. Maximum heat generated by an irradiated core element is $2.5 \mathrm{MW}$. Safe temperatures are maintained by forced convection cooling by nitrogen. Fans draw air over the nitrogen heat exchanger, exhausting the heat to the atmosphere. Elements can be inspected and identified by an introscope fitted to the base of the machine, with viewing throuqh a stabilized qlass window in the machine casing. The machine can be motor-driven or hand-driven. (Fig. XII.J-1) (Ref. 1) 
DOUNREAY XII.J.

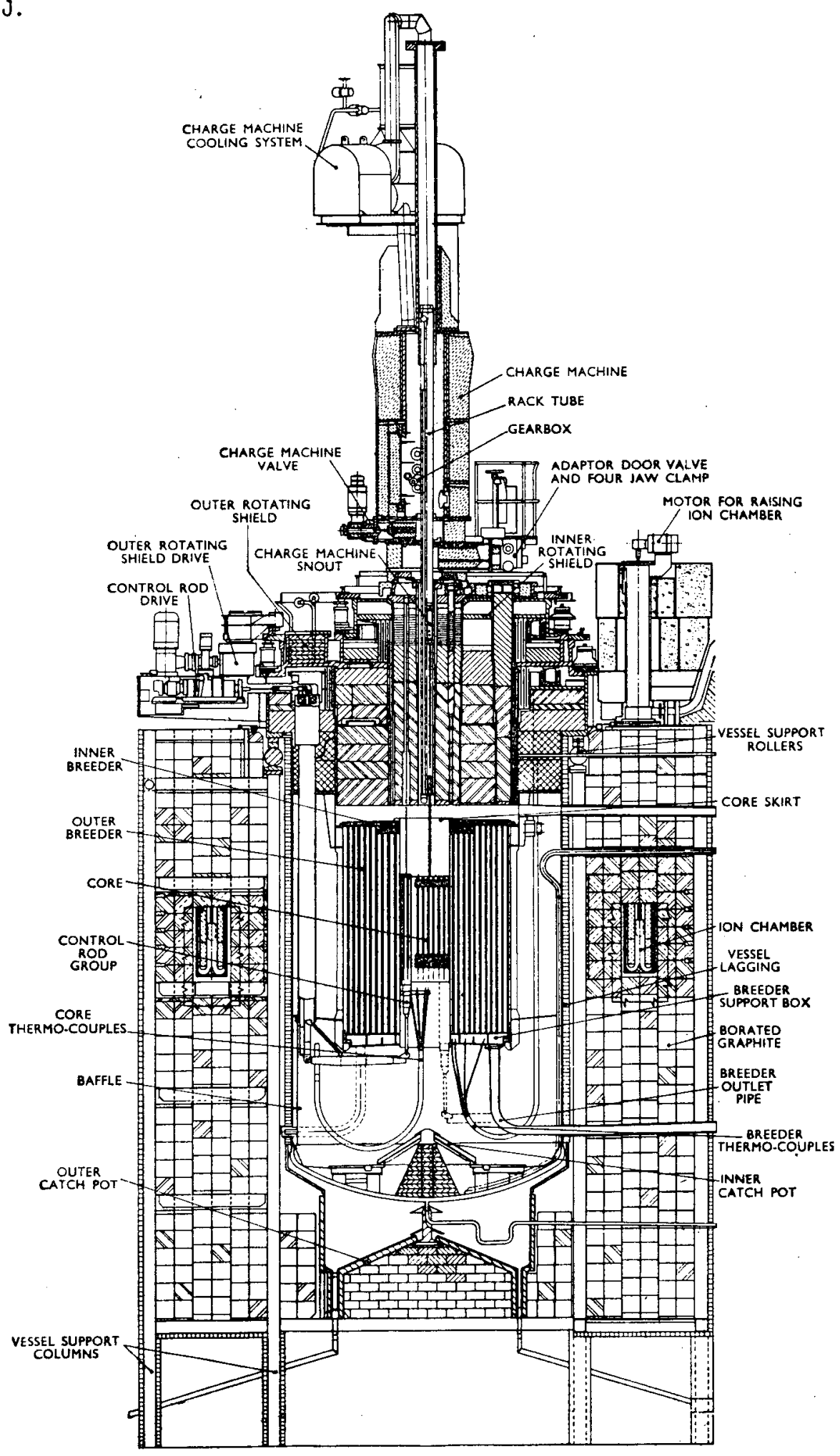

Figure XII.J-1 Dounreay Core, Vessel and Charge Machine (Ref. 1) 
XII.K. CONTAINMENT

The reactor vault containing the primary system is located within the reactor building, which is a $135 \mathrm{ft}$. diameter steel sphere. The main vault is surrounded by a secondary, 5-ft. thick concrete shield. Air cooling holds the temperature of the concrete to less than $50^{\circ} \mathrm{C}$. The reactor control room is outside the sphere.

(Ref. 1)

XII.K-I 
XIII. PFR

LOCATION: Dounreay, Scot Tand OPERATION: March 3, 1974

Construction was started on a site near the Dounreay Fast Reactor in 1967, following completion of the conceptual design. During construction, modifications were made to parts of the design to take into account the latest experimental work.

PFR is a pot-type system using $\mathrm{UO}_{2}-\mathrm{PuO}_{2}$ fuel. Nominal output is 250 MWe and $600 \mathrm{MWt}$. Depleted fuel is stored in the primary vessel for about thirty days.

PFR achieved criticality on the first core loading on March 3, 1974. Contractor for completion of PFR was the Nuclear Power Group, fuel manufacturer is British Nuclear Fuels Ltd., Windscale. 
INDEX

REFERENCES

Page

REACTOR PARAMETERS

XIII-5

XIII -9

SECTIONS

A. CORE AND BLANKET

XIII.A-I

B. CORE SUPPORT AND VESSEL INTERNALS

XIII.B-1

C. REACTOR VESSELS AND SHIELDING

XIII.C- 1

D. CONTROL ELEMENTS

XIII.D-1

E. HEAT TRANSFER SYSTEMS

XIII.E-1

F. SODIUM PURIFICATION AND INSTRUMENTATION

XIII.F-1

G. COVER GAS AND AUXILIARY SYSTEMS

XIII.G-1

H. STEAM GENERATORS

XIII.H-1

I. REACTOR INSTRUMENTATION AND CONTROL

XIII.I-I

J. FUEL HANDLING

XIII.J-1

K. CONTAINMENT

XIII.K-1 
REFERENCES

1. Design, Construction, and Commissioning of PFR as of December 14, 1973

A.D. Evans, et. al.

Fast Reactor Power Stations, Proc. BNES Conf. March 1974

p. 1-11

British Nuclear Energy Society, 1974

2. Design of the Prototype Fast Reactor

A. G. Frame, et. al.

Proc. London Conf. Fast Breeder Reactors, BNES, May 1966

p. 291-315

British Nuclear Energy Society, 1967

3. Performance Development of the PFR Fuel and Use of PFR as a Fuel Development Facility

J.F.W. Bishop

Fast Reactor Power Stations, Proc. BNES Conf. March 1974

p. 295-306

British Nuclear Energy Society, 1974

4. Manufacture of the First Fuel Element Charge for the

Prototype Fast Reactor

A. S. Davidson, T.L.J. Moulding

Fuel and Fuel Elements for Fast Reactors, Proc. Symposium, Brussels, July 1973

Vol. 2, p. 423-440

STI/PUB $/ 346$

IAEA, 1974

5. Support of PFR Subassemblies and Associated Developments J.A.G. Holmes

Fast Reactor Power Stations, Proc. BNES Conf. March 1974

p. 307-318

British Nuclear Energy Society, 1974

6. Safety Considerations in Fast Reactor Core Design

J.A.G. Holmes

Engineering of Fast Reactors for Safe and Reliable Operation,

Proc. Int]. Conf, Karlsruhe, Oct. 1972

Vol. 1, p. 29-43

GfK, Karlsruhe, 1973

7. Progress on the Prototype Fast Reactor (PFR)

Sodium Cooled Fast Reactor Engineering, Proc. Symposium, Monaco, March 1970

p. $19-32$

STI/PUB $/ 256$

IAEA, 1970

8. PFR Design and Construction - a Progress Statement

R. H. Campbe 11

Nuclex-69, \#4/1

Nuclex, 1969

9. PFR Core Support

G. 0 . Jackson

Sodium Cooled Fast Reactor Engineering, Proc. Symposium, Monaco, March 1970

p. 273-281

STI/PUB $/ 256$

IAEA, 1970 
PFR XIII

10. Development and Manufacture of Some Important Components for the Prototype Fast Reactor at Dounreay L. F. Bowles, et. al. Peaceful Uses of Atomic Energy, Proc. 4th International Conference, Geneva, 1971

Vol. 5, p. 201-212

United Nations, 1972

11. Heat Removal Systems Design for the Sodium Cooled Fast Reactors. E. C. Cobb, K. M. Leigh Engineering of Fast Reactors for Safe and Reliable Operation, Proc. Int1. Symposium, Karlsruhe, Oct. 1972

Vol. 1, p. 44-64

Gesellschaft fur Kernfurschung, Karlsruhe, 1972

12. Prototype Fast Reactor Heat Transport System

D. Taylor

Sodium Cooled Fast Reactor Engineering, Proc. Symposium,

Monaco, 1970

p. $455-470$

STI/PUB/256

IAEA, 1970

13. Sodium Pumps for Fast Reactors

J. M. Laithwaite, et. al.

Sodium Cooled Fast Reactor Engineering, Proc. Symposium,

Monaco, 1970

p. $319-330$

STI/PUB/256

IAEA, 1970

14. Hydraulic Problems in the PFR Cooling Circuit

J. M. Laithwaite, A.F. Taylor

Sodium Cooled Fast Reactor Engineering, Proc. Symposium,

Monaco, 1970

p. $75-85$

STI PUB $/ 256$

IAEA, 1970

15. Erection and Testing of PFR Secondary Circuits and

Steam Generators

D. Taylor, B. P. Millican

Fast Reactor Power Stations, Proc. BNES Intl. Conf., March 1974

p. 223.236

British Nuclear Energy Society 1974

16. Impurity Monitoring and Analys is in PFR.

R. A. Davies, C. M. Robertson

Fast Reactor Power Stations, Proc. BNES Intl. Conf., March 1974

p. 481-486

British Nuclear Enerqy Society, 1974

17. Burst Pin Detection (BPD) Equipment

S. Hackney, J. T. Wood

Sodium Cooled Fast Reactor Engineering, Proc. Symposium,

Monaco, 1970

p. $853-865$

STI $/$ PUB $/ 256$

IAEA, 1970 
18. Some Aspects of the UK Prototype Fast Reactor Project

H. Cartwright

Technical Meeting $\# 7 / 3$

Nuclex-72

Nuclex, 1972

19. The PFR Station Control System

P. W. Mummery, et. al.

Technical Meeting \#10/7

Nuclex-72

Nuclex, 1972

20. Fuel Handling and 0ther In-Reactor Mechanisms in PFR

C. R. Hunt, et. al.

Fast Reactor Power Stations, Proc. BNES Conf., March 1974

p. 585-595

British Nuclear Energy Soc. 1974

21. Containment Design in Fast Reactors

J. M. Laithwaite

Engineering of Fast Reactors for Safe and Reliable Dperation,

Proc. Int1. Conf., Karlsruhe, October 1972

Vol. 1, p. 454-469

Gesellschaft fur Kernforschung, Karlsruhe, 1973

22. The Dounreay Prototype Fast Reactor

R. V. Moore, et. al.

Nuclear Engineering Int1., Vo1. 16, Aug. 1971, p. 629-640

(and pull-out diagram and chart)

22. Structural Design Criteria in the Context of Strength,

Stiffness, and Fatigue

W. T. Lawton

Engineering of Fast Reactors for Safe and Reliable Operation,

Proc. Int1. Conf., Karlsruhe, October 1972

Vol. 1, p. 116-132

Gesellschaft fur Kernforschung, Karlsruhe, 1973 
Table - 1

GENERAL PARAMETERS

Type

Pot-type

No. Toops 3

Coolant Sodium

Core inlet temp. $400^{\circ} \mathrm{C}$

Core outlet temp. $600^{\circ} \mathrm{C}$

Flow direction Upward

Driver fuel $\mathrm{UO}_{2}-\mathrm{PuO}_{2}$

Blanket fuel $\mathrm{UO}_{2}$ (depleted)

No. enrichment zones in core 2

Output MWe/MWt $250 \mathrm{MWe} / 600 \mathrm{MWt}$

Max. can temperature $700^{\circ} \mathrm{C}$ (hot spot)

Linear power, max. $450 \mathrm{w} / \mathrm{cm}$

Neutron flux, total $8.9 \times 10^{15} \mathrm{n} / \mathrm{cm}^{2} \mathrm{sec}$ (center)

№. Driver elements 78

No. Radial blanket elements 52

No. In-core control elements $10+1$ safety

In-core storage: Transfer rotor buckets

Goal burnup $7.5 \%$ 
PFR XIII
Table - 2
CORE AND BLANKET

\begin{tabular}{|c|c|c|c|}
\hline & Driver Zone & Axial blanket & Radial blanket \\
\hline Fuel material & $\mathrm{UO}_{2} \mathrm{PuO}_{2}$ & $\mathrm{UO}_{2}$ & $\mathrm{UO}_{2}$ \\
\hline Form & Annular pellet & $\begin{array}{l}\text { Annular and } \\
\text { solid pellet }\end{array}$ & Pellet \\
\hline Composition & $25 \% P_{u}+$ nat. $U$ & & \\
\hline${ }^{240} \mathrm{Pu}$ & $278 \%$ & & \\
\hline $235_{U}$ & & Depleted & Depleted \\
\hline Density & $80 \%$ TD smear & & 95\% TD smear \\
\hline Rod cladding & Stainless steel & & Stainless steel \\
\hline od & $5.84 \mathrm{~mm} / 5.08 \mathrm{~mm}$ & $5.84 \mathrm{~mm} / 5.08 \mathrm{~mm}$ & $13.49 \mathrm{~mm} / 12.50 \mathrm{~mm}$ \\
\hline Wall thickness & $\sim 0.38 \mathrm{~mm}$ & $\sim 0.38 \mathrm{~mm}$ & \\
\hline Bond material & gas & & \\
\hline Column length & $914 \mathrm{~mm}$ & $\frac{\text { Lower } 458 \mathrm{~mm}}{\text { Upper } 702 \mathrm{~mm}}$ & \\
\hline Gas plenum length & $711 \mathrm{~mm}$ (bottom) & & \\
\hline Pin length & $2.3 \mathrm{~m}$ & & \\
\hline Vented/ non-vented & No & & No \\
\hline Assembly material & SS and Nimonic & & SS and Nimonic \\
\hline Shape & Hexagona? & & Hexagonal \\
\hline Across flats (dia.) & $142 \mathrm{~mm}$ & & $142 \mathrm{~mm}$ \\
\hline Overall length & $3810 \mathrm{~mm}$ & & $3810 \mathrm{~mm}$ \\
\hline No. pins/assembly & 325 & 325 & 85 \\
\hline & $\begin{array}{l}\text { Each assembly ha } \\
\text { wrapped breeder }\end{array}$ & rown of 19 wire- & \\
\hline Pin spacing & $\begin{array}{l}\text { Honeycomb grid/ } \\
\text { egg-crate }\end{array}$ & & Wire wrap \\
\hline Pin pitch & $P / D=1.26$ & & \\
\hline Assy. pitch & $144.8 \mathrm{~mm}$ & & \\
\hline Assy. in core & 78 & & 52 \\
\hline
\end{tabular}

XIII-10 


\section{XIII.A. CORE AND BLANKET}

The subassembly is a hexagonal wrapper, $142.2 \mathrm{~mm}$ across the fiats, containing a 325-pin bundle. Pins are supported within the wrapper by a honeycomb grid on the fuel section and an egg-crate type grid on the plenum section. A top crown assembly of nineteen wire-wrapped breeder pins is supported between grids. These pins swirl the exiting coolant. The upper tube assembly is cylindrical. The lower end of the assembly terminates in a bending bar which plugs into the support. In the first core loading two wrapper materials are used, a stainless steel and a Nimonic alloy. Overall assembly length is $3.81 \mathrm{~mm}$. (Fig. XIII.A-l)

The fuel pin is a stainless steel tube, $5.84 \mathrm{~mm}$ od, wall thickness $0.38 \mathrm{~mm}$. The ends are sealed by swaging and spotwelding. Overall length is $2.3 \mathrm{~m}$. Arrangement from the top down consists of $100 \mathrm{~mm}$ of depleted $\mathrm{U}_{2} 2$ solid pellets; $914 \mathrm{~mm} \mathrm{U0} 2-\mathrm{PuO}_{2}$ annular pellets; a $19 \mathrm{~mm}$ fuel support platform with a molybdenum wire mesh plug; $457 \mathrm{~mm}$ depleted $\mathrm{UO}_{2}$ annular pellets; a $19 \mathrm{~mm}$ fuel support platform; a $711 \mathrm{~mm}$ gas plenum, with the pin od in this section reduced to $5.33 \mathrm{~mm}$. Fissile pellet smear density is $80 \%$ TD. Pin pitch-to-diameter is 1.26 .

(Fig. XIII.A-2)
The radial blanket assembly holds 85 wire-wrapped pins $12.5 \mathrm{~mm}$ id and 13.49 $\mathrm{mm}$ od. Smear density of the depleted $\mathrm{UO}_{2}$ column is $95 \%$. Pellets are solid. The radial assembly also has the 19-pin mixer-breeder crown unit above the pin bundle.

Neutron shield rods are thick steel tubes with the outer rows containing graphite and the inner steel. The inner three rows are force cooled, and the others cooled by bypass flow from the hot core sodium passing through the shield to the intermediate heat exchangers.

The PFR core contains 78 fue] assemblies plus 13 positions for absorber rods and experiments, surrounded by 126 breeder and reflector assemblies. The core has two enrichment zones. There is one row of radial breeder, except for a $120^{\circ}$ sector in which there are three rows. No long-term in-vessel storage is provided. Contol rods are located on the boundary of the inner core zone. (Fig. XIII.A-3)

(Ref. 3, 4, 8)

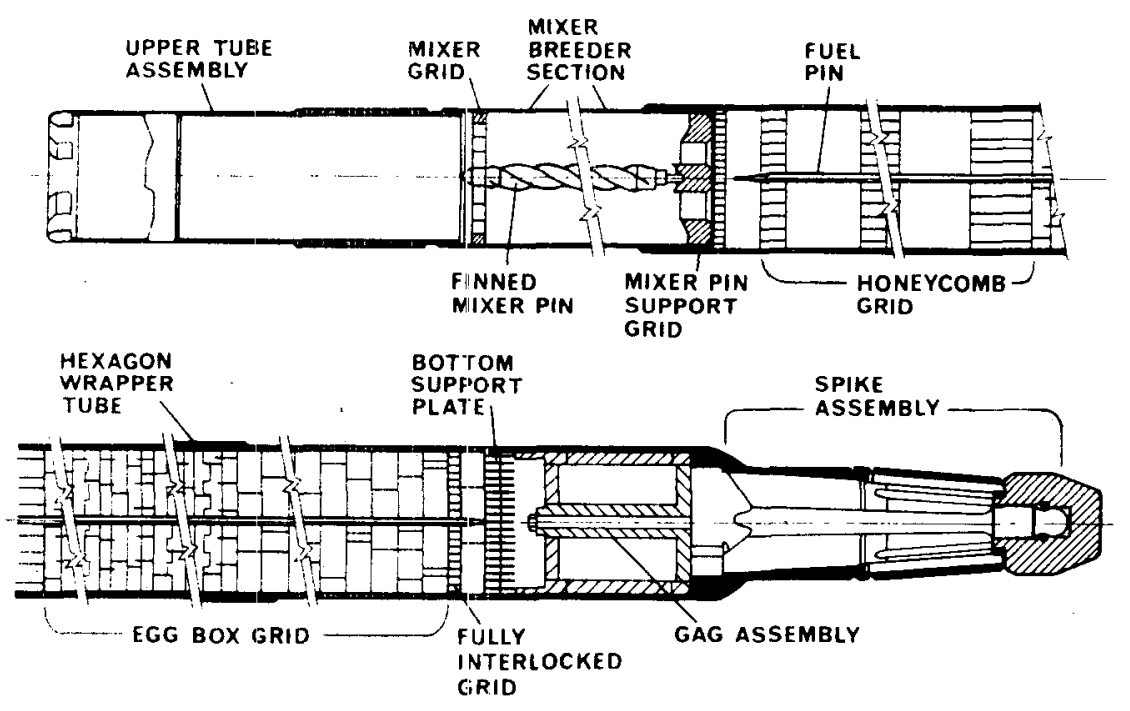

Figure XIII.A-1 PFR Subassembly (Ref. 4) 
PFR XIII.A.
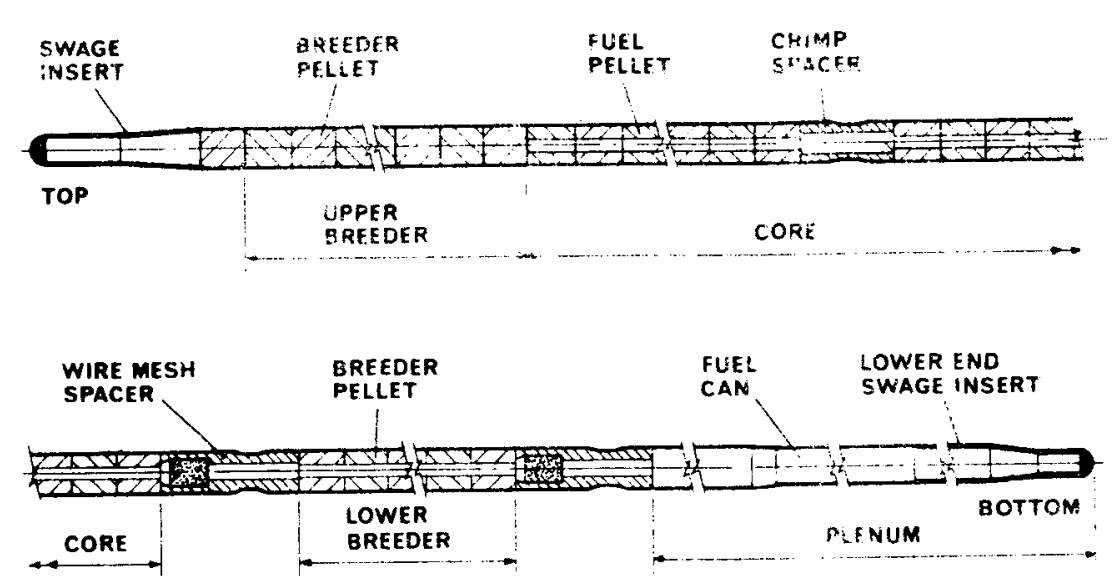

Figure XIII.A-2 PFR Fuel Pin (Ref. 4)

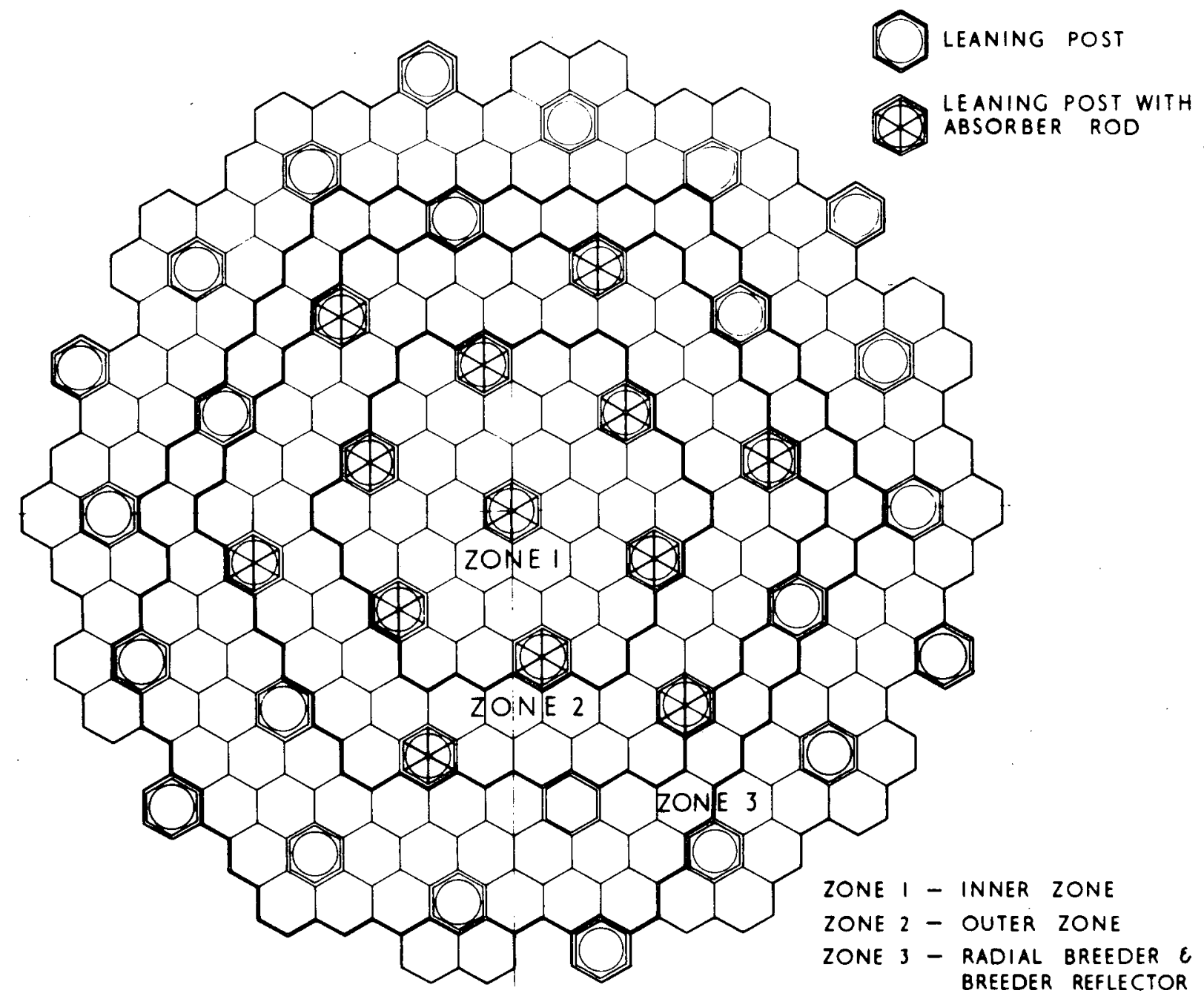

Figure XIII.A-3 PFR Core (Ref. 2) 
PFR XIII.B.

XIII.B. CORE SUPPORT AND VESSEL INTERNALS

The PFR core is free-standing, the top support point being level with the bottom of the active fuel. The core is divided into modules of six subassemblies, each with an associated control rod or leaning post. The leaning post, in the central position, has pads positioned at the level of the fuel/lower axial breeder boundary. Each of the module positions has a fuel carrier, or pressure chamber, fixed in a hole in the diagrid. In each carrier there are six upper and lower bearings which carry the support spike of the six subassemblies. The leaning post accommodates a tube extending close to the top of the core, which provides guidance for control and shutdown rods. (Fig. XIII.B-1,2)
The diagrid supports the core and forms a high-pressure plenum for feeding sodium to the core, the radial breeder, and the inner rows of the neutron shielding. It transmits the load by means of a support skirt and a strongback to the main diagrid support structure attached to the top of the primary tank. It is a titanium-stabilized stainless steel structure composed of circular top and bottom plates spaced by a circumferential cylindrical part and carrier support tubes. (Fig. XIII.B-3)

Design for a restrained core has been studied as a possible alternative to the free-standing core. This consists of an external ring which would clamp the subassemblies close to their tops. (Ref. 5, 9, 10) 
PFR XIII.B.

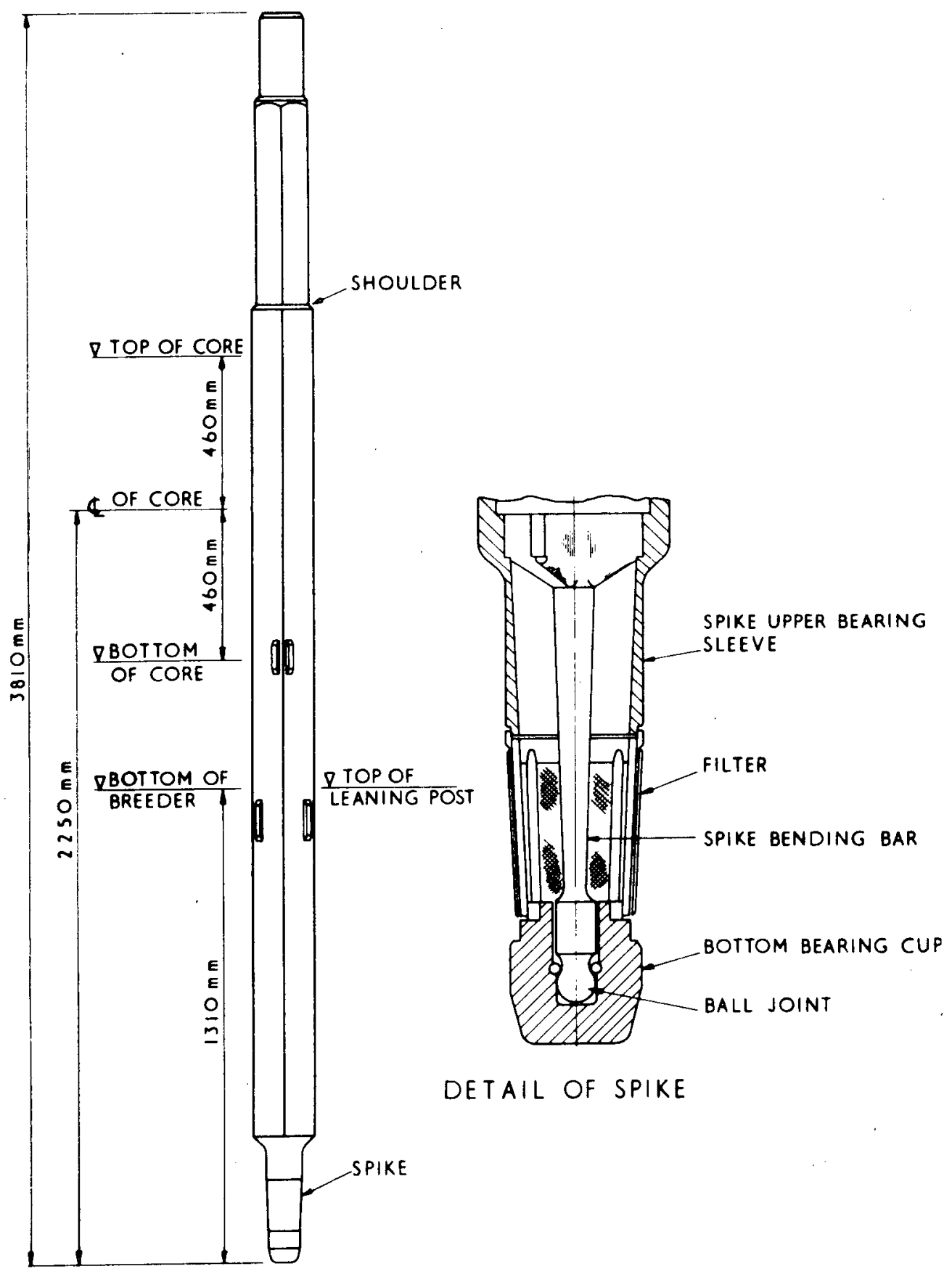

Figure XIII.B-1 PFR Subassembly, Spike Detail (Ref. 5) 
PFR XIII.B.

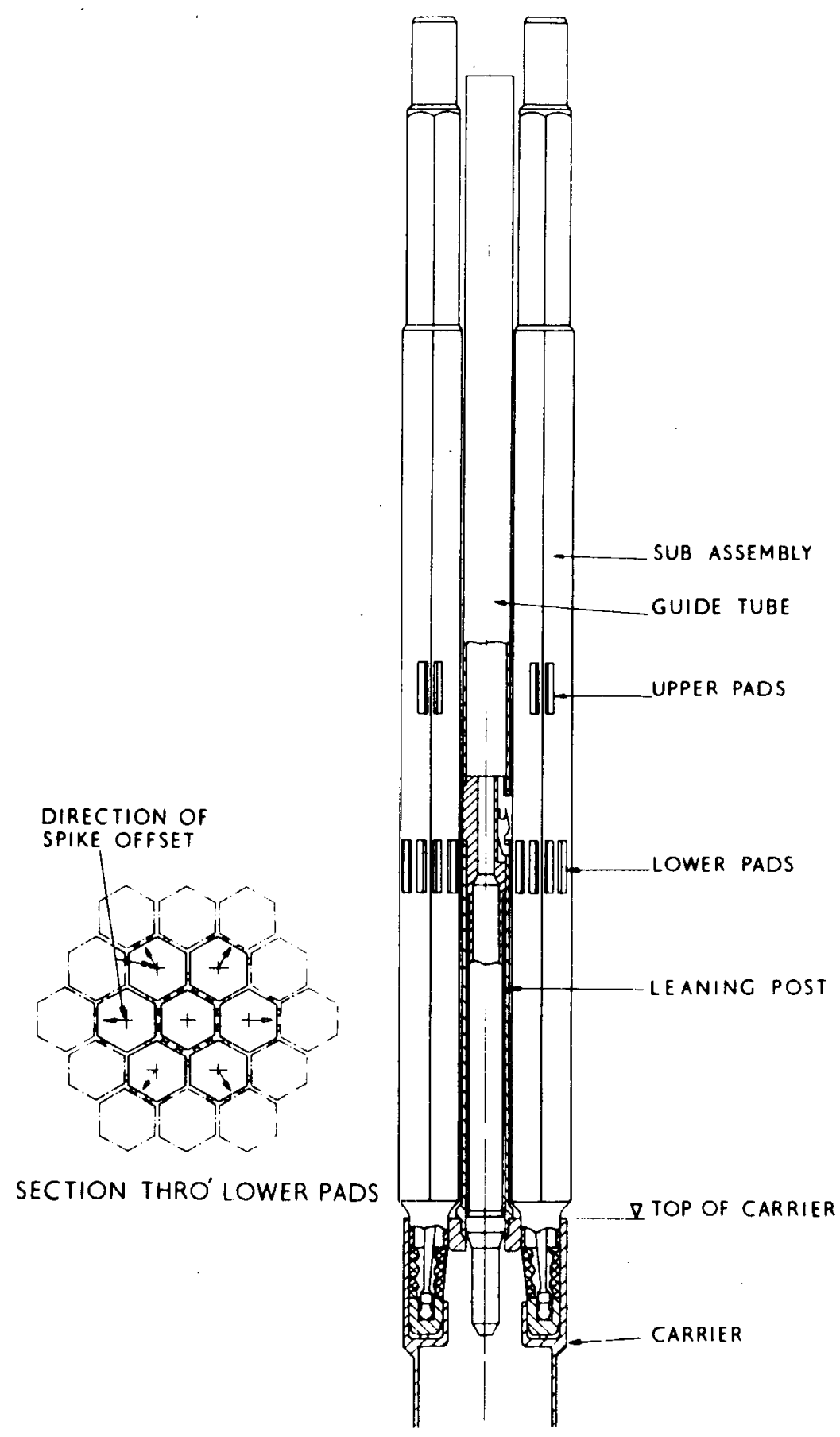

Figure XIII.B-2 PFR Subassembly Support (Ref. 5)

XIII.B-3 
PFR XIII.B.

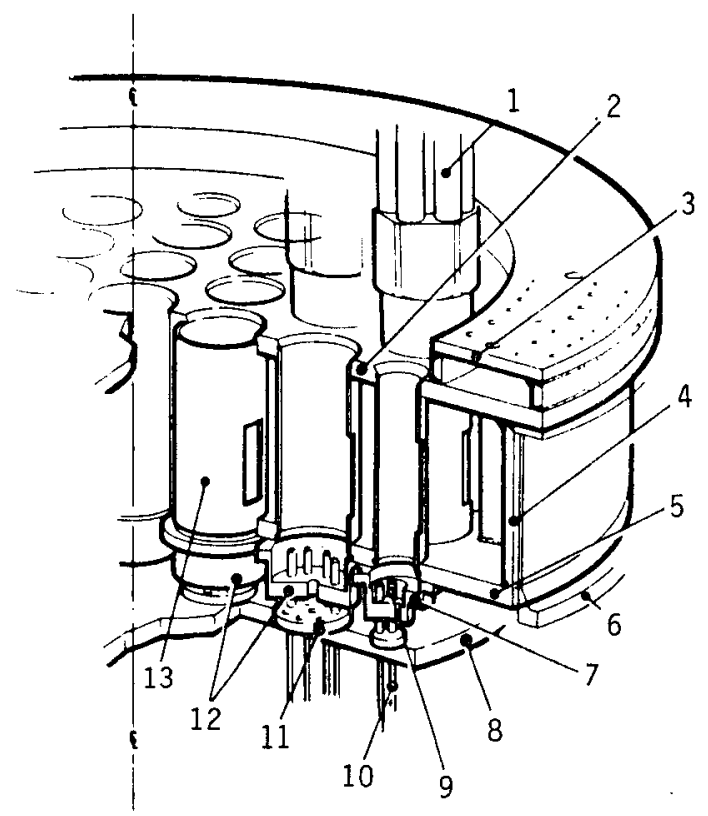

1. FUEL ELEMENT CARRIER

2. TOP PLATE (50 MM THICK)

3. LOW PRESSURE PLENUM

4. CIRCUMFERENTIAL WALL MEMBER (38 MM THICK)

5. BOTTOM PLATE (50 MM THICK)

6. SUPPORT SKIRT

7. FUEL ELEMENT CARRIER LOCATION NUT

8. B.P.D. CONNECTOR PLATE

9. B.P.D. CONNECTOR STUBS

10. B.P.D. PIPES

11. B.P.D. CONNECTOR BLOCK

12. FUEL ELEMENT CARRIER LOCATION NUT

13. FUEL ELEMENT CARRIER SUPPORT TUBE (9.5MM THICK)

LEADING DIAGRID DIMENSIONS

OVERALL DIAMETER 3.25 METERS

MASS DEPTH 0.8 METERS

Figure XIII.B-3 PFR Diagrid (Ref. 10) 


\section{XIII.C. REACTOR VESSEL AND SHIELDING}

The whole of the primary circuit is contained in the primary reactor tank, a cylindrical stainless steel vessel suspended from the roof support structure. A low-alloy leak jacket surrounds the vessel. A reinforced concrete vault below ground level contains the vessels. The primary vessel is $12.2 \mathrm{~m} \mathrm{dia}$. and $15.2 \mathrm{~m}$ deep.

A reactor jacket ducts the sodium from the core to six intermediate heat exchangers. The jacket is stainless steel with $12 \mathrm{~mm}$ wall thickness, $12 \mathrm{~m}$ iigh and $16 \mathrm{~m}$ across the Intermediate Heat Exchanger (IHX) trays. There are four layers of a quilted stainless steel insulation fitted to all inside surfaces of the jacket, and eight layers in the area around the neutron shield support toroids. This toroid is fitted to the top of the reactor jacket. The reactor jacket sits on the core support structure. (Fig. XIII.C-1, 2)
All primary components are supported from the roof structure of the primary vesse1. The roof is a ferritic steel structure composed of an outer ring girder connected by ten spokes to the central section in which the rotating shield operates. The leak jacket is suspended from the outer ring girder and a "tuning fork" forging of the inside member of this ring.

A single rotating shield plug is mounted in the roof structure concentric with the core. The rotating plug is $336 \mathrm{~cm}$ dia., mounted on a ball race and provided with a dip seal. Cooling is by a forced convection argon system. Stainless stee 1 plates give thermal insulation, and shielding is provided by concrete. (Ref. 1, 8, 10) 
PFR XIII.C.

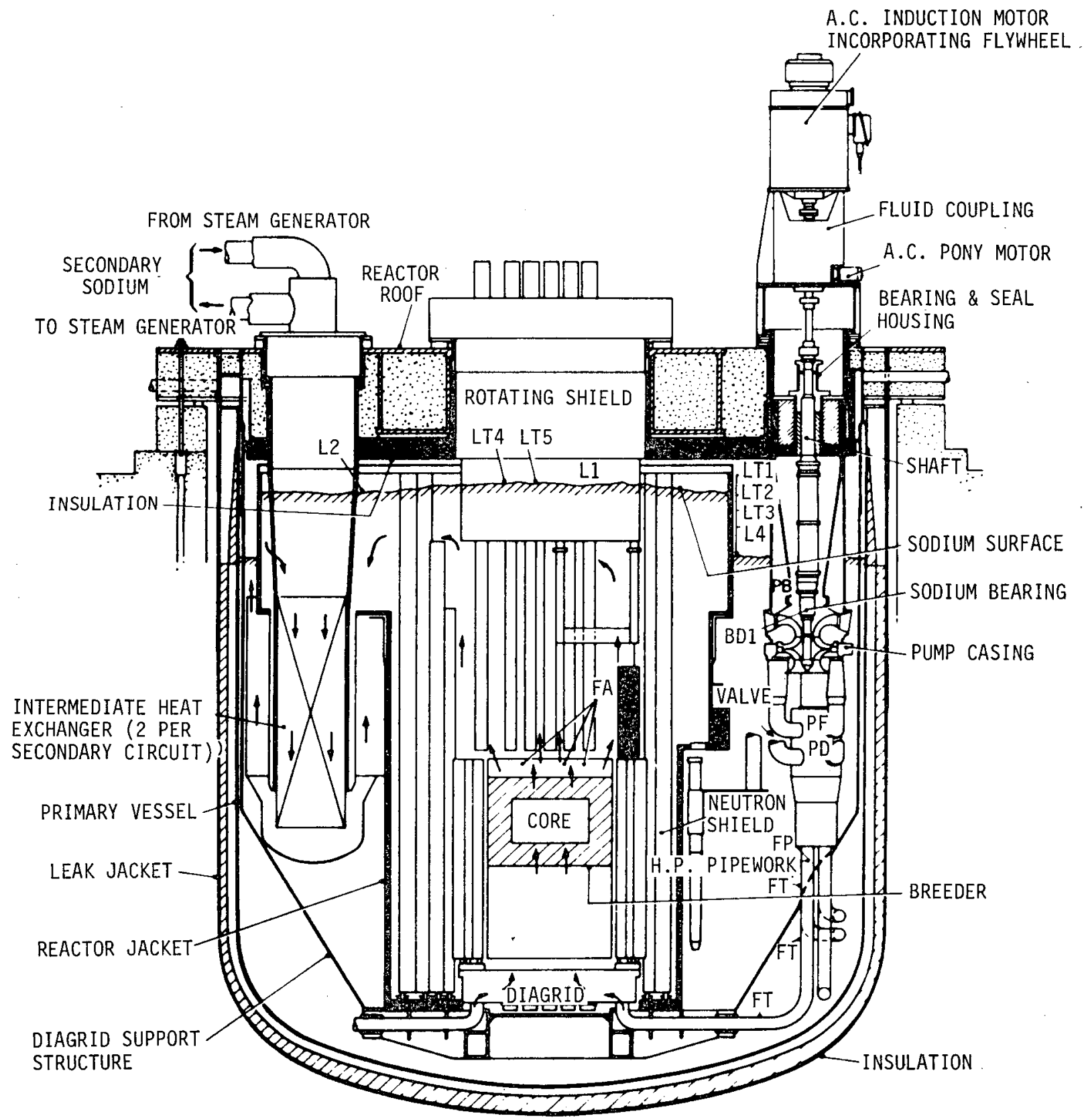

Figure XIII.C-1 PFR Reactor Vessels and Shielding (Ref. 18) 
PFR XIII.C.

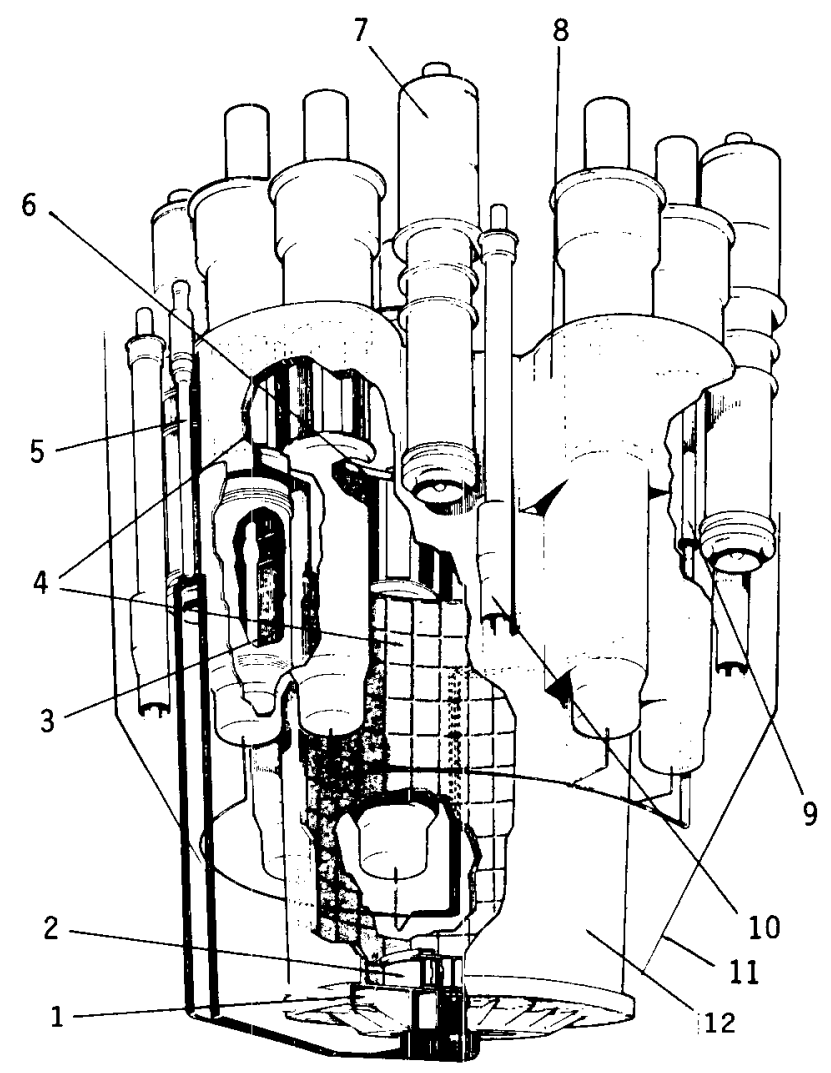

1. STRONGBACK

2. DIAGRID

3. INTERMEDIATE HEAT EXCHANGER TUBE BUNDLE

4. REACTOR JACKET QUILTED THERMAL INSULATION

5. BURST PIN DETECTION THIMBLE (BULK \& LOCATION)

6. NEUTRON SHIELD SUPPORT TORROID
7. PRIMARY CIRCULATING PUMP

8. HEAT EXCHANGER TRAY

9. BURST PIN DETECTION THIMBLE (BULK)

10. PRIMARY NON-RETURN VALVE

11. DIAGRID SUPPORT STRUCTURE

12. REACTOR JACKET

Figure XIII.C-2 PFR Vessel Components (Ref. 10) 
PFR XIII.D.

XIII.D. CONTROL ELEMENTS

Control is by means of five control rods and six shutoff rods. The control rod is a shell and tube assembly with sodium flowing through the tubes. The shut-off rod is an assembly of stainless steel cans containing enriched $\mathrm{B}_{4} \mathrm{C}$ within a stainless steel hexagonal wrapper. Control and shutoff guide tubes are suspended from the rotating shield. They also house thermocouple conduits, each serving one group of six subassemblies.

A secondary shutdown mechanism or oscillator occupies the center hole in the rotating plug. The concept is entirely different from the other control mechanisms. (Ref. 20) 


\section{XIII.E. HEAT TRANSFER SYSTEMS}

Each of the three primary loops includes two intermediate heat exchangers mounted in pairs, and a cold-leg pump. Sodium from the cooler outer region of the primary tank is driven by the pumps through twelve separate delivery pipes to the inlet plenum/core support grid. Flow is upward through the core and radial breeder into an upper and inner pool contained within an insulated jacket structure, then into tray extensions of the jacket which house the IHX units. Primary sodium flow is downward through the tubes of the IHX. The IHX pairs are supplied with three sets of subcritical pressure steam generators. Each secondary loop is independent of the others. Within the reactor hall, secondary pipes are double-jacketed, with nitrogen in the annulus. Each heat exchanger has an associated decay heat removal coil. cold traps are used in the primary and secondary systems. (Fig. XIII.E-1)

The intermediate heat exchanger consists of a counterflow shell and tube unit, with a decay heat removal coill, a primary isolation sleeve valve, a biological shield plug containing the secondary sodium pipes, and a valve drive unit. The assembly is supported from the primary tank roof. Secondary sodium flows through a central downcomer to the bottom of the IHX shell and then upward through the unbaffled shel1. Differential expansion between tube and shell is accommodated by a sine wave in the tubes. The sleeve valve located above the top tube plate can isolate the primary flow to facilitate loop maintenance.

(Fig. XIII.E-2)
Decay heat following a reactor trip can be removed by an independent NaK circuit. The heat exchangers for this circuit are coils positioned inside the valve sleeve above the top tube plate. Inlet and outlet pipes to the outside Nak/air heat exchangers pass through the shield plug. There are three independent loops, each capable of removing 5 MWt of heat. Each loop includes two coils. NaK pipework is jacketed with an inert gas and has a leak-detection system. The system is designed for completely automatic operation, although operator initiation from the control room or from a remote emergency control room is possible.

(Fig. XIII.E-3) (Ref. 11, 12)

Primary pump is a vertical shaft, centrifugal unit with double entry. A rubbing face shaft seal seals the primary circuit argon. The bottom bearing is a hydrostatic sodium-fed bearing immersed in the sodium. The top bearing consists of an integral oil-lubricated hydrostatic annular slot-fed sleeve with a hydrodynamic thrust step bearing. One oil system supplies both the seal and the top bearing. Bearing center-1ine distance is about $15 \mathrm{ft}$. The shaft incorporates a tubular section welded to two solid end forgings. A flywheel gives minimum rundown time of eight seconds to half-speed. (Fig. XIII. $\mathrm{E}-4$ )

The secondary pump is a vertical mechanical unit with a cold flange. Anticonvection baffles are incorporated into the tank structure. There is a conical bottom section. (Fig. XIII.E-5) (Ref. 13) 
PFR XIII.E.

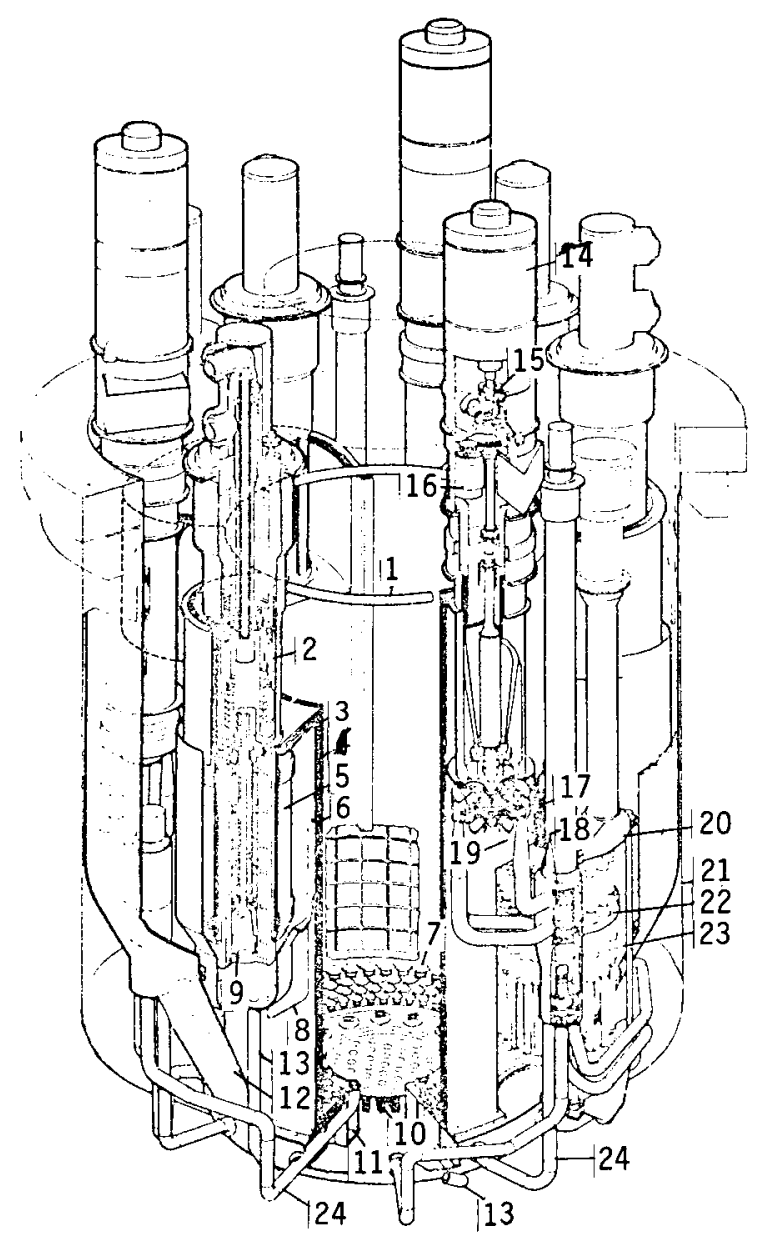

1. TOROID

2. PRIMARY HEAT EXCHANGER SHUT OFF VALVE

13. DIAGRID COOLING PIPES

3. PROTECTIVE LAYER

4. REACTOR JACKET

14. PRIMARY PUMP MOTOR

5. BELLOWS SLEEVE

6. INSULATION

7. NEUTRON SHIELD SUPPORT STOOLS

15. FLUID COUPLING

16. PONY MOTOR

17. SHIELDING

18. FLUX DISTORTION FLOW METER GUIDE TUBE

8. BULK MONITORING PIPE

19. DISCHARGE PORT

20. SHOCK ABSORBER ASSEMBLY

9. PRIMARY HEAT EXCHANGER

21. PRIMARY TANK

22. ROTOR PLATE

10. B.P.D. PIPEW

12. DIAGRID SUPPORT STRUCTURE

23. VALVE

24. LOW TEMPERATURE PIPEWORK

Figure XIII.E-1 PFR Primary Circuit Excluding Shields and Core (Ref. 7)

XIII.E-2 
PFR XIII.E.

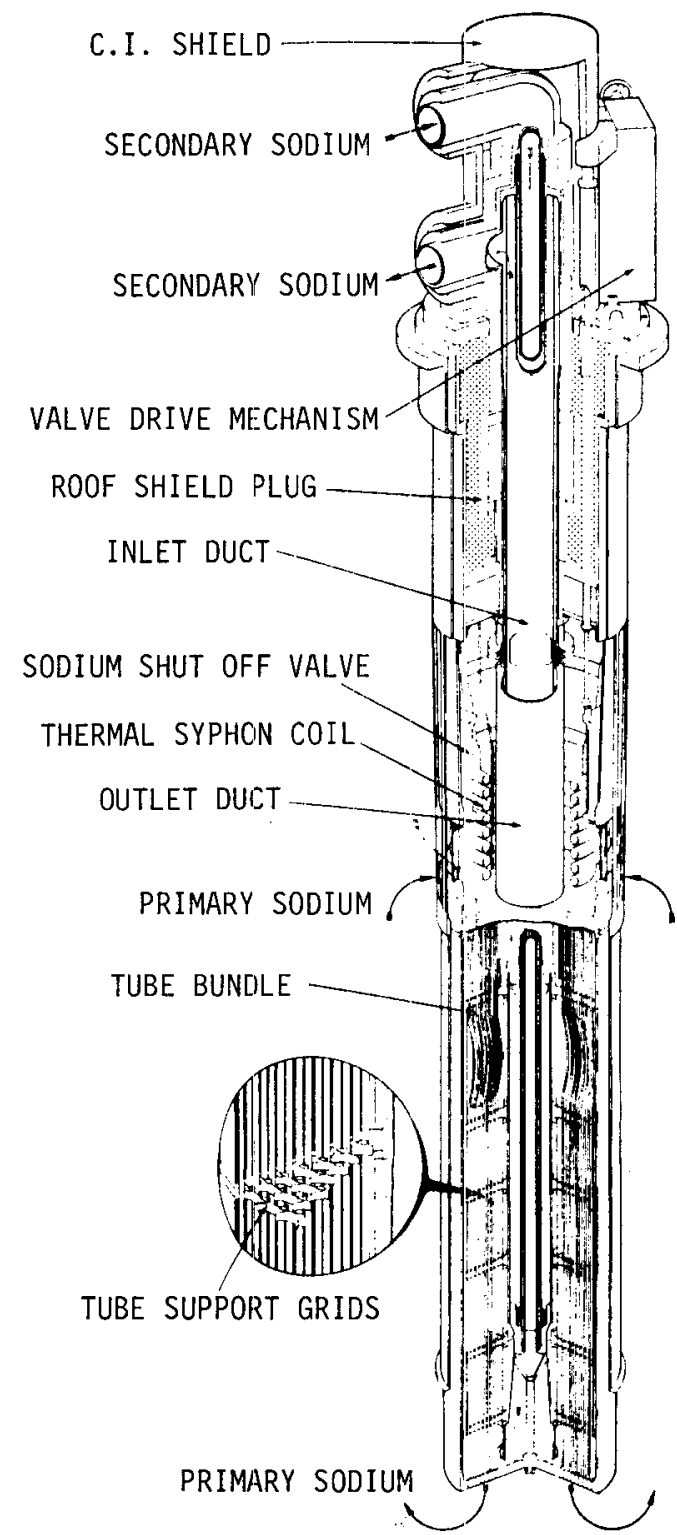

Figure XIII.E-2a PFR Intermediate Heat Exchanger (Ref. 12)

XIII.E-3 
PFR XIII.E.

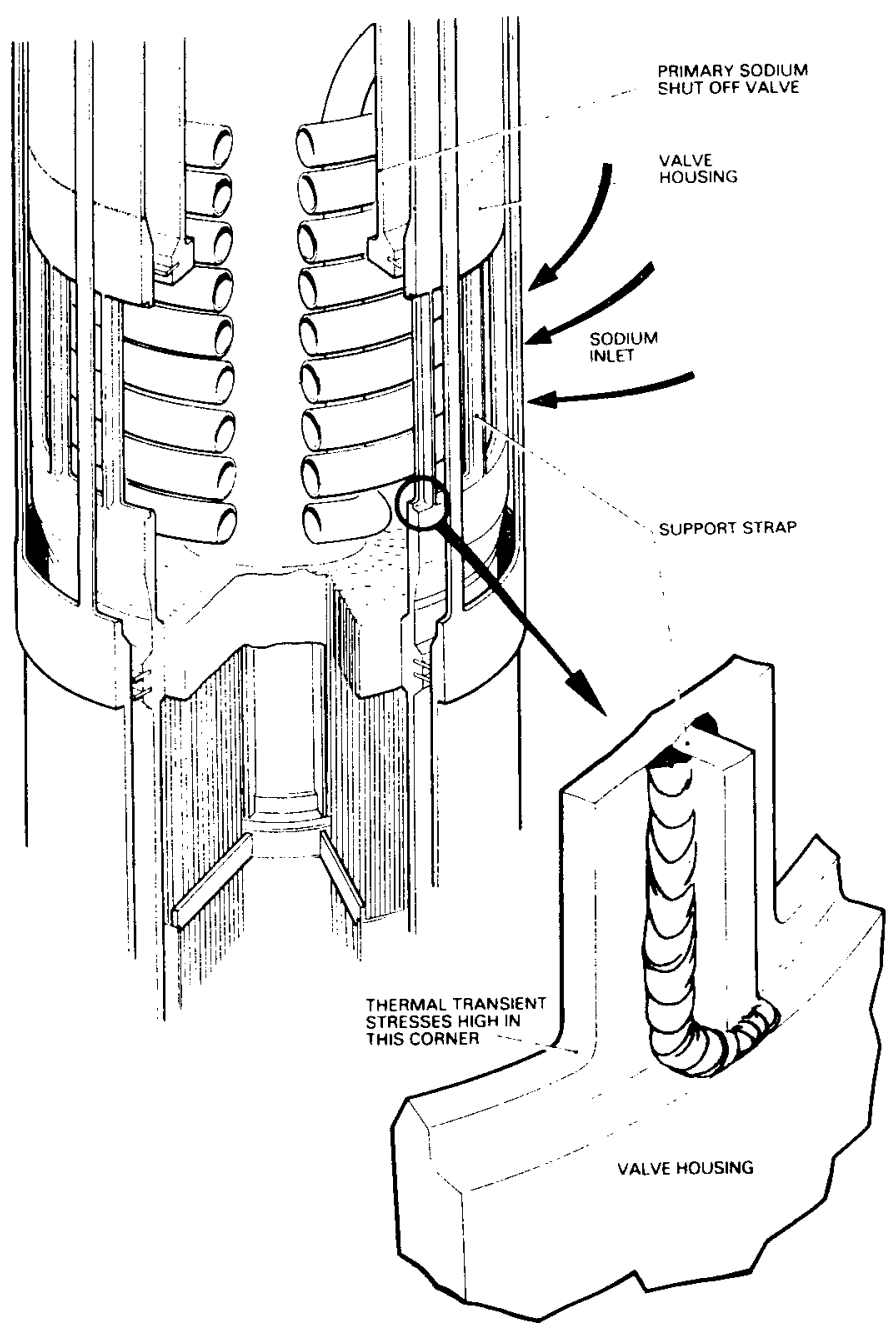

Figure XIII.E-2b PFR Inlet Region of IHX (Ref. 22) 
PFR XIII.E.

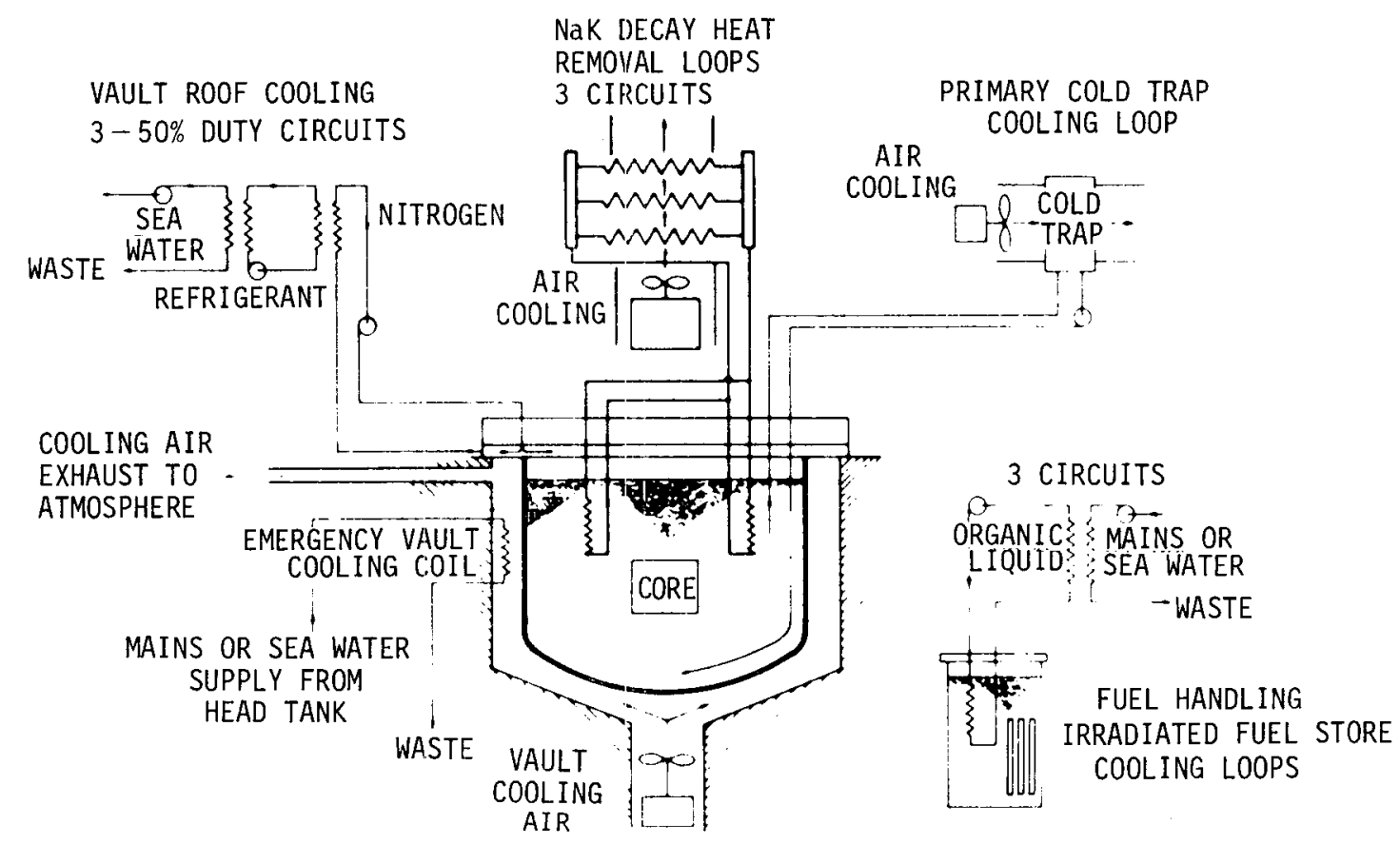

Figure XIII.E-3 PFR Decay Heat Removal (Ref. 11)

XIII.E-5 


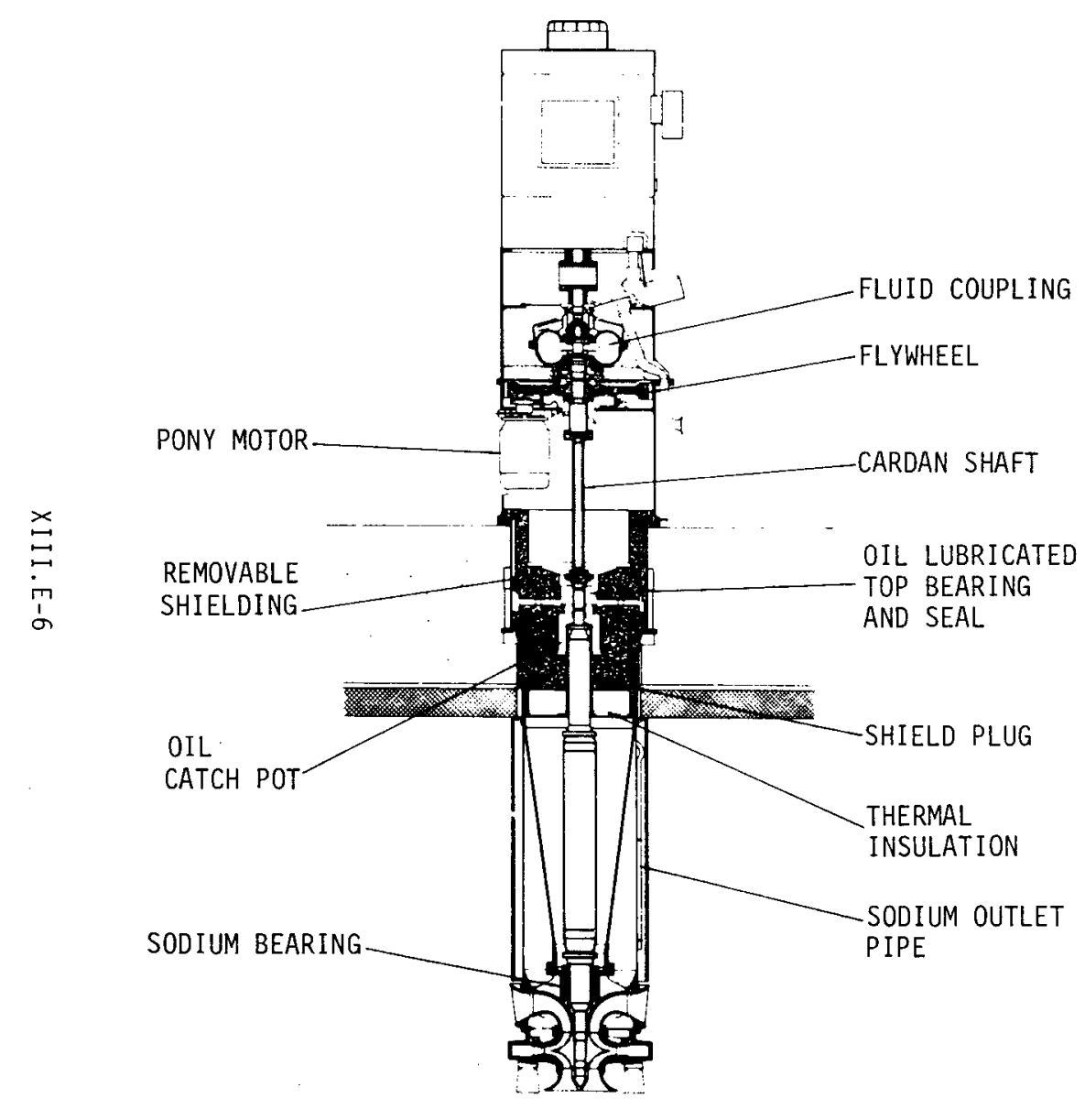

Figure XIII.E-4 PFR Primary Pump (Ref. 13)

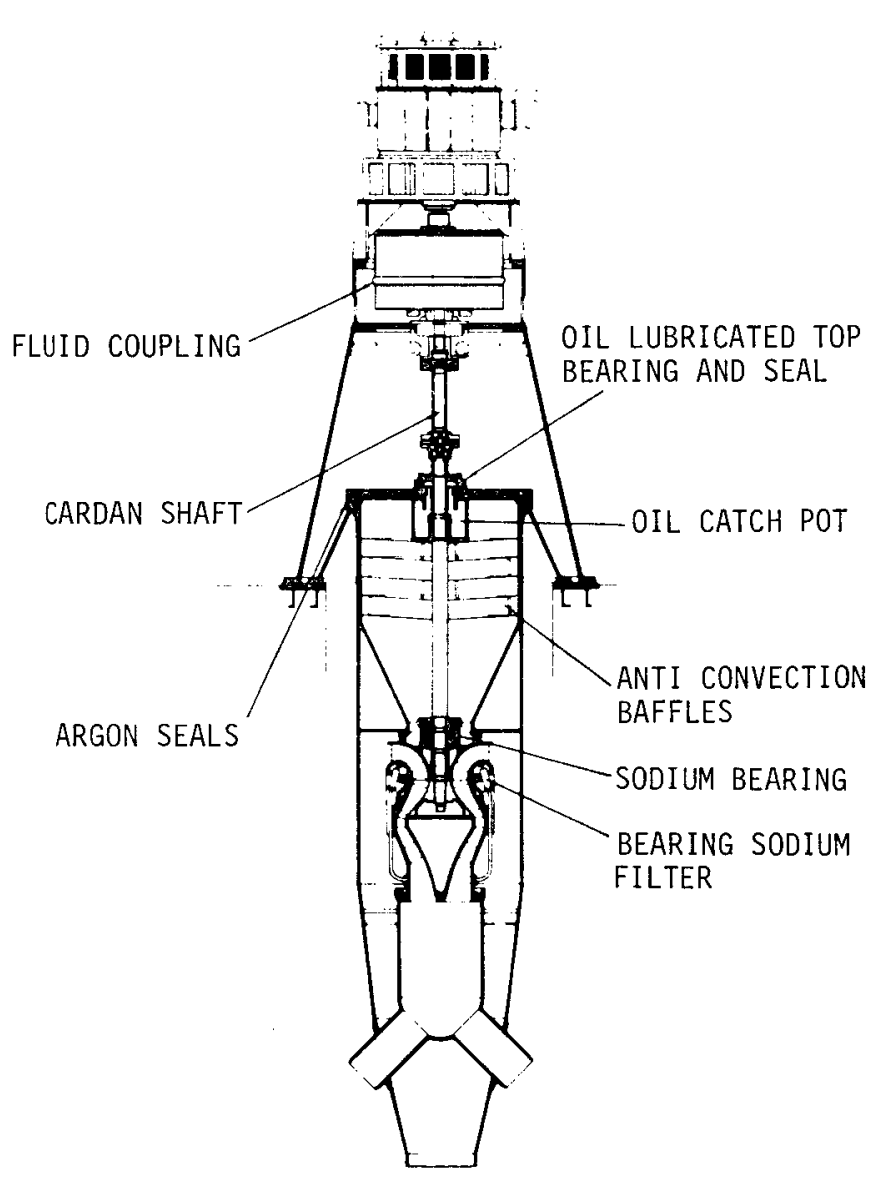

Figure XIII.E-5 PFR Secondary Pump (Ref. 13) 


\section{XIII.F. SODIUM PURIFICATION AND INSTRUMENTATION}

Cold traps are used in both the primary and secondary circuits. In the primary circuit, the cold trap loop includes a regenerative heat exchanger on the forced air flow cooling system. Primary cold traps are housed in shielded, air-cooled concrete vaults adjacent to the reactor. A cold trap pump moves sodium at a rate of $6.5 \mathrm{~kg} / \mathrm{second}$ from the cooler sodium pool to the cold trap basket via the regenerative heat exchanger. Sodium is returned to cool the debris tray situated below the diagrid. An additional decay heat removal system is provided by valving, which allows by-pass of the regenerative heat exchanger. A $1 \mathrm{MW}$ heat rejection capability is possible by this means. (Ref. 1)

Primary loop monitoring facilities include coolant sampling and distillation, a plugging meter, two carbon meters, a demountable subassembly for the collection of particulate material, specimens for material monitoring, and a blanket gas sampling point. The coolant sampling facility is incorporated in the cold trap loop. (Fig. XIII.F-1)

The plugging meters are installed at the inlet and outlet of the primary cold trap. They are a variant on the servocontrolled continuous reading clevice, utilizing an NaK filled loop inserted between the orifice region and the air cooler. Two versions of a carbon meter are installed in the primary 10op; they monitor sodium at the inlet of one of the IHX. There is no carbon meter in the secondary circuit.

Four hydrogen meters installed in a heated by-pass at the evaporator outlet serve for detection of small water leaks. (Ref. 16)

Two systems for the detection of cladding failure are utilized in PFR. The Bulk and Location System monitors samples taken directly from the coolant channels. The Bulk Only System monitors samples of the bulk coolant taken from the outlets of the primary loop heat exchangers. The samples are monitored for delayed neutrons. The loops include D.C. electromagnetic pumps and flowmeters, and a selector valve. The two systems differ somewhat in the operation of the flowmeter and the selector valve. (Fig. XIII.F-2, 3) (Ref. 17)

The boiling noise detection system depends on the measurement and detection of boiling noise against background noise. Detection is by means of abovecore wave guides.

Temperature of the sodium coolant is measured by standard instruments mounted at subassembly outlets.

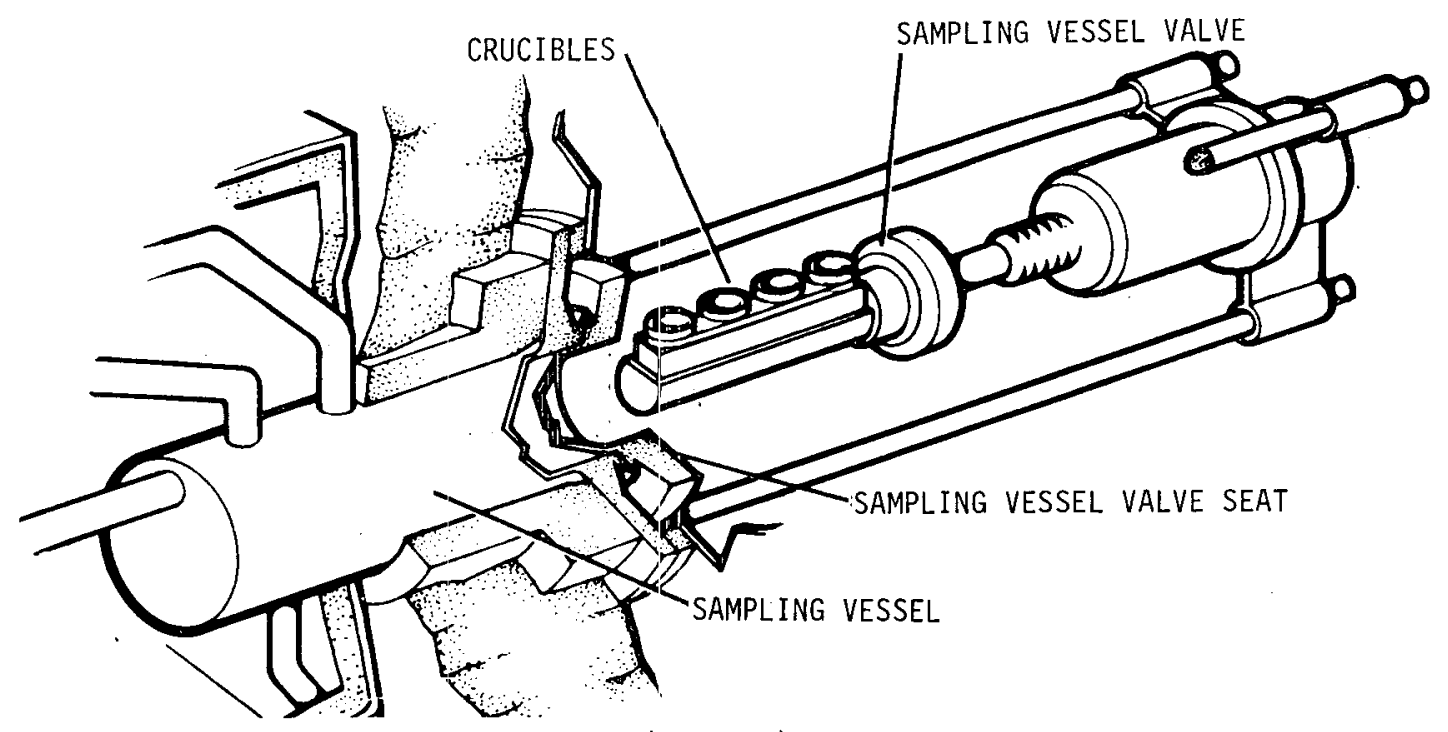

Figure XIII.F-1 PFR Primary Loop Sampling (Ref. 16) 


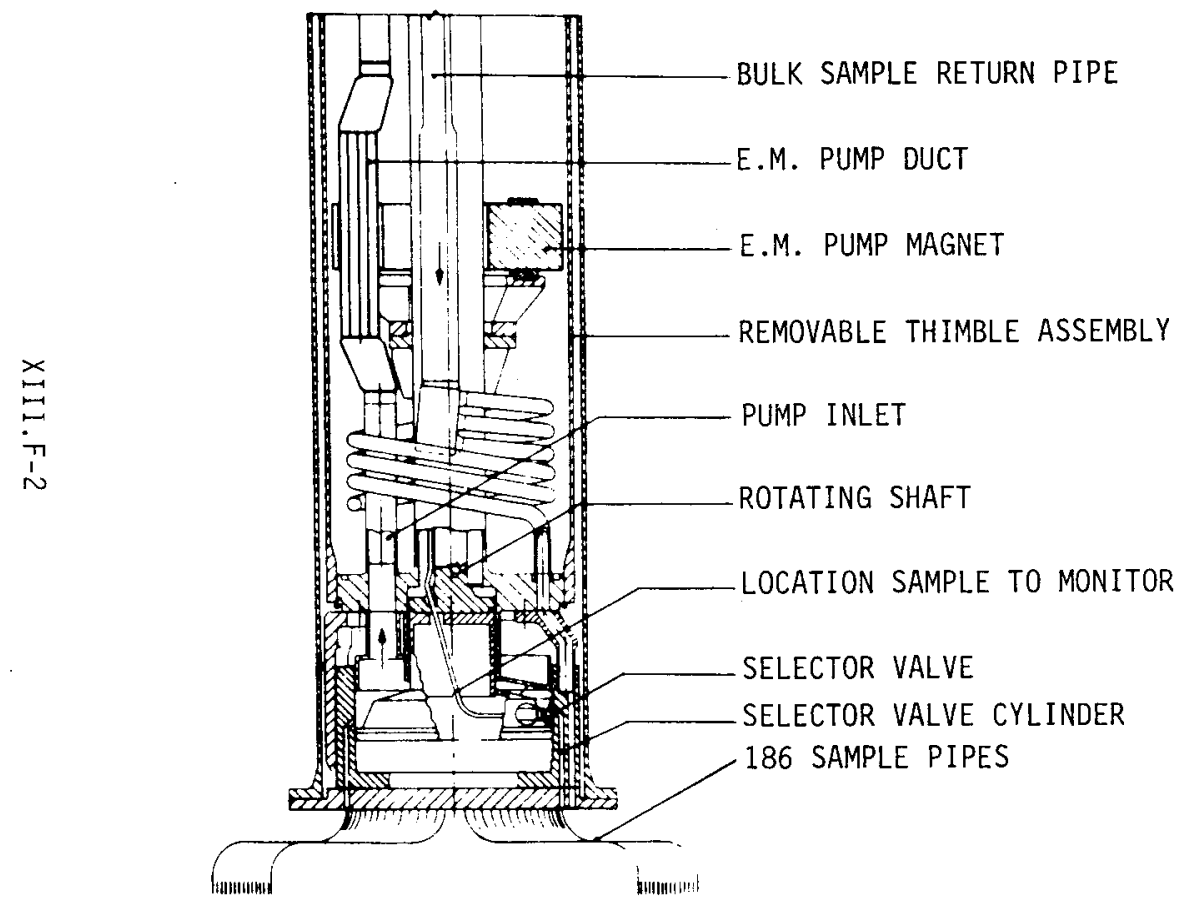

Figure XIII.F-2 PFR Bulk and Location Selector Valve Assembly - BPD (Ref. 17)

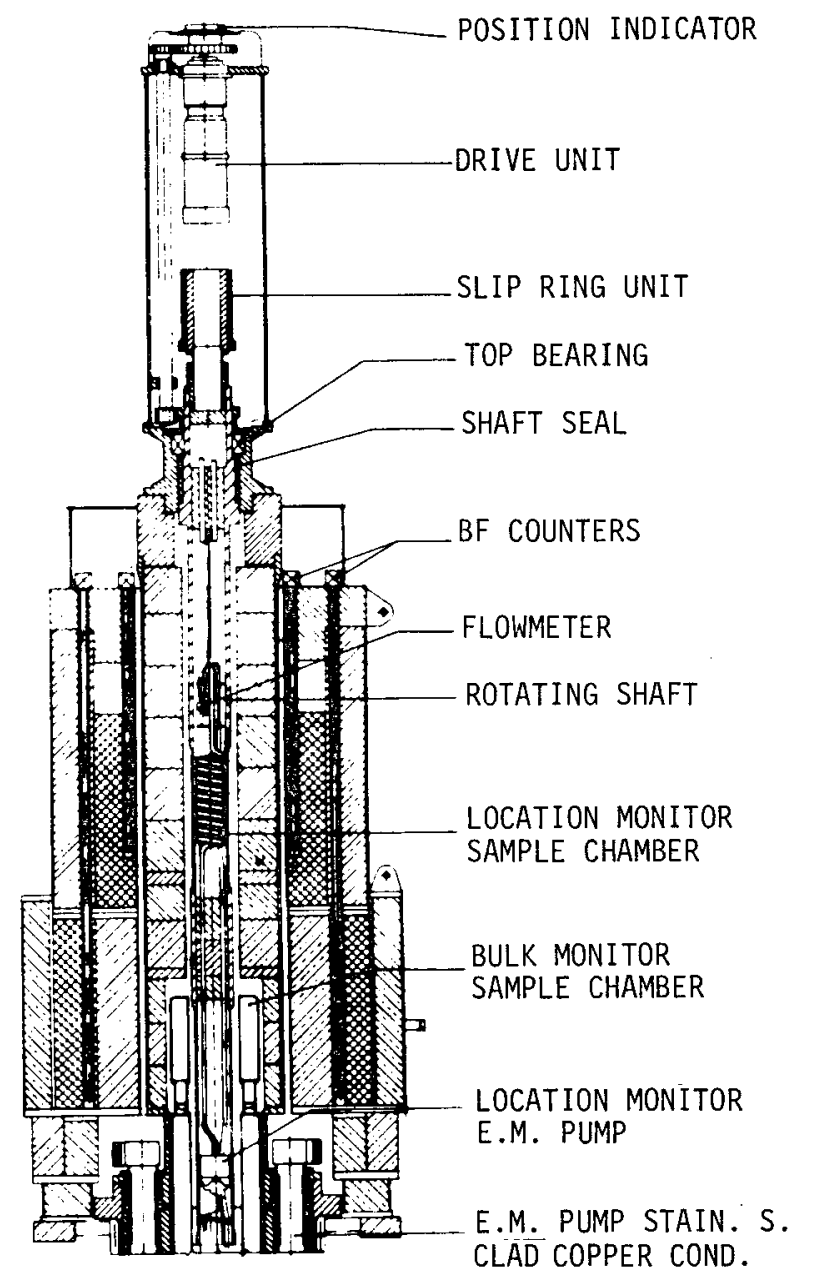

Figure XIII.F-3 PFR BuTk and Location Monitor Assembly - BPD (Ref. 17) 
XIII.G. COVER GAS AND AUXILIARY SYSTEMS

Decay heat removal system:
See Section $E$
Cold trap systems: See Section F

Cover gas is argon. There is an argon supply line and a vent line to each gas volume.

Ancillary cooling systems include a system to maintain the vault concrete below $90^{\circ} \mathrm{C}$; a reactor vault roof cooling system; the primary cold trap loops; an irradiated fuel cooling system; and a vault emergency cooling coil.

The system to cool the reactor vault consists of three two-stage axial flow fan units. Shut-off dampers prevent air ingress under no-flow conditions. A single fan stage can provide a cooling flow of $850 \mathrm{~m}^{3} / \mathrm{sec}$. An emergency flow five times the normal operating value can be obtained by full use of all fan units.

The vault roof cooling system maintains the concrete temperature in the roof below $40^{\circ} \mathrm{C}$. Nitrogen gas is fed into the roof via annular ducts in the perimeter of the plant roof. The gas passes downward through penetrations to the lower face of the roof and then radially outwards in a gap between the main roof structure and a diaphragm plate attached to the lower face, passes down over the outside of the reactor tank top insulation, and discharges through ducts at the top of the leak jacket. The nitrogen system is designed for a pressure of $1001 \mathrm{~b} \mathrm{ft} / \mathrm{in}^{2}$.

In PFR, irradiated assemblies are moved from the reactor core to a buffer storage within the primary tank, with the fuel at all times immersed in sodium.

After a period of decay time the assemblies are removed into a transfer flask provided with an argon cooling system, fed by circulating fans. The fuel transfer and subassembly storage tanks are both cooled by similar organic liquid systems. Each tank is divided into three separate sections, containing three, four, and three separate cooling coils connected to three organic liquid/water heat exchangers.

The vault emergency cooling coil is a simple loop of thick-walled stainless steel tube mounted in the vault aircooling inlet duct, and connected to a header tank fed by the site water supply. Gravity flow through the system can remove $4 \mathrm{MW}$ of heat with a sodium temperature of $450^{\circ} \mathrm{C}$. (Ref. 11) 
PFR XIII.H.

\section{XIII.H. STEAM GENERATORS}

The IHX pairs supply three sets of sub-critical pressure steam generators. Each generator unit consists of a superheater and reheater in parallel, with combined sodium outlet flows feeding a recirculating flow evaporator. Each set is located in a separate bay in the turbine hall, and is provided with an individual sodium fire fighting system.

Al1 units are $U$-tube and she 11 geometry with water or steam in the tubes. The evaporator employs parallel flow, with water in the tubes and sodium in the she 11. The superheater and reheater operate with counterflow. The evaporator tube material is ferritic steel, and 316 stainless for the superheater and reheater. Tubes are single-wall construction.
There is a conventional steam drum and circulating pump piped together to form a forced circulation steam generator system. Blanket gas spaces on the sodium inlet and outlet of each heat exchanger unit are completely independent. Sodium levels are monitored continuously by probes and hydrogen detectors are mounted in all heat exchanger gas spaces, and in the flowing sodium between the evaporator and the pump tank. A sodium dump and blanket gas system serves all three circuits in turn. Plugging meters are located in the line between the pump and the intermediate heat exchanger. Bursting disks are provided which vent to a cleanup system. (Fig. XIII.H-1 to XIII.H-4) (Ref. 11, 15)

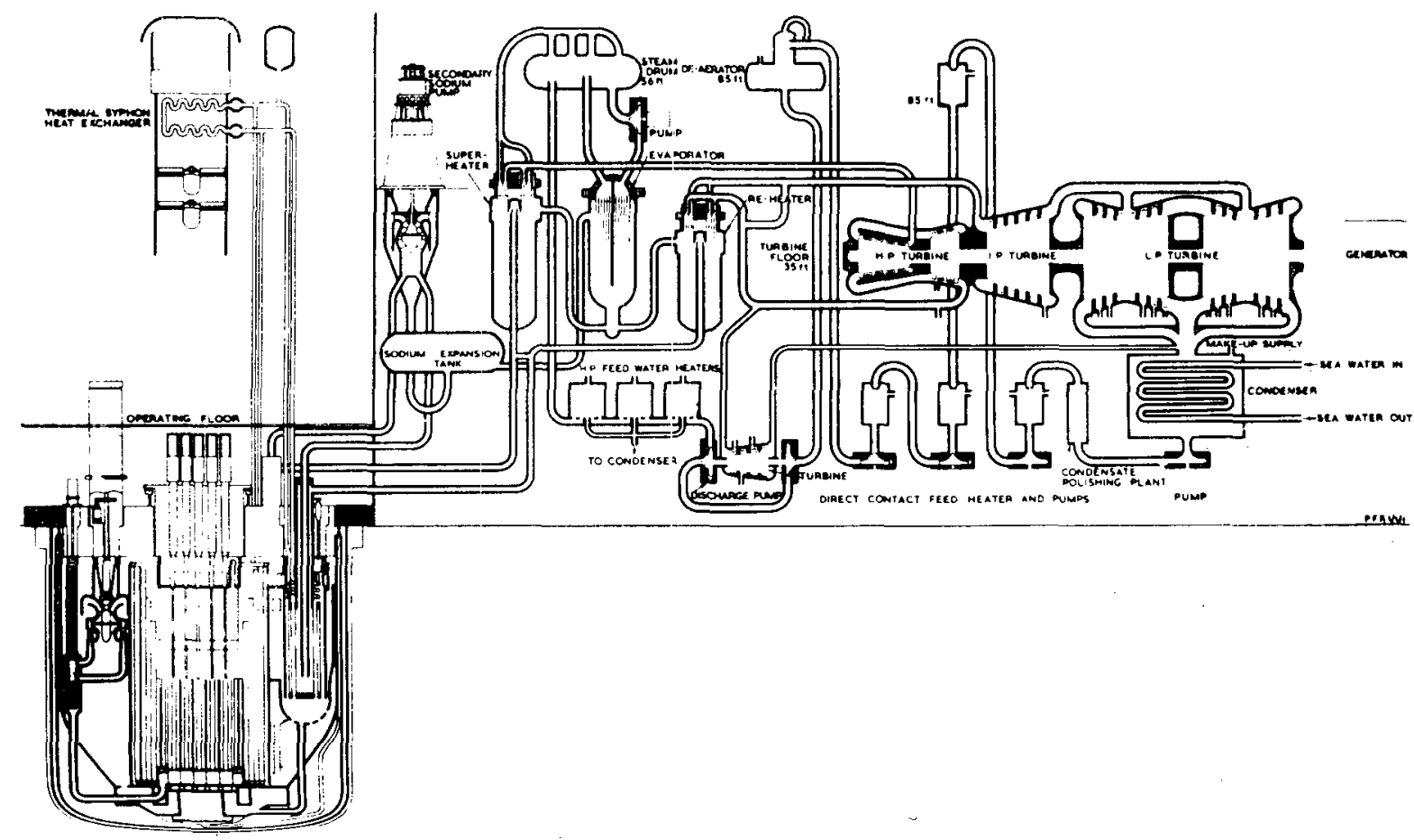

Figure XIII.H-I PFR Heat Removal and Steam Plant (Ref. 12) 
PFR XIII.H.

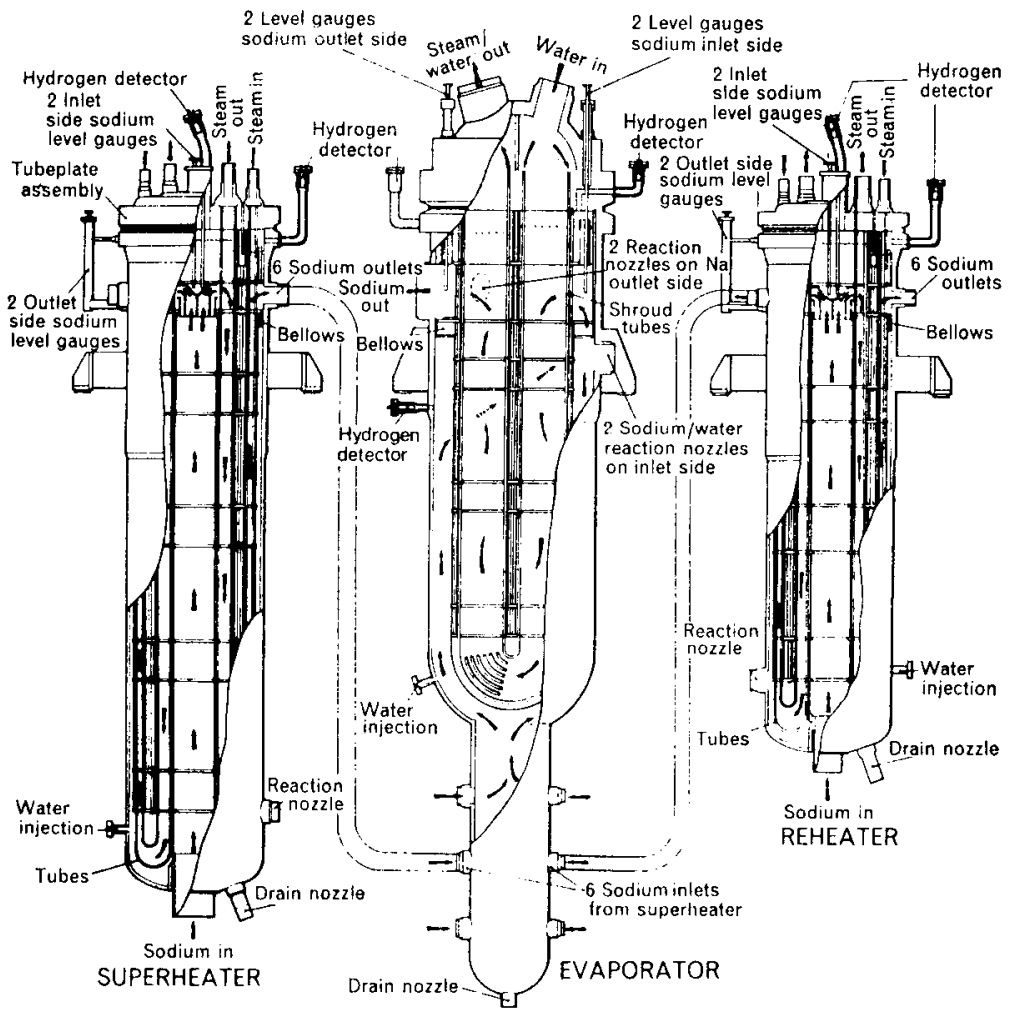

Figure XIII.H-2 PFR Steam Generator Heat Exchangers (Ref. 12) 


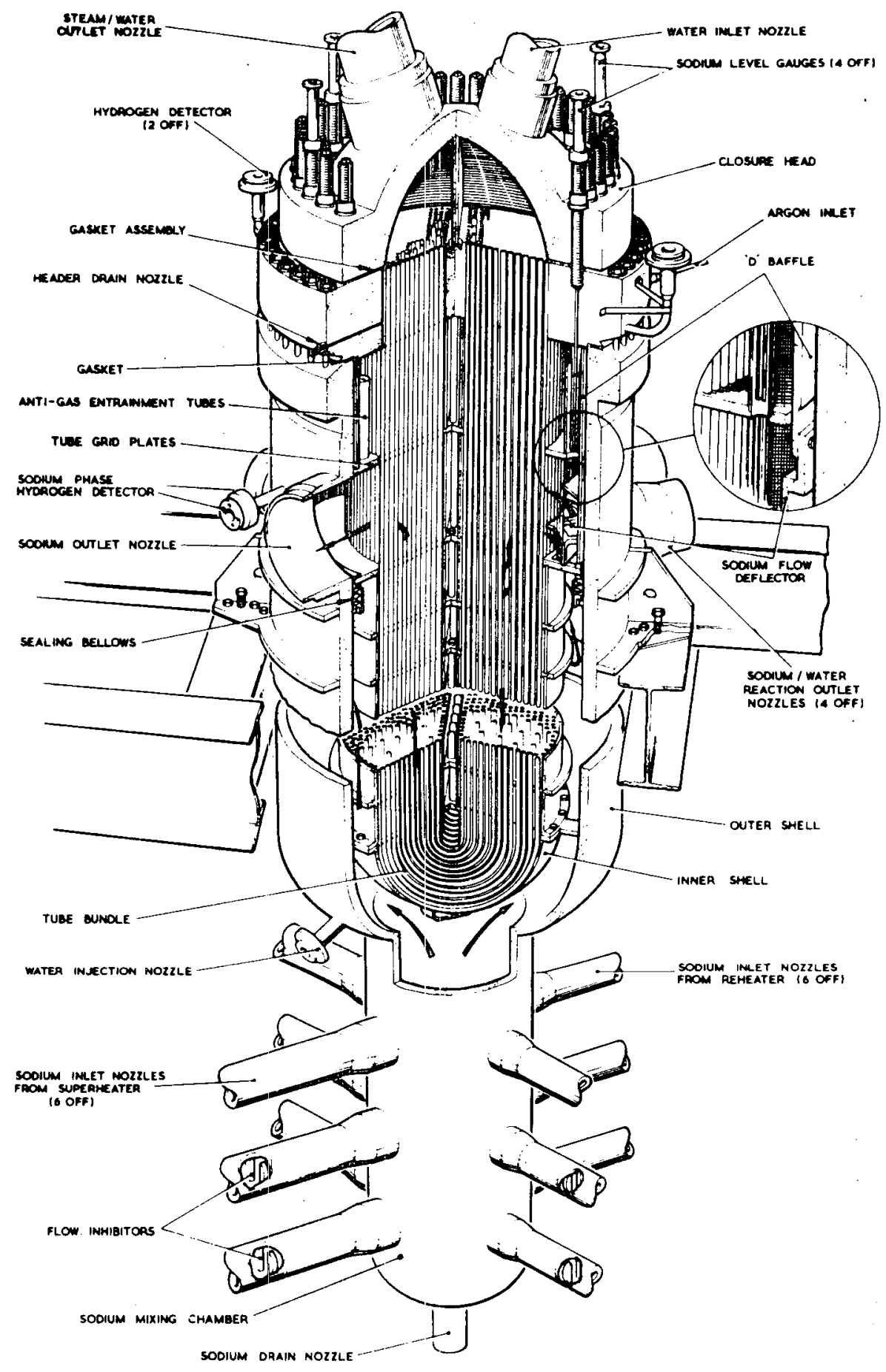

Figure XIII.H-3 PFR Evaporator (Ref. 15) 
PFR XIII.H.

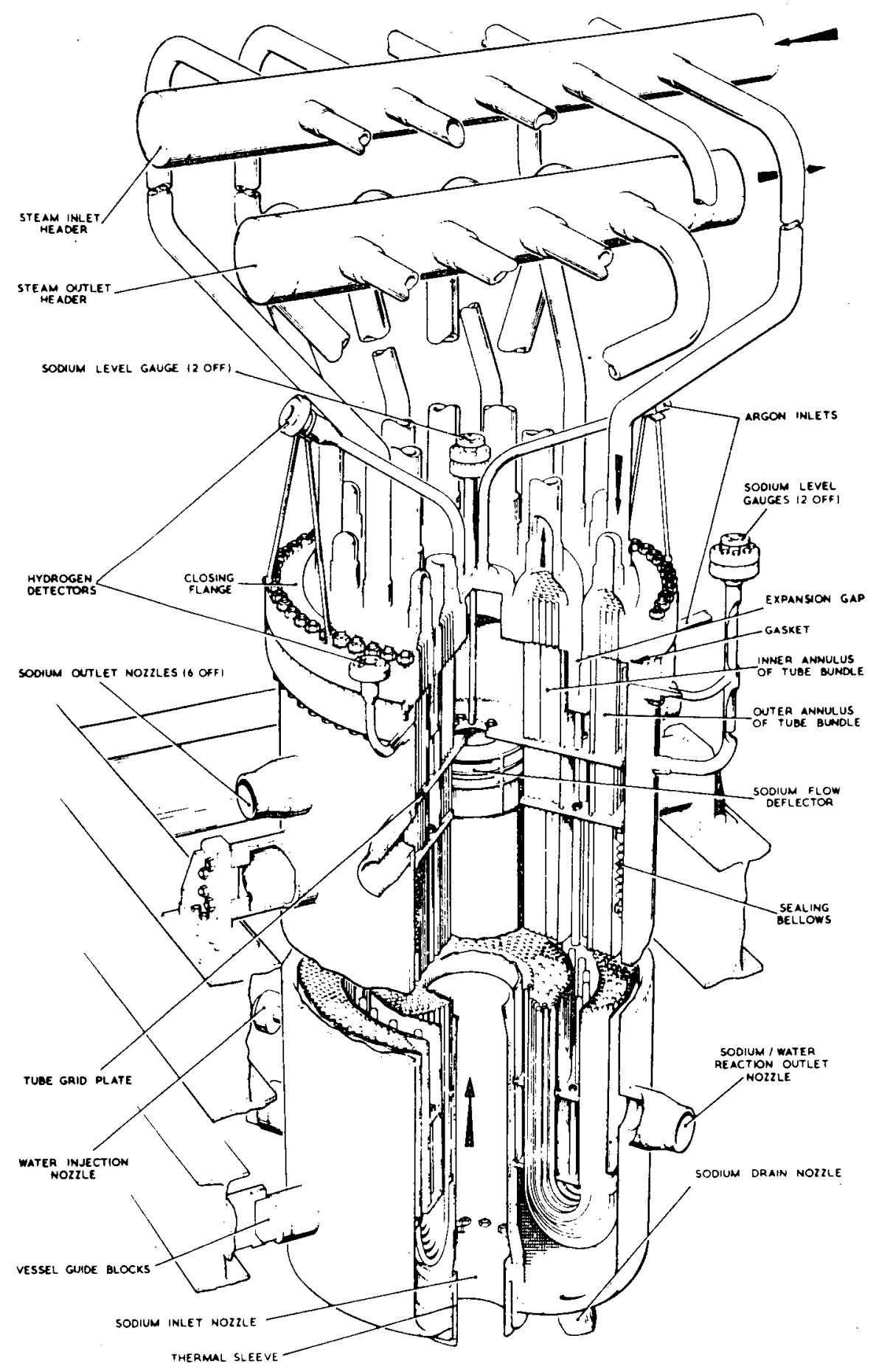

Figure XIII.H-4 PFR Superheater - Reheater (Ref. 15) 
XIII.I. REACTOR INSTRUMENTATION AND CONTROL.

The PFR has a sophisticated computerized system for data monitoring, called the Data Reduction Equipment (DRE). The acquisition, processing, display, and recording of data from plant sensors, including detection, display, and recording of alarm conditions, are with few exceptions vested in the DRE. The system also performs several monitoring and analysis functions. It provides a permanent record of plant variables, storing and sorting information which can be printed out, displayed, or played back through the computer system to isolate the record of especially significant variables. The CRT picture can be photographed with an installed polaroid camera. Normal functions are the display of plant operating data, provision of information for the main automatic control loops, programming and control of sequential operations such as fueling and startup. The data system consists of two identical, linked, digital computer subsystems, either of which can sustain plant operation if necessary. A data link enables the subsystems to update each other. Manual controls for system operation are provided on the operator's desk and by a keyboard at the printout station, but the operator's task is primarily supervisory. Automatic control is based on the use of direct digital control as much as possible.

For core and primary system monitoring standard nucleonic instrumentation is used. Chambers are enclosed in cooled thimbles inserted in the neutron shield. Each subassembly has a thermocouple. Measurements of level and flow use electromagnetic coupling principles so that transducers can operate through pipe walls, or the instruments are contained in thimbles. A boiling noise detector to detect the presence of small obstructions to coolant flow in the core is either through wave guides, or the analysis of power

fluctuations arising from the voiding effect. (Ref. 19) 
XIII.J. FUEL HANDLING

Fuel handling is done with the reactor shutdown. The single, large rotating plug carries the charge machine, orientation machine, transfer rotor, and other equipment. It rotates on a greaselubricated wire race ball bearing. Sealing is by a mercury dip seal. An anti-vibration grid below the shield, and attached to it, supports the lower end of the guide tubes in which the control rods and shut-off rods operate and which carry the abovecore thermocouples. (Fig. XIII.J-1)

The charge machine is a pantograph type. It provides a facility for the insertion or withdrawal of subassemblies while holding down adjacent ones. Controls and instrumentation are carried on the upper half of the machine. A small CRT in the machine gives the operator access to all data in the DRE. (Fig. XIII.J-2)

An orientation machine above the core operates in conjunction with the charge machine. It provides a facility for rotating the subassemblies to the correct angular position. Three sweep arms interlocked with the charge machine and the rotating shield sweep the space between the bottom of the instrument guide tubes and the top of the core, making certain that nothing is inadvertently left between the stationary and moving parts of the transfer rotor.

The transfer rotor is a magazine type device carrying twenty buckets for storing subassemblies and other components prior to their removal from the reactor, or new assemblies for loading. Irradiated subassemblies are posted into the rotor through a discharge port valve, which forms a nonhermetic seal between the hot sodium inside the reactor jacket and the cooler sodium outside of it. Storage within the reactor vessel in the transfer rotor is about thirty days.

New fuel is posted to the transfer rotor from the ex-reactor charge machine through a reactor transfer port. This port is provided with a long guide tube spanning the underside of the reactor roof and the top side of the transfer rotor, and is provided with a valve which seals the reactor atmosphere and provides shielding when the reactor is in operation.

The irradiated fuel transfer cask is a shielded and cooled flash used to transfer irradiated assemblies in sodiumfilled buckets to the cave, and to bring new assemblies to the transfer rotor. This operation can be carried out with the reactor on-load.

When the reactor is on power, the charge machine is removed and replaced by the charge hole instrument plug. This plug is inserted into the hole vacated by the charge machine. It is opened out in-situ to provide thermocouples within the slot required by the charge machine.

Decontamination and fuel handling buildings and an active work area are in a building in line with the reactor hall. The building also houses facilities for storage of spent fuel. (Ref. 1, 20) 
PFR XIII.J.
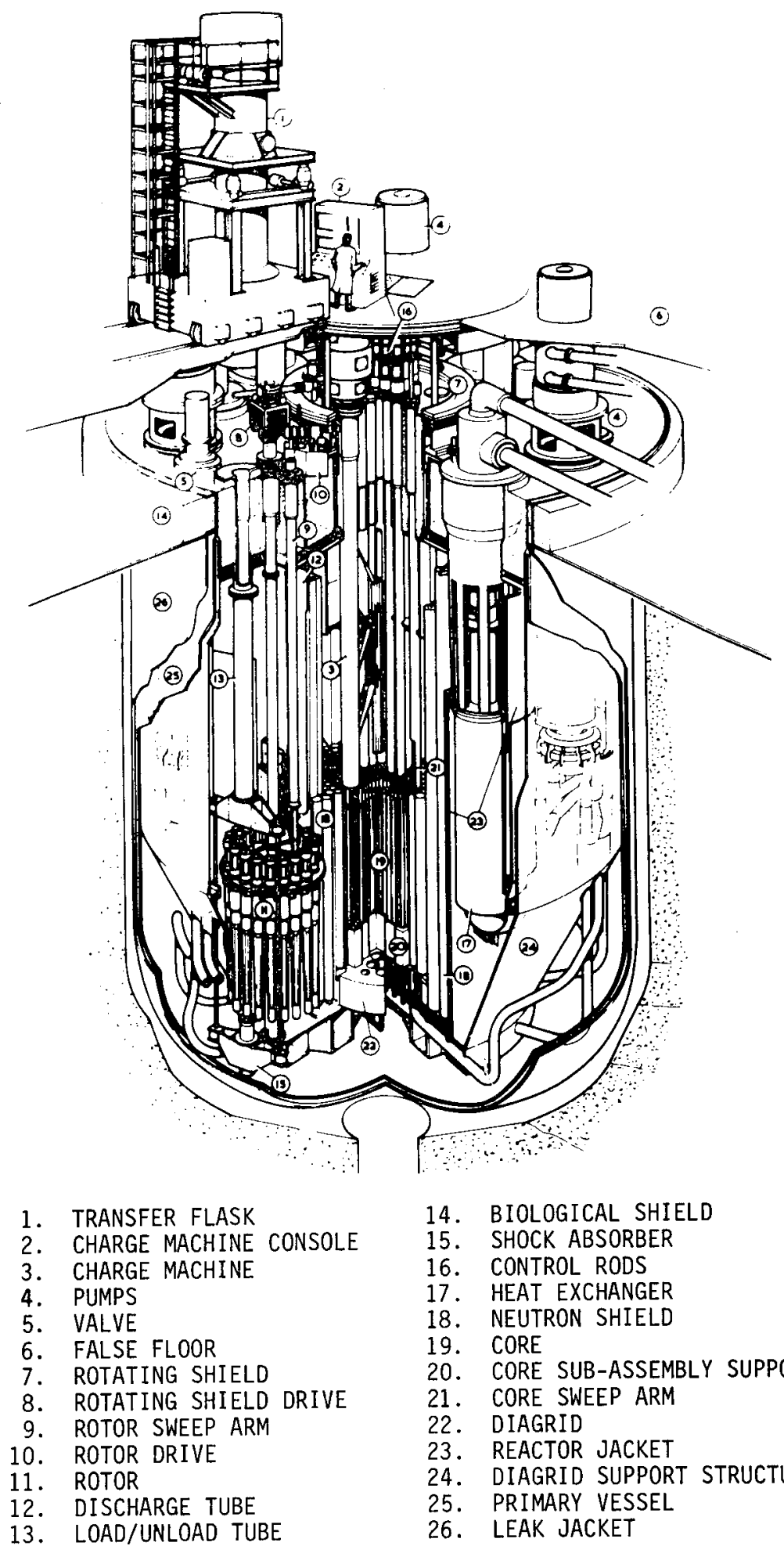

14. BIOLOGICAL SHIELD

15. SHOCK ABSORBER

16. CONTROL RODS

17. HEAT EXCHANGER

18. NEUTRON SHIELD

19. CORE

20. CORE SUB-ASSEMBLY SUPPORTS

21. CORE SWEEP ARM

22. DIAGRID

23. REACTOR JACKET

24. DIAGRID SUPPORT STRUCTURE

25. PRIMARY VESSEL

26. LEAK JACKET

Figure XIII.J-1 PFR Fuel Handling Equipment (Ref. 7) 
PFR XIII.J.

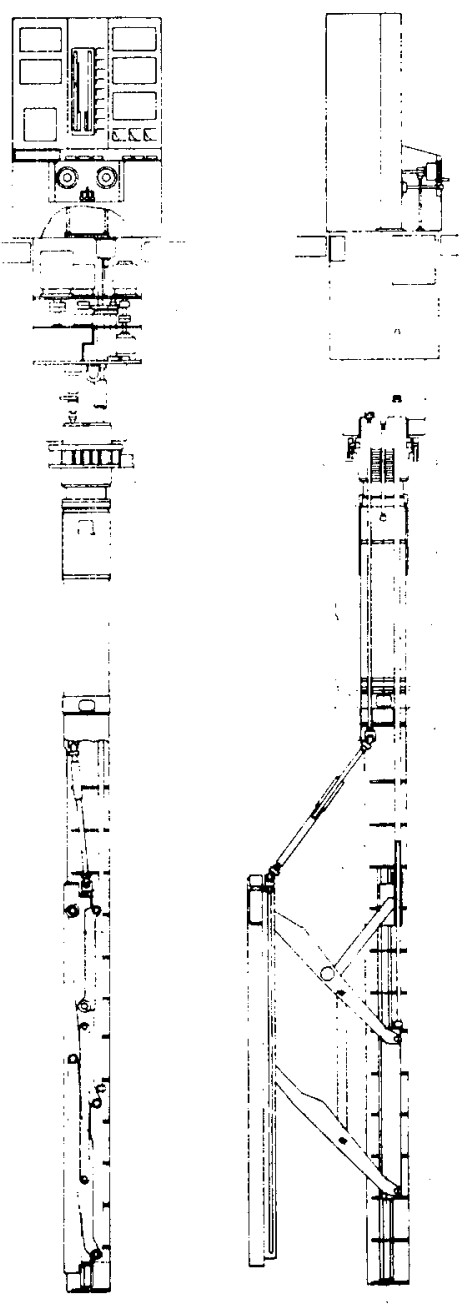

Figure XIII.J-2 PFR Change Machine (Ref. 21) 
PFR XIII.K.

\section{XIII.K. CONTAINMENT}

The reactor hall is a low-pressure containment building designed to withstand an internal pressure of $50.8 \mathrm{~m} . \mathrm{b}$. with a low leak rate. The whole of the active area is enclosed in the secondary containment building. Construction is of concrete panels bolted and sealed onto supporting steel framework. Joints are sealed with a plastic compound.

(Fig. XIII.K-l) (Ref. 21)

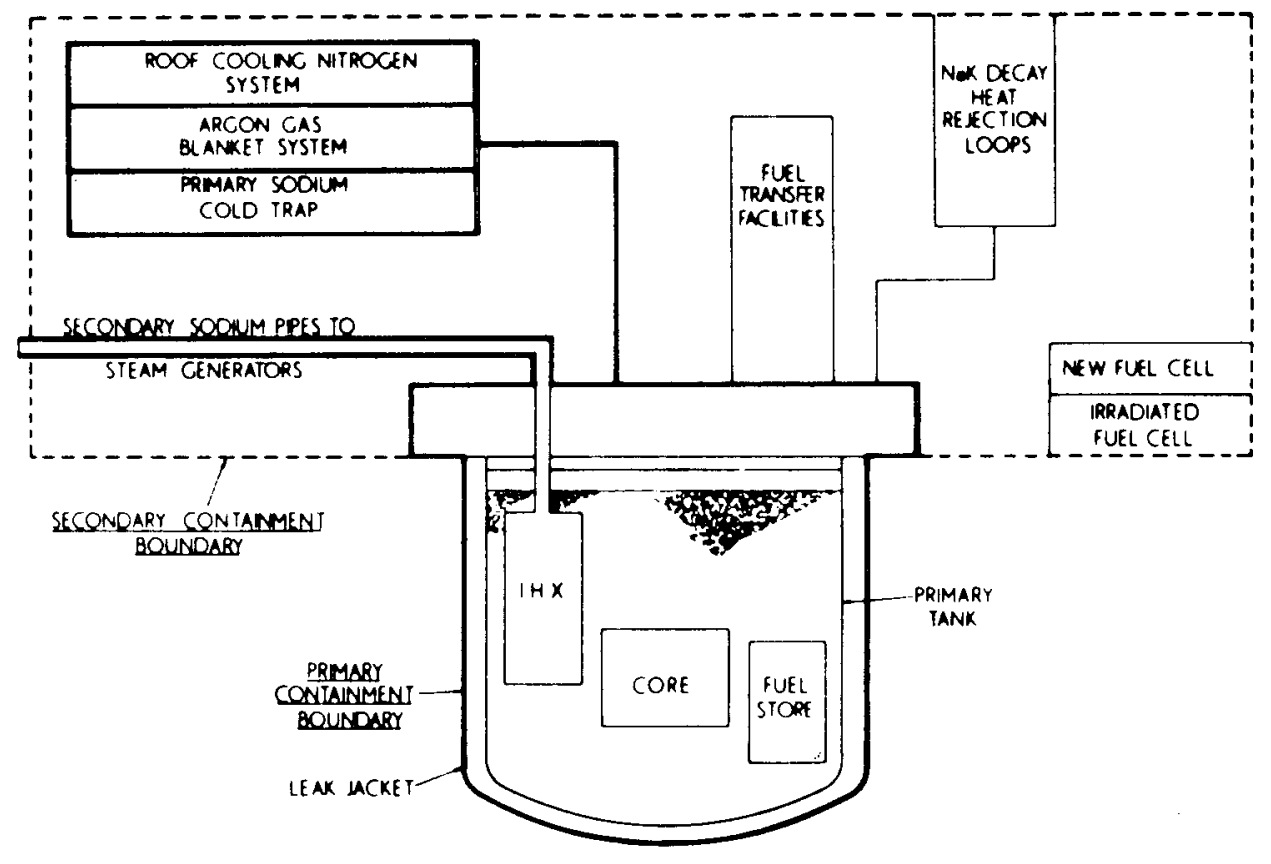

Figure XIII.K-1 PFR Containment Sys tems (Ref. 21) 


\section{FERMI}

LOCATION: Monroe, Michigan U.S.A.

OPERATION: August, 1963

The Enrico Fermi Atomic Power Plant is a power demonstration station, designed by Atomic Power Development Associates, Inc. (APDA) and operated by the Power Reactor Development Company (PRDC).

Construction was started at a site near Monroe, Michigan, in 1956. Initial criticality was achieved in August 1963. A three year test period followed. The power test program was initiated in December 1965. Maximum power level was reached in May 1967. Numerous shutdowns were caused by small leaks from water-side to sodium-side in the steam generators. Fermi was shut-down on October 5, 1966, following damage to fuel assemblies. This damage was caused by obstruction of core coolant flow from a broken piece of a zirconium sheet covering the flow guide.

After cleanup, inspection, and addition of improved instrumentation to the reactor, it was relicensed. The reactor was loaded with new fuel and reached criticality on July 18, 1970. A power of 67 MWt was achieved by September 1970 .

An oxide core was designed for Fermi, the work supported mainly by the Edison Electric Institute, Belgonucleaire, Central Research Institute of Electric Power (CRIEP) of Japan, and Detroit Edison Company.

However, a decision for permanent shutdown was reached, and Fermi is being dismantled. 


\section{INDEX}

REFERENCES

REACTOR PARAMETERS

SECTIONS
Page

XIV -5

XIV -7

XIV.A-I

XIV.B-I

XIV.C -1

XIV.D-1

XIV.E-T

XIV.F-1

XIV.G-I

XIV.H-

XIV. I-1

XIV.J-I

XIV.K-I 


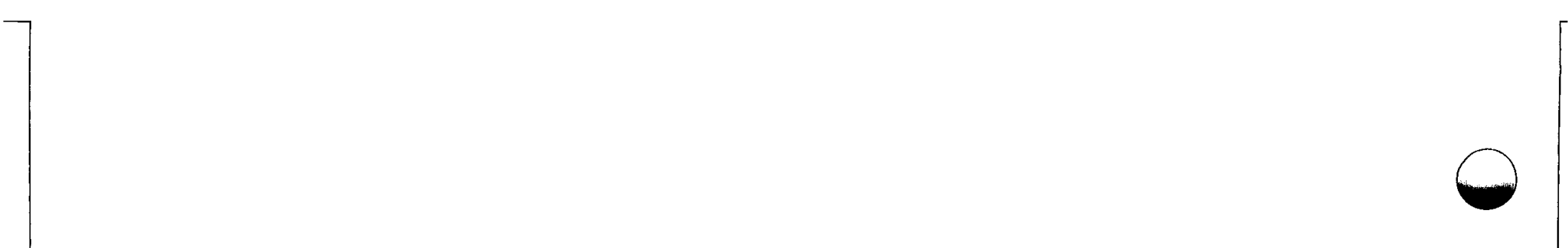

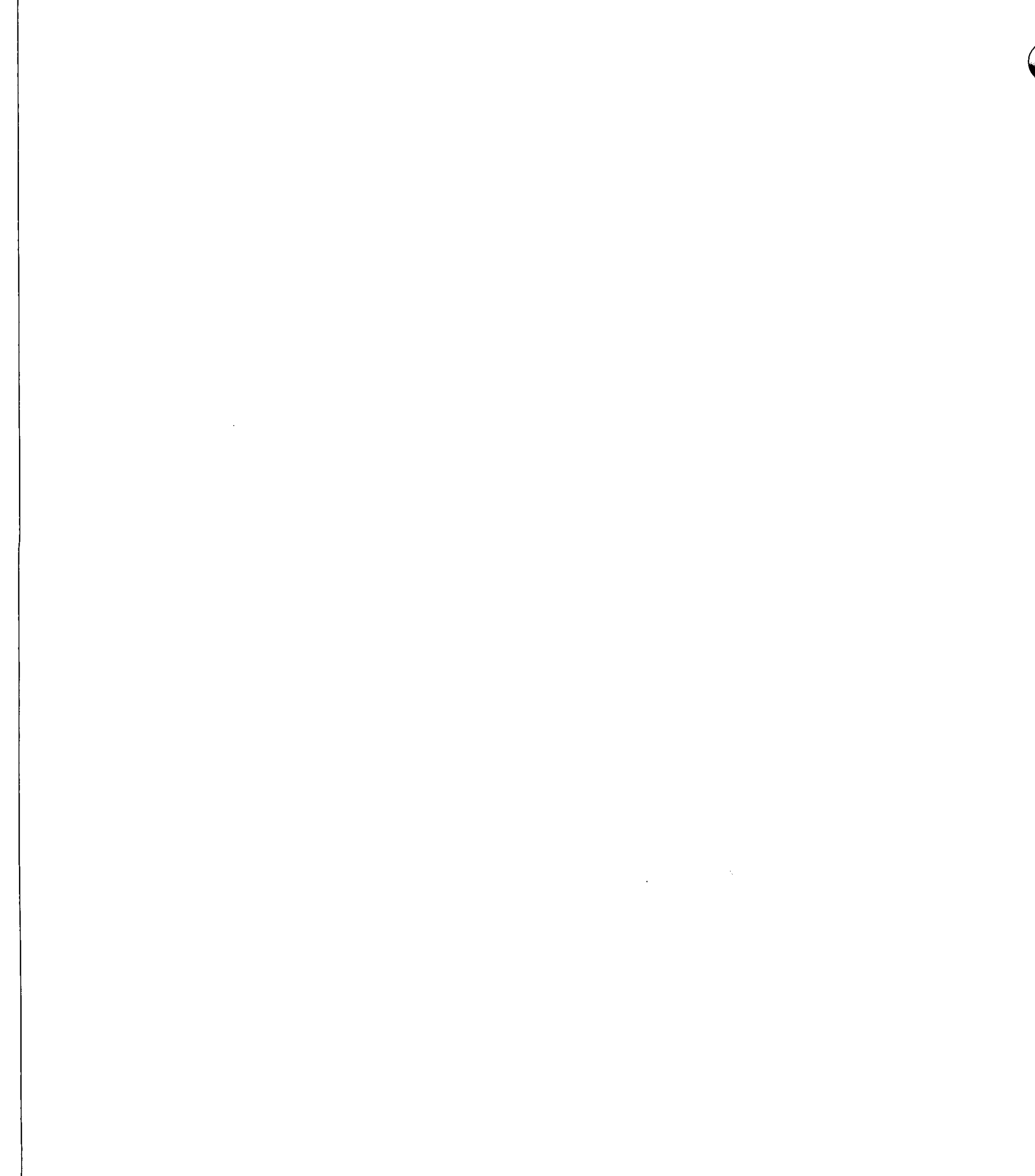
0 (

$\vartheta$

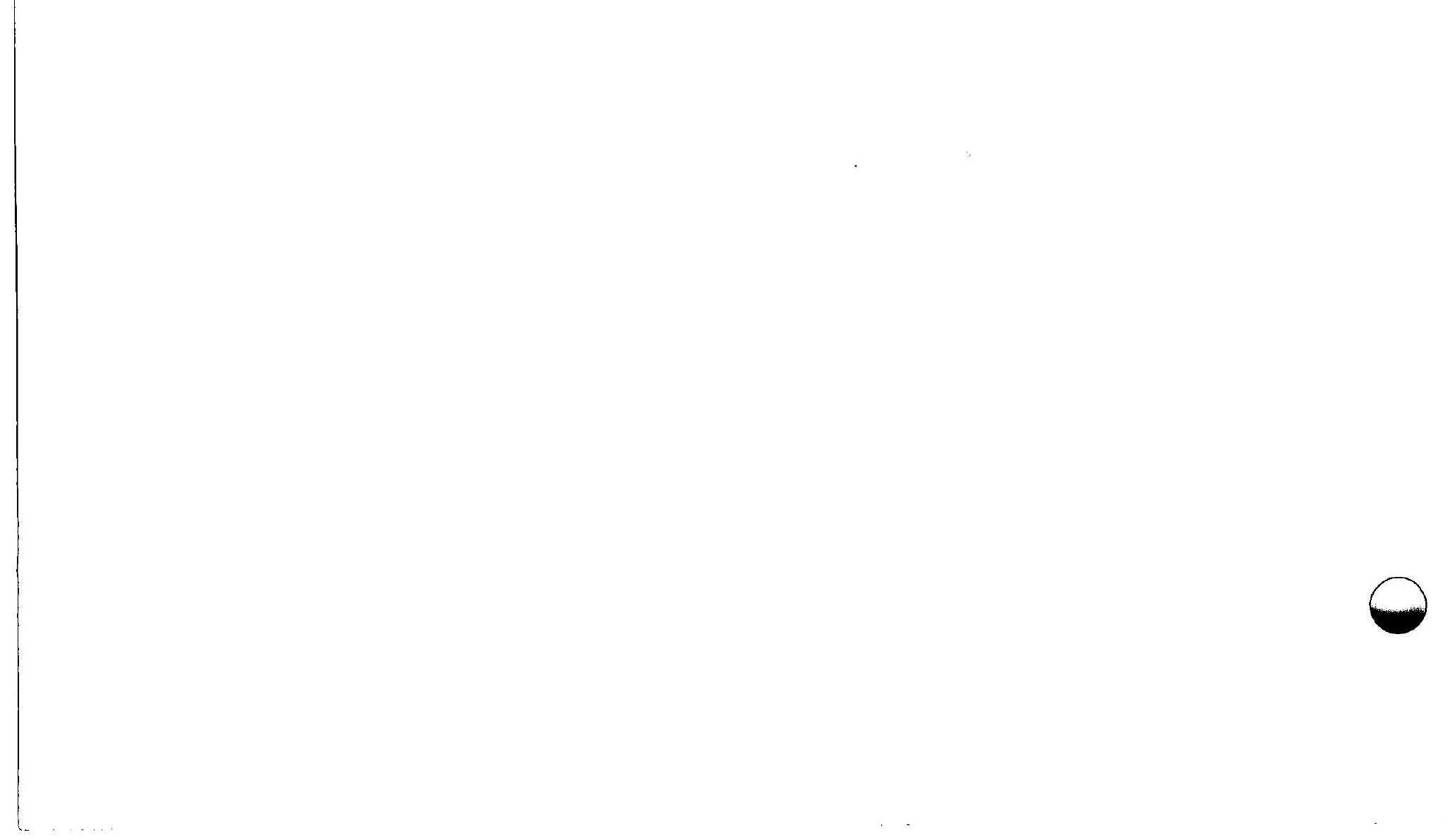


RE.FERENCES

1. Fast Reactor Technology Plant Design

J. G. Yevick, editor

MIT Press 1966

2. Enrico Fermi Atomic Power Plant

Atomic Power Development Associates, Inc.

APDA-124 (January 1959)

3. The Enrico Fermi Atomic Power Plant

R. W. Hartwell

Operating Experience with Power Reactors, Proc. Conference,

IAEA, Vienna, June 1963

Vol. 1 p. 151-185

STI/PUB/76

IAEA, 1963

4. The Enrico Fermi Atomic Power Plant

A. P. Donnell, et. al.

Second Int']. Conf.-Peaceful Uses of Atomic Energy, Geneva 1958

Vol. 8 p. 535-542

United Nations, 1958

5. Enrico Fermi Atomic Power Plant Revised License and

Application. Part B, Technical Information and Hazards

Summary Report

Power Reactor Development Co.

NP-10458 (1961)

6. Preliminary Design of a $\mathrm{PuO}_{2}-\mathrm{UO}_{2}$ Core for Demonstration

in the Fermi Reactor.

T. A. Doyle, et. al.

Plutonium as a Power Reactor Fuel, Prcc. Symposium, Brussels 1967

p. $285-299$

STI/PUB/153/IAEA, 1967 
○

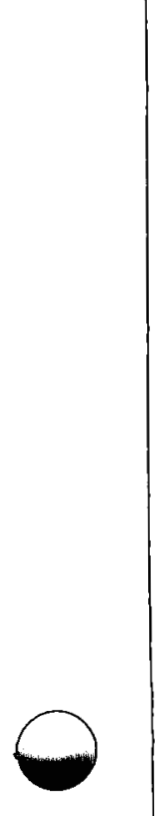


Table - 1

Reactor type

No. loops

coolant

Core inlet temperature

Core outlet temperature

Flow direction

Driver fuel

Blanket fuel

Core diameter

Core height

Core volume

No. enrichment zones

Output

Neutron 1 ifetime

Delayed neutron fraction

Max. can temperature

Fuel centerline temperature

Neutron flux, ave

Doppler $(\Delta K / K)^{\circ} \mathrm{C}$

Specific power

Power density

No. driver elements

No. radial blanket elements

No. in-core control elements

Goal burnup
GENERAL PARAMETERS

Pool-type. Demonstration

3

Sodium

$552^{\circ} \mathrm{F}$

$910^{\circ} \mathrm{F}$

Upward

Enriched U-Mo alloy

Depleted U-Mo alloy

30.5 in

30.5 in

$11.65 \mathrm{ft}^{3}$

1

65 MWe, 300 MWt

$2 \times 10^{-7}$

0.0069

$940^{\circ} \mathrm{F}$

$1134^{\circ} \mathrm{F}$

$0.5 \times 10^{16} \mathrm{n} / \mathrm{cm}^{2} \mathrm{sec}$.

$-1.6 \times 10^{-6}$ (total)

$605 \mathrm{kw} / \mathrm{kg}^{235 \mathrm{U}}$

$23,000 \mathrm{kw} / \mathrm{ft}^{3}$

91

548

10

$21.0 \%$ 
FERMI XIV

Table - 2

CORE AND BLANKET

\begin{tabular}{|c|c|c|c|}
\hline & Driver zone & Axial blanket & Radial blanket \\
\hline Fuel material & Uranium alloy & Uranium alloy & Uranium alloy \\
\hline Form & Round pin & Round rod & Round rod \\
\hline Composition & $\mathrm{U}-10 \mathrm{Mo}$ & $\mathrm{U}-2.75 \mathrm{Mo}$ & $\mathrm{U}-2.75 \mathrm{Mo}$ \\
\hline $235_{U}$ & $25.6 \%$ & $0.35 \%$ & $0.35 \%$ \\
\hline Pin od & $0.148 \mathrm{in}$. & $0.415 \mathrm{in}$. & $0.415 \mathrm{in}$. \\
\hline Rod cladding & Zirconium & Stainless steel & Stainless steel \\
\hline od & $0.158 \mathrm{in}$. & $0.443 \mathrm{in.}$ & 0.443 in. \\
\hline Wa11 thickness & 0.005 in. & $0.010 \mathrm{in.}$ & $0.010 \mathrm{in.}$ \\
\hline Fuel-clad gap & & Bond $0.004 \mathrm{in.}$ & Bond 0.004 in. \\
\hline Bond material & Metallurgical bond & Sodium & Sodium \\
\hline Active length & 30.5 in. & 14 in. $\times 2$ & 65 in. \\
\hline Gas plenum length & & (top) & \\
\hline Pin length & $32-1 / 16$ in. & $18 \mathrm{in.}$ & $71.5 \mathrm{in.}$ \\
\hline Vented/non-vented & No & No & No \\
\hline Assembly material & Stainless steel & Stainless steel & Stainless steel \\
\hline Shape & Square & Square & Square \\
\hline Side & $2.646 \mathrm{in.}$ & $2.646 \mathrm{in.}$ & 2.646 in. \\
\hline Wall thickness & $0.096 \mathrm{in.}$ & 0.096 in. & $0.096 \mathrm{in}$. \\
\hline Overall length & $96-9 / 16$ in. & $96-9 / 16$ in. & 96-9/16 in. \\
\hline No. pins/assembly & 144 & 16 & 25 \\
\hline Pin spacing & Grid-egg crate & Grid-lattice & Wire and grid \\
\hline Pin pitch & $0.200 \mathrm{in}$. & & 0.483 in. \\
\hline Assy. pitch & 2.693 in. (square) & & $2.693 \mathrm{in.}$ (square) \\
\hline Assy. in core & 91 & 182 & 548 \\
\hline \multicolumn{4}{|l|}{ Volume fraction (Vol.\%) } \\
\hline \multirow[t]{2}{*}{ Fue I } & $235 U$ & 28.3 & 44.6 \\
\hline & $235 \mathrm{U} \quad 20.8$ & & \\
\hline Steel & 24.9 & 18.2 & 20.7 \\
\hline Sodium & 47.2 & 53.5 & 37.4 \\
\hline
\end{tabular}

XIV -8 


\section{XIV.A. CORE AND BLANKET}

In the fuel region of the assembly, 144 rods of $25.6 \%$ enriched $U-10$ Mo alloy are loaded into a square cartridge, maintained on a square pitch of $0.200 \mathrm{in}$. by a wire and plate arrangement. Fuel pin fabrication is by the coextrusion of the uranium alloy slug in zirconium tubing. The ends are pointed, and zirconium caps are locked on the pin by cold swaging. The upper and lower blanket sections, each containing sixteen depleted U-2.75 Mo pins in stainless steel tubes, are mechanically incorporated into the core subassembly cartridge. Lugged grids hold the top and bottom sections of the pins within the cartridge. Thermal bonding for the axial blnaket pins is sodium. There is a gas space above the rod. The central positions within the cartridge contain no rods. (Fig. XIV.A-1)
Radial blanket rods are the same as axial blanket rods except for their length, which is 71.5 , and the spacing which is by spiral wire and lugged grids. The inner radial assemblies have a thermal expansion spring like that of the core assemblies in the support structure. Outer radial assemblies have a simple support structure. The lattice consists of twenty-five blanket rods of depleted U-2.75 Mo in stainless steel cladding. Bonding is by sodium. (Fig. XIV.A-2) (Ref. 2)

Preliminary design of the mixed oxide core was initiated in 1965. A single-zone core divided into two regions was selected for the reference design. The inner zone would contain $\mathrm{PuO}_{2}$-depleted $\mathrm{UO}_{2}$ and the outer zone enriched $\mathrm{UO}_{2}$. The inner region would represent about $85 \%$ of the initial core volume. (Ref. 2.)

Summary of firal core design data

Core size

Fuel enrichment

Breeding ratio

Neutron flux

Fuel pin

Max. burnup
48 in. height

37 in. diameter

844 1. volume

Center pins $31.7 \mathrm{w} / \mathrm{O} \mathrm{Pu} / \mathrm{Pu}+$ depleted $\mathrm{U}$ 305 clay pins $28.2 \mathrm{w} / 0{ }^{235} \mathrm{U} / \mathrm{U}$ 1.08 total $8 \times 10^{15} \mathrm{n} / \mathrm{cm}^{2} \mathrm{sec}$. total central

$\begin{array}{ll}\text { Clad od } & 0.25 \mathrm{in} . \\ \text { Clad thickness } & 0.076 \mathrm{in} . \\ \text { Clad material } & 316 \text { or } 347 \mathrm{SS} \\ \text { Overall length } & 70 \mathrm{in} . \\ \text { Gas plenum } & 2 \times 9 \\ \begin{array}{l}\text { Smeared fuel } \\ \text { derisity }\end{array} & 83.5 \% \mathrm{TD}\end{array}$

90,0C10 MWD/MT

(Ref. 6) 
FERMI XIV.A

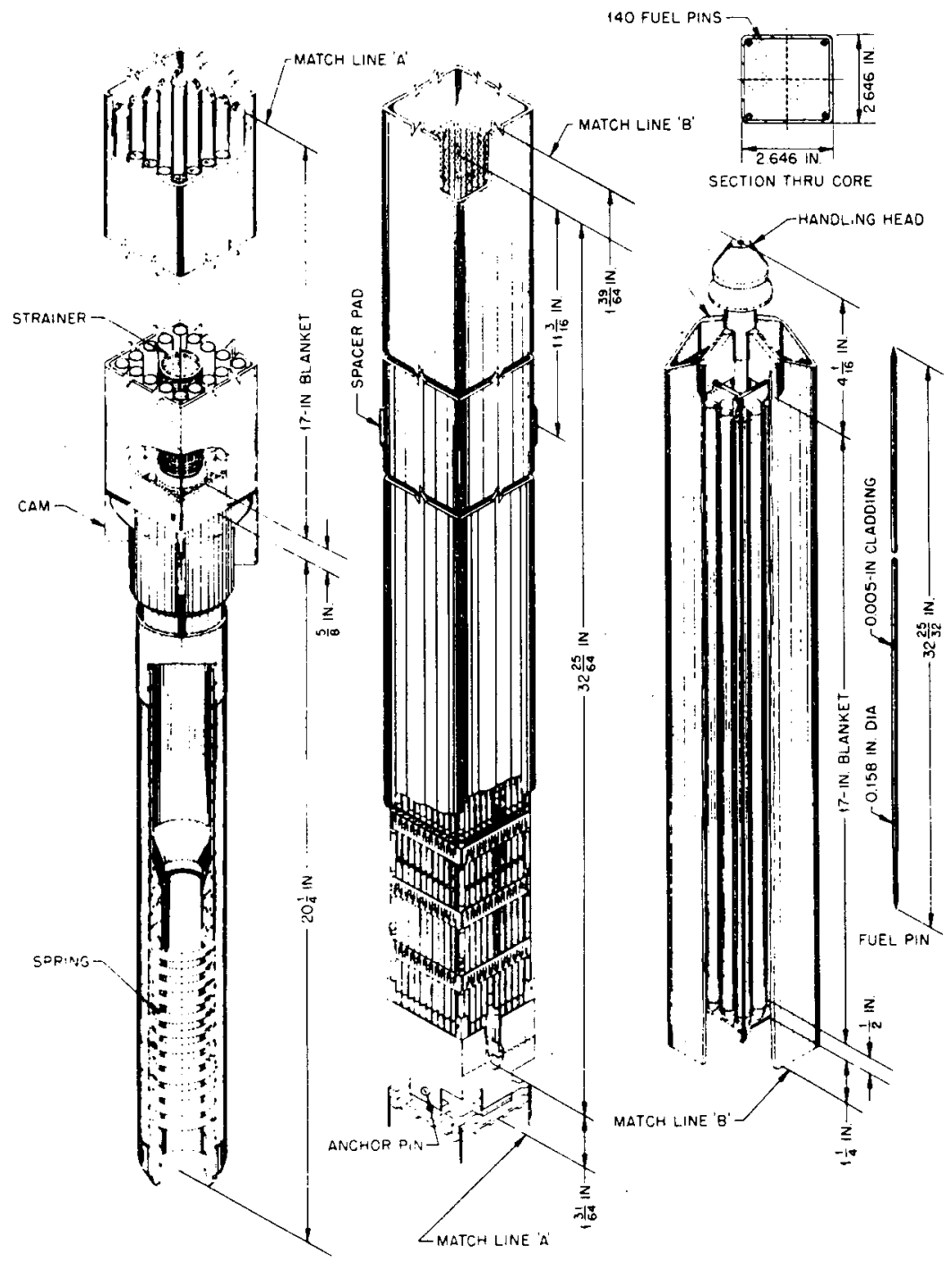

Figure XIV.A-1 Fermi Core Assembly (Ref. 2) 


$$
\therefore
$$

XIV.B. CORE SUPPORT AND VESSEL INTERNALS

Core and radial blanket assemblies are supported by two plates. These are 2 in. thick and spaced $14 \mathrm{in}$. apart by ribs welded to them. There are openings to take the subassembly nozzles, which are $18 \mathrm{in}$. in length. The center section which supports the core assemblies is removable. The support plates rest on a ledge ring and seal rai]. (Fig. B X[V.B-I)

The upper section of the vessel contains a hold-down device or plate. Hold-down of the assemblies is accomplished by engaging the handling lug of the assembly with a finger attached to the hold down plate, compressing a spring in the assembly nozzle to hold it firmly against the finger and provide for thermal expansion. Alignment of the device is maintained by a three arm spider. When the plate is lowered into position, sockets attached to the lower ends of the arms are positioned by the subassembly support plates and at the top of brackets attached to the lower vessel inner shield assembly. (Fig. XIV.B-2)

A thermal shield section of subassemblies containing stainless stee] rods surrounds the radial blanket.

(Ref. 2) 


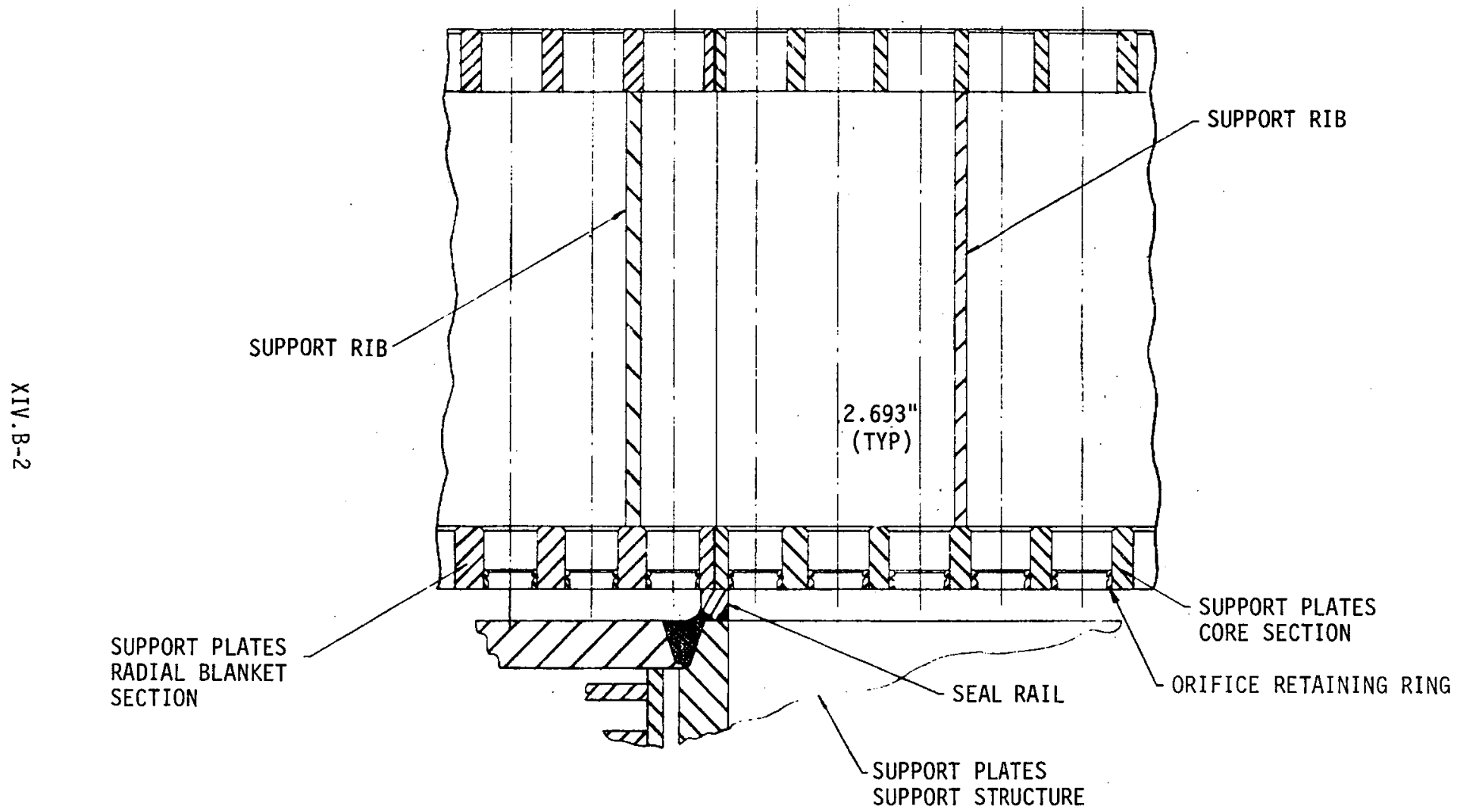

Figure XIV.B-1 Fermi Section through Support Plates (Ref. 2) 
FERMI XIV.B

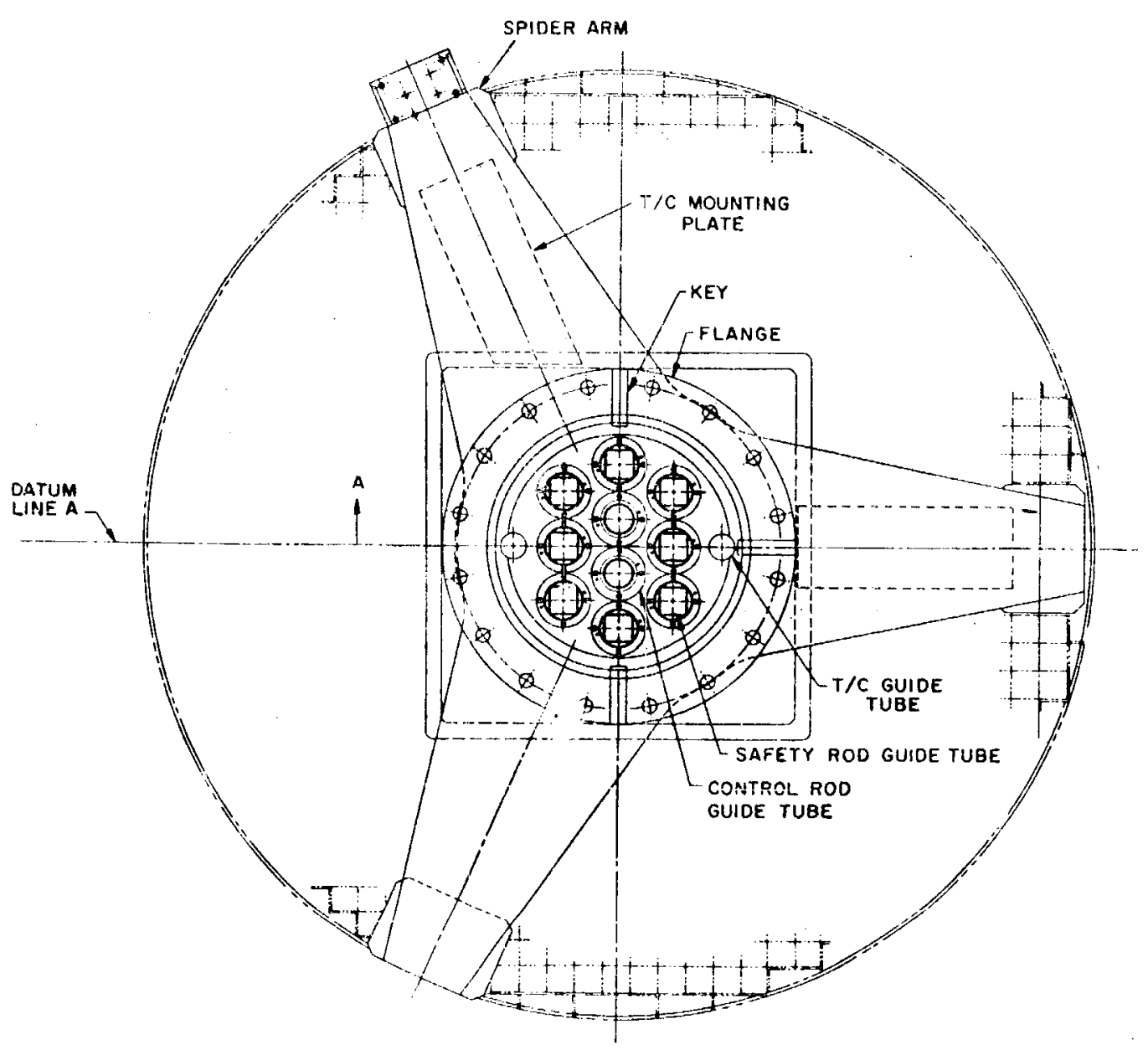

Figure XIV.B-2a Fermi Hold-Down Device - Plan Section (Ref. 2)

XIV.B-3 
FERMI XIV.B

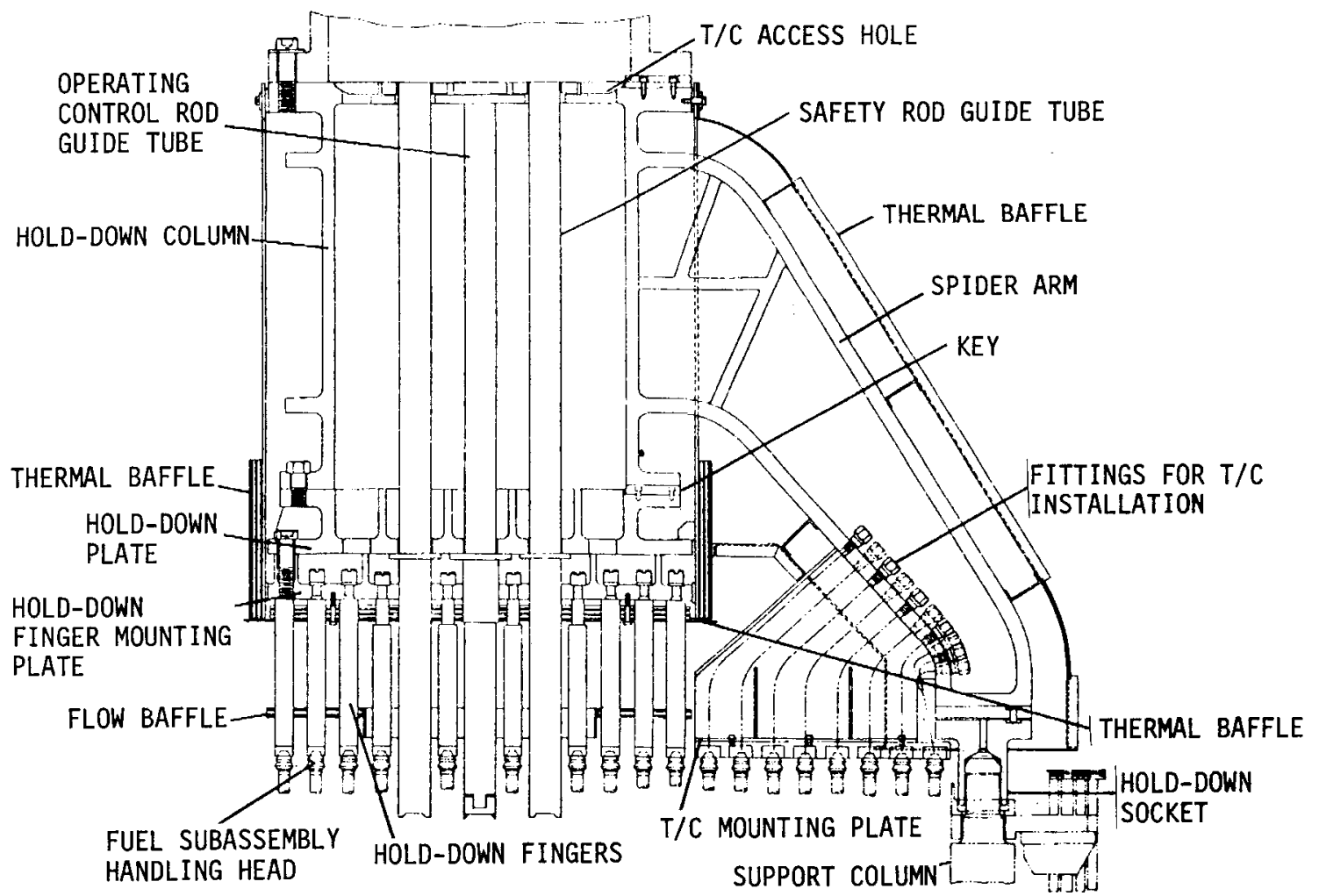

Figure XIV.B-2b Fermi Hold-Down Device - Elevation (Ref. 2)

XIV.B-4 
FERMI XIV.C

XIV.C. REACTOR VESSEL AND SHIELDING

The Fermi reactor vessel is an irregularly staged cylinder. The upper vessel houses the core hold-down device and the offset fuel handling mechanism. The lower vessel, $9.5 \mathrm{ft}$. dia., contains the core, blanket, and thermal shield assemblies and the core support structure. Inlet piping for radial blanket and core coolant are at the lower part, feeding to the core inlet plenum and the radial blanket inlet plenum. A melt-down section is located in the core-flow section inlet plenum. (Fig. XIV.C-1)

The melt-down section consists of a flat $1 / 8$ in. thick zirconium liner bolted to the top of a $1 / 2$ in. chick baffle plate, which is part of the shielding and baffling for the lower head of the vessel. Material from a melt-down would collect as a flat, circular, subcritical slab about $7 \mathrm{ft}$. dianeter. Three vertical baffles and a conical flow guide direct the coolant flow and serve to disperse molten fuel as it enters the plenum. A secondary melt-down section is located immediately below the bottom head of the vessel. This consists of 6 in. cubes of $5 \%$ borated graphite bonded together with boron-containing cement, to form a crucible capable of containing molten uranium. (Fig. XIV.C-2)

The rotating shield plug is located at the top of the reactor vessel. The hold-down device and the offset handling mechanism are mounted eccentrically on it. The plug serves as an integral part of the biological shielding and as part of the fuel handling equipment. It consists of a 1-1/32 in. thick stainless steel shell containing layers of shielding material and insulation composed of stainless steel, borated graphite, and carbon steel. The 12 in. thick cover plate carries the hold-down and offset handling equipment. The weight of the plug is transmitted to the reactor vessel plug container flange through a loadcarrying ring and ball-bearing assembly. Sealing is by a liquid NaK dip seal, with a mechanical seal as backup. 0-ring gaskets seal all bolted covers and flanges. (Fig. XIV.C-3)

Primary shielding is provided by the two rows of stainless steel elements surrounding the b]anket, and several layers of cylindrical plate sections mounted eccentrically with the reactor vessel. Including the vessel wall, the thickness of this part of the shield is 7.5 in. Sodium coolant flows between the inner layers. Outside the vessel, a graphite shield consisting of six inches of borated graphite is placed next to the reactor vessel. This is followed by an insulating layer. The upper and lower vessel shielding systems are similar. A primary shield tank encloses the reactor vessel and shielding. Its primary function is to act as a standpipe for secondary containment of molten sodium in the event of a leak. The dense lattice of the neutron shielding around the reactor vesse] leaves a small enough void space in the primary tank so that the sodium coolant level will not drop below the centerline of the $30 \mathrm{in}$. outlet pipe. Void spaces are filled with a low pressure inert gas. The bottom of the tank is a flat reinforced base for the reactor vessel supports. (Fig. XIV.C-4) (Ref. 1,2) 
FERMI XIV.C

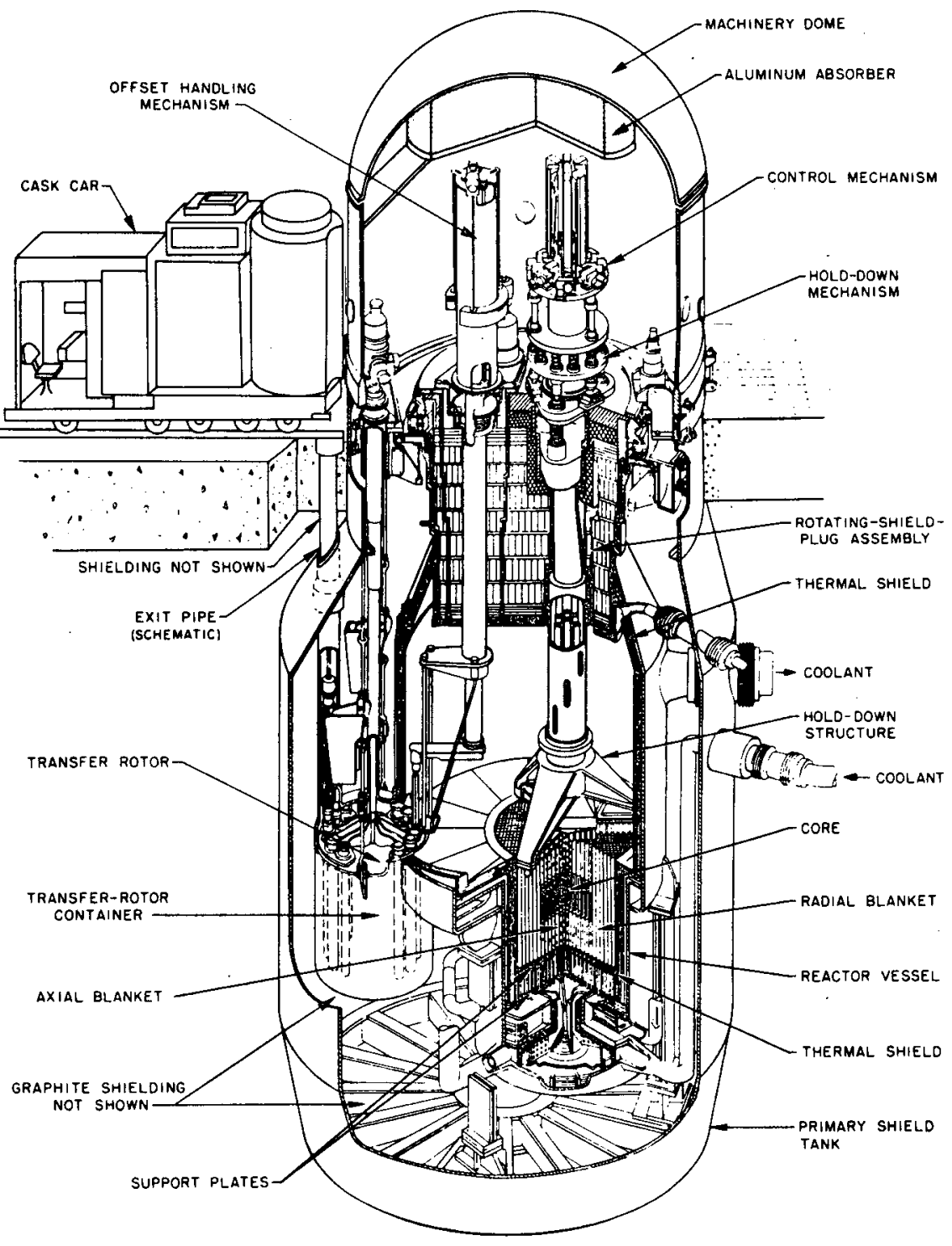

Figure XIV.C-1 Fermi Reactor Vessels (Ref. 3) 


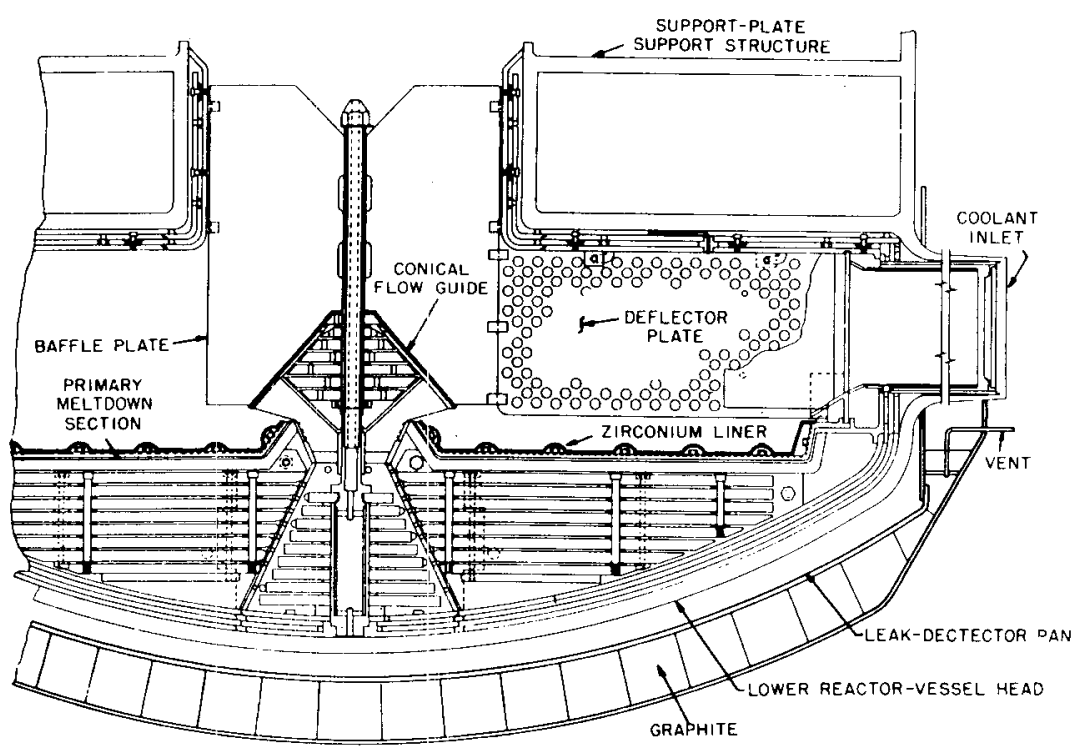

Figure XIV.C-2 Fermi Melt-Down Section (Ref. 2)

XIV.C -3 


\section{FERMI XIV.C}

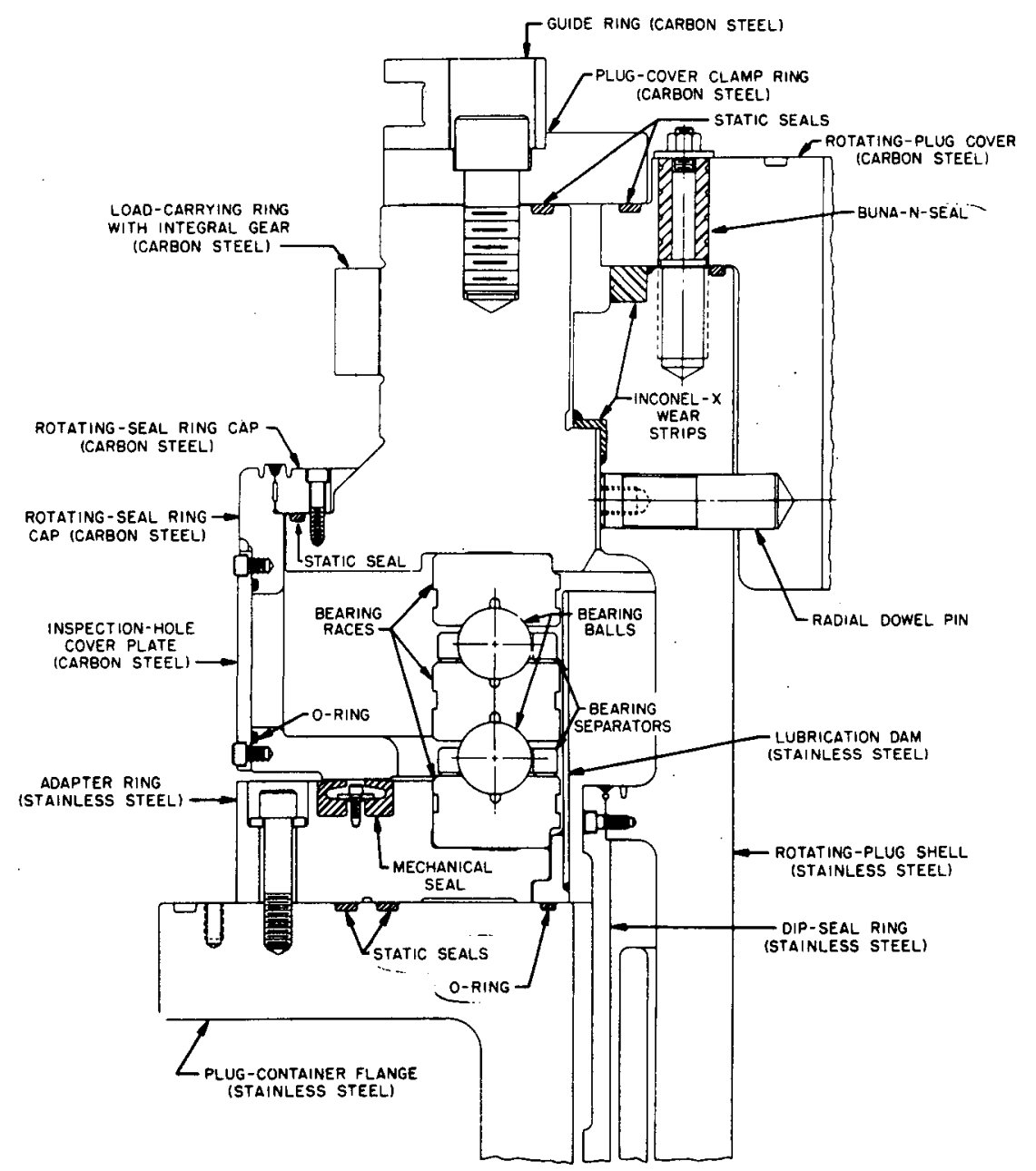

Figure XIV.C-3 Fermi Reactor Plug Support (Ref. 2) 
FERMI XIY.C

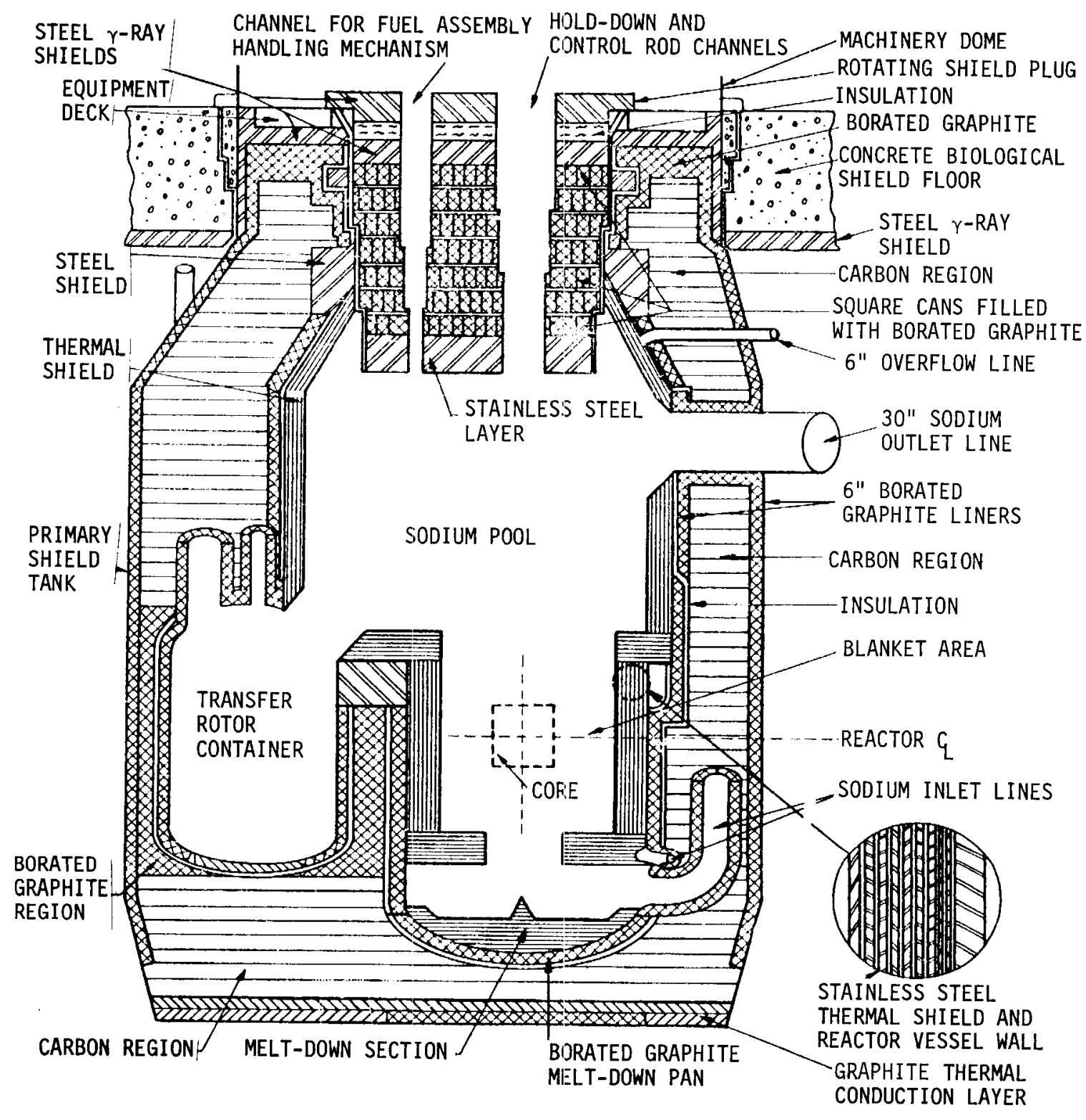

Figure XIV.C-4 Fermi Reactor Shielding (Ref. 2) 


\section{XIV.D. CONTROL ELEMENTS}

Eight safety rods and two operating control rods control the Fermi reactor. Poison material is 10B-enriched boron carbide. The rods are spaced uniformly in the core, with the two operating control rods on opposite sides of the vertical center. Each safety and control rod is housed in a cylindrical guide tube, which in turn is mounted inside a square tube. The upper part of the guide tube is permanent]y attached to the hold-down mechanism and moves with it. The lower part is seated in the support plates and can be removed and replaced. (Fig. XIV.D-7)

The safety rod is made up of four sections, consisting of the dash ram, the poison section, the extension rod, and the handling head. The poison section is 236 in. long and is a 2-1/4 in. od stainless steel tube containing six hermetically sealed stainless steel tubes $5 / 8$ in. dia. Hollow cylinders of boron carbide fill the six tubes. Sodium is admitted to the poison section tube from the guide tube by $3 / 8 \mathrm{in}$. dia. holes at the lower end of the rod. Safety-rod stroke is $254 \mathrm{in.}$, with a maximum velocity during scram of $6.5 \mathrm{ft} / \mathrm{sec}$. (Fig. XIV.D-2)

The two operating control rods are identical. Each rod has three sections; the poison section, the extension rod, and the pickup head. The poison section consists of nineteen sealed stainless tubes about $30 \mathrm{in}$. long, located on a triangular pitch within a $2-1 / 4$ in. od tube. The boron carbide is located in the lower ten inches of the containment tubes. The poison cylinders are solid. Coolant holes permit sodium circulation around the poison tubes. Total stroke is v20 in.

Safety-rod drive mechanisms are electromechanical devices consisting of a power unit and a drive extension, mounted above the rotating shield plug on the top plate of the hold-down mechanism vertical drive assembly. The rods are raised or lowered through a ball screw and nut. The drive extension penetrates the rotating shield plug through a seal thimble bolted to the shield plug cover. The reciprocating stroke is sealed by a bellows connecting the seal thimble to the drive extension. Loss of current to a latch magnet at the upper end of the drive extension scrams the reactor. Total time to insert the more than eight dollars of negative reactivity in the eight safety rods is approximately 0.9 seconds from scramsignal initiation. Rods can be scrammed from any point in their stroke.

(Fig. XIV.D-3)

Operating control rod mechanisms are similar in design, except in the use of a variable-speed drive for the regulating rod, and a special safety-latch arrangement to ensure non-release of the control rods except by operator initiation, and then only when the rods are seated in their guide tubes or are within one inch of being seated. (Fig. XIV.D-4) (Ref.1,2) 
FERMI XIV.D

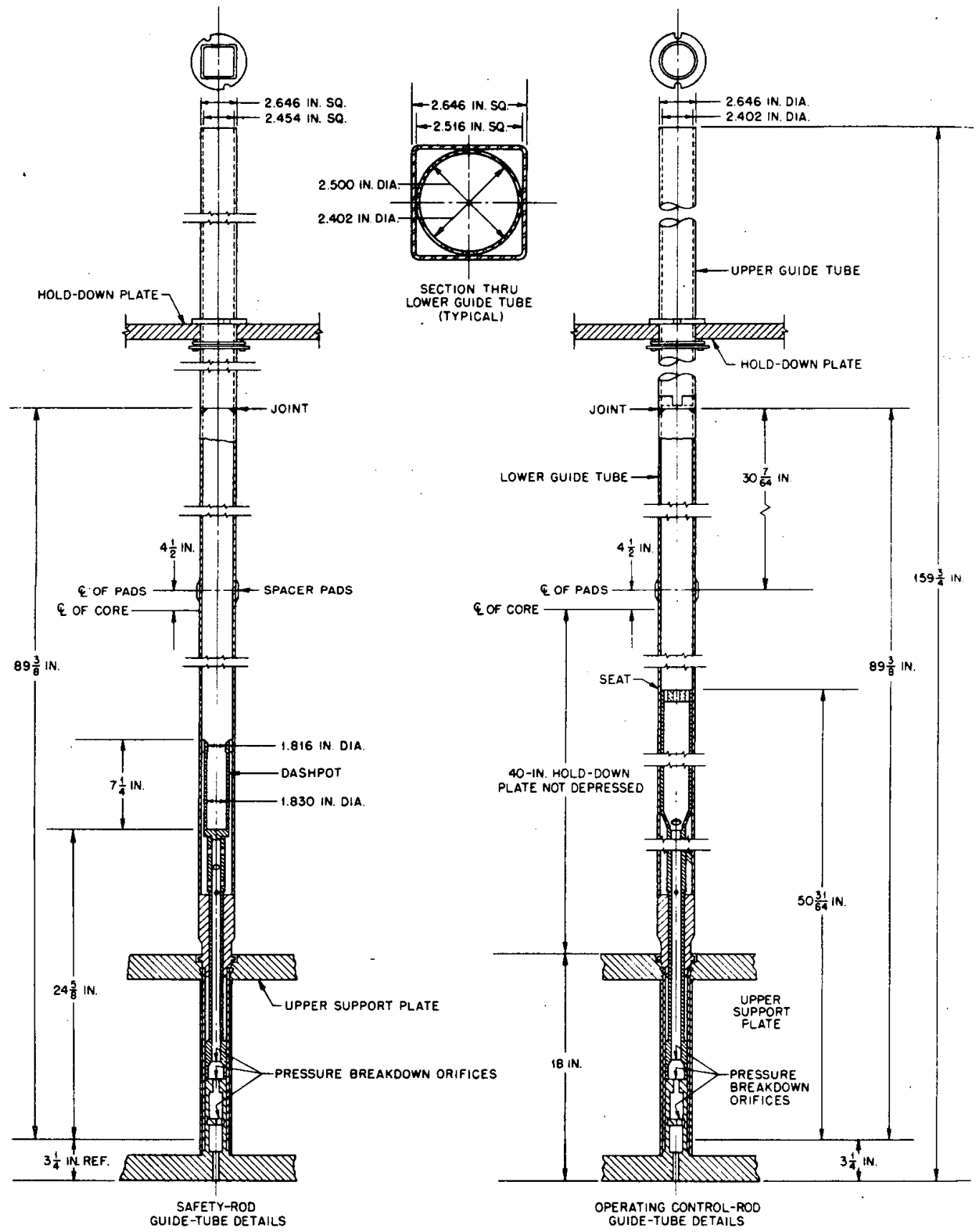

Figure XIV.D-1 Fermi Safety and Control Rod Guide Tube (Ref. 5) 
FERMI XIV.D

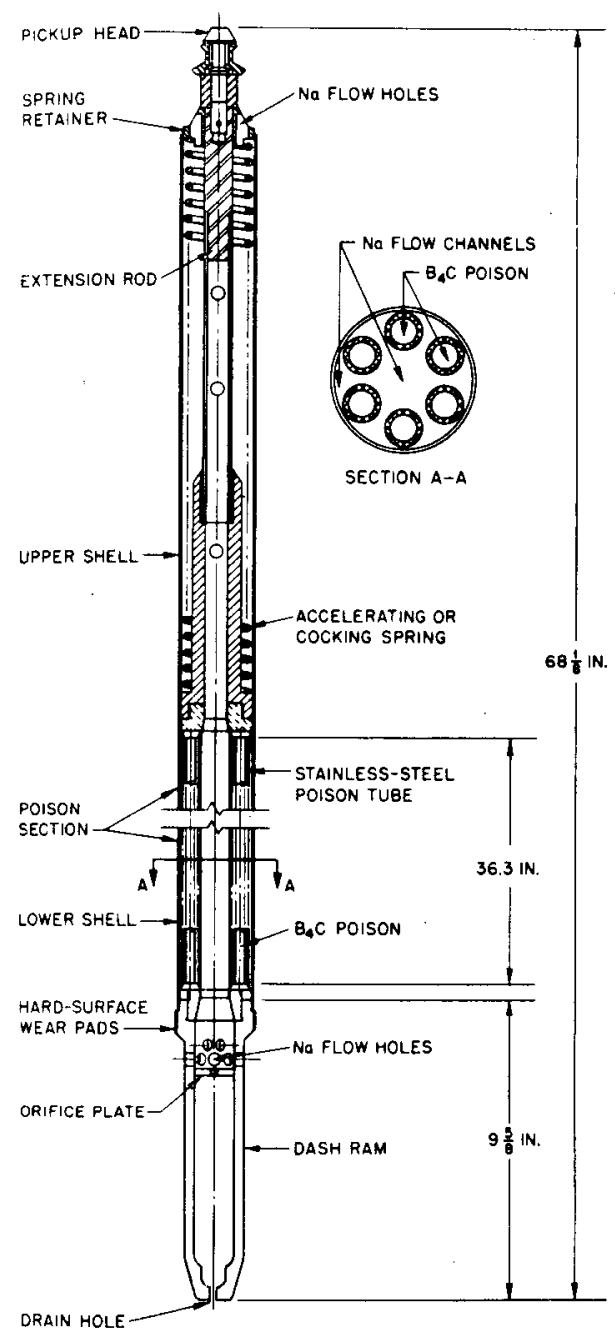

Figure XIV.D-2 Fermi Safety Rod Assembly (Ref. 5)

XIV.D-3 
FERMI XIV.D

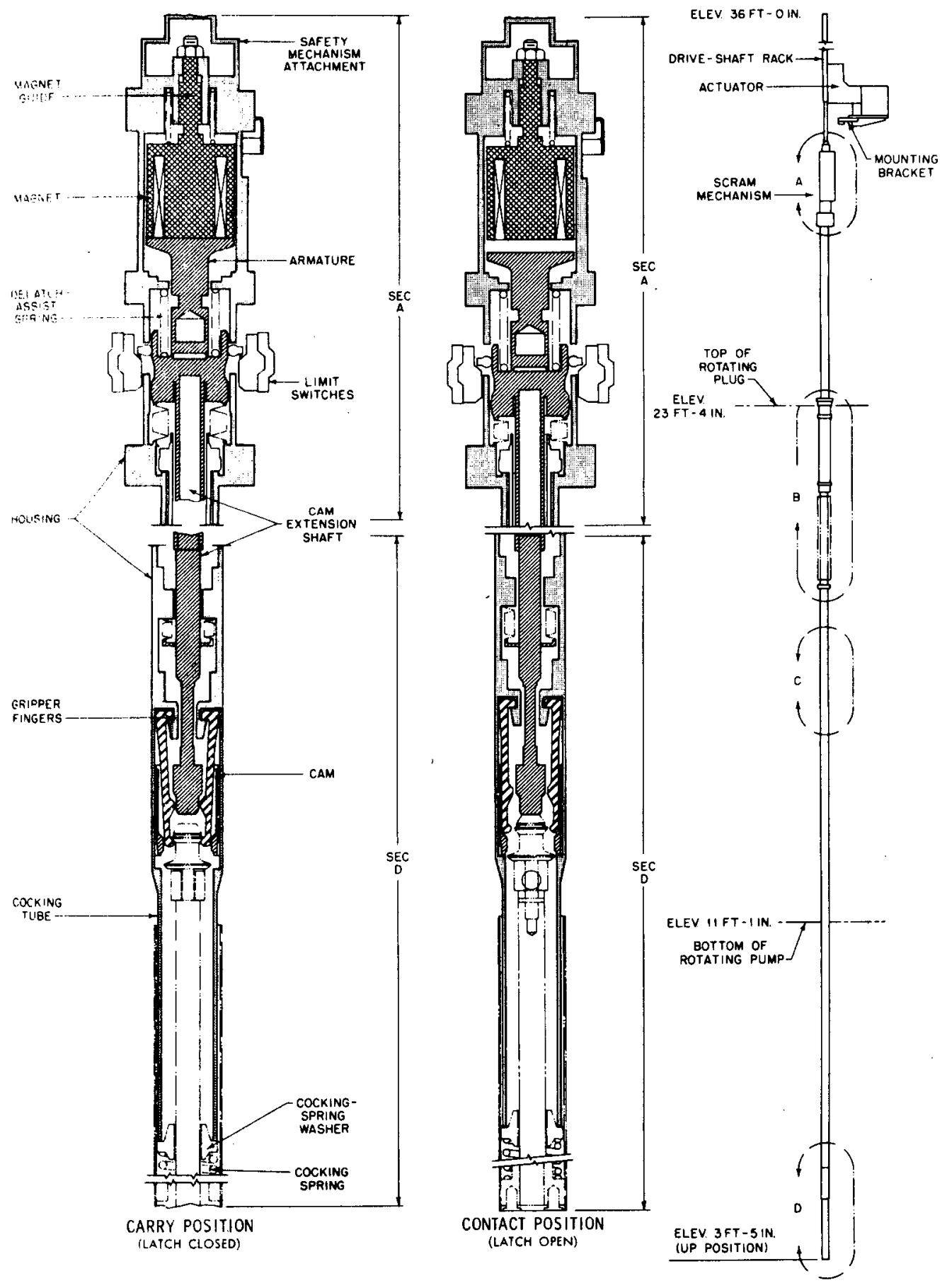

Figure XIV.D-3 Fermi Safety Rod Drive Extension (Ref. 5) 

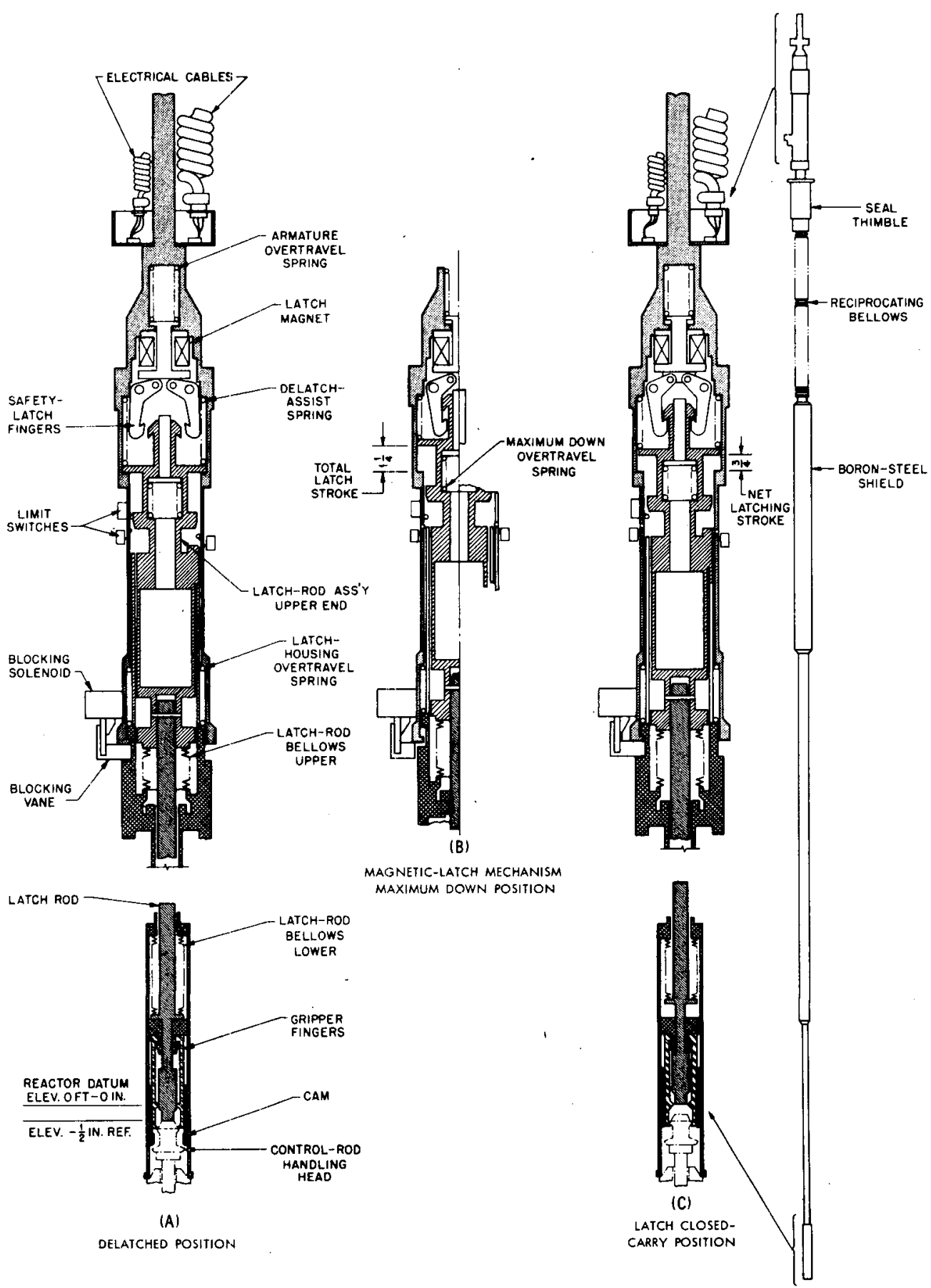

Figure XIV.D-4 Fermi Control Rod Latch Mechanism (Ref. 5) 


\section{XIV.E. HEAT TRANSFER SYSTEMS}

Fermi is a pool-type, three loop system with sodium as primary and secondary coolant.

Each primary loop includes check and throttle valve, the shell side of the intermediate heat exchanger, and a coldleg pump. Primary sodium flows by gravity from the free-surface pool of the upper reactor vessel to the Intermediate Heat Exchanger (IHX), then to the pump tank to be sent back to the reactor, entering the core and blanket plenums at the lower end of the reactor vessel. About $90 \%$ of the flow is delivered to the core plenum, and $10 \%$ to the blanket plenum. Blanket flow is controlled by a throttle valve. Primary piping is stainless steel, $30 \mathrm{in.}$ dia. from reactor to pump, 16 in. at pump discharge, 14 in. piping in flow to core, and for flow to blanket, 6 in. All walls are $3 / 8$ in. thick. All primary components are enclosed by secondary containment.

The secondary loop transfers heat from the primary system to the steam generator. Each loop includes the tube side of the IHX, the shell side of the steam generator, and the secondary coolant pump. There are no check valves. System pressure is higher than in the primary system.

The three intermediate heat exchangers are counter flow shell-and-tube units, with primary sodium on the shell side. Tube bundles are removable. Secondary sodium enters through upper nozzles, flows downward through a central downcomer, and upward through the tubes. The downcomer is shielded inside and outside by stainless steel plates. Leakage of secondary sodium into the primary side is prevented by gaskets. The top shield extends through the operating floor, and the plug is filled with serpentine. Heat transfer surface is $5840 \mathrm{ft}^{2}$. Primary inlet temperature is $900^{\circ} \mathrm{F}$, outlet is $600^{\circ} \mathrm{F}$. Secondary sodium temperature at the inlet is $520^{\circ} \mathrm{F}$, outlet $820^{\circ} \mathrm{F}$. Tubes and shell are stainless steel. (Fig. XIV.E-l)

The primary sodium pumps are vertical shaft, centrifugal, sump-type units with oil-lubricated mechanical shaft seals. Each pump is designed to deliver 11,800 gpm at $310 \mathrm{ft}$. The pump shield plug, shaft, impeller and casing are removable. (Fig. XIV.E-2)

Secondary pumps are vertically mounted units with single suction and single discharge welded to the piping. The sodium-lubricated lower bearing is above the impeller. The upper pump bearing is a combination radial and thrust bearing. (Fig. XIV.E-3)

An overflow tank located in the reactor building collects overflow sodium from the reactor. The sodium can be returned to the system by pumping it to the IHX. Two sump-type pumps are located in the tank. The pump shield plug, shaft, impeller and casing can be removed as a unit.

Primary loop valves include a check valve to prevent sodium back-flow in case of pump failure, and a blanket throttle valve to control coolant flow to the radial blanket. The check valves are a balanced disk type, with the body welded to the pump case discharge nozzle. The blanket throttle valve (Fig. XIV.E-4) is an angle-type, double-bellows seal valve. The whole assembly is contained in a pipe-riser sealed above reactor level.

Secondary loops do not include valving.

Heat energy following a scram will be removed by natural thermal circulation of the primary and secondary coolants. Water is supplied by gravity to the steam generators and steam is vented to the atmosphere. (Ref. 2,5) 


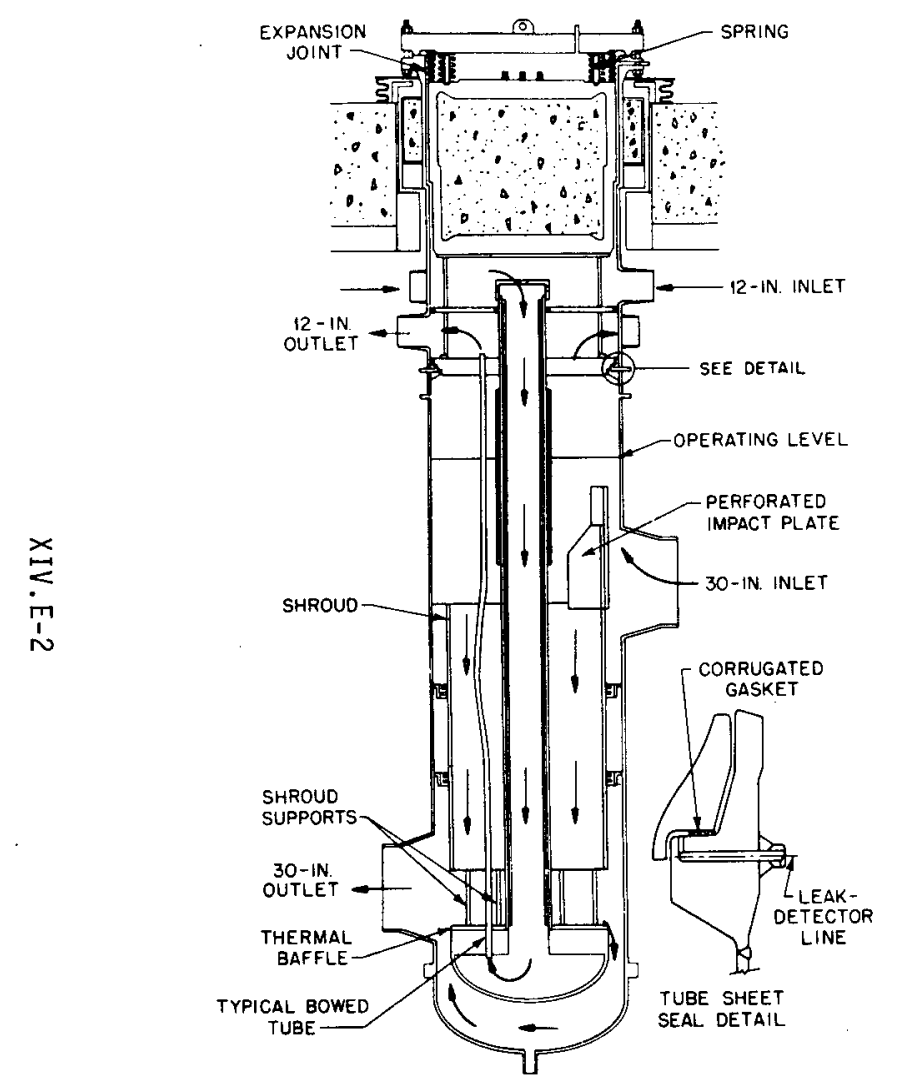

Figure XIV.E-1 Fermi Intermediate Heat Exchanger (Ref. 2)

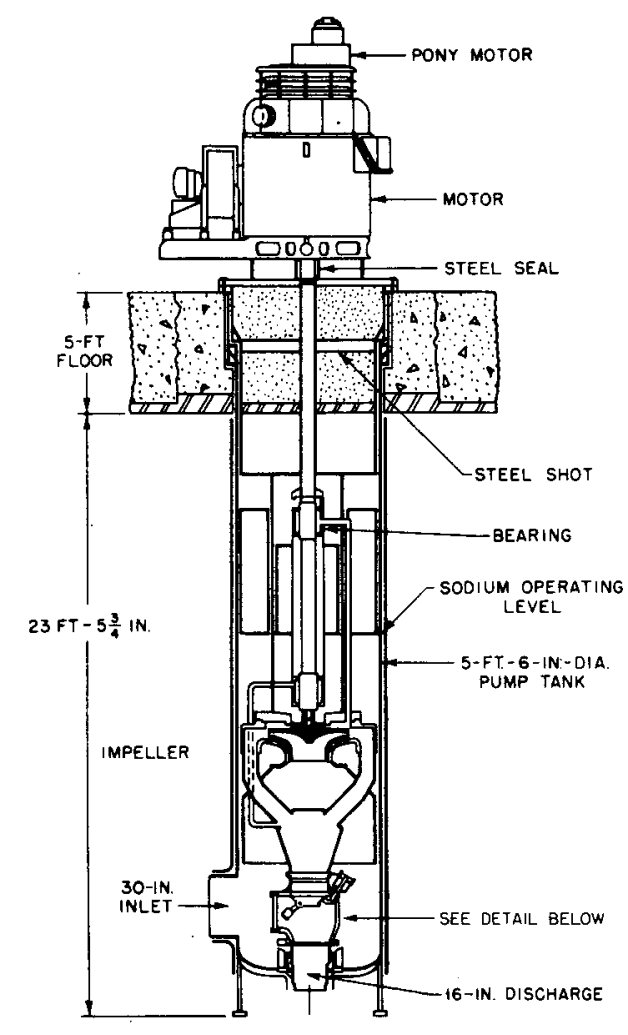

Figure XIV.E-2 Fermi Primary Pump (Ref. 2) 

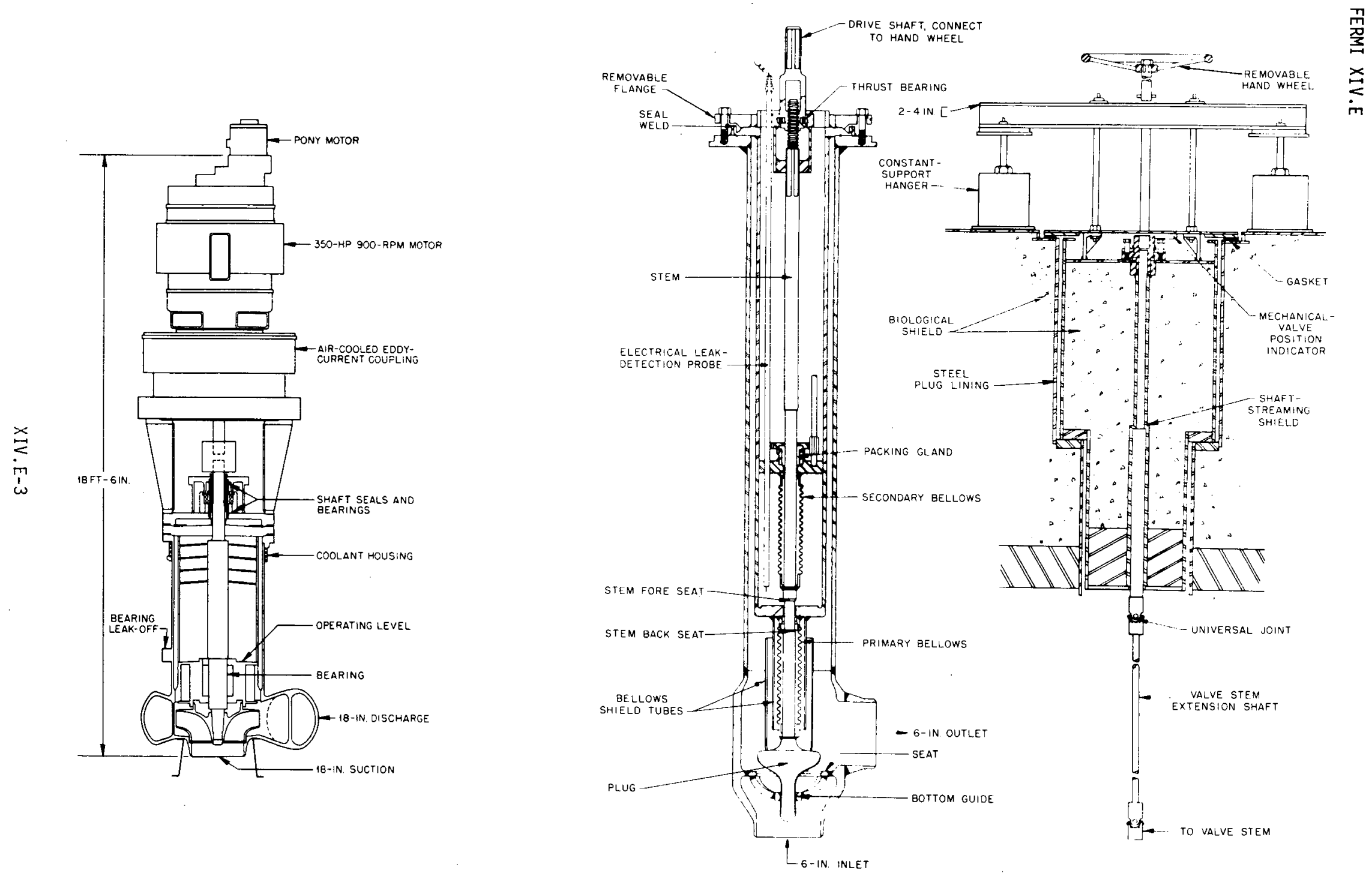

Figure XIV.E-3 Fermi Secondary Pump (Ref. 2)

Figure XIV.E-4 Fermi Throttle Valve (Ref. 2) 
XIV.F. SODIUM PURIFICATION AND INSTRUMENTATION

The primary sodium system receives, stores, and repurifies sodium when it is received. The sodium is filtered as it fills the storage tanks, and is coldtrapped in the storage tanks to remove sodium oxides. Purity is checked by a plugging indicator. The system can purify and monitor the purity of sodium from the primary system, which can be recirculated to the service system when desired. Hydrides as well as oxides are monitored and removed. Sampling is from the cold trap cell. The cell containing the purification equipment is shielded by $6 \mathrm{ft}$. thick concrete walls. A separate cell holds the storage tanks. A third unshielded cell serves the sodium building ventilation and heater-cooler system for the cold trap and the plugging indicator.

The cold trap is an NaK cooled unit. Sodium passes through the shell side of an economizer to reduce the temperature, then into the trap where the temperature is further reduced. It rises through the center portion packed with stainless steel wire mesh, leaves the cold trap through the tube side of the economizer. (Fig. XIV.F-1)

Sodium enters the plugging indicator past a flowmeter, and into a hairpin-bend Na-Nak heat exchanger to the plugging indicator device. Inlet is at $900^{\circ} \mathrm{F}$ and outlet at $250^{\circ} \mathrm{F}$.
Temperature measurements inside the primary shield tank and inside the reactor vessel are made by means of iron-constantan thermocouples encased in stainless steel sheaths with magnesium oxide insulation. Thermocouples installed on the hold-down plate are used to measure temperatures in the safety system. Outside the primary tank, resistance elements with integral wells are used. Resistance elements used in control are installed in the sodium pipe outlets of the reactor plenum and the outlets of the steam generator. Other standard type thermocouples are used for measurements of pipe and component heating.

NaK-filled high temperature pressure detectors and conventional pressure transmitters are used. Flow measurements in sodium loops and sodium service systems are by means of permanent magnet flowmeters, which require no penetrations of the sodium piping. Submerged pressure detectors in. the reactor vessel and primary system measure the sodium head. In some applications, resistance-type level detectors are used.

Leakage of liquid sodium from primary loop components is detected by a double probe type of detector which utilizes the electrical conductivity of sodium to complete a circuit. It has a test and annunciator circuit. (Ref. 2) 
FERMI XIV.F

MATERIALS OF CONSTRUCTION: TYPÉ 30 A STAINLESS STEEL

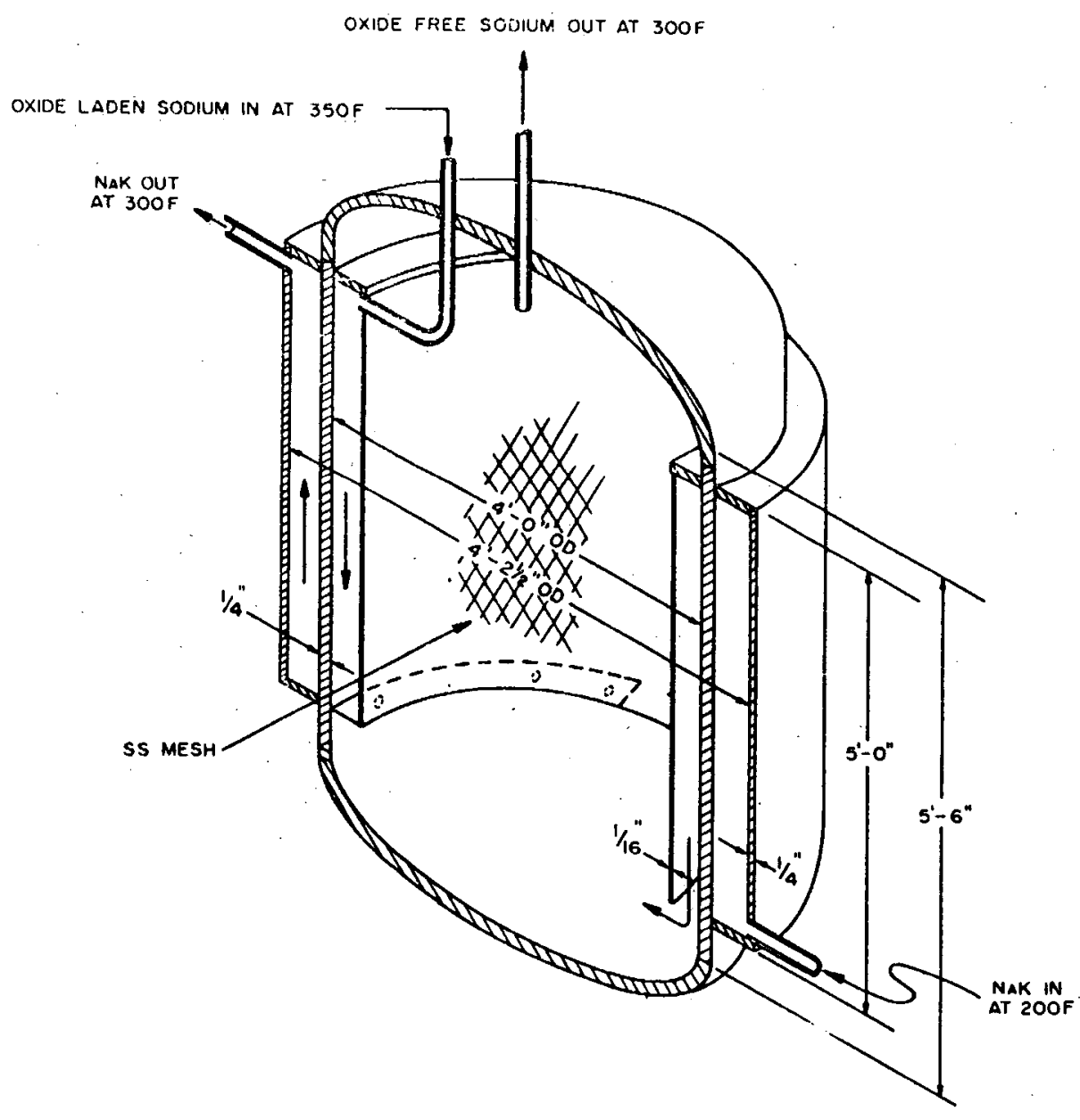

Figure XIV.F-1 Fermi Cold Trap (Ref. 2) 
XIV.G. COVER GAS AND AUXILIARY SYSTEMS

Cover gas is argon. A recirculating system maintains a gas blanket over al] primary system units, furnishes cooling gas to the fuel exit port, and supplies shaft purging gas to the primary sodium and overflow pumps. A11 spaces are interconnected by piping. The cover gas is held at a slight over-pressure. When the reactor operates at a constant temperature there is no recirculation of the cover gas. Discharge is to a vacuum tank, and makeup gas is taken from a hold-up and surge tank. Gas compressors provide the pressure differential. A vapor trap and a cyclone separator are located downstream from the vacuum tank. Detector installations monitor the escape of radioactive materials in both components and piping. A secondary inert gas system maintains a gas blanket over sodium in the steam generator, over the secondary pumps, and the auxiliary units. This system exhausts directly to the atmosphere. (Fig. XIV.G-l)

The primary shield tank has an independently controlled nitrogen atmosphere. The primary sodium service building is charged with nitrogen, and the atmosphere is continuously filtered and cooled. It is kept at a slight overpressure.

(Ref. 2) 


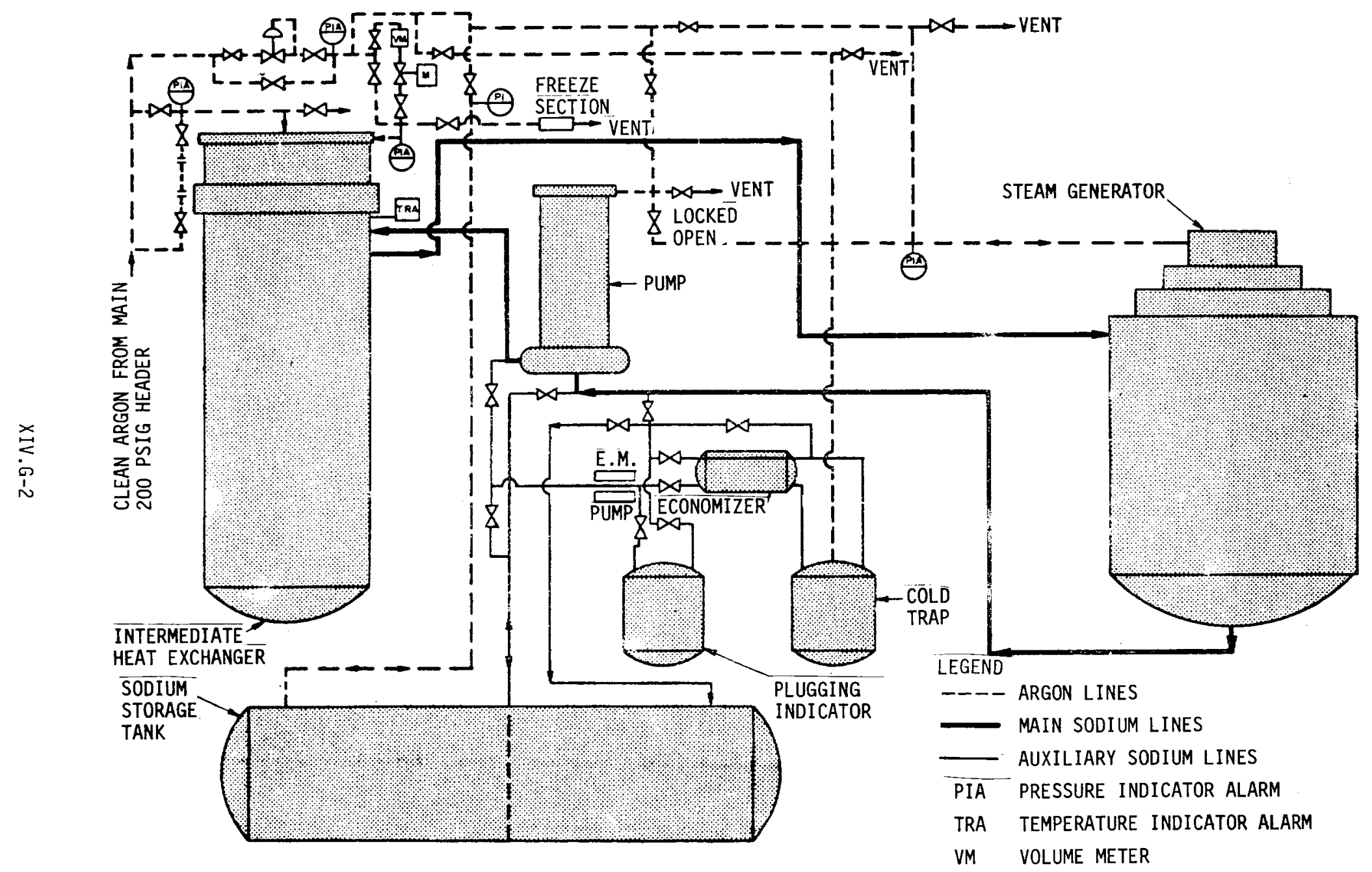

蛋

Figure XIV.G-1 Fermi Inert Gas System for Secondary Circuit (Ref. 2) 


\section{XIV.H. STEAM GENERATORS}

Fermi steam generators are vertical shell, single-wall tube, once-through units with cross-and counter-flow. Tubes are horizontal U-tubes nested in banks of eight, and attached to the stationary head. Each unit includes an economizer, evaporator, and superheater in one integral component. There are no steam drurns. Feedwater enters an upper manifold and passes through a down-comer inside a sodium flow shield. Steam leaves from the other manifold at $780^{\circ} \mathrm{F}$. Sodium enters the shell side through side nozzles, at: $820^{\circ} \mathrm{F}$, and leaves by the nozzle at the bottom of the shell at $520^{\circ} \mathrm{F}$. There are three steam generator units. Tubes, headers and shell are a $\mathrm{Cr}-\mathrm{Mo}$ alloy. (Fig. XIV.H-1) (Ref. 2)

When a normal steam flow path is interrupted because of the loss of a turbine generator, an alternate flow path is provided in Fermi. The main condenser is used as a heat sink by by-passing the turbine. Two large steam dump valves in the de-aerating heater open if turbine stop valves and control valves are closed suddenly. These valves admit steam to the steam space of the de-aerator, reducing steam pressure from the 600 psig operating pressure to $130 \mathrm{psig}$ heater pressure. Increase in the internal pressure in the de-aerator heater causes the condenser dump valve to open, and the heat is dumped to the main condenser. (Fig. H-2) (Ref. 1)

The turbine-generator is a tandem compound, single-flow, 1800 rpm machine with an expected gross output of 156 MWe. The condenser is a single-pass unit with divided water box and hotwell. (Ref. 2) 
FERMI XIV.H •

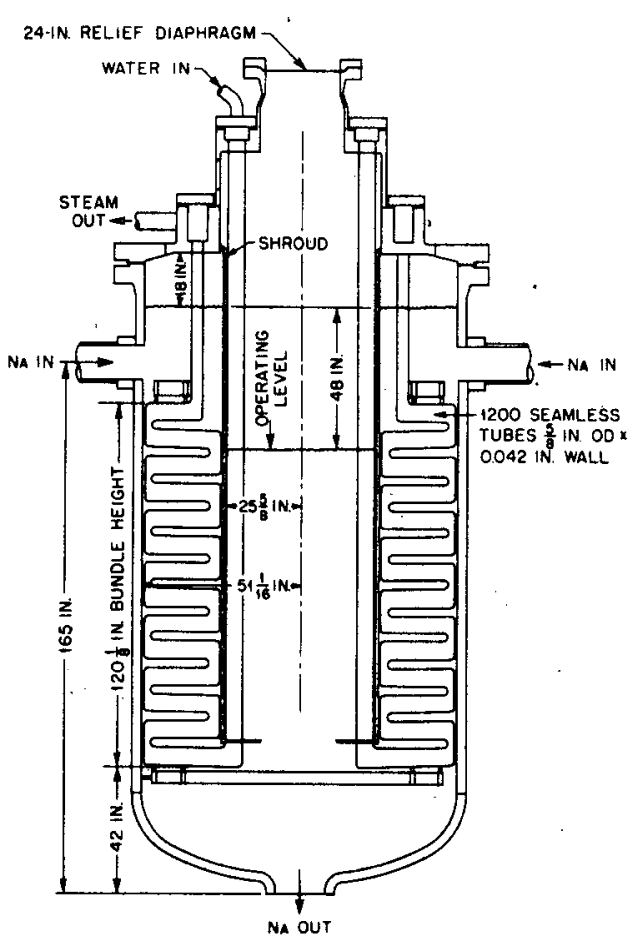

Figure XIV.H-1 Fermi Steam Generator (Ref. 2)

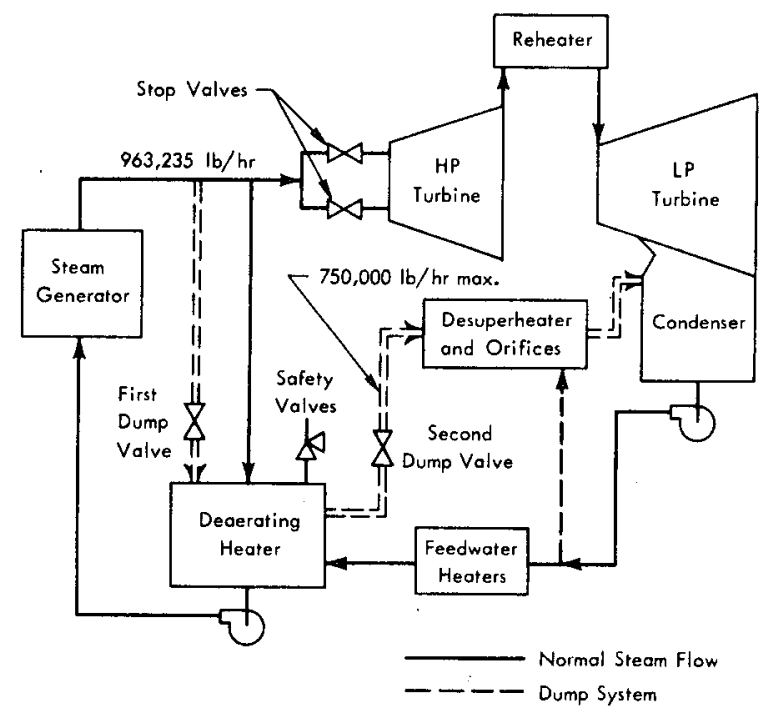

Figure XIV.H-2 Fermi Steam Dump System (Ref. 1)

XIV. $\mathrm{H}-2$ 
XIV.I. REACTOR INSTRUMENTATION AND CONTROL

Systems are designed for centralized control of the reactor plant and auxiliaries. One operator and assistant in the central control room, and one roving operator, can operate the plant.

Functions of the Reactor Plant Operating Control are automatic/manual control of primary and secondary coolant temperatures; manual control of primary and secondary coolant flows; provision of a signal to control feedwater flow to the steam generators; automatic/manual control of reactor power level, automatic power level set-back by partial insertion of operating control rods.
The Reactor Plant Safety System initiates scram operation by various abnormal conditions.

The Steam Generator Isolation System acts to isolate a steam generator from feedwater and steam headers in case of a sodium-water leak reaction.

Inert Gas Systems Control regulates the gas blanket pressures and flow in the primary systems and monitors pressures in the secondary system. (Ref. 2) 


\section{XIV.J. FUEL HANDLING}

A single rotating plug with a fixed fuel handling machine is used to insert and remove fuel from the reactor core. The machine, called the offset handling mechanism, rotates around its vertical axis. A transfer rotor is provided to allow decay storage within the reactor vesse1. Subassemblies are moved from core positions to the transfer rotor by the handling machine. Transfer from the rotor position to a cask car is also done by the offset handling machine. Spent assemblies are moved in the cask car outside the containment building to the fuel and repair building, and lowered in their pots into the cask car unloading station transfer rotor. After a decay period of one or two weeks the spent assemblies are cleaned and transferred to the water-decay pool.

The offset handling machine consists of four concentric tubes, an elevation drive unit, an azimuth drive unit, seals and shielding. (Fig. XIV.J-1)

The transfer rotor consists of a rotary drive unit with indexing equipment, a vertical drive shaft, and a jarge rotating disk at the bottom of the drive shaft in which finned pots to contain subassemblies are stored. Eleven spent assemblies can be stored between unloadings. The rotor is contained in a tank attached to the reactor vessel and the tank is filled with sodium. A low sodium flow is maintained to the transfer rotor through connections in the blanket plenum.

(Fig. XIV.J-2)

The cask car, which can handle eleven new assemblies and eleven spent assemblies in each cycle, has three main components: a vertical twelve position cask and rotor, a shielded heat exchanger, and a control cab. The main load is supported in two four-wheel trucks. It is self-propelled. by an electric motor drive, has brakes, and hydraulic snubbers fore and aft. The hoisting mechanism is housed in the upper part of the cask and rotor section. The fuel storage rotor of the cask car consists of eleven guide tubes to receive the transfer pot flanges. A twelfth position is for storing the exit-pot shield plug. Argon gas sweeps the finned section of the transfer pots. Thermocouples monitor fuel assembly temperatures. The heat exchanger is an argon-to-air device, and its compartment is lead shielded. Lead and depleted uranium are used for shielding in the cask car storage space and the front end of the cask car. (Fig. XIV.J-3) (Ref. 1,5) 


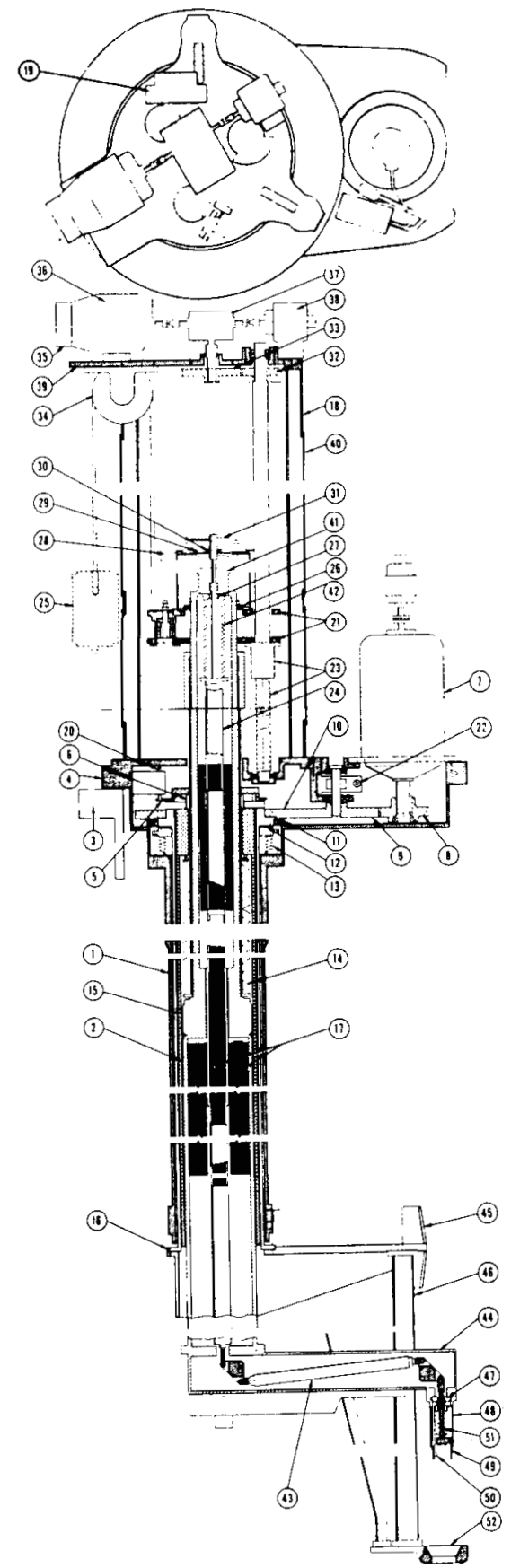

1 Housing Pipe

2 Recipracating Tube

3 Shield Basket

4 Azimuth Housing

5 Ring Gear (Analog-to-digital Converter)

6 Backup Packing Seal

7 Azimuth Drive Motor-gear Reducer

8 Azimuth Drive Pinion

9 Azimuth Idler Gear

10 Azimuth Gear (Driven)

11 Azimuth Bearing

12 Rotating Face Seal

3 Face-seal Bellows

14 Reciprocating Bellows Assembly

15 Elevation Bearing Pipe

16 Azimuth Bearing Pipe

17 Powdered Shieiding

18 Frame-elevation Housing

19 Anolog-to-digital Converter

20 Drive Shaft (Anolog to Digital)

21 Overload Plate Assembly

22 Azimuth Brake

23 Ball Screw and Ball Nut

24 Latch-tube Assembly

25 Counterweight Assembly

26 Elevation Bearing

27 Latch-rad Guide Bushing

28 Latch-closed Limit Switch

29 Latch-slide Plate

30 Latch-rod Collar

31 Slide-plate Retracting Solenoid

32 Ball-screw Drive Gear

33 Vertical Drive Pinion

34 Counterweighi Pulley (3)

35 Motor Brake

36 Elevation Drive Motor

37 Gear Reducer

38 Elevation Selsyn Transmitter

39 Top Plate-elevation Housing

40 Frame-elevation Housing Cover Plate

41 Larch-rod Counterbalance Spring

42 Latch-rod Bellow Seals (Upper)

43 Bell-crank Linkage

44 Offset Arm and Gripper Assembly

45 Stabilizer Plate

46 Stabilizer Guide Bors

47 Gripper-finger Retainer Collar

48 Gripper Housing

$49 \mathrm{Cam}$

50 Gripper Finger

51 Latch-rod Extension

52 Stabilizer Foot

Figure XIV.J-1 Fermi Offset Handling Machine (Ref. 5) 


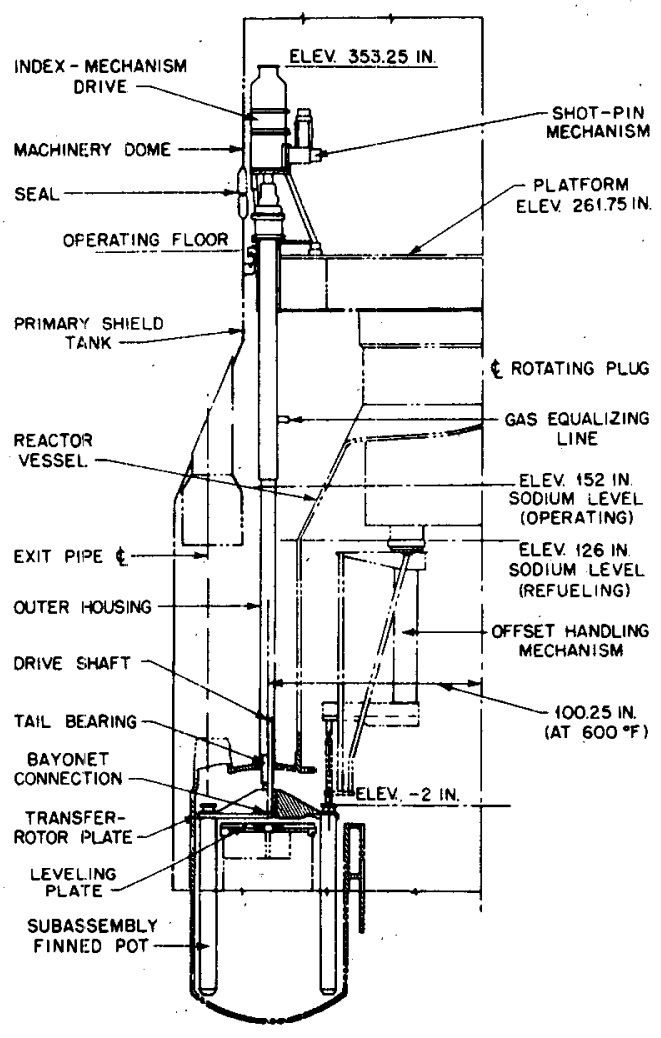

Figure XIV.J-2 Fermi Transfer Rotor Assembly (Ref. 2)

XIV.J-3 


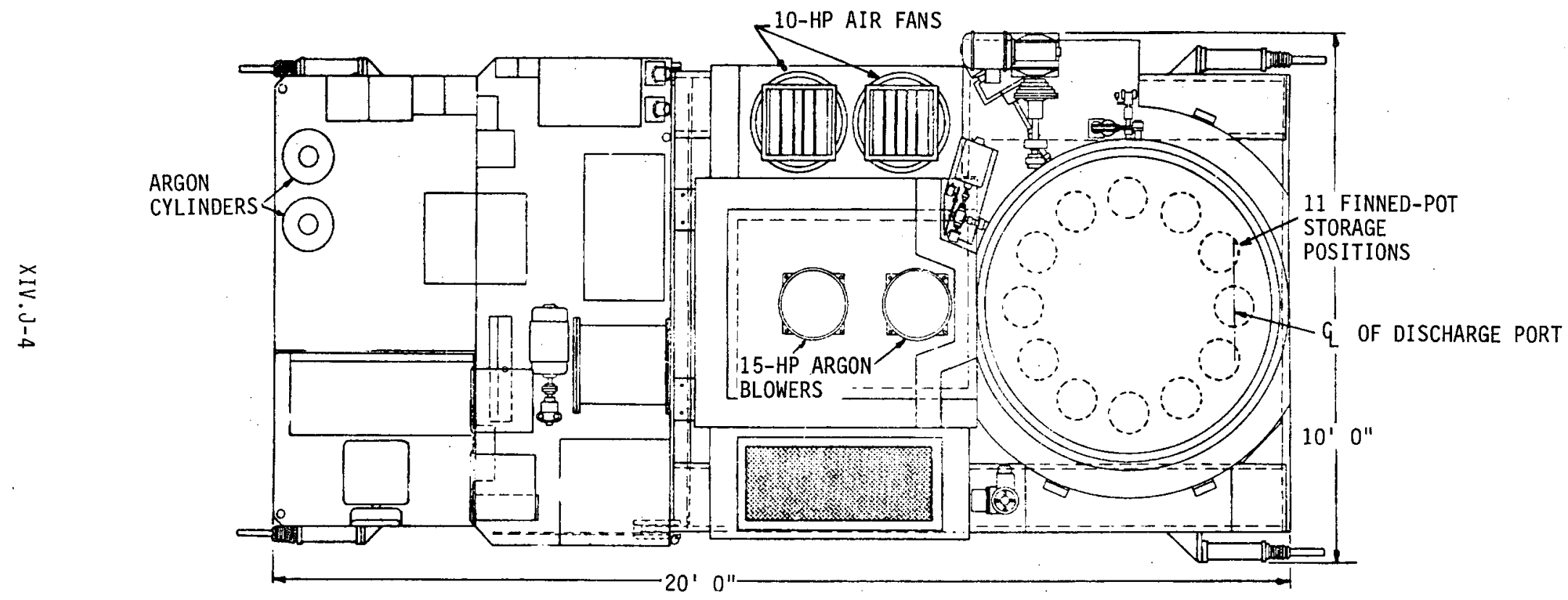

Figure XIV.J-3 Fermi Cask Car Sectional and Plane Views (Ref. 2) 
XIV.K. CONTAINMENT

The reactor building is an uninsulated steel pressure vessel, consisting of a vertical cylinder with hemispherical top head and elipsoidal bottom head. Inside diameter is $72 \mathrm{ft}$., overall height $120 \mathrm{ft}$, with $51 \mathrm{ft}$. below grade. Reinforced concrete foundations are in contact with the top and bottom surfaces of the steel, and rest on the underlying rock stratum. Vessel walls are 1.03 in. thick. All penetrations have gas-tight seals located 18 in. beyond the building wall. A rotary crane supported from the vesse? wall is used for equipment handling. A $5 \mathrm{ft}$. thick operating floor supported on structural steel columns has a stepped radiation seal around the periphery. The seal is bridged with a rubber strip to prevent mixing atmospheres above and below the floor. A secondary shield wall consists of $30 \mathrm{in}$. concrete, clad on both sides with steel. The area above the operating floor is accessible to personnel. The lower area has a dehumidified nitrogen atmosphere. (Ref. 2) 


\section{EBR-2}

LOCATION: Idaho Fa11s, Idaho OPERATION: 1964

EBR-2 was authorized in 1955, and the first construction contracts awarded in 1957. Power was delivered to the electrical distribution system on August 7, 1964. EBR-2 has since operated as a base-load experimental LMFBR power station, although emphasis has shifted to experimental irradiation of LMFBR fuels and structural materials. A core loading can include $25 \%$ or more experimental assemblies, which contribute about $10 \%$ of the power output.

EBR-2 is a 20 MWe, 65 MWt pool-type system using uranium alloy fuel. Spent fuel is transferred to an on-site reprocessing and fabrication facility. 


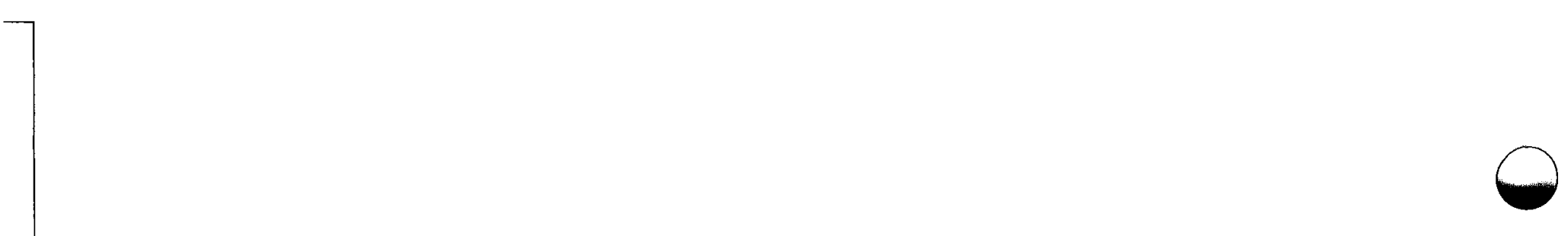

$\bullet$

\section{-}

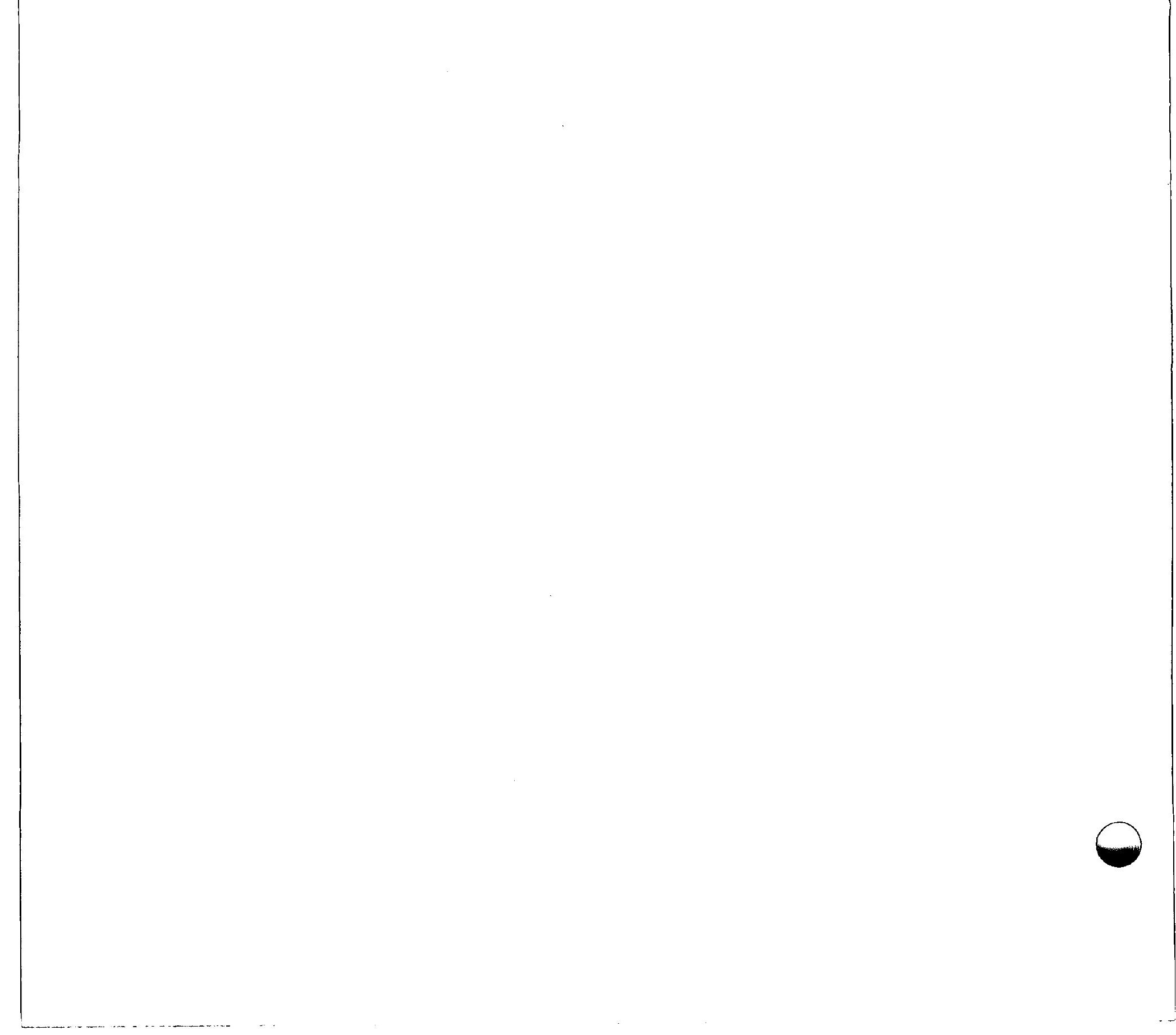


INDEX

\begin{tabular}{|c|c|c|}
\hline \multirow{2}{*}{\multicolumn{2}{|c|}{ REFERENCES }} & Page \\
\hline & & $X V-5$ \\
\hline \multicolumn{2}{|c|}{ REACTOR PARAMETERS } & $X V-7$ \\
\hline \multicolumn{3}{|c|}{ SECTIONS } \\
\hline & CORE AND BLANKET & $X V \cdot A-1$ \\
\hline & CORE SUPPORT AND VESSEL INTERNALS & $X V . B-1$ \\
\hline & REACTOR VESSELS AND SHIELDING & $X V . C-1$ \\
\hline & CONTROL ELEMENTS & $X V . D-1$ \\
\hline & HEAT TRANSFER SYSTEMS & $X V . E-T$ \\
\hline & SODIUM PURIFICATION AND INSTRUMENTATION & $X V . F-1$ \\
\hline & COVER GAS AND AUXILIARY SYSTEMS & $X V . G-1$ \\
\hline & STEAM GENERATORS & $X V . H-1$ \\
\hline I. & REACTOR INSTRUMENTATION AND CONTROL & $X V . I-1$ \\
\hline J. & FUEL HANDL ING & $X V . J-1$ \\
\hline K. & CONTAINMENT & $X V . K-1$ \\
\hline
\end{tabular}


REFERENCES

1. EBR-2: An Experimental LMFBR Power Plant

L. J. Koch

Reactor Technology Vol. 14, Fall 1971, p. 286-311

2. Fuel Element Experience in Nuclear Power Reactors

An AEC Monograph

M. T. Simnad

Gordon and Breach, 1971

3. Hazard Summary Report Experimental Breeder Reactor II

(EBR II)

L. J. Koch, et. al. (Argonne Hational Laboratory)

ANL-5719 (May 1957)

and

ANL-5719 addendum (June 1962)

4. EBR-II Initial Operation - Highlights

H. O. Monson

Fast Breeder Reactors, Proc. London Conf., BNES, May 1966

p. $135-152$

British Nuclear Energy Society, 1967

5. In-core Monitoring in the Experimental Breeder Reactor-II

C. C. Price, et. al.

Irradiation Experiments in Fast Reactors, Proc. ANS

Topical Meeting, Jackson Lodge, Wyoming Sept. 1973

p. 401-411

American Nuclear Society, 1973

6. Fuel Failure Detection in Sodium-Cooled Reactors

K. G. Porges

Conf. on Safety, Fue1s, and Core Design in Large Fast Power Reactors

Proc. Conf., ANL, October 1965

ANL-7120, p. 862-867 


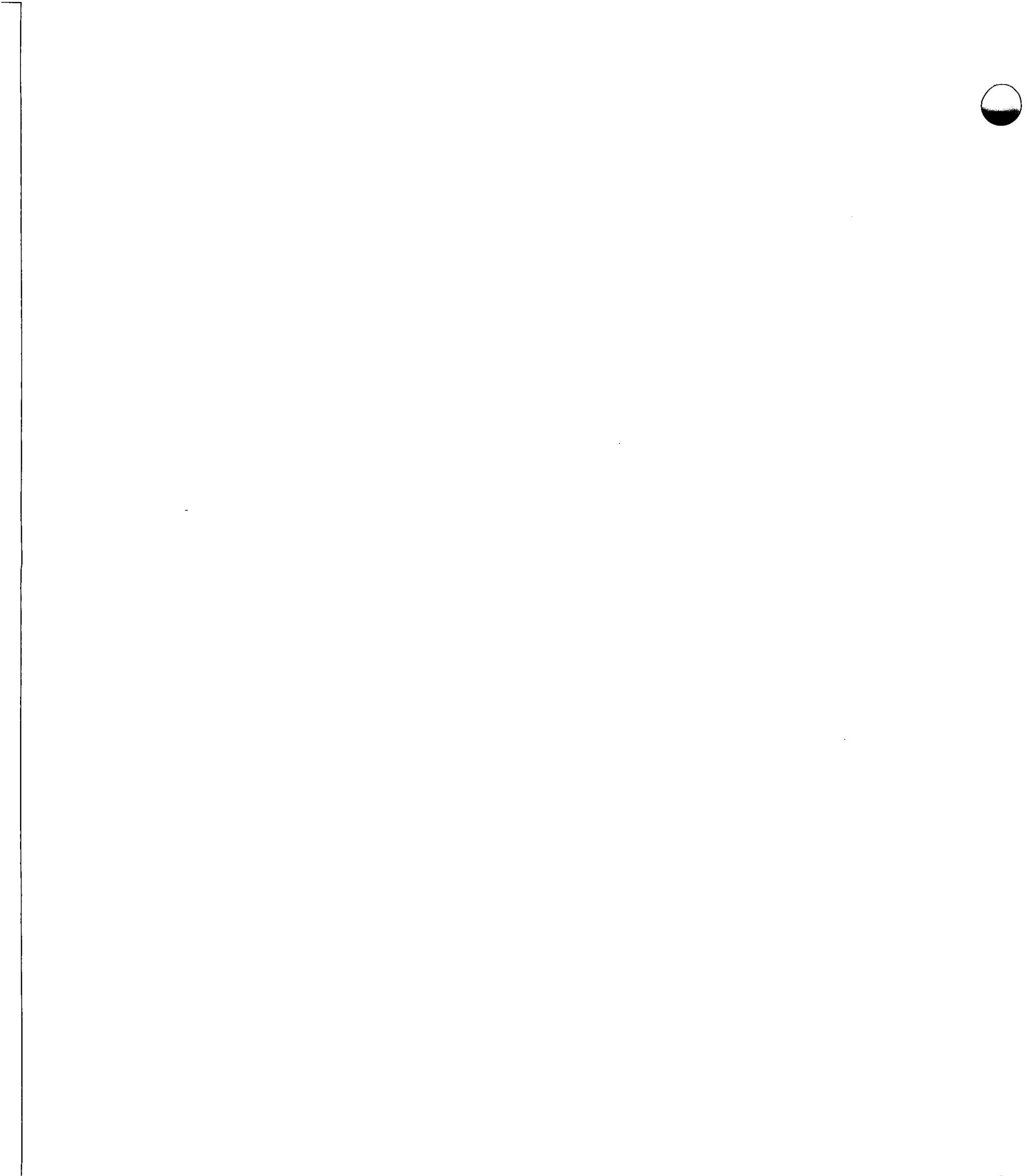

$\vartheta$

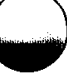




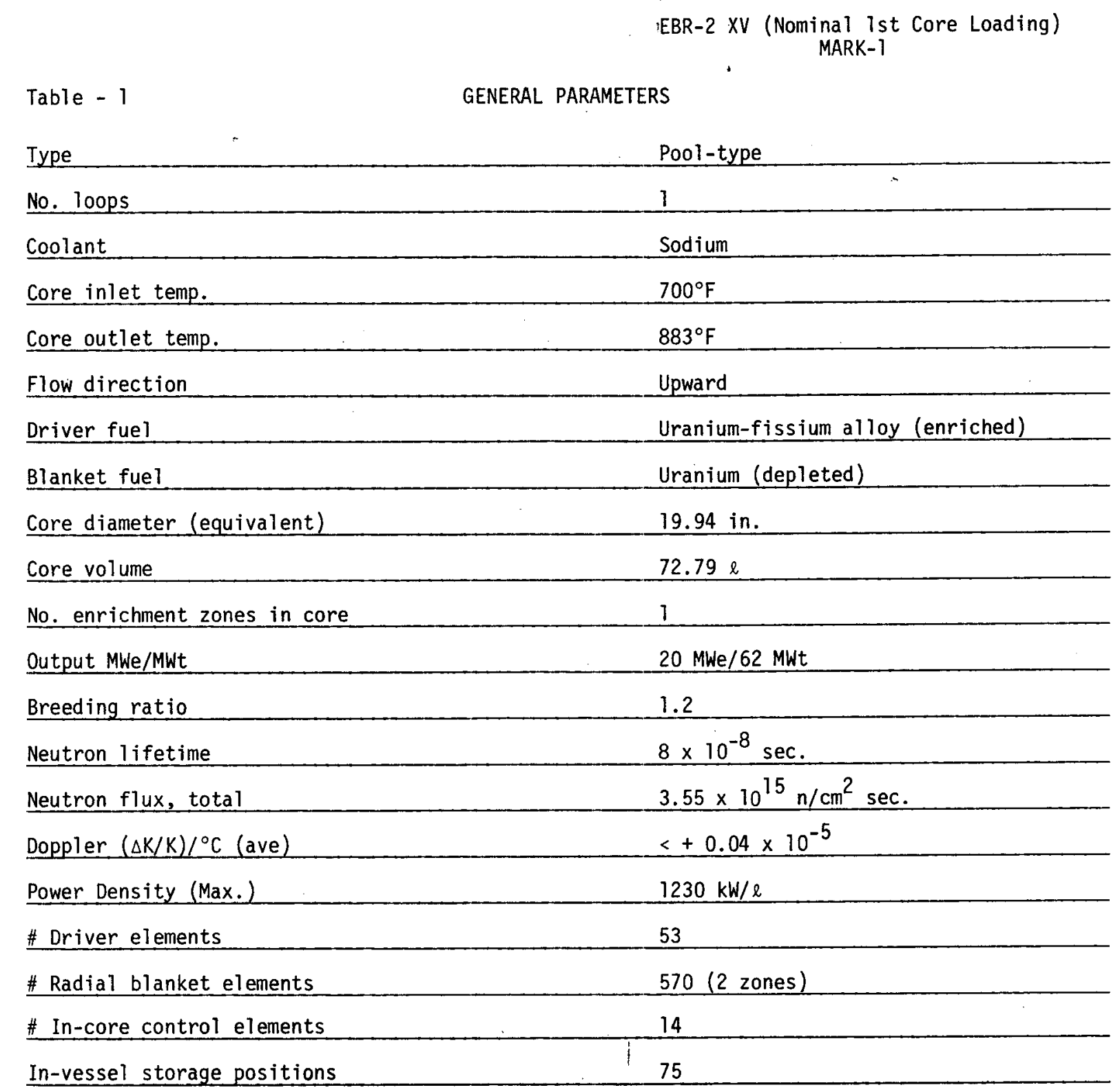


EBR-2 XV (Nominal 1st Core Loading)

MARK- I

Table - 2

CORE AND BLANKET

\begin{tabular}{|c|c|c|c|}
\hline$\dot{1}$ & Driver zone & Axial blanket & Radial blanket \\
\hline Fuel material & Uranium alloy & Uranium & Uranium \\
\hline Form & Pin & Pin & Pin \\
\hline Composition & U-5 fissium & Uranium metal & Uranium metal \\
\hline $235_{U}$ & $48.4 \mathrm{a} \%$ & Depleted & Depleted \\
\hline Alloy density & $17.95 \mathrm{gm} / \mathrm{cc}$ & $>18.7 \mathrm{gm} / \mathrm{cc}$ & $>18.7 \mathrm{gm} / \mathrm{cc}$ \\
\hline Pin od & 0.144 in. & 0.3165 in. & $0.433 \mathrm{in}$. \\
\hline Pin cladding & Stainless steel & Stainless steel & Stainiess steel \\
\hline od & $0.174 \mathrm{in}$. & $0.376 \mathrm{in}$. & $0.493 \mathrm{in}$. \\
\hline Wall thickness & $0.009 \mathrm{in}$. & 0.022 in. & $0.018 \mathrm{in}$. \\
\hline Fuel-clad gap & $0.006 \mathrm{in}$. & $0.008 \mathrm{in}$. & $0.012 \mathrm{in}$. \\
\hline Bond material & Sodium & Sodium & Sodium \\
\hline Active length & $14.22 \mathrm{in}$. & 18 in. (total) & $55.0 \mathrm{in.}$ \\
\hline Gas plenum length & 2.35 in. (top) & & \\
\hline Vented/non-vented & No & No & No \\
\hline Assembly material & Stainless steel & & Stainless steel \\
\hline Shape & Hexagonal & & Hexagonal \\
\hline Across flats (dia.) & $2.290 \mathrm{in.}$ & & $2.290 \mathrm{in.}$ \\
\hline Wall thickness & $0.040 \mathrm{in}$. & & $0.040 \mathrm{in}$. \\
\hline Overall length & $\sim 7-1 / 2 \mathrm{ft}$. & & $27-1 / 2 \mathrm{ft}$ \\
\hline No. pins/assembly & 91 & 18 & 19 \\
\hline Pin spacing & Grid & Grid & Wire wrap \\
\hline Assy. pitch & 2.320 in. & & \\
\hline Assy. in core & $53+14$ as control & & $60+510$ \\
\hline Volume fraction (Vol.\%) & & & Inner Outer \\
\hline Fuel & 31.8 & 30.3 & 60 \\
\hline Steel & 19.5 & 18.5 & $19.6 \cdot 20.9$ \\
\hline Sodium & 48.7 & 51.2 & 19.1 \\
\hline
\end{tabular}

$X V-8$ 
XV.A. CORE AND BLANKET

The nominal MARK-1 core had 67 subassemblies, fourteen of these being operated as control and safety rods. Two sections were loaded with 570 radial blanket assemblies. The inner and outer sections differed slightly in flow adapter arrangement. Nominal core size was increased from the original design by adding six core-type subassemblies in the sixth row. (Fig. XV.A-T)

Alterations to the fuel subassembly included a redesign of the cap, and the provision of holes rather than slots in the lower adapter for coolant entry into the subassembly from the high pressure plenum. The central elements of the axial blanket bundles were replaced by a steel tie rod which interconnects the upper and lower blanket support grids.

(Fig. XV.A-2)
Lower adapter sections on the radial blanket subassemblies were also modified. The inner and outer oblanket subassemblies differ in the method of coolant flow orificing. (Fig. XV.A-3)

Each subassembly has spacer buttons approximately at the midplane of the core. The subassemblies are free-standing, supported only by the lower grid structure. (Ref. 3)

MARK-1A elements, loaded in 1966, have a shorter fuel alloy length, 13.50 in. instead of 14.221 in., and an increase in the size of the gas plenum, the volume being $52.5 \%$. Enrichment was increased to $52.5 \% 235 \mathrm{U}$. (Ref. 4 ) 


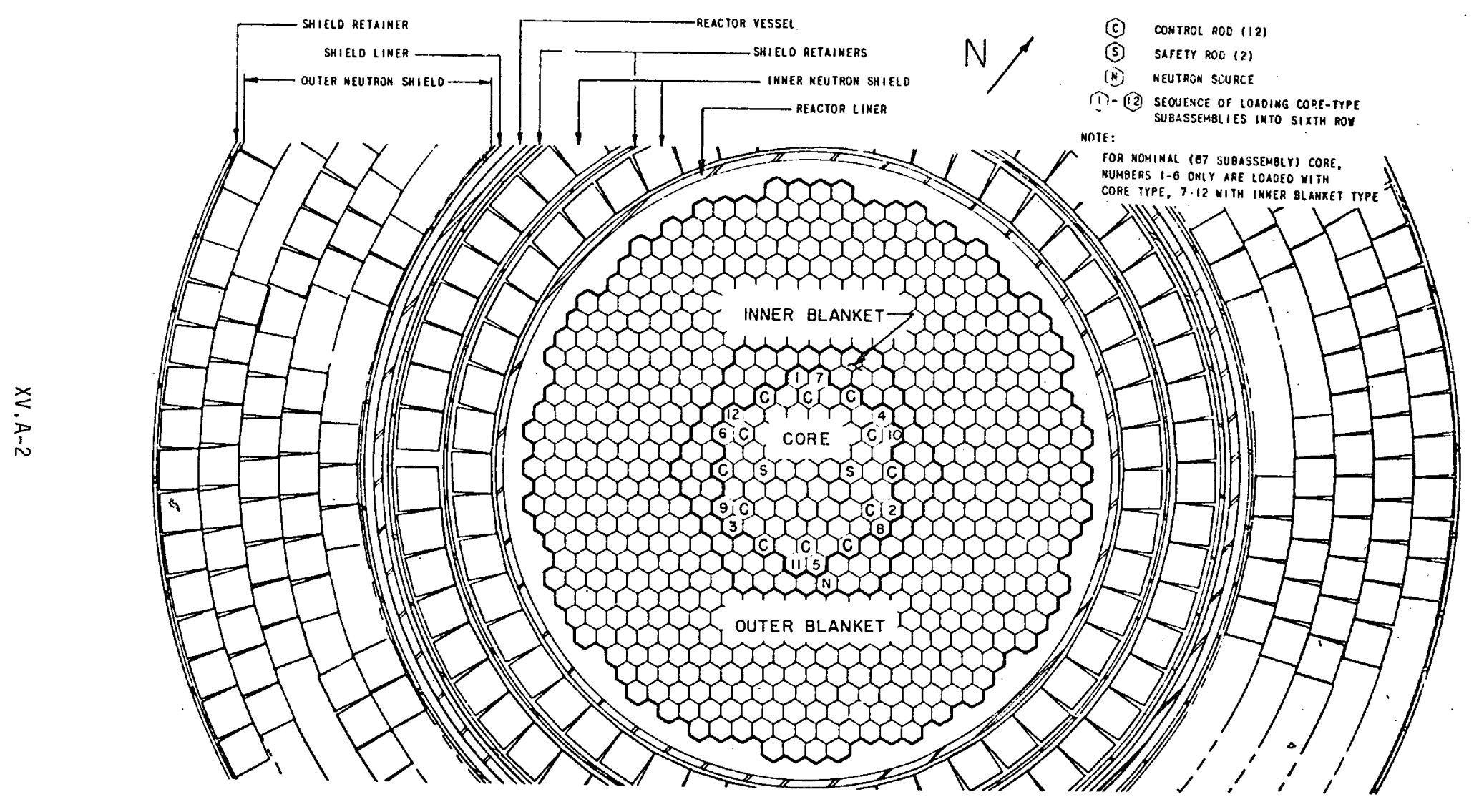

Figure XV.A-1 EBR-2 Reactor Arrangement (Ref. 3 add) 

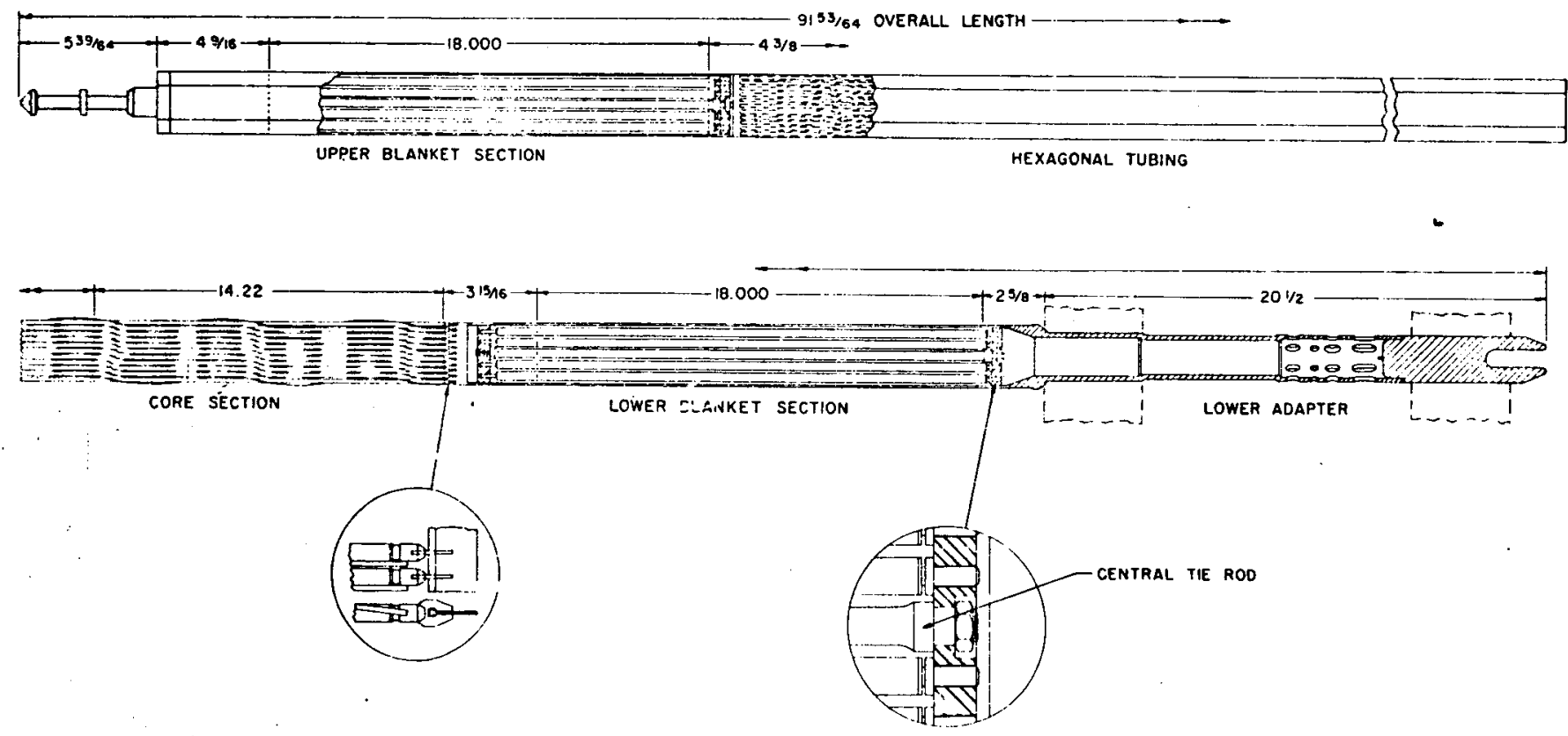

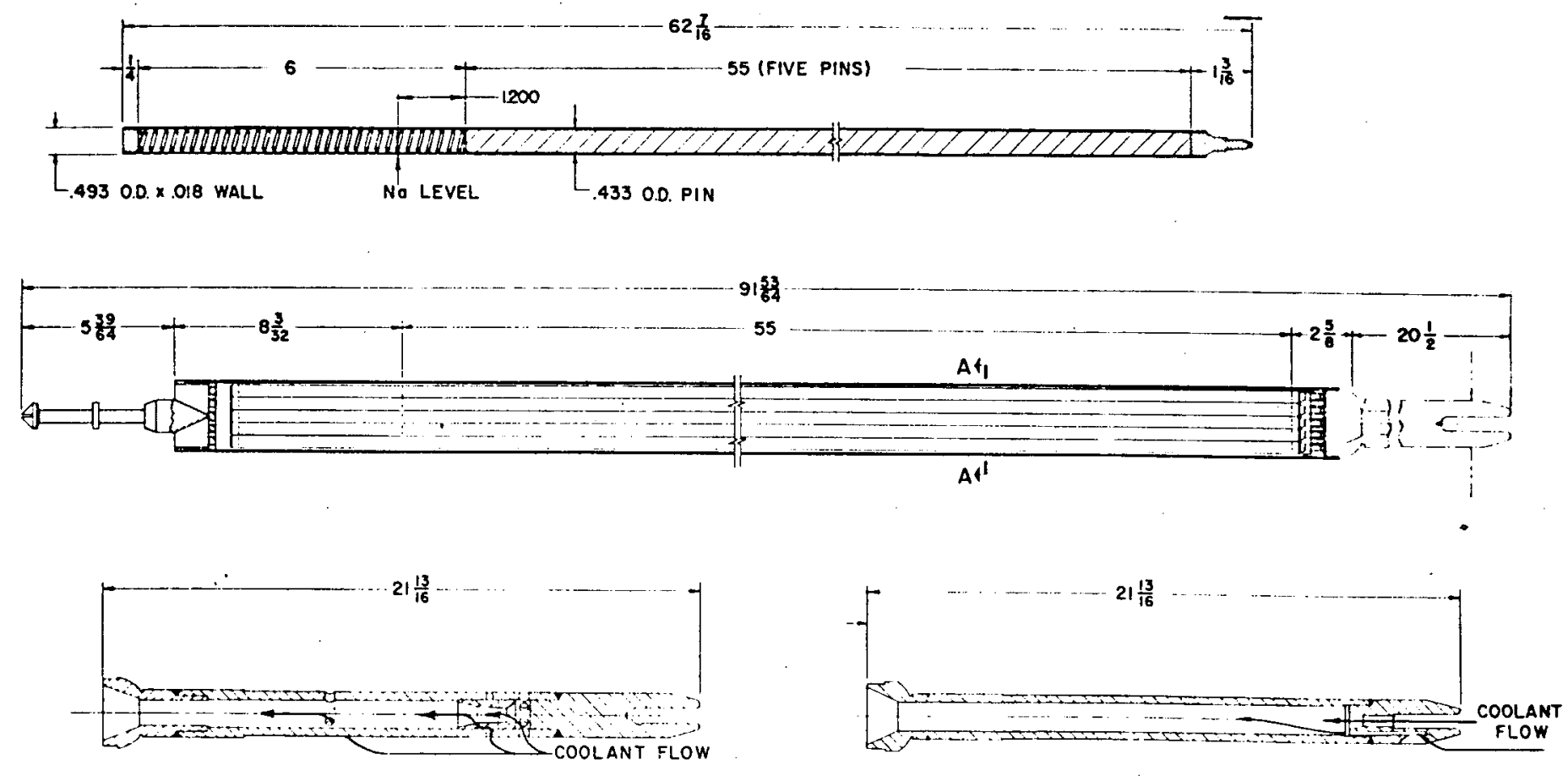

INNER BLANKET SUBASSEMBLY BOTTOM ADAPTER

OUTER BLANKET SUBASSEMBLY BOTTOM ADAPTER 


\section{XV.B. CORE SUPPORT AND VESSEL INTERNALS}

The grid plenum assembly supports and locates the subassemblies and forms the coolant inlet chambers. It consists of two 4.in. thick stainless steel plates, interconnected by tubes welded to each plate in the outer blanket zone. The low-pressure plenum is an annular chamber immediately below the lower grid plate. The plates contain holes for locating the lower adapters of the subassemblies. The subassemblies are supported by a spherical shoulder which engages a conical seat in the upper grid plate to provide a seal. They extend through the lower plate. The lower end of the subassembly nozzle is closed. The holes for coolant entry are located between the upper and lower grid plates. The outer radial blanket assemblies have coolant inlet orifices at the bottom. The lower grid plate is stepped for flow orificing. (Fig. XV.B-la-1b, XV.B-2) (Ref. 3-add.)

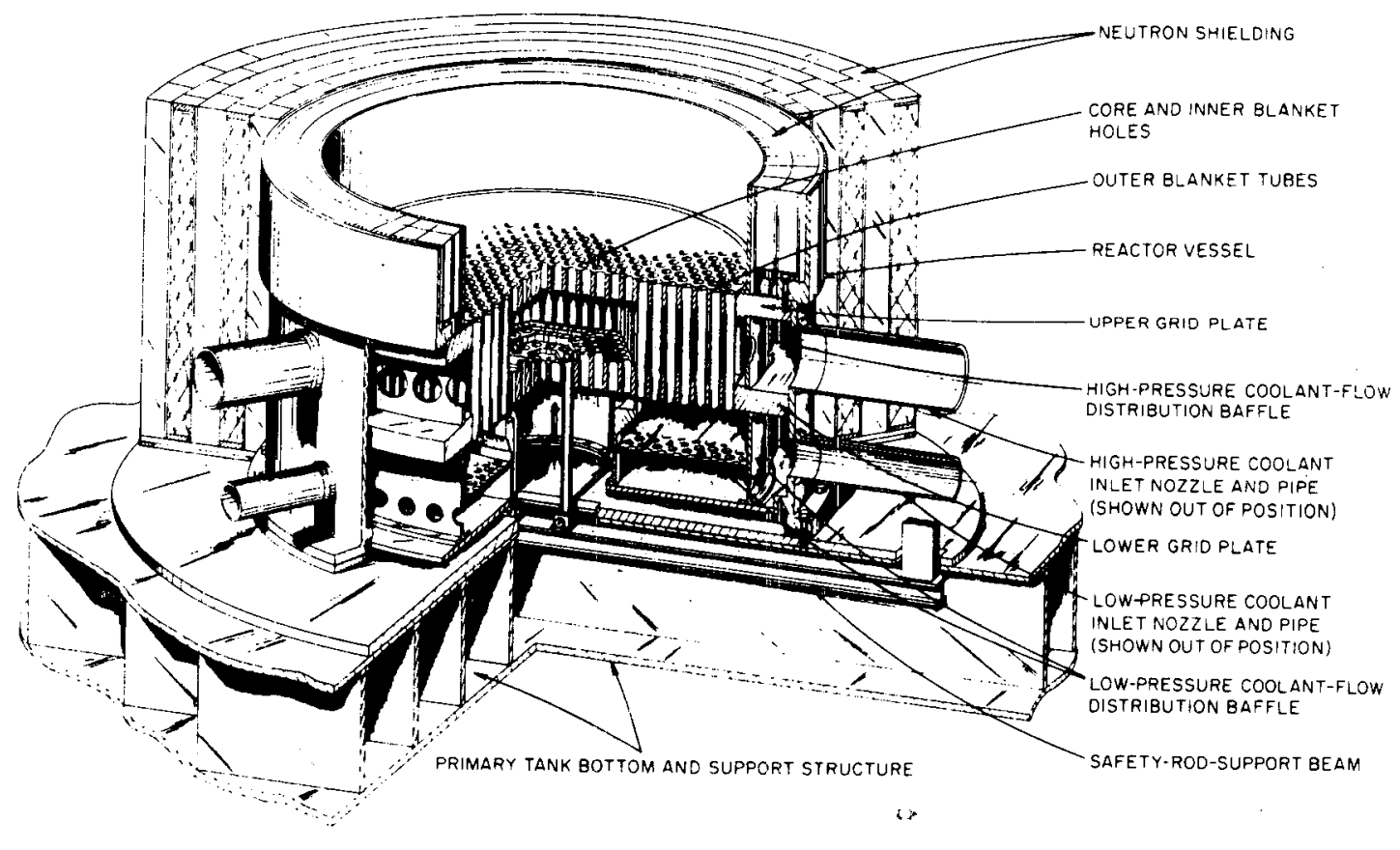

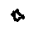

Figure XV.B-1a EBR-2 Grid Plenum Assembly (Ref. 3 add)

$X V . B-1$ 


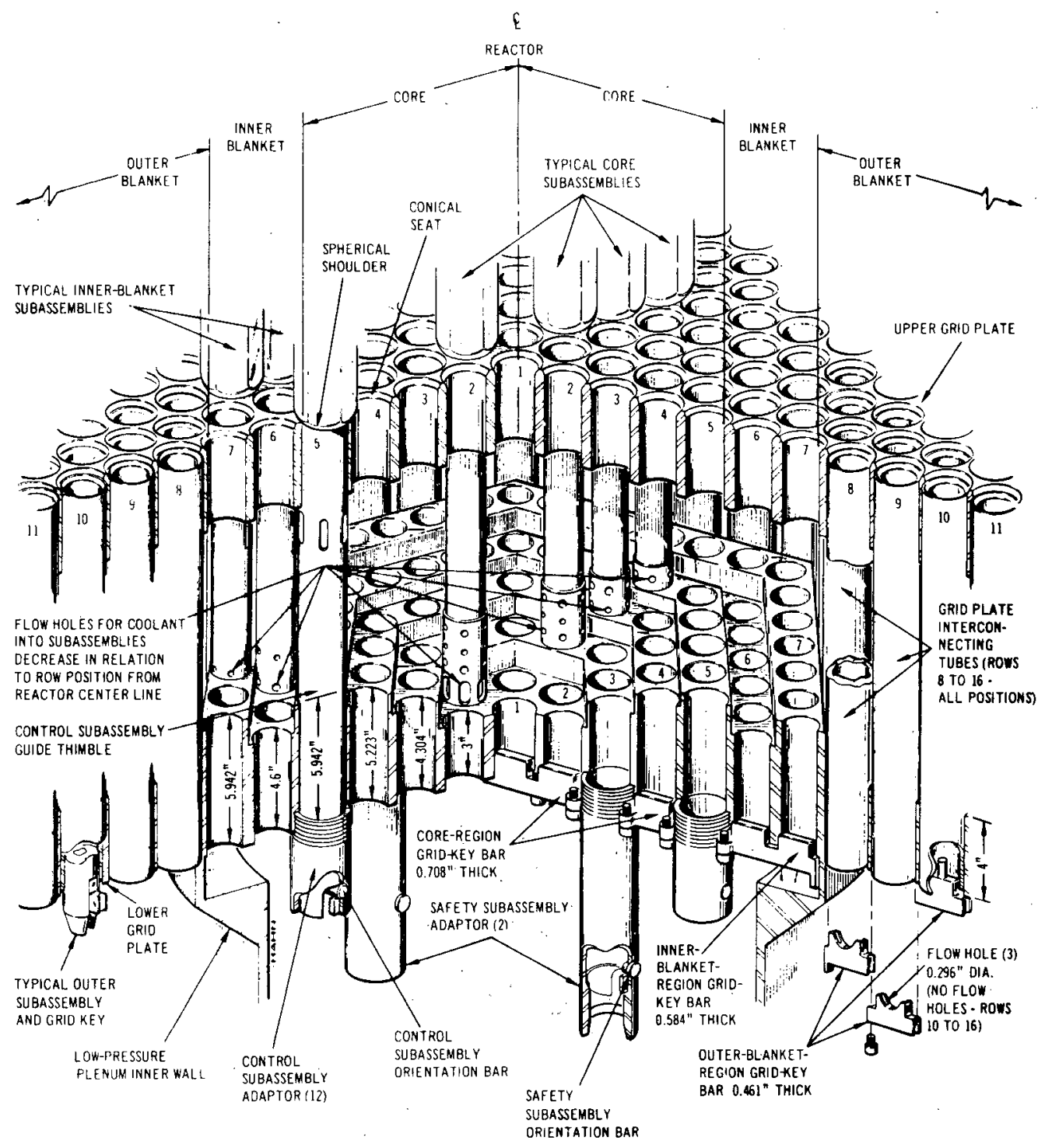

Figure XV.B-1b EBR-2 Bottom Section of Grid Plenum Assembiy (Ref. 1) 
$E B R-2$ XV.B.

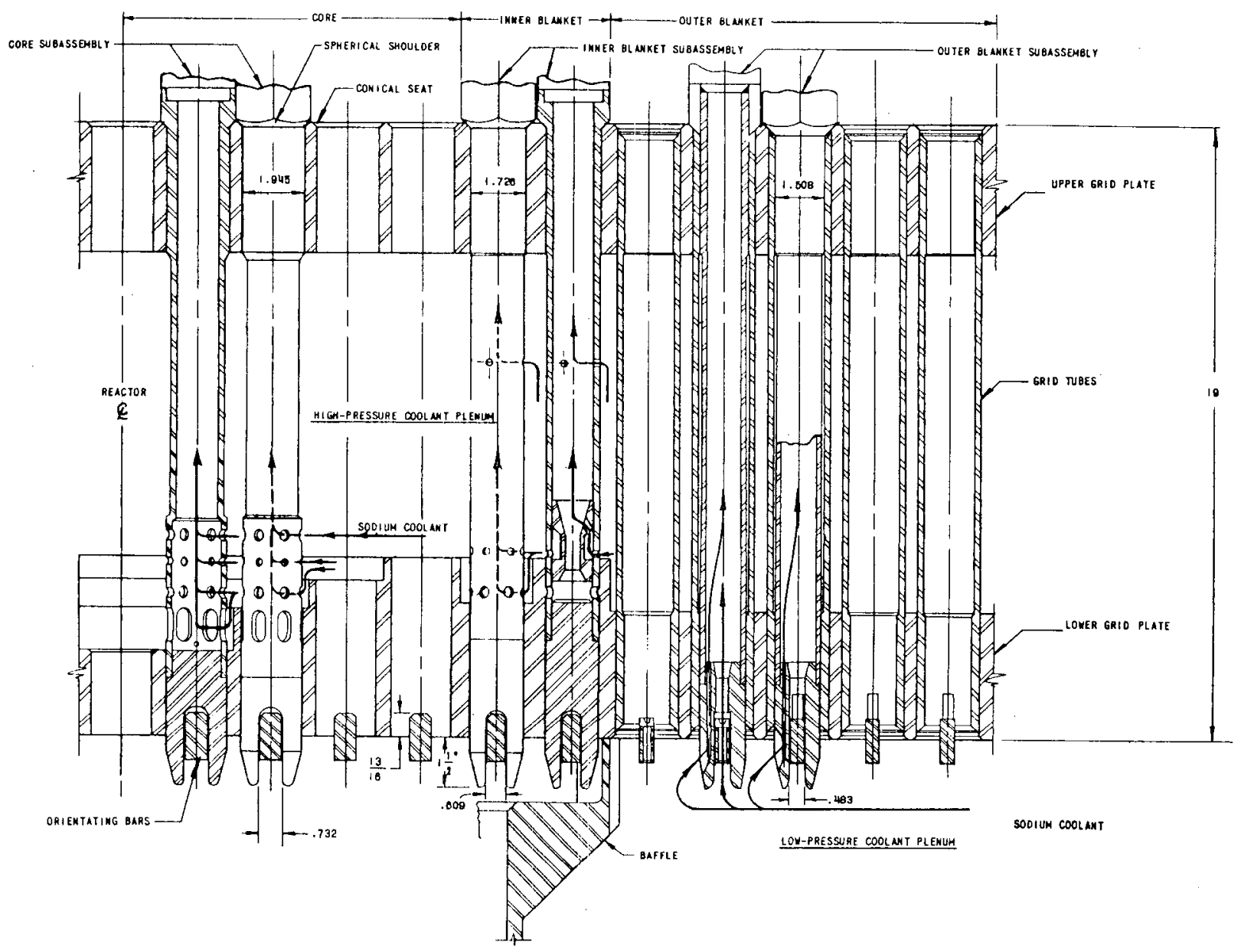

Figure XV.B-2 EBR-2 Grid Plenum Section (Ref. 3 add)

$X V \cdot B-3$ 


\section{XV.C. REACTOR VESSELS AND SHIELDING}

The reactor vessel assembly is supported at the bottom of the primary tank, on the structural members which reinforce the bottom of the inner primary tank. The grid-plenum assembly is bolted to the reactor vessel. A portion of the radial neutron shield is located inside the reactor vessel, another portion outside the vessel. The shielding consists of canned borated graphite. Retainers and liners provide positive positioning of the shiclded cans. Below the reactor vessel, borated stainless steel plates are located between the vertical webs of the beams on the bottom of the primary tank. The reactor cover closes the upper end of the reactor vessel and forms the upper surface of the outlet plenum chamber. It contains the top part of the neutron shield and has two rotating plugs. Pin projections on the underside of the cover are positioned about $] / 4$ inch above core and inner blanket assemblies, serving as a secondary hold-down device. (Fig. XV.C-1, XV.C-2)

The reactor, primary system equipment, and fuel handling system are immersed in the sodium contained by the primary tank. The tank is a double-walled, stainless steel cylindrical structure. The inner vessel is $26 \mathrm{ft}$. od, the outer vessel $26 \mathrm{ft}$. $11 \mathrm{in}$. id and has $0.25 \mathrm{in}$. thick walls. An inert gas fills the annulus. The tank support structure is a system of beams and columns which form a boxlike structure. The six radial top beams frame into circular rings with additional stiffening members. The primary tank is hung from this top structure by means of roller-type support hangers. The columns are tied together at the bottom by beams which are anchored to the concrete. The inside of the vertical steel columns is approximately the inner diameter of the $6-\mathrm{ft}$ thick concrete biological shield. Together, the structures form a pressure vessel around the primary tank. (Fig. XV.C-3)

A laminated blast shield formed by a] ternate layers of $1 / 2$-in carbon stee] plate shells and 4-in. thick low-density concrete is located between the primary tank and the biological shield. The biological shield is constructed of ordinary concrete reinforced with hoops of reinforcing rods. It is cooled by a forced circulation of air. (Ref. 3, 3add.) 
EBR-2 XV.C.

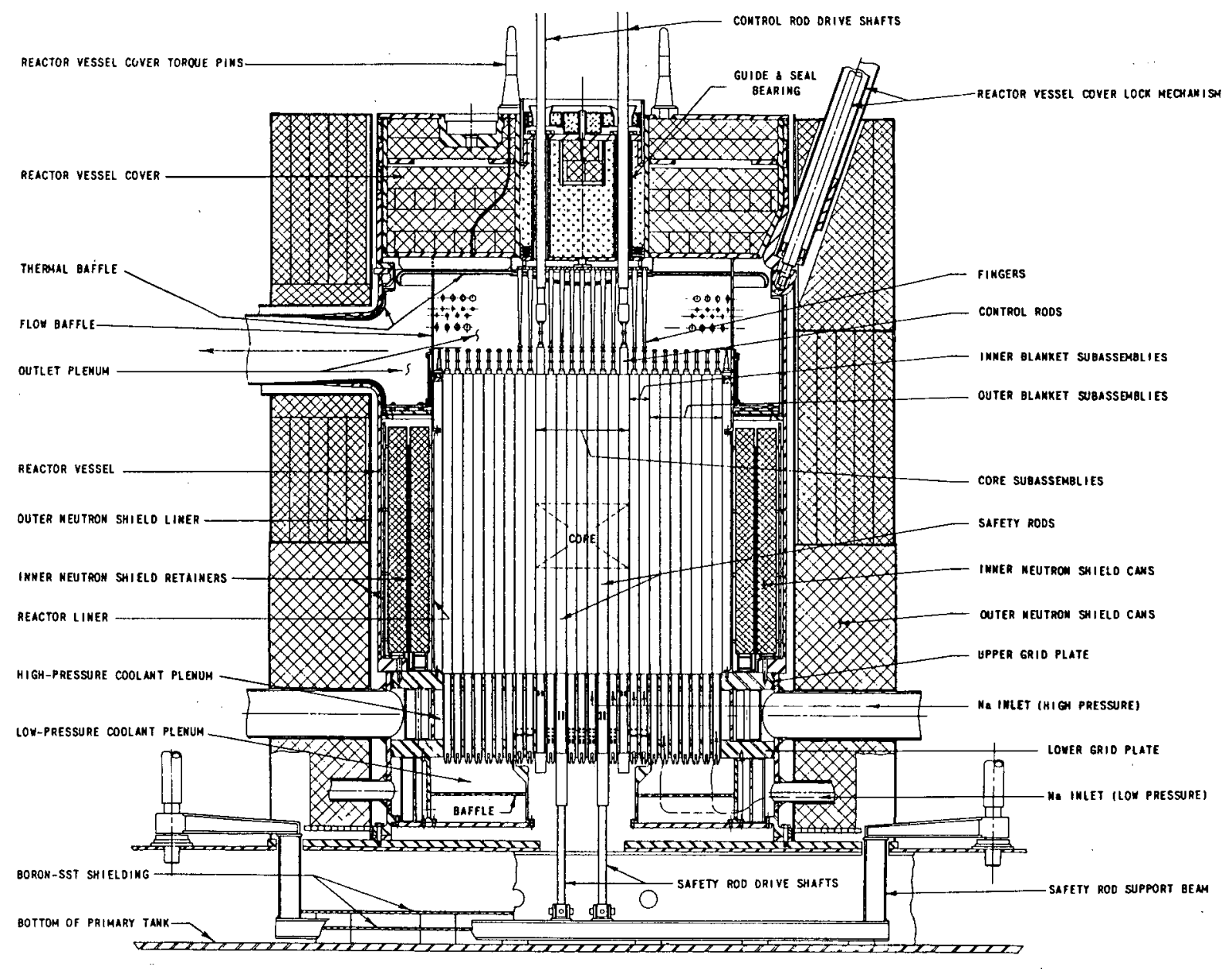

Figure XV.C-1 EBR-2 Reactor Vessel Assembly (Ref. 3 add) 
EBR-2 XV.C.

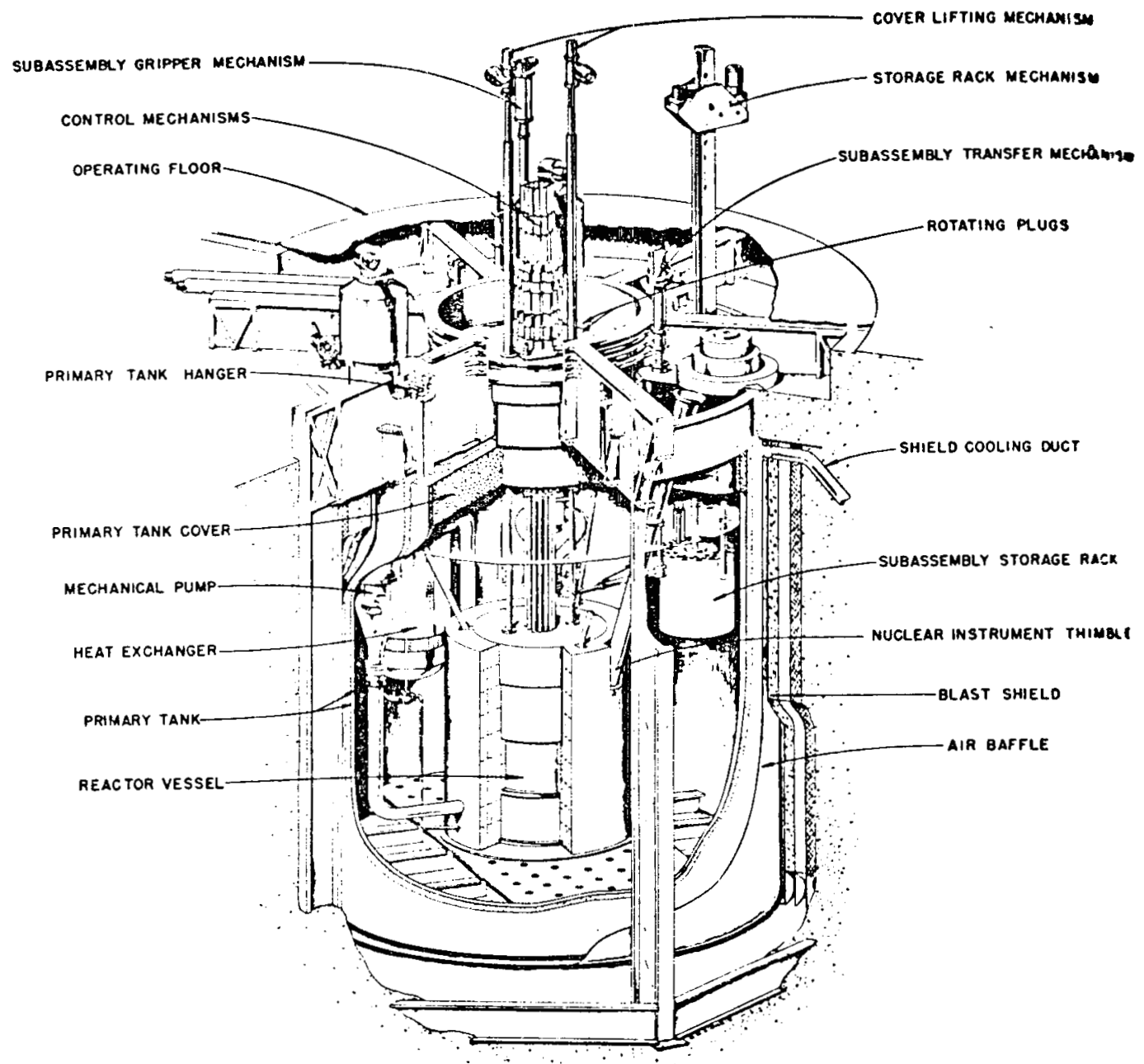

Figure XV.C-2 EBR-2 Primary Tank and Internals (Ref. 3 add)

$X V . C \cdot-3$ 
EBR-2 XV.C.

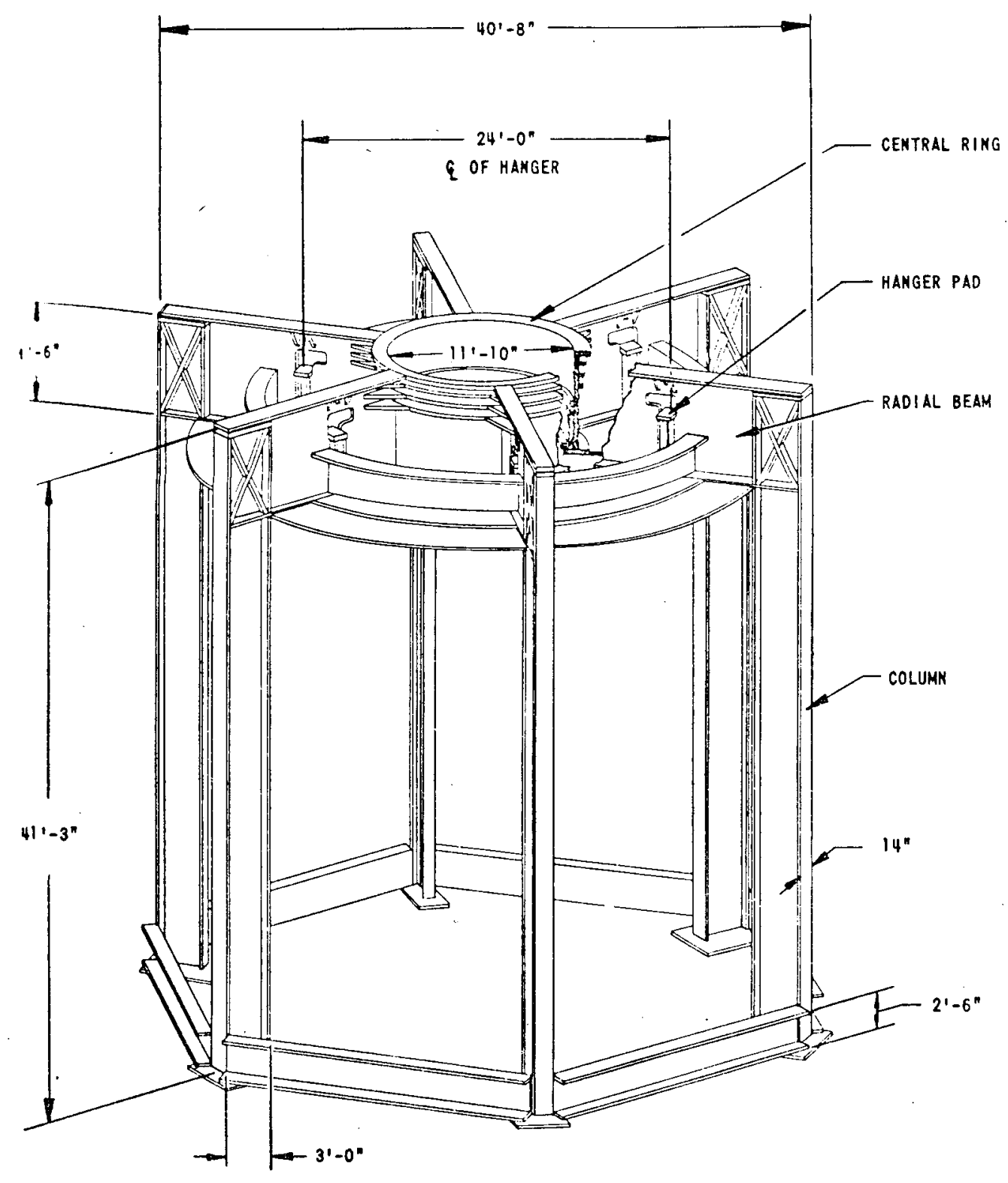

Figure XV.C-3 EBR-2 Primary Tank Support Structure (Ref. 3 add)

$X V . C-4$ 


\section{XV.D. CONTROL ELEMENTS}

EBR-2 has twelve contro] rods and two safety rods. All are fueled rod assemblies, consisting of a control rod and guide thimble. The guide thimble is hexagonal in cross section and has the same dimensions as the subassembly tube. Rods are modified core assemblies.

The control rod is encased in a hexagonal tube $1.908 \mathrm{in}$. across the flats. It is smaller than the thimble by the equivalent of one row of fuel elements. There is no axial blanket, but a void section equivalent in height to the reactor core is provided above the fuel section. The void is filled with sodium during operation. Vertical movement of the control rod adjusts the proportion of fuel or void in the reactor core region. A reflector section of steel is located above the void section. The upper end of the rod has an adapter section identical to that of the fuel subassemblies. The lower end is a cylindrical tube with a steel reflector section. The assembly is cooled by the high-pressure sodium which enters through a series of holes in the lower end of the thimble and the lower end of the control rod. A flowtwister device is installed immediately above the core section to minimize bowing of the control rod within the thimble. (Fig. XV.D-1)
The safety subassemblies are essentially identical to the control rod assemblies, except that there is no flowtwister device. They are fully inserted in the reactor at all times during operation and shutdown. They are attached to a common drive unit extending below the reactor structure. (Fig. XV.D-2)

The control rod is actuated by a long shaft extending through the upper biological shield, connecting the control rod to the drive mechanism. The shaft is driven by a rack and pinion at a rate of $5 \mathrm{in./minute} \mathrm{by} \mathrm{a} \mathrm{constant} \mathrm{speed,}$ reversible, polyphase motor. A magnetic latch connects the rack tube to the drive shaft. Interlocks insure that all parts are in proper operating position. A scram signal de-energizes the magnetic clutch, releases the shaft from the drive rack and drives the control rod down out of the reactor core. A release time of 0.008 seconds is expected. Deceleration of the stroke is provided by a hydraulic shock absorber connected to an air cylinder. A mechanical stop is built into the system. The twelve contro] drive mechanisms are mounted on a platform surrounding a central support structure. (Fig. XV.D-3) (Ref. 3,3-add.) 


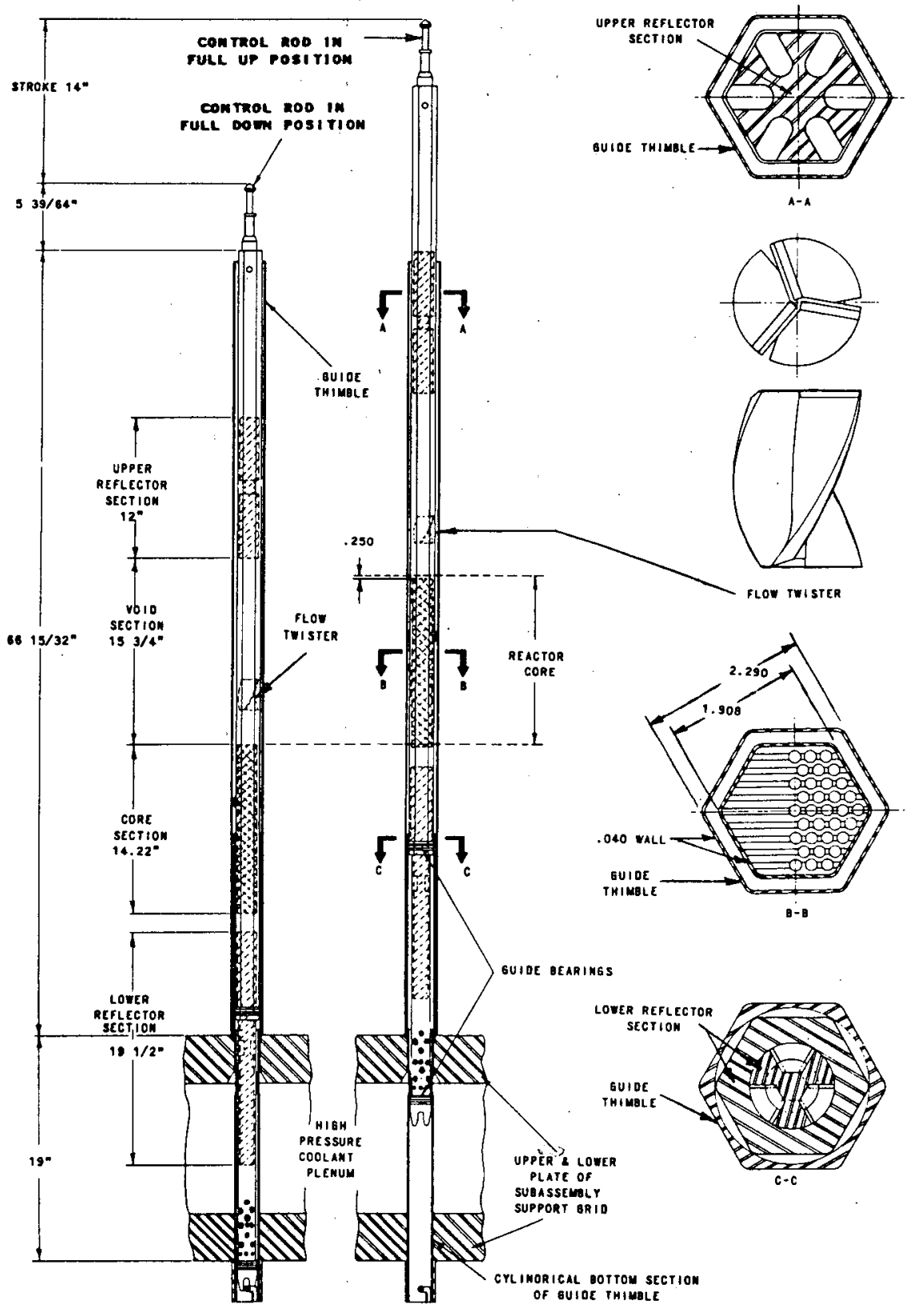

Figure XV.D-1 EBR-2 Control Rod (Ref. 3 add) 


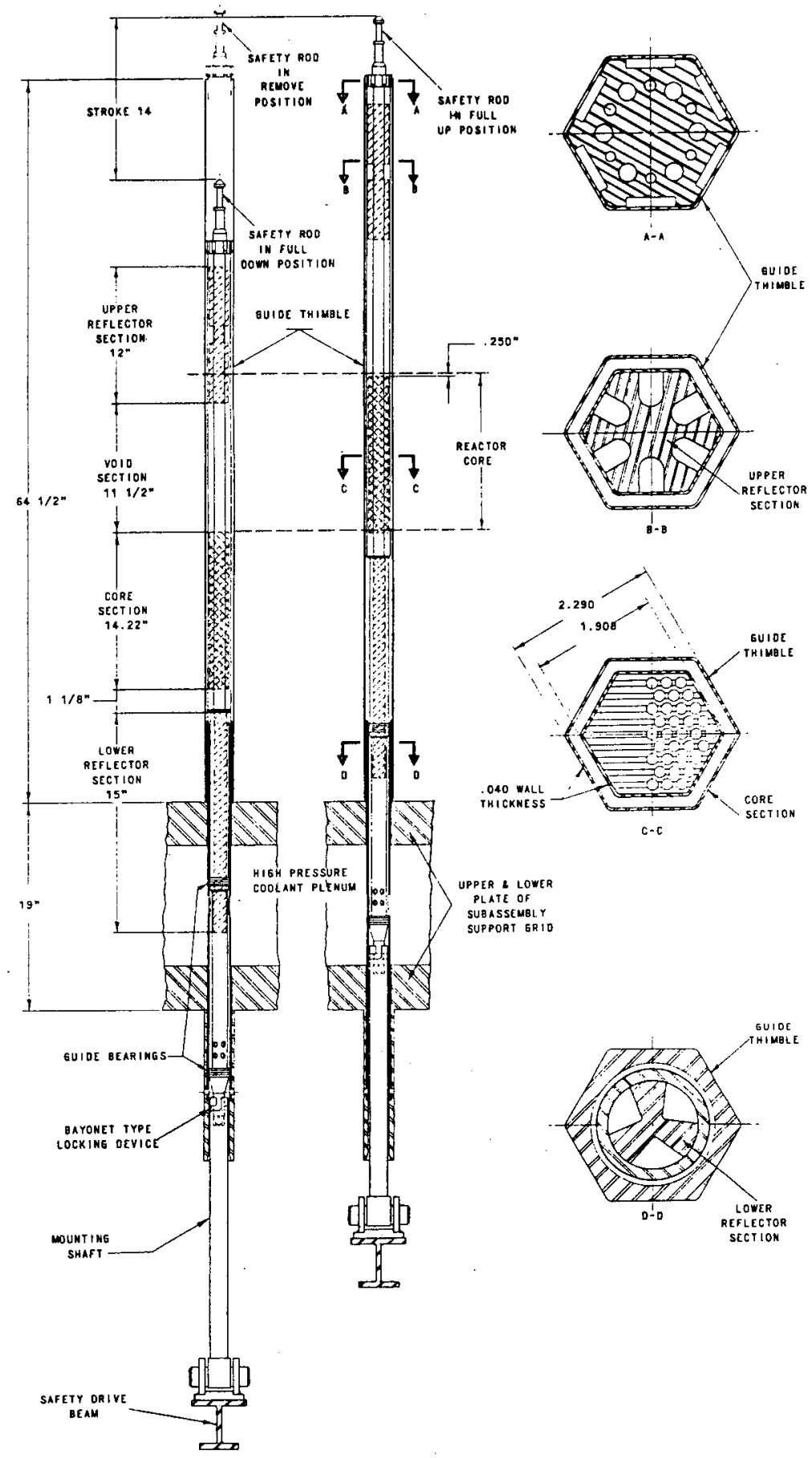

Figure XV.D-2 EBR-2 Safety Rod (Ref. 3 add) 
EBR-2 XV.D.

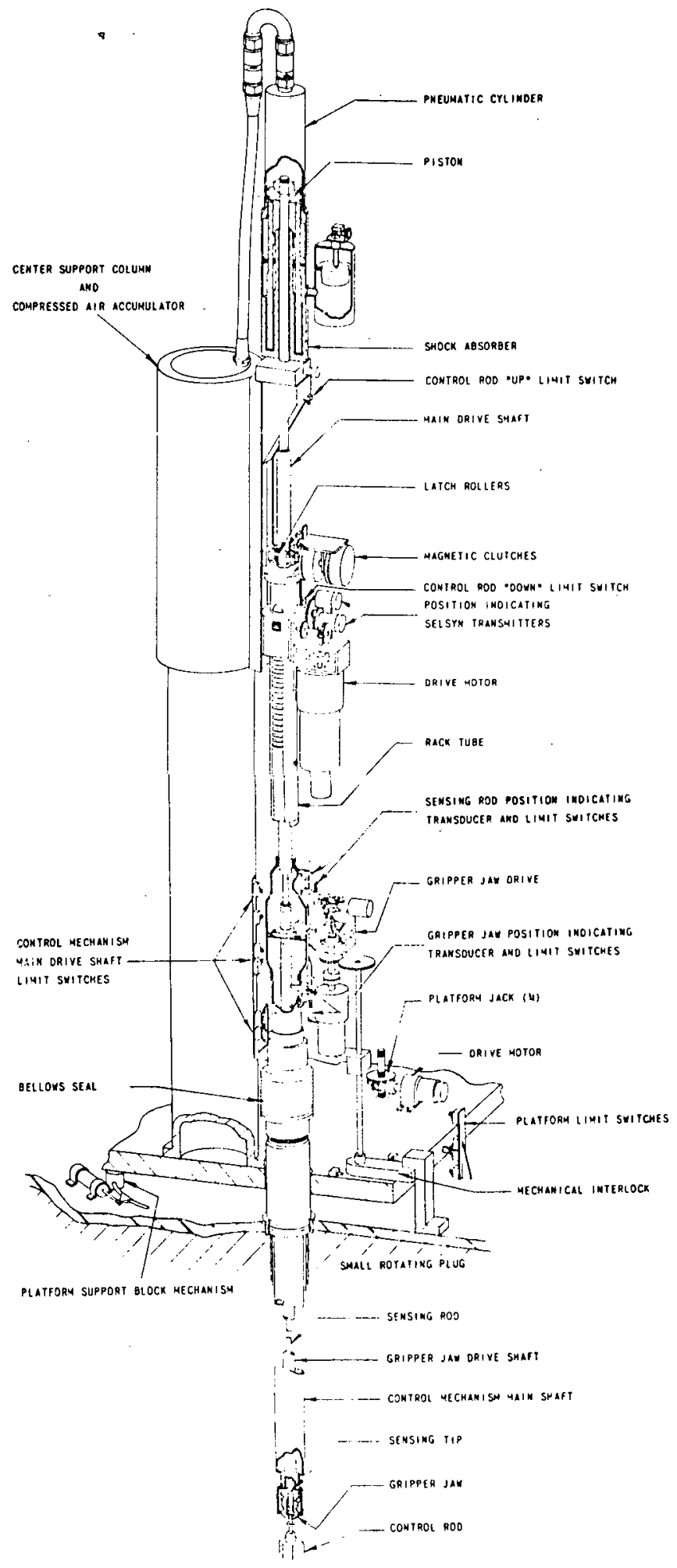

Figure XV.D-3 EBR-2 Control Rod Drive Mechanism (Ref. 3 add)

XV.D-4 


\section{XV.E. HEAT TRANSFER SYSTEMS}

EBR-2 has two centrifugal pumps which take sodium from the primary tank and feed it in two streams to the highpressure and low-pressure plenums of the reactor. Sodium flow is upward through the subassemblies to a common upper plenum with a single 14 in. outlet. The outlet nozzle is located on the opposite side of the vessel from the intermediate heat exchanger, and the connecting piping forms a helix-like spiral which accommodates thermal expansion. An auxiliary pump is located in this 1 ine. Primary sodium flows downward through the shell side of the intermediate heat exchanger and back into the primary vessel.

Pumps are vertically mounted, single stage centrifugal units driven by variable speed motors. Each pump delivers 4500 gal/min at full reactor power, with a maximum capacity of $5,000 \mathrm{gpm}$ at $85 \mathrm{psig}$. An integral shield plug contains about $33 \mathrm{in}$. of carbon steel balls and $34 \mathrm{in}$. high density concrete. Direct-coupled pump drives are totally enclosed, gastight, 480 volt a.c. motors. Labyrinth shaft seals are used. A radial hydrostatic bearing is located immediately above the impeller, to which sodium is supplied directly from the impeller discharge. The pump has a plug-in capability. (Fig. XV.E-1)

The secondary pump is an a.c. linear induction electromagnetic unit with a capacity of $6500 \mathrm{gpm}$ at $53 \mathrm{psi}$, and flow control almost down to zero.

The auxiliary pump is a $500 \mathrm{gal} / \mathrm{min}$ d.c. electromagnetic pump connected to a rectifier and batteries. Its purpose is to smooth transition from forced convection to natural convection under abnormal circumstances. (Ref. 1,3-add.)
The intermediate heat exchanger is a tube-in-shell unit with a removable tube bundle. Primary sodium flows downward through the shell side. Secondary sodium enters at the top and flows down through a down-comer, upward in the tube side of the heat exchanger. Tubes and she1l are stainless steel. Tube od is 0.625 in., wal1 thickness 0.062 in., and effective tube length is $9.16 \mathrm{ft}$. Effective surface is $4539 \mathrm{ft}^{2}$. Primary sodium inlet temperature is $880^{\circ} \mathrm{F}$, outlet $692^{\circ} \mathrm{F}$. (Fig. XV.E-2)

EBR-2 was designed to operate without valves in the primary or secondary systems. Fine flow is achieved in the secondary system by an a.c. electromagnetic pump.

Shut-down cooling is either by forced convection or natural convection. During normal shut-down the primary pumps continue to operate, with assistance from the auxiliary pump, and heat is transferred to the secondary system, following the normal circuit back to the bulk sodjum.

If the secondary system is inoperative, and heat is not removed from the primary tank, the gradual increase in temperature of the sodium is relieved by two shut-down coolers, which remove heat entirely by natural circulation. Each cooler system consists of a bayonet-type exchanger immersed in the primary tank, with NaK as the coolant. An NaK/air heat exchanger mounted in a stack outside the containment building exhausts to the atmosphere.

- Each cooler is designed to remove $250 \mathrm{~kW}$ of heat. (Fig. XV.E-3) 
$E B R-2 \quad X V . E$

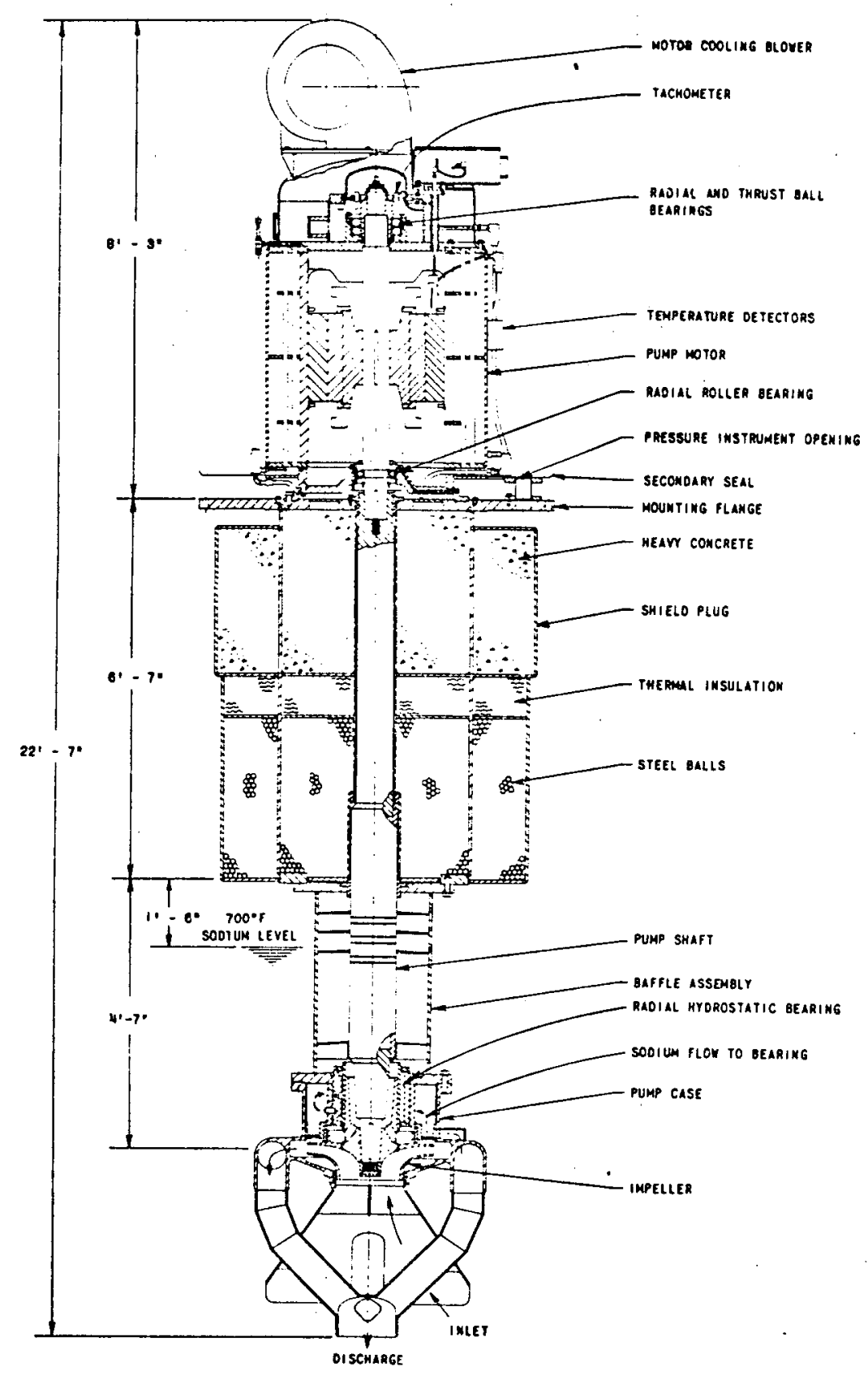

Figure XV.E-1 EBR-2 Primary Pump (Ref. 3 add)

$X V . E-2$ 
EBR-2 XV.E.

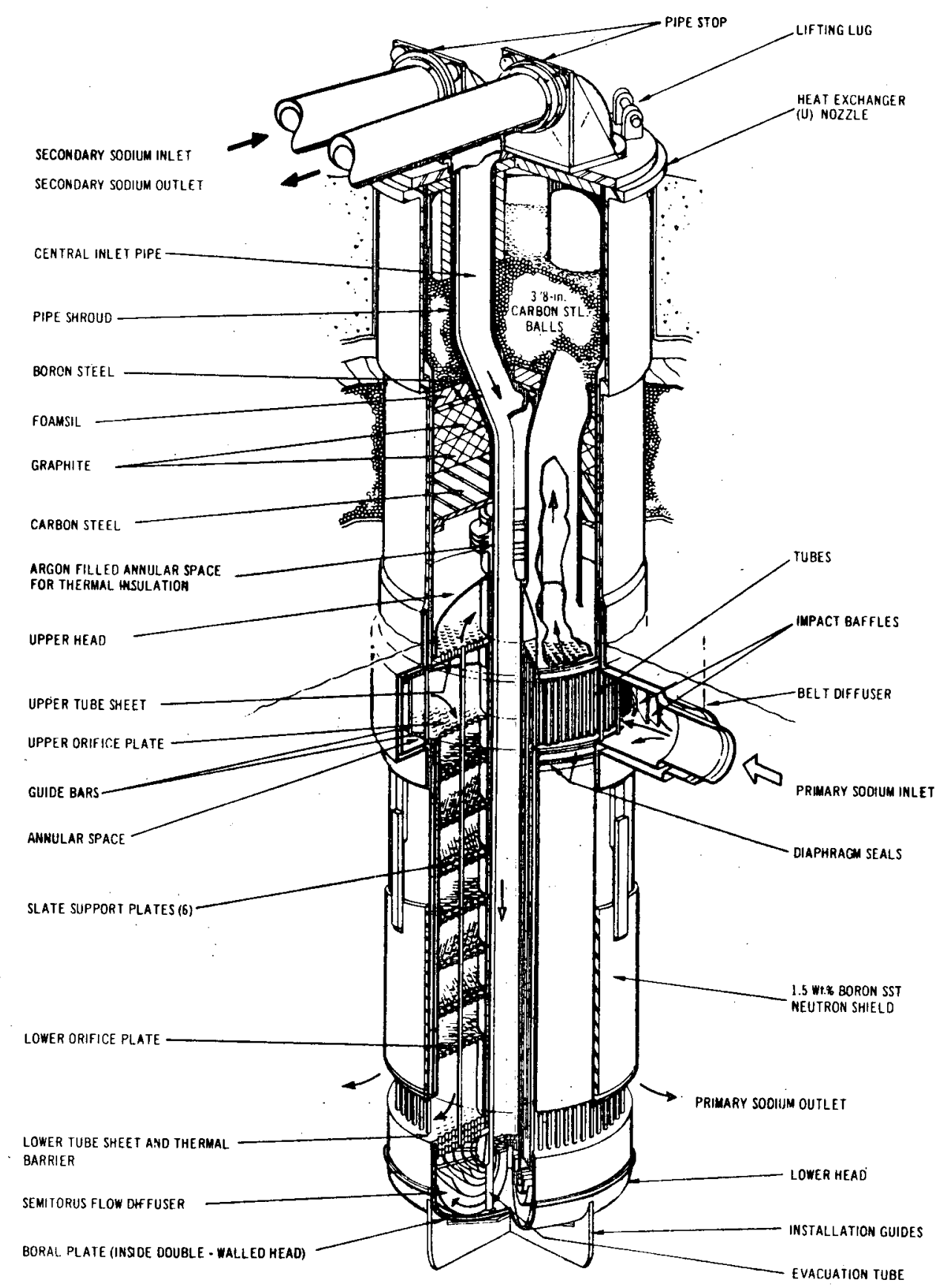

Figure XV.E-2 EBR-2 Intermediate Heat Exchanger (Ref. 3 add)

$X V . E-3$ 
EBR-2 XV.E.
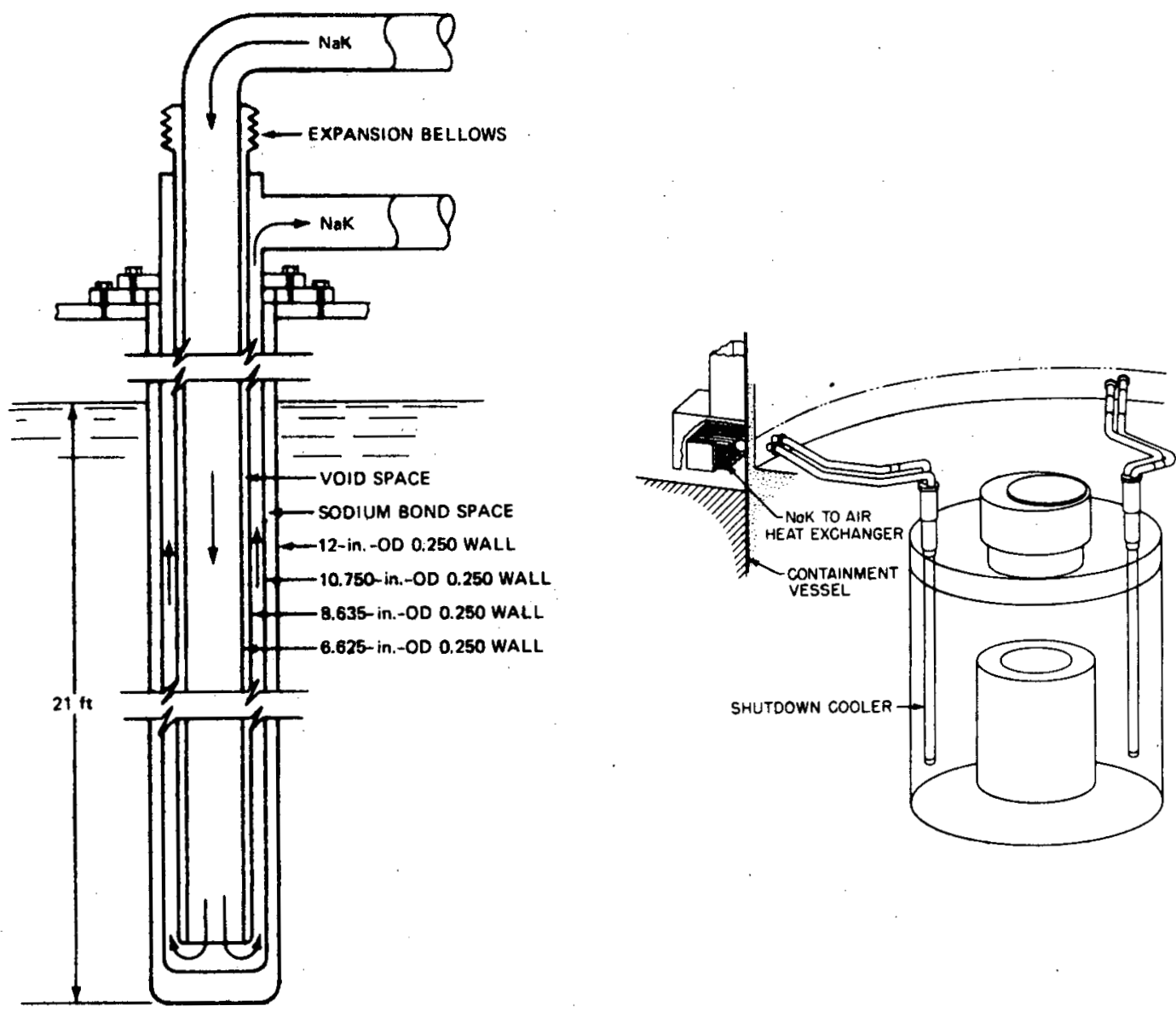

Figure XV.E-3 EBR-2 Shut-Down Cooler and Cooling System (Ref. 1)

$X V . E-4$ 
XV.F. SODIUM PURIFICATION AND INSTRUMENTATION

A recirculating cold-trap system is used for continuous primary sodium purification. The trap is a 500 gal. tank filled with stainless steel wire-mesh. A regenerative heat exchanger is incorporated in the main sodium stream to reduce heat losses in the cold-trap system. Operational temperature of $350^{\circ} \mathrm{F}$ is maintained by a secondary sodium cold-trap loop. For monitoring sodium quality, a plugging indicator is mounted on the cold-trap inlet line, and two vacuum cup samplers remove sodium samples from the cold-trap inlet or discharge line. A single tank is included in the cold-trap line to prevent syphoning of the primary sodium. The cold-trap discharge line empties into a splash sleeve in the gas space of the primary tank. Five remotely controlled valves on the cold-trap line can isolate various sections of the circuit. The cold-trap inlet and discharge lines are pitched to drain back into the primary tank. An argon blanket is maintained over all free surfaces.

Contact leak detectors are installed in the pump housing and on the floor of the Sodium Purification Cell. A leak monitoring device is included in the ventilation system for this cell. Any one of the devices can shut down the purification'system. (Ref. 3,3-add.)

Four permanent magnet flow-meters have been installed in subassembly inlet regions. Chromel-alumel thermocouples are used as active in-core sensors to monitor temperatures of the cladding, coolant, structural specimens, and metal fuel. Tungsten/rhenium couples are used to monitor fuel centerline temperatures of experimental oxide fuels. (Ref. 5) 
XV.G. COVER GAS AND AUXILIARY SYSTEMS

Argon cover gas over EBR-2 primary sodium is normally stagnant, except for mixing due to natural convection currents. Fission product activities are monitored by three on-line systems and by periodic sampling. On-line systems withdraw gas from one nozzle, which also feeds the Xenon tag trap system, the cover gas purge system, the gas chromatograph, and several experimental facilities. A floating-head tank controls argon blanket-gas pressure to within $t$ in. $\mathrm{H}_{2} \mathrm{O}$ pressure differential with respect to the building atmospheric pressure. (Ref. 3-add.)
Shut-down cooling is described in Section XV.E.

The biological shield is cooled by a forced circulation of air. The system is part of the building ventilation system, and the air is exhausted from the building through the shield cooling system, which operates at a pressure slightly below that of the building atmosphere. The top structure and shield plugs, the radial shield and the structure below the primary tank, are cooled primarily by recirculating air. (Ref. 3) 


\section{XV.H. STEAM GENERATORS}

The steam generator consists of a natural circulation evaporator, a conventional steam drum, and a once-through superheater. Individual units are shel1and-tube design with double tubes and double tube sheets. The evaporator section has eight identical units connected in parallel on the tube side to a horizontal, overhead steam drum with conventional moisture separation internals. Dry and saturated steam flows from the top of the steam drum down through four identical, vertical superheaters and into the turbine generator unit. The steam system is all chrome-moly steel. Two evaporators were modified by coring the evaporator tubes with an 0.812 in. od tube to be used as superheaters, increasing steam velocity in the annulus. (Fig. XV. $\mathrm{H}-1, \mathrm{H}-2$ )
The secondary sodium system has been provided with a relief system to accommodate a pressure surge in the event of a sodiumwater reaction. The system consists of two duplex, 10 in. blow-out diaphragms, one connected to the 10-in. header which interconnects the superheaters and evaporators. Rupture of the diaphragms allows sodium to flow from the header into a 1200 gal. relief tank. The tank communicates with the atmosphere via two 12 in. lines, each supplied with a rupture diaphragm set at 25 psi.

Turbine steam admission valves are controlled as a function of the pressure in the steam system to maintain a constant steam pressure. Electrical energy generated is a direct function of reactor power, and is independent of electrical demands. (Ref. 3-add.) 
EBR-2 XV.H.

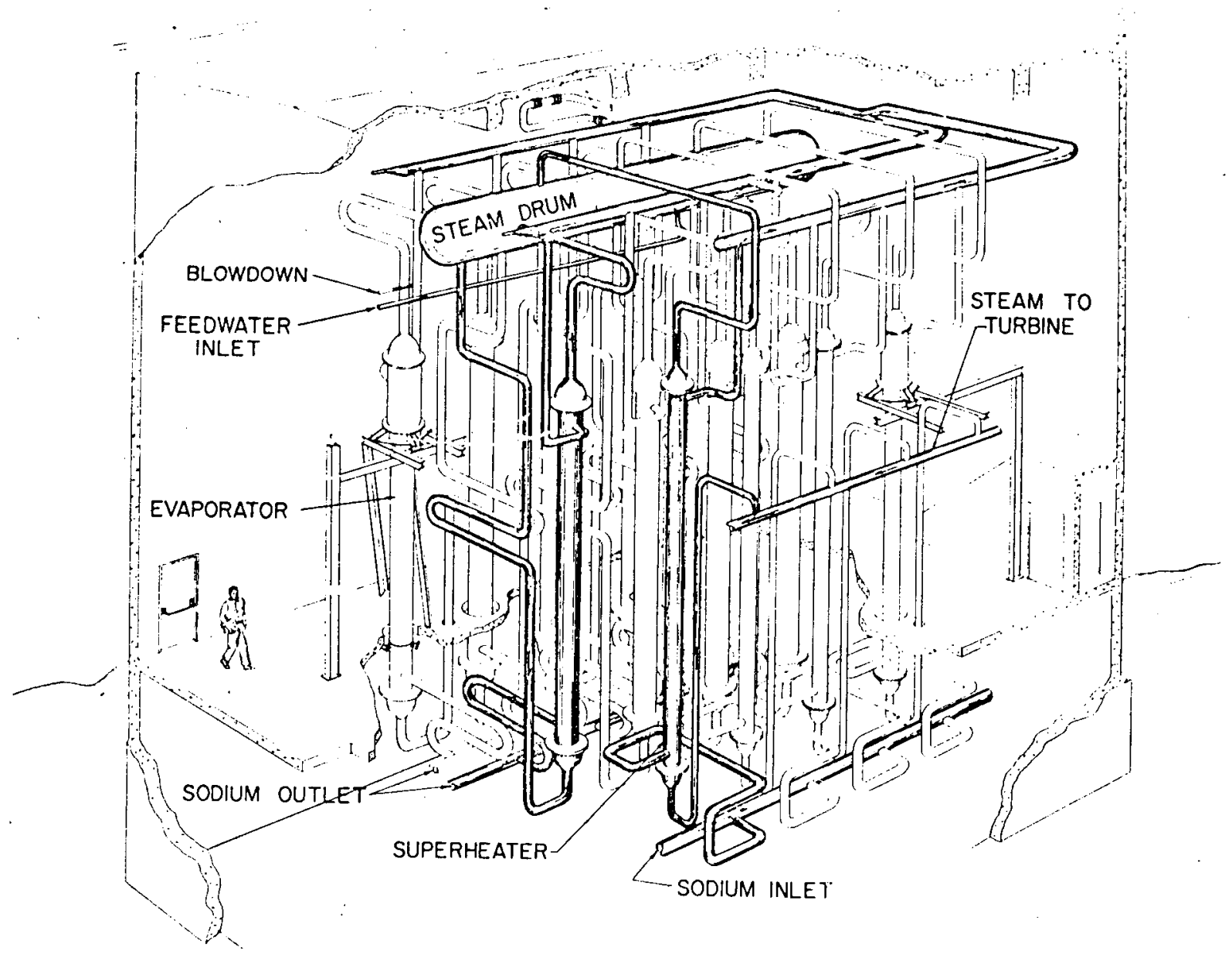

Figure XV.H-1 EBR-2 Steam Generator (Ref. 3 add)

$X V . H-2$ 

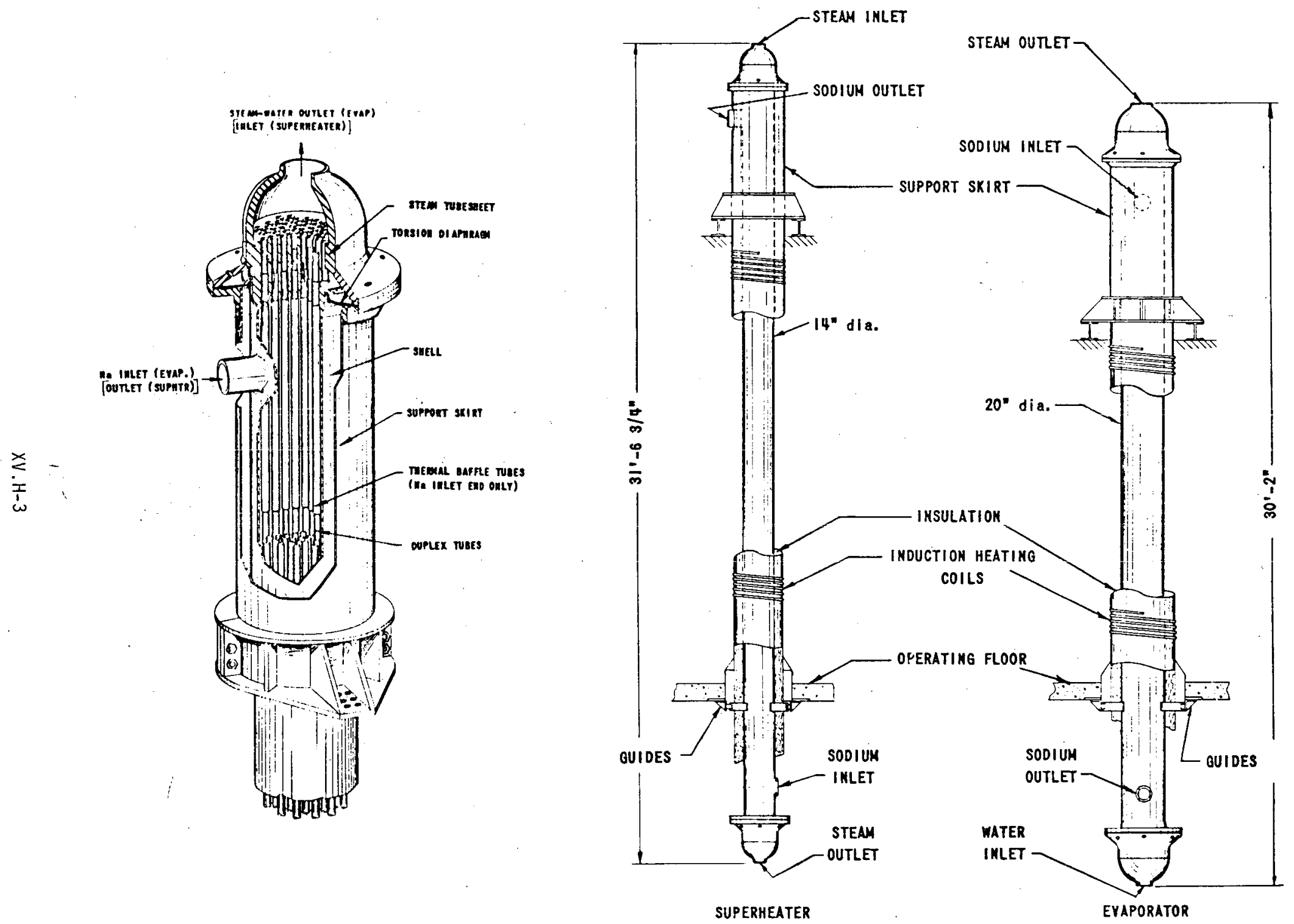

Figure XV.H-2 Superheater and Evaporator Assemblies (Ref. 3 add) 
EBR-2 XV.I.

XV.I. REACTOR INSTRUMENTATION AND CONTROL.

Instruments for measuring neutron flux and reactor period include eleven channels. Each channel has detectors, amplifiers, and read-out equipment.

Three fission counter channels indicate reactor period and record $10 \mathrm{~g}$ count rate, and provide a startup level interlock which withholds control power for reactor operation or for fuel handling. For reactor operation, period trips are connected in coincidence, with two out of three channel trips causing reactor scram. For fuel handling operation, the period trips, long count rate trips, and counter high-voltage trips are connected in series. Any trip will scram the safety rods.

Three compensated ion chamber channels indicate reactor period and record $\log N$. During operation or fuel handling, two out of three trips will scram the reactor.

One compensated ion chamber covers the linear level range and records reactor power level. Linear indication of reactor power level is given on an expanded scale obtained by manual range switching. Trips may be by-passed by a keyswitch on the console, and will be used only for experimental operations. An interlock requires that the range switch be set at the correct low range.
The high-flux level range is covered by three compensated ion chamber channels which record reactor power level. Trip of two out of three channels scrams the reactor. Channel trips are connected in coincidence.

The automatic flux level control system is designed to maintain reactor power at $+1 \%$ of a preselected power level after equilibrium operation at that level has been established manualiy by the operator. It consists of a comparator circuit and amplifier with a relay output. The system provides automatic flux level control, using only one rod at a time. Any of the twelve control rods may be selected for this purpose. (Ref. 3-add.)

The EBR-2 fuel failure monitor (Fuel Element Rupture Detection Loop) samples coolant at the Intermediate Heat Exchanger (IHX) At a site shielded from core neutrons, a graphite stack surrounds a section of this loop in order to moderate fast neutrons emitted by the delayed neutron emitters down to the region of cross-sections useful for detection. Th $20 \mathrm{ft} .{ }^{3}$ stack has eight $\mathrm{BF}_{3}$ proportional counters. Signals are processed through electronic circuitry and provide two to four output channels. A mag-tape memory can temporarily store and display data on command. The system disseminates against gamma background. Detection efficiency is nearly $1 \%$. (Ref. 6) 


\section{XV.J. FUEL HANDLING}

In EBR-2 fuel handling, the first step is a transfer of subassemblies between the reactor and the storage basket, with the reactor shut-down. The second step is a transfer of subassemblies between the storage basket and the fuel-cycle facility via an interbuilding coffin while the reactor is operating.

The fuel-handling system includes the gripper and hold-down mechanisms for removing (and installing) subassemblies from the reactor, the transfer arm for transferring subassemblies between the gripper and the storage rack, and the storage rack. Operation of the rotating plugs and their freeze seals, and certain operations of the control rod and safety rod drives, are included. The gripper mechanism is an electro-mechanical device mounted on the small rotating shield plug and extending into the sodium of the primary tank. The hold-down mechanism is an electro-mechanical device working in conjunction with the gripper mechanism, also mounted on the small rotating shield plug. The transfer arm is a manually operated and electricaliy controlled device which transports subassemblies between various points in the fuelhandling and unloading systems. The storage rack is an electro-mechanical mechanism to provide temporary storage for new and spent fuel and blanket assemblies. It is suspended from the primary tank cover and fully submerged in sodium at all times. The rack is cylindrical, with a capacity of seventy-five subassemblies. (Fig. XV.J-T)
A subassembly dropped from the transfer arm at any point will drop into a funnel-shaped trough or "subassembly basin" which traverses the area under much of the transfer arm path. It would slide into a retrieving position, standing in a vertical attitude. (Fig. $X V . J-2)$

The fuel unloading system transfers subassemblies between the primary tank and the interbuilding coffin. Components include the storage rack, transfer arm, transfer port, and fue] unloading machine. The transfer port provides access to the inside of the primary tank, and is basically a large manually operated valve. There are provisions for argon gas during operation.

The fuel unloading machine is an electro-mechanical device which transfers the subassemblies from the transfer arm inside the primary tank to the interbuilding coffin. It is a shielded container carriage assembly mounted on tracks. Mechanisms include a gripping device, an argon gas circulating system, and a drive unit. (Fig. XV.J-3)

Fuel handling is semi-automatic, with the operator initiating instructions relating to the sequence of operations. The system will only respond to correct instructions. (Ref. 3-add.)

Subassemblies decay in the primary tank storage rack for about two weeks, generating about 2300 watts of decay heat at the end of the two week period. Burnup has usually been about $1 \%$. 
EBR-2 XV.J.

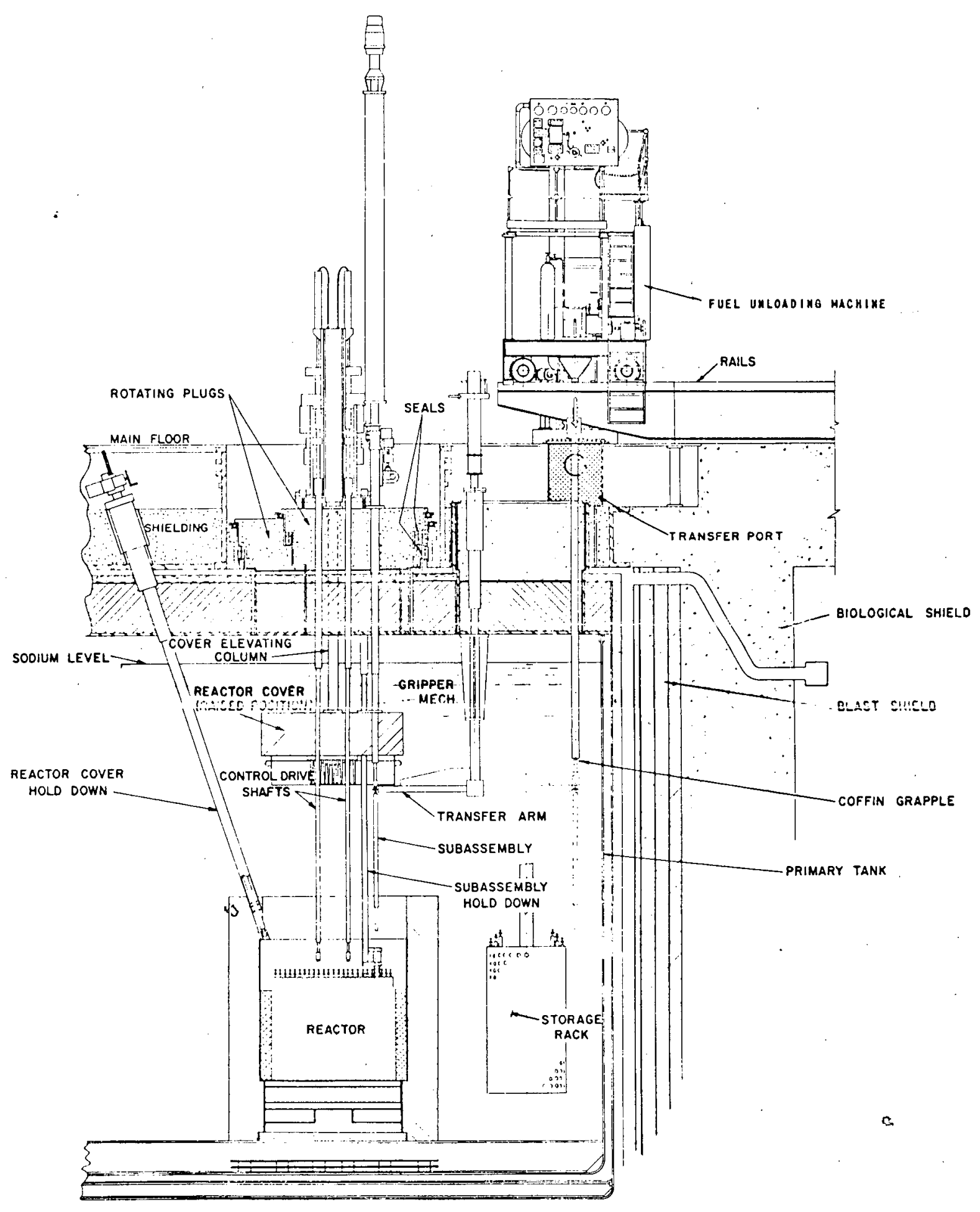

Figure XV.J-1 EBR-2 Fuel Handling System (Ref. 3 add)

XV.J-2 

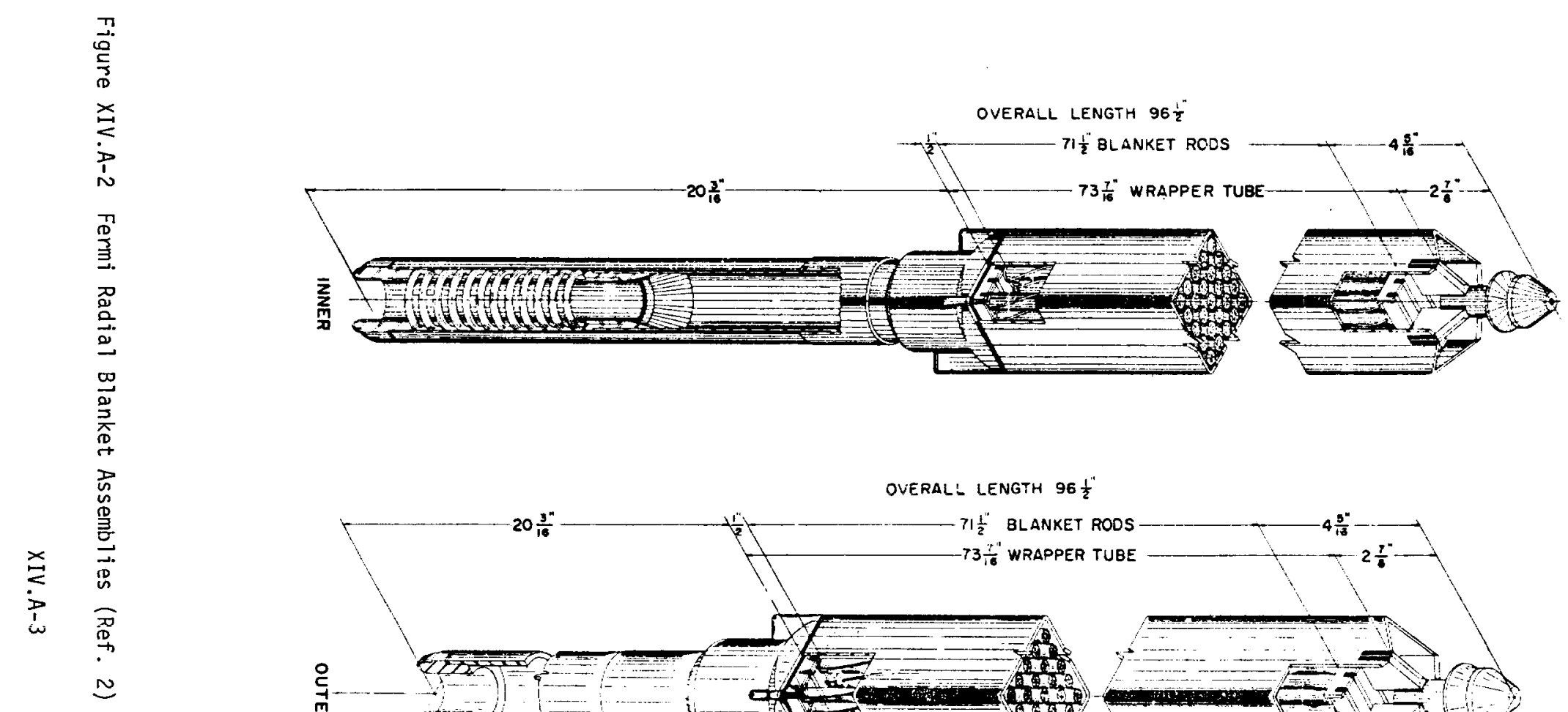

OVERALL LENGTH $96 \frac{1}{2}$

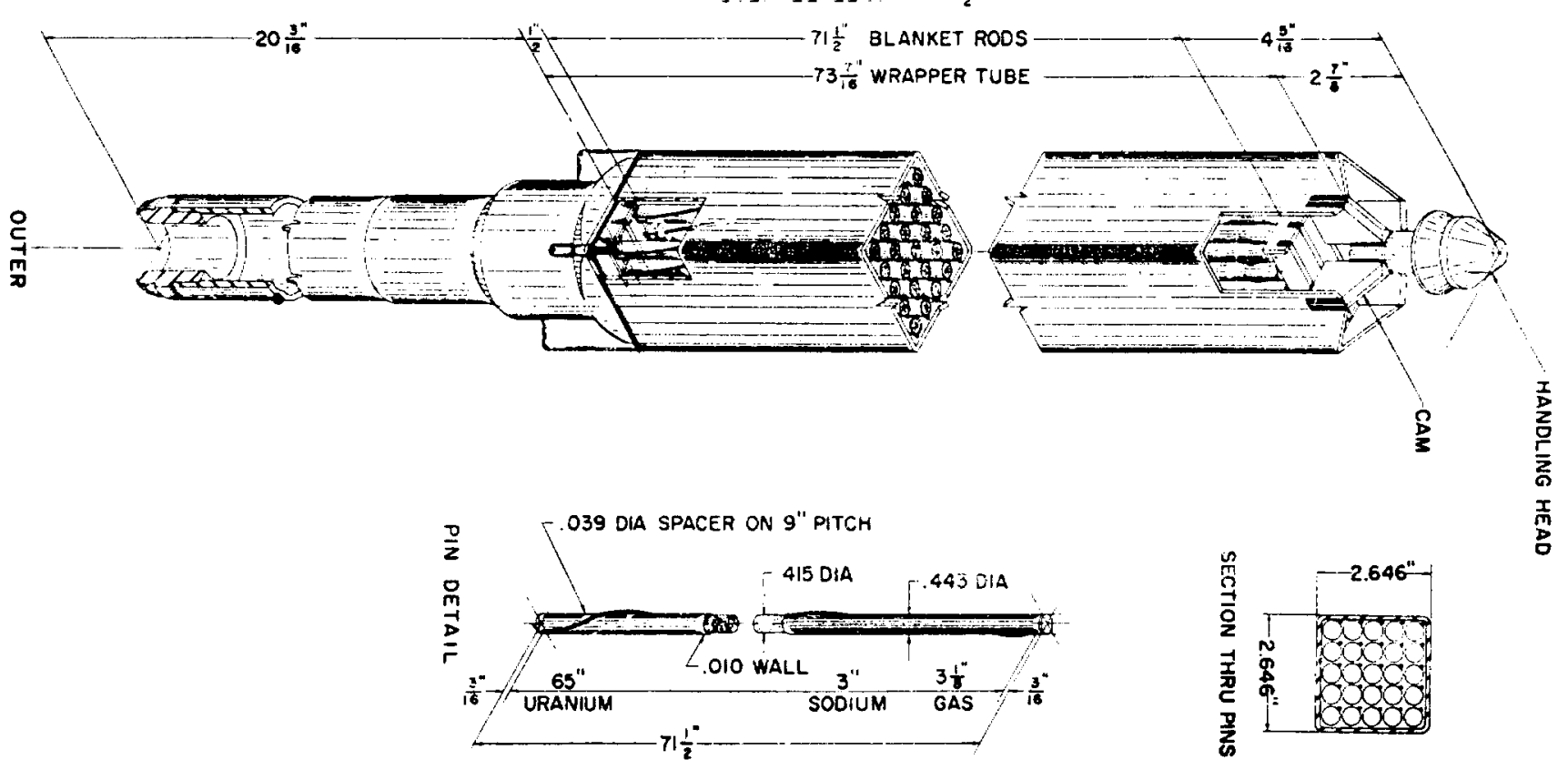


EBR-2 XV.J.

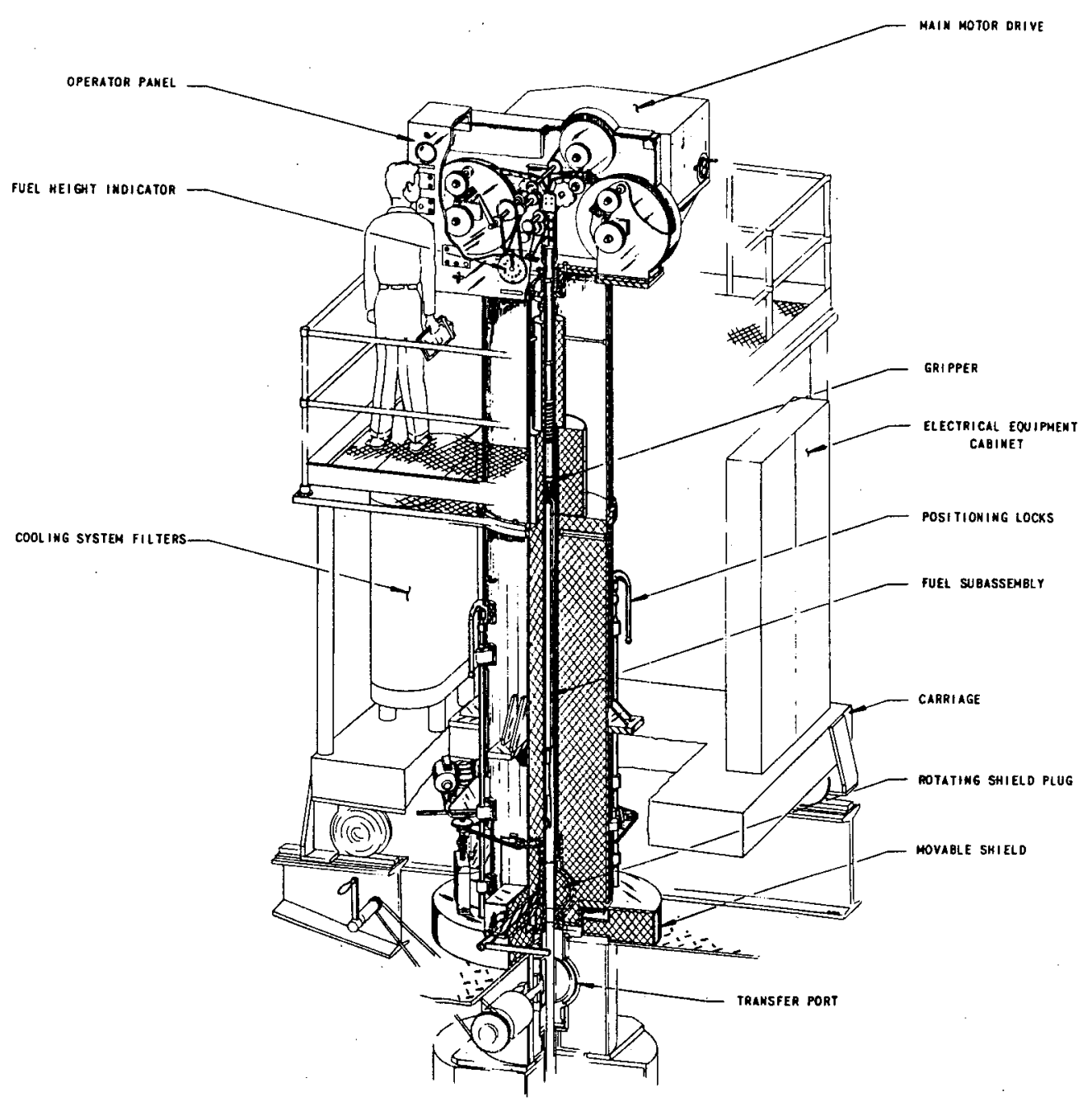

Figure XV.J-2 EBR-2 Subassembly Basin (Ref. 3 add) 

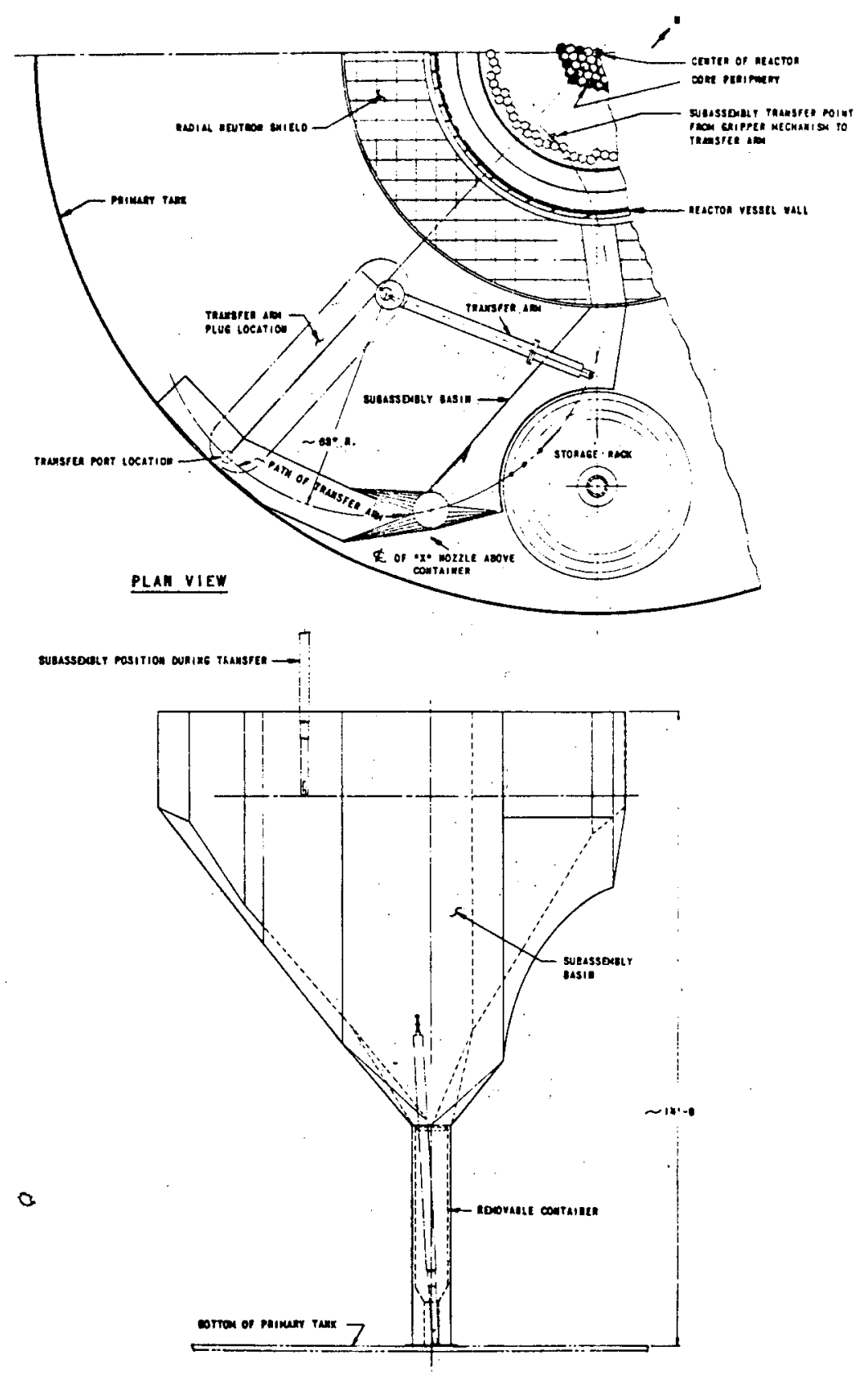

Figure XV.J-3 EBR-2 Fuel Unloading Machine (Ref. 3 add) 


\section{XV.K. CONTAINMENT}

The containment shell is a steel cylinder with hemispherical top head,

$80 \mathrm{ft}$. id and $2746 \mathrm{ft}$. high. $48 \mathrm{ft}$. are

below grade. Thickness of the cylindrical

section is 1 in. The shell is gas-tight.

Concrete insulation over the inner surface

is a minimum of $14 \mathrm{in}$. thick. The top

shell closure is protected by 6 in. thick

high temperature insulation lined with

sheet steel. (Ref. 3) 
LOCATION: Richland, Washington OPERATION: Target: 1977

The Fast Flux Test Facility (FFTF) under construction near Richland, Washington, will be the primary test installation in the United States LMFBR program.

Prime contractor for the project is the Westinghouse Hanford Company, Hanford Engineering Development Laboratory, under contract to the AEC (now ERDA). Site preparation was started in 1970. Target date for project completion is November 1977.

The Final Safety Analysis Report is being prepared. 


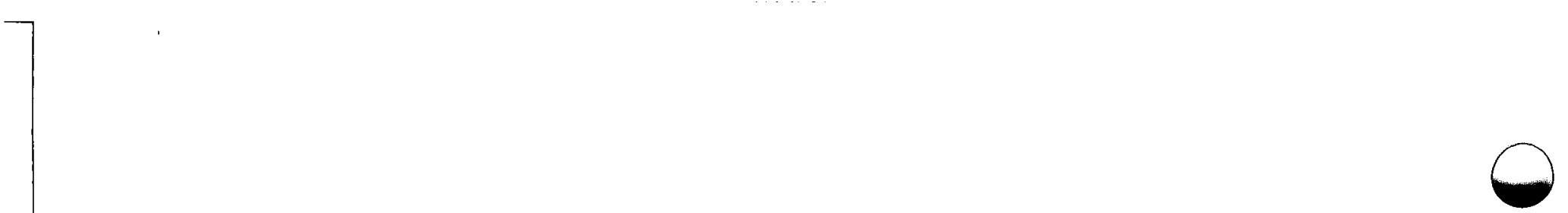

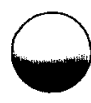

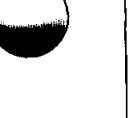

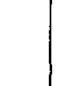


INDEX

REFERENCES

REACTOR PARAMETERS

SECTIONS
Page

XVI-5

XVI -7

XVI.A-1

XVI.B-1

XVI.C-1

XVI.D-1

XVI.E-1

XV I.F-1

XVI.G-1

XVI.I-1

XVI.J-1

XVI.K-I 


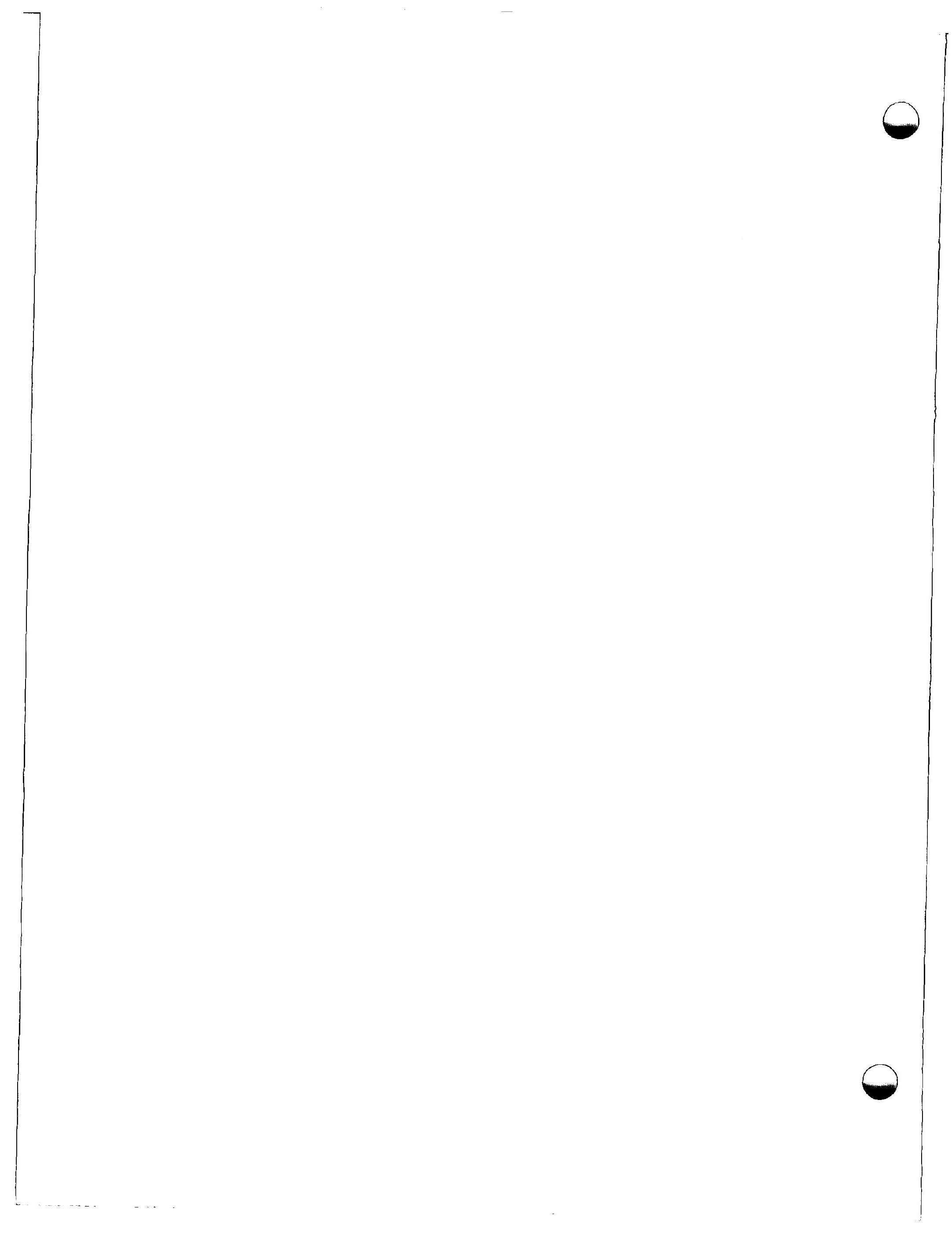




\section{REFERENCES}

1. Fast Flux Test Facility Preliminary Safety Analysis Report WADCO Corporation WASH-1227, Vol. 1 and 2, Sept. 1970

2. Fast Flux Test Facility Nuclear Eng. Int?., Vol. 17 No. 195 (August 1972)

FFTF site and Construction. A.A. Simons, p. 615-617

Fuel, Component Design, and Technology. S. Cerni, G. Last, p. 617-619

The FFTF Reactor and Coolant System. J.E. Werle, et. al., 619-623 Fuel and Core Component Handling. C.L. Boyd, et. al., p. 623-625 Instrumentation and Control. J.W. Mitchel1, F.M. Heck, p. 625-627 Sodium Technology. D.W. Shannon, W.R. Wykoff, p. 627-628

3. Status and Experimental Progress in the LMFBR Program

E. E. Kintner, et. al.

Proc. Fourth Int]. Conf. Peaceful Uses of Atomic Energy, Geneva 1971, vol. 5, p. 169-184

4. Development and Testing of Sodium Components

H. Diekamp, et. al

Proc. Fourth Int1. Conf. Peaceful Uses of Atomic Energy, Geneva 1971, Vol. 5, p. 185-200

5. Fast Flux Test Facility

J. E. Nolan, et. al.

Fast Reactor Power Stations, Proc. BNES, Int1. Conf. London, March 1974, p. 71-84

British Nuclear Energy Soc., 1974

6. FFTF Fuel Pin Design Bases and Performance

C. M. Cox, et. a1.

Nuclear Energy Maturity Trans., Ist Conf. European Nuclear Soc., Apri1 1975

ANS Trans., Vol. 20, April 1975, p. 313-315

7. Evolution: FTR Fuel Pin Design to procurement

C. A. Burgess, P.M. French

Fast Reactor Fuel Element Technology, Proc. ANS Conf.,

Apri1 1971, p. 21-45

American Nuclear Society, 1971

8. Irradiation Test Capabilities of the FFTF

D. P. Schively

Radiation Experimentation in Fast Reactors, Proc. ANS Topical

Meeting, Sept. 1973, p. 137-165

American Nuclear Society, 1973

9. The Design of the Intermediate Heat Exchanger for

the Main Coolant Loop of the FFTF

W. Wolowodiuk, B. E. Dawson

ASME 73-PWR-12, (ASME-IEEE Joint Power

Generation Conference, Sept. 1973-preprint)

- American Society Mechanical Engineers 
10. Large Sodium Valve Design and Operating Experience

in the United States

J. D. Melton

International Working Group on Fast Reactors,

Specialists Meeting on Operating Experience and Design

Criteria of Sodium Valves, Richland Washington, Sept. 1974

CONF-740964, p. 413-464

IAEA.

11. Boron Carbide Performance in Fast Reactors

W. F. Sheely, et. al. (Oral presentation text)

HEDL-SA-756 (1975)

12. Fast Flux Test Facility In-Vessel Handling Machine

J. E. Kinzer

ASME 74-PWR-9

Preprint, IEEE-ASME Joint Power Generation Conf., Florida, Sept. 1974

American Soc. Mechanical Engineers

13. FFTF Scale Model Structural Dynamics Tests

D. D. Stepnewskie, et. al.

Proc. Fast Reactor Safety Meeting, California, April 1974

CONF-740401-P2, p. 679-700

14. Testing Experience with Fast Flux Test Facility (FFTF)

Prototype Components

B. H. Noordhoff, et. al.

HEDL-SA-916 (March 1975)

15. Analysis of a Static Core-Restraint System for FTR

P. J. Fulford, et. al.

ANS Trans., Vol. 15, p. 325-326 (June 1972)

16. Fuel Pin Enrichment for FTR Cores 1 and 2

S. Ramchandran, et. al.

WARD-2171-26 (Jan. 1973)

17. Design of the Intermediate Heat Exchanger for the Main Coolant Loop of the FFTF

W. Wolowodiuk, B. E. Dawson

Joint Power Generation Conf. Sept. 1973

CONF-730918-1 (1973) 
Table - 1

Type

No. Toops

Coolant

Core inlet temp.

Core outlet temp.

Flow direction

Driver fuel

Blanket fuel

Core volume

No. enrichment zones in core

Output MWt

Max. can temperature

Neutron flux, total

Doppler $(\Delta k / k) /{ }^{\circ} \mathrm{C}$ total

Power Density

No. Driver Elements

No. Radial blanket elements

No. In-core control elements

Test positions

In-vessel storage positions

Goal burnup
GENERAL PARAMETERS

Loop-type

3

Sodium

$376^{\circ} \mathrm{C}\left(600^{\circ} \mathrm{F}\right)$

$482^{\circ} \mathrm{C}\left(900^{\circ} \mathrm{F}\right)$

Upward

$\mathrm{UO}_{2}-\mathrm{PuO}_{2}$

No. breeder blanket

$1040 \ell$

2 (28 inner elements, 45 outer)

$400 \mathrm{MWt}$

$670^{\circ} \mathrm{C}$ (hot spot)

Peak $7 \times 10^{15} \mathrm{n} / \mathrm{cm}^{2} \mathrm{sec}$

(-) 0.005

$0.39 \mathrm{MW} / \mathrm{e}$

73

Reflectors: 99

$9\left(B_{4} C\right)$

Open 5, closed loop capability 6

3 modules

$80,000 \mathrm{MWD} / \mathrm{T}$ peak

XVI -7

$D$ 


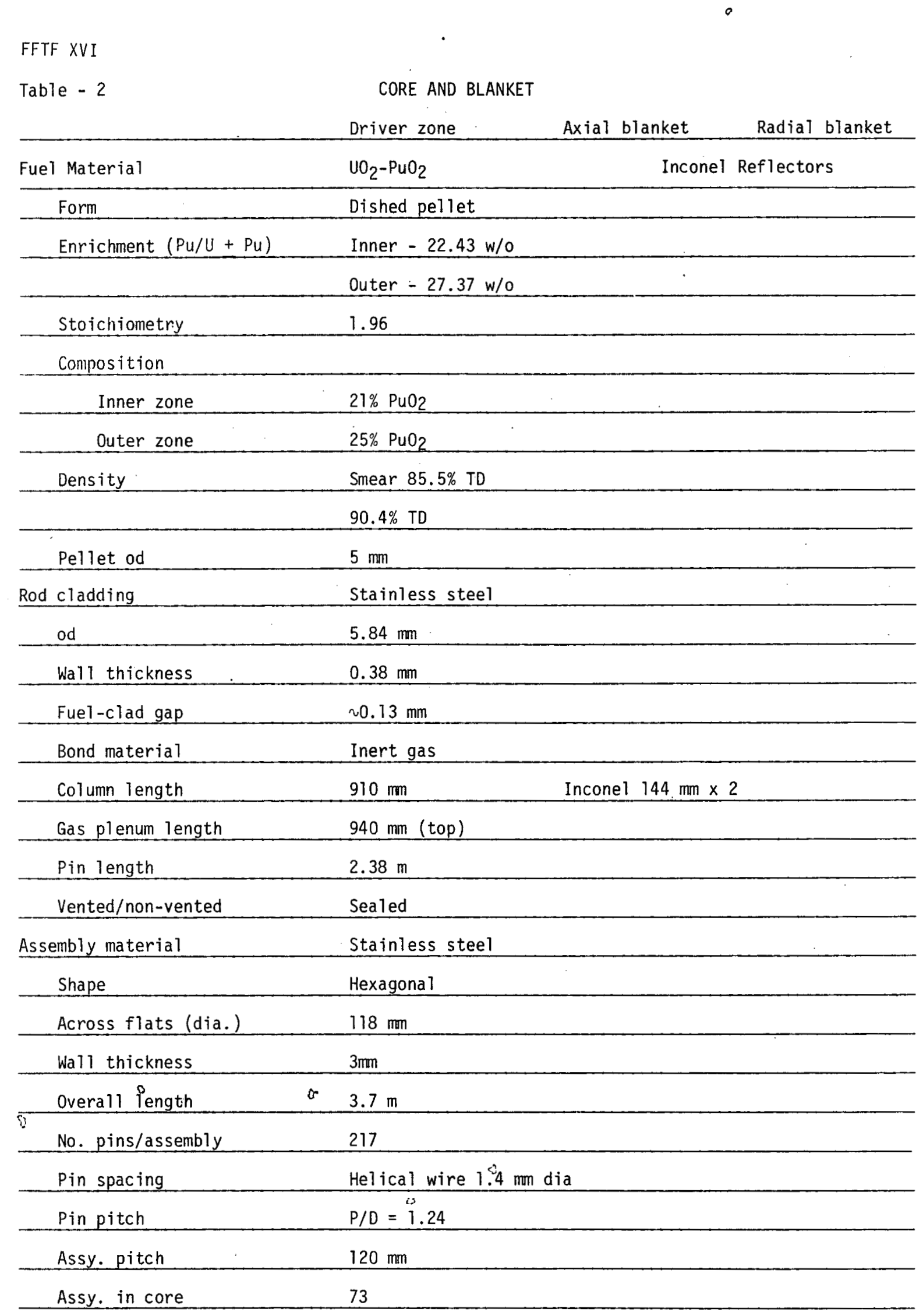




\section{XVI.A. CORE AND REFLECTOR ELEMENTS}

FFTF has 199 lattic positions making up the core. They are arranged in a hexagonal lattice. The cells are on 4.715 in. centers. Of these positions, 73 are occupied by driver assemblies, and around these, 99 are occupied by reflector assemblies. There is no breeding blanket. There are two fueled zones, $\mathrm{PuO}_{2}$ content in the inner region is $21 \%$ and in the outer region $25 \%$. Three safety rods are located in the inner region, and six shim/ scram rods in the outer region. Up to nine movable or fixed shim rods can be located in the reflector zone. General and special purpose test loops, and two closed loops, occupy nine of the available lattice positions. Core volume is 1040 liters. (Fig. XVI.A-T)

The driver assembly is a hexagonal stainless steel can containing a bundle of 271 fueled pins. The hexagonal can is $3.7 \mathrm{~m}$ long overal1, with a $3 \mathrm{~mm}$ thick wall and a distance across the flats of $118 \mathrm{~mm}$. Coolant inlet ports in the nozzle assembly provide for radial innlet of the primary sodium. There are wear pads located on the outside of the duct. The top ends in a hand)ing socket. (Fig. XVI.A2a).

The fuel pin cladding is a stainless steel tube $5.84 \mathrm{~mm}$ od, with a wall thickness of $0.38 \mathrm{~mm}$. Overall length is $2.38 \mathrm{~m}$. Spacing of the pins in the bundle is by helically-wrapped, $1.4 \mathrm{~mm}$ dia. wire, to give a pitch/diametter ratio of 1.24 . The pins are sealed at both ends after loading, and arranged in hexagonal bundles of 217 pins. Each tube contains a $910 \mathrm{~mm}$ high stack of dished, $\mathrm{UO}_{2}-\mathrm{PuO}_{2}$ pellets. Stoichiometry is 1.96 , and smear density is $85.5 \%$ TD. The pellet-clad gap is 20.13 $\mathrm{mm}$. Insulator pellets of $\mathrm{UO}_{2}$ are located above and below the fuel pellet stack, and Inconel reflector elements beyond the insulator pellets in place of the usual axial breeder elements. The fission gas plenum occupies a space $940 \mathrm{~mm}$ long at the top of the pin, and a spring is located in this space. The pins are linked together at the bottom with a grid and support assembly. A grid at the top of the bundle provides lateral restraint. (Fig. XVI.A-2b)

Reflector assemblies, supported by the center section of the core support plate, have the same outer configuration as the fuel assemblies. Reflector assemblies inserted in receptacles in the inner shield segments are about twelve inches shorter, and differ as to inlet nozzles. Each assembly is composed of flat, hexagonal plates, stacked vertically, and fitted over an array of parallel, vertical flow tubes. The active core region of the reflector assembly has Inconel plates. Above and below this region the plates are stainless steel. The assembly nozzle, like the fuel assembly nozzle, provides hydraulic holddown. (Ref. 1, 2)

The Open Test Assembly (OTA) supports and contains irradiation tests to be placed in open test positions in the reactor. It is the same geometrically as the driver fuel assembly, and the nozzle is the same. The top is fitted with a modified driver assembly handling socket. Secondary holddown is by an instrument stalk located above the OTA duct, wilich consists of an outer holddown tube and an inner instrument tube. Both fuels and materials can be tested. (Fig. XVI.A-3a, $X V I: A-3 b)$

FFTF will provide four Closed Loop In-Reactor Assemblies (CLIRA) for irradiation testing. The components of CLIRA are the pressure tube, flow tube, instrument tube, spool piece, and meltdown cup. The pressure tube is double-walled stainless steel. The flow tube which fits inside the pressure tube is single-walled in the active core region and doublewalled above. An annulus between the pressure tube and the flow tube serves as the inlet coolant passage. Inner diameter of the flow tube is $2-1 / 2$ in. A meltdown cup at the bottom of the pressure tube contains any test fuel meltdown that might occur. The instrument tube forms the return flow annulus with the flow tube, and contains instrument leads. The pressure tube, flow tube, and instrument tube are supported from the spool piece attached to the reactor vessel head. The spool assembly directs inlet flow of the test coolant. Seals at the bottom separate the test coolant from the FFTF cover gas, and top seals isolate the test coolant from the containment. Test assemblies for insertion into the system will be supplied by the users. (Fig. XVI.A-4) (Ref. 8) 


\section{FFTF CORE MAP}

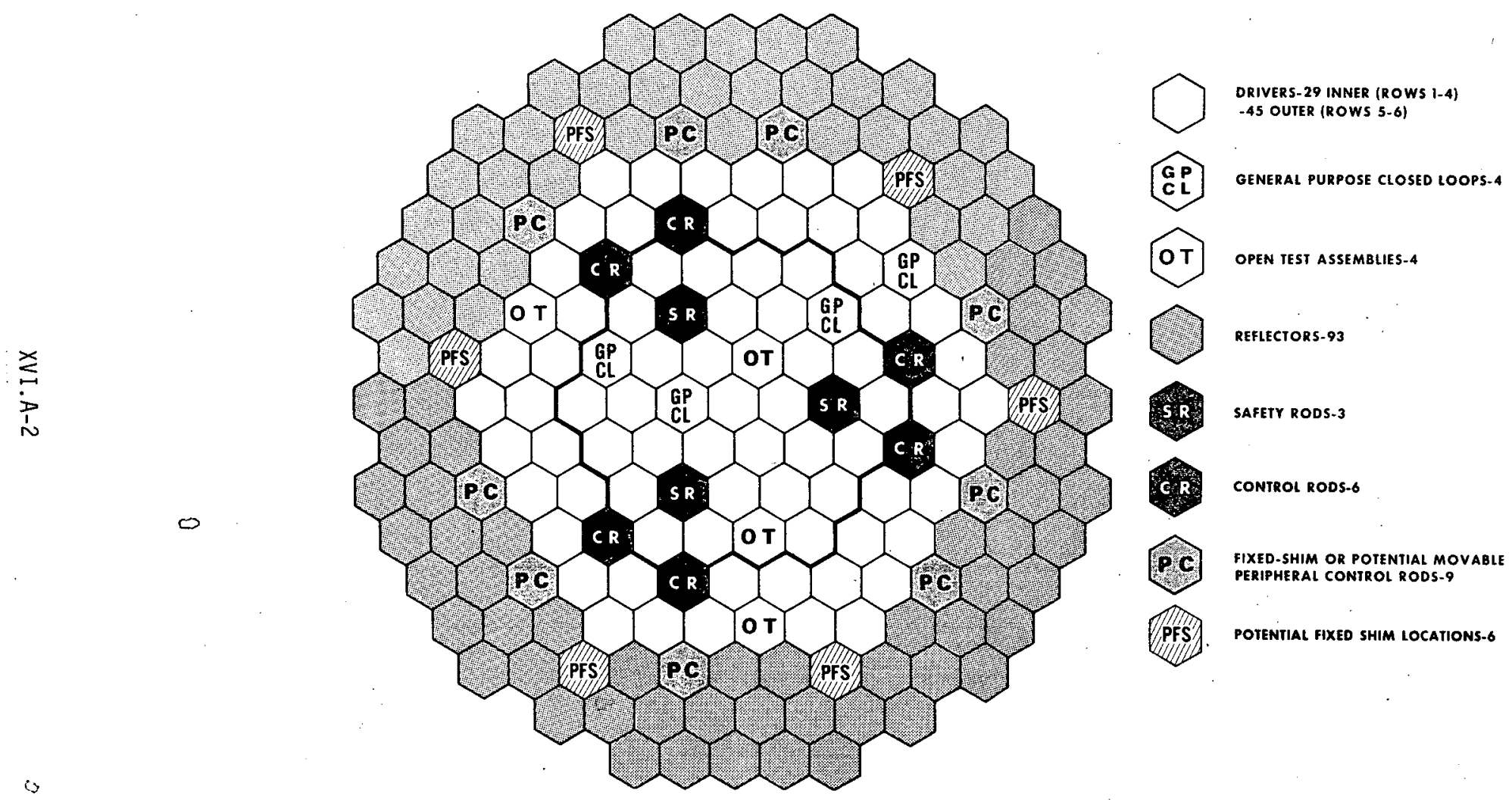

Figure XVI.A-1 FFTF Core Map 


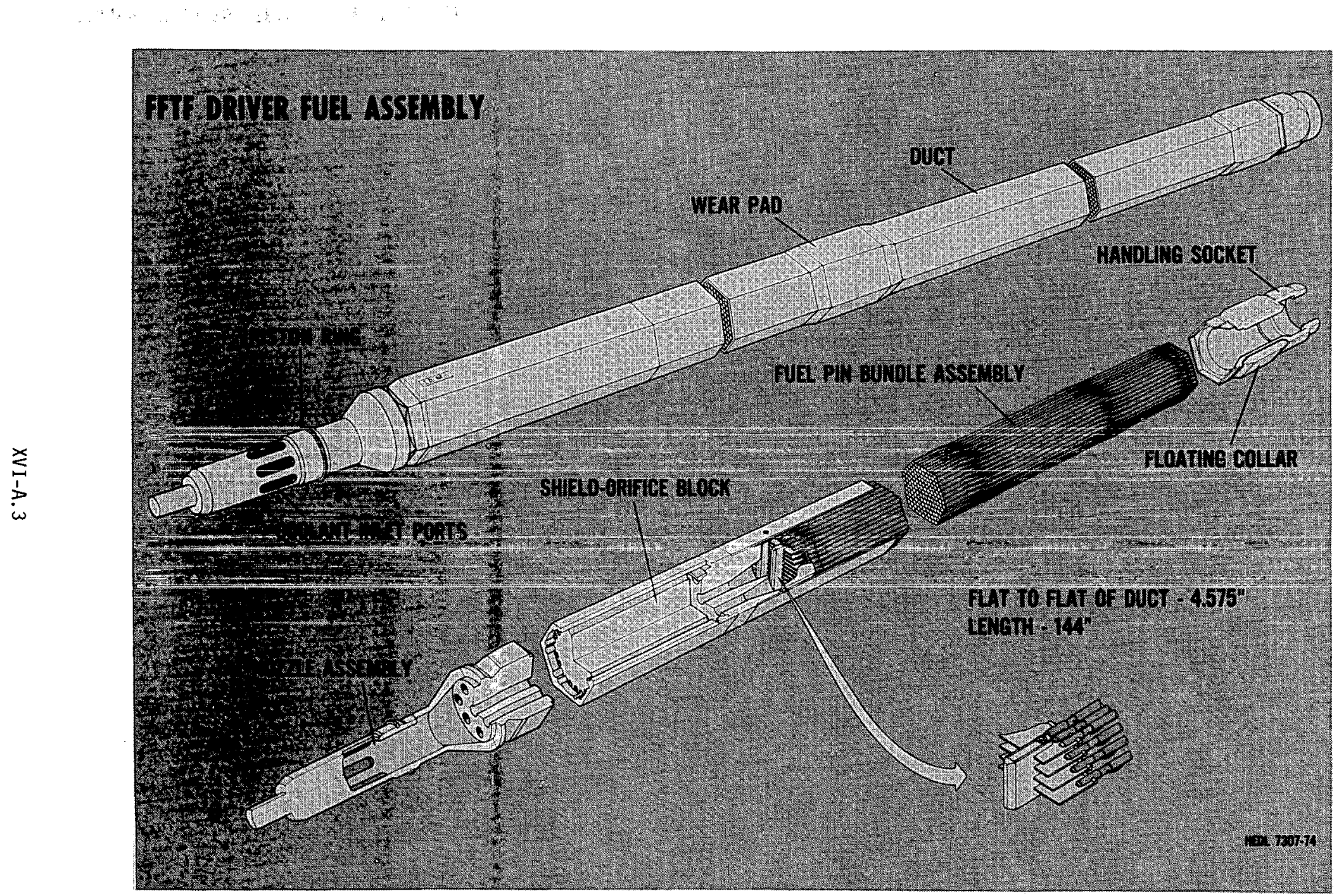

Figure XVI.A-2a FFTF Driver Fuel Assembly 


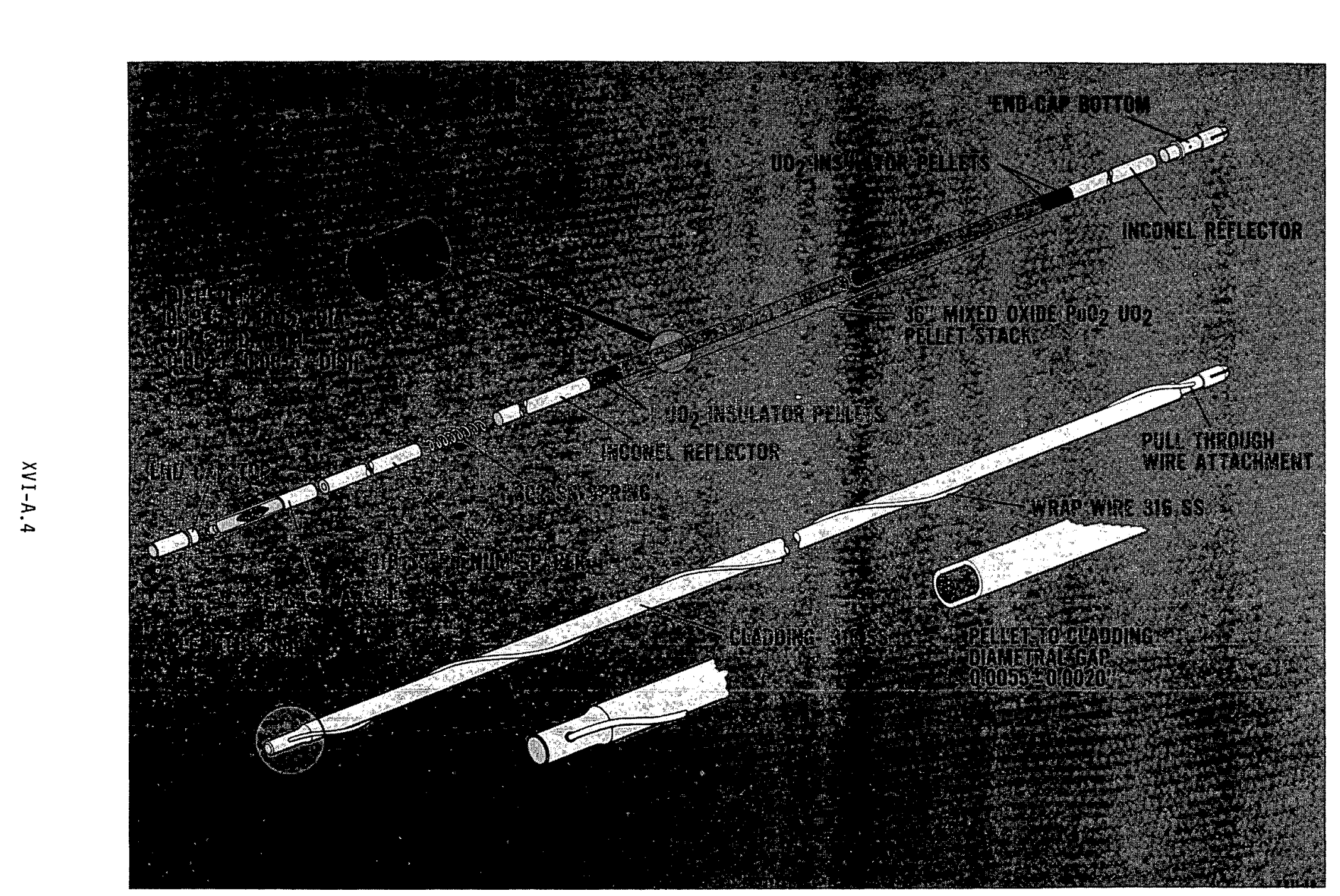

Figure XVI.A-2b FFTF Driver Fuel Pin 


\section{FUELS OPEN TEST ASSEMBLY (FOTA)}

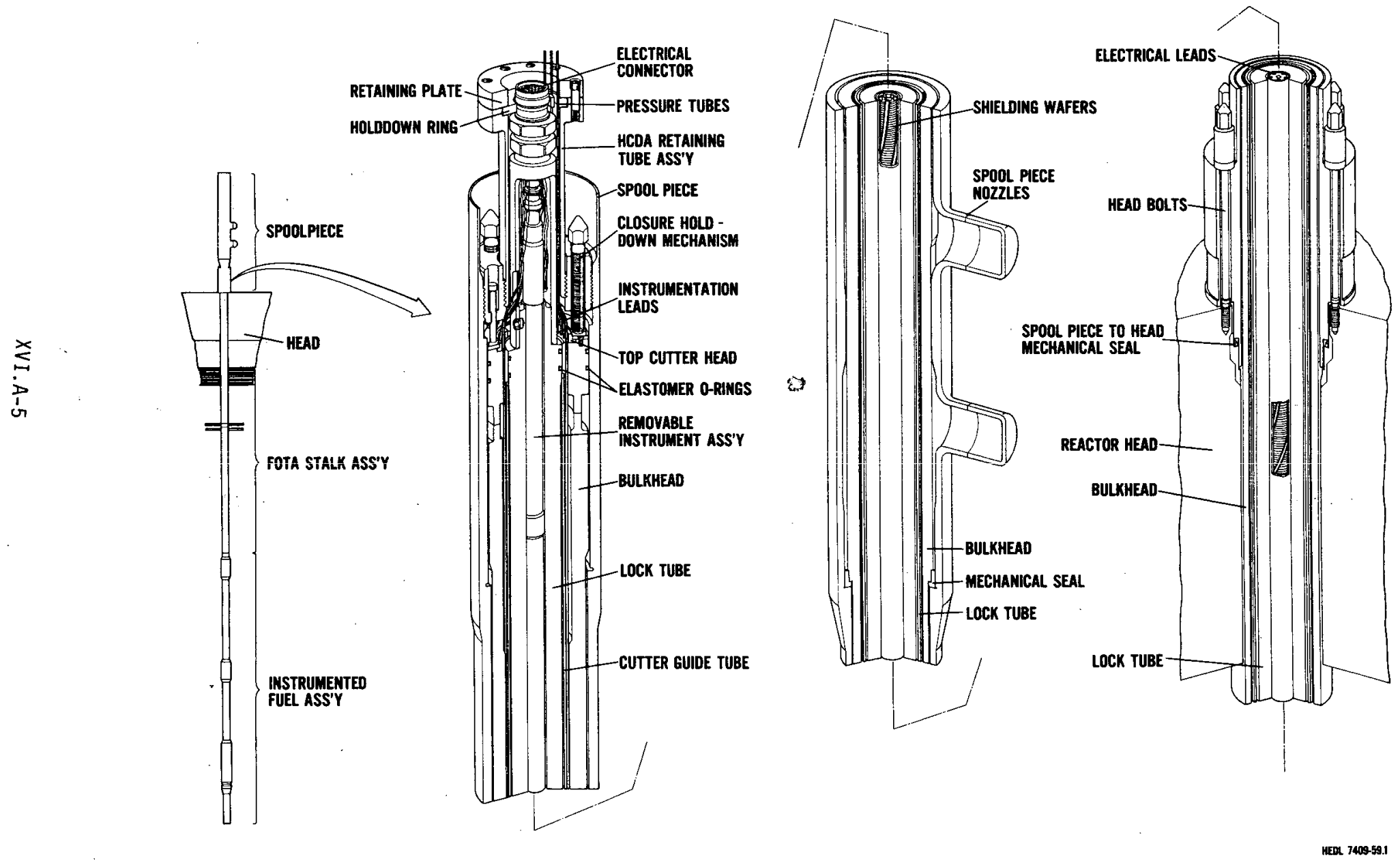




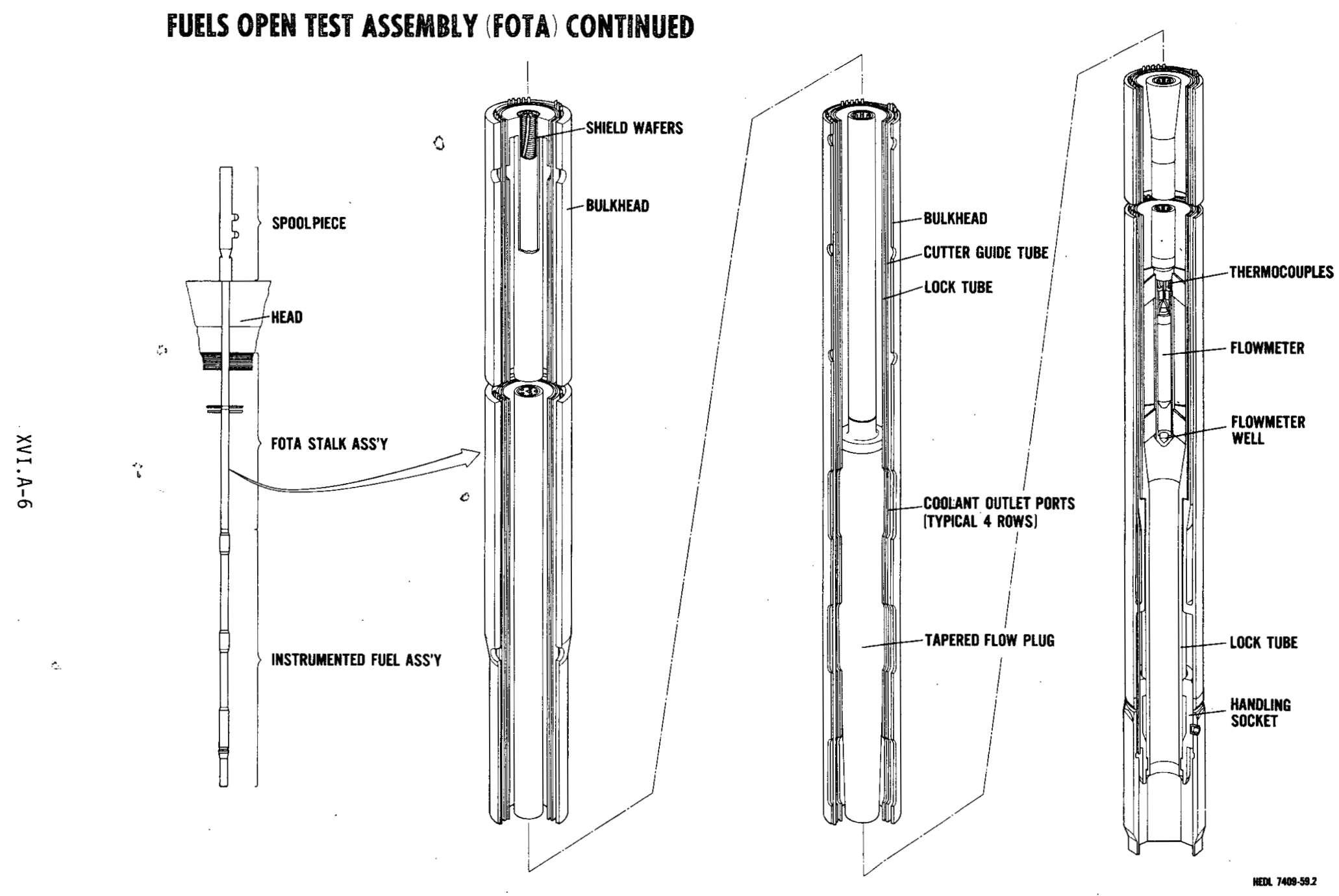

Figure XVI.A-3b Fuels Open Test Assembly (Photo No. 750156-1) 
FFTF XVI.A.

\section{CLOSED LOOP IN REACTOR ASSEMBLY}

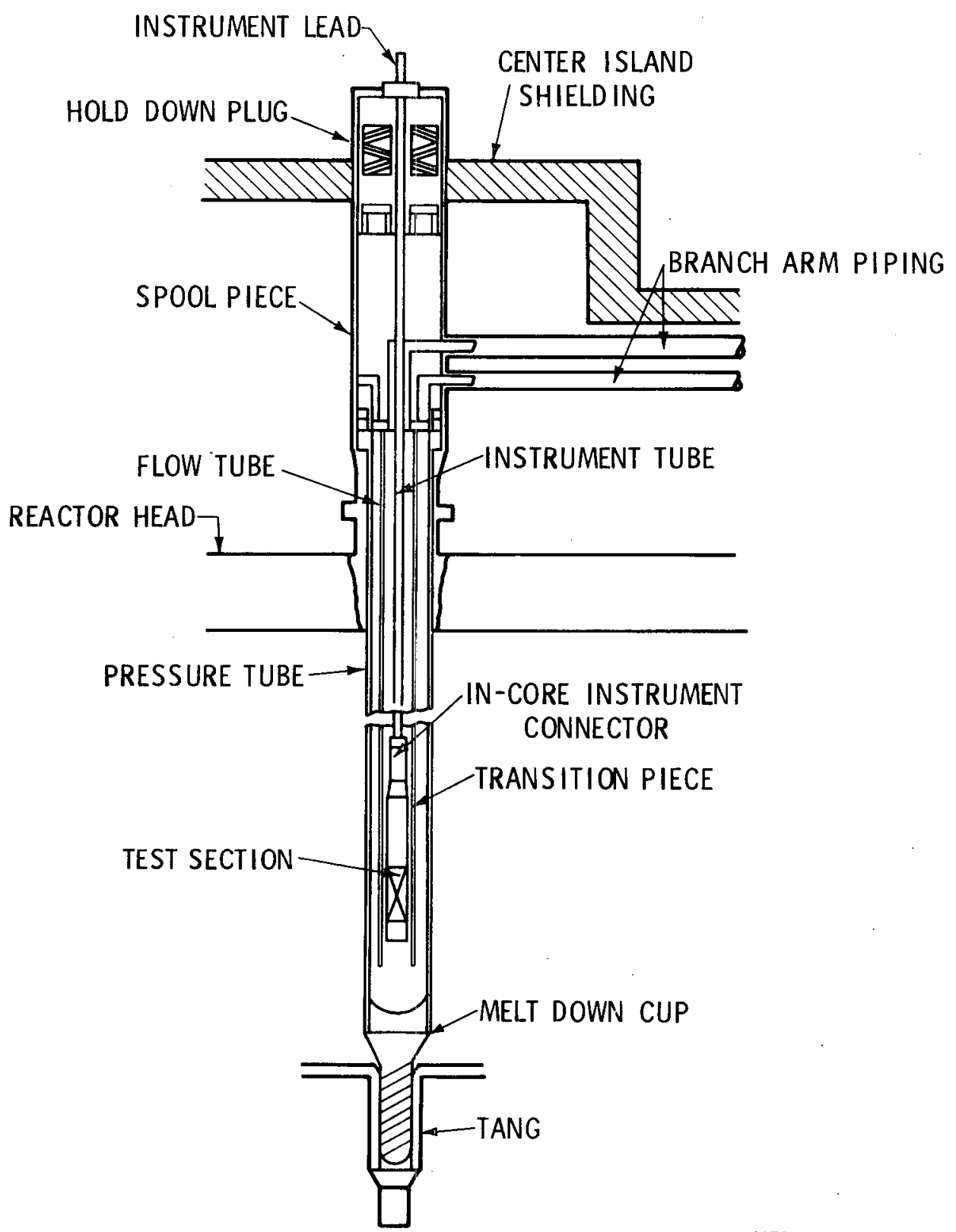

HEDL 7312-36.2

Figure XVI.A-4 FFTF Closed Loop In-Reactor Assembly (Photo No. 736943-7) 
FFTF XVI.B.

\section{XVI.B. CORE SUPPORT AND VESSEL INTERNALS}

Core support is by means of a welded bridge structure formed by a conical lower surface and a horizontal upper deck. The lower structure is welded to the core barrel. Vertical support is provided by the conical skirt, welded to the outer ring forging of the core support structure and attached to a ring forging on the reactor vessel. The central section consists of a removable core basket containing fuel assemblies, control rods, test positions and inner reflectors. Outside this removable section there is space for in-vessel radial shielding, supported laterally by the core barrel. The region outside the core barrel is used for in-vessel storage positions and vertical components of the core restraint system. The structure is fabricated of stainless steel. In addition to supporting core components, the core support structure provides the pressure barrier between the high pressure inlet plenum and the outlet sodium pool. (Fig. XVI.B-I)

The active core restraint system described in Reference 1 has been changed in favor of a passive mechanical system. The passive concept for core restraint consists of unyielding static restraint rings installed at the core periphery, at the elevations of load pads above the core and below the top of the reactor assemblies. (The active-clamp system consisted of six hydraulic yokes applying load to the top of the core components, and six hydraulic yokes applying load in a plane above the active core region. The peripheral active clamps required in-vessel mechanisms.) (Fig. XVI.B-2) (Ref. 15)
Three instrument trees. are located in the space above the tops of the fuel ducts. Each tree consists of a column which penetrates a fixed plug in the reactor vessel head, and an in-reactor structure which includes instrument ducts. The column is mounted on a bearing in the fixed plug and on a bearing on the core barrel at the bottom of the column. The lift and rotation mechanism is installed on the reactor vessel head. The trees provide support and location of instrumentation for each driver fuel assembly, some reflector assemblies, and each movable control rod assembly. They also provide control rod drive shaft quidance and secondary holddown for driver fuel assemblies and control rod ducts. The instrument assembly is a completely replaceable unit. Each of the three units is within a guard vessel. (Fig. XVI.B-3)

Three In-Vessel Handling Machines (IVHM) are mounted in rotating plugs in the reactor top shield. All contact between sodium and air, or the escape of sodium, fission gases or contamination, is prevented or minimized by double barriers and multiple seals.

Three in-vessel storage modules are supported by the core barrel and the core support structure. They provide in-vesse 1 storage for spent fuel and other core assemblies in the annular region between the core barrel and the reactor vesse? thermal liner. (Ref. 1,2) 
FFTF XVI.B.

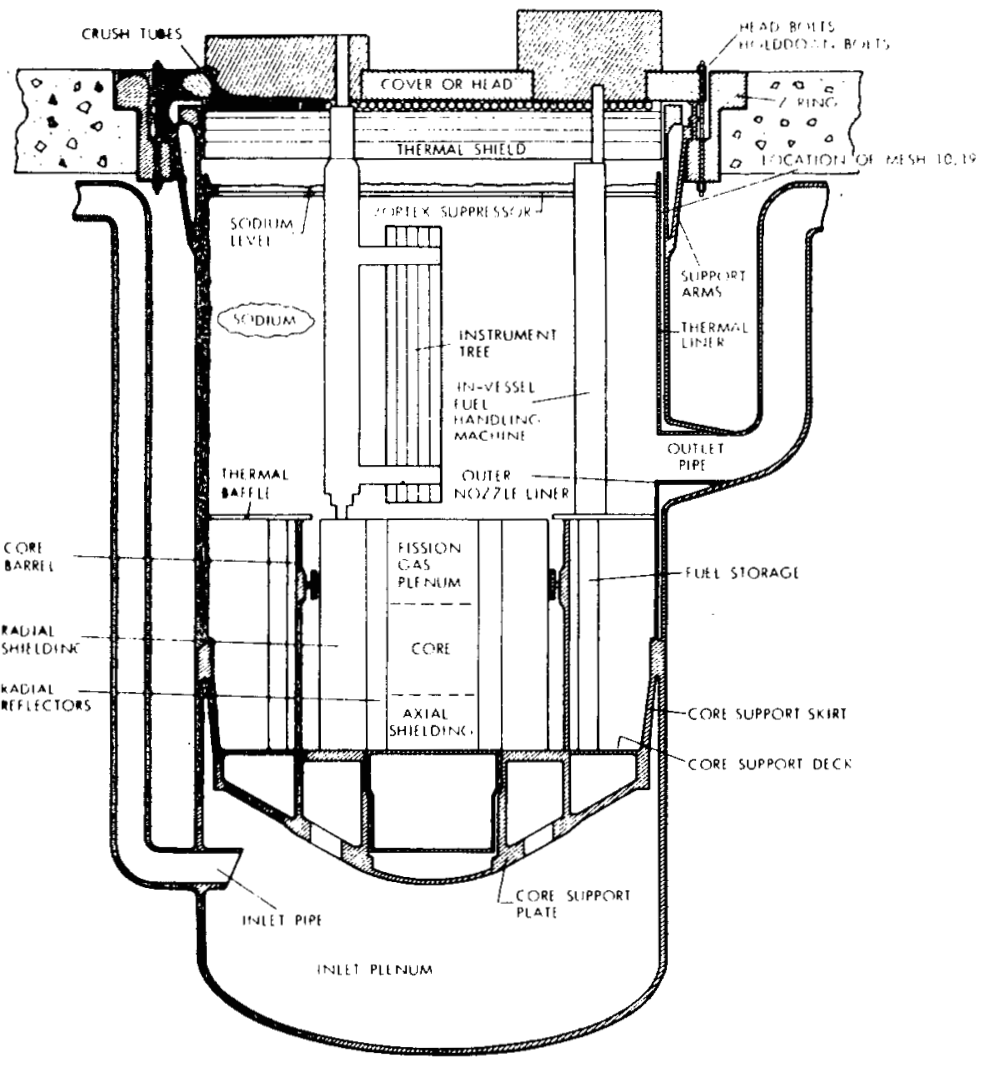

Figure XVI.B-1 FFTF Core Support and Internals (Ref. 13) 
FFTF XVI.B.

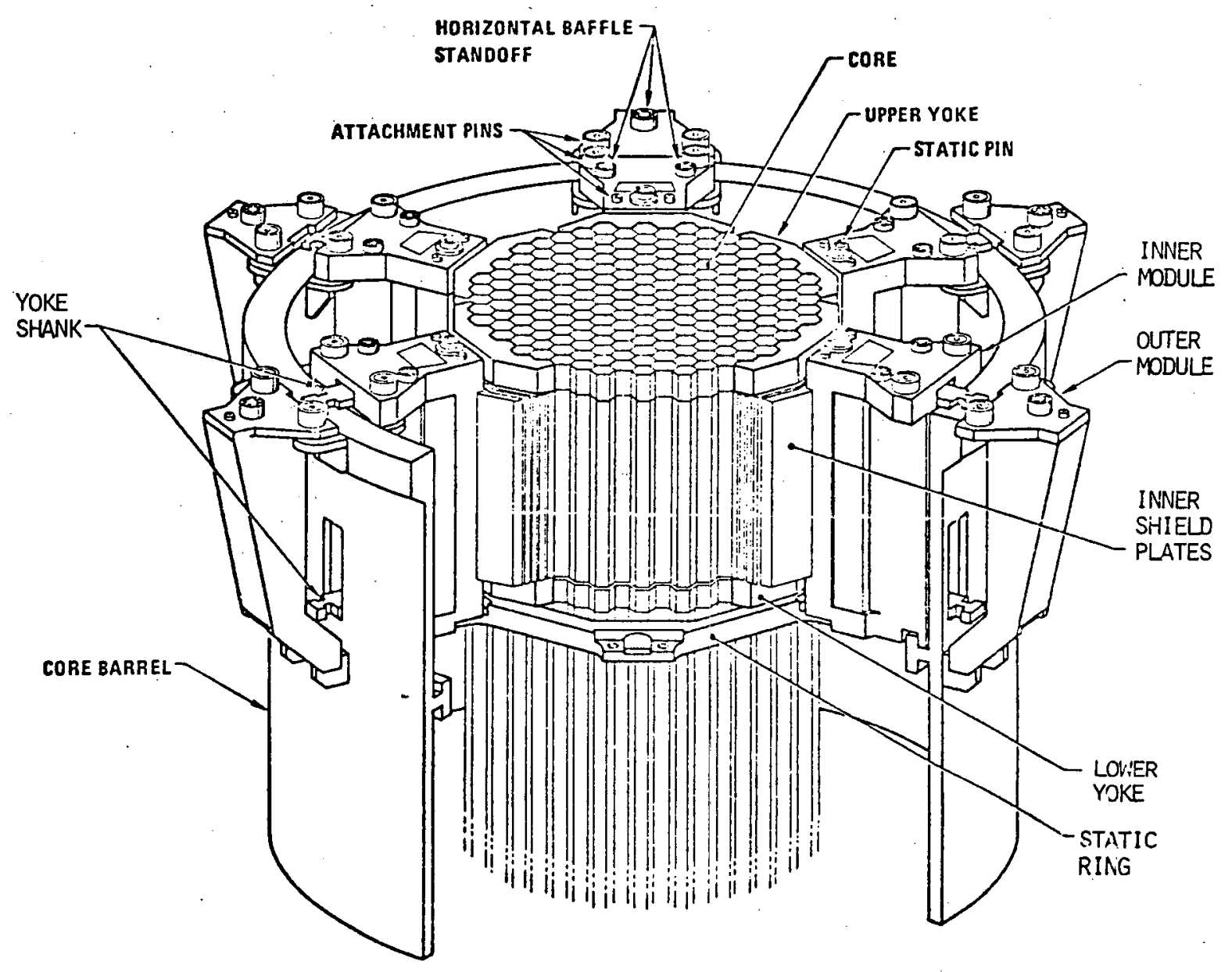

Figure XVI.B-2 FFTF Core Restraint Modules

XVI.B-3 


\section{INSTRUMENT TREE}

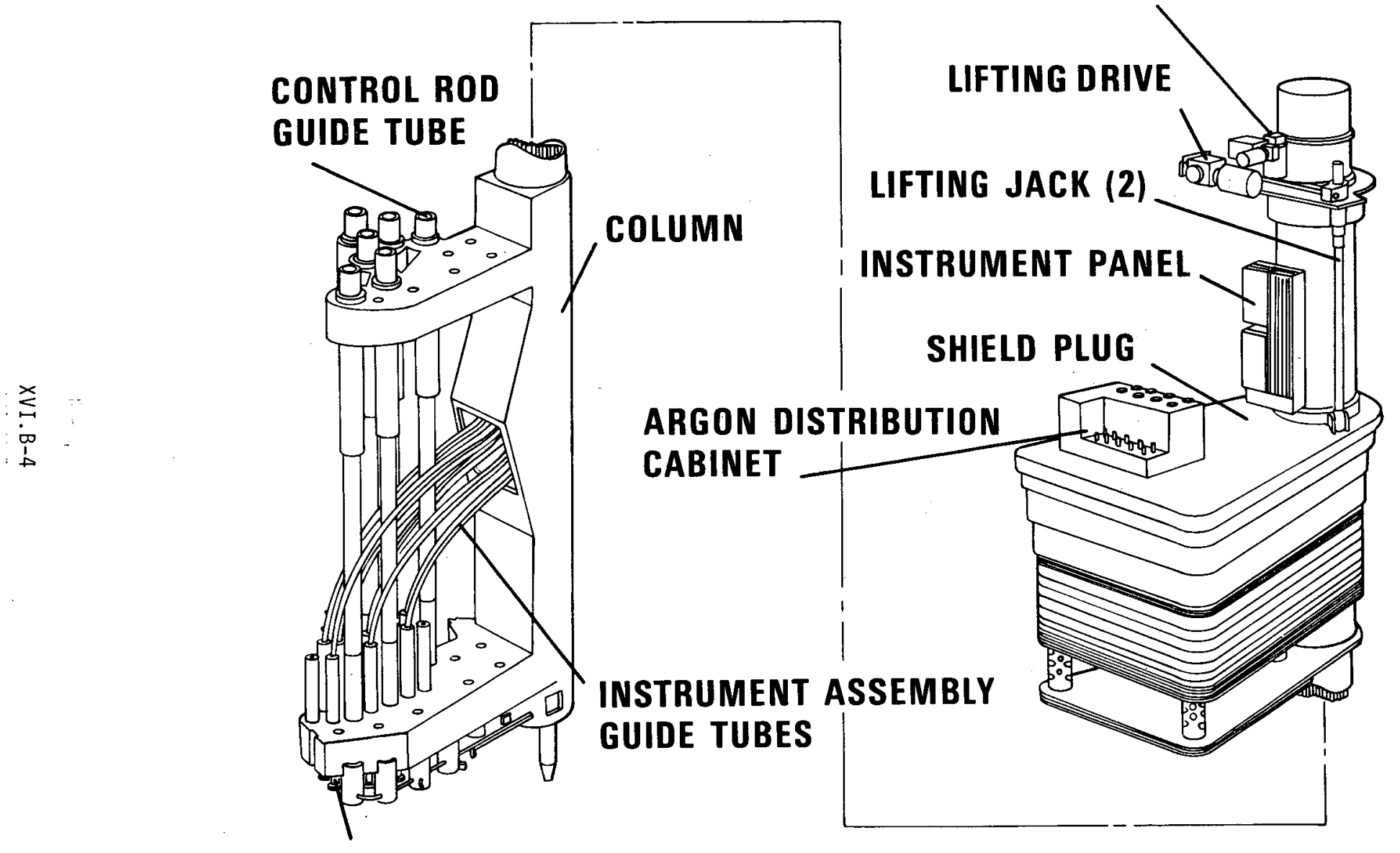

TUBE \& HOLD DOWN FLOW GUIDE

Figure XVI.B-3 FFTF Instrument Tree Photo \#720425-18 


\section{XVI.C. REACTOR VESSELS AND SHIELDING}

The reactor vessel is a cylindrical stainless steel structure, $6.1 \mathrm{~m}(20 \mathrm{ft}$. id and $13.1 \mathrm{~m}(43.5 \mathrm{ft})$ high. Walls are greater than $5 \mathrm{~cm}$ ( 2 in.) in thickness. Three $406 \mathrm{~mm}$ (16 in.) diameter inlet nozzles are located near the bottom, and three $710 \mathrm{~mm}$ (28 in.) dia. outlet nozzles above core level and below the level of the sodium pool. The reactor vessel head is $7.6 \mathrm{~m}$ (25 ft.) in diameter and $550 \mathrm{~mm}$ (21.81 in.) thick, formed by welding together two semicircular forgings of carbon steel. The vessel head has penetrations for instrumentation, control, and test devices, and for the in-vessel handling machines. It is attached to a support flange (Z-ring) by bolts. A stack of stainless steel shield plates is mounted under the vessel cover, with crush tubes between the top plate and the vessel head. A stack of thin plate thermal reflectors is suspended below the shielding stack, about $30 \mathrm{~cm}$ ( $1 \mathrm{ft}$ ) above the top of the sodium pool. Vortex suppressor plates are located just below the sodium surface. A thermal baffle covers the annular area between the core barrel and the vessel wall. Support for the core support structure is provided by a ring forging on the reactor vessel. (Fig. XVI.C-l)

Radial shielding within the core barrel is furnished by vertical steel plates set in a hexagonal pattern, tangentially to the core. Additional plates fill the corners of the hexagon to conform to the cylindrical core barrel. Coolant channels are maintained by spacers between the plates. The reactor vessel thermal liner is in the form of a $2.5 \mathrm{~cm}$ ( 1 in.) thick cylinder concentric with the vessel wall. There is a small sodium flow in the annulus. In-vessel fuel storage modules, supported by the core support structure, are surrounded by guard vessels.
The vessel is supported from the Z-ring part of the support structure by steel arms bolted to the ring. The lower ends of the arms are welded to a ring in the vessel wall. The Z-ring is formed on the concrete ledge which is an extension of the reactor cave shield walls.

A guard vessel surrounding the reactor vessel is designed to maintain core decay heat removal in the event of a pipe or vessel rupture. The downcomer for the inlet of primary sodium is installed vertically in this annular space. Guard vessel dimensions are $6.7 \mathrm{~m}(>22 \mathrm{ft})$ od and $11.8 \mathrm{~m}(\sim 38 \mathrm{ft})$ high. There are no piping penetrations. It is bottomsupported in the reactor cavity, with ties to provide lateral support for the reactor vessel.

The reactor cavity forms part of the inner containment barrier. It is a reinforced concrete cell in the shape of a hollow cylinder, closed at the bottom by a slab. The vessel support ring is located at the top of the cavity, which is $11 \mathrm{~m}$ ( $36 \mathrm{ft}$ ) dia., and 14-1/2 $\mathrm{m}(\sim 48 \mathrm{ft}$ ) high to the top of the support ring. Interior surfaces are lined with steel plate. A pipeway space is located between the reactor cavity and each equipment cell. (Ref. 1,2)

No final decision has been made on the inclusion of a core-catcher device. It is felt that core debris can be contained and cooled within the primary system. 
FFTF XVI.C.

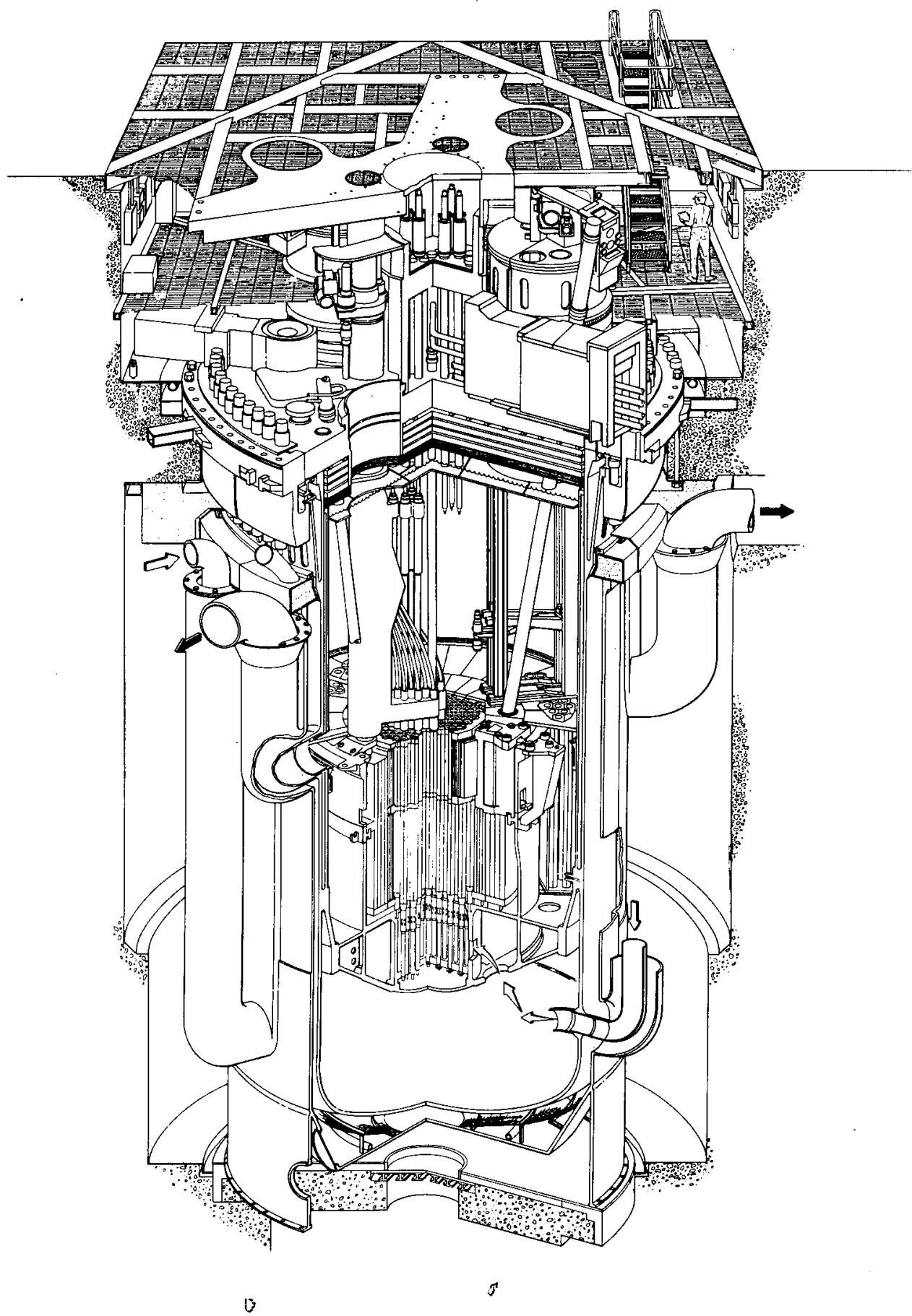

Figure XVI.C-1 FFTF Reactor Vessel

XVI.C-2 


\section{XVI.D. CONTROL ELEMENTS}

Two completely independent sets of control systems are provided. One is a primary shutdown system, and the other system is for control and secondary shutdown. Each system has similar components, consisting of control rod assemblies, drive shafts and drive mechanisms, in-core channel ducts, and drive shaft drive tubes. $B_{4} C$ is the neutron absorber material. Three types of absorbers will be used:

Safety rods: Three in row three for shutdown

Control rods: Six in row five for startup and regulation

Shim rods: As needed in row seven for reactivity balance
Pin bundle design is basically the same for all three types, consisting of a hexagonal bundle of 61 sealed pins.

Spacing is by wire wrap, to give a pitch of $12.65 \mathrm{~mm}$. Cladding tube is stainless steel, $12.07 \mathrm{~mm}$ od with a wall thickness of $1.30 \mathrm{~mm}$. Natural $\mathrm{B}_{4} \mathrm{C}$ pellets $9.19 \mathrm{~mm}$ dia. are stacked in a column $914.4 \mathrm{~mm}$ high. Pellet density is $92 \%$. There is an upper and a lower gas plenum. Control rod channels in the core have the same dimensions as the fuel assembly channels. (Fig. XVI.D-1) (Ref. 11)

Vented control rods are being studied. 


\section{FFTF FUEL SYSTEM}

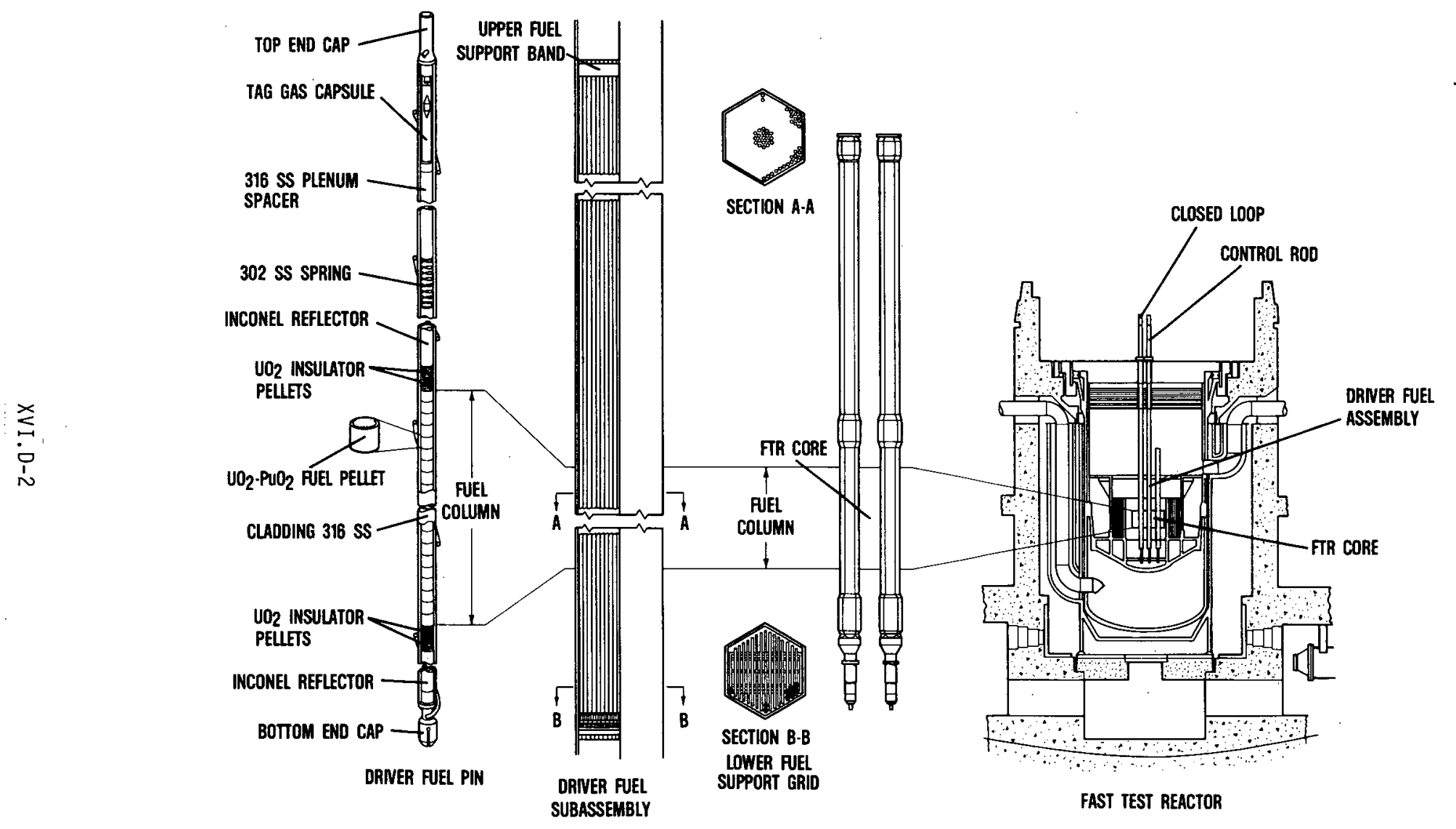

7302-57

Figure XVI.D-1 FFTF Control Rod Absorber System 


\section{XVI.E. HEAT TRANSFER SYSTEMS}

FFTF has three independent heat transfer loops. Each primary loop includes a hot-leg pump, two isolation valves, a check valve, and the shell side of an intermediate sodium/sodium heat exchanger. The three secondary loops include the tube sides of the intermediate heat exchangers, cold-leg pumps, expansion tanks, valves, and forced draft sodium/air dump heat exchangers. The system removes heat for all modes of operation including emergency cooling and shutdown, except for the closed loops. The closed Loop InReactor Assembly (CLIRA) has its own primary and secondary systems and dump heat exchangers. Each loop can operate independently. Piping and components of each primary loop are contained under an inert atmosphere in separate shielded cells beneath the reactor operating floor. Equipment elevation and low system hydraulic resistance provide natural circulation cooling capability. (Fig. XVI.E-1)

Sodium coolant enters near the bottom of the vessel through three 16 in. nozzles in the high pressure plenum, flows vertically upward through the core, reflector and shield to the upper plenum, where it is mixed. It leaves by way of three 28 in. outlet nozzles to the primary pump.

Primary pumps are single stage, double suction, vertical shaft, freesurface centrifugal units. Design capacity per pump is $14,500 \mathrm{gpm}$ at a head of $500 \mathrm{ft}$. Sodium is pumped by the impeller at the bottom of the drive shaft, drawn through the double suction impeller inlet, and discharged through the outlet nozzle at the bottom of the pump tank: The free sodium surface in the tank has an argon gas cover, kept at the same pressure as the cover gas in the reactor vessel by connecting, equalizing lines. Thermal baffles in the pump tank and a. biological shield are provided. The main shaft has an oil pressure seal. Wound rotors with liquid rheostat controllers provide variable pump speed control. There are auxiliary pony motors for pump operation at about $1 / 2$ of the rated speed at low flow rates. Each pump is within a guard vessel.

(Fig. XVI.E-2)
The three intermediate heat exchangers are vertical tube and shell units with bayonet downcomers. Primary sodium enters the unit below the top of the tube sheet and flows downward along the outside of the tubes, around the perimeter of the lower tube sheet, and out through the bottom nozzle. Secondary sodium enters at the top of the unit and flows through the central downcomer into the lower plenum area, through the lower tube sheet, upward through the tubes to the upper plenum, and leaves by an outlet nozzle. The tube bundle is removable. The Intermediate Heat Exchanger (IHX) is 78-3/8 in. dia. and $35 \mathrm{ft}$. long. Tubing is $7 / 8$ in. od stainless steel, with a minimum wall thickness of 0.047 in. Each tube has a compound bend. There are tube support plates, with orifices for sodium flow, located along the straight parts of the tubes. Inner and outer shrouds direct primary sodium flow over the tubes. A hemispherical head welded to the lower tube sheet provides the boundary between primary and secondary sodium. There is a thermal liner between the shell and the tube bundle. Each IHX is enclosed by a guard vessel. (Fig. XVI.E-3)

There are twelve dump heat exchange modules. The heat exchange bundle is composed of 4-pass serpentine tubes attached to horizontal headers, with finned sections. There is a fan and drive, air control vanes, and an oil-fired preheater for each module. (Fig. XVI.E-4) (Ref. 1,9)

Single isolation valves are installed in the $28 \mathrm{in}$. dia. hot legs and in the 16 in. dia. cold legs of the primary loops. They are hinged rotating gate valves with rotary motion freeze seals. They have no safety function, but are associated with maintenance and loop isolation. (Fig. XVI.E-5)

Each primary loop has a check valve installed in the $16 \mathrm{jn}$. dia. cold leg piping to limit flow reversal in a loop with pump failure or loss of power. These are tilting disk type valves with dashpot pistons. (Fig. XVI.E-6) 
Each secondary loop has eight angleglobe type set/isolation valves, installed at inlet and outlet connections of the DHX modules to isolate the module and to balance flow for uniform heat exchange performance. (Fig. XVI.E-7)

Guard vessels around the IHX and the primary pumps are supported from the floors of the equipment vaults. They are not concentric with the components, but located to accomodate vertical downcomers. The annular free volumes are $21000 \mathrm{ft}^{3}$ for the IHX and $2000 \mathrm{ft}^{3}$ for the primary pump. They are fabricated of stainless steel. (Ref. 1, 4)

Each CLIRA has its own primary and secondary heat removal system. Primary flow is driven by a helical induction electromagnetic pump located in the cold leg, directly upstream of the CLIRA.
Immediately downstream of CLIRA, the sodium enters the tube side of an intermediate heat exchanger, and then a surge tank. The primary pump takes its suction head from the surge tank and returns the flow to the CLIRA. Hot and cold leg connecting piping runs from branch arm piping traversing the top of the reactor vessel head, through pipeways to the primary closed loop cell. A small electromagnetic booster pump provides sample flow. The secondary loop is located mainly outside the FFTF containment. The DHX is outside the building. The secondary pump is an electromagnetic unit located in a cold leg. A side stream is removed ahead of the pump for sampling and returned to the main loop through a secondary surge tank. Cold traps are located in by-pass lines. Flow is measured by electromagnetic flow-meters. (Fig. XVI.E-8) (Ref. 8)

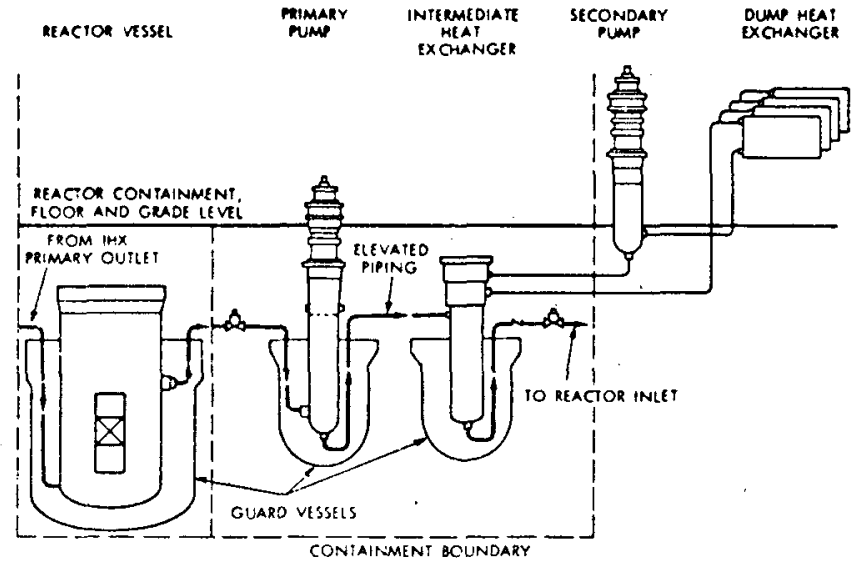

Figure XVI.E-1 FFTF Heat Transport System 
FFTF XVI.E.

\section{PRIMARY PUMP WITH GUARD VESSEL}

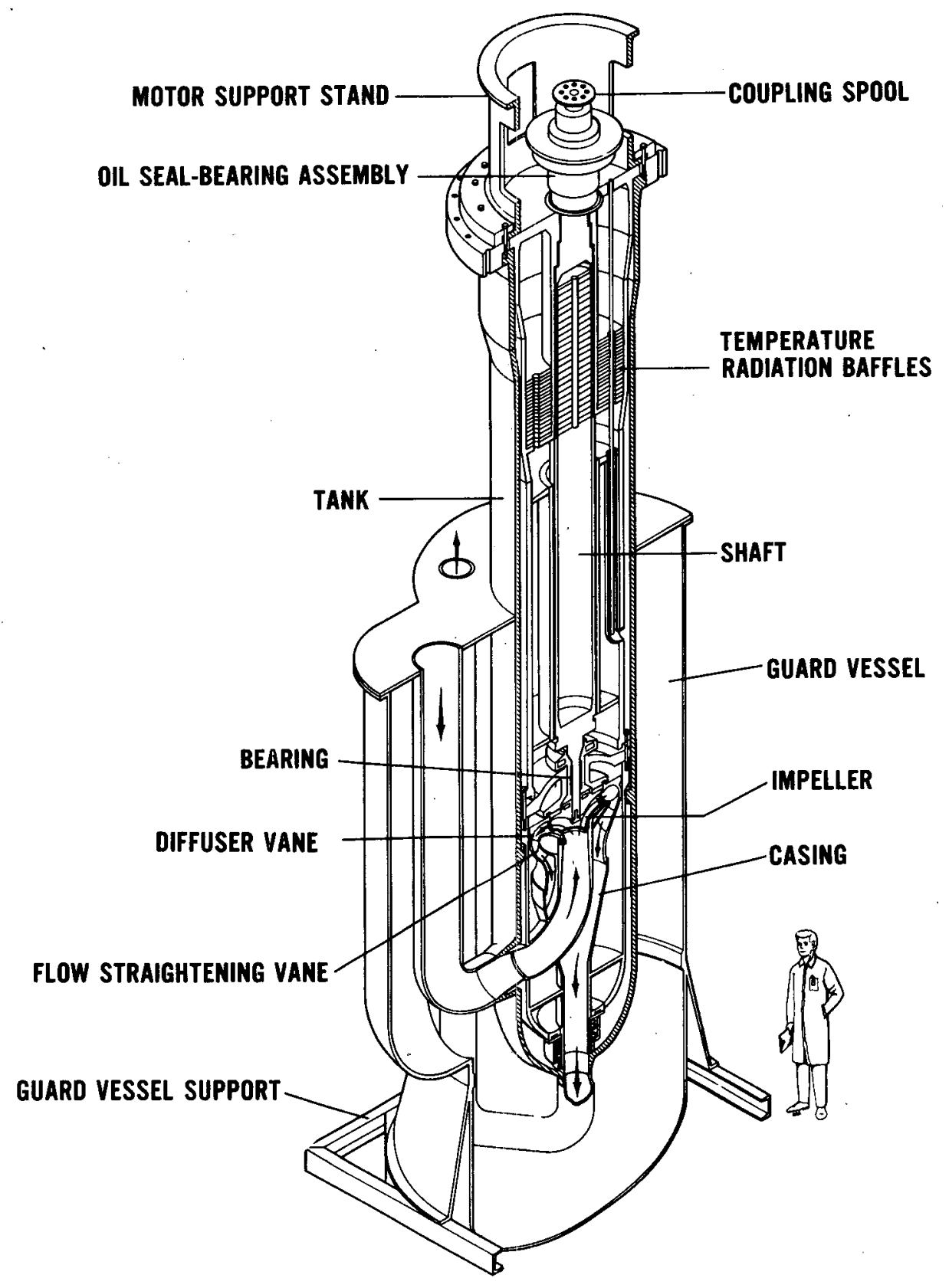

Figure XVI.E-2 FFTF Primary Pump 
FFTF XVI.E.

\section{INTERMEDIATE HEAT EXCHANGER (IHX)}

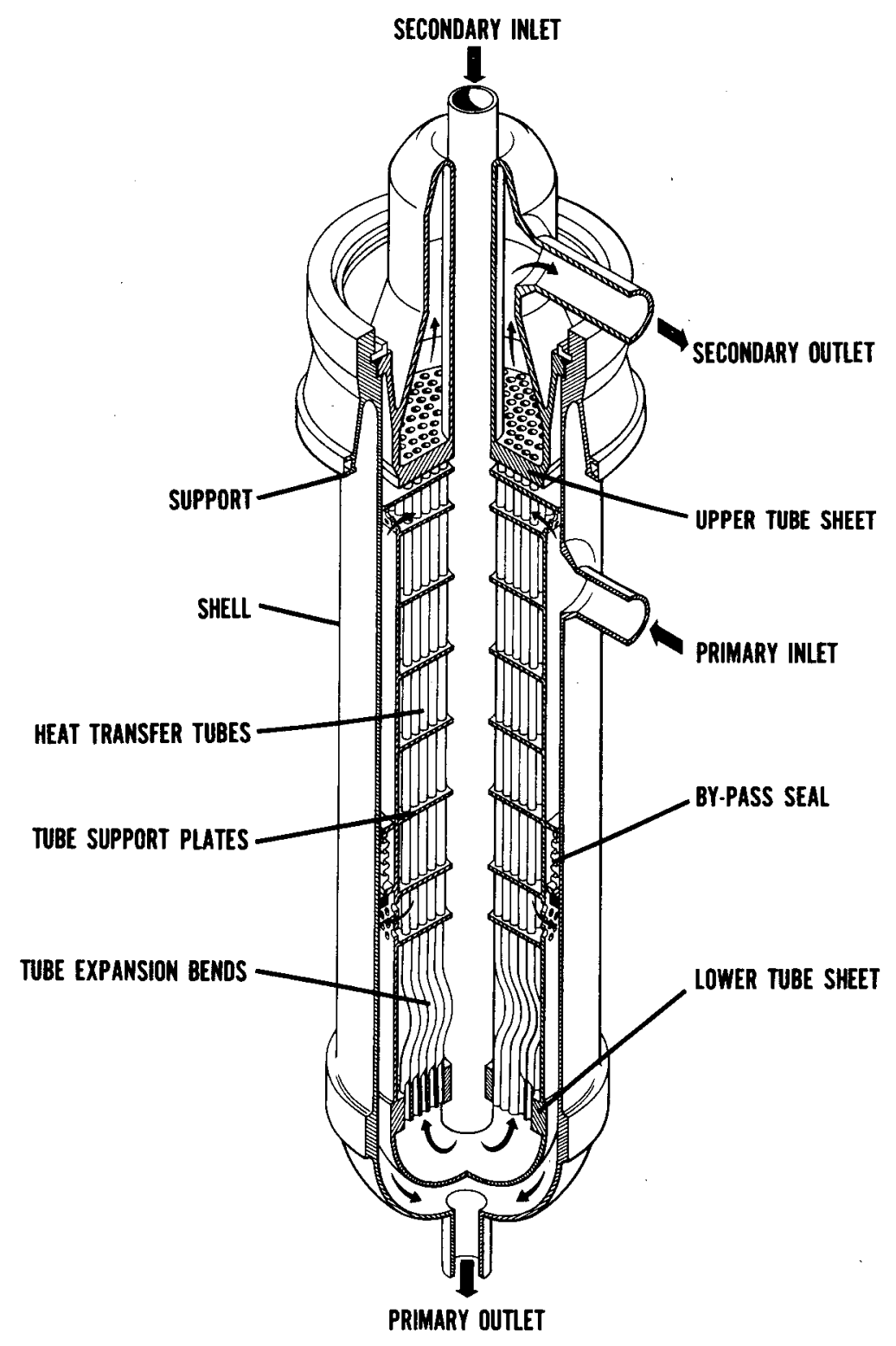

Figure XVI.E-3 Intermediate Heat Exchanger (IHX)

XVI.E-4 


\section{HTS DHX MODULE}

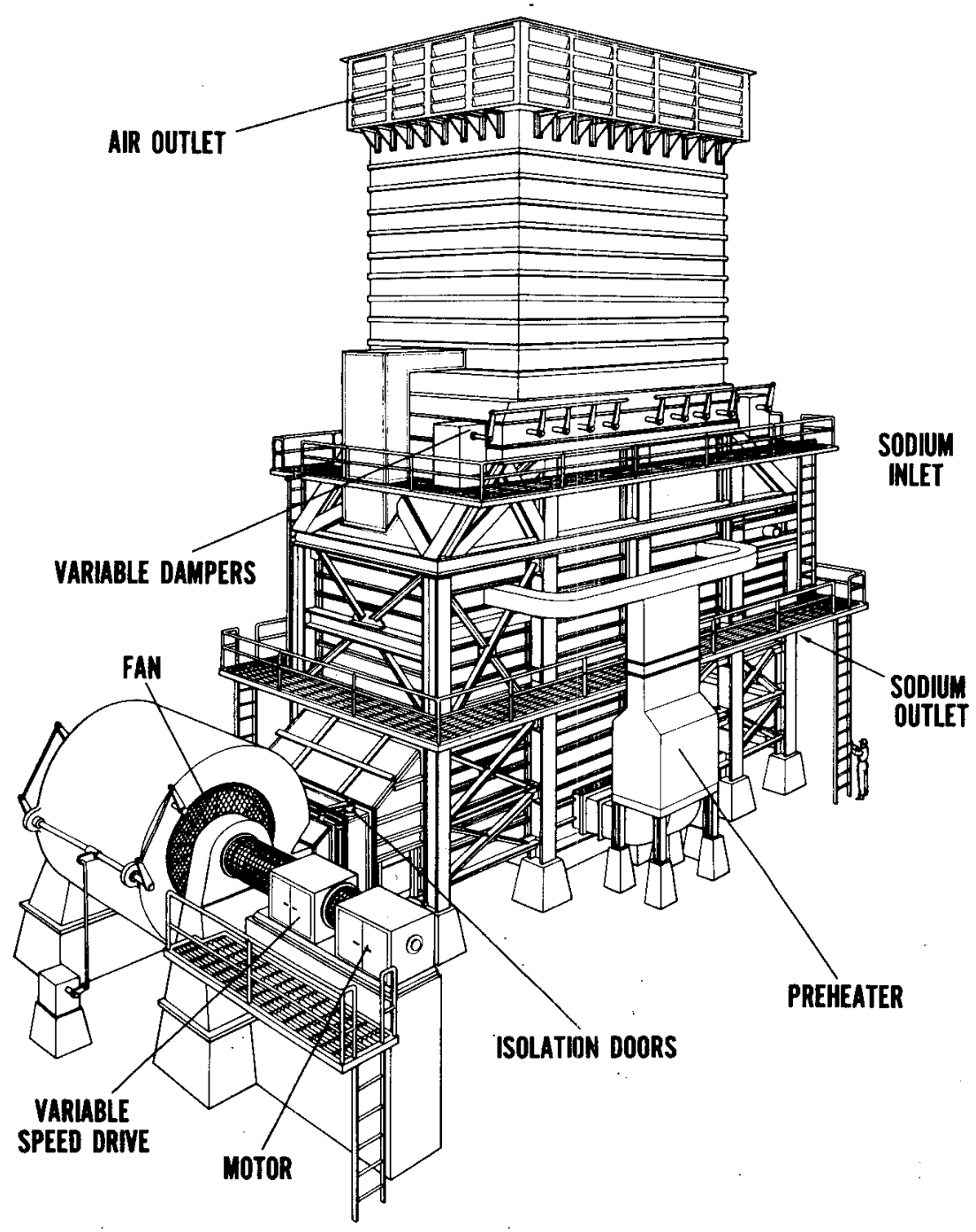

Figure XVI.E-4 FFTF Dump Heat Exchanger 


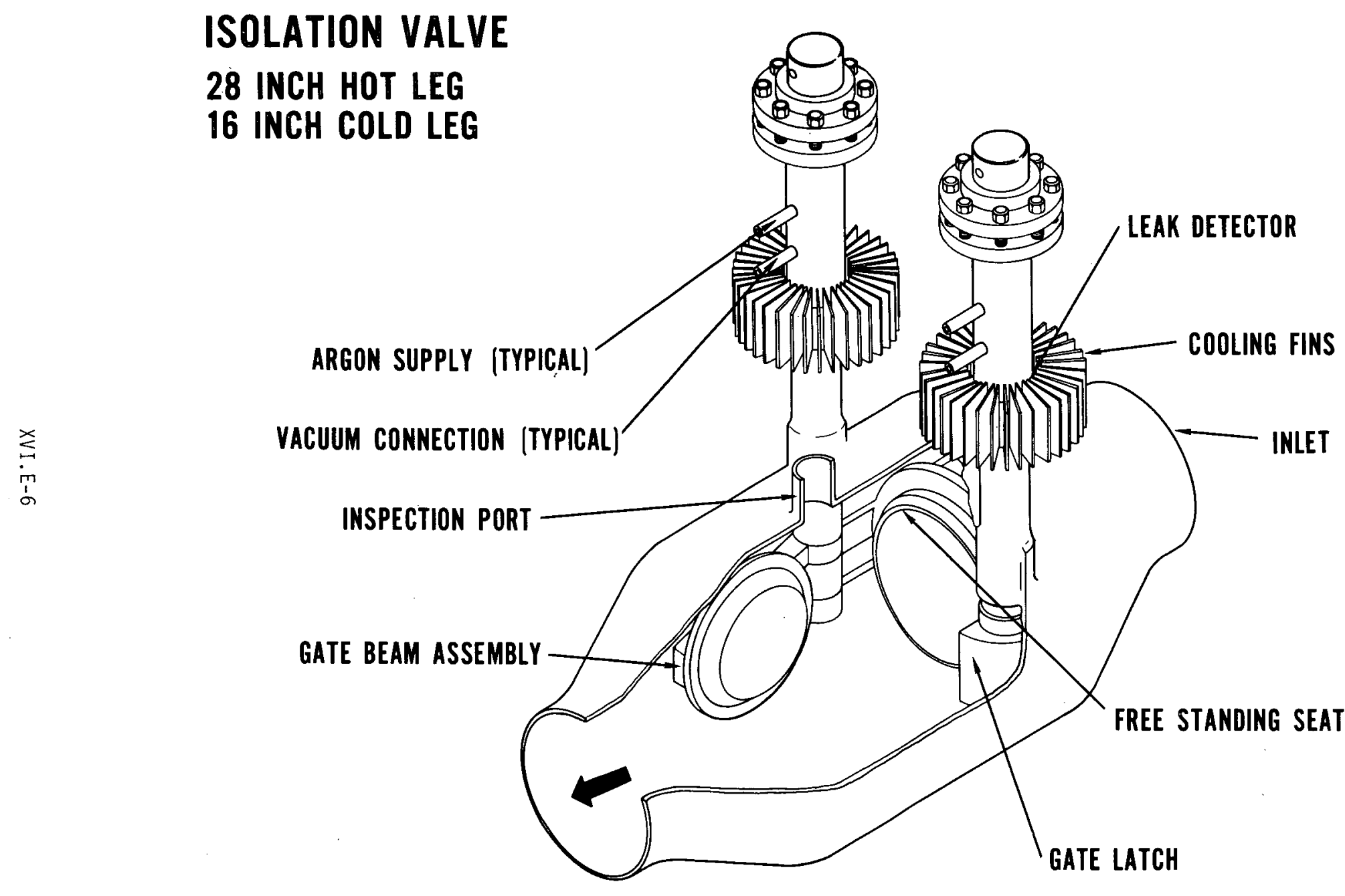

Figure XVI.E-5 FFTF Primary System Isolation Valves 


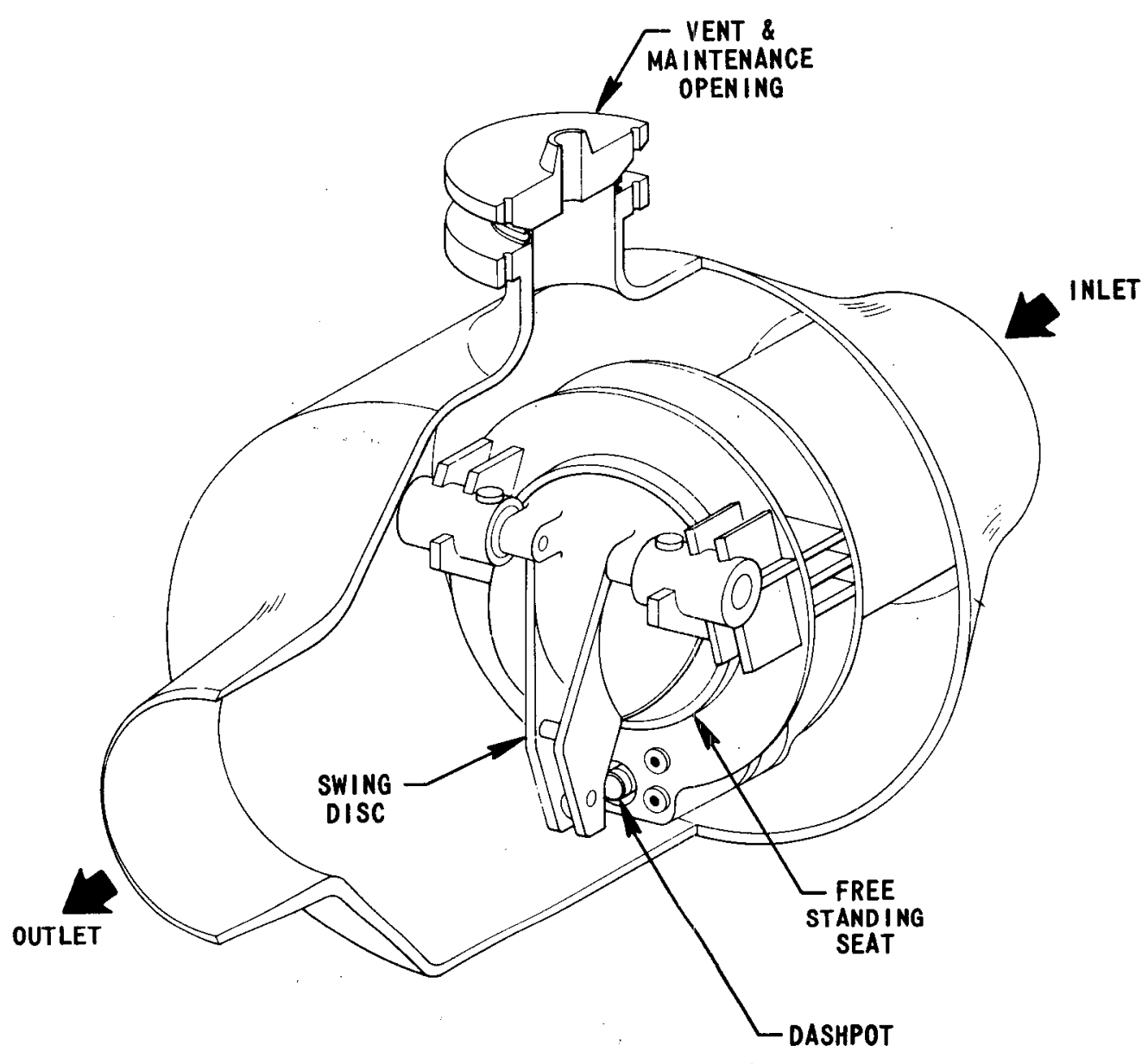

Figure XVI.E-6 Primary System 16 Inch Cold Leg Check Valve

XVI.E-7 
FFTF XVI.E.

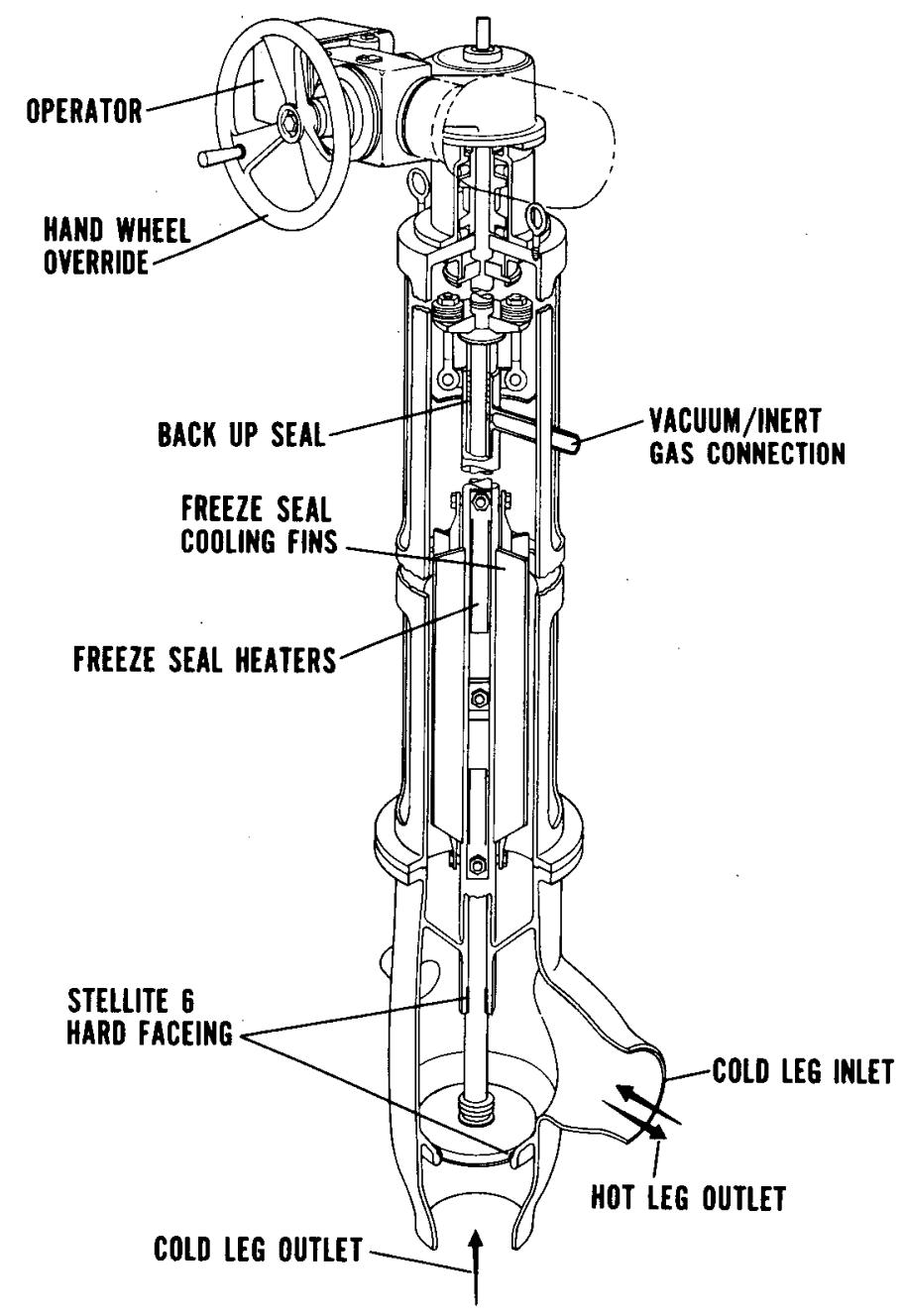

Figure XVI.E-7 FFTF Secondary Set/Isolation Valve

XVI.E-8 


\section{CLOSED LOOP SYSTEM}

FOR TESTING OF FAST REACTOR FUELS AND MATERIALS IN FFTF

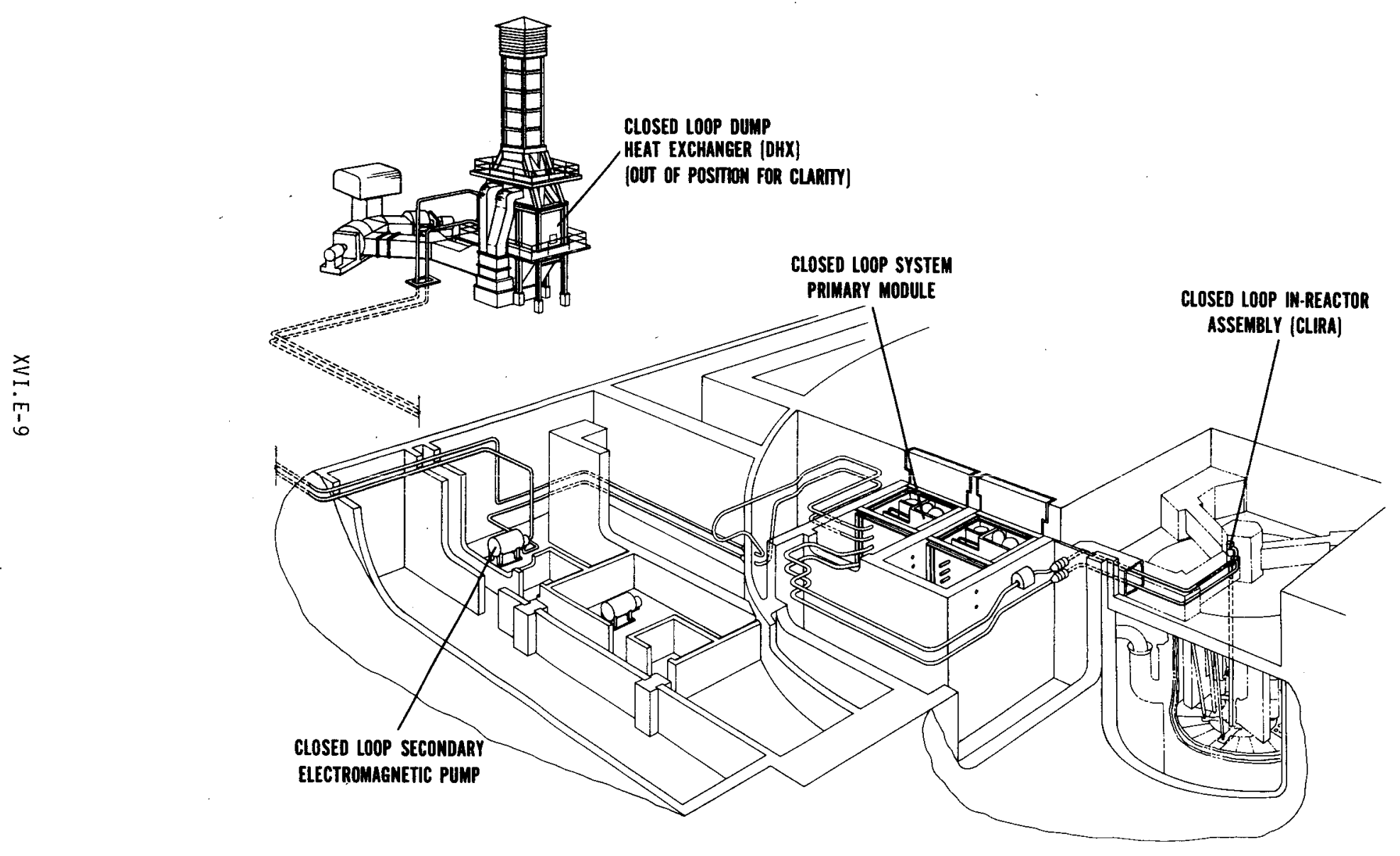




\section{XVI.F. SODIUM PURIFICATION AND INSTRUMENTATION}

Planned system for sodium purification is by cold-trapping. Sampling and monitoring devices in test operation include on-line oxygen meters, hydrogen meter, carbon activity meter, plugging meters, sodium sampling devices and flow meters. Chromel-Alumel thermocouples and platinum wire resistance temperature detectors measure reactor outlet and inlet

temperatures. Flow and outlet temperature are measured for each fuel channel.

Coolant inlet and outlet temperature and flow are monitored for each CLIRA. (Ref.2)
FFTF will use one NaK-cooled cold trap for the primary system (two are installed); one gas-cooled unit for each secondary system; and a gas-cooled unit for the interim decay storage facility. A gas-cooled prototype is being developed.

Two types of vapor traps will be used: a controlled temperature profile condenser, and aerosol filter units. (Ref. 14) 


\section{XVI.G. COVER GAS AND AUXILIARY SYSTEMS}

Argon cover gas is provided for the reactor vessel and the primary pumps at a controlled pressure by the argon receiving and distribution system. Secondary pumps and expansion tanks are supplied with argon gas to maintain a positive pressure differential with respect to the primary sodium in the IHX. Argon cover gas is maintained over all free sodium surfaces. Exhaust from the gas spaces is discharged to the radioactive gas decay system or to the neating and ventilating system according to its radioactivity. Argon gas can be pumped directly to a radioactive sampling area. Nonradioactive gas is manually sampled from vent lines. Argon cover gas of the CLIRA system and of the reactor is continuously monitored. Supply is not automatically isolated in the event of containment isolation. Check valves and shutoff valves are operated from the control room, and there are overpressure relief valves on the cover gas systems. Liquid argon is stored outside the containment system. The distribution system has feed-and-bleed components.

A nitrogen atmosphere is maintained in cells handling radioactive sodium, and the circulation of nitrogen through cooling coils cools cell atmospheres. Exhaust gas from the cells is discharged to the radioactive gas decay system or to the heating and ventilating system. Liquid nitrogen is stored outside the containment building.
Two independent NaK loops are provided, for the decay storage tanks $\left(4400^{\circ} \mathrm{F}\right)$ and for the sodium cold traps $\left(125^{\circ}-200^{\circ} \mathrm{F}\right)$.

Primary sodium can be pumped directly to the radioactive sampling area and returned to the loop. There are no crossconnections or shared components between loops. The primary sodium is monitored continuously for oxygen and carbon. Secondary sodium can be circulated through plugging meters located in purification loops, and samples removed with removable section samplers in by-pass loops in the secondary circuits.

A preheat system for sodium piping and components uses electrical resistance heaters. $0 i 1$ and/or gas-fired preheaters are provided for the DHX modules.

Primary sodium level is maintained by continuous feed and bleed from the reactor vessel through the sodium receiving and processing system. Expansion tanks in the secondary loop account for thermal expansion requirements, with a small bleed taken to the secondary sodium processing system. (Ref. 1) 
FFTF XVI.I.

\section{XVI.I. INSTRUMENTATION AND CONTROL}

Three low-level flux monitors located in the reactor vessel monitor the core neutron activity during refueling, shutdown, and startup operations. The monitor consists of a fission chamber, in-vessel thimble, in-line drive assembiy, and a common nitrogen cooling system. The fission chambers are withdrawn from the maximum flux zone for power operation.

Three fission counters and three compensated ion chambers are located outside the reactor vessel to measure flux beyond the startup range.

Chromel-Alumel thermocouples and platinum wire resistance temperature detectors measure reactor outlet and inlet temperatures. Flow and exit temperature are measured for each fuel channel. The sodium flowmeter is a probe type operating on the eddy current principle. Coolant inlet and outlet temperature and flow are instrumented for each CLIRA. Open test loops have the same type of flow and temperature instrumentation as the driver fuel channels, except that one open test loop is instrumented by sensors in nearproximity to the channel.

The fuel failure monitoring system detects fuel failure by sensing the presence of released xenon or other fission gases. A high resolution $\mathrm{Ge}$ ( $\mathrm{L} \mathrm{i}$ ) spectrometer system monitors the cover gas for Xenon isotopes. Sodium is continually monitored for soluble fission products. Delayed neutron monitors detect iodine and bromine neutron precursors and characterize the severity of a failure. Grab samples of sodium and cover gas can be taken for laboratory analysis.
Techniques under study for failed fuel location are gas tagging and eddy current flowmeter monitoring for released gases. With gas tagging, small amounts of mixed lighter isotopes of Xenon or krypton are incorporated into the gas plenum of each fuel pin, a specific isotope ratio being placed in each pin of a fuel assembly. With failure, part of the tagged gas is released to the sodium coolant and thence to the cover gas.

The plant protection system provides automatic monitoring of variables, and initiates protective action when necessary. The system includes all active equipment required for protective functions from sensors through final devices such as valves, poison rods, etc. There are two totally independent systems for reactor shutdown.

During startup, the reactor is brought up to 40 MWt on manual control. At or above 40 MWt one of the row five rods can be placed in automatic control, with the operator manually shimming the remaining five rods one at a time. Manual control can be resumed at any time. There are overpower limiters to prevent manual or automatic rod withdrawal if the power level exceeds a set value.

Primary pumps have automatic flow feedback control, with set points adjusted manually by the operator. Flow control is by varying pump speed. Control for the secondary pumps is identical. (Ref. 2) 
XVI.J. FUEL HANDLING

On. completion of irradiation, driver fuel assemblies are transferred by the In-Vessel Handling Machine (IVHM) to in-vessel storage positions for decay during the next operating cycle. From the in-vessel storage station, core components, in finned pots, are transfeirred by the Closed Loop Ex-Vessel Machine (CLEM) to the Interim Decay Storage (IDS) system, and then transferred by CLEM into the Core Component Transfer Cask (CCTC). This cask is lifted by the containment polar crane from the cask loading pit and transferred through the containment transfer air lock on a transfer cart. Outside, the cask is lifted by crane from the transfer cart for loading and shipment from FFTF.

Fresh core components are transferred into the containment building on a transfer cart to an inerting/heating/storage station where air atmosphere and surface films are removed by vacuum heating and back-filling with argon, and the temperature is conditioned. CLEM lifts the component and transports it to a position in the IDS system, where it is lowered into a finned pot for storage before transfer to the reactor vesse1. Finned pots with core components are transferred to in-vessel storage positions by CLEM, and then the core component is lifted from the finned pot by the IVHM and transferred to its designated core position. (Fig. XVI.J-1)

There are three identical. In-Vessel Handling Machines (IVHM) mounted in refueling plugs in the reactor top shield. Each machine services a $120^{\circ}$ sector of the reactor and can transport core components under sodium to and from the core, in-vessel storage positions, and the in-vessel transfer station. The IVHM consists of a grapple system which engages a handling socket at the top of the core component. A rising stem and offset arm provide vertical grapple operation. Each IVHM weighs $\sim 50$ ton and is $33 \mathrm{ft}$. high. The part below the vessel head extends into the sodium pool to a depth of $16.125 \mathrm{ft}$. The rotating plug is positioned in an opening in the reactor vessel head. The IVHMs are operated during reactor shutdown. Operation and control is by a console located on the operating floor. (Fig. XVI.J-2) (Ref. 12)
CLEM is a single-barrel, shielded fuel handling machine, permanently mounted on a transporter consisting of a gantry and a trolley. Overall height is $61.25 \mathrm{ft}$. above the operating floor. Its weight is 217 ton. CLEM handles fuel as semblies in a sodium-filled core component pot and performs transfer or irradiated and non-irradiated components between the reactor and various fuel-handling stations in the containment building. Control is semi-automatic and is accomplished from a control panel. Components of CLEM include a grapple, dual grapple chain drives and drive units, a shielded cask body, cold wall assembly, drip pan, bottom and closure valve, movable shielded skirt assembly, a NaK cooling system, and an argon gas pinge system. Normal cooling mode is by internal radiation of decay heat to the cold wall, externally cooled by NaK. The NaK is circulated by two electromagnetic pumps in a closed system, with heat dumped to an air blast heat exchanger mounted on the CLEM. (Fig. XVI.J-3)

The Interim Decay Storage (IDS) comprises three separate facilities: Reactor Core Decay Storage Tank (CCDT); the Test Assembly Decay Tank (TADT); and the A11 Component Inerting/Heating/ Storage (ACIHS). Its functions are to store irradiated and unirradiated core components (in sodium-filled pots), test assemblies, test sections, and closedloop in-reactor tubes, and to establish an inert gas coverage and to preheat new core components. The IDS is located within the containment vessel, below floor level, in steel-lined cavities. There are 1.10 storage positions for core components in the CCDT. Full-length test assemblies are stored in four sodiumcooled: storage positions in the TADT. Sodium-filled tanks in CCDT and TADT are connected to a normal and to an alternate cooling system.

The Core Component Transfer Cask has six fuel positions. It provides the capability of handling one test assembly after thirty days decay with an initial rating of $100 \mathrm{MWd} / \mathrm{kgm}$, and five driver assemblies at ninety days decay with an initial rating of $45 \mathrm{MWd} / \mathrm{Kgm}$. (Ref. 1) 


\section{FUEL HANDLING CYCLE}

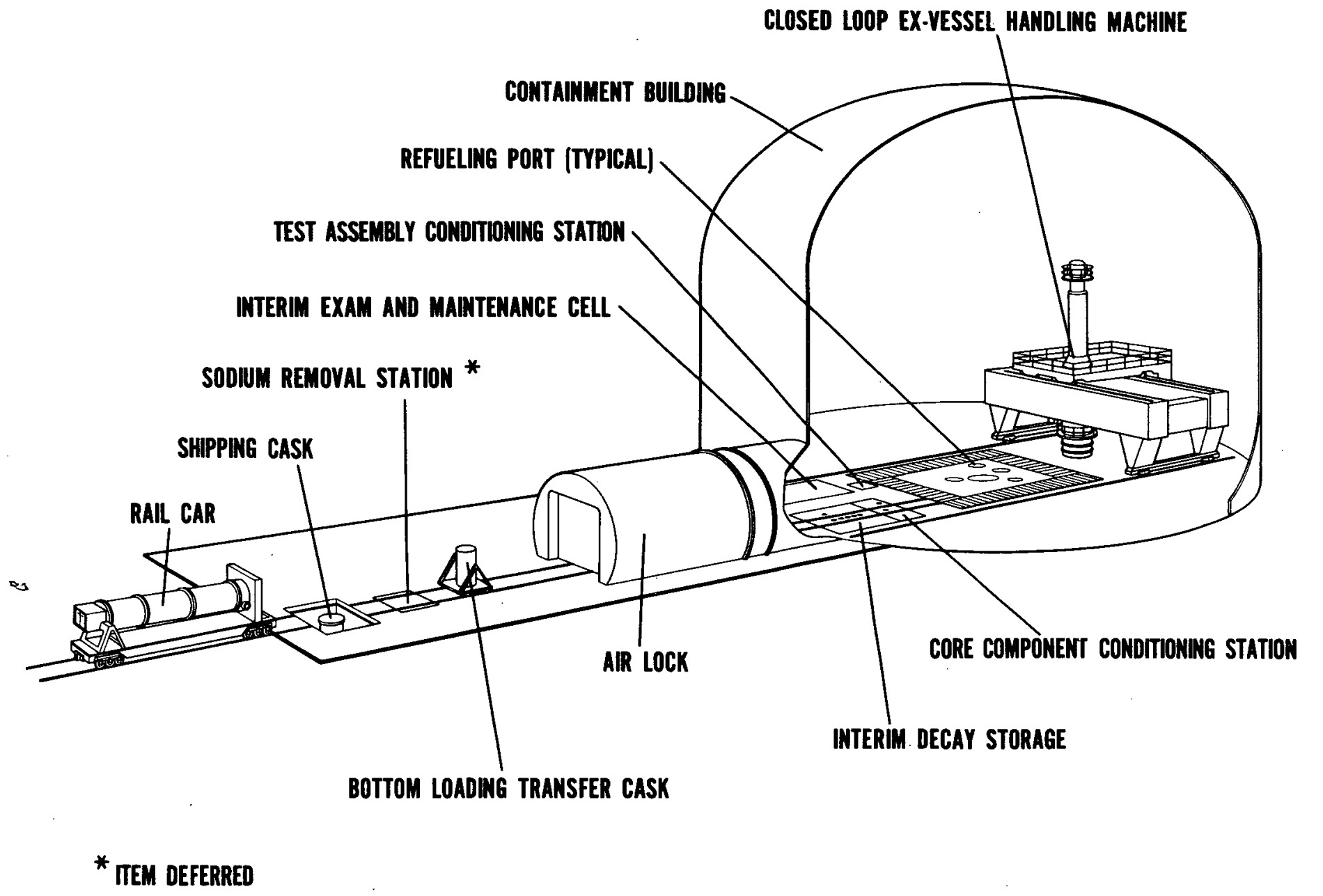

Figure XVI.J-1 FFTF Fuel Handling Cycle 
FFTF XVI.J.

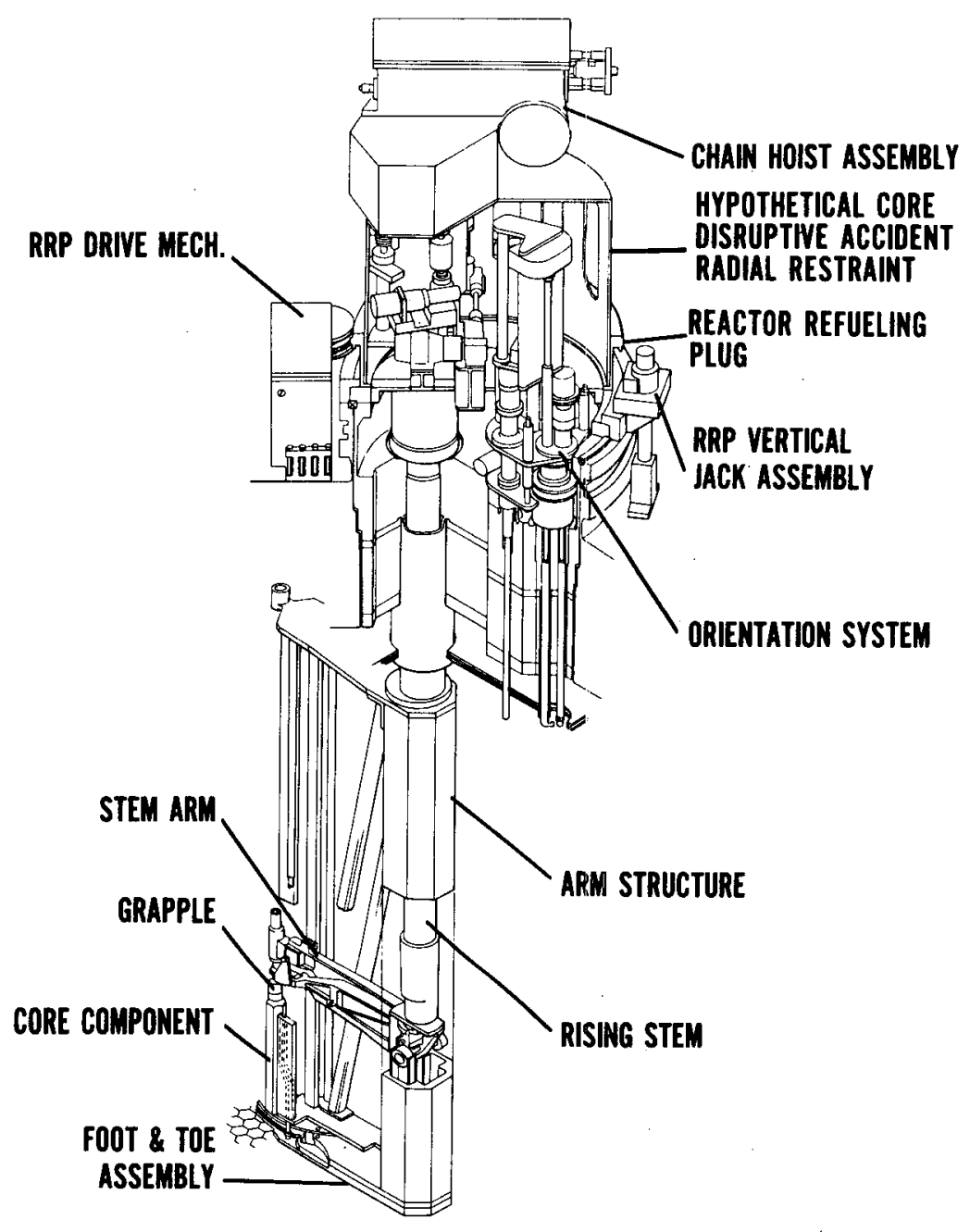

Figure XVI.J-2 FFTF In-Vessel Handling Machine (IVHM)

XVI.J-3 
FFTF XVI.J.

\title{
CLOSED LOOP EX-VESSEL MACHINE (CLEM) AND TRANSPORTER
}

GANTRY

\author{
AND TRANSPORTER
}


XVI.K. CONTAINMENT AND STRUCTURES

Major structures are the reactor containment building, reactor service building, control building, auxiliary buildings and dump heat exchanger enclosures. The reactor containment building is a carbon steel she $1141.1 \mathrm{~m}$ (135 ft.) dia. and $55.5 \mathrm{~m}$ (182 ft.) high. $24.4 \mathrm{~m}$ (80 ft.) of the structure is below grade. The cylindrical shell has $3.5 \mathrm{~cm}(\sim 1-1 / 2$ in.) thick walls and hemispherical heads. The bottom head is embedded in concrete. Maximum design leak rate is $0.1 \%$ of total volume per day. All penetrations are leak-tight. All radioactive components and systems are within the containment structure, housed in reinforced and shielded concrete cells below the operating floor. The shielded cells have carbon stee 1 liners. The structure has a 200-ton capacity polar gantry crane.
The reactor service building contains facilities for transfer of assemblies and radioactive components to shipping containers for off-site disposal. Rail and truck access is provided to the adjacent containment structure through an equipment air lock. Below grade there are concrete shielded cells for some auxiliary systems, including cryogenic systems for storage and processing of radioactive waste gases.

The control building is located with a portion of the building adjacent to the containment structure, with access through an air lock and monitored areas. Auxiliary buildings housing ancillary systems and equipment are of steel superstructure. The DHX structures are steel, and provided with insulation to reduce noise levels. (Fig. XVI.K-1) (Ref. 2) 


\section{FFTF PLANT ARRANGEMENT}

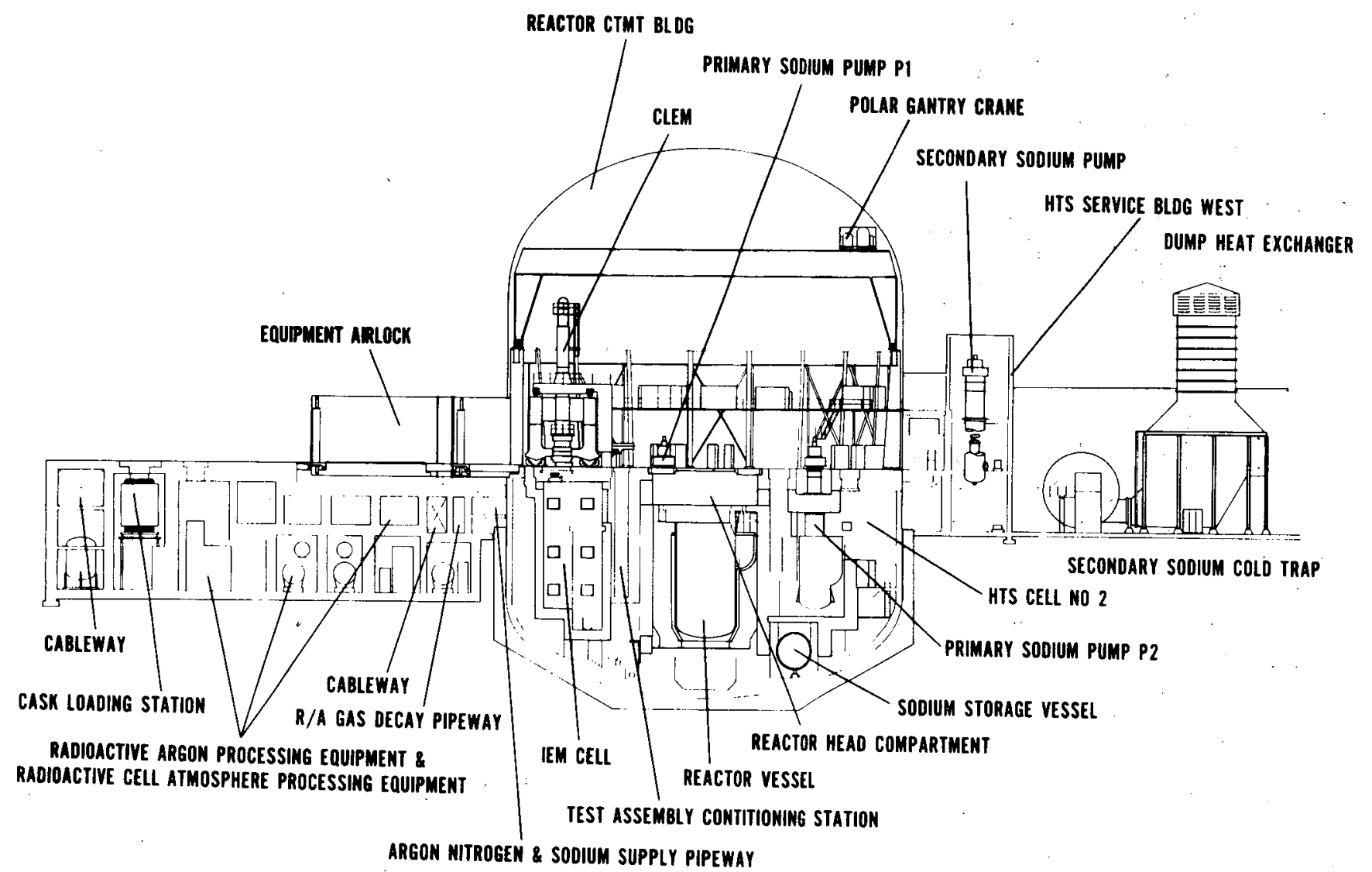

Figure XVI.K-1 FFTF Plant Arrangement 
XVII. CLINCH RIVER BREEDER REACTOR

(CRBR)

\author{
LOCATION: Clinch River \\ Oak Ridge, Tennessee \\ (TVA site) \\ OPERATION: Construction \\ 1976-1980 target
}

The objective of the Clinch River Breeder Reactor (CRBR) project is the design and construction of a 350 MWe demonstration fast breeder reactor. A joint proposal for the design, construction, and operation of CRBR by Commonwealth Edison Co. of Chicago and Tennessee Valley Authority was accepted by the AEC in January 1972. In March 1972, two non-profit groups were formed to implement the CWE-TVA proposal. The Project Management Corporation (PMC) was to provide centralized management of the Project and the demonstration program. The Breeder Reactor Corporation (BRC) served as liaison between project participants and the utility industry. BRC represents 350 utilities which have contributed to the project. In November 1972, AEC and PMC announced the selection of Westinghouse Advanced Reactors Division as prime contractor, with responsibility for designing and supplying the Nuclear Steam Supply System, and assisting PMC in overall planning. Burns and Roe was retained as architect-engineer in December 1972, with Holmes and Narver, Inc. assisting in selected phases. Contract between Westinghouse and PMC was signed on November 14, 1973, and the contract between AEC and Westinghouse for supporting technology was signed January 30, 1974. General Electric Co. Breeder Reactor Department and Atomics International are subcontractors to Westinghouse.

The schedule announced by PMC in January 1974 was for filing the environmental report by December, 1974, construction permit expected about 14 months later, and a construction period from 1976 to 1980. The, first application was rejected because of lack of detailed information on site meteorology, seismology, and aquatic environment. 
Under a realignment of industry-government relationships in the Liquid Metal Fast Breeder Reactor (LMFBR) program in 1975, the Energy Research and Development Administration (ERDA) will now assume direct management of the CRBR Project, with PMC assuming an advisory role along with the TVA group and a three member Project Steering Committee.

The Nuclear Regulatory Commission docketed the Clinch River application in April 1975. Debates over the requirement for a core-catcher are still progressing. 


\section{INDEX}

REFERENCES

REACTOR PARAMETERS

SECTIONS
Page

XVI I - 5

XVI I -7

A. CORE AND BLANKET

XVII.A-1

B. CORE SUPPORT AND VESSEL INTERNALS

XVII.B-1

C. REACTOR VESSELS AND SHIELDING

XVII.C-1

D. CONTROL ELEMENTS

XVII.D-1

E. HEAT TRANSFER SYSTEMS

F. SODIUM PURIFICATION AND INSTRUMENTATION

XVII .E-1

XVII.F-1

G. COVER GAS AND AUXILIARY SYSTEMS

XVI I.G-1

H. STEAM GENERATORS

XVII.H- I

I. REACTOR INSTRUMENTATION AND CONTROL

XVII.I-T

J. FUEL HANDL ING

XVII.J-I

K. CONTAINMENT

XVII.K-I 


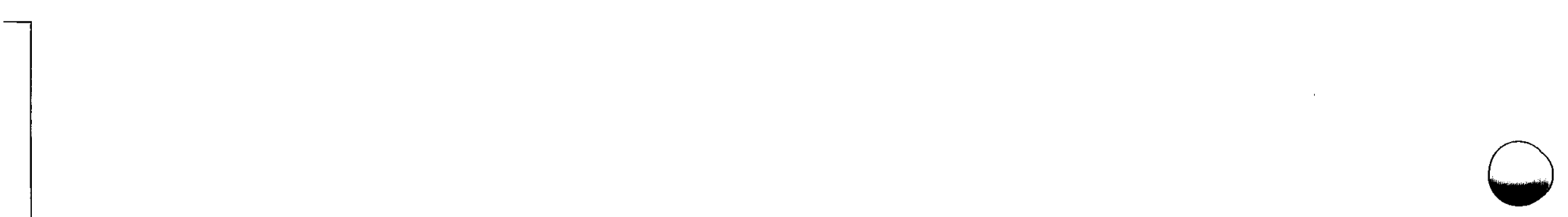

0

$\odot$
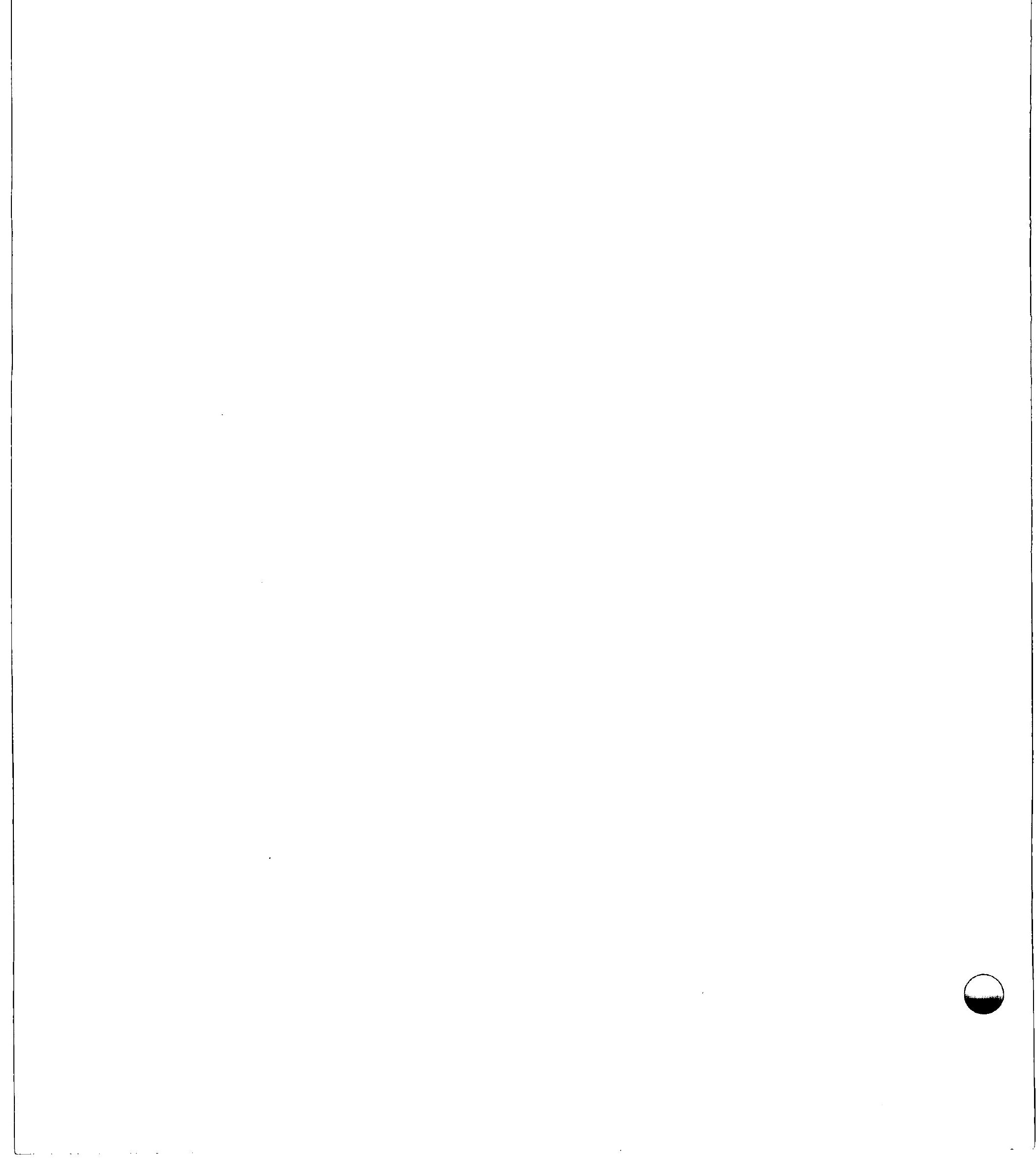
REFERENCES

1. Clinch River Breeder Reactor Project, Proc. Breeder Reactor Corporation Jan. 1974 Information Sessions

PMC-04-01 (1974) (CONF-740116)

2. Clinch River Breeder Reactor Project

Nuclear Engineering International Vol. 19, \#221 (Oct. 1974)

- LMFBR Fuels and Materials Development:

G. W. Cunningham, p. 840-842

- Wa11 chart, p. 843

- The Clinch River Breeder Reactor Project Nuclear Steam Supply System W. M. Jacobi, p. 846-850

- Environmental Aspects of the CRBRP J. H. Wright, p. 851-853

- Safety of the Clinch River Breeder Reactor Project J. Graham, et. a i. p. 854-856

- Steam Generator for the United States LMFBR Plant R. E. Skardaht, F.E. Tippets, p. 857-859

- CRBRP Reactor Refueling K. W. Foster, p. 860-862

- Clinch River Breeder Reactor Plant and Balance-of-Plant Design S. McPherson, p. 863-864

3. Safety Related Criteria and Design Features of the Clinch River Breeder Reactor Plant.

L. E. Strawbridge

Proc. Fast Reactor Safety Meeting, ANS, April 1974

CONF-740401-P1, p. 72-92 (1974)

4. Clinch River Breeder Reactor Project, 1974 Technical Progress Report U.S. GPO 1975

5. Proposed Reference Design for the Clinch River Breeder Reactor Plant Proc. Breeder Reactor Corp., Oct. 1974 Information Session

PMC-74-02

CONF-741087 


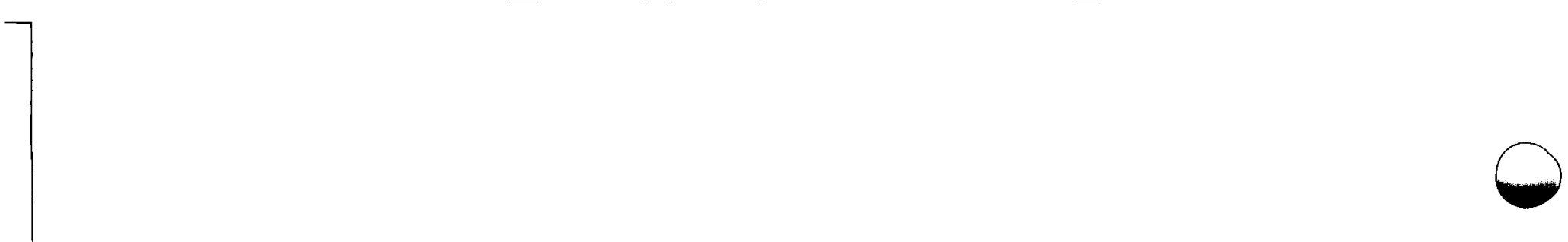

-

$\bullet$

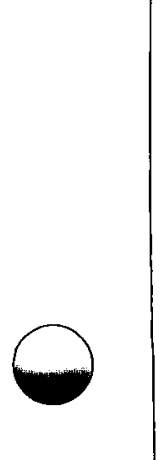


Table - 1

Type

No. Loops

Coolant

Core inlet temp.

Core outlet temp.

Flow direction

Oriver fuel

GENERAL PARAMETERS

Blanket fuel

Core diameter

Core volume

Enrichment zones

Output MWe/MWt

Breeding ratio

Max. can temperature

Linear power

Doppler $\left(-T \frac{d k}{d t}\right)$

Driver elements

Rad. blanket el ements

In-core control elements

In-vessel storage

Goa] Burnup
Loop

3 (+ Overflow Heat Removal System) Sodium

$730^{\circ} \mathrm{F}$

$995^{\circ} \mathrm{F}$

Upward

Mixed oxide

oxide

$6.2 \mathrm{ft}$.

$2400 \ell$

2

$350 / 975$

1.2

$1215^{\circ} \mathrm{F}$

$14.5 \mathrm{kw} / \mathrm{ft} . \max .(7 \mathrm{kw} / \mathrm{ft}$. ave) .0073 (Beginning of first cycle) 198

150

15/4 Primary/secondary

None

80,000 peak 
CRBR XVII

Table - 2

CORE AND BLANKET

\begin{tabular}{|c|c|c|c|}
\hline$\therefore$ & Driver Zone & Axial Blanket & Radial Blanket \\
\hline Fuel material & $\mathrm{UO}_{2}-\mathrm{PuO}_{2}$ & $\mathrm{UO}_{2}$ & $\mathrm{UO}_{2}$ \\
\hline Form & Pellet & Pellet & Pellet \\
\hline Stoichiometry & Substoichiometric & & \\
\hline Enrichment $\mathrm{Pu}(\mathrm{U}+\mathrm{Pu})$ & & Depleted & Depleted \\
\hline Inner & $22 \%$ & & \\
\hline Outer & $32 \%$ & & \\
\hline Rod cladding material & Stainless steel 376 & & Stainless steel \\
\hline od & 0.23 in. & $0.23 \mathrm{in}$. & 0.52 in. \\
\hline Wall thickness & 0.015 in. & $0.015 \mathrm{in}$. & $0.015 \mathrm{in.}$ \\
\hline Column length & 36 in. & 14 in. $\times 2$ & $64 \mathrm{in.}$ \\
\hline Gas plenum length & 48 in. (top) & & 36 in. (top) \\
\hline Vented-non-vented & No & & \\
\hline Assembly material & Stainless steel & \multirow{3}{*}{$\begin{array}{l}\bar{\Xi} \\
己 \\
\pm \\
\pm \\
+\frac{5}{3} \\
-\end{array}$} & Stainless steel \\
\hline Shape & Hexagonal & & Hexagonal \\
\hline Across flats & $4-1 / 2$ in. & & $4-1 / 2$ in. \\
\hline Overall length & $180 \mathrm{in.}$ & \multirow{6}{*}{ 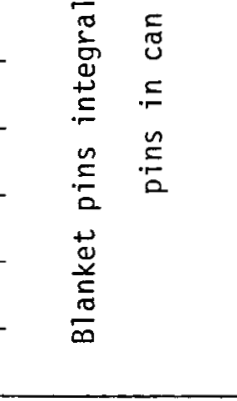 } & $180 \mathrm{in}$. \\
\hline Pins/assembly & 217 & & 61 \\
\hline Pin spacing & Spiral wire & & Spiral wire \\
\hline Pin pitch & $1.26 \mathrm{P} / \mathrm{D}$ & & \\
\hline Assembly pitch & $4.76 \mathrm{in.}$ & & \\
\hline Assemblies in core & 198 & & 150 \\
\hline Fuel & .325 & & \\
\hline
\end{tabular}

XVII -8 
XVII.A. CORE AND BLANKET

CRBR fuel assemblies are similar to the Fast Flux Test Facility (FFTF) assemblies. The driver core consists of 198 assemblies in a triangular pitch of 4.76 in. Feed enrichments are $22 \%$

$\mathrm{Pu} / \mathrm{U}+\mathrm{Pu}$ for the inner core zone and $32 \%$ for the outer zone for the equilibrium cycle. First core enrichments are $18.7 \%$ and $27.1 \%$. Surrounding the core are 150 radial blanket assemblies. The reflector and restraint assemblies quoted in the General Parameters have been replaced by 174 removable radial shield assemblies to protect the two core restraint former rings and the core barrel. Overall lengths of all reactor assemblies and the reactor vessel have been shortened. Inlet and zutlet nozzles of the assemblies have been modified to improve handling and location in the core lattice. Coolant flow distributions in the ducts and rod bundles have been improved by reducing the space between the outer rods or pins and the hexagonal can. Smaller spacer wires are used on the outer row rods, while maintaining the same spacings. (Fig. XVII.A-1, A-2) (Ref. 4) 


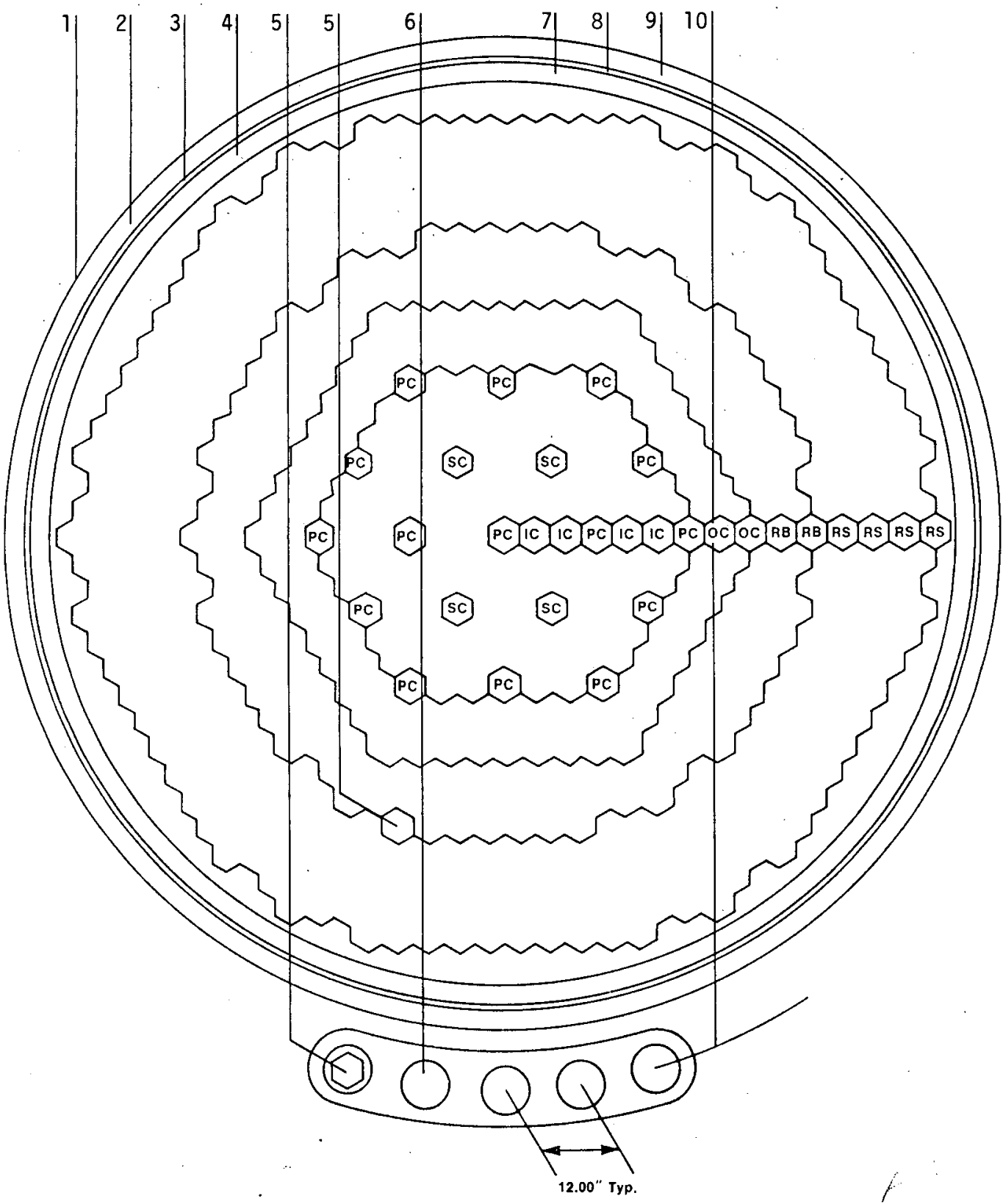

1. $77.50 \mathrm{R}$

2. $75.50 \mathrm{R}$

.3. $75.00 \mathrm{R}$

4. $70.00 \mathrm{R}$

5. SURVEILLANCE SPECIMENS
6. FUEL TRANSFER/STORAGE 8.625 0.D., 7.981 I.D. (4 PLACES)

7. 5.00 FIXED SHIELDING

8. $.50 \mathrm{GAP}$

9. 2.00 CORE BARREL 10. $85.70 \mathrm{R}$
Sym.

Component Name

IC INNER ZONE FUEL ASSEMBLY

OC OUTER ZONE FUEL ASSEMBLY

RB RADIAL BLANKET ASSEMBLY

RS RADIAL SHIELD ASSEMBLY

PC PRIMARY SYSTEM CONTROL ASSEMBLY

SC SECONDARY SYSTEM CONTROL ASSEMBLY
Quan.

108

90

150

324

324
15
4

Figure XVII.A-1 Reactor Cross Section (Ref. 4) 


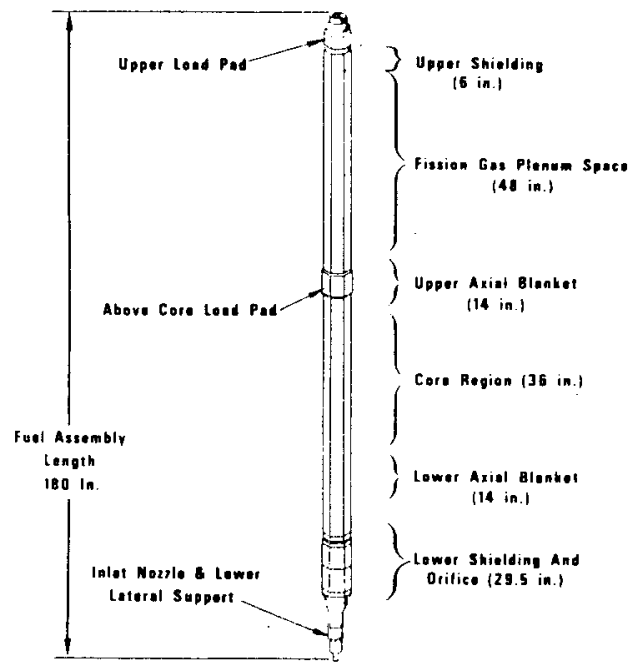

Figure XVII.A-2a Core Fuel Assembly (Ref. 1)

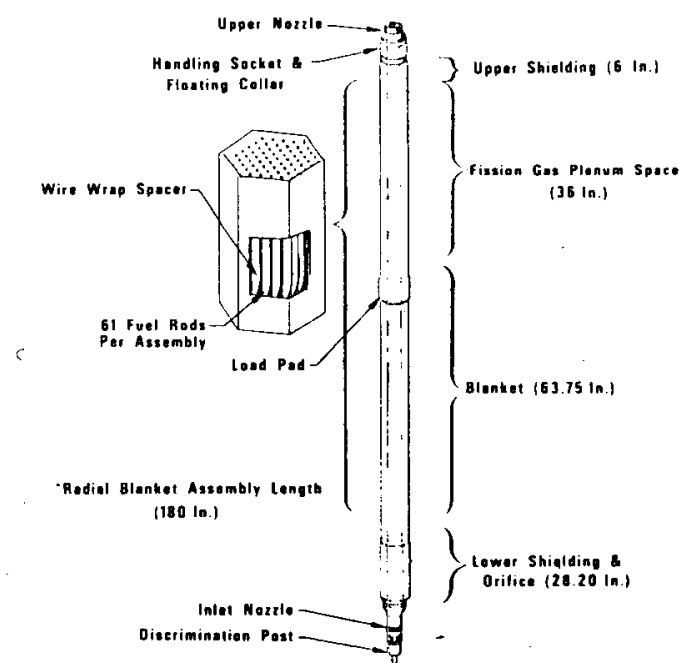

Figure XVII.A-2b Radial Blanket Assembly 
XVII.B. CORE SUPPORT AND VESSEL INTERNALS

The lower internal structure consists of the core support plate and core support skirt, core barrel, horizontal baffles, core restraint former rings, fixed radial shielding, and inlet and by-pass flow modules.

The core support structure is composed of a 24 in. thick core support plate with holes into which liners are inserted. The inlet nozzles fit into the liners. Each module holds the nozzle for a group of reactor assemblies, and most modules have flow orifices to assist flow distribution. The orifices also establish pressure zones upon which hydraulic balance of the fuel, control, and radial blanket assemblies is based. With the hydraulic balance arrangement, the upper core plate is not required.
The skirt of the bottom support plate attaches to the reactor vessel wall at a ring forging. The core barrel is a welded structure of 2 in. thick plate, 151 in. dia. It is supported on the support plate and is external to the radial shielding. The core barrel rings provide lateral restraint for the reactor assemblies. Constraint former rings apply against load pads, above the core zone. The upper internals structure utilizes transverse plates connecting four jack-operated lift columns used to roise the structure during refueling. (Fig. XVII.B-1, B-2, B-3)

Outlet modules above the assembly outlet nozzles guide the flow into the outlet plenum. Each outlet module collects the flow from a group of reactor assemblies. (Fig. XVII.B-4)

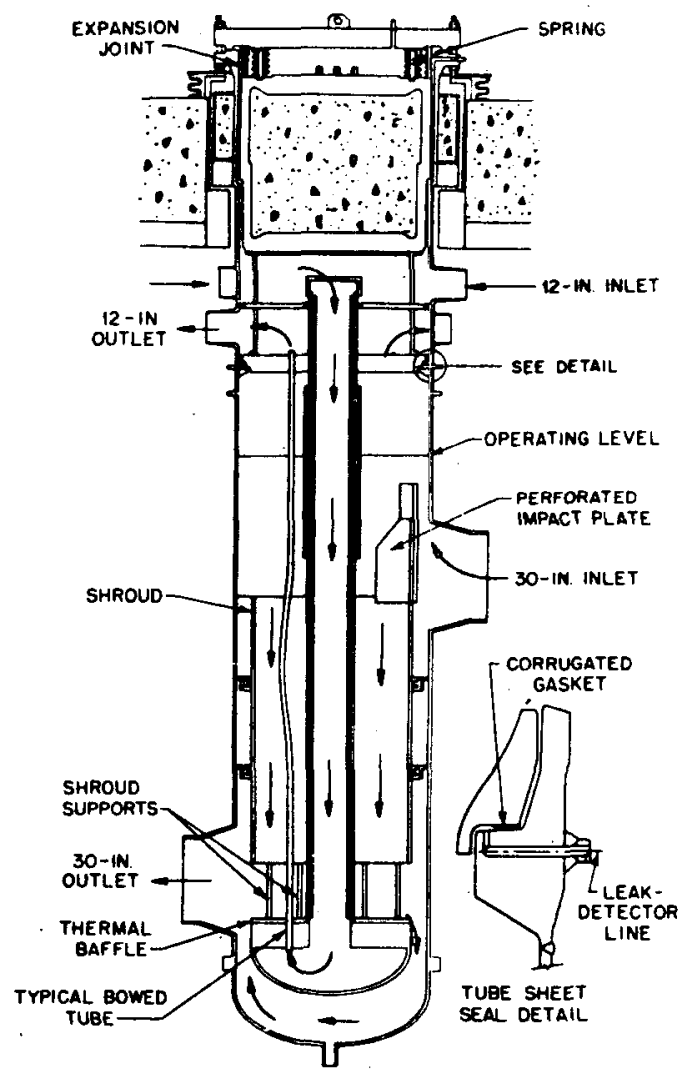

Figure XVII.B-1 CRBR Core Support Structure (Ref. 5) 
CRBR XVII.B. -

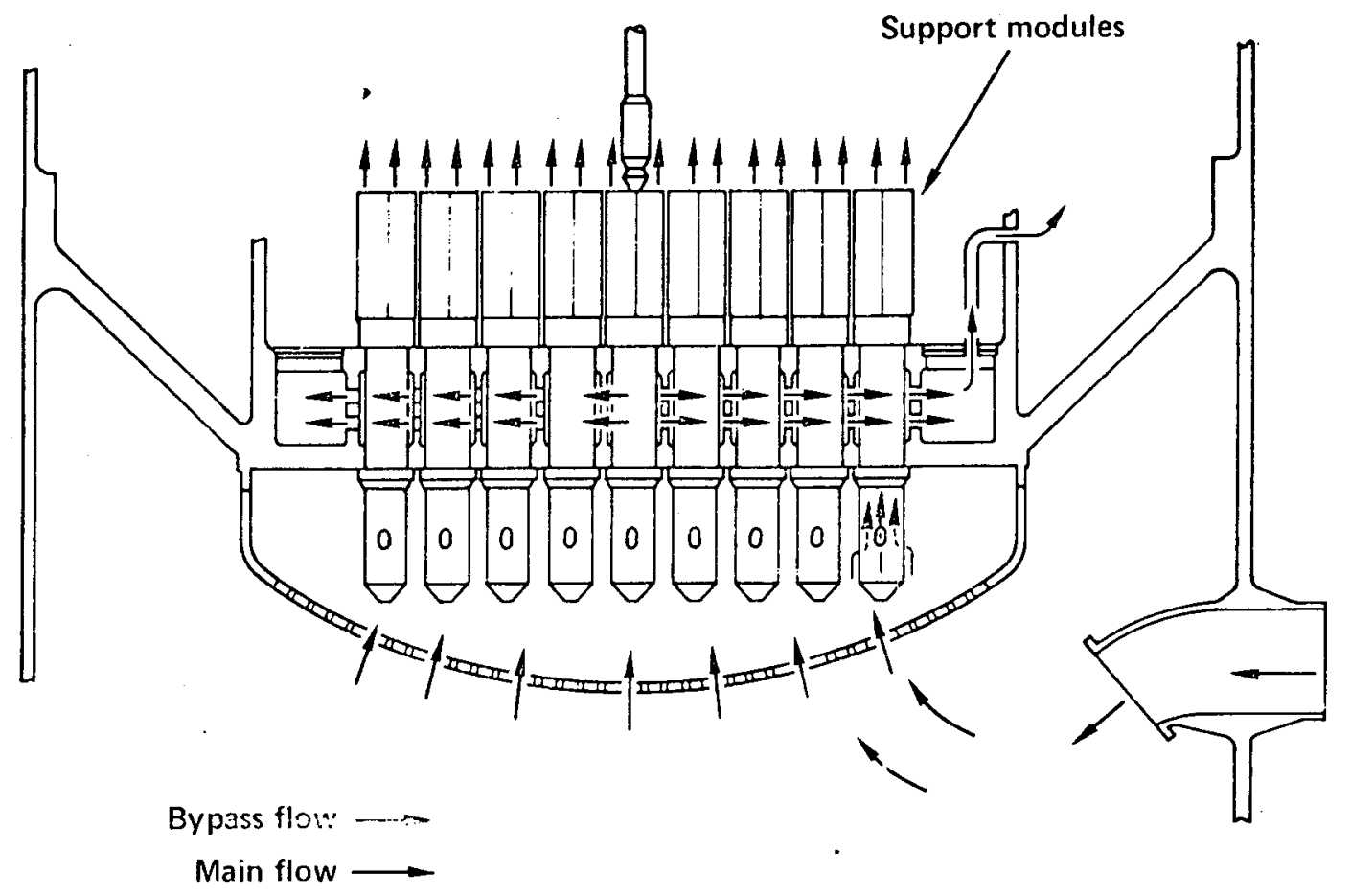

Figure XVII.B-2 CRBR Modular Core Support System Assembly Flow Paths (Ref. 1)

XVII. B-2 


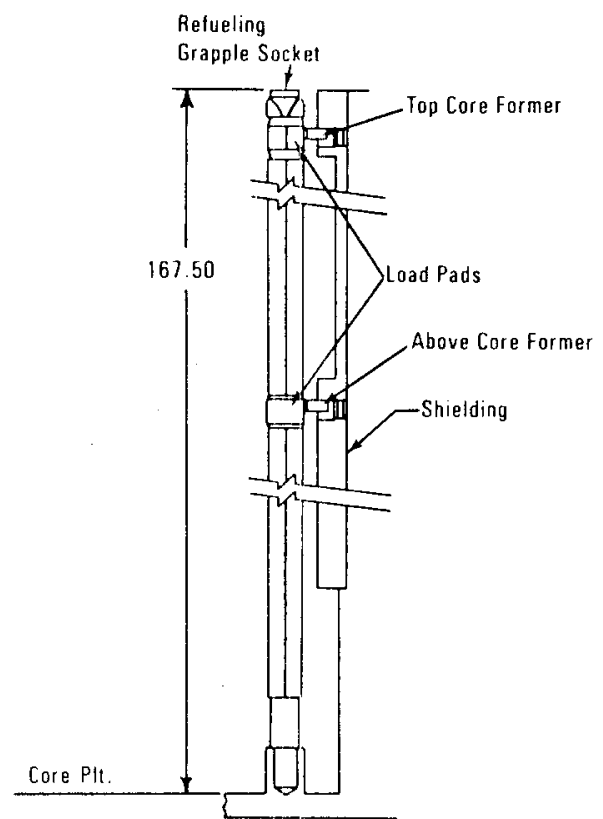

Figure XVII.B-3 CRBR Core Restraint (Ref. 1)

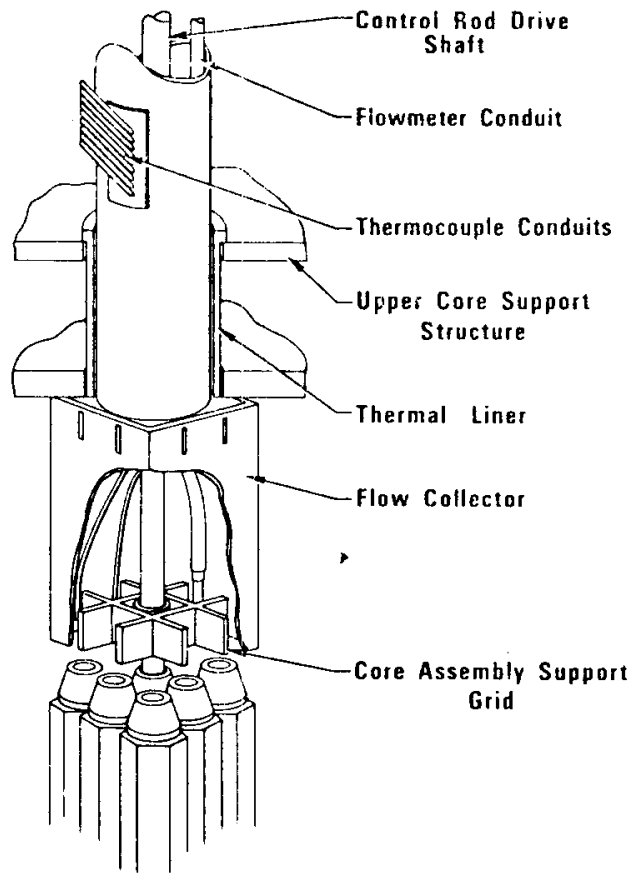

Figure XVII.B-4 CRBR Upper Package Outlet Module (Ref. 1) 
XVII.C. REACTOR VESSELS AND SHIELDING

The reactor vessel is a vertical cylindrical shell with a torospherical bottom head and an upper flange. Inside diameter is 243 in., overall length 658.35 in. Material is stainless steel, with alloy steel used for the flange and stationary outer ring, and a transition shell of Inconel between the low alloy and the stainless steel. The vessel flange is bolted to the stationary outer ring, and the ring is supported by the concrete ledge of the reactor cave. (Fig. XVII.C-1)
21-1/2 in closure head assembly is a steel. It has radiation shielding, thermal insulation plates, and a suspended vortexsuppressor plate. The head is composed of three independent rotating plugs, contained one inside the other. The ex-vessel transfer machine is located in the largest plug, and the in-vessel transfer machine in the smallest plug. (Fig. XVII.C-2, C-3)
The guard vessel provides secondary containment and limits total leakage in the event of a leak from the primary vessel or piping. The cylinder has an id of $262.5 \mathrm{in}$. and is $570.5 \mathrm{in}$. high. A skirt bolted to the floor of the reactor cavity supports the guard vessel. Leakage sensors and in-service inspection equipment can be located in the space between the two vessels. The inlet piping downcomer is protected by an extension of the guard vessel. (Fig. XVII.C-4)

The reactor vessel cavity is sealed and filled with an inert gas. Below the cavity there is an area which will house an ex-vessel core retention device if required.

Individual cells house the heat transport system loops. A11 primary system components are surrounded by guard vessels. (Ref. 4) 
CRBR XVII.C.

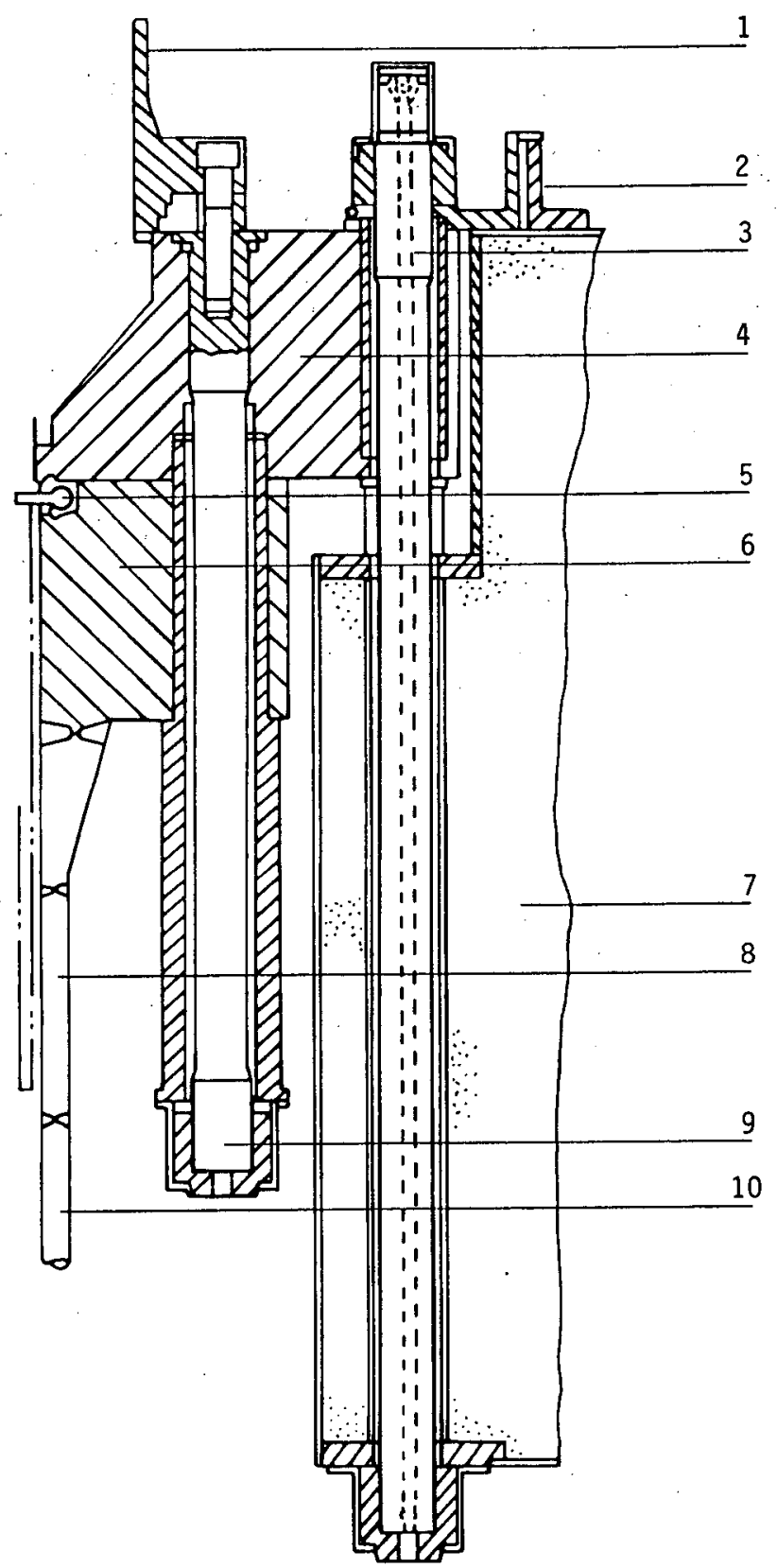

1. PLUG RISER

2. REACTOR CAVITY SEAL

3. CLOSURE HEAD VESSEL HOLDDOWN BOLT

4. STATIONARY OUTER RING

5. OMEGA SEAL
6. VESSEL FLANGE

7. CONCRETE LEDGE

8. INCONEL 600 TRANSITION

9. HEAD TO VESSEL BOLT

10. VESSEL WALL

Figure XVII.C-1 CRBR Vessel Support System (Ref. 4)

XVII.C-2 


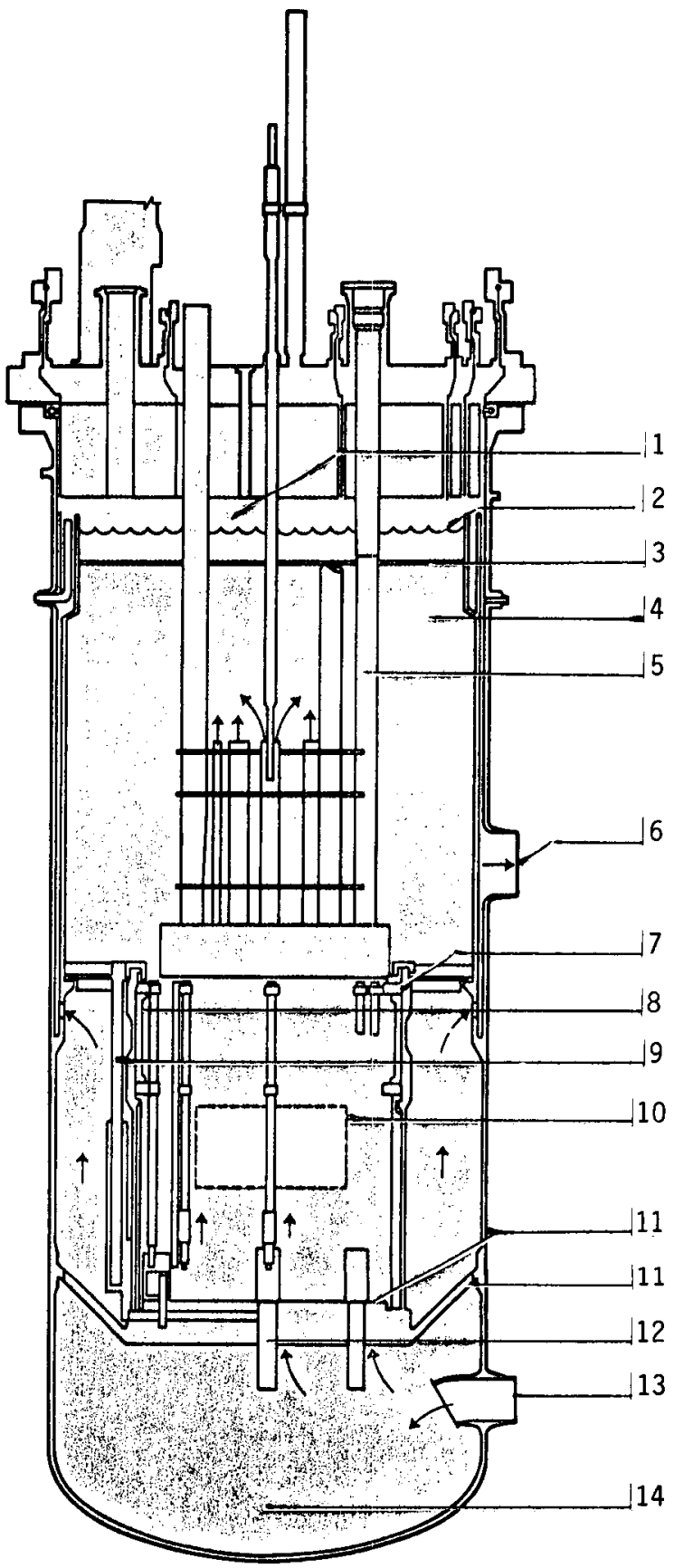

1. COVER GAS

2. SODIUM LEVEL

3. VORTEX SUPPRESSOR PLATE

4. OUTLET PLENUM

5. UPPER INTERNALS STRUCTURE

6. OUTLET NOZZLE

7. CORE RESTRAINT FORMER RINGS
8. RADIAL SHIELD ASSEMBLIES

9. FUEL TRANSFER AND STORAGE POSITIONS

10. REACTOR CORE

11. CORE SUPPORT STRUCTURE

12. INLET MODULE

13. INLET NOZZLE

14. INLET PLENUM

Figure XVII.C-2 CRBR Reactor System (Ref. 4) 


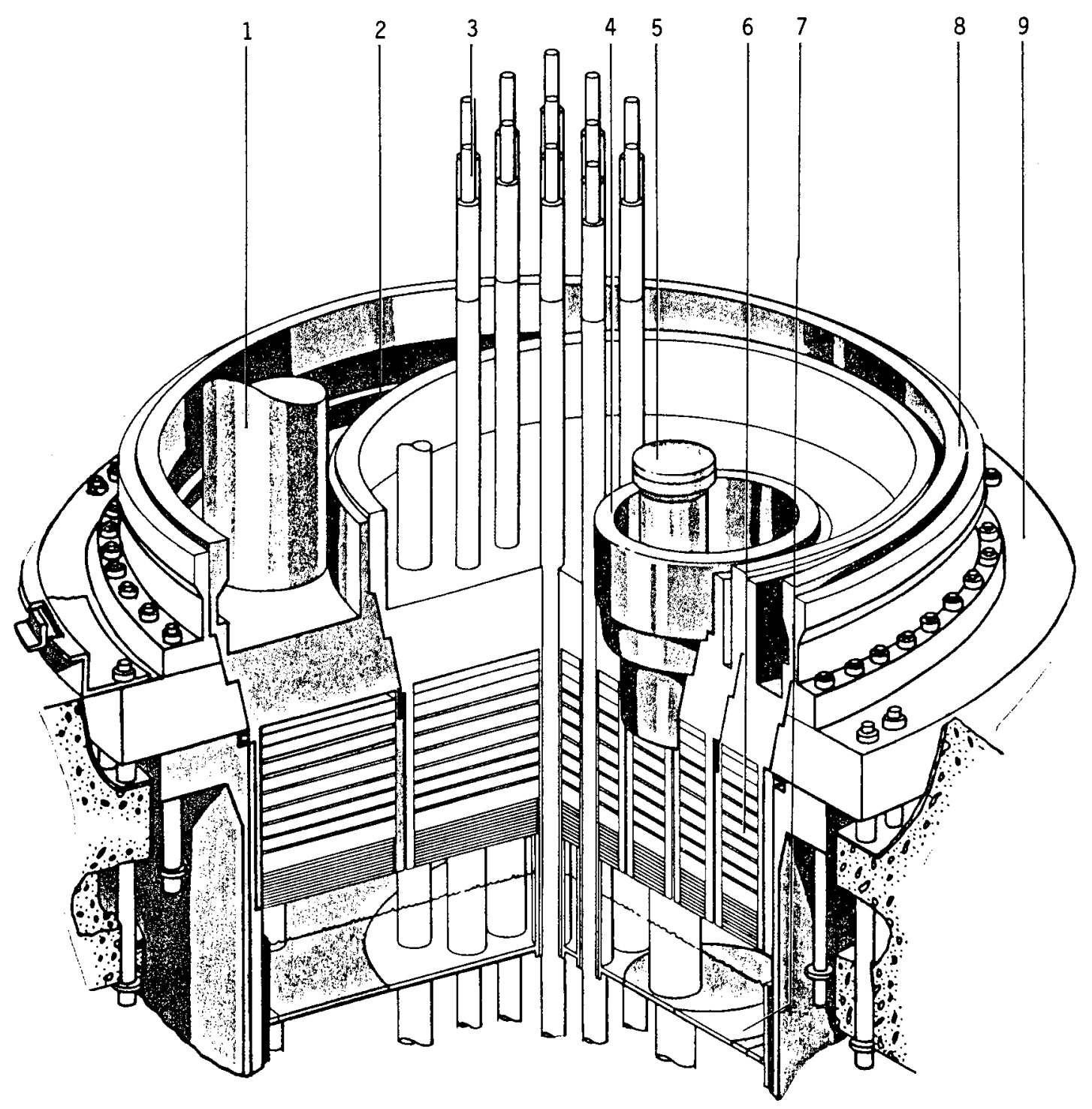

1 EX-VESSEL TRANSFER MACHINE PORT

2. INTERMEDIATE ROTATING PLUG

3. CONTROL ROD DRIVE MECHANISM

4. SMALL ROTATING PLUG
5. IN-VESSEL TRANSFER MACHINE PORT

6. SHIELDING

7. SUPPRESSOR PLATE

8. LARGE ROTATING PLUG

9. STATIONARY RING

Figure XVII.C-3 CRBR Closure Head Assembly (Ref. 4) 


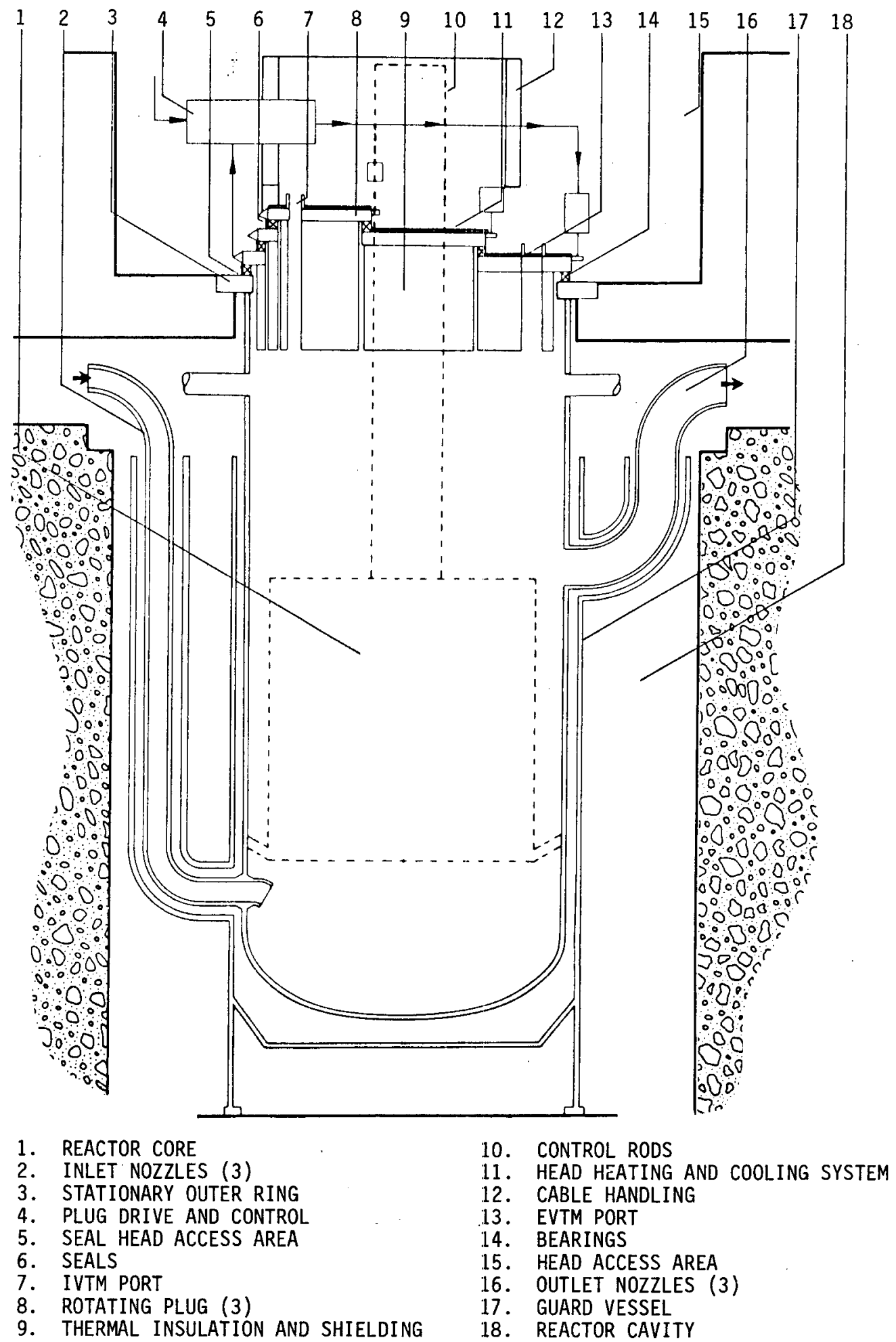

Figure XVII.C-4 CRBR Reactor Enclosure (Ref. 4) 
XVII.D. CONTROL ELEMENTS

There are fifteen primary and four secondary control assemblies. Each primary system control rod has 37 absorber pins. Secondary assemblies each have 19 absorber pins. The secondary system utilizes a hydraulic scram assist, the primary system a spring assist. Primary and secondary reactivity control systems are independent. Pin bundles consist of $\mathrm{SS}$ tubes containing $\mathrm{B}_{4} \mathrm{C}$ pellets. The rods are wire-wrapped and include a gas plenum. The outer duct remains in the core. The inner duct is connected to the control rod drive and moves relative to the outer duct. (Fig. XVII.D-1)

(Ref. 1, 4)

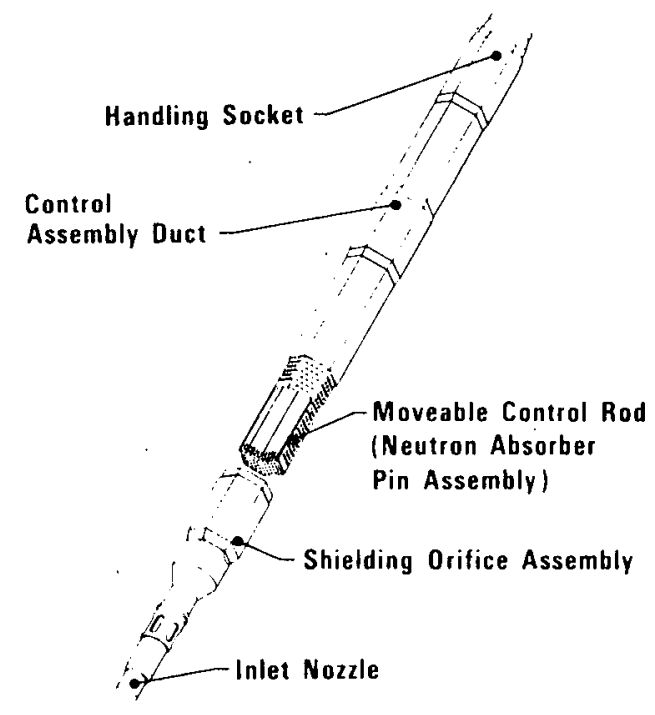

Figure XVII.D-1 CRBR Control Assembly (Ref. 1) 


\section{XVII.E. HEAT TRANSFER SYSTEMS}

There are three secondary independent loops. The primary system includes a hot-leg pump, the shell side of an intermediate heat exchanger, and a check valve. No isolation valves are used. Piping between the reactor and the primary pump is 36 in., between the pump and the heat exchanger 24 in. All primary loop piping is either elevated or contained within guard vessels, and there are guard vessels around the pumps and the Intermediate Heat Exchanger (IHX) Reactor vessel outlet nozzles are $\sim 16 \mathrm{ft}$. below the normal sodium level in the reactor vessel.

The intermediate system includes a cold leg pump, the tube side of the IHX, and incorporates an expansion tank in each loop. The system is arranged to accommodate "hockey stick" steam generator modules (evaporator and super heater).

Preliminary design for the primary and secondary pumps is being done by Byron Jackson and Westinghouse-EMD. Vertical centrifugal units are proposed. The primary pump operates in the hot leg of the loop at $995^{\circ} \mathrm{F}$. Intent at the present time is to make the primary and secondary pumps hydraulically identical. (Fig. XVII.E-1)

The design concept for the Intermediate Heat Exchanger is a straight tube component, with a flexible downcomer. (Fig. XVII.C-2) (Ref. 5)

The check valve concept under consideration uses a tilting disc housed within a cylindrical body with conical end closures. The tilting disc seats against a free-standing seat. A dashpot controls the rate of disc closure upon flow reversal and limits pressure surges in the loop. A flanged access opening is provided at the top of the valve. (Fig. XVII.E-3)

The reference design provides for forced convection decay heat removal and heat removal by natural circulation, under normal or off-normal conditions. Elevation of piping and the provision of guard vessels assure continued decay heat removal, with primary pumps operating at pony motor speed. The steam generator auxiliary heat removal system functions by first venting steam to the atmosphere. In the event of loss of normal feedwater, steam is generated from water from a protected storage tank. Steam from the steam drum is naturally circulated to the tube-side of an air-cooled condenser, condensed, and returned to the steam drum. A major change made recently is the addition of a system to allow decay heat removal without the use of the main coolant loops and the steam generators. This system, the Overflow Heat Removal System (OHRS), was created by adding a heat exchanger to the existing overflow loop and adding two small air-blast heat exchangers. The OHRS is rated at $5.6 \mathrm{MWt}$. (Fig. XVII.E-4) (Ref. 4)

All loop vaults are independent and shielded from one another. Al] main components are supported by their flanges at the operating floor level in the containment building. Vault atmosphere is nitrogen. (Ref. 5) 
CRBR XVII.E.

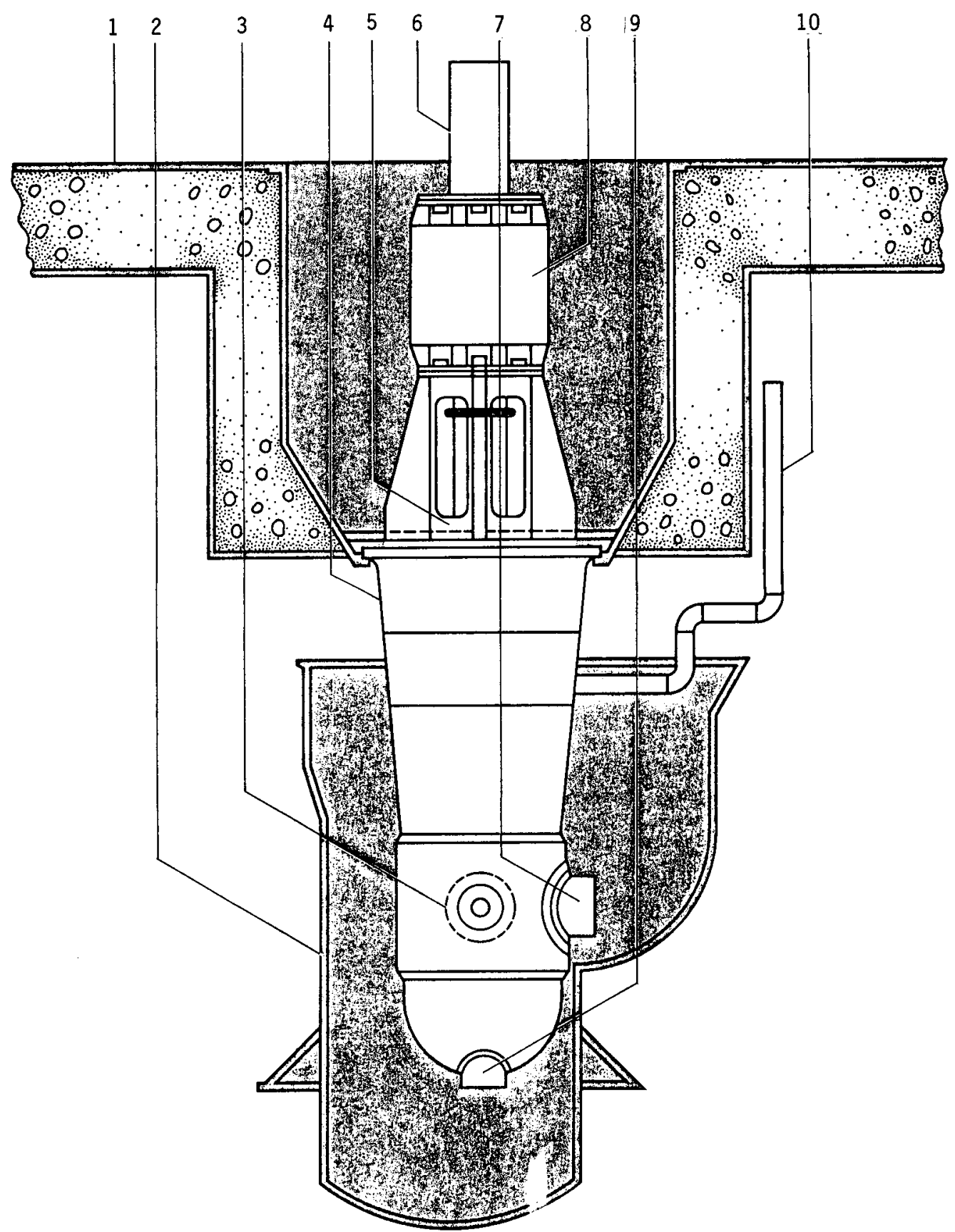

1. OPERATING FLOOR

2. GUARD VESSEL

3. ALTERNATE DISCHARGE $90^{\circ}$ FROM SUCTION

4. RADIATION SHIELD PLUG

5. SHAFT SEAL
6. PONY MOTOR $75 \mathrm{HP} / 85 \mathrm{RPM}$

7. PRIMARY SUCTION NOZZLE

8. MAIN MOTOR $5000 \mathrm{HP} / 1170 \mathrm{RPM}$

9. PRIMARY DISCHARGE NOZZLE

10. STANDPIPE BUBBLER

Figure XVII.E-1 CRBR Primary Sodium Pump Concept (Ref. 4) 
1. INTERMEDIATE INLET

2. SUPPORT CYLINDER

3. DOWNCOMER EXPANSION ELEMENT (BELLOWS)

4. INTERMEDIATE OUTLET

5. PRIMARY VENT NOZZLE

6. UPPER TUBESHEET

7. DISTRIBUTION CYLINDER (EXT. OF OUTER SHROUD)

8. OUTER SHROUD

9. DOWNCOMER

10. PRIMARY INLET

11. BAFFLES AND TUBE SUPPORT

12. SHELL

13. PRIMARY BY-PASS SEAL ASSEMBLY

14. TUBES

15. LOWER TUBESHEET

16. PRIMARY OUTLET

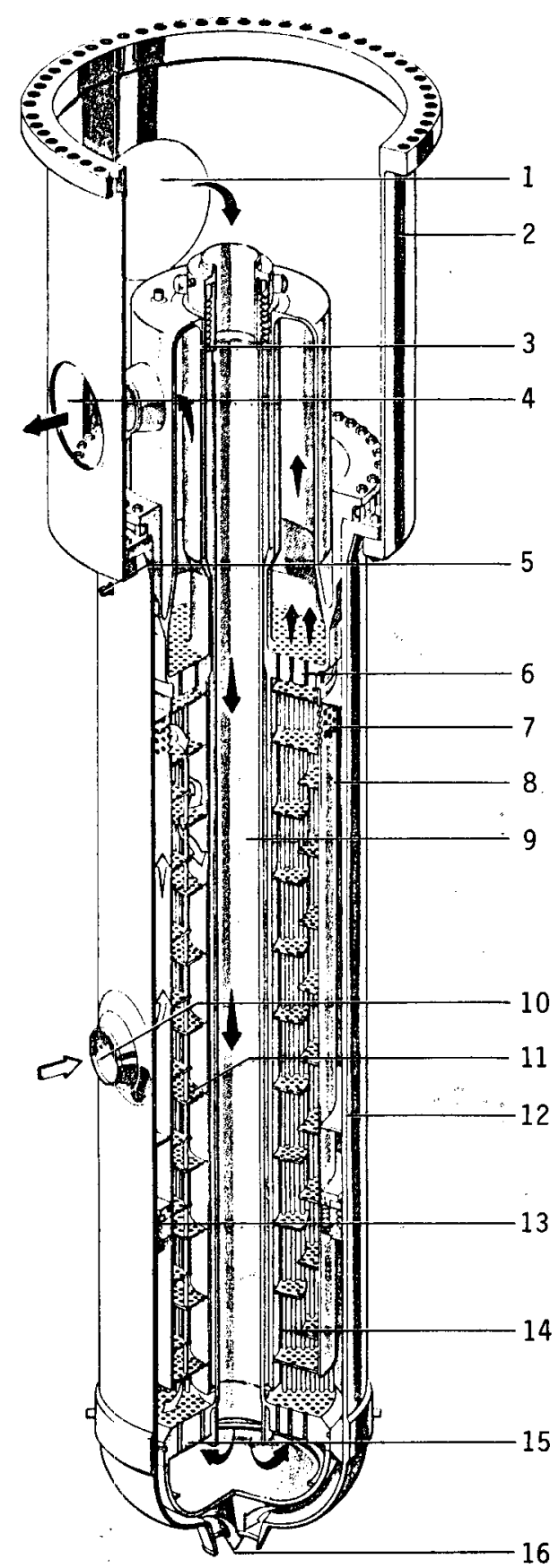

Figure XVII.E-2 CRBR Intermediate Heat Exchanger (Ref. 4) 
CRBR XVII.E.

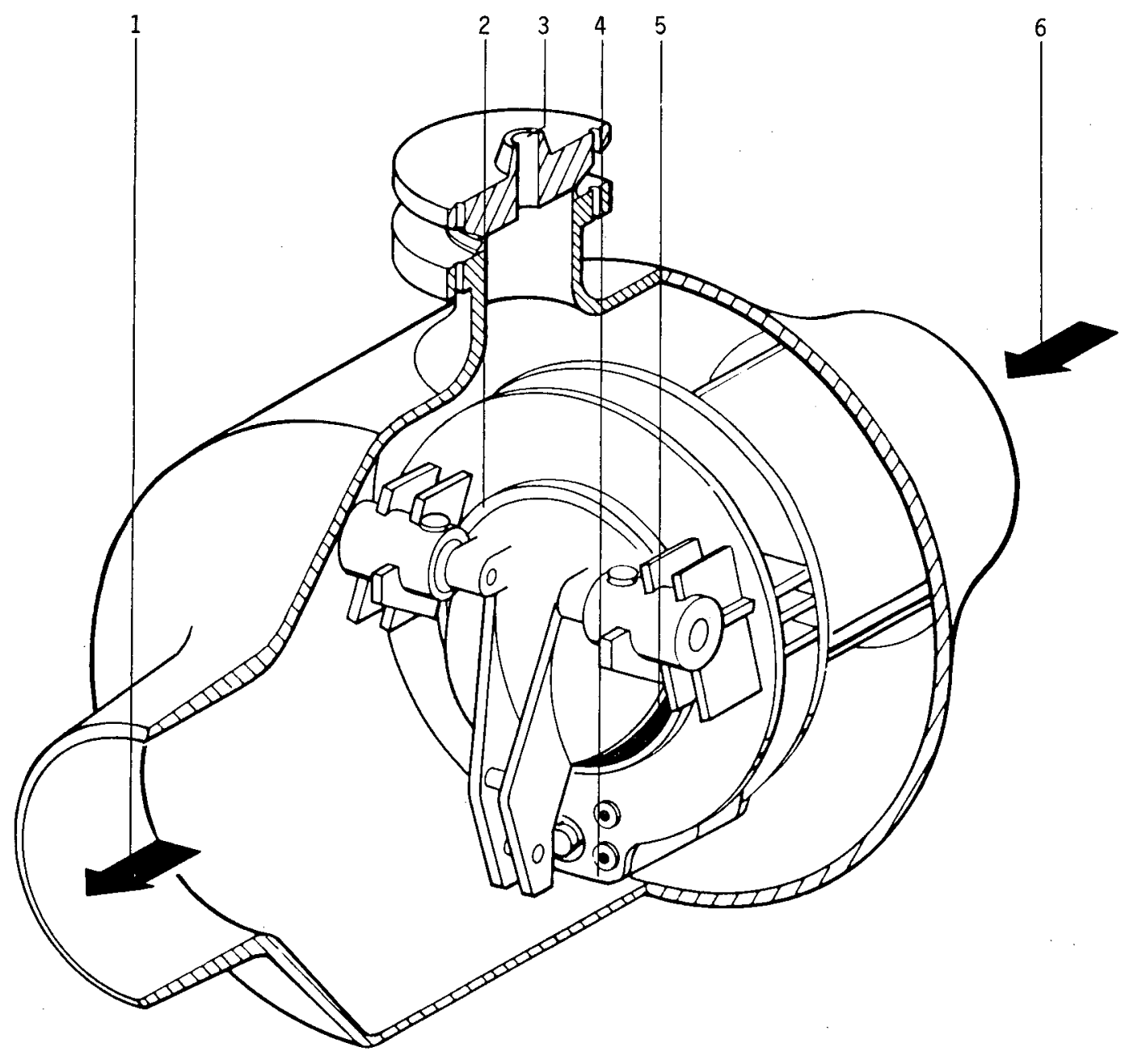

1. OUTLET

2. SWING DISC

3. VENT AND MAINTENANCE OPENING

4. DASHPOT

5. FREE STANDING SEAT

6. INLET

Figure XVII.E-3 CRBR Cold Leg Check Valve Concept (Ref. 4) 


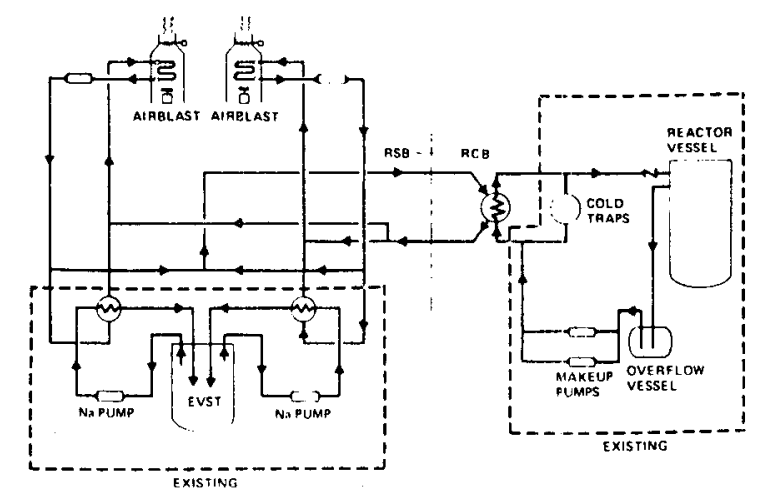

Figure XVII.E-4a CRBR Overflow Heat Removal System (Ref. 5)

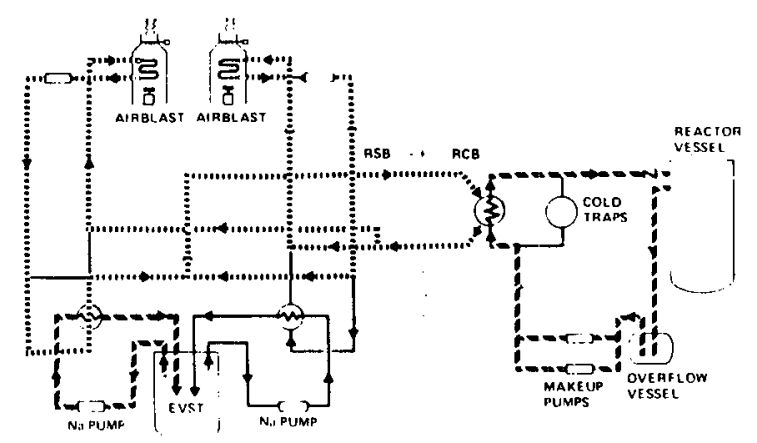

Figure XVII.E-4b CRBR Operation During Decay Heat Removal (Ref. 5)

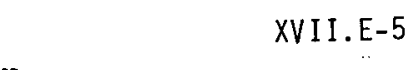


CRBR XVII.F.

\section{XVII.F. SODIUM PURIFICATION AND INSTRUMENTATION}

The auxiliary liquid metal system provides for receipt, storage, and purification of liquid metal, and provides the capability for reactor sodium level control, accommodates primary sodium volume changes, and provides cooling for core components stored in the ex-vessel storage tank. There are three $60 \mathrm{gpm}$ cold traps for purification, one active trap in the primary sodium processing subsystem and one in each of the intermediate sodium processing subsystem. Cold traps have NaK cooling, with heat rejected to the auxiliary coolant fluid system consisting of an electromagnetic pump, diffusion-type cold traps, heat exchangers, a storage tank and an expansion tank.

Hydrogen and oxygen meters monitor sodium after exit from each unit, the bulk sodium in the intermediate loop cold leg, and the argon cover gas in the expansion tank. Each monitoring location has an electromagnetic pump, flow-meter, heat exchanger and heater. 
XVII.G. COVER GAS AND AUXILIARY SYSTEMS

Liquid metal coolant cover gas is argon. An impurity monitoring and analysis system samples plant liquid metal and argon systems. Equipment is cooled by an auxiliary system using an organic fluid. A recirculating gas cooling system provides cooling to inert cells and equipment.
The auxiliary liquid metal system provides for receipt, storage, handling and purification of sodium and NaK. The rad-waste system collects, stores, monitors, and packages and transfers liquid and solid radioactive waste materials. (Ref. 2) 
CRBR XVII.H.

\section{XVII.H. STEAM GENERATORS}

There are three steam generator loops, one for each intermediate loop. The steam generator module chosen for the reference design consists of two evaporators and superheater per loop, utilizing the hockey-stick concept. Evaporators and superheaters are identical and interchangeable, except that inlet water orifice inserts will be added to the evaporators. Overall height of the evaporator or superheater is $65 \mathrm{ft}$, shell od. 52 in. There are 757 heat transfer tubes $0.625 \mathrm{in}$. od with single 0.109 in. thick walls. Active tube length is $46 \mathrm{ft}$. Tube triangular pitch is $1.22 \mathrm{in}$. Sodium flows in the shel? side and water/steam in the tubes. A hydrogen diffusion tube detector was selected as the steam generator leak detector. (Fig. XVII.H-1)

The sodium/water reaction pressure relief subsystem protects the sodium side of the evaporators and superheaters and the intermediate loop by the use of rupture disks in the main sodium piping close to the superheater and evaporator nozzles. There are three rupture disks per loop. Pressure-relief system piping routes the reaction products to a separation tank. Gaseous products are vented to the atmosphere, 1iquid and solid wastes remain in the separation tank or the storage tank of a centrifugal separator. There is a sodium leak detector at each rupture disk location. (Ref. 4)

A sodium dump subsystem is provided to renove sodium from an affected loop of the intermediate sodium system in case of a sodium/water reaction, before the IHX has been excessively contaminated. Drain lines located at low points include pairs of dump valves in series. Drain lines route the sodium to a dump tank located below the appropriate superheater/ evaporator cell of the steam generator building. (Ref. 4)

The steam generator auxiliary heat removal system removes decay heat and/or sensible heat from the reactor and heat transport system in the event the main heat sink is unavailable. It can be activated when desirable. The concept incorporates two subsystems; a longterm system and a short-term system. The short-term system uses a direct steam dump to the atmosphere through power relief valves in the steam lines. The long-term system uses three protected air-cooled condensers on the roof of the steam generator building to condense steam from the steam drums. (Ref. 4) 
CRBR XVII.H.
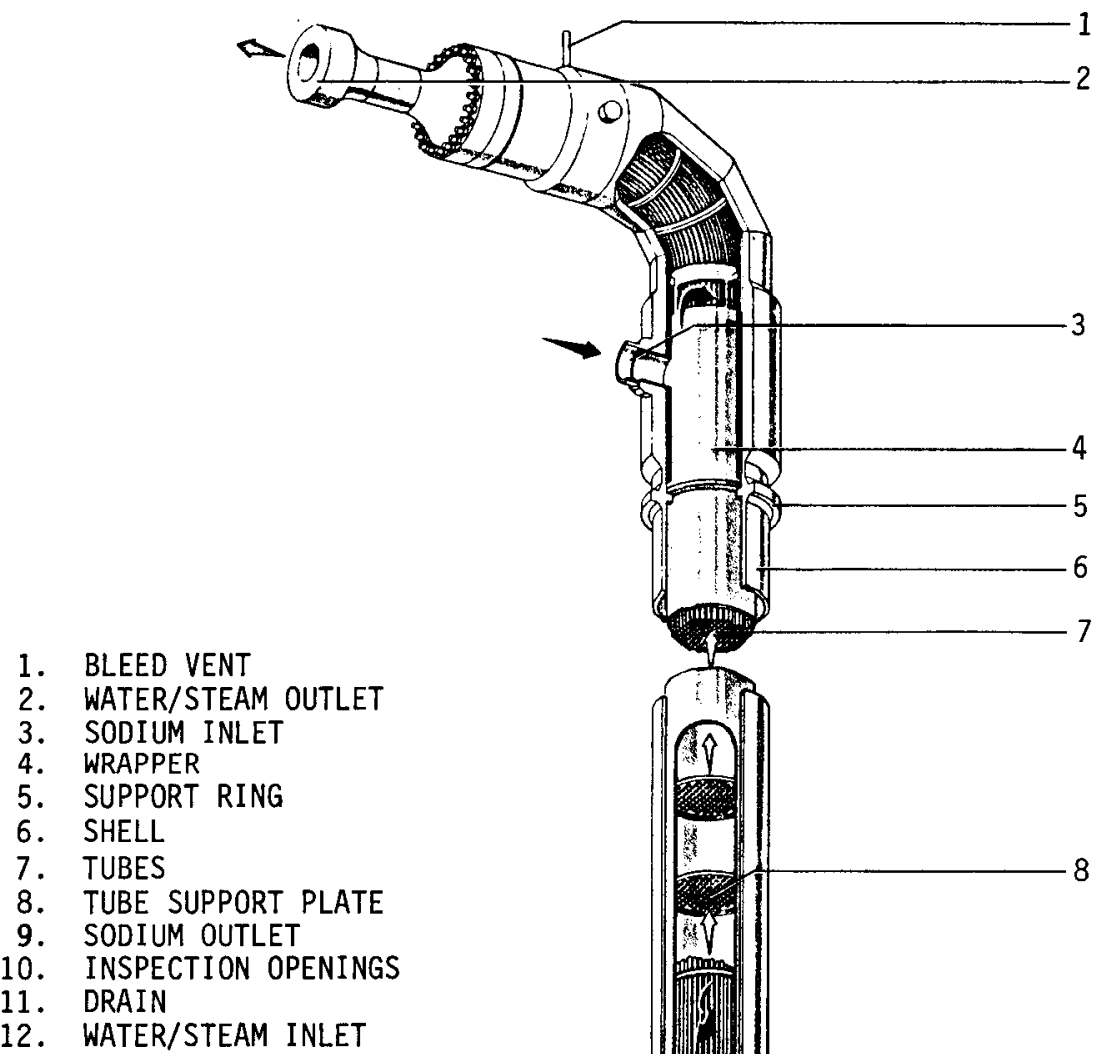

2. WATER/STEAM OUTLET

3. SODIUM INLET

4. WRAPPER

5. SUPPORT RING

6. SHELL

7. TUBES

8. TUBE SUPPORT PLATE

9. SODIUM OUTLET

10. INSPECTION OPENINGS

12. WATER/STEAM INLET

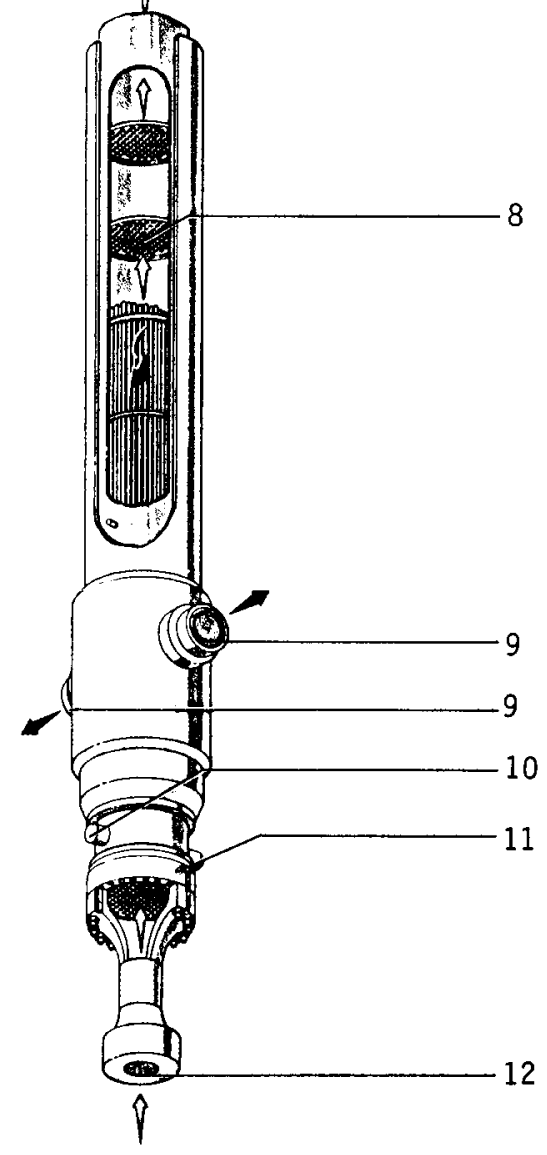

Figure XVII.H-1 CRBR Steam Generator Module (Ref. 4) 
XVII.I. REACTOR INSTRUMENTATION AND CONTROL

The overall plant control system is designed to provide load-following capacity at a maximum of $3 \%$ per minute over a load range from $40 \%$ to $100 \%$ of full power. Basic control is from a central supervisory control system, providing for either automatic load dispatch or operator load control capability. Main areas of control are the reactor, primary and intermediate sodium flows, primary and intermediate sodium pumps, and feedwater flow. Two out of three logic is maintained throughout the plant. Twelve functions are projected to cover the entire shutdown system. (Fig. XVII.I-1) (Ref. 5)
Fuel failure monitoring is similar to the FFTF system, with three subsystems. The cover gas monitoring subsystem includes a charcoal chromatograph column, a germanium detector, a fixed-channe? spectrometer, a multi-channel spectrometercomputer and printer, gas sampling equipment and associated control panels. The delayed neutron monitoring system includes $\mathrm{BF}^{3}$ neutron detectors and the shielding moderator assembly, adjacent to each of the three primary loops. The failed fuel location system includes gas tag sampling traps, mass spectrometer, minicomputer and printer. (Ref. 4)

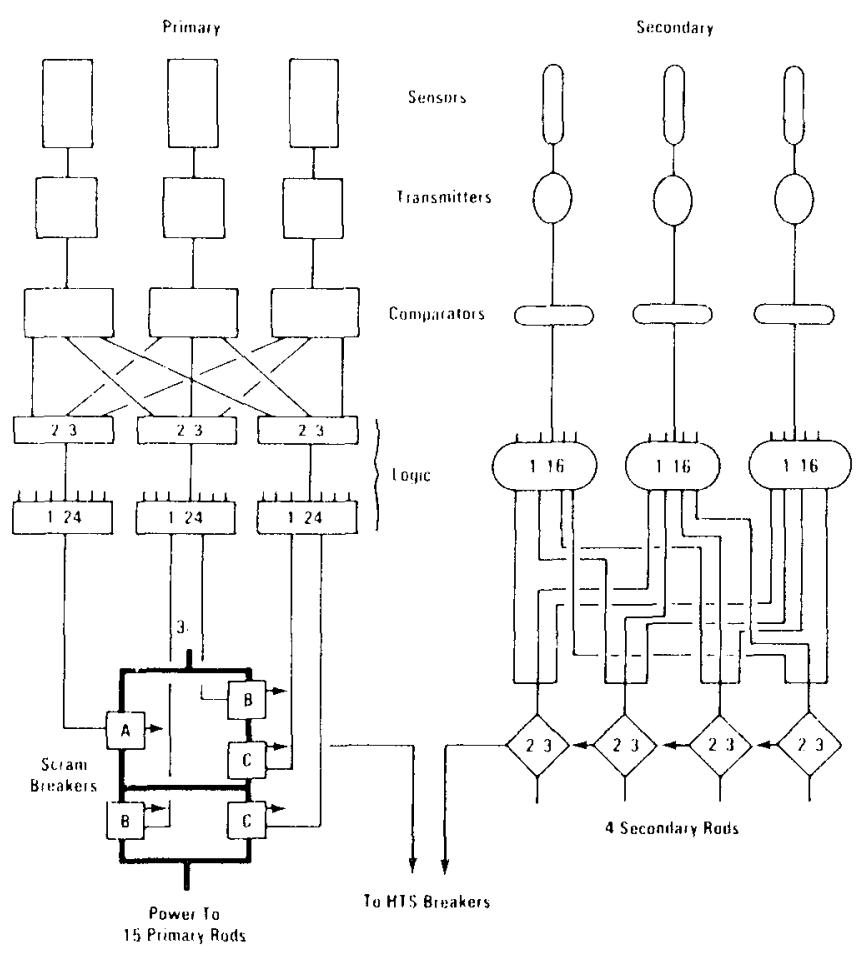

Figure XVII.I-1 CRBR Protective Subsystems (Ref. 5)

\section{PROTECTIVE SUBSYSTEMS} PRIMARY

Flux - Delayed Flux (Compensated I on Chamber! High Flux

Flux - Pressure

Primary Pump Electrics

Primary - Intermediate Speed

Steam - Feedwater Flow

Reactor Vessel Level

\section{SECONDARY}

Modified Nuclear Rate (Fission Chambers) Flux Level - Startup

Flux - Total Flow

Primary - Intermediate Flow

Steam Drum Level 


\section{XVII.J. FUEL HANDLING}

A new core component is received as a fully assembled element in a singleassembly shipping container, with twelve containers per shipment, and transferred in the containers to the new fuel storage cell. It is removed from the container inside the cell and stored in separate thimbles. About a month before scheduled refueling the assembly is removed from storage by a new component transfer machine to the ex-vessel storage tank, a large two tier sodium tank with 650 positions. Reactor port plugs are removed and the In-Vessel Transfer Machine (IVTM) is installed. The Ex-Vessel Transfer Machine (EVTM) moves a new fuel assembly from the ex-vessel tank while the IVTM and rotating plugs remove a spent assembly from the core and place it in an in-vessel transfer position. The EVTM places the new fuel in another in-vessel transfer position and removes the spent fuel assembly, transferring it to the tank. The IVTM and the rotating plugs install the new fuel in the core open lattice position. All fuel handled by the EVTM is in a sodium-filled core component pot. Heat is dissipated from the machine by forced air cooling on the outside of the cold wall. On completion of refueling the IVTM is removed from the reactor. Spent fuel decays for one hundred days in the ex-vessel tank before being shipped off-site. Maximum use of FFTF technology has been used in design and development of the equipment.

The IVTM conceptual design employs a rising-stem grapple drive. Seals and bushings, drive components, grapple alignment, and IVTM prototype programs are under way. (Fig. XVII.J-I)
The EVTM reference concept is essentially identical to the FFTF CLEM. Changes include the deletion of almost a17 in-vessel storage, requiring removal of spent fuel during the same refueling shutdown during which it is removed from the core. Decay heat removal capability required is $220 \mathrm{kw}$. Alternate approaches to cold-wall heat removal system are being studied, for example forced convection of argon, al though it is concluded that the cold wall EVTM will be capable of handling fuel with $20 \mathrm{kw}$ decay heat. The height has been reduced from $61 \mathrm{ft}$. to about $34 \mathrm{ft}$. (Fig. XVII.J-2)

A two-tier, rotatable storage rack was selected for the ex-vessel storage tank, where 650 core assemblies can be stored in ten circular rows. A fuel transfer port for each circular row is excessible to the EVTM. Storage positions are cylindrical tubes restrained and supported by a stainiess steel grid in the rotatable rack. Each tube can hold two core component pots, one above the other. There are 24 argon-filled positions where new assemblies will be placed for radiant preheating before immersion in sodium. Two independent and redundant heat removal systems are provided, each capable of removing the maximum design decay heat and holding sodium outlet temperatures below $600^{\circ} \mathrm{F}$. (Fig. XVII.J-3)

Spent fuel is transferred from EVST storage, after a suitable decay period, by the EVTM to the Fuel Handling Cell. The pot containing the spent assembly is lowered into a sodium-filled storage tank in the floor of the cell. An in-cell crane will lower the assembly through a port in the cell floor into the spent fuel shipping cask. (Fig. XVII.J-4) (Ref. 4) 
CRBR XVII.J.

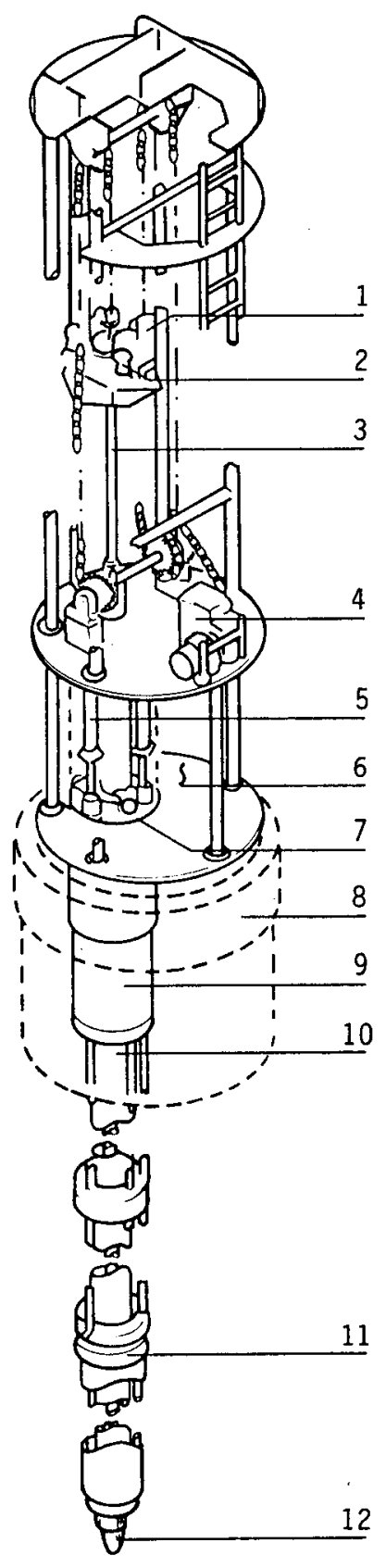

1. GRAPPLE ROTATION DRIVE

2. PNEUMATIC LOAD CONTROL SYSTEM

3. GRAPPLE STEM

4. GRAPPLE VERTICAL DRIVE

5. HOLDDOWN ACTUATORS (3 PLACES)

6. IVTM SERVICE EQUIPMENT BAY

7. IDENTIFICATION/ORIENTATION SYSTEM COMPONENTS

8. SMALL ROTATING PLUG

9. IVTM SUPPORT COLUMN

10. IDENTIFICATION/ORIENTATION SHAFT

11. HOLDDOWN SLEEVE

12. GRAPPLE

Figure XVII.J-1 CRBR In-Vessel Transfer Machine (Ref. 4)

XVII.J-2 


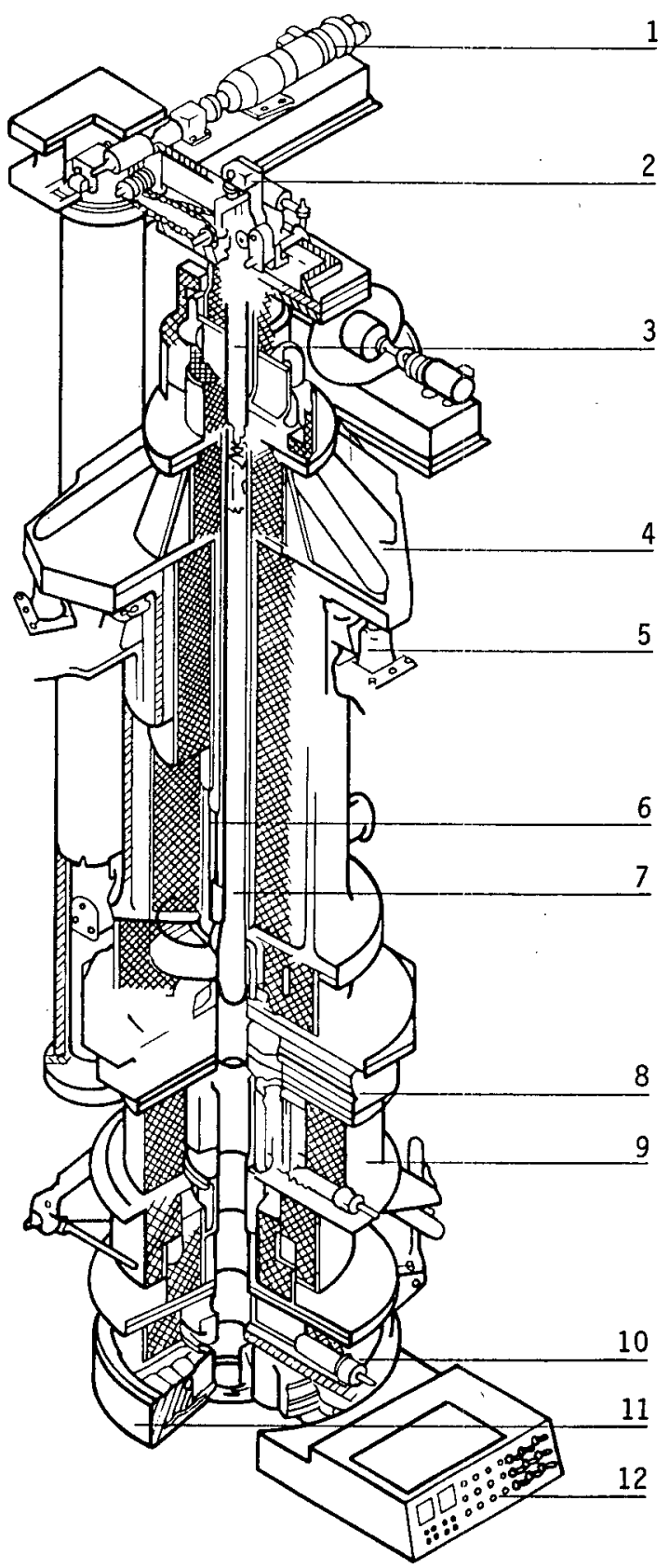

1. GRAPPLE DRIVE ASSY

2. GRAPPLE FINGER ACTUATOR

3. GRAPPLE

4. BODY MOUNT

5. LEVELING JACKS

6. COLD WALL
7. COL.D WALL

8. VIEW PORT

9. DRIP PAN

10. CLOSURE VALVE

11. FLOOR VALVE

12. FLOOR VALVE CONTROL PANEL

Figure XVII.J-2 CRBR Ex-Vessel Transfer Machine (Ref. 4) 
CRER XVII.J.

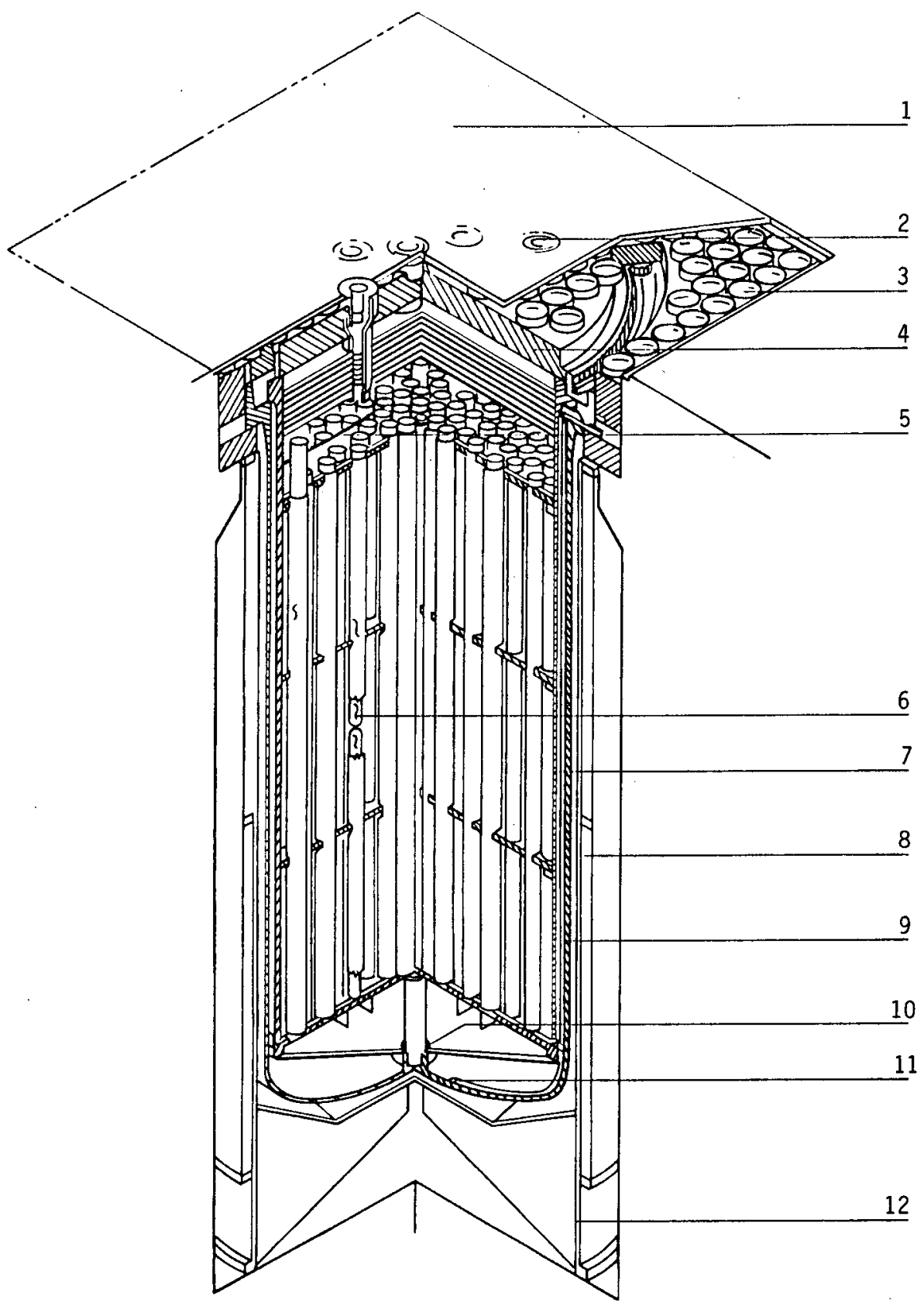

1. RSB OPERATING FLOOR

2. FUEL TRANSFER PORT

3. CRUSH CYLINDERS

4. TOP SHIELD

5. SODIUM LEVEL

6. CORE COMPONENT POTS
7. ROTATING STORAGE RACK

8. INSULATION AND HEATER

9. PRIMARY VESSEL

10. SEISMIC RESTRAINT

11. SODIUM INLET PIPE

12. GUARD JACKET

Figure XVII.J-3 CRBR Ex-Vessel Storage Tank (Ref. 4) 


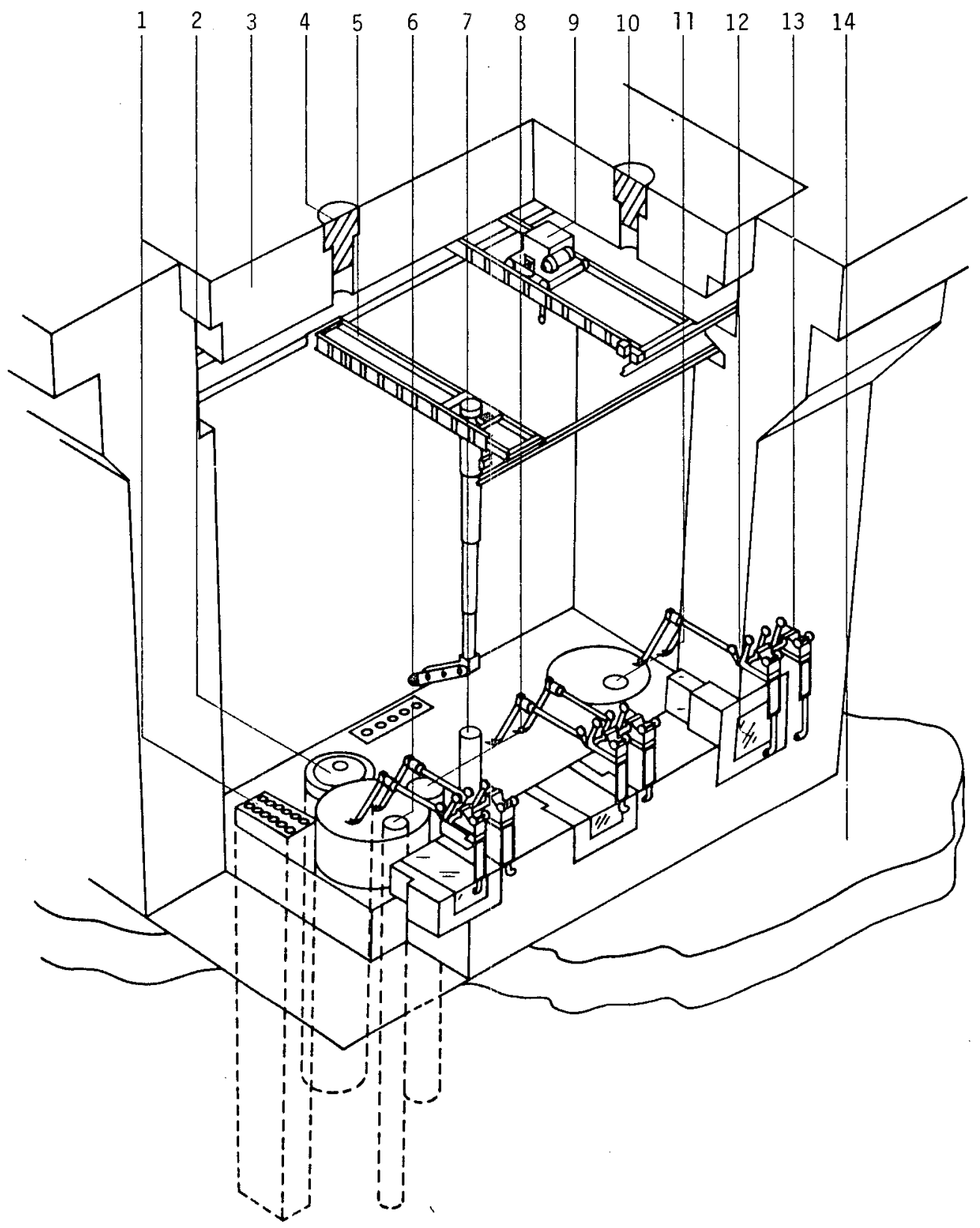

1. CC POT DRY STORAGE

2. SPENT FUEL STORAGE TANK

3. OPERATING ROOF PLUG

4. SPENT FUEL TRANSFER PORT PLUG

5. POWERED MANIPULATOR

6. MAINTENANCE AND SERVICE STATION

7. FUEL EXAMINATION STATION
8. HOT GAS CLEANING STATION IN FLOOR

9. IN CELL CRANE

10. CASK LOADING ROOF ACCESS PORT PLUG

11. FLOOR-CASK LOADING PORT

12. FLOOR VALVE CONTROL PANEL

13. MASTER/SLAVE MANIPULATORS

14. OPERATING GALLERY FLOOR

Figure XVII.J-4 CRBR Fuel Handling Cell (Ref. 4) 

1. GENERATOR
2. LOW-PRESSURE TURBINES
3. HIGH-PRESSURE TURBINE
4. STEAM GENERATOR
$\begin{array}{lrl}\text { STEAM GENERATOR } & 9 . & \text { REACTION PRODUCTS TANK } \\ \text { AUXILIARY HEAT REMOVAL } & 10 . & \text { INTERMEDIATE PUMP }\end{array}$
5. SUPERHEATER
7. STEAM DRUM
8. STEAM GENERATOR BUILDING GANTRY CRANE
11. LARGE COMPONENT CLEANING
12. REACTOR VESSEL
13. REACTOR GUARD VESSEL
14. PRIMARY PUMP
15. REACTOR BUILDING POLAR CRANE
16. INTERMEDIATE HEAT EXCHANGER
17. PRIMARY CHECK VALVE
18. EX-VESSEL TRANSPORT MACHINE
19. FUEL HANDLING CELL
20. NEW CORE COMPONENT STORAGE
21. EX-VESSEL STORAGE TANK
22. SPENT FUEL SHIPPING CASK ON RAILROAD CAR

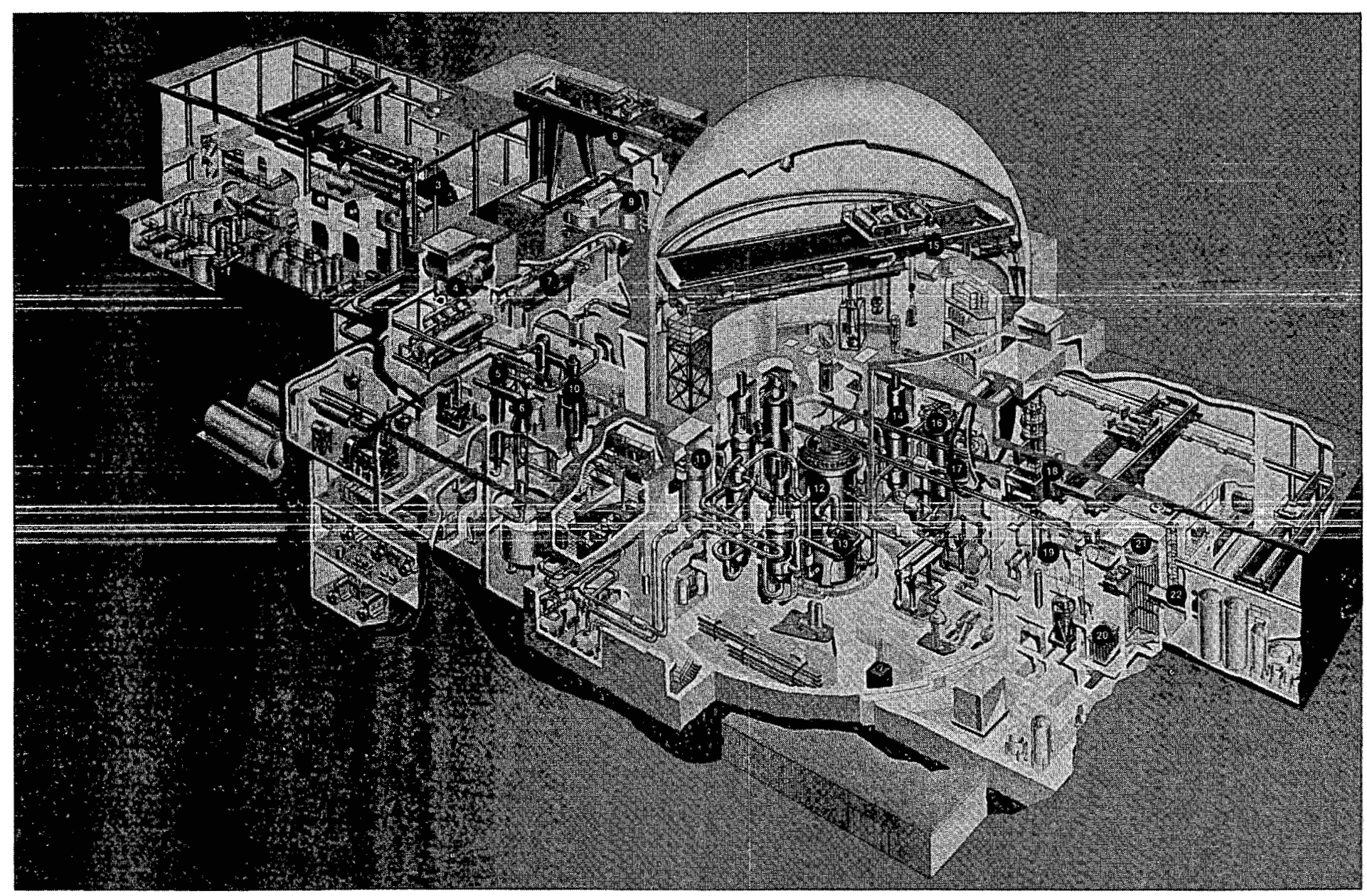

Figure XVII.K-1 CRBR Reactor Plant (Ref. 4) (Photo No. 755315-1) 


\section{XVII.K. CONTAINMENT}

The containment building concept is for a cylindrical steel vessel embedded in concrete up to the operating floor, with a hemispherical head and a flat bottom. Inner diameter is $186 \mathrm{ft}$. and height is $159 \mathrm{ft}$. to the spring line. The operating floor is one foot above finished grade and $76 \mathrm{ft}$. below the spring line. Below the top floor, the freestanding steel containment vessel is bounded by inner and outer, $3 \mathrm{ft}$. thick concrete walls. Above the operating floor the vessel is of $1-1 / 2 \mathrm{in}$. thick steel, internally reinforced by steel stiffener rings. A polar crane is located near the spring line. Vessel centerline is $6 \mathrm{ft}$. of $\mathrm{f}$ the containment centerline. A $7 \mathrm{ft}$. thick hollow cylinder extending from the base mat to $14 \mathrm{ft}$. below the operating floor supports the reactor vessel. The reactor vessel cavity is sealed and inerted, and the guard vessel is supported in the cavity from below. The head access area has an air atmosphere, but can be sealed and inerted. Within containment, individual cells house the sodium heat transfer loops, radioactive component cleaning facilities, sodium cold traps, sodium storage tank and major support equipment. Services and auxiliaries are housed in support buildings adjoining the Containment Building. (Fig. XVII.K-I) (Ref. 4) 


\section{ACKNOWLEDGEMENT}

My thanks to personnel of the Westinghouse Hanford Company who have verified the information and supplied illustrations; and to Joe Gilles, Interatom representative to Hanford Engineering Development Laboratory, for his assistance in the collection of data for KNK and SNR-300. My thanks also to the publishers who have granted permission to reproduce copyrighted illustrations in this document. 